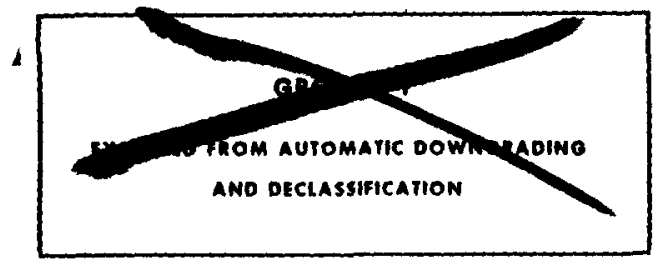

318

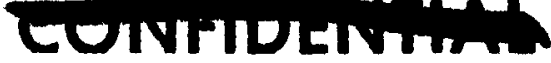

This report was prepared as an account of work sponsared by the United States Government Neither the United States nor the United States Energy Research and Development Admunistration, nor any of ther employees, nor any of thetr contractors subcontractors, or their employees, makes any
warranty, express or implied, or assumes any legal lability or responsibulity for the accuracy, completeness or usefulness of any information, apparatus, product or process disclosed, or represents that its use would not infringe privately owned rights

\section{MASTER}

-

OLstroncear

WANL-TME-466 ADDENDUM NO.2 DECEMBER 26, 1963

Dr. W.H. Esselman

SUBMITTED BY:

Mr. H.F. Faught

Dr. W.H. Arnold

Mr. H.S. McCreary

Mr. G.R. Thomas

Mr. J. Coombe

All Instrumentation

Laboratory Engineers

PREPARED BY:

D.RT Teyssin

D.R. Teyssier

Westinghouse Electric Corporation

Instrumentation Laboratory

Experimental Engineering

APPROVED BY:

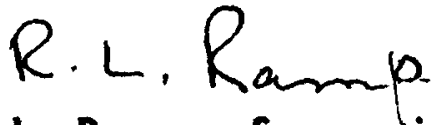

R.L. Ramp, Superviser

Instrumentation Laboratory, Experimental Engineering

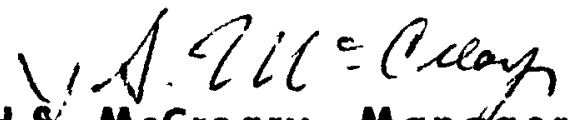
H.9. McCreary, Manglger Experimental Engin'ering

\section{ADDENDUM NO.2 \\ CANDIDATE TRANSDUCER \\ DATA SHEETS FOR INSTRUMENTATION \\ DATA BOOK}

(Title Unclassified)

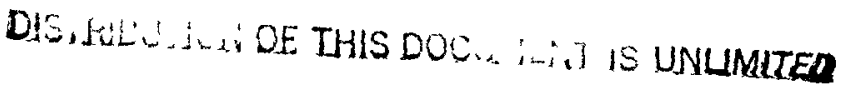

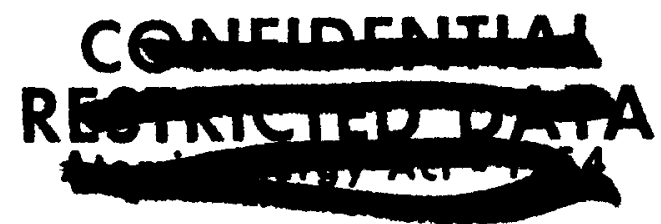




\section{DISCLAIMER}

This report was prepared as an account of work sponsored by an agency of the United States Government. Neither the United States Government nor any agency Thereof, nor any of their employees, makes any warranty, express or implied, or assumes any legal liability or responsibility for the accuracy, completeness, or usefulness of any information, apparatus, product, or process disclosed, or represents that its use would not infringe privately owned rights. Reference herein to any specific commercial product, process, or service by trade name, trademark, manufacturer, or otherwise does not necessarily constitute or imply its endorsement, recommendation, or favoring by the United States Government or any agency thereof. The views and opinions of authors expressed herein do not necessarily state or reflect those of the United States Government or any agency thereof. 


\section{DISCLAIMER}

Portions of this document may be illegible in electronic image products. Images are produced from the best available original document. 


\section{CONIFIDIENIIAL

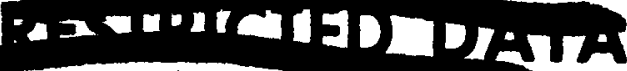

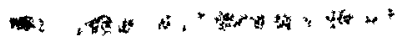

to

Addendum No. 2

Introduction

The Candidate Transducer Data Sheets contained in this addendum represent the latest revisions of transducers selected by WANL for test purposes.

This transmittal should be used in conjunction with the initial volume, WANLTME-466 dated July 31, 1963 and Addendum No. 1 dated September 15, 1963.

The following Candidate Transducer Data Sheets are included in this transmittal:

Updated Candidates - dated 1 January 1964

Absolute Pressure $\operatorname{Pr}-6 ; \operatorname{Pr}-9 ; \operatorname{Pr}-10 ; \operatorname{Pr}-15$

Differential Pressure DPr-1 thru DPr-11 inclusive

Thermocouples TR-6 thru Tr-16 inclusive; Tr-25 thru Tr-28 inclusive; Tr-30

Strain $\quad \mathrm{Sr}-5$

Vibration Gr-1 thru Gr-21 inclusive

Position Lr-5 thru Lr-13 inclusive

Acoustic $\quad A r-1$

The above sheets replace those previously issued in initial issue of WANL-

TME-466 and Addendum No. 1. Please destroy all previous issues of these sheets.

$\frac{\text { New Candidates }}{\text { Absolute Pressure }}-\frac{\text { dated } 1 \text { January } 1964}{\mathrm{Pr}-1 \text { thru } \mathrm{Pr}-5 \text { inclusive }}$
$\begin{aligned} & \text { Thermocouples } \\ & \mathrm{Tr}-1 \text { thru } \mathrm{Tr}-5 \text { inclusive }\end{aligned}$

Resistance Thermometers RTr-1, RTr-2

Strain Gages $\quad \mathrm{Sr}-3 ; \mathrm{Sr}-4$

Position Lr-1; Lr-2; Lr-19 
Addendum No. 2

$$
\frac{\text { Introduction }}{\text { (continued) }}
$$

The following sheets have minor additions or corrections to be made. New sheets are not issued in this adendum for these due to the minor inportance of the changes. However, the old sheets should be marked according to this list for your information.

$$
\begin{aligned}
& \text { Pr-8, Pr-11, Pr-12 - Sensing element should read "Twisted Tube" } \\
& \text { Pr-14 - Sensing element should read "Diaphragm" - Add P.O. No. } 34726 \\
& \text { Pr-16 - Add P.O. No. } 27087 \\
& \text { Pr-17 - Add P.O. No. } 41911 \\
& \text { Pr-20 - Add P.O. No } 39291 \\
& \text { Pr-21 - Add P.O. No. } 39291 \\
& \text { DPr-16 - Add P.O. No. } 41911 \text { J } \\
& \text { DPr-18 - Change Spec. Cont. Dwg. No. to } 945 \text { C } 934 \mathrm{H} 01 \\
& \text { DPr-19 - Change Spec. Cont. Dwg. No. to } 945 \text { C } 934 \mathrm{HO} 04 \\
& \text { DPr-21 - Add P.O. No. } 39347
\end{aligned}
$$

Replacement sheets for the above will be issued when sufficient changes or additions warrant a need.

All sheets not contained in either of the above lists are to be maintained as the latest available information. Replacement sheets for these along with any additional new Candidate will be transmitted as information becomes available.

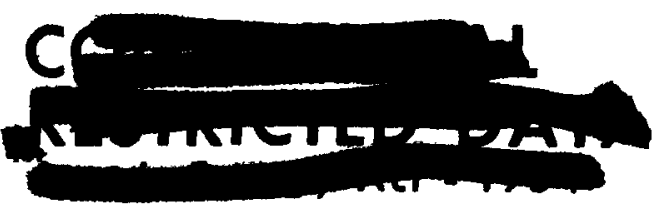



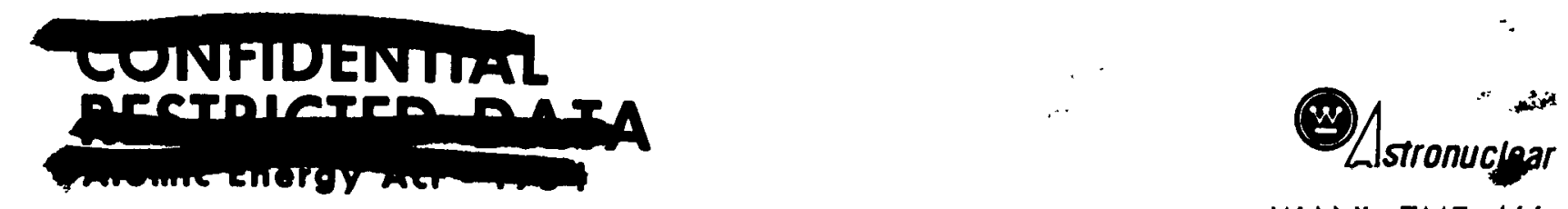

WANL-TME -466

Addendum No. 2

$\underline{\text { Index }}$

The candidates listed in th is index include all the transducers which are still applicable in the initial issue, Adendum No. 1, and Addendum No. 2. All sheets containing an earlier issue date than that listed herein should be destroyed.

Absolute Pressure Transducers

$\mathrm{Pr}-1$ thru $\mathrm{Pr}-6$ inclusive

$\operatorname{Pr}-7, \operatorname{Pr}-8$

$\mathrm{Pr}-11$ thru $\mathrm{Pr}-14$ inclusive

Pr-15

Pr-16 thru Pr-18 inclusive; Pr-20, Pr-21
Pr-9, Pr-10

\begin{tabular}{ll} 
Date & \multicolumn{1}{c}{ Issue } \\
1 January 1964 & $\begin{array}{l}\text { Add. No. 2 } \\
\text { 31 July 1963 }\end{array}$ \\
I January 1964 & Add. No. 2 \\
31 July 1963 & Initial \\
1 January 1964 & Add. No. 2 \\
31 August 1963 & Add. No. 1
\end{tabular}

1 January 1964

Add. No. 2

Add. No. 1

not issued

31 August 1963 Add. No. 1

DPr-15, DPr-16

DPr-17

DPr-18 thru DPr-21 inclusive not issued

31 August 1963

Add. No. 1

Thermocouples

$\mathrm{Tr}-1$ thru $\mathrm{Tr}-16$ inclusive

$\mathrm{Tr}-17$ thru $\mathrm{Tr}-24$ inclusive

$\mathrm{Tr}-25$ thru $\mathrm{Tr}-28$ inclusive

$\operatorname{Tr}-29$

$\operatorname{Tr}-30$
1 January 1964

31 July 1963

1 January 1964

not issued

1 January 1964
Add. No. 2

Initial

Add. No. 2

Add. No. 2

Resistance Thermometers

$$
\begin{aligned}
& \text { RTr-1, RTr-2 } \\
& \text { RTr-3, RTr-4 } \\
& \text { RTr-5 thru RTr-7 }
\end{aligned}
$$

1 January 1964

not issued

31 July 1963
Add. No. 2

Initial 


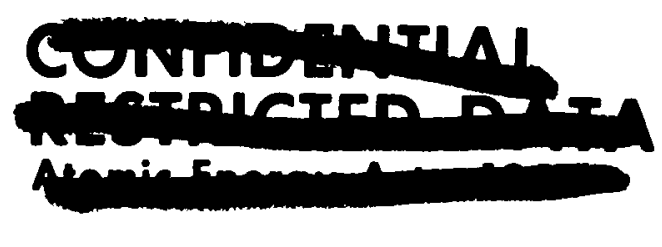

$\frac{\text { Index }}{\text { (continued) }}$

Strain Gages

$\mathrm{Sr}-1, \mathrm{Sr}-2$

$\mathrm{Sr}-3$ thru $\mathrm{Sr}-5$ inclusive

$\mathrm{Sr}-6$ thru $\mathrm{Sr}-17$ inclusive

$\mathrm{Sr}-18$ thru $\mathrm{Sr}-23$ inclusive

Vibration Transducers

$\mathrm{Gr}-1$ thru $\mathrm{Gr}-21$ inclusive

Position Transducers

$L r-1, L r-2$

$\mathrm{Lr}-3, \mathrm{Lr}-4$

$\mathrm{Lr}-5$ thru $\mathrm{Lr}-13$ inclusive

$\mathrm{Lr}-14$ thru $\mathrm{Lr}-16$ inclusive

$\operatorname{Lr}-17, \operatorname{Lr}-18$

$\mathrm{Lr}-19$

Acoustic (SPL) Transducers

Ar-1 (replaces SPr-1)

Cables

$\mathrm{Cr}-1$ thru $\mathrm{Cr}-5$ inclusive

Connections

$\mathrm{Jr}-1$ thru $\mathrm{Jr}-3$ inclusive

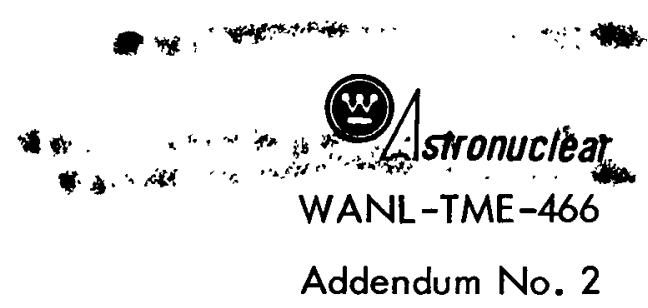

not issued

1 January 1964

31 July 1963

Add. No. 2

Initial

31 August $1963 \quad$ Add. No. 1

1 January 1964 Add. No. 2

1 January 1964

31 July 1963

1 January 1964

31 July 1963

31 August 1963

1 January 1964

Add. No. 2

Initial

Add. No. 2

Initial

Add. No. 1

Add. No. 2

1 January $1964 \quad$ Add. No. 2

31 August 1963 Add. No. 1

31 August 1963 Add. No. 1
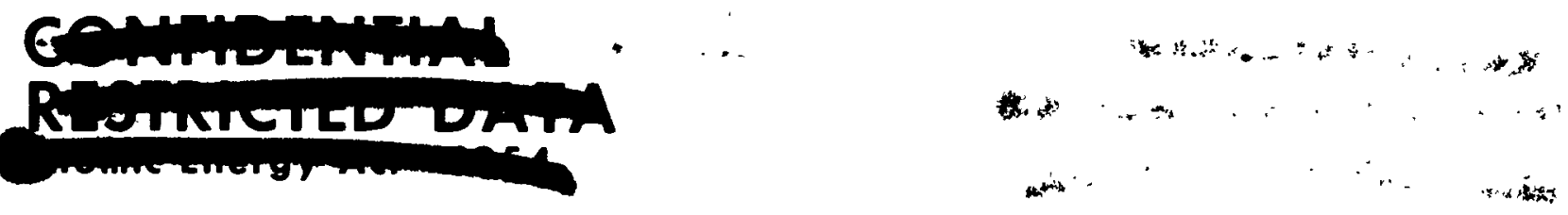


\section{PRESSURE TRANSDUCER}

Code No: $\operatorname{Pr}-1$

Type:

Mfgr:

Variable Reluctance

Range:

Wiancko

$0-30$ psig
Planning Parts List No:

Evaluation By:

WANL

Model No:

$\mathrm{PX} 100$

Sensing Element:
Twisted Tube

\begin{tabular}{|c|c|c|c|c|}
\hline Test & Condition & NERVA Requirements & Manufacturer's Specs & $\begin{array}{l}\text { Summary of } \\
\text { Test Results }\end{array}$ \\
\hline A & Overload & $1000 \mathrm{psia}$ & $150 \%$ of range & \\
\hline$B$ & Compt. Temp Range & $140^{\circ} \mathrm{R}$ to $640^{\circ} \mathrm{R}$ & $140^{\circ} \mathrm{R}$ to $640^{\circ} \mathrm{R}$ & \\
\hline C & Excitation & $20 \mathrm{VDC}$ or $\mathrm{AC}$ (nom.) & \multicolumn{2}{|c|}{ carrier system P.S. 28 VDC (req.) $19 \mathrm{~m}$} \\
\hline D & Sensitivity & $40 \mathrm{mv}$ FR (nom.) & $4 \mathrm{v} / \mathrm{v}$ & \\
\hline$E$ & Input Impedance & 1000 ohms or less & \multicolumn{2}{|l|}{28 VDC $18 \mathrm{ma}$. (carrier) } \\
\hline$F$ & Output Impedance & & 5,000 ohms (carrier) & \\
\hline $\mathbf{G}$ & Response time & $5 \mathrm{msec}$ to $63 \%$ & & \\
\hline $\mathrm{H}$ & Freq. Response & $0-50 \mathrm{cps}$ flat $\pm 3 \mathrm{db}$ & & \\
\hline 1 & Resolution & $<0.1 \% \mathrm{FR}$ & Continuous & \\
\hline $\mathrm{J}$ & Linearity & $\pm 0.2 \% \mathrm{FR}$ & $0.5 \%$ of $\mathrm{Fr}$ & \\
\hline$K$ & Hysteresis & $0.1 \% \mathrm{FR}$ & $0.1 \%$ of $\mathrm{FR}$ & \\
\hline$\underline{L}$ & Accuracy & $\pm 0.2 \% \mathrm{FR}$ & & \\
\hline$M$ & Acceleration Error & $<0.05 \%$ FR $/ \mathrm{g}$ & \multicolumn{2}{|c|}{$0.001 \%$ to $0.02 \%$ of range per $\mathrm{g}$} \\
\hline$N$ & Vibration Error & $<0.05 \% \mathrm{FR} / \mathrm{g} 0-2 \mathrm{Kc}$ & & \\
\hline 0 & Shock & MIL-E-5422 & & \\
\hline $\mathbf{P}$ & Noise Limit & MIL-S-446A & & \\
\hline $\mathbf{Q}$ & Neutron Flux & $2 \times 10^{11} \mathrm{n} / \mathrm{cm}^{2}-\mathrm{sec}$ & & \\
\hline$\underline{R}$ & Gamma Flux & \multicolumn{2}{|c|}{$2.1 \times 10^{9} \mathrm{ergs} / \mathrm{gm}(\mathrm{C})-\mathrm{hr}$} & \\
\hline $\mathbf{S}$ & Dimensions & $1.3 "$ O.D. $\times 3 " \mathrm{lg}$. & $1.6^{\prime \prime}$ O.D. x 3-1/8"lg. & \\
\hline$T$ & Weight & $7 \mathrm{oz}$ & $1.2 \mathrm{lbs}$. & \\
\hline$U$ & Resonant Freq. & $3000 \mathrm{cps}$ min. & \multicolumn{2}{|c|}{1000 to $5000 \mathrm{cps}$ depending on range } \\
\hline $\mathbf{v}$ & Insulation Res. & $50 \mathrm{M}$ ohms at $250 \mathrm{VDC}$ & $100 \mathrm{M}$ ohms at $50 \mathrm{VDC}$ & \\
\hline$W$ & Material & stainless steel & stainless steel cases & \\
\hline & & & & \\
\hline & & & & \\
\hline & & & & \\
\hline
\end{tabular}




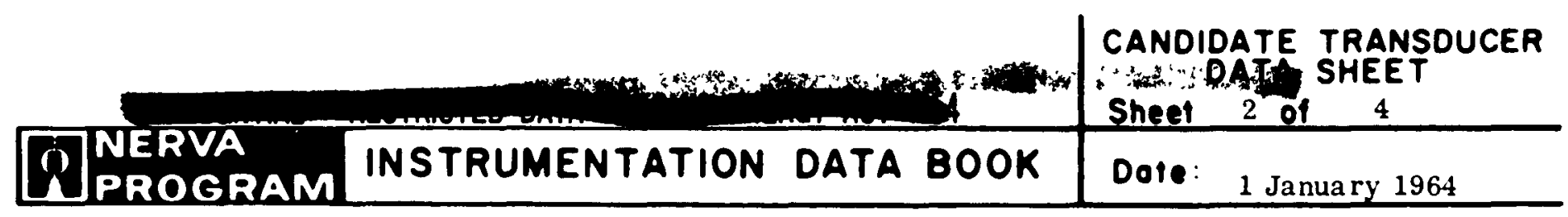

RADIATION TESTS

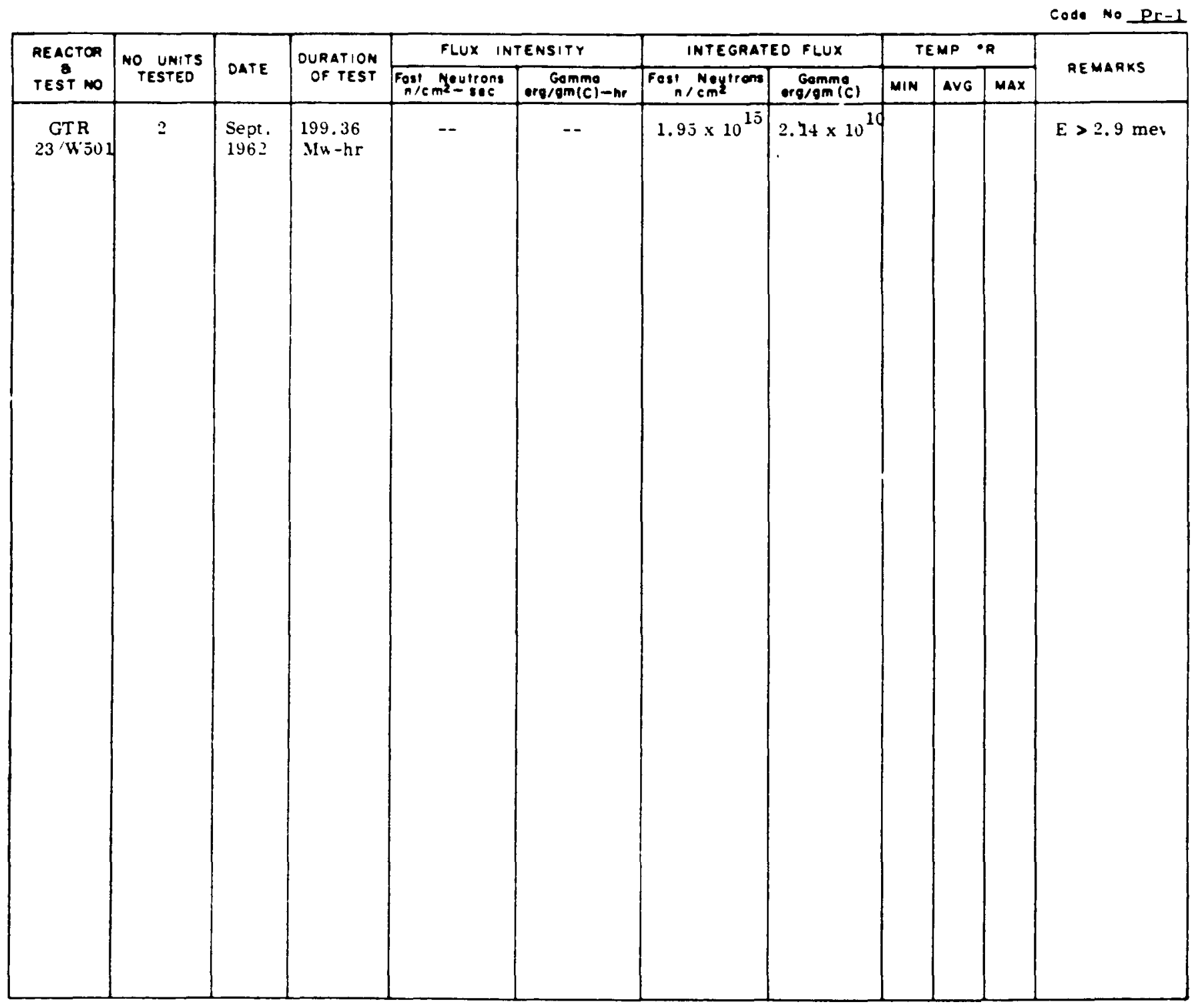

comers

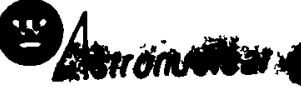




\section{DEVELOPMENT HISTORY}

Code No:

Pr-1

Model No.

PX 100

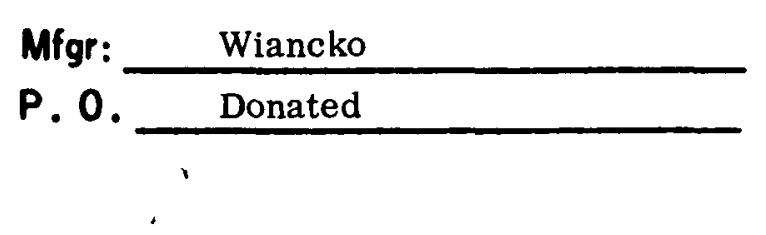

\section{REMARKS:}

Two Wiancko Engineering pressure transducers - one Type PX-101, 476-BS, and one Type PX-100, 476-A-N - both 0-30 psig, were irradiated while immersed in liquid nitrogen.

These transducers have sensitive elements consisting of a 2-arm variable reluctance bridge. These pickups use a twisted tube as the pressure element. They have a pressure range of from 0 to $30 \mathrm{psig}$ and use an ac excitation voltage at 3000 cycles. The output of the rectifier demodulator is 0 -to-5 VDC.

Radiation Test No. 23/W501, S/N's 476AN \& 476BS, Concluded 10/2/62

The test was performed in the Radiation-Effects Testing System of the Nuclear Aerospace Research Facility of General Dynamics/Fort Worth to evaluate the effect of radiation on some selected commercial transducers being considered for use in the NERVA program. A stimulus was applied to the transducers during the test so that a dynamic response in a radiation field could be obtained.

The test specimens, mounted on test fixtures, were furnished by Westinghouse Astronuclear Laboratory. The specimens were placed in an environmental chamber in the Irradiated Materials Laboratory (IML) of GD/FW and calibrated. The resulting data were compared with data taken by WANL to check the condition of the specimens immediately prior to irradiation.

The environmental chamber was then transferred to the test facility and integrated into the test setup. Immediately before the chamber was moved into irradiation position, the performance of each specimen was again checked and the data reviewed by GD/FW and WANL engineers to ensure that all specimens were operating normally. Then the environmental chamber was moved into irradiation position, where the specimens were exposed for a total of $199.36 \mathrm{Mw}-\mathrm{hr}$. During the test, the environmental chamber was held at liquid-nitrogen temperature $\left(-320^{\circ} \mathrm{F}\right)$.

The test fixture with the transducers installed was set up in the IML, with the operation of the transducer and data acquisition system being checked at ambient temperature. The test fixture was then moved to the reactor and filled with liquid nitrogen. The preirradiation data were then taken. The reactor was brought to power and the transducer irradiated for 57 hours. The reactor was shut down and a postirradiation data cycle taken at $\mathrm{LN}_{2}$ and at ambient temperature. The environmental chamber was then returned to the IML and the specimens removed for postirradiation analysis.

The transducers were excited with a unit furnished by Wiancko. The same unit also rectified and demodulated the output so that it could be read with a dc meter. The power to the Wiancko carrier system was a 28 -volt regulated $(0.05 \%)$ supply. The output of the transducer and demodulator was monitored with a $+0.01 \%$-accuracy digital voltmeter. The $28.00-\mathrm{VDC}$ input to the carrier system was also monitored before each pressure cycle with the same digital meter. The helium-gas pressure used to drive the transducers was measured with a calibrated Heise gage of $0.1 \%$ accuracy. 


\section{DEVELOPMENT HISTORY}

Code No: $\frac{\text { Pr-1 }}{\text { Model No. PX 100 }}$

Mfgr: $\frac{\text { Wiancko }}{\text { P. O. }}$

\section{REMARKS:}

Test Summary:

These transducerswere exposed to an integrated neutron flux of $1.95 \times 10^{15} \mathrm{n} / \mathrm{cm}^{2}$ (E $>2.9 \mathrm{Mev}$ ) and a gamma dose of $2.14 \times 10^{10} \mathrm{ergs} / \mathrm{gm}(\mathrm{C})$.

The output of Wiancko transducer S/N $476 \mathrm{AN}$ was within $+5 \%$ of an average pressure curve throughout the irradiation. The zero shift between the ambient temperature data cycles and the $L N$, data cycles was less than 0.1 volt. The voltage output versus pressure was linear and repeatable throughout the irradiation.

The output of Wiancko transducer S/N 476BS varied less than $1 \%$ during the irradiation; however, the re was a maximum zero shift in the output of the transducer of 0.76 volts when it was immersed in $\mathrm{LN}_{2}$. The transducer recovered from this condition upon being removed from the $\mathrm{LN}_{2}$, and pre and postirradiation ambient temperature responses were very similar. The output of the transducer, while being pressure-cycled during the irradiation, was linear and within $1^{\prime \prime}$ from data cycle to data cycle. These two Wiancko transducers were returned to Westinghouse for postirradiation inspection.

Reference: 'Radiation Effects Investigation of Selected Transducers and Materials for NERVA Program." FZK-159-2

\section{General:}

One unit was not affected by the combined liquid nitrogen and irradiation test time; performance was good. The second unit was not affected by the irradiation but did show a change due to the low temperature. This was due to improper evacuation of the reference pressure side before sealing.

Pre-irradiation ambient and $\mathrm{LN}_{2}$ data at WANL and GTR agreed satisfactorily and indicated good performance. Based on the above data, Wiancko has reduced the size and weight of the unit by approximately $2 / 3$ (integral cables are also attached as a prototype for NRX). One absolute and one differential unit are now ready for the second GTR test (see evaluation history per code D Pr-1).

\section{September 1963}

No further evaluation testing will be conducted on this type model. All future evaluation testing will be conducted on models developed from this model. Reference Code No's. $\mathrm{Pr}-10$, Pr-11, Pr-12, Pr-17, and Pr-18 for superseding transducers. 


\section{PRESSURE TRANSDUCER}

Code No:

Type:

Mfgr:

Range:
$\operatorname{Pr}-2$

Strain Gage (Unbonded) Statham

$0-600$ psig
Planning Parts List No:

Evaluation By:

Model No:

WANI.

PG 732 TC

Sensing Element : Diaphragm/Strain Gage

\begin{tabular}{|c|c|c|c|c|}
\hline Test & Condition & NERVA Requirements & Manufacturer's Specs & $\begin{array}{l}\text { Summary of } \\
\text { Test Results }\end{array}$ \\
\hline A & Overload & 1000 psia & $200 \%$ of rated range & \\
\hline B & Compt. Temp-Range & $140^{\circ} \mathrm{R}$ to $640^{\circ} \mathrm{R}$ & $35^{\circ} \mathrm{R}$ to $640^{\circ} \mathrm{R}$ & \\
\hline C & Excitation & $5 \mathrm{VDC}$ or $\mathrm{AC}$ (nom.) & $5 \mathrm{VDC}$ & \\
\hline D & Sensitivity & $40 \mathrm{mv}$ FR (nom.) & $7 \mathrm{mv} / \mathrm{v}$ & \\
\hline$E$ & Input Impedance & 1000 ohms or less & $350 \mathrm{ohms}$ & \\
\hline$F$ & Output Impedance & 350 ohms (nom.) & 350 ohms & \\
\hline $\mathbf{G}$ & Response time & $5 \mathrm{msec}$ to $63 \%$ & & \\
\hline $\mathrm{H}$ & Freq. Response & $0-50$ CPS flat $3 \mathrm{db}$ & & \\
\hline 1 & Resolution & $<0.1 \% \mathrm{FR}$ & Infinite & \\
\hline$J$ & Linearity & $\pm 2 \%$ FR & $\pm 0.75 \%$ of F.S. output & \\
\hline$K$ & Hysteresis & $50.1 \% \mathrm{FR}$ & & \\
\hline$L$ & Accuracy & $\pm 2 \%$ FR & & \\
\hline$M$ & Acceleration Error & $<0.05 \% \mathrm{FR} / \mathrm{g}$ & $.01 \%$ F.S. $/ \mathrm{g}$ for $1000 \mathrm{psi}$ & \\
\hline$N$ & Vibration Error & $<0.05 \% \mathrm{FR} / \mathrm{g} 0-2 \mathrm{Kc}$ & Erom 0 to ${ }^{2} 5 \mathrm{kc} 0,01 \%$ & \\
\hline 0 & Shock & MILE-E -5422 & & \\
\hline$P$ & Noise Limit & MLL-S-446A & & \\
\hline$Q$ & Neutron Flux & $2 \times 10^{11} \mathrm{n} / \mathrm{cm}^{2}-\mathrm{sec}$ & & \\
\hline$R$ & Gamma Flux & \multicolumn{2}{|l|}{$2.1 \times 10^{9} \mathrm{ergs} / \mathrm{gm}(c)-\mathrm{hr}$} & \\
\hline$\underline{s}$ & Dimensions & $1.3^{\prime \prime}$ O.D. $\times 3^{\prime \prime} \mathrm{lg}$ & $1,12 " 0.0 . \times 3 " 1 \mathrm{~g}$ & \\
\hline$T$ & Weight & $7 \mathrm{oz}$ & $7 \mathrm{oz}$ & \\
\hline$U$ & Resonant Freq. & 3000 CPS min. & & \\
\hline 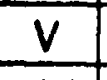 & Insulation Res. & $50 \mathrm{M}$ ohms at $250 \mathrm{VDC}$ & & \\
\hline$w$ & Material & stainless steel & stainless steel & \\
\hline & & & & \\
\hline & & & & \\
\hline & & & & \\
\hline
\end{tabular}



- CANOTOATE TRANSPUCER

Sheet 2 of 5

\begin{tabular}{|l|l|l|l}
\hline DERVA & INSTRUMENTATION DATA BOOK & Dote ${ }_{1}$ January 1964 \\
\hline
\end{tabular}

RADIATION TESTS

Code No $\mathrm{Pr}-2$

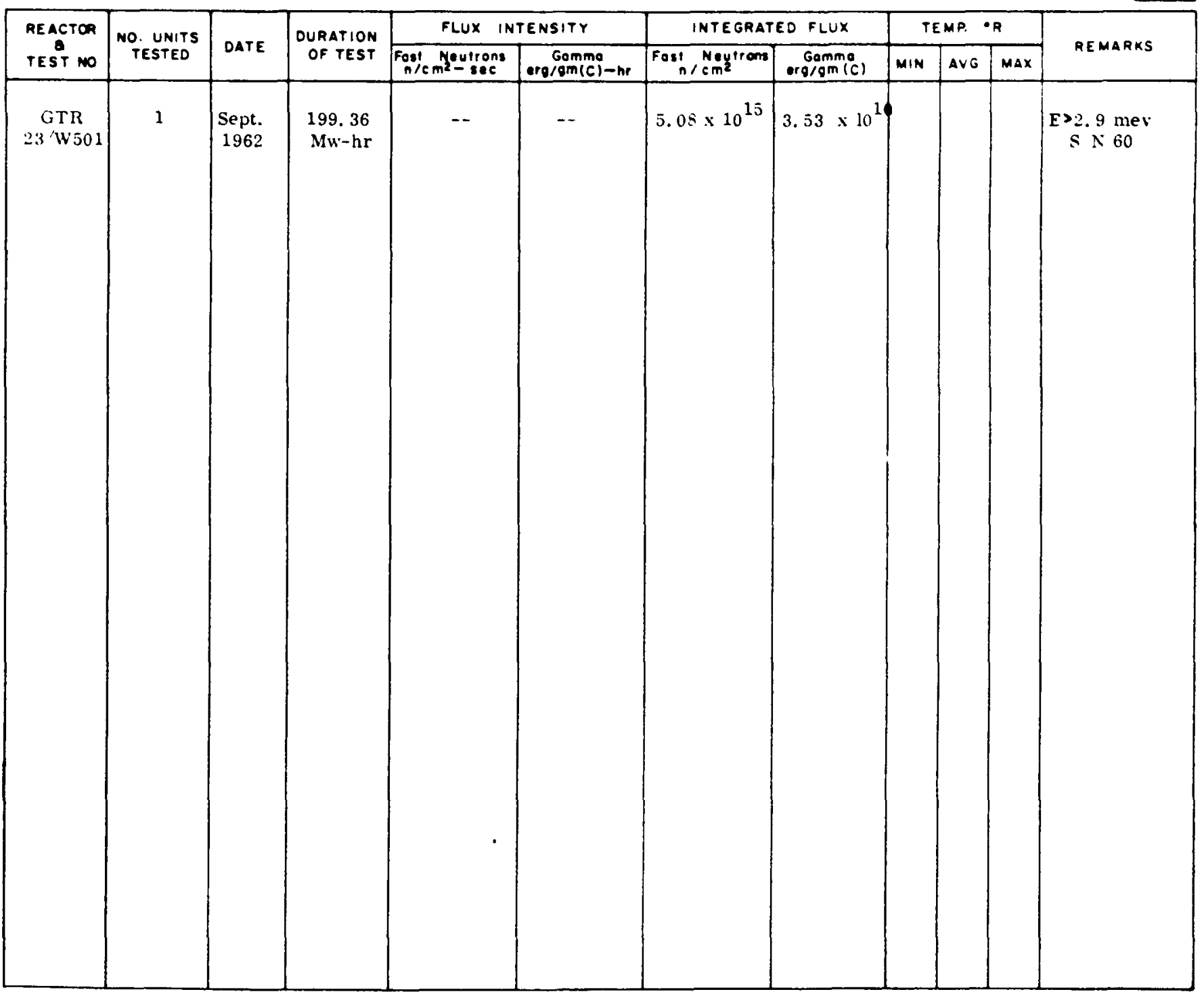




\section{'DEVELOPMENT HISTORY}

Code No:

$\operatorname{Pr}-2$

Model No.

PG 732-TC
Mfgr:

P. 0. 26901

\section{REMARKS:}

A Statham Instruments, Inc., pressure transducer, Type PG-732, 0-to-600 psia, was tested in a combined liquid-nitrogen and radiation environment. This transducer has strainsensitive wire elements arranged in the form of a Wheatstone bridge. It is compensated with temperature-sensitive resistors to operate within the temperature range of from $-425^{\circ} \mathrm{F}$ to $75^{\circ} \mathrm{F}$. The zero shift with temperature should not be more than $\pm 1 \%$ per $100^{\circ} \mathrm{F}$ when operated with a constant voltage input circuit. This temperature compensation should make the instrument suitable for use in a cryotemperature environment.

Radiation Test No. 23/W501, S/N 60, Concluded 10/2/62.

The test was performed in the Radiation-Effects Testing System of the Nuclear Aerospace Research Facility of General Dynamics/ Fort Worth to evaluate the effect of radiation on a stathem pressure transducer being considered for use in the NERVA program. The recommended input voltage was 5.00 VDC, and the input and output resistance of the bridge was 343.6 ohms. The calibration factor was 9,895 microvolts per volt per psi.

The test specimen, mounted on the test fixture, was furnished by Westinghouse Astronuclear Laboratory. The specimen was placed in an environmental chamber in the Irradiated Materials Laboratory (IML) of GD/FW and calibrated. The resulting data were compared with data taken by WANL to check the condition of the specimens immediately prior to irradiation.

The environmental chamber was then transferred to the test facility and integrated into the test setup. Immediately before the chamber was moved into irradiation position, the performance of each specimen was again checked and the data reviewed by GD/FW and WANL engineers to ensure that all specimens were operating normally. Then the environmental chamber was moved into irradiation position, where the specimens were exposed for a total of 199. $36 \mathrm{Mw}-\mathrm{hr}$. During the test, the environmental chamber was held at liquid-nitrogen temperature $\left(-320^{\circ} \mathrm{F}\right)$.

The transducer was excited with $5.00 \mathrm{VDC}, 0.1 \%$ regulation, and the output was monitored with a high-input-impedance digital meter with $\pm 0.01 \%$ accuracy. The excitation voltage and pressure were applied every two hours during the irradiation and the data recorded. The excitation voltage was adjusted to 5.00 VDC prior to each pressure-data cycle. The pressure applied to the transducer was monitored with a calibrated gage of $0.1 \%$ accuracy.

Prior to the irradiation, the transducer was pressure cycled several times at both ambient and liquid-nitrogen temperatures.

After irradiation, two data cycles were run prior to removing the environmental chamber from the test position: one at $\mathrm{LN}_{2}$ temperature, the other at ambient temperature. The environmental chamber was then returned to the IML and the specimens removed for postirradiation analysis.

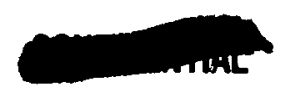




\section{DEVELOPMENT HISTORY}

Code No:

Model No.

Pr-2

PG 732-TC
Mfgr: Statham

P. 0 . 26901

\section{REMARKS:}

Test Summary:

This transducer was exposed to an integrated neutron flux of $5.08 \times 10^{15} \mathrm{n} / \mathrm{cm}^{2}$ ( $E>2.9$ Mev) and a gamma dose of $3.53 \times 10^{10} \mathrm{ergs} / \mathrm{gm}(\mathrm{c})$.

The preirradiation ambient temperature data cycles coincide with the preirradiation $\mathrm{LN}_{2}$ cycles, which indicates normal operation of the temperature compensation. The calibration factor of the transducer varied 5\% during the test. The operation of the transducer was normal throughout the test except for a zero shift. The maximum zero shift was between the preirradiation and postirradiation data cycles and was +6 millivolts. The postirradiation ambient temperature data cycle was $21 \%$ low at the maximum pressure of 600 psia.

An erratic voltage output and a pronounced zero shift of -0.024 volts occured on data cycle No. 9, and the zero pressure point continued to shift up and down during the remainder of the test. The transducer output was not linear on data cycles 9,11 , and 14 . These erratic data cycles could have been caused by icing in the pressure inlet to the transducer.

The input and output resistance of the transducer did not change during the test.

The transducer was disassembled after the test by a representative of Statham Instruments. The following observations were made:

1. The welded or brazed wire connections were still mechanically strong.

2. The insulation on the input wires at the binding posts was badly frayed but still operational.

3. An epoxilite insulation had become unglued because of the breakdown of the adhesive between the insulator and the metal, but had not caused any operational problems.

4. The Teflon wiring insulation was cracked and broken but still operational.

5. A sapphire insulating post that supports the bridge had moved very slightly.

6. A balance resistor used to zero the transducer had changed resistance slightly. This probably caused the zero shifts seen in the data curves.

7. A coating of corrosion almost completely covered the precious-metal plating inside the transducer. 


\begin{tabular}{|c|c|c|c|}
\hline & & & $\begin{array}{l}\text { CANDIDATE TRANSDUCER } \\
\text { DATA SHEET } \\
\text { Sheet } 5 \text { of } 5 \\
\end{array}$ \\
\hline 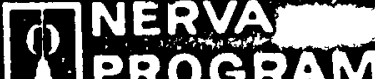 & INSTRUMENTATIOR & DATA BOOK & Dole: 1 January 1964 \\
\hline
\end{tabular}

\section{DEVELOPMENT HISTORY}

Code No:

Pr-2

Model No.

PG 732-TC

Mfgr:

Statham

P. 0 .

26901

\section{REMARKS:}

Reference: "Radiation Effects Investigation of Selected Transducers and Materials for Nerva Program." FZK-159-2.

\section{General}

Pre-irradiation ambient and $\mathrm{LN}_{2}$ data at WANL and GTR agreed satisfactorily and indicated good performance. Based on the above data and a post-irradiation examination, Statham has redesigned two units which are ready for the second GTR test.

Statham selection was based on the following reports:

a. Two models tested at KEWB; no effect after $10^{17} \mathrm{n} / \mathrm{cm}^{2}$

b. NBS tested in $\mathrm{LH}_{2}$; found some zero shift. 


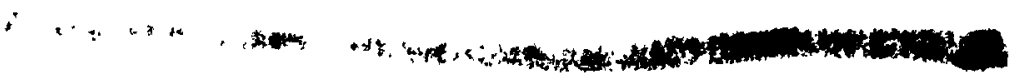

THIS PAGE INTENTIONALLY LEFT BLANK 


\section{PRESSURE TRANSDUCER}

Code No:

$\mathrm{Pr}-3$

Type:

Mfgr: Consolidated Electrodynamics Corp.

Range:

$0-350$ psia

Spec. Control Dwg. No.

Evaluation By:

WANL

Model No:

171300

Sensing Element:

Diaphragm

PERFORMANCE \& ENVIRONMENTAL SPECIFICATIONS

\begin{tabular}{|c|c|c|c|c|}
\hline Test & Condition & NERVA Requirements & Manufacturer's Specs & $\begin{array}{l}\text { Summary of } \\
\text { Test Results }\end{array}$ \\
\hline$A$ & Overload & $1000 \mathrm{psia}$ & $150 \%$ range & \\
\hline B & Compt. Temp Range & $140^{\circ} \mathrm{R}$ to $640^{\circ} \mathrm{R}$ & $35^{\circ} \mathrm{R}$ to $640^{\circ} \mathrm{R}$ & \\
\hline$C$ & Excitation & $5 \mathrm{VDC}$ or AC (nom.) & $5 \mathrm{VDC}$ & \\
\hline D & Sensitivity & $40 \mathrm{mv}$ FR (nom.) & $5 \mathrm{mv} / \mathrm{v}$ & \\
\hline$E$ & Input Impedance & 1000 ohms or less & & \\
\hline$F$ & Output Impedance & 350 ohms (nom.) & $350 \mathrm{ohms} \pm 10 \%$ at $537^{\circ} \mathrm{R}$ & \\
\hline $\mathbf{G}$ & Response time & $5 \mathrm{msec}$ to $63 \%$ & & \\
\hline $\mathrm{H}$ & Freq. Response & $0-50 \mathrm{cps}$ flat $\pm 3 \mathrm{db}$ & & \\
\hline 1 & Resolution & $<0.1 \% \mathrm{FR}$ & Infinite & \\
\hline$J$ & Linearity & $\pm 2 \% \mathrm{FR}$ & $\begin{array}{l}\text { Combined etects }< \pm 0.50 \% \\
\text { of full range }\end{array}$ & \\
\hline$K$ & Hysteresis & $0.1 \% \mathrm{FR}$ & & \\
\hline$L$ & Accuracy & $\pm 2 \% \mathrm{FR}$ & & \\
\hline$M$ & Acceleration Error & $<0.05 \% \mathrm{FR} / \mathrm{g}$ & $\begin{array}{l}\text { at loog the max. }<0.01 \% \\
\text { FR/g for } 1000 \text { psi }\end{array}$ & \\
\hline $\mathrm{N}$ & Vibration Error & $\leq 0.05 \% \mathrm{FR} / \mathrm{g} 0-2 \mathrm{kc}$ & $\begin{array}{l}\text { at 35g peak trom 5-2000 } \\
<0.02 \% \mathrm{FR} / \mathrm{for} 1000 \mathrm{ps}\end{array}$ & \\
\hline 0 & Shock & MIL-E-5422 & $\begin{array}{l}\text { six } 100 \mathrm{~g} \text { impacts in each } \\
\text { (6 millisec duration) }\end{array}$ & xis \\
\hline$P$ & Noise Limit & $M L-S-446 \mathrm{~A}$ & & \\
\hline$Q$ & Neutron Flux & $2 \times 10^{11} \mathrm{n} / \mathrm{cm}^{2}-\mathrm{sec}$ & & \\
\hline $\mathbf{R}$ & Gamma Flux & \multicolumn{2}{|c|}{$2.1 \times 10^{9} \mathrm{ergs} / \mathrm{gm}(\mathrm{C})-\mathrm{hr}$} & \\
\hline $\mathbf{S}$ & Dimensions & \multicolumn{2}{|c|}{$1-1 / 4 "$ × $1-1 / 4 "$ " $3 "$ lg. $1-1 / 4 "$ × $1-1 / 4$ " × 3 " lg. } & \\
\hline$T$ & Weight & $13 \mathrm{oz}$. & $13 \mathrm{oz}$. & \\
\hline$U$ & Resonant Freq. & $3000 \mathrm{cps}$ min. & & \\
\hline $\mathrm{v}$ & Insulation Res. & $50 \mathrm{M}$ ohms at $250 \mathrm{VDC}$ & $\begin{array}{l}100 \text { megohms at } 45 \mathrm{VDC} \\
\text { over comp. temp. range }\end{array}$ & \\
\hline$w$ & Material & stainless steel & stainless steel & \\
\hline & & & & \\
\hline & & & & \\
\hline & & & & \\
\hline
\end{tabular}




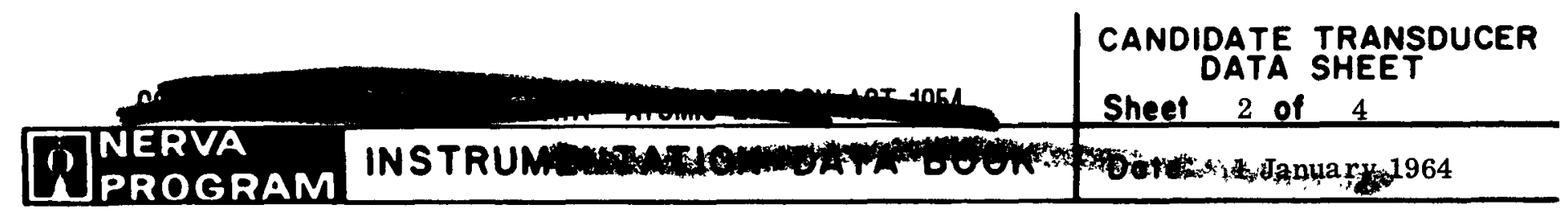

RADIATION TESTS

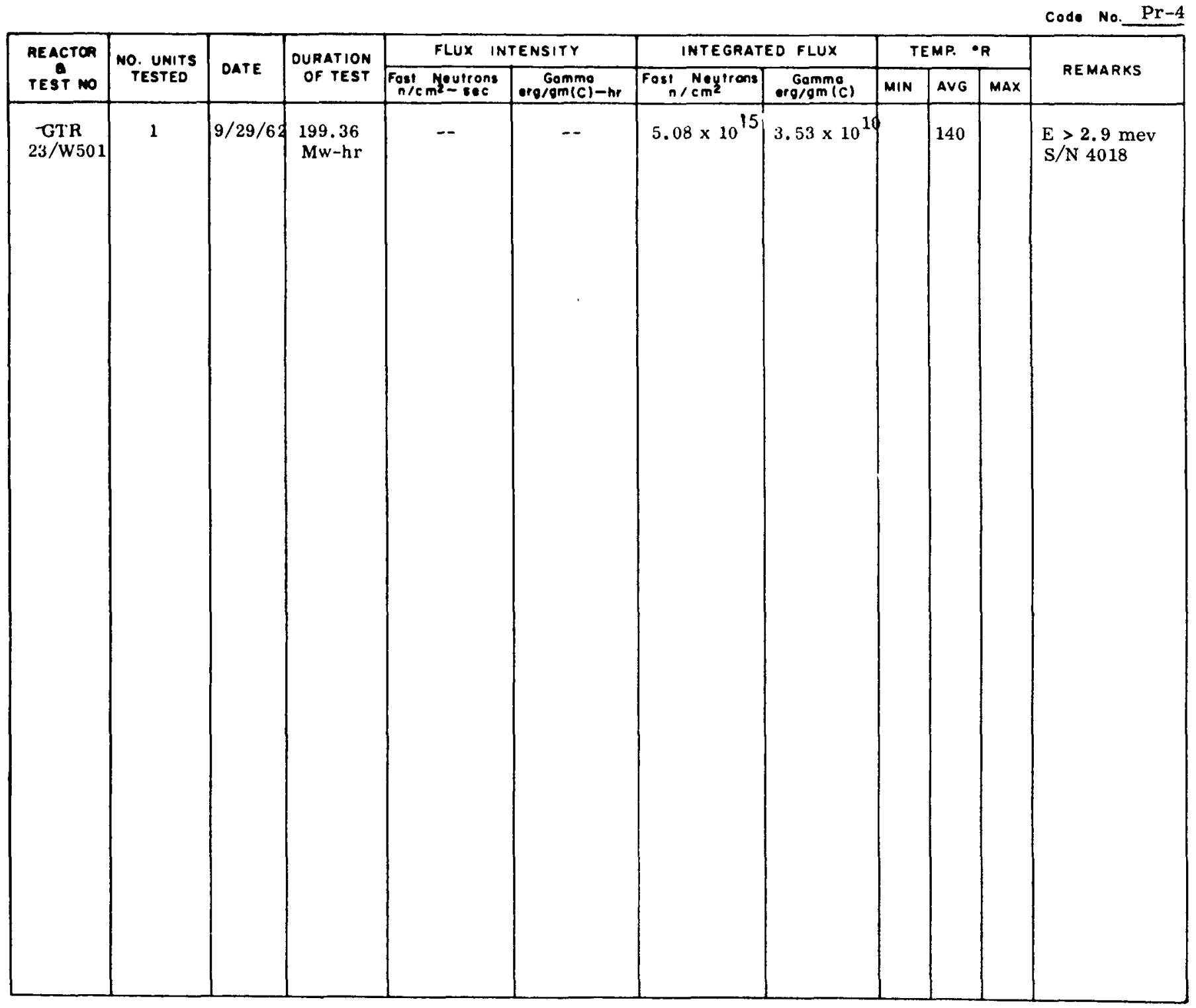

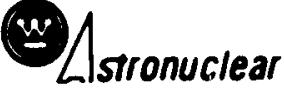




\begin{tabular}{|c|c|c|c|}
\hline & & & $\begin{array}{l}\text { CANDIDATE TRANSDUCER } \\
\text { DATA SHEET } \\
\text { Sheef } 3\end{array}$ \\
\hline n. NERNA & INSTRUMENTATION & DATA BOOK & Dafe: 1 January 1964 \\
\hline
\end{tabular}

\section{DEVELOPMENT HISTORY}

Code No:

Pr-3

Model No.

171300
Mfgr: Consolidated Electrodynamics Corp.

P. 0. Donated

\section{REMARKS:}

Serial Number T1022 -

Two CEC differential pressure units (See Code DPr-3) were tested at GTR on 10/2/62 in the first combined effects test.

Based upon this data and the post-irradiation examination, CEC has redesigned the 4-360 and procured this new model per WANL requirements. July 1963.

This unit will be dynamically tested in the second combined effects test at GTR in

Radiation Test No. 23/W502, S/N T1022, Concluded July 1963

This test was performed in the Radiation Effects Testing System of the Nuclear Aerospace Research Facility of General Dynamics/Fort Worth.

The validity of the test data on some of the items that were in $\mathrm{LN}_{2}$ Dewars was affected by detonations that took place in and around the Dewars after a reactor shutdown at 1409 on May 14 (to repair a control-rod magnet). A preliminary report concerning the detonations is contained in Appendix B of Vol. I: GTR Test 4, FZK-170-1. Some units failed during or shortly after the detonations and, in these cases, failure can probably be attributed to the detonations. In other cases, however, the data indicate impaired operation or subsequent failure so that it is impossible to separate the effects of the detonations from the effects of the radiation. The problem is made more difficult by the wide variance in operating temperatures before and after the detonations. After the detonations, temperatures were restricted to a low of $-170^{\circ} \mathrm{F}$ (using gaseous nitrogen as coolant) in order to preclude the possibility of further detonations. While operating with gaseous nitrogen it was impossible to maintain constant temperatures in the Dewars.

A separate pneumatic system was used for each of the pressure transducers. Helium pressure, monitored with Heise gages, was applied in ten increments covering the transducer range, then was decreased in ten increments. At each point, increasing and decreasing, the transducer output was read on an NLS digital voltmeter and recorded.

Prior to submerging the transducer in liquid nitrogen, the lines were evacuated to 30 microns and purged with helium.

Excitation voltage was applied to the CEC pressure transducer (5VDC) from a Mideastern MP-40-2 power supply. Two copper-constantan thermocouples were attached to the CEC pressure transducer.
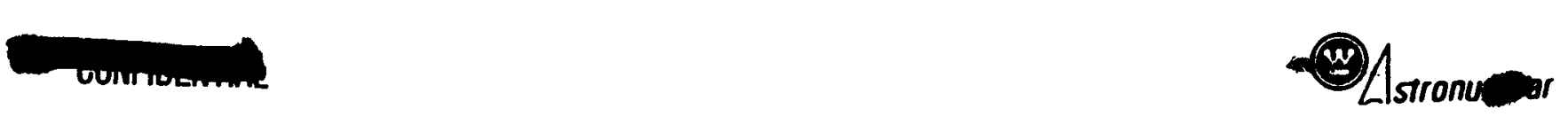


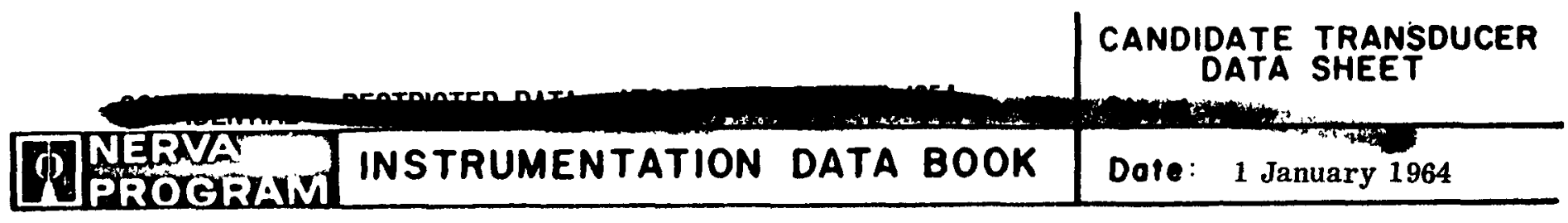

\section{DEVELOPMENT HISTORY}

Code No:

Model No.

$\operatorname{Pr}-3$

171300
Mfgr: Consolidated Electrodynamics Corp.

P. 0. Donated

\section{REMARKS:}

Pre- and postirradiation resistance readings for the pressure transducers were measured and recorded. CEC pressure transducer (0-350 psia) operated until the detonations occurred, then became noisy and would not follow pressure changes. After being returned to the IML, instrumentation and pressure lines were connected to the unit and it was cycled in the same manner as during the test. The results compare very favorably with preirradiation data. It was determined that the erratic behavior of this unit (after the detonations) had been caused by damage to the Physical Sciences T106-10-6S cable assembly that was attached to the transducer. Disassembly of the transducer revealed no internal damage.

At first it was not known to what extent the pressure transducer failures could be attributed to the detonations in the Dewar - either directly, or as a result of possible damage to pressure lines and signal leads when the Dewar was withdrawn from the irradiation cell for examination. Since the Dewar was highly radioactive, special care could not be given to the handling of the lines and leads during movement of the system out of, and back into, the irradiation cell. Before the detonations occurred, the transducer was operative. After the detonations, the transducer was operative. It was subsequently found to be unaffected by the radiation. 


\section{PRESSURE TRANSDUCER}

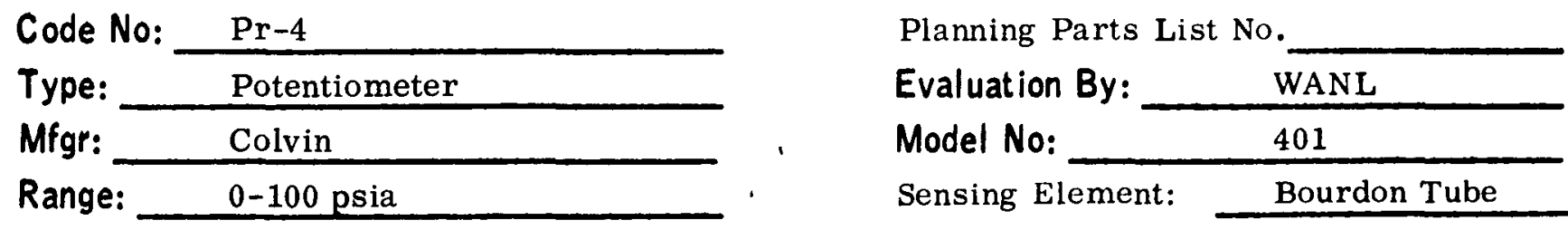

\begin{tabular}{|c|c|c|c|c|}
\hline Test & Condition & NERVA Requirements & Manufacturer's Specs & $\begin{array}{l}\text { Summary of } \\
\text { Test Results }\end{array}$ \\
\hline A & Overload & 1000 psia & $150 \%$ of rated range & \\
\hline$B$ & Compt. Temp Range & $140^{\circ} \mathrm{R}$ to $640^{\circ} \mathrm{R}$ & $140^{\circ} \mathrm{R}$ to $660^{\circ} \mathrm{R}$ & \\
\hline C & Excitation & $5 \mathrm{VDC}$ or $\mathrm{AC}$ (nom.) & $5 \mathrm{VDC}$ & \\
\hline D. & Sensitivity & $40 \mathrm{mv}$ FR (nom.) & $1 \mathrm{v} / \mathrm{v}$ F.S. & \\
\hline$E$ & Input Impedance & 1000 ohms or less & & \\
\hline $\mathbf{F}$ & Output Impedance & 350 ohms (nom.) & \multicolumn{2}{|l|}{ Std. resistance $5000 \mathrm{ohms}$} \\
\hline $\mathbf{G}$ & Response time & $5 \mathrm{msec}$ to $63 \%$ & \multicolumn{2}{|c|}{$63 \%$ of final output in 3 millisec. } \\
\hline $\mathrm{H}$ & Freq. Response & $0-50 \mathrm{cps}$ flat $\pm 3 \mathrm{db}$ & within .25\% F.S. & \\
\hline 1 & Resolution & $<0.1 \% \mathrm{FR}$ & within $\pm .75 \%$ F.S. & \\
\hline $\mathrm{J}$ & Linearity & $\pm 2 \%$ FR & within .6\% F.S. & \\
\hline$K$ & Hysteresis & $0.1 \% \mathrm{FR}$ & & \\
\hline$L$ & Accuracy & $\pm 2 \% \mathrm{FR}$ & & \\
\hline$M$ & Acceleration Error & $<0.05 \% \mathrm{FR} / \mathrm{g}$ & at $109 g$ the max. ${ }^{\circ} .02 \%$ & \\
\hline$N$ & Vibration Error & $<0.05 \% \mathrm{FR} / \mathrm{g} \mathrm{0-2 \textrm {kc }}$ & \multicolumn{2}{|c|}{$\begin{array}{l}35 \mathrm{~g} \text { peak to } 5000 \mathrm{cps} \text { thax. } \\
<1 \% \text {. Sor range }\end{array}$} \\
\hline 0 & Shock & MIL-E-5422 & $100 \mathrm{~g}$ for 3 millisec. & \\
\hline$P$ & Noise Limit & MIL-S-446A & & \\
\hline$Q$ & Neutron Flux & $2 \times 10^{11} \mathrm{n} / \mathrm{cm}^{2}$ sec. & & \\
\hline $\mathbf{R}$ & Gamma Flux & \multicolumn{2}{|l|}{$2.1 \times 10^{9} \mathrm{ergs} / \mathrm{gm}(\mathrm{C})-\mathrm{hr}$} & \\
\hline s & Dimensions & $1.3 " 0 . D . \times 3 " \lg$ & 1" O.D. $\times 3$ 3"lg. & \\
\hline$T$ & Weight & $7 \mathrm{oz}$ & $4.5 \mathrm{oz}$. & \\
\hline$U$ & Resonant Freq. & 3000 CPS min. & & \\
\hline $\bar{v}$ & Insulation Res. & $50 \mathrm{M}$ ohms at $250 \mathrm{VDC}$ & $50 \mathrm{M}$ ohms at $250 \mathrm{VDC}$ & \\
\hline$w$ & Material & stainless steel & stainless steel & \\
\hline & & & & \\
\hline & & & & \\
\hline
\end{tabular}




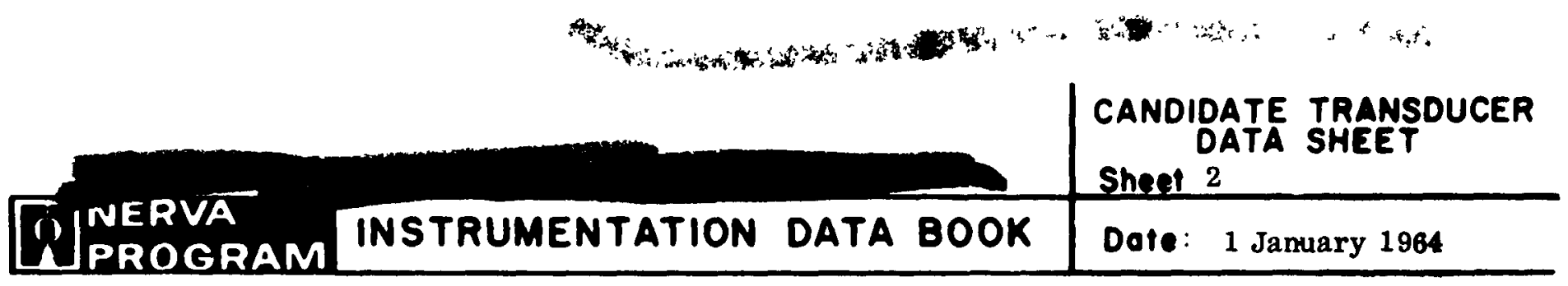

RADIATION TESTS

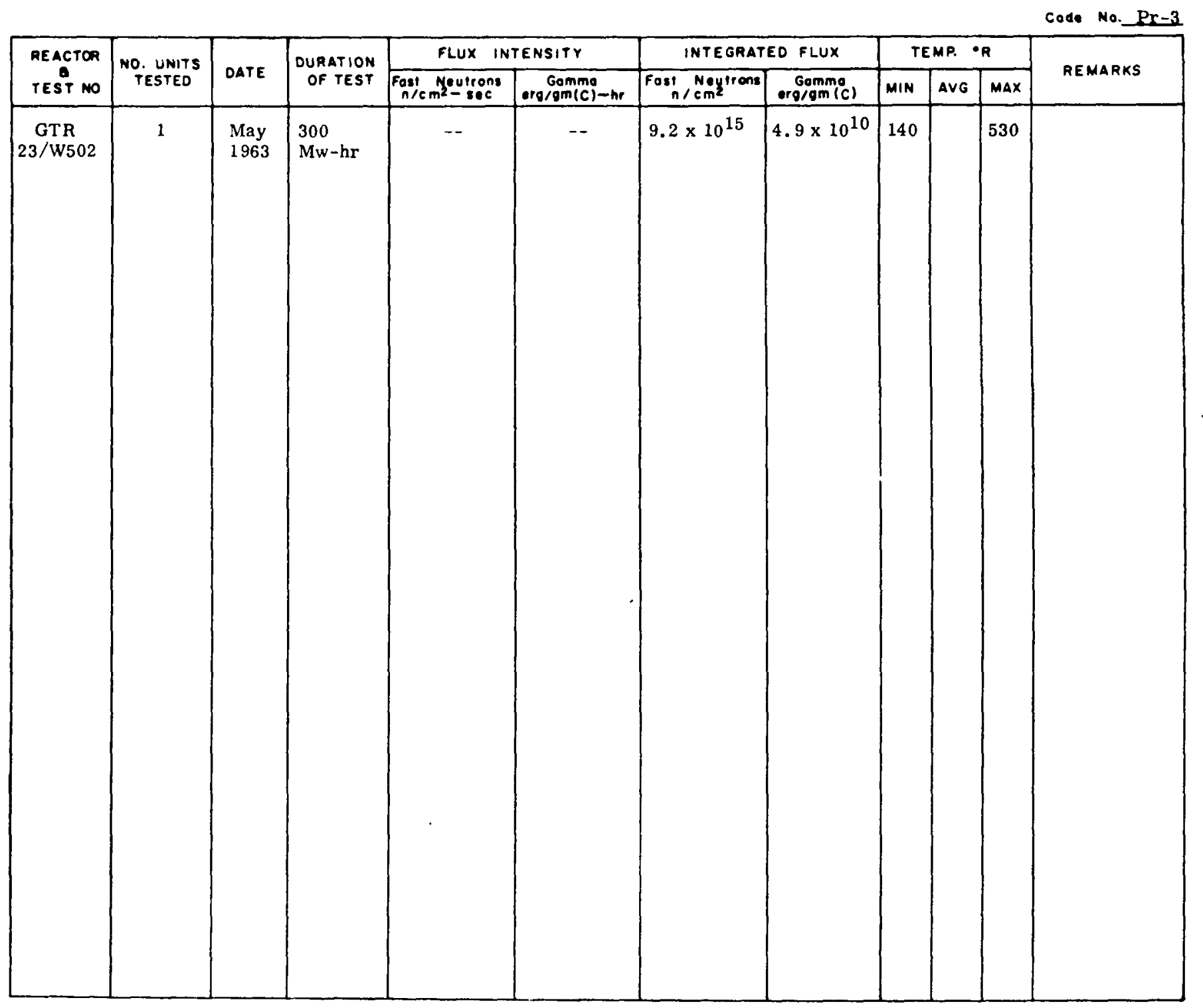

Listronuclear 


\section{DEVELOPMENT HISTORY}

Code No:

Model No.

Pr-4 401
Mfgr: Colvin

P. $0 . \quad 26919$

\section{REMARKS:}

A Colvin pressure transducer, Type 401B, 0-to-100 psig, was tested in a combined radiation and liquid-nitrogen environment.

This pressure transducer has a diaphragm capsule that responds to absolute pressure. The capsule motion actuates the wiper of a precision potentiometer, thus changing the resistance ratio. Application of a voltage across the potentiometer allows this potentiometer to provide an output voltage proportional to the input pressure.

Radiation Test No. 23/W501, S/N 4018, Concluded 10/2/62

The test was performed in the Radiation-Effects Testing System of the Nuclear Aerospace Research Facility of General Dynamics/Fort Worth to evaluate the effect of radiation on a Colvin pressure transducer being considered for use in the NERVA program. A stimulus was applied to the transducer during the test so that a dynamic response in a radiation field could be obtained. The resistance of the potentiometer was $5,000 \mathrm{ohms}$ and the recommended excitation voltage was 5 VDC. The output at maximum pressure was also 5 VDC.

The test specimen, mounted on the test fixture, was furnished by Westinghouse Astronuclear Laboratory. The specimen was placed in an environmental chamber in the Irradiated Materials Laboratory (IML) of GD/FW and calibrated. The resulting data were compared with data taken by AGC to check the condition of the specimens immediately prior to irradiation.

The environmental chamber was then transferred to the test facility and integrated into the test setup. Immediately before the chamber was moved into irradiation position, the performance of each specimen was again checked and the data reviewed by GD/FW and WANL engineers to ensure that all specimens were operating normally. Then the environmental chamber was moved into irradiation position, where the specimens were exposed for a total of 199.36 Mw-hr. During the test, the environmental chamber was held at liquid-nitrogen temperature $\left(-320^{\circ} \mathrm{F}\right)$.

The test fixture, with the transducer installed, was set up in the IML in order to calibrate the transducer. This calibration was performed at ambient temperatures and was satisfactory.

The transducer was energized with a regulated $(0.1 \%)$ dc supply and the output was monitored with an $( \pm 0.01 \%)$ accuracy digital meter. The input pressure was monitored with a calibrated gage of $0.1 \%$ accuracy.

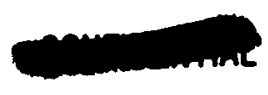




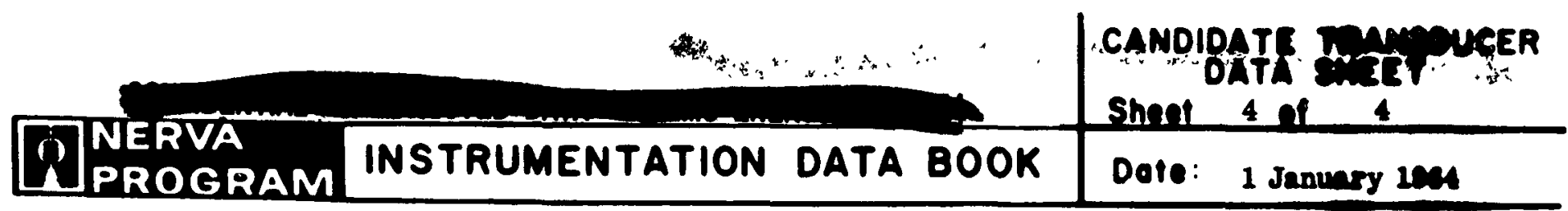

Code No: Model No. $\operatorname{Pr}-4$ 401

\section{DEVELOPMENT HISTORY}

\section{REMARKS:}

Mfgr: $\frac{\text { Colvin }}{26919}$

The transducer was irradiated for 57 hours at liquid nitrogen temperatures. A pressure cycle was performed approximately every two hours and the data recorded. Postirradiation data were taken at liquid-nitrogen temperatures and at ambient $\left(+50^{\circ} \mathrm{F}\right)$ temperature.

After irradiation, two data cycles were run prior to removing the environmental chamber from the test position: one at $\mathrm{LN}_{2}$ temperature, the other at ambient temperature. The environmental chamber was then Feturned to the IML and the specimens removed for postirradiation analysis.

\section{Test Summary:}

This pressure transducer was exposed to an integrated neutron flux of $5.08 \times 10^{15} \mathrm{n} / \mathrm{cm}^{2}$ ( $E>2.9 \mathrm{Mev}$ ) and a gamma dose of $3.53 \times 10^{10} \mathrm{ergs} / \mathrm{gm}(\mathrm{C})$.

The calibration of the transducer at ambient temperature was normal; however, upon being immersed in $\mathrm{LN}_{2}$, the transducer had a zero shift of +0.05 volts. This zero shift remained while the transducer was immersed in $\mathrm{LN}_{2}$. The output of the transducer was relatively stable and linear during the ir radiation. After the irradiation, the temperature was allowed to increase to $+50 \mathrm{~F}$, and the output of the transducer returned to its preirradiation values.

There were no discernible radiation effects on this transducer; however, there was a definite and constant zero shift caused by the $\mathrm{LN}_{3}$ environment. This transducer was not disassembled at GD/FW and has been returned to Westinghouse for analysis. The maximum deviation during the irradiation occurred between Runs 1 and 5. Run 17 was a postirradiation data cycle at ambient temperature.

Reference: "Radiation Effects Investigation of Selected Transducers and Materials for NERVA Program." FZK-159-2

\section{General:}

Due to the inherent design of a potentiometer type transducer, the wiper is subject to vibration and, therefore, the wiper will wear on the coil winding. This can be a serious disadvantage at a steady-state operation. Therefore, this type transducer (now that its combined effects characteristics are known) is shelved for further analysis, pending a need for a back-up if other types prove unsuccessful.

\section{$\underline{30}$ September $\underline{1963}$}

WANL has requested the manufacturer to submit a report on a vibration test of this unit. This report has been received and will be evaluated. Further evaluation (including tests) will be made on this unit before additional radiation test work will be done. 


\section{PRESSURE TRANSDUCER}

Code No: $\quad$ Pr-5

Type: Differential Transformer (Variable Mu)

Mfgr: International Resistance Corp.

Range: $0-1000$ psia
Planning Parts List No:

Evaluation By: WANL

Model No: $\quad 70$

Sensing Element:_Coil Wound on Press. Tube

PERFORMANCE \& ENVIRONMENTAL SPECIFICATIONS

\begin{tabular}{|c|c|c|c|c|}
\hline Test & Condition & NERVA Requirements & Manufacturer's Specs & $\begin{array}{l}\text { Summary of } \\
\text { Test Results }\end{array}$ \\
\hline$A$ & Overload & 1,000 psia & $700 \%$ of range & \\
\hline$B$ & Compt. Temp Range & $140^{\circ} \mathrm{R}$ to $640^{\circ} \mathrm{R}$ & Any $200^{\circ} \mathrm{R}$ span & \\
\hline $\mathrm{C}$ & Excitation & $5 \mathrm{vdc}$ or ac (nom) & $5 \mathrm{vdc}$ ea. 400 to $10 \mathrm{Kc}$ & \\
\hline D & Sensitivity & $40 \mathrm{mv}$ FR (nom) & \multicolumn{2}{|l|}{$0.5 \mathrm{v}$ into $10 \mathrm{k}$ ea. $400 \mathrm{cps}$} \\
\hline$E$ & Input Impedance & 1,000 ohms or less & & \\
\hline$F$ & Output Impedance & 350 ohms (nom) & & \\
\hline$G$ & Response time & $5 \mathrm{msec}$ to $63 \%$ & & \\
\hline $\mathrm{H}$ & Freq. Response & $0-50 \mathrm{cps}$ flat $\pm 3 \mathrm{db}$ & & \\
\hline 1 & Resolution & $<0.1 \% \mathrm{FR}$ & Infinite & \\
\hline $\mathrm{J}$ & Linearity & $\pm 2 \% \mathrm{FR}$ & $\pm 1 / 2 \%$ at 400 cps excit. & \\
\hline$K$ & Hysteresis & $0.1 \% \mathrm{FR}$ & $0.1 \%$ & \\
\hline$L$ & Accuracy & $\pm 2 \% \mathrm{FR}$ & & \\
\hline$M$ & Acceleration Error & $<0.05 \% \mathrm{FR} / \mathrm{g}$ & & \\
\hline $\mathrm{N}$ & Vibration Error & $<0.05 \% \mathrm{FR} / \mathrm{g} 0-2 \mathrm{Kc}$ & $\begin{array}{l}\text { at } 35 \mathrm{~g} \text { from } 65 \text { to } 5000 \mathrm{c} \\
\text { not to exceed } 0 .\end{array}$ & $\begin{array}{l}\text { ps max, respons } \\
\text { or range }\end{array}$ \\
\hline 0 & Shock & MIL-E-5422 & & \\
\hline$P$ & Noise Limit & MIL-S $-446 \mathrm{~A}$ & & \\
\hline$Q$ & Neutron Flux & $2 \times 10^{11} \mathrm{n} / \mathrm{cm}^{2}-\mathrm{sec}$ & & \\
\hline$R$ & Gamma Flux & \multicolumn{2}{|l|}{$2.1 \times 10^{9} \mathrm{ergs} / \mathrm{gm}(\mathrm{C})-\mathrm{hr}$} & \\
\hline$\underline{S}$ & Dimensions & $1-1 / 8^{\prime \prime}$ dia $\times 3 " \mathrm{lg}$ & $1-1 / 8^{\prime \prime}$ dia $\times 3^{\prime \prime} \lg$ & \\
\hline$T$ & Weight & $3 \mathrm{oz}$ & $3 \mathrm{oz}$ & \\
\hline $\mathrm{U}$ & Resonant Freq. & $3000 \mathrm{cps} \mathrm{min}$ & & \\
\hline $\mathrm{V}$ & Insulation Res. & $50 \mathrm{M} \mathrm{ohms}$ at $250 \mathrm{vdc}$ & & \\
\hline$W$ & Material & stainless steel & stainless steel & \\
\hline & & & & \\
\hline & & & & \\
\hline & & & & \\
\hline
\end{tabular}





\section{DEVELOPMENT HISTORY}

Code No:

Model No. $\operatorname{Pr}-5$

70
Mfgr: International Resistance Corp.

P. 0.26918

\section{REMARKS:}

Two IRC pressure transducers, Type 70-62081-2542-1 and Type 70-62081-2542-2, were irradiated at liquid-nitrogen temperatures.

The primary coil of this pressure transducer is excited by a source of alternating current. The two secondary coils are connected in series opposition; thus, any equal ac magnetic flux induced in the two secondaries will result in a very low null output in the millivolt level. When pressure is applied to one side, the magnetic coupling between the primary winding and the corresponding secondary coil will change. Thus, the balance of the bridge will be upset and a new output voltage will result.

\section{Radiation Test No. 23/W501, Concluded 10/2/62}

The test was performed in the Radiation-Effects Testing System of the Nuclear Aerospace Research Facility of General Dynamics/Fort Worth to evaluate the effect of radiation on some selected commercial transducers being considered for use in the NERVA program. A stimulus was applied to the transducer during the test so that a dynamic response in a radiation field could be obtained. The recommended excitation voltage was 6 volts at 400 cycles. The net ac output voltage from the bridge is converted to direct current.

The test specimen, mounted on test fixture, were furnished by Westinghouse Astronuclear Laboratory. The specimens were placed in an environmental chamber in the Irradiated Materials Laboratory (IML) of GD/FW and calibrated. The resulting data were compared with data taken by WANL to check the condition of the specimens immediately prior to irradiation.

The environmental chamber was then transferred to the test facility and integrated into the test setup. Immediately before the chamber was moved into irradiation position, the performance of each specimen was again checked and the data reviewed by GD/FW and WANL engineers to ensure that all specimens were operating normally. Then the environmental chamber was moved into irradiation position, where the specimens were exposed for a total of 199.36 Mw-hr. During the test, the environmental chamber was held at liquid-nitrogen temperature $\left(-320^{\circ} \mathrm{F}\right)$.

The test fixture, with the transducers installed, was set up in the IML, and the transducer and the data-acquisition-system calibration were checked at ambient temperature. This calibration was satisfactory. The 400-cycle excitation voltage was continuously monitored and reset before each pressure cycle. The rectified and demodulated output of the transducers was monitored with a high-impedance $\pm 0.01 \%$-accuracy digital meter. The helium pressure applied to the transducer was monitored on each data cycle with a calibrated Heise pressure gage of 0.1 accuracy.

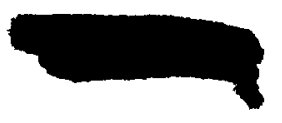




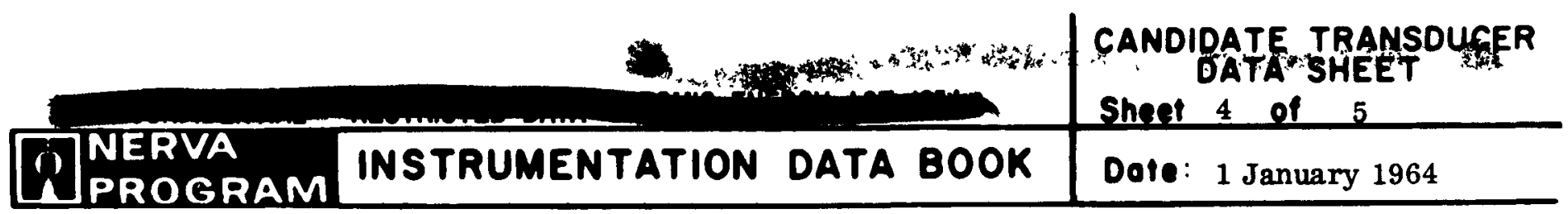

\section{DEVELOPMENT HISTORY}

$\begin{array}{ll}\text { Code No: } \frac{\operatorname{Pr}-5}{70} & \text { Mfgr: } \frac{\text { International Resistance Corp. }}{26918} \\ \text { Model No. }\end{array}$

REMARKS:

The transducers were pressure-cycled several times at both ambient and liquid-nitrogen temperature prior to the irradiation. After irradiation, two data cycles were run prior to removing the environmental chamber from the test position: one at $\mathrm{LN}_{2}$ temperature, the other at ambient temperature. The environmental chamber was then returned to the IML and the specimens removed for postirradiation analysis.

\section{Test Summary:}

These transducers were exposed to an integrated neutron flux of $1.95 \times 10^{15} \mathrm{n} / \mathrm{cm}^{2}$ ( $\mathrm{E}>2.9 \mathrm{Mev}$ ) and a gamma dose of $2.14 \times 10^{10} \mathrm{ergs} / \mathrm{gm}(\mathrm{C})$.

Pressure transducer No. 1 (Model 70-62081-2542-1) malfunctioned when first immersed in liquid nitrogen. The output voltage at maximum pressure decreased from 45 millivolts to 12 millivolts. The output versus input also became very unlinear at cryotemperatures. The transducer remained in this condition until the end of the irradiation. The transducer recovered when returned to ambient room temperature, the response being within $10 \%$ of the preirradiation ambient temperature curves. This transducer was returned to WANL for postirradiaton analysis.

The output voltage at maximum pressure from IRC pressure transducer No. 2 decreased to $35 \%$ of its ambient temperature value when subjected to liquid-nitrogen temperatures. The output remained relatively stable at this value for the remainder of the test. The maximum variation in output voltage response during the irradiation was $10 \%$. After the test, the Dewar was allowed to return to ambient temperature and a data cycle was recorded. This ambient postirradiation data cycle was within $2 \%$ of the ambient preirradiation data cycle.

Both IRC transducers had a pronounced decrease in output voltage when immersed in liquid nitrogen, but there were no discernible effects of radiation. These transducers have been returned to Westinghouse for postirradiation inspection.

Reference: "Radiation Effects Investigation of Selected Transducers and Materials for NERVA Program." FZK-159-2

\section{General}

Liquid nitrogen temperatures effect the permeability of the magnetic material so that the low temperature output is approximately $50 \%$ of the ambient output. The reduced output was maintained to the end of the test. Pre-irradiation and post-irradiation data was approximately the same.

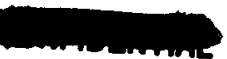




\section{DEVELOPMENT HISTORY}

Code No: $\operatorname{Pr}-5$

Model No.

70
Mfgr: International Resistance Corp.

P. 0. 26918

\section{REMARKS:}

Since thereare no moving parts in this type transducer, it appears to be advantageous for severe requirements for pressure measurements near the core. Further analysis is required.

\section{$\underline{30} \underline{\text { September }} \underline{1963}$}

No work has been done on this unit since the first test. At present it is not known if a different type material can be used to decrease the $\mathrm{LN}_{2}$ temperature effects on the magnetic material. This will be determined in the near future in order to determine the value of continuing further with this principle. 


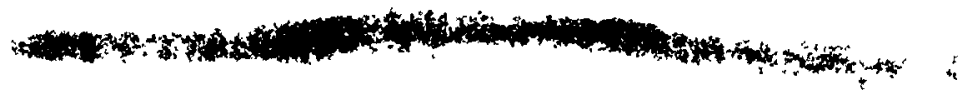

THIS PAGE INTENTIONALLY LEFT BLANK 


\section{INSTRUMENTATION DATABOOK}

CANDIDATE TRANSDUCER

DATA SHEET

Sheet 1 of 4

Date: 1 January 1964

\section{PRESSURE TRANSDUCER}

Code No: $\operatorname{Pr}-6$

Type: Strain Gage

Mfgr: Consolidated Electrodynamics

Range: $\quad 0-300$ psia
Planning Parts List No: $964 \mathrm{~B} 002 \mathrm{H} 02$
Model No: 171835-0101

Sensing Element: Diaphragm

PERFORMANCE \& ENVIRONMENTAL SPECIFICATIONS

\begin{tabular}{|c|c|c|c|c|}
\hline Test & Condition & NERVA Requirements & Manufacturer's Specs & $\begin{array}{l}\text { Summary of } \\
\text { Test Results }\end{array}$ \\
\hline A & Pressure Overrange & \multicolumn{3}{|c|}{$2.5 \mathrm{FR}, 3 \mathrm{~min},<0.5 \%$ aerro $1.5 \mathrm{FR}, 3 \mathrm{~min},<1 \%$ gerf $<0.1 \%$} \\
\hline B & Compt. Temp Range & $140^{\circ}-535^{\circ} \mathrm{R}$ & $140^{\circ}-735^{\circ} \mathrm{R}$ (operable) & $140^{\circ} \mathrm{R}$ to $535^{\circ} \mathrm{R}$ \\
\hline C & Excitation & $5 \mathrm{~V}$ (nom) DC or AC rms & \multicolumn{2}{|c|}{$5 \mathrm{~V}$ (nom) DC or AC rms 5.0VDC } \\
\hline D. & Sensitivity & $20 \mathrm{mv}$ (nom) & $20 \mathrm{mv}+30 \%-10 \% \mathrm{FR}$ & $22.44 \mathrm{mv}$ \\
\hline E & Input Impedance & 350 ohms nom, & 350 ohms $\pm 5 \%$ at $77^{\circ} \mathrm{F}$ & 350 ohms \\
\hline $\mathbf{F}$ & Output Impedance & $350 \mathrm{ohms} \pm 10 \%$ at $77^{\circ} \mathrm{F}$ & 350 ohms $\pm 5 \%$ at $77^{\circ} \mathrm{F}$ & 350 ohms \\
\hline G & Response time & $5 \mathrm{msec}$ to $63 \%$ & info. later & info. later \\
\hline $\mathrm{H}$ & Freq. Response & flat between $0-500 \mathrm{cps}$ & info. later & info. later \\
\hline 1 & Resolution & $0.01 \% \mathrm{FR}$ & & $0.0045 \%$ FR \\
\hline$J$ & Linearity & \multirow{2}{*}{$\begin{array}{l}\text { combined effects less } \\
\text { than } \pm 0.75 \% \text { of full } \\
\text { range output }\end{array}$} & \multirow{2}{*}{$\begin{array}{l}\text { combined effects less } \\
\text { than } \pm 0.5 \% \text { of full } \\
\text { range output }\end{array}$} & $0.12 \%$ FR \\
\hline K & Hysteresis & & & \\
\hline $\mathbf{L}$ & Accuracy & info. later & info. later & $0.2 \% \mathrm{FR}$ \\
\hline$M$ & Acceleration Error & $<0.05 \% \mathrm{FR} / \mathrm{g}$ at $100 \mathrm{~g}$ & $<0.5 \% \mathrm{FR} / \mathrm{g}$ at $100 \mathrm{~g}$ & $0.003 \% \mathrm{FR} / \mathrm{g}$ \\
\hline$\underline{N}$ & Vibration Error & \multicolumn{3}{|c|}{$<0.04 \% \mathrm{FR} / \mathrm{g}$ at $50 \mathrm{~g}$ peak $<0.03 \% \mathrm{FR} / \mathrm{g}$ at $15 \mathrm{~g}$ peak $0.012 \% \mathrm{FR} / \mathrm{g}$} \\
\hline 0 & Shock & $1 \mathrm{msec}, 100 \mathrm{~g}$ & info. later & less $\pm 10 \%$ FR \\
\hline $\mathbf{P}$ & Noise Limit & $150 \mathrm{db}$ & info. later & not available \\
\hline Q & Neutron Flux & $\mathrm{NA}$ & & NA \\
\hline $\mathbf{R}$ & Gamma Flux & NA & & NA \\
\hline $\mathbf{S}$ & Dimensions & $0.75^{\prime \prime} \mathrm{OD} \times 1.9^{\prime \prime} \mathrm{LG}$ & $0.75^{\prime \prime}$ OD $\times 1.9^{\prime \prime} \mathrm{LG}$ & $0.75^{\prime \prime}$ OD $\times 1.9^{\prime \prime}$ \\
\hline$T$ & Weight & mfgr. to specify & 54 grams max. & \\
\hline $\mathbf{U}$ & Resonant Freq. & $1000 \mathrm{cps}$ & $8000 \mathrm{cps}$ approx. & $20,400 \mathrm{cps}$ \\
\hline V & Insulation Res. & 100 megohms at $45 \mathrm{VDC}$ & \multicolumn{2}{|c|}{500 megohms min at $45 \mathrm{VDC}$} \\
\hline \multirow[t]{3}{*}{$W$} & Material & compatible with $\mathrm{LH}_{2}$ & 416 Stainless Steel & \\
\hline & & & & $\mathrm{S} / \mathrm{N} 1685$ \\
\hline & & & & \\
\hline
\end{tabular}





\section{DEVELOPMENT HISTORY}

\begin{tabular}{ll} 
Code No: $\frac{\text { Pr-6 }}{171835-0101}$ & Mfgr: Consolidated Electrodynamics \\
Model No. & P. 0. 30635 \\
\hline
\end{tabular}

\section{REMARKS:}

In order to solve the mechanical mounting problems in final assembly, extreme emphasis was placed on physical size of these units.

A literature search for units specified by the manufacturers to satisfy the environmental conditions for NRX-AI has been made and the initial selection is based on these results.

Confirmation of the guarantees will be made in subsequent evaluation tests by WANL.

The actual models selected are similar in design principle in all instances to units previously tested.

The supplier reports that he has performed a submerged $\mathrm{LN}_{2}$ test on a standard unit temperature compensated only to $-65^{\circ} \mathrm{F}$. The performance meets with our specification requirements.

\section{September 1963}

Qualification tests for linear vibration, static acceleration, shock, and time constant (in addition to standard calibration acceptance tests) are nearing completion by the manufacturer. WANL will further test these units to confirm the manufacturers stated performance.

\section{December 1963}

The following is a summary of the Performance and Environmental tests and test data performed on two 0-300 psia CEC strain gage pressure transducers (CEC 171835-0101) during October 1963.

1. The unit was pressurized to full range and the pressure was released. The residual unbalance (zero) was recorded. Then the output voltage as a function of input pressure was plotted for three ascending and descending pressure runs. The combined effects of linearity and hysteresis was measured from the'best straight line through the above calibration points.

2. The unit was vibrated in each of its three mutually perpendicular axis at $15 \mathrm{~g}$ 's peak sinusoidal excitation from 5 to $2000 \mathrm{cps}$ (limited by $1 / 2^{\prime \prime} \mathrm{D}$.A.). Time duration was five minutes for each axis. The maximum vibration response in the sensitive axis (i.e., perpendicular to diaphragm) was recorded.

3. The unit was given an acceleration test of $100 \mathrm{~g}$ 's along each of its three mutually perpendicular axes. The maximum acceleration response which occurred in the sensitive axis of the transducer was recorded.

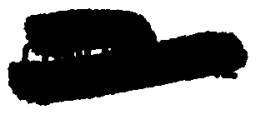




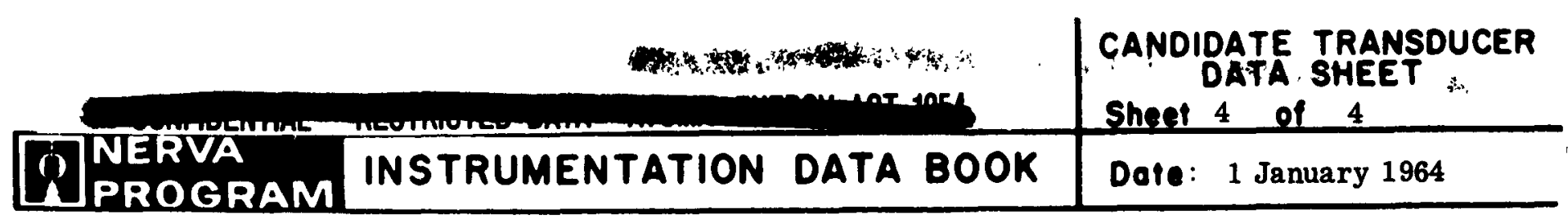

DEVELOPMENT HISTORY

Code No:

Model No. Pr-6

$171835-0101$
Mfgr: Consolidated Electrodynamics

P. 0. 30635

\section{REMARKS:}

4. The unit was subjected to three shocks in each axis of $50 \mathrm{~g}^{\prime} \mathrm{s}$ half sine with a time duration of $11 \pm 1 \mathrm{~ms}$. The residual unbalance was recorded both before and after shock.

5. To measure the natural frequency of the unit, it was installed in a pressure shock tube and a step pressure function was applied to excite the natural frequency of the unit. The output of the unit was connected to an oscilloscope and the natural frequency as displayed on the scope was recorded.

6. Five units, S/N's $17465,17468,17478,3723$ and 3721 were tested at ambient and liquid nitrogen $\left(\mathrm{LN}_{2}\right)$ temperatures. Combined linearity-hysteresis and zero shift were measured and recorded. in all cases.

The results of these tests indicate that the transducers were within specification limits

1

23

35

Residual Linearity and Vibration Error Acceleration Error Natural Frequency $\underline{\mathrm{S} / \mathrm{N}}$ Unbalance (mv) Hysteresis $(\%$ FR) $(\%$ FR/g) $-(\%$ FR/g)

$\begin{array}{rrrrrr}1685 & -1.14 & \pm 0.12 & 0.012 & 0.003 & 20,400 \\ 18077 & -1.28 & \pm 0.30 & 0.008 & 0.004 & 21,700\end{array}$

\begin{tabular}{|c|c|c|c|}
\hline$\underline{s / N}$ & $\begin{array}{l}\text { Ambient Linearity } \\
\text { \& Hysteresis (\% FR) }\end{array}$ & $\begin{array}{c}\mathrm{LN}_{2} \text { Linearity } \\
\& \text { Hysteresis (\% FR) }\end{array}$ & $\begin{array}{l}\text { Zero Shift } \\
1 \% \mathrm{FR} /{ }^{\circ} \mathrm{F}\end{array}$ \\
\hline 3723 & \pm 0.23 & \pm 0.13 & 0.014 \\
\hline 3721 & \pm 0.15 & -- & -0.003 \\
\hline 17465 & \pm 0.16 & -- & -0.012 \\
\hline 17468 & \pm 0.09 & -- & -0.011 \\
\hline 17478 & \pm 0.11 & -- & -0.020 \\
\hline
\end{tabular}




\section{PRESSURE TRANSDUCER}

Code No: $\operatorname{Pr}-9$

Type: Piezoelectric (Dynamic)

Mfgr: Kistler

Range: \pm 25 psid
Planning Parts List No: 964B015H01

Evaluation By: WANL

Model No: 601

Sensing Element: Diaphragm

PERFORMANCE \& ENVIRONMENTAL SPECIFICATIONS

\begin{tabular}{|c|c|c|c|c|}
\hline Test & Condition & NERVA Requirements & Manufacturer's Specs & $\begin{array}{l}\text { Summary of } \\
\text { Test Results }\end{array}$ \\
\hline A & Pressure Overrange & \multicolumn{2}{|c|}{$2.5 \mathrm{FR}, 3 \mathrm{~min} .<5 \%$ drift $5000 \mathrm{psi}$} & 5000 psi \\
\hline B & Compt. Temp Range & $37^{\circ}-535^{\circ} \mathrm{R}$ & $10^{\circ}-960^{\circ} \mathrm{R}$ & \\
\hline C & Excitation & NA & $\mathrm{NA}$ & NA \\
\hline D & Sensitivity & $1.0 \mathrm{pcmb} / \mathrm{psi}$ & $1.0 \mathrm{pcmb} / \mathrm{psi}+30 \%-5 \%$ & $1 \mathrm{pcb} / \mathrm{psi}+26 \%-0 \%$ \\
\hline$E$ & Input Impedance & IA & NA & NA \\
\hline$F$ & Output Impedance & 100 ohms (nom) at amplifie & er 5 Pico farads & $100 \mathrm{ohms}$ amplifie \\
\hline $\mathbf{G}$ & Response time & $3 \mu \mathrm{sec}$ to $63 \%$ & 3 micro seconds & info. later \\
\hline $\mathrm{H}$ & Freq. Response & info. later & info. later & infa. later \\
\hline 1 & Resolution & $1 \% \mathrm{FR}$ & $0.1 \mathrm{psi}$ & $0.1 \mathrm{psi}$ \\
\hline$J$ & Linearity & $\pm 0.5 \% \mathrm{FR}$ or less & $1 \%$ per data shect & $0.66 \%$ \\
\hline $\mathbf{K}$ & Hysteresis & info. later & info. later & $1^{\prime} / \mathrm{c}$ \\
\hline$L$ & Accuracy & info. later & info. later & $2 \%$ \\
\hline$M$ & Acceleration Error & $0.01 \% \mathrm{FR} / \mathrm{g}$ al $1000 \mathrm{~g}$ & $0.01 \mathrm{psi} / \mathrm{g}$ fopplicable $1000 \mathrm{psi}$ & info. later \\
\hline$N$ & Vibration Error & $0.04 \% \mathrm{FR} / \mathrm{g}$ at $50 \mathrm{~g}$ & info. later & $0.046 \% \mathrm{FR} / \mathrm{g}$ \\
\hline 0 & Shock & $100 \mathrm{~g}, 1 \mathrm{~m} \mathrm{sec}$. & $15,000 \mathrm{~g}$ & $1000 \mathrm{~g}, 1 \mathrm{~ms}$ \\
\hline$P$ & Noise Limit & $150 \mathrm{db}$ & info. later & info. later \\
\hline$Q$ & Neutron Flux & NA & NA & NA \\
\hline $\mathbf{R}$ & Gamma Flux & $\mathrm{NA}$ & $\mathrm{NA}$ & $\mathrm{NA}$ \\
\hline $\mathbf{S}$ & Dimensions & 0.25 " OD $\times 0.6$ " LG & $0.248^{\prime \prime}$ OD $\times 0.591^{\prime \prime} \mathrm{LG}$ & $0.248 \mathrm{OD} \times 0.591$ \\
\hline$T$ & Weight & info. later & $0.08 \mathrm{oz}$ & $0.08 \mathrm{oz}$ \\
\hline U & Resonant Freq. & $14,000 \mathrm{cps}$ & $>120,000$ & $>120,000 \mathrm{cps}$ \\
\hline $\mathbf{V}$ & Insulation Res. & $10^{14}$ ohms & $10^{14} \mathrm{ohms}$ & $10^{14} \mathrm{ohms}$ \\
\hline$W$ & Material & compatible with $\mathrm{LH}_{2}$ & stainless steel & $\begin{array}{l}\text { compatible } \\
\text { with }{ }_{2} \mathrm{H}_{2}\end{array}$ \\
\hline & & & & \\
\hline & & & & \\
\hline
\end{tabular}





\section{DEVELOPMENT HISTORY}

Code No:

Model No.

Pr-9

601
Mfgr:

Kistler

P. O. 30498

\section{REMARKS:}

In order to solve the mechanical mounting problems in final assembly, extreme emphasis was placed on physical size of these units.

A literature search for units specified by the manufacturers to satisfy the environmental conditions for NRX-A1 has been made and the initial selection is based on these results.

Confirmation of the guarantees will be made in subsequent evaluation tests by WANL. tested.

The actual models selected are similar in design principle in all instances to units previously

\section{$\underline{31} \underline{\text { July }} \underline{1963}$}

Manufacturer has tested twenty (20) of these units for NRX-A-1 ambient $\left(70^{\circ} \mathrm{F}\right.$ ) and $-320^{\circ} \mathrm{F}$ : Performance was well within the specification limitations. Sensitivity variations between ambient and $-320^{\circ} \mathrm{F}$. fell within a 2.5 percent change with only one unit having a -4.20 percent change. Specifications state that a $19.5 \%$ change is satisfactory.

Further tests are in progress at the WANL laboratories on four (4) in-house units for qualification of the production lot.

\section{September 1963}

This unit was tested at WANL with the Kistler Model 566 Charge Amplifier for temperature effects of cryogenic temperatures $\left(-320^{\circ} \mathrm{F}\right)$ due to a thermal shock. The results showed the maximum output to be equivalent to $7 \mathrm{psi}$ at the thirty-second-after-submersion-point for six (6) transducers tested. The maximum output for the first five seconds after submersion was equivalent to 3 psi. The transducer became stable after 60 seconds. With the transducer mounted in a 5 "L $\mathrm{x} 11 / 2^{\prime \prime} \mathrm{W} \times 3 / 4$ " $\mathrm{D}$ aluminum heatsink, there was no discernible output due to thermal shock.

The transducers were vibrated in the longitudinal direction at $5 \mathrm{~g}^{\prime} \mathrm{s}$ from $50-2000 \mathrm{cps}$. The maximum output for six (6) transducers tested was equivalent to 0.25 psi.

Further tests are to be performed and a formal report of all results will be issued as WANL-TME-535.

The test data tabulated on Page 1 has been summarized from tests conducted both by the manufacturer and WANL in order to establish qualification, acceptance and calibration requirements.

Testing consisted of calibration at ambient and $\mathrm{LN}_{2}$ checking parameters as listed. The transducers were vibrated in the longitudinal and transverse axes by both WANL and Kistler. Vibration was at $10 \mathrm{~g}^{\prime} \mathrm{s}$ by WANL and $20 \mathrm{~g}$ 's by Kistler. 


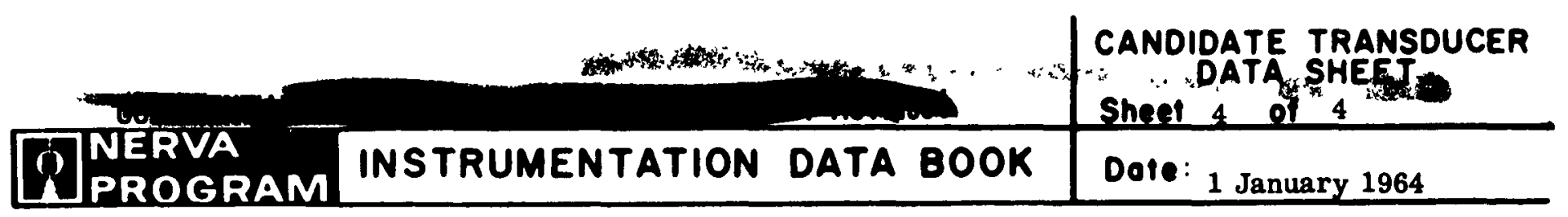

\section{DEVELOPMENT HISTORY}

Code No:

Pr-9

Model No. 601
Mfgr: Kistler

\section{REMARKS:}

The Kistler 566 charge amplifier was used for all tests. The units were vibrated on a MB-C-10, $1200 \mathrm{lb}$. shaker at WANL. The transducers were vibrated at $10 \mathrm{~g}^{\prime} \mathrm{s} \mathrm{rms}$ from 30 to 2000 cps.

The transducers were placed in liquid nitrogen for cryogenic calibration. Dry nitrogen was used as the cal ibrating media. 


\section{PRESSURE TRANSDUCER}

Code No: $\mathrm{Pr}-10$

Type: Variable Reluctance

Mfgr: Wiancko

Range: _ 0-750 PSIA
Spec. Control Dwg. No.

Evaluation By: WANL

Model No: PX-105

Sensing Element Twisted Tube

\begin{tabular}{|c|c|c|c|c|}
\hline Test & Condition & NERVA Requirements & Manufacturer's Specs & $\begin{array}{l}\text { Summary of } \\
\text { Test Results }\end{array}$ \\
\hline$A$ & Press. Overrange 1.: & FR, 3 min. , <0.5\% zero & & \\
\hline B & Compt. Temp Range & $140^{\circ} \mathrm{R}$ to $535^{\circ} \mathrm{R}$ & $435^{\circ} \mathrm{R}$ to $640^{\circ} \mathrm{R}$ & \\
\hline C & Excitation & 5,10, or $20 \mathrm{Vac}, 3 \mathrm{KC}$ & 20 volts, $3000 \mathrm{cps}$ & $20 \mathrm{~V} 3000 \mathrm{cps}$ \\
\hline D. & Sensitivity & $0.1 \mathrm{~V} / \mathrm{V}$ FR at $77^{\circ} \mathrm{F}$ & 5 volts F.S. & 5 volts $F . S$. \\
\hline $\mathbf{E}$ & Input Impedance & NA & NA & $\mathrm{NA}$ \\
\hline $\mathbf{F}$ & Output Impedance & $<1000$ ohms at $77^{\circ} \mathrm{F}$ & $\mathrm{NA}$ & $\mathrm{NA}$ \\
\hline G & Response time & $10 \mathrm{msec}$ to $63 \%$ & & \\
\hline $\mathrm{H}$ & Freq. Response & $0-500 \mathrm{cps}$ flat $\pm 3 \mathrm{db}$ & & \\
\hline 1 & Resolution & $<0.01^{\prime} \mathrm{FR}$ & continuous & \\
\hline $\mathrm{J}$ & Linearity & \multirow{2}{*}{$\begin{array}{l}\text { combincd effects } \\
\text { less than } \pm 0.75 \% \mathrm{FR}\end{array}$} & $0.5 \%$ F.S. & $0.2^{\prime \prime \prime} \mathrm{F} . \mathrm{s}$. \\
\hline K & Hysteresis & & $0.1^{\prime \prime}$, cading & $0.25 \% \mathrm{~F} . \mathrm{S}$ \\
\hline $\mathbf{L}$ & Accuracy & $6 \%$ & & $0.95 \% \mathrm{~F} . \mathrm{S}$. \\
\hline M & Acceleration Error & $<0.05 \% \mathrm{FR} / \mathrm{g}$ at $20 \mathrm{~g}$ & $0.05 \%$ F.S./g & \\
\hline $\mathbf{N}$ & Vibration Error & $<0.02 \% \mathrm{FR} / \mathrm{g}$ at $25 \mathrm{~g}$ & & \\
\hline 0 & Shock & MIL-E-5422 & & \\
\hline $\mathbf{P}$ & Noise Limit & MIL-S-446A & & \\
\hline $\mathbf{Q}$ & Neutron Flux & $1.5 \times 10^{11} \mathrm{n} / \mathrm{cm}^{2}-\mathrm{sec}$ & & \\
\hline $\mathbf{R}$ & Gamma Flux & \multicolumn{2}{|l|}{$5.9 \times 10^{9} \mathrm{ergs} / \mathrm{gm}(\mathrm{c})-\mathrm{h}$. } & \\
\hline $\mathbf{s}$ & Dimensions & $2.2^{\prime \prime} \mathrm{L} \times 1.4^{\prime \prime}$ dia. & $2.2^{\prime \prime} \mathrm{L} \times 1.4^{\prime \prime}$ dia. & $2.2^{\prime \prime} \mathrm{L} \times 1.4^{\prime \prime} \mathrm{di}$ \\
\hline$T$ & Weight & mfgr. to specify & & \\
\hline$U$ & Resonant Freq. & 30000 cps approx. & $3000 \mathrm{cps}$ & \\
\hline $\mathbf{v}$ & Insulation Res. & \multicolumn{2}{|c|}{$>100$ Megohms at $50 \mathrm{VDC}$} & \\
\hline$w$ & Material & \multicolumn{2}{|l|}{ inorganic with combined } & \\
\hline & & boron \& cadmium & & \\
\hline & & content $<30 \mathrm{PPM}$ & & \\
\hline & & & & \\
\hline
\end{tabular}



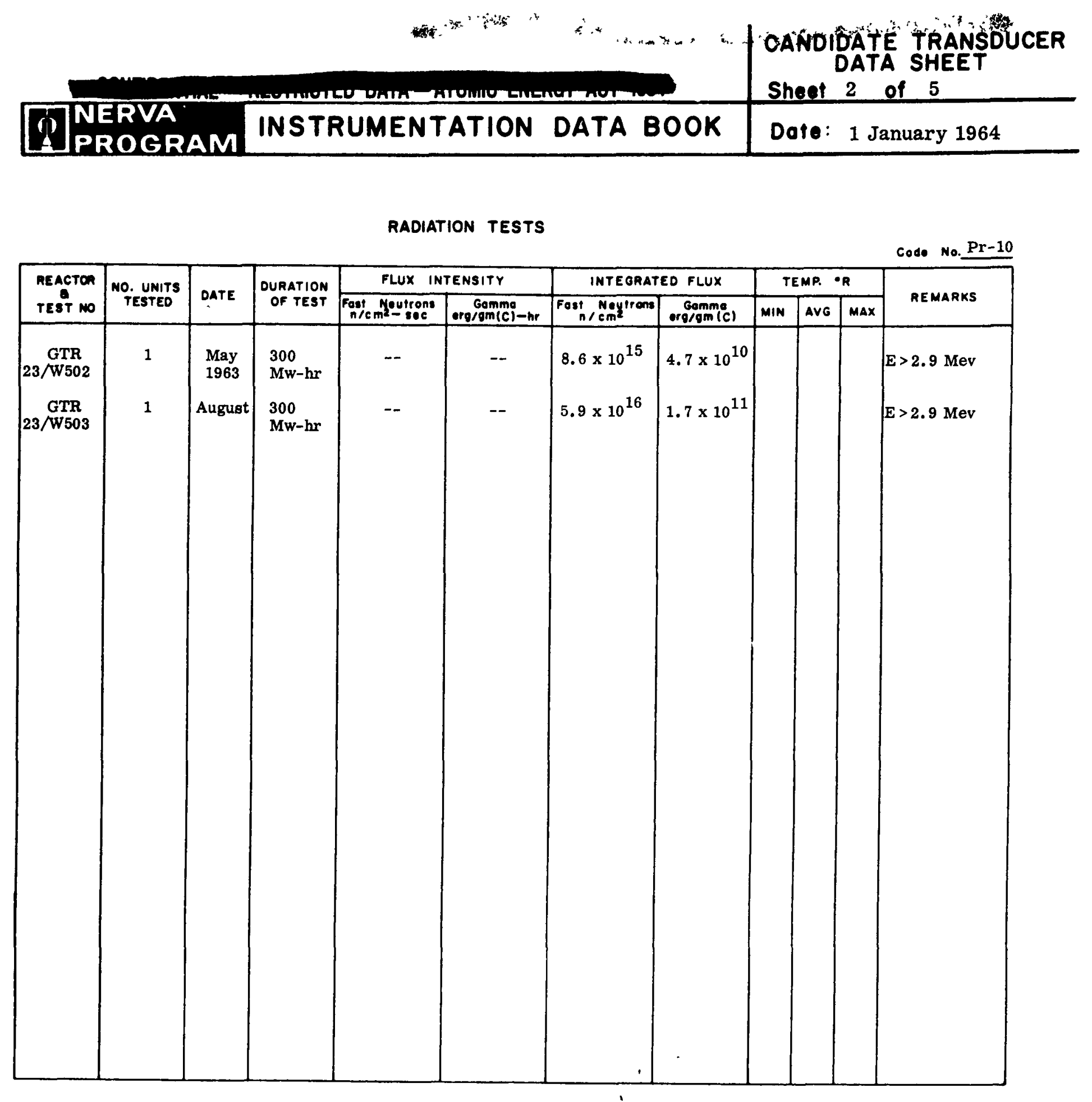


\section{DEVELOPMENT HISTORY}

Code No: $\quad$ Pr-10

Mfgr: Wiancko

Model No. PX-105

P. 0.34727

\section{REMARKS:}

Summary Test Results

A. Combined Effects Test

1. Radiation-Cryogenic Test No. 23/W501 - unit passed - ref. PR-1

2. Radiation-Cryogenic Test No. $23 /$ W502 - unit passed - ref. DPr-1

B. WANL Pre-Irradiation Test per No. 23/W503

Ambient and Vibration vs. $\mathrm{LN}_{2}$ and Vibration - performance good - ref. PR-10 \& DPr-7

General

1. Per 23/W503 one each Wiancko 0-50 psid and 0-750 psia units have been tested by' pressure cycling while being vibrated from 50 to $1000 \mathrm{cps}$ at $3 \mathrm{~g}$ 's in ambient and $5 \mathrm{~g}$ 's submerged in $\mathrm{LN}_{2}$.

2. The ambient data vs. the $\mathrm{LN}_{2}$ data indicates good performance as follows:

Wiancko P1464 (PX-105)

750 PSIA

Tests made at 600 psig reference at both ambient and $\mathrm{LN}_{2}$ temperatures.

Max. Hysteresis in $\mathrm{LN}_{2}-0.58 \%$ F.S.

Max. Non-Linearity in $\mathrm{LN}_{2}-0.3 \% \mathrm{~F} . \mathrm{S}$.

Max. zero shift from ambient to $\mathrm{LN}_{2}-2 \% \mathrm{~F} . \mathrm{S}$.

Repeatability in $\mathrm{LN}_{2}-0.48 \%$ F.S.

Data shown on candidate sheet is data taken at ambient.

Radiation Test No. 23/W502 - Concluded July 1963

This test was performed in the Radiation Effects Testing System of the Nuclear Aerospace Research Facility of GD/FW.

Before moving the items to the reactor area, all instrumentation was connected to the test specimen (using the same harnesses as those to be used in the irradiation test) and data were recorded in the laboratory with the specimen at ambient temperature and at the test temperatures.

The validity of the test data on some of the items that were in $\mathrm{LN}_{2}$ Dewars was affected by detonations that took place in and around the Dewars after a reactor shutdown at 1409 on May 14 (to repair a control-rod magnet). A preliminary report concerning the detonations in contained in Appendix B of Vol. I: GTR Test 4, FZK-170-1. Some units failed during or shortly after the

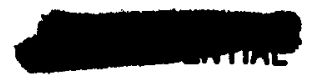




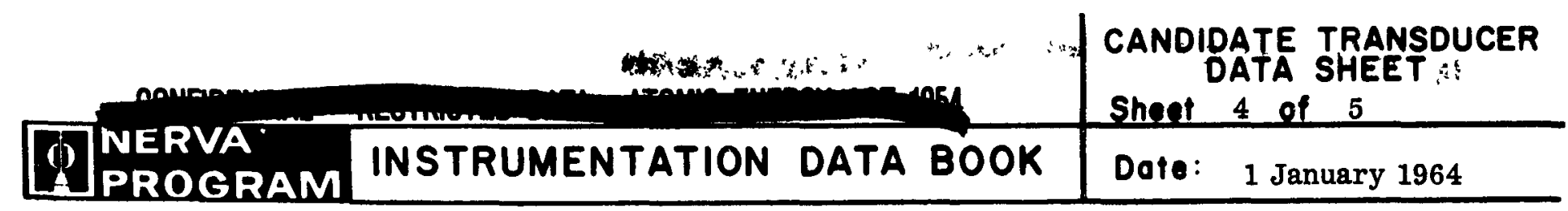

\section{DEVELOPMENT HISTORY}

Code No: $\operatorname{Pr}-10$

Model No. PX-105

Mfgr: $\frac{\text { Wiancko }}{34727}$

\section{REMARKS:}

detonations and, in these cases, failure can probably be attributed to the detonations. In other cases, however, the data indicate impaired operation or subsequent failure so that it is impossible to separate the effects of the detonations from the effects of the radiation. The problem is made more difficult by the wide variance in operating temperatures before and after the detonations. After the detonations, temperatures were restricted to a low of $-170^{\circ} \mathrm{F}$ (using gaseous nitrogen as coolant) in order to preclude the possibility of further detonations. While operating with gaseous nitrogen it was impossible to maintain constant temperatures in the Dewars.

A separate pneumatic system was used for each of the pressure transducers. Helium pressure, monitored with Heise gages, was applied in ten increments covering the transducer range, then was decreased in ten increments. At each point, increasing and decreasing, the transducer output was read on an NLS digital voltmeter and recorded.

Prior to submerging the transducers in liquid nitrogen, the lines were evacuated to 30 microns and purged with helium.

Excitation voltage was applied to the Wiancko unit $(28 \mathrm{v}-\mathrm{dc})$ from a Krohn Hite UHR-220 power supply. Copper-constantan thermocouples were attached to the Wiancko pressure transducer.

Wiancko transducer was inoperative after the detonations, but operated satisfactorily in postirradiation tests. The output at maximum pressure vs dose and the output during pressure cycles were measured and recorded.

It is not known to what extent the pressure transducer failures can be attributed to the detonations in the Dewar - either directly, or as a result of possible damage to pressure lines and signal leads when the Dewar was withdrawn from the irradiation cell for examination. Since the Dewar was highly radioactive, special care could not be given to the handling of the lines and leads during movement of the system out of, and back into, the irradiation cell. Before the detonations occurred, the transducer was operative. After the detonations it was inoperative. The Wiancko transducer was subsequently found to be unaffected by the radiation.

This transducer will be tested again in August 1963.

Radiation Test No. 23/W503 - Concluded August 1963

The test was performed with the Radiation Effects Testing System and the 3-Mw Ground Test Reactor (GTR). The irradiation period was $300 \mathrm{Mw}-\mathrm{hr}$ for all of the test items. In order to observe dose-rate effects, data were recorded at reactor power levels of $10 \mathrm{kw}, 100 \mathrm{kw}$, and $1 \mathrm{Mw}$ before reaching the 3-Mw power level.

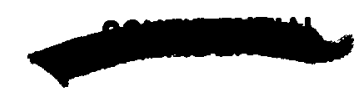




\section{DEVELOPMENT HISTORY}

Code No: $\operatorname{Pr}-10$

Model No. $\mathrm{PX}-105$
Mfgr: Wiancko

P. 0.34727

\section{REMARKS:}

All of the test items were submerged in liquid nitrogen $\left(\mathrm{LN}_{2}\right)$ during the test. A modified NASA-type $\mathrm{LN}_{2}$ Dewar was used at each of the three irradiation positions in the irradiation cell.

Before moving the items to the reactor area, all instrumentation was connected to the test specimens (using the same harnesses to be used in the irradiation test) and data were recorded in the laboratory with the specimens at ambient temperature and at the test temperatures.

The pressure transducers were pressure cycled while being vibrated. Helium pressure, monitored with Heise gages, was increased and decreased in increments of the transducer ranges. At each step in pressure the outputs from the transducers were read on an NLS digital voltmeter, and were recorded on the magnetic tape system. Preirradiation data were recorded at vibration frequencies of 50,450 , and $1050 \mathrm{cps}$. During the irradiation, data were recorded at only one of these frequencies during each cycle. The vibration level was from 3-1/2 g's at $50 \mathrm{cps}$ to $1 \mathrm{~g}$ at $1050 \mathrm{cps}$ for $100 \mathrm{hrs}$.

Resistance measurements were made on the pressure transducer signal leads periodically during the test. Also, the AC and DC vibration-generator coil resistances were measured. The vibration-generators were energized throughout the test except while the resistance measurements were being made.

Sample test data for the pressure transducer is presented in Table 3.5 of GD/FW Preliminary Test Report GTR-7A. Pin-to-pin resistance measurements and transducer outputs (in millivolts) are included in the tables.

After the test specimens were returned to the IML and removed from the Dewar, calibration checks were made individually on the components.

The pressure transducers were pressure cycled in the IML (at ambient temperature) in the same manner as during the irradiation. The data obtained for the three transducers compared favorably with preirradiation ambient data. A preliminary examination of the test data leads to the conclusion that none of the pressure transducers were affected by the radiation or the vibration. radiation.

This type of unit will be tested next at Plumbrook in October 1963 at higher levels of

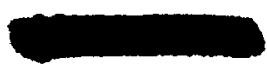




\section{PRESSURE TRANSDUCER}

Code No: $\quad \operatorname{Pr}-15$

Type:

Strain Gage

Mfgr:

Statham

Range:

0-300 PSIA
Spec. Control Dwg. No.

Evaluation By:

Model No:

Sensing Element: Diaphragm

PERFORMANCE \& ENVIRONMENTAL SPECIFICATIONS

\begin{tabular}{|c|c|c|c|c|}
\hline Test & Condition & NERVA Requirements & Manufacturer's Specs & $\begin{array}{l}\text { Summary of } \\
\text { Test Results }\end{array}$ \\
\hline A & Pressure Overrange & $\begin{array}{l}2.5 F \mathrm{Fr}, 3 \text { min.<0.5\% } \\
\text { zero drift }\end{array}$ & & \\
\hline$B$ & Compt. Temp Range & $140-535^{\circ} \mathrm{R}$ & $395-710^{\circ} \mathrm{R}$ & \\
\hline $\mathrm{C}$ & Excitation & $5 \mathrm{~V}$ (nom) $\mathrm{DC}$ or $\mathrm{AC} \mathrm{rms}$ & $7 \mathrm{VDC}$ or $\mathrm{AC} \mathrm{rms}$ & \\
\hline$D$ & Sensitivity & $20 \mathrm{mv}$ (nom) & $56 \mathrm{mv}$ approx. & \\
\hline$E$ & Input Impedance & 350 ohms nom & 350 ohms nom & \\
\hline$F$ & Output Impedance & 350 ohms $\pm 10 \%$ at $77^{\circ} \mathrm{F}$ & $350 \mathrm{ohms}$ nom & \\
\hline$G$ & Response time & $5 \mathrm{msec}$ to $63 \%$ & & \\
\hline $\mathrm{H}$ & Freq. ? sponse & flat between $0-500 \mathrm{cps}$ & & \\
\hline 1 & Resolution & $<0.01 \%$ Fli & infinitesimal & \\
\hline $\mathrm{J}$ & Linearity & \multirow{2}{*}{$\begin{array}{l}\text { combined effects less } \\
\text { than }=0.75 \% \text { of full } \\
\text { range output }\end{array}$} & \multirow{2}{*}{$\begin{array}{l}\text { combined effects less } \\
\text { than } \pm 0.75 \text { of full } \\
\text { range output }\end{array}$} & \\
\hline$K$ & Hysteresis & & & \\
\hline$L$ & Accuracy & info. later & & \\
\hline$M$ & Acceleration Error & $<0.05 \% \mathrm{FR} / \mathrm{g}$ at $100 \mathrm{~g}$ & $0.01 \% \mathrm{FR} / \mathrm{g}$ & \\
\hline$N$ & Vibration Error & peak $0.04 \%$ FR/g at $50 \mathrm{~g}$ & $0.01 \% \mathrm{FR} / \mathrm{g}$ & \\
\hline 0 & Shock & $1 \mathrm{msec}, 100 \mathrm{~g}$ & & \\
\hline$P$ & Noise Limit & $150 \mathrm{db}$ & & \\
\hline$Q$ & Neutron Flux & $\mathrm{NA}$ & & \\
\hline $\mathbf{R}$ & Gamma Flux & NA & & \\
\hline$S$ & Dimensions & $0.75^{\prime \prime} \mathrm{OD} \times 1.9^{\prime \prime} \mathrm{lg}$ & $0.61 "$ OD X $1.3125^{\prime \prime} \mathrm{lg}$ & \\
\hline$T$ & Weight & info. later & $0.5 \mathrm{oz}$. approx. & \\
\hline$U$ & Resonant Freq. & $>1000 \mathrm{cps}$ & $14,500 \mathrm{cps}$ & \\
\hline $\mathrm{V}$ & Insulation Res. & 100 megohm a $45 \times$ DC & & \\
\hline$w$ & Material & compatible with $\mathrm{LH}_{2}$ & & \\
\hline & & & & \\
\hline & & & & \\
\hline & & & & \\
\hline
\end{tabular}




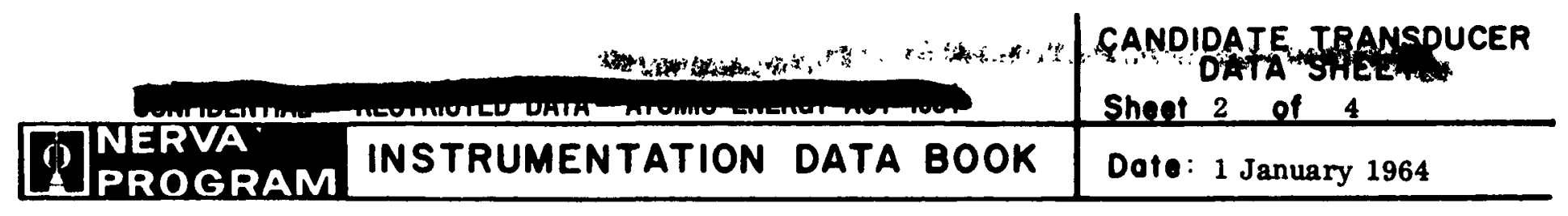

RADIATION TESTS

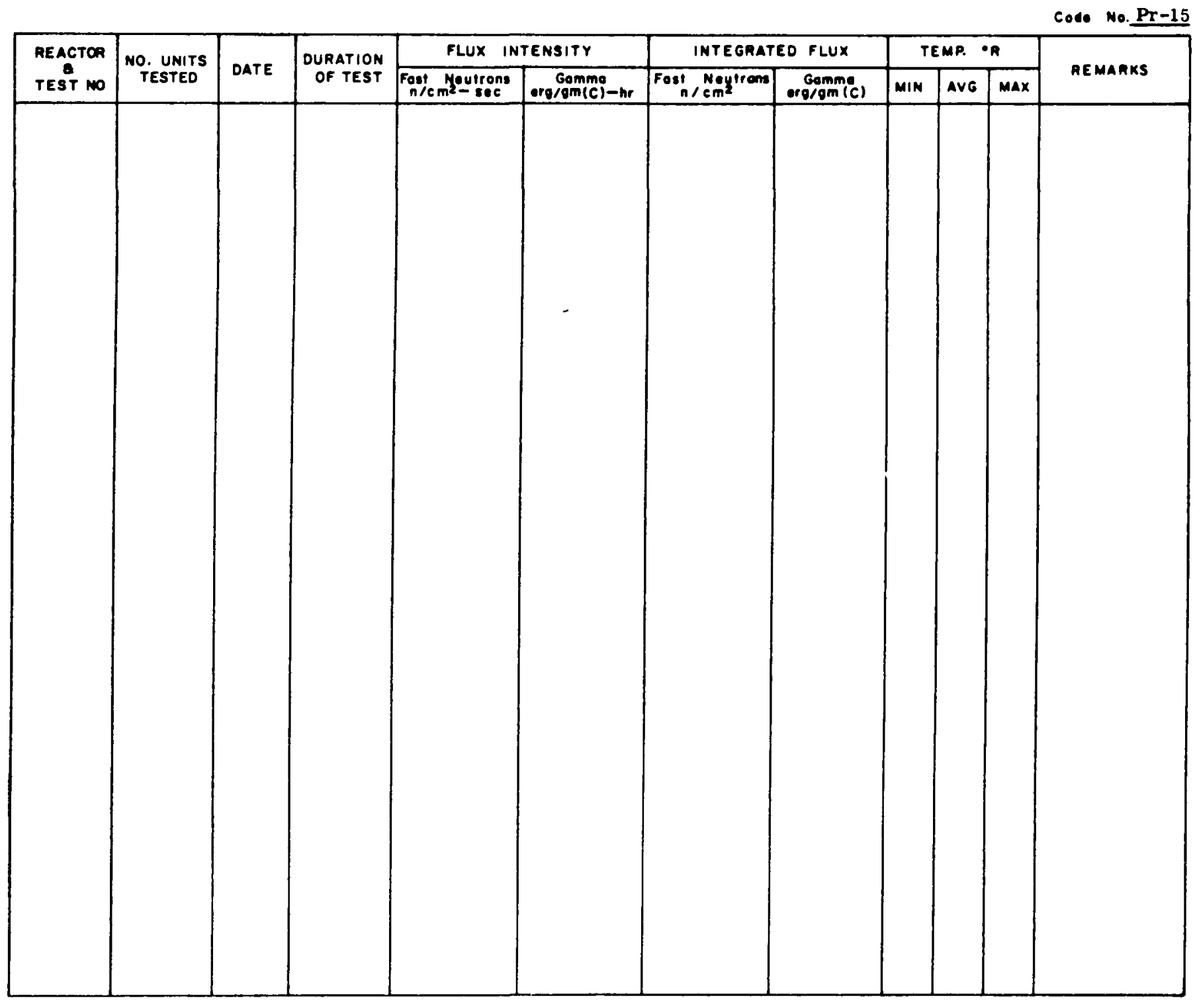

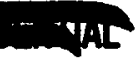

(w) Lstronuclear 


\section{DEVELOPMENT HISTORY}

Code No:

Pr-15

Model No. PA 208e
Mfgr: Statham

P. 0. 30635, 30636

\section{REMARKS:}

In order to solve the mechanical mounting problems in final assembly, extreme emphasis was placed on physical size of these units.

A literature search for units specified by the manufacturers to satisfy the environmental conditions for NRX-A-1 has been made and the initial selection is based on these results.

Confirmation of the guarantees will be made in subsequent evaluation tests by WANL.

The actual models selected are similar in all instances to units previously tested.

\section{$\underline{15}$ December 1963 - Vibration Test}

Several strain gage type pressure transducers of the types to be utilized in NRX-A-1 instrumentation have been vibrated to determine degree of vibration induced output and observe operation characteristics under conditions of vibration. This is a report of obtained test results.

Test Equipment and Instrumentation

An MB Model C10 Vibration Exciter was used as the vibration generator. This equipment, rated at $1200 \mathrm{lbs}$. force, is self-resonant at approximately $2.1 \mathrm{kcs}$. It is useable in the present application to about $2.0 \mathrm{kcs}$ although at this frequency operation is along the lower slope of the resonance curve.

Vibration level was sensed by an Endevco accelerometer and indicated by a Bruel and Kjaer VTVM. The accelerometer-voltmeter combination was calibrated by use of a standard accelerometer. The transducer excitation voltage was indicated by a Simpson Model 260 Multimeter. The oscilloscope was calibrated against its internal calibration voltage.

\section{Test Procedure}

The testing was generally in accordance with the following procedure.

A. The vibration frequency was set to $30 \mathrm{cps}$ and vibration level to $10 \mathrm{~g}$ 's $\mathrm{rms}$.

B. The frequency was slowly increased to $2000 \mathrm{cps}$. The vibration level was manually held to $10 \mathrm{~g}$ 's $\mathrm{rms}$.

C. The transducer and accelerometer outputs were observed on the dual beam oscilloscope and photographed.

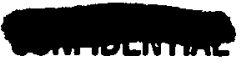




\section{DEVELOPMENT HISTORY}

Code No:

Model No.

Pr-15

PA 208e
Mfgr:

P. 0 .

Statham

30635,30636

\section{REMARKS:}

D. The above steps were repeated with pressure applied to the transducer.

E. Transducer output waveforms were observed and recorded at the frequencies which resulted in the highest vibration induced output.

F. The transducer response to application and removal of pressure was observed and recorded at the frequency of highest vibration induced output.

The above procedures were employed for each of the three axes of the tested transducer.

Summary of Results

Vibration Induced ac Output: The maximum observed vibration induced ac output at the $10 \mathrm{~g} \mathrm{rms}$ vibration level was $0.18 \mathrm{mv}$ or $0.45 \%$ nominal fs output. vibration.

Vibration Induced dc Output Shift: There was no dc output shift as a result of $10 \mathrm{~g}$ rms normal.

Response to Pressure Variation: The response to $4.2 \%$ rated pressure variation was 


\section{PRESSURE TRANSDUCER}

Code No: $\quad$ DPr-1

Type: Variable Reluctance

Mfgr: Wiancko

Range: $\quad 0-125$ psid
Planning Parts List No.

Evaluation By:

WANL

Model No:

PX-102-D

Sensing Element__ Twisted Tube

PERFORMANCE \& ENVIRONMENTAL SPECIFICATIONS

\begin{tabular}{|c|c|c|c|c|}
\hline Test & Condition & NERVA Requirements & Manufacturer's Specs & $\begin{array}{l}\text { Summary of } \\
\text { Test Results }\end{array}$ \\
\hline A & Overload & \multicolumn{2}{|c|}{$1.5 \mathrm{FR}, 3 \mathrm{~min} .<.1 \%$ terrff } & \\
\hline $\mathbf{B}$ & Compt. Temp Range & $140^{\circ}-640^{\circ} \mathrm{R}$ & $140^{\circ}-640^{\circ} \mathrm{R}$ & \\
\hline C & Excitation & 20 VDC or AC (nom.) & $28 \mathrm{VDC}, 18 \mathrm{ma}$ (carrier) & \\
\hline D & Sensitivity & $40 \mathrm{mv}$ FR (nom.) & $140 \mathrm{mv} / \mathrm{v}$ & \\
\hline$E$ & Input Impedance & & & \\
\hline$F$ & Output Impedance & & $<5,000$ ohms (carrier) & \\
\hline $\mathbf{G}$ & Respo.ise time & $5 \mathrm{msec}$ to $63 \%$ & & \\
\hline $\mathrm{H}$ & Freq. Response & $0=50 \mathrm{cps}$ flat $\pm 3 \mathrm{db}$ & & \\
\hline 1 & Resolution & $\angle 0.1 \% \mathrm{FR}$ & Infinute & \\
\hline $\mathrm{J}$ & Linearity & $\pm 2 \% \mathrm{FR}$ & $0.5 \%$ of press. span & \\
\hline $\mathbf{K}$ & Hysteresis & $0.1 \% \mathrm{FR}$ & $0.1 \%$ of press. span & \\
\hline$L$ & Accuracy & $\pm 2 \% \mathrm{FR}$ & & \\
\hline$M$ & Acceleration Error & $<0.05 \% \mathrm{FR} / \mathrm{g}$ & $0.001 \%$ to $.2 \%$ of perge & \\
\hline$N$ & Vibration Error & $<0.05 \% \mathrm{FR} / \mathrm{g} 0-2 \mathrm{Kc}$ & & \\
\hline 0 & Shock & MIL-E-5422 & & \\
\hline$P$ & Noise Limit & MIL-S $-446 \mathrm{~A}$ & & \\
\hline$Q$ & Neutron Flux & $2 \times 10^{11} \mathrm{n} / \mathrm{cm}^{2}-\mathrm{sec}$ & & \\
\hline $\mathbf{R}$ & Gamma Flux & \multicolumn{2}{|c|}{$2.1 \times 10^{9} \mathrm{ergs} / \mathrm{gm}(\mathrm{C})-\mathrm{hr}$} & \\
\hline $\mathbf{s}$ & Dimensions & $1.3^{\prime \prime}$ dia.. $\times 11 / 4^{\prime \prime} \lg$. & $1.3^{\prime \prime}$ dia. $\times 11 / 4 " \mathrm{lg}$ & \\
\hline$T$ & Weight & $12 \mathrm{oz}$ & $4 \mathrm{oz}$. & \\
\hline U & Resonant Freq. & 30000 CPS min. & & \\
\hline $\mathbf{v}$ & Insulation Res. & 50 megohms at $250 \mathrm{vdc}$ & 100 megohms at $50 \mathrm{vdc}$ & \\
\hline$w$ & Material & stainless steel case & stainless steel case & \\
\hline $\mathrm{x}$ & Max Line Press & & 1,000 psia & \\
\hline & & & & \\
\hline & & & & \\
\hline
\end{tabular}




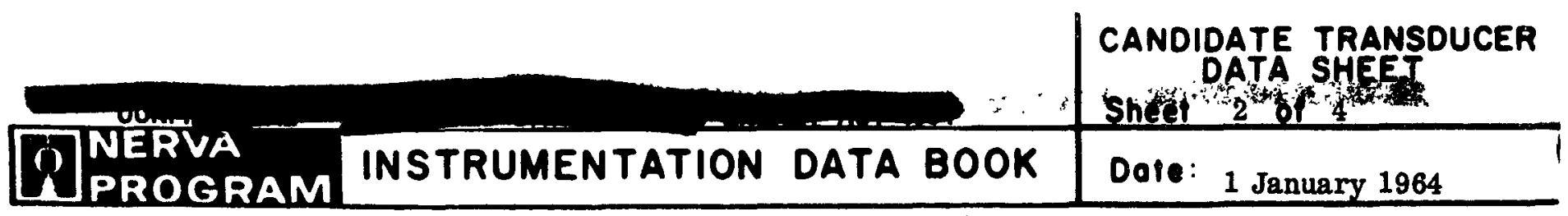

RADIATION TESTS

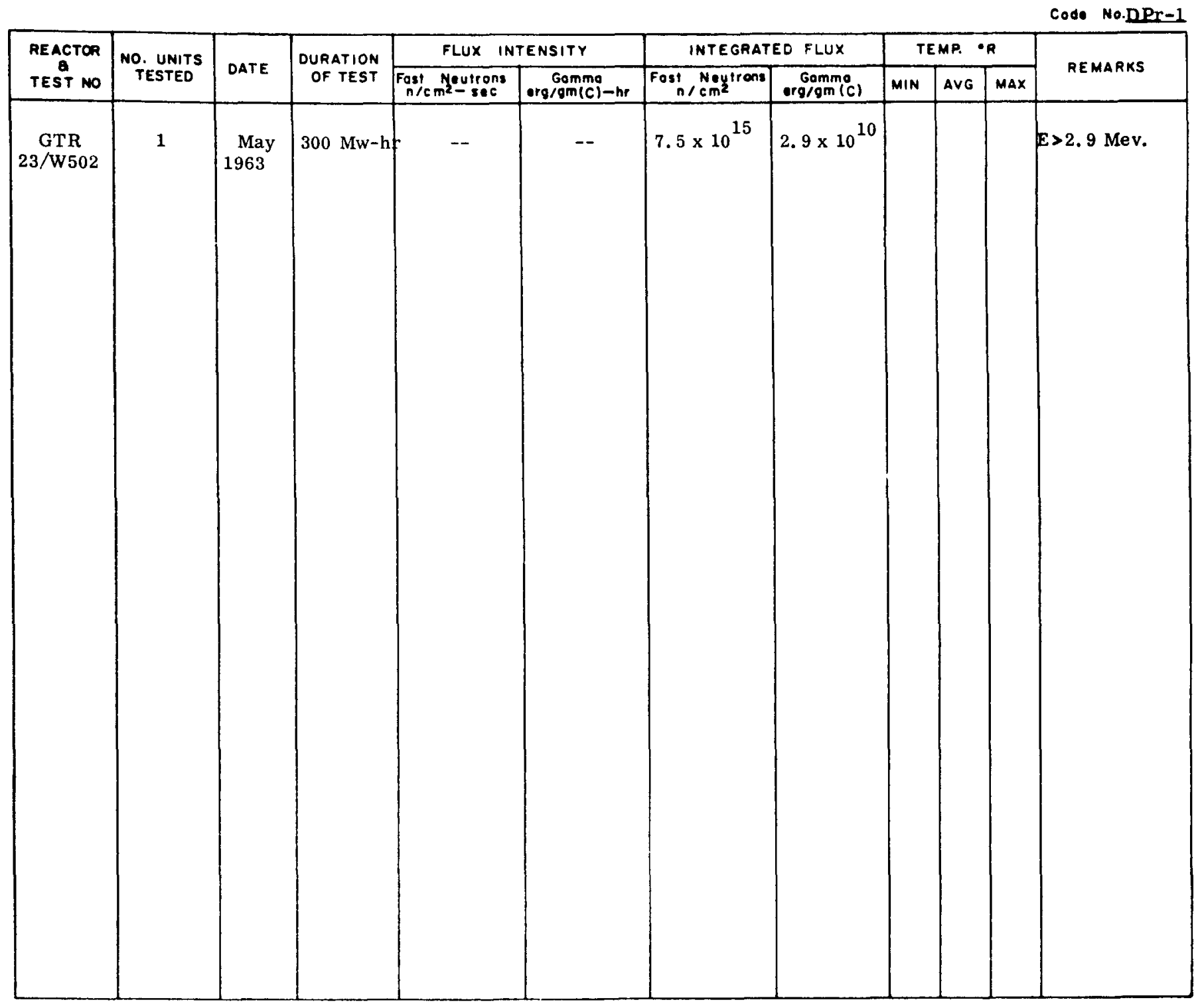

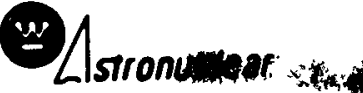




\section{DEVELOPMENT HISTORY}

Code No: $\frac{\mathrm{DPr}-1}{\mathrm{PX}-102-\mathrm{D}}$

Mfgr: $\frac{\text { Wiancko }}{26939}$

REMARKS:

1. A Wiancko gage unit (Serial No. 476-AN) successfully passed the first combined effects test concluded at GTR on 10/2/62. Based on these results, Wiancko designed and fabricated this unit (also an absolute unit) per WANL specifications. Physical Science Corp. was consulted for integrally attaching the metal sheathed cable as a prototype for NRX.

2. This unit will be combined effects tested in the second GTR test in April, 1963.

3. Ref: See Development History for Code $\mathrm{Pr}-1$.

Radiation Test No. 23/W502 Concluded July, 1963

This test was performed in the Radiation Effects testing System of the Nuclear Aerospace Research Facility of General Dynamics/Fort Worth.

The validity of the test data on some of the items that were in $\mathrm{LN}_{2}$ Dewars was affected by detonations that took place in and around the Dewars after a reactor shutdown at 1409 on May 14 (to repair a control-rod magnet). A preliminary report concerning the detonations is contained in Appendix B of Vol. I: GTR Test 4, FZK-120-1. Some unit failed during or shortly after the detonations and, in these cases, failure can probably be attributed to the detonations. In other cases, however, the data indicate impaired operation or subsequent failure so that it is impossible to separate the effects of the detonations from the effects of the radiation. The problem is made more difficult by the wide variance in operating temperatures before and after the detonations. After the detonations, temperatures were restricted to a low of $-170^{\circ} \mathrm{F}$ (using gaseous nitrogen as coolant) in order to preclude the possibility of further detonations. While operating with gaseous nitrogen it was impossible to maintain constant temperatures in the Dewars.

A separate pneumatic system was used for each of the pressure transducers. Helium pressure, monitored with Heise gages, was applied in ten increments covering the transducer range, then was decreased in ten increments. At each point, increasing and decreasing, the transducer output was read on an NLS digital voltmeter and recorded.

Before starting the pressure cycle, 600 psig was applied to both sides of the differential pressure transducers. Prior to submerging the transducers in liquid nitrogen, the lines were evacuated to 30 microns and pruged with helium.

Excitation voltage was applied to the Wiancko units (28 v-dc) from a Krohn Hite UHR-220 power supply.

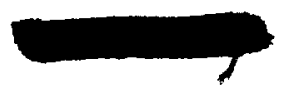




\section{DEVELOPMENT HISTORY}

Code No:

DPr-1

Model No.

$\mathrm{PX}-102-\mathrm{D}$
Mfgr:

Wiancko
26939

\section{REMARKS:}

The Wiancko transducer operated throughout the test, although there was a slight increase in output and a hysteresis effect in the pressure cycles toward the end of the test. Postirradiation tests revealed that it had a slight internal leak.

It is not known to what extent the pressure transducer failures can be attributed to the detonations in the Dewar -- either directly, or as a result of possible damage to pressure lines and signal leads when the Dewar was withdrawn from the irradiation cell for examination. Since the Dewar was highly radioactive, special care could not be given to the handling of the lines and leads during movement of the system out of, and back into, the irradiation cell. Before the detonations occurred, the transducer was operative. After the detonations, the transducer was operative. Plumbrook.

This unit passed this GTR test. Further testing is being planned for this type of unit at

Refer to $\mathrm{Pr}-10$ for further development history on this type model. 


\section{PRESSURE TRANSDUCER}

Code No:

DPr-2

Type: Strain Gage

Mfgr: Statham

Range: $0-50$ psid
Planning Parts List No.

Evaluation By:

Model No:

WANL

Sensing Element:
PL 732 - TC

Diaphragm

\begin{tabular}{|c|c|c|c|c|}
\hline Test & Condition & NERVA Requirements & Manufacturer's Specs & $\begin{array}{l}\text { Summary of } \\
\text { Test Results }\end{array}$ \\
\hline$A$ & Overload & 75 psid & 100 psid & \\
\hline$B$ & Compt. Temp Range & $140^{\circ} \mathrm{R}$ to $640^{\circ} \mathrm{R}$ & $35^{\circ} \mathrm{R}$ to $640^{\circ} \mathrm{R}$ & \\
\hline C & Excitation & 5v DC or AC (nom) & & \\
\hline D. & Sensitivity & $40 \mathrm{mv}$ FR (nom) & & \\
\hline$\underline{E}$ & Input Impedance & $1000 \mathrm{ohms}$ or less & 350 ohms & \\
\hline$F$ & Output Impedance & 350 ohms (nom) & $350 \mathrm{ohms}$ & \\
\hline $\mathbf{G}$ & Response time & $5 \mathrm{msec}$ to $63 \%$ & & \\
\hline $\mathrm{H}$ & Freq. Response & $0-50 \mathrm{cps}$ flat $\pm 3 \mathrm{db}$ & & \\
\hline 1 & Resolution & $<0.1 \% \mathrm{FR}$ & Infinite & \\
\hline J & Linearity & $\pm 2 \%$ FR & $< \pm 0.75 \%$ F.S. & \\
\hline$K$ & Hysteresis & $0.1 \% \mathrm{FR}$ & $< \pm 0.75 \%$ F. S. & \\
\hline$L$ & Accuracy & $\pm 2 \% \mathrm{FR}$ & & \\
\hline$M$ & Acceleration Error & $<0.05 \% \mathrm{FR} / \mathrm{g}$ & $.01 \%$ F.S. $/ \mathrm{g}$ & \\
\hline$N$ & Vibration Error & $<0.05 \% \mathrm{FR} / \mathrm{g} 0-2 \mathrm{kc}$ & $0-2.51$ Kcps $.01 \%$ F.S. $/$ & \\
\hline 0 & Shock & MIL-E-5422 & & \\
\hline $\mathbf{P}$ & Noise Limit & MIL-S-446A & & \\
\hline Q & Neutron Flux & $2 \times 10^{11} \mathrm{n} / \mathrm{cm}^{2}-\mathrm{sec}$ & & \\
\hline $\mathbf{R}$ & Gamma Flux & \multicolumn{2}{|l|}{$2.1 \times 10^{9} \mathrm{ergs} / \mathrm{gm}(\mathrm{C})-\mathrm{hr}$} & \\
\hline $\mathbf{s}$ & Dimensions & $1.12 "$ dia $\times 3 " 1 \mathrm{~g}$ & 1.12 " dia. $\times 3$ "long & \\
\hline$T$ & Weight & $12 \mathrm{oz} \cdot \max$ & $7 \mathrm{oz}$ & \\
\hline $\mathrm{U}$ & Resonant Freq. & $3000 \mathrm{cps}$ min & $11,000 \mathrm{cps}$ & \\
\hline $\mathrm{V}$ & Insulation Res. & \multicolumn{2}{|c|}{50 megohms @ $250 \mathrm{vdc}$} & \\
\hline$w$ & Material & & SS Case & \\
\hline & & & & \\
\hline & & & & \\
\hline & & & & \\
\hline
\end{tabular}




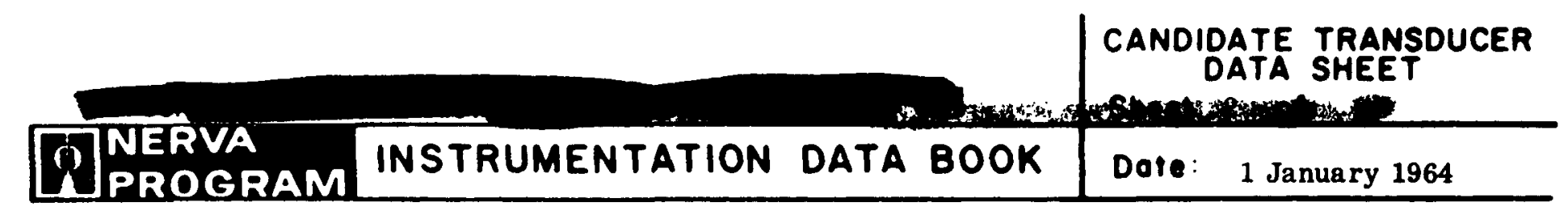

RADIATION TESTS

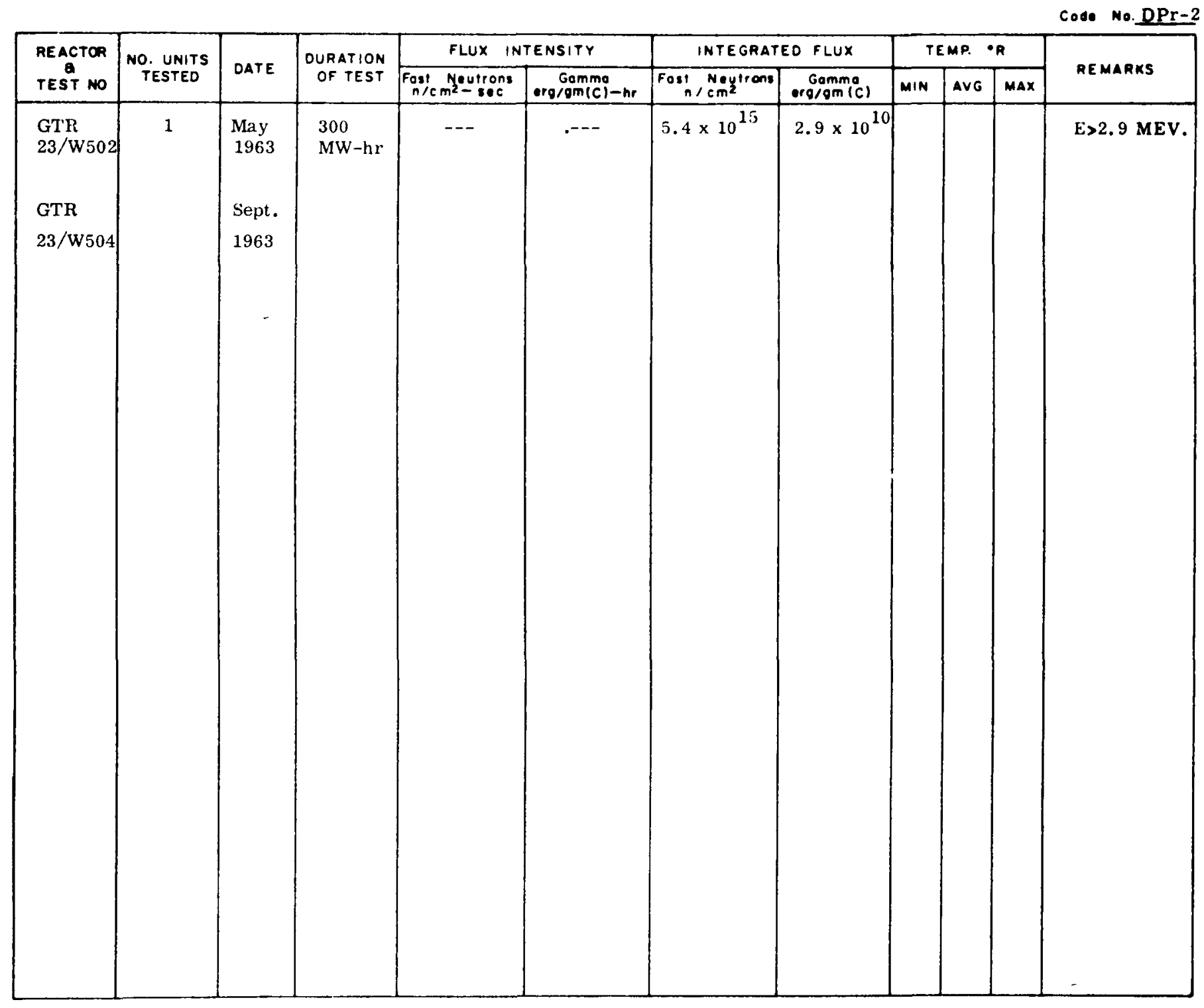

w 


\section{DEVELOPMENT HISTORY}

Code No:

DPr-2

Model No.

PL 732-TC
Mfgr: Statham

P. O. 26940

\section{REMARKS:}

A Statham gage unit (Serial No. 60) was tested on the first combined effects test concluded 10/2/62 at GTR. (See Development History per code Pr-2). Based on this data and a post-irradiation examination, Statham has designed and fabricated this unit (also an absolute unit) per WANL requirements.

This unit will be combined effects tested in the second GTR test in July 1963.

Radiation Test No. 23/W502 - Concluded July, 1963

This test was performed in the Radiation Effects Testing System of the Nuclear Aerospace Research Facility of General Dynamics/Fort Worth.

The validity of the test data on some of the items that were in $\mathrm{LN}_{2}$ Dewars was affected by detonations that took place in and around the Dewars after a reactor shutdown at 1409 on May 14 (to repair a control-rod magnet). A preliminary report concerning the detonations is contained in Appendix B of Volume I: GTR Test 4, FZK-170-1. Some units failed during or shortly after the detonations and, in these cases, failure can probably be attributed to the detonations. In other cases, however, the data indicate impaired operation or subsequent failure so that it is impossible to separate the effects of the detonations from the effects of the radiation. The problem is made more difficult by the wide variance in operating temperatures before and after the detonations. After the detonations, temperatures were restricted to a low of $-170^{\circ} \mathrm{F}$ (using gaseous nitrogen as coolant) in order to preclude the possibility of further detonation. While operating with gaseous nitrogen it was impossible to maintain constant temperatures in the Dewars.

A separate pneumatic system was used for each of the pressure transducers. Helium pressure, monitored with Heise gages, was applied in ten increments covering the transducer range, then was decreased in ten increments. At each point, increasing and decreasing, the transducer output was read on an NLS digital voltmeter and recorded.

Before starting the pressure cycle, 600 psig was applied to both sides of the differential pressure transducers. Prior to submerging the transducers in liquid nitrogen, the lines were evacuated to 30 microns and purged with helium.

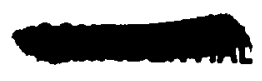




\section{DEVELOPMENT HISTORY}

Code No:

DPr-2

Model No.

PL 732-TC
Mfgr:

P. 0 . Statham

\section{REMARKS:}

Excitation voltage was applied to the Statham unit (5 v-dc) from a Mideastern MP-40-2 power supply. Copper-constantan thermocouples were attached to the Statham pressure transducer.

Output from Statham 2 became erratic at a reactor power level of $100 \mathrm{kw}$, and a large increase in output was noted at the 1-Mw power level. Postirradiation resistance measurements made at the pins on the Statham unit revealed that all pins were open. When the transducer was disassembled for inspection, it was found that the strain wire was broken in all four legs of both units.

It is not known to what extent the pressure transducer failures can be attributed to the detonations in the Dewar - either directly, or as a result of possible damage to pressure lines and signal leads when the Dewar was withdrawn from the irradiation cell for examination. Since the Dewar was highly radioactive, specal care could not be given to the handling of the lines and leads during movement of the system out of, and back into, the irradiation cell. Before the detonations occurred, the transducer was operative, but was becoming erratic. After the the transducer was inoperative. Another redesigned unit will be tested at GTR in September, 1963 which will also include vibration. 


\section{PRESSURE TRANSDUCER}

Code No:

DPr-3

Type:

Mfgr:

Strain Gage

Range:
CEC

$0-100$ psid
Planning Parts List No.

Evaluation By: WANL

Model No: 4-360

Sensing Element Diaphragm

PERFORMANCE \& ENVIRONMENTAL SPECIFICATIONS

\begin{tabular}{|c|c|c|c|c|}
\hline Test & Condition & & Manufacturer's Specs & $\begin{array}{l}\text { Summary of } \\
\text { Test Results }\end{array}$ \\
\hline$A$ & Overload & 125 psid & & \\
\hline$B$ & Compt. Temp Range & $140^{\circ} \mathrm{R}$ to $640^{\circ} \mathrm{R}$ & $35^{\circ} \mathrm{R}$ to $640^{\circ} \mathrm{R}$ & \\
\hline$C$ & Excitation & $5 \mathrm{VDC}$ or $\mathrm{AC}$ (nom.) & & \\
\hline D. & Sensitivity & $40 \mathrm{mv}$ FR (nom.) & $5 \mathrm{mv} / \mathrm{v} \mathrm{F} . \mathrm{s}$. & \\
\hline$E$ & Input Impedance & 1000 ohms or less & $350 \mathrm{ohms} \pm 10 \%$ & \\
\hline$F$ & Output Impedance & 350 ohms (nom.) & 350 ohms $\pm 10 \% @ 537^{\circ} \mathrm{R}$ & \\
\hline $\mathbf{G}$ & Response time & $5 \mathrm{msec}$ to $63 \%$ & & \\
\hline $\mathrm{H}$ & Freq. Response & $0-50$ CPS flat $\pm 3 \mathrm{db}$ & & \\
\hline 1 & Resolution & $<0.1 \% \mathrm{FR}$ & Infinite & \\
\hline $\mathrm{J}$ & Linearity & $\pm 2 \% \mathrm{FR}$ & $\pm .5 \%$ & \\
\hline $\mathrm{K}$ & Hysteresis & $0.1 \% \mathrm{FR}$ & $\pm .5 \%$ & \\
\hline$L$ & Accuracy & $\pm 2 \% \mathrm{FR}$ & & \\
\hline$M$ & Acceleration Error & $<0.05 \% \mathrm{FR} / \mathrm{g}$ & $0.01 \%$ FR $/ \mathrm{g} @ 100 \mathrm{~g}$ & \\
\hline$N$ & Vibration Error & $<0.05 \% \mathrm{FR} / \mathrm{g} 0-2 \mathrm{KC}$ & \multicolumn{2}{|c|}{$0.02 \mathrm{~T} F R / \mathrm{g} @ 35 \mathrm{~g}(5-2000 \mathrm{cps})$} \\
\hline 0 & Shock & MIL-E-5422 & Six $100 \mathrm{~g}$ impacts $6 \mathrm{~ms}$ & \\
\hline$p$ & Noise Limit & MIL-S-446A & $150 \mathrm{db}$ & \\
\hline$Q$ & Neutron Flux & $2 \times 10^{11} \mathrm{n} / \mathrm{cm}^{2}-\mathrm{sec}$ & & \\
\hline $\mathbf{R}$ & Gamma Flux & $2.1 \times 10^{9} \mathrm{ergs} / \mathrm{gm}(\mathrm{C})-\mathrm{hr}$ & & \\
\hline 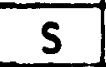 & Dimensions & $11 / 4^{\prime \prime} \times 11 / 4^{\prime \prime} \times 3 " \mathrm{~g}$ & $11 / 4 \times 11 / 4^{\prime \prime} \times 3^{\prime \prime} \mathrm{lg}$ & \\
\hline$T$ & Weight & $12 \mathrm{oz}$. & $12 \mathrm{oz}$. & \\
\hline $\bar{U}$ & Resonant Freq. & 3000 CPS min. & & \\
\hline V & Insulation Res. & 50 megohms 250 VDC & & \\
\hline$w$ & Material & & stainless steel case & \\
\hline & & & & \\
\hline & & & & \\
\hline & & & & \\
\hline
\end{tabular}


RADIATION TESTS

Codo No. nox-3

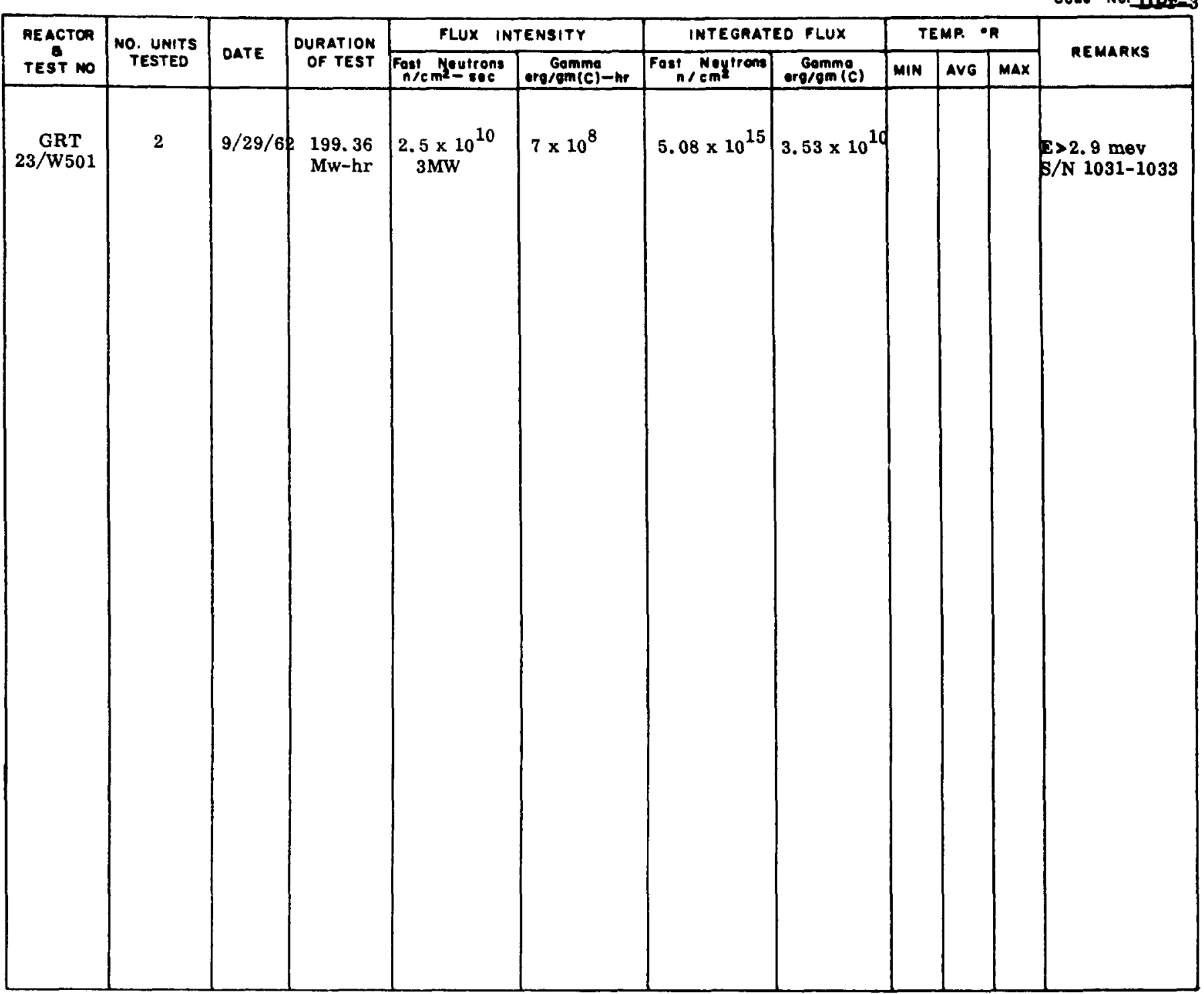




\section{DEVELOPMENT HISTORY}

Code No: $\frac{\text { DPr-3 }}{4-360}$

Mfgr: $\frac{\text { CEC }}{269004 \text { (one unit donated) }}$

\section{REMARKS:}

These transducers have a pressure range of from 0 to 100 psid. They utilize the unbonded strain-gage principle with a four-active-arm, spring-type sensing element and a diaphragm summing area. The sensing unit is of all-welded construction and includes ceramic insulations that are essentially free from boron. The design of this transducer should make it suitable for a cryogenic and nuclear environment.

\section{Radiation Test No. 23/W501, S. N 1031, Concluded 10/2/62}

The test was performed in the Radiation-Effects Testing System of the Nuclear Aerospace Research Facility of General Dynamics/ Fort Worth to evaluate the effect of radiation on CEC Pressure transducers being considered for use in the NERVA program. The excitation voltage used for the test was 5.0 VDC. The bridge output resistance was $350 \mathrm{ohms}$, and the voltage output was approximately 30 millivolts at rated input.

The test specimens, mounted on test fixtures, were furnished by Westinghouse Astronuclear Laboratory. The specimens were placed in an environmental chamber in the Irradiated Materials Laboratory (IML) of GD/FW and calibrated. The resulting data were compared with data taken by WANL to check the condition of the specimens immediately prior to irradiation.

The environmental chamber was then transferred to the test facility and integrated into the test setup. Immediately before the chamber was moved into irradiation position, the performance of each specimen was again checked and the data reviewed by GD/FW and WANL engineers to ensure that all specimens were operating normally. Then the environmental chamber was moved into irradiation position, where the specimens were exposed for a total of $199.36 \mathrm{mw}-\mathrm{hr}$. During the test, the environmental chamber was held at liquid nitrogen temperature $\left(-320^{\circ} \mathrm{F}\right)$.

The excitation voltage was placed on the transducers at 2-hour intervals, and the transducers were then pressure-cycled through their 0- to 100-psid range. The excitation voltage and transducer output voltage were monitored and recorded with a digital voltmeter of $+0.01 \%$ accuracy. The helium pressure to the transducers was monitored with a calibrated Heise pressure gage of $0.1 \%$ accuracy. The pressure transducers were not re-zeroed after the irradiation began, and all zero drift that occurred was measured and recorded.

After irradiation, two data cycles were run prior to removing the environmental chamber from the test position: one at $\mathrm{LN}_{2}$ temperature, the other at ambient temperature. The environmental chamber was then returned to the IML and the specimens removed for postirradiation analysis.

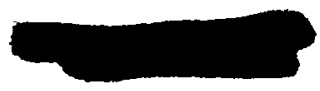




\section{DEVELOPMENT HISTORY}

Code No: $\frac{\mathrm{DPr}-3}{4-360}$

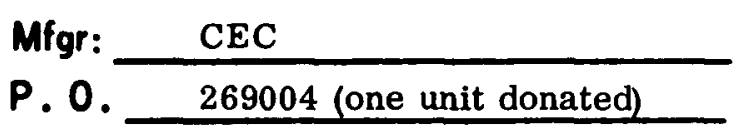

REMARKS:

\section{Test Summary:}

These transducers were exposed to an integrated neutron flux of $5.08 \times 10^{15} \mathrm{n} / \mathrm{cm}^{2}$ (E>2.9 MeV) and a gamma dose of $3.53 \times 10^{10} \mathrm{ergs} / \mathrm{gm}(\mathrm{C})$. Both transducers malfunctioned after being irradiated for 16 hours, when they had received an integrated neutron flux of $1.8 \mathrm{x}$ $10^{15} \mathrm{n} / \mathrm{cm}^{2}$ (E>2.9 Mev).

When the transducer performance changed, the output at zero pressure decreased to a negative potential and remained there throughout the test. As the irradiation proceeded, the output voltage of the transducers decreased to zero and became quite erratic. The transducers did not recover after being removed from the $\mathrm{LN}_{2}$.

The transducers were disassembled for postirradiation inspection by a representative of CEC. During this inspection, broken spot welds of wires from the header pins to the connector were found. These broken welds had been ma de between 410 stainless-steel wires $(0.002$ in. diam.) and 302 stainless-steel wire (.008 in. diam.). All welds between these two materials that had not broken were found to be extremely weak and broke under very slight pressure. It was noted that all the wire of the same size and material (410 stainless steel) that had been spot welded still retained good mechanical and electrical integrity. These welds were tested by applying pressure with long-nose pliers.

The sensing-element case on both transducers was torqued at 25 foot-pounds into the main housing and had bottomed out on a shoulder. The first thread on both transducers had cracked, apparently as a result of the stress caused by immersion in the $\mathrm{LN}_{2}$. The case was made from 17-4 PH stainless-steel. Both transducers had cracks in almost identical places.

The malfunction of these differential units was not attributed to this cracked condition; however, it could have caused difficulties in an absolute unit.

Reference: "Radiation Effects Investigation of Selected Transducers and Materials for Nerva Program." FXK-159-2.

At the same time that WANL was conducting the first combined effects test at GTR, AGC was also testing one CEC 4-360 model; but at a temperature of $510^{\circ} \mathrm{R}$ to $620^{\circ} \mathrm{R}$. The AGC unit did not fail this test. The post-irradiation examination of all four units disclosed that the combined effects of irradiation and liquid nitrogen temperature causes specific malfunctions and failures to the three WANL units but not to the AGC unit. The CEC design engineer present at the postir radiation examination was convinced that combined effects was responsible for the WANL failure. Consequently, the model has been redesigned per WANL requirements.

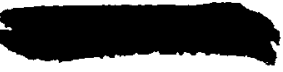




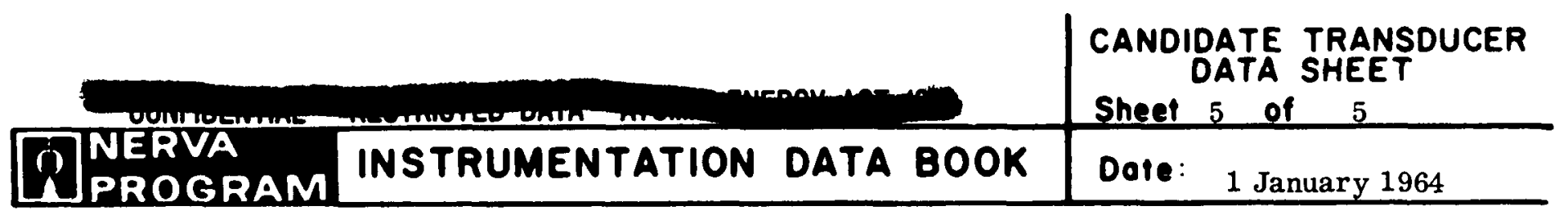

\section{DEVELOPMENT HISTORY}

Code No: DPr-3

Model No. 4-360

Mfgr:

CEC

P. 0. 269004 (one unit donated)

\section{REMARKS:}

One absolute and one differential unit (new design) are on hand for the second GTR combined effects test (see (Code $\mathrm{DPr}-4$ ).

$\underline{30}$ September 1963

There will be no further tests conducted on this unit. It has been replaced by Code No. DPr-4 (CEC Model 171300). 
(4)

\section{THIS PAGE INTENTIONALLY LEFT BLANK}




\section{PRESSURE TRANSDUCER}

$\begin{array}{lll}\text { Code No: } \frac{D P r-4}{\text { Strain Gage }} & \text { Spec. Control Dwg. No. } \\ \text { Type: } & \text { Evaluation By: } & \begin{array}{l}\text { WANL } \\ \text { Mfgr: }\end{array} \\ \text { Range: } & 0-100 \text { psid } & \text { Model No: }\end{array}$

\begin{tabular}{|c|c|c|c|c|}
\hline Test & Condition & NERVA Requirements & Manufacturer's Specs & $\begin{array}{l}\text { Summary of } \\
\text { Test Results }\end{array}$ \\
\hline A & Overload & 125 psid & & \\
\hline $\mathbf{B}$ & Compt. Temp Range & $140^{\circ} \mathrm{R}$ to $640^{\circ} \mathrm{R}$ & $35^{\circ} \mathrm{R}$ to $640^{\circ} \mathrm{R}$ & \\
\hline C & Excitation & 5VDC or AC (nom.) & & \\
\hline D & Sensitivity & $40 \mathrm{mv}$ FR (nom.) & $5 \mathrm{mv} / \mathrm{v}$ & \\
\hline$E$ & Input Impedance & 1000 ohms or less & 350 ohms $\pm 10 \% @ 537^{\circ} \mathrm{R}$ & \\
\hline $\mathbf{F}$ & Output Impedance & 350 ohms (nom.) & 350 ohms $\pm 10 \% @ 537^{\circ} \mathrm{R}$ & \\
\hline $\mathbf{G}$ & Response time & $5 \mathrm{msec}$ to $63 \%$ & & \\
\hline $\mathrm{H}$ & Freq. Response & $0-50 \mathrm{cps}$ flat $\pm 3 \mathrm{db}$ & & \\
\hline 1 & Resolution & $<0.1 \% \mathrm{FR}$ & Infinite & \\
\hline$J$ & Linearity & $\pm 2 \% \mathrm{FR}$ & $\pm 0.5 \%$ & \\
\hline$K$ & Hysteresis & $\pm 0.1 \%$ FR & $\pm 0.5 \%$ & \\
\hline$L$ & Accuracy & $\pm 2 \%$ FR & & \\
\hline$M$ & Acceleration Error & $<0.05 \% \mathrm{FR} / \mathrm{g}$ & $.01 \%$ FR/g@100g & \\
\hline $\mathbf{N}$ & Vibration Error & $<0.05 \% \mathrm{FR} / \mathrm{g} \mathrm{0-2 \textrm {kc }}$ & \multicolumn{2}{|c|}{$.02 T$ FR/g@ $@ 35$ (5 - 2000 cps) } \\
\hline 0 & Shock & MIL-E-5422 & six $100 \mathrm{~g}$ impacts $6 \mathrm{~ms}$ & \\
\hline $\mathbf{P}$ & Noise Limit & MIL-S-446A & $150 \mathrm{db}$ & \\
\hline Q & Neutron Flux & $2 \times 10^{2} \mathrm{n} / \mathrm{cm}^{2}-\mathrm{sec}$. & & \\
\hline $\mathbf{R}$ & Gamma Flux & \multicolumn{2}{|l|}{$2.1 \times 10^{9} \mathrm{ergs} / \mathrm{gm}(\mathrm{C})-\mathrm{hr}$} & \\
\hline $\mathbf{S}$ & Dimensions & $1.2^{\prime \prime}$ dia. $\times 3 " \mathrm{lg}$ & $1.2 "$ dia. $\times 3 "$ long & \\
\hline$T$ & Weight & $7 \mathrm{oz} . \max$ & $6 \mathrm{oz}$. & \\
\hline $\mathrm{U}$ & Resonant Freq. & $3000 \mathrm{cps} \min$. & & \\
\hline $\mathbf{V}$ & Insulation Res. & 50 megohms @250VDC & & \\
\hline$w$ & Material & stainless steel case & stainless steel case & \\
\hline & & & & \\
\hline & & & & \\
\hline & & & & \\
\hline
\end{tabular}




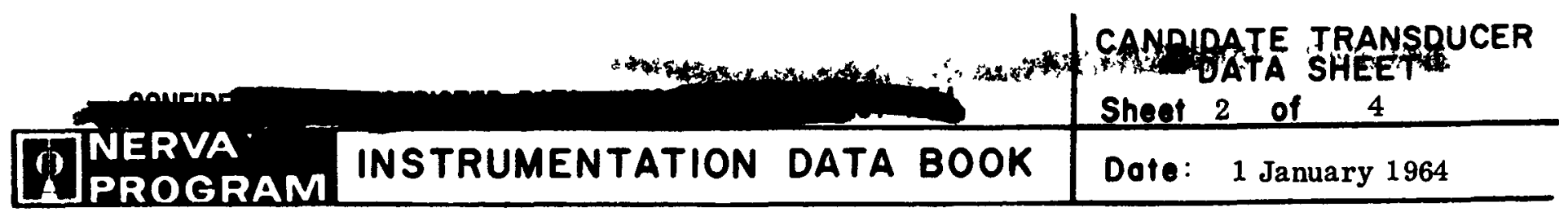

RADIATION TESTS

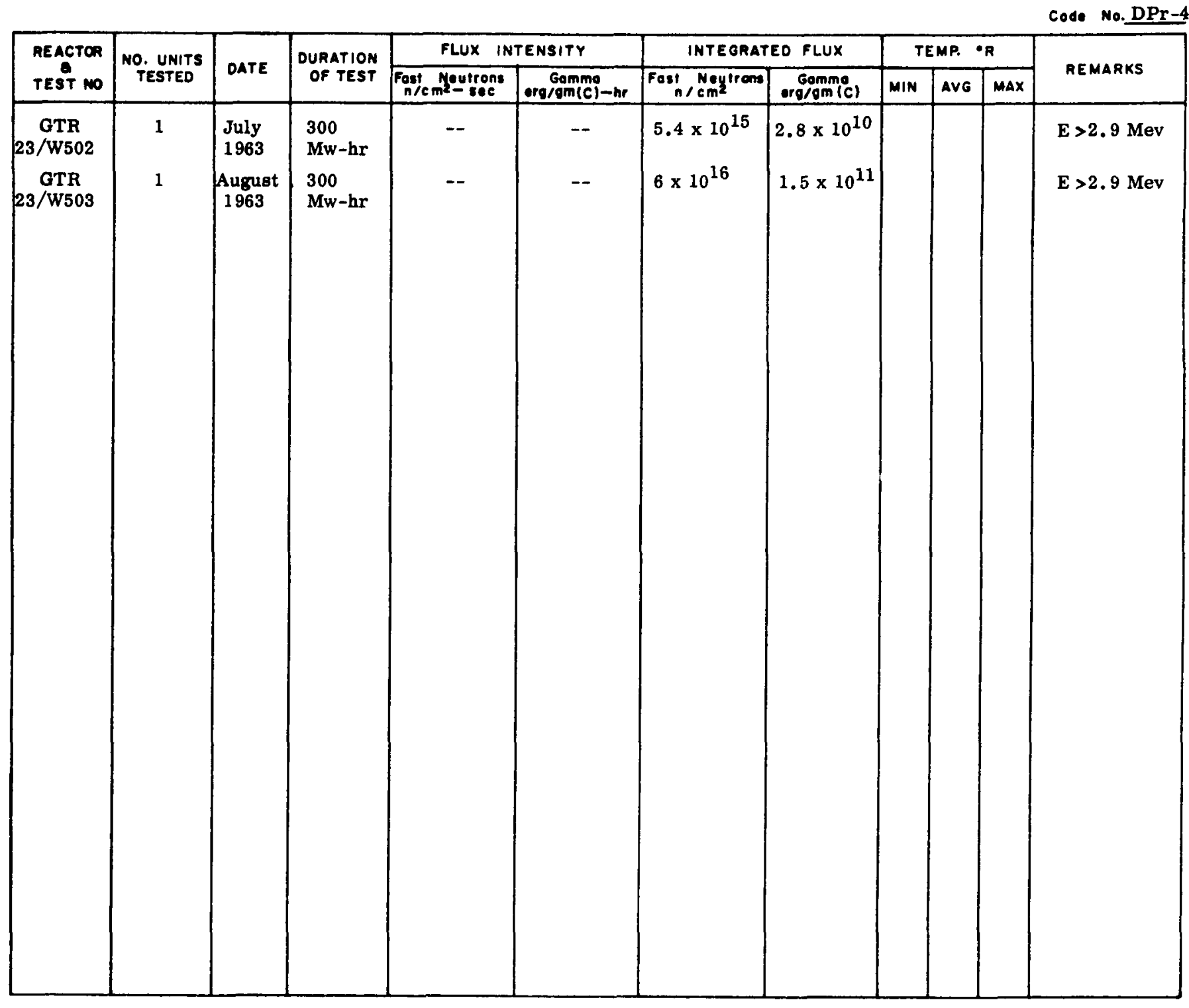

w

;

Istronuclear 


\section{DEVELOPMENT HISTORY}

Code No:

Model No. $\mathrm{DPr}-4$

171300
Mfgr: CEC

P. 0 . Donated

REMARKS:

Serial Number T1021 -

This unit developed for WANL requirements based on the first GTR combined effects test data and post-irradiation examination. (Ref: DPr-3).

This unit (and also an absolute unit) are on hand for the second GTR combined effects test.

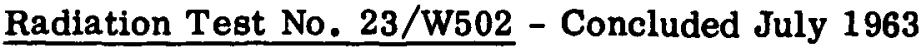

This test was performed in the Radiation Effects Testing System of the Nuclear Aerospace Research Facility of General Dynamics/Fort Worth.

The validity of the test data on some of the items that were in $\mathrm{LN}_{2}$ Dewars was affected by detonations that took place in and around the Dewars after a reactor shutdown at 1409 on May 14 (to repair a control-rod magnet). A preliminary report concerning the detonations is contained in Appendix B of Vol. I: GTR Test 4, FZK-170-1. Some units failed during or shortly after the detonations and, in these cases, failure can probably be attributed to the detonations. In other cases, however, the data indicate impaired operation or subsequent failure so that it is impossible to separate the effects of the detonations from the effects of the radiation. The problem is made more difficult by the wide variance in operating temperatures before and after the detonations. After the detonations, temperatures were restricted to a low of $-170^{\circ} \mathrm{F}$ (using gaseous nitrogen as coolant) in order to preclude the possibility of further detonations. While operating with gaseous nitrogen it was impossible to maintain constant temperatures in the Dewars.

A separate pneumatic system was used for each of the pressure transducers. Helium pressure, monitored with Heise gages, was applied in ten increments covering the transducer range, then was decreased in ten increments. At each point, increasing and decreasing, the transducer output was read on an NLS digital voltmeter and recorded.

Prior to submerging the transducer in liquid nitrogen, the lines were evacuated to 30 microns and purged with helium.

Excitation voltage was applied to the CEC pressure transducer (5 v-dc) from a Mideastern MP-40-2 power supply. Two copper-constantan thermocouples were attached to the CEC pressure transducer.

CEC 2 (0-100 psid) operated throughout the test. Data from six pressure cycles were measured and recorded.

This unit will be tested again in the August 1963 test at GTR.

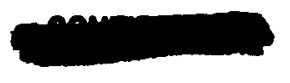




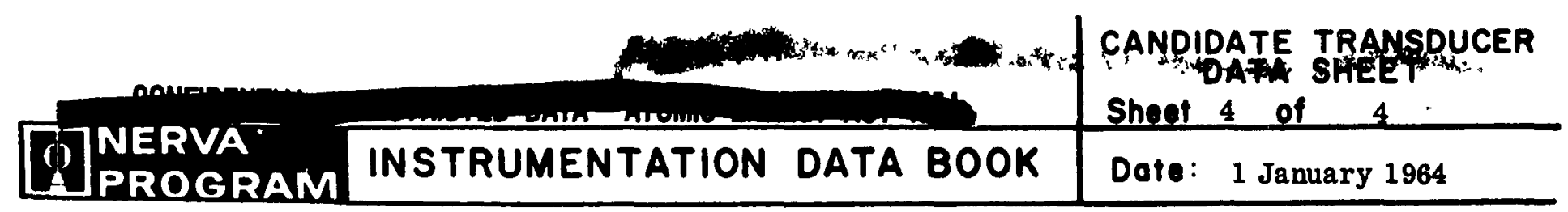

DEVELOPMENT HISTORY

Code No:

Model No. DPr-4

171300
Mfgr: $\quad$ CEC

P. $0 . \quad$ Donated

REMARKS:

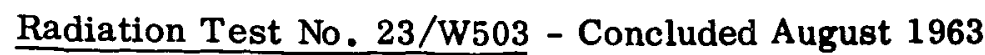

The test was performed with the Radiation Effects Testing System and the 3-Mw Ground Test Reactor (GTR). The irradiation period was $300 \mathrm{Mw}-\mathrm{hr}$. for all of the test items. In order to observe dose-rate effects, data were recorded at reactor power levels of $10 \mathrm{kw}, 100 \mathrm{kw}$, and $1 \mathrm{Mw}$ before reaching the $3 \mathrm{Mw}$ power level.

All of the test items were submerged in liquid nitrogen $\left(\mathrm{LN}_{2}\right)$ during the test. A modified NASA-type LN2 Dewar was used at each of the three irradiation positions in the irradiation cell.

Before moving the items to the reactor area, all instrumentation was connected to the test specimens (using the same harnesses to be used in the irradiation test) and data were recorded in the laboratory with the specimens at ambient temperature and at the test temperatures.

The pressure transducers were pressure cycled while being vibrated. Helium pressure, monitored with Heise gages, was increased and decreased in increments of the transducer ranges. Before starting the pressure cycle, 600 psig was applied to both sides of the differential units. At each step in pressure the outputs from the transducers were read on an NLS digital voltmeter, and were recorded on the magnetic tape system. Preirradiation data were recorded at vibration frequencies of 50,450 , and $1050 \mathrm{cps}$. During the irradiation, data were recorded at only one of these frequencies during each cycle. The vibration level was from 3-1/2 $\mathrm{g}^{\prime} \mathrm{s}$ at $50 \mathrm{cps}$ to $1 \mathrm{~g}$ at $1050 \mathrm{cps}$ for $100 \mathrm{hrs}$.

Resistance measurements were made on the pressure transducer signal leads periodically during the test. The vibration-generators were energized throughout the test except while the resistance measurements were being made.

Sample test data for the pressure transducer is presented in Table 3.4 of GD/FW Preliminary Test Report GTR-7A. Pin-to-pin resistance measurements and transducer outputs (in millivolts) are included in the tables.

After the test specimens were returned to the IML and removed from the Dewar, calibration checks were made individually on the components.

The pressure transducers were pressure cycled in the IML (at ambient temperature) in the same manner as during the irradiation. The data obtained for the three transducers compared favorably with preirradiation ambient data. A preliminary examination of the test data leads to the conclusion that none of the pressure transducers were affected by the radiation or the vibration.

This unit will be tested next at Plum Brook in October 1963 at higher levels of fadiation. $^{2}$ 


\section{PRESSURE TRANSDUCER}

Code No: DPr-5

Type: Strain Gage

Mfgr: Consolidated Electrodynamics

Range: 0-50 psid

Spec. Control Dwg. No. 964B008H03

Evaluation By: WANL

Model No:

171835-0101

Sensing Element: Diaphragm

PERFORMANCE \& ENVIRONMENTAL SPECIFICATIONS

\begin{tabular}{|c|c|c|c|c|}
\hline Test & Condition & NERVA Requirements & Manufacturer's Specs & $\begin{array}{l}\text { Summary of } \\
\text { Test Results }\end{array}$ \\
\hline$A$ & Pressure Overrange & $\begin{array}{l}2.5 \mathrm{FR}^{2} \mathrm{R}^{3} \mathrm{~min},<5 \% \\
\mathrm{zero}\end{array}$ & Tero drift min, <1\% & $0.5 \%$ \\
\hline B & Compt. Temp Range & $140^{\circ}-535^{\circ} R$ & $140^{\circ}-735^{\circ} \mathrm{R}$ (operable) & $140^{\circ} \mathrm{R}$ to $535^{\circ} \mathrm{R}$ \\
\hline c & Excitation & $5 \mathrm{v}$ (nom) $\mathrm{DC}$ or $\mathrm{AC} \mathrm{rms}$ & $5 \mathrm{v}$ (nom) DC or AC rms & 5v DC \\
\hline D. & Sensitivity & $20 \mathrm{mv}$ (nom) & $20 \mathrm{mv}+30 \%-10 \% \mathrm{FR}$ & 20.72 \\
\hline $\mathbf{E}$ & Input Impedance & 330 ohms min & 350 ohms $\pm 5 \%$ at $77^{\circ} \mathrm{F}$ & $345 \Omega$ \\
\hline $\mathbf{F}$ & Output Impedance & 350 ohms $\pm 10 \%$ & 350 ohms $\pm 5 \%$ at $77^{\circ} \mathrm{F}$ & $345 \Omega$ \\
\hline G & Response time & $5 \mathrm{msec}$ to $63 \%$ & info. later & info. later \\
\hline H & Freq. Response & flat between $0-500 \mathrm{cps}$ & info. later & info. later \\
\hline 1 & Resolution & $0.01 \% \mathrm{FR}$ & infinite & infinite \\
\hline$J$ & Linearity & \multirow{2}{*}{$\begin{array}{l}\text { combined effects less } \\
\text { than } \pm 0.75 \% \text { of full } \\
\text { range output }\end{array}$} & \multirow{2}{*}{$\begin{array}{l}\text { combined effects less } \\
\text { than } \pm 0.50 \% \text { of full } \\
\text { range output }\end{array}$} & \\
\hline$K$ & Hysteresis & & & \\
\hline L & Accuracy & info. later & info. later & $\pm 0.31 \%$ F.S. \\
\hline M & Acceleration Error & $<0.05 \% \mathrm{FR} / \mathrm{g}$ at $100 \mathrm{~g}$ & $<0.05 \% \mathrm{FR} / \mathrm{g}$ at $100 \mathrm{~g}$ & $.057 \% \mathrm{FR} / \mathrm{g}$ \\
\hline $\mathbf{N}$ & Vibration Error & $<0.03 \% \mathrm{FR} / \mathrm{g}$ at $50 \mathrm{~g}$ & $<0.03 \%$ FR/G at $15 \mathrm{~g}$ peak & $.019 \% \mathrm{FR} / \mathrm{g}$ \\
\hline 0 & Shock & $1 \mathrm{msec}, 100 \mathrm{~g}$ & info. later & less than $\pm 10 \% \mathrm{~F}$. \\
\hline$P$ & Noise Limit & $150 \mathrm{db}$ & info. later & not available \\
\hline$Q$ & Neutron Flux & NA & & $\mathrm{NA}$ \\
\hline $\mathbf{R}$ & Gamma Flux & $\mathrm{NA}$ & & $\mathrm{NA}$ \\
\hline 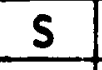 & Dimensions & 0.75 "OD $\times 3.9 " \mathrm{LG}$ & $0.75^{\prime \prime} \mathrm{OD} \times 3.9 " \mathrm{LG}$ & 0.75 "O D x \\
\hline $\mathrm{T}$ & Weight & info. later & 80 grams max & \\
\hline$\underline{U}$ & Resonant Freq. & $>1000 \mathrm{cps}$ & 8000 cps approx. & $9,700 \mathrm{cps}$ \\
\hline $\mathbf{v}$ & Insulation Res. & 100 megs at $45 \mathrm{VDC}$ & 500 megohms at $45 \mathrm{VDC}$ & \\
\hline$w$ & Material & compatible with LH2 & 416 stainless steel & \\
\hline & & & & \\
\hline & & & & \\
\hline
\end{tabular}





\section{DEVELOPMENT HISTORY}

Code No:

DPr -5

Model No. 171835-0101
Mfgr: Consolidated Electrodynamics

P. 0. 30635

\section{REMARKS:}

In order to solve the mechanical mounting problems in final assembly, extreme emphasis was placed on physical size of these units.

A literature search for units specified by the manufacturers to satisfy the environmental conditions for NRX-A1 has been made and the initial selection is based on these results.

by WANL.

Confirmation of the guarantees will be made in subsequent evaluation tests

The actual models selected are similar in design principle in all instances to units previously tested.

The supplier reports that he has performed a submerged $\mathrm{LN}_{2}$ test on a standard unit temperature compensated only to $-65^{\circ} \mathrm{F}$. The performance meets with our specification requirements.

The following is a summary of the Performance and Environmental tests and test data performed on eight 0-50 psid CEC strain gage pressure transducers (CEC 171835-0101) during October, 1963.

1. The unit was pressurized to full range and the pressure was released. The residual unbalance (zero) was recorded. Then the output voltage as a function of input pressure was plotted for three ascending and descending pressure runs. The combined effects of linearity and hysteresis was measured from the best straight line through the above calibration points.

2. The unit was vibrated in each of its three mutually perpendicular axis at $15 \mathrm{~g}^{\prime} \mathrm{s}$ peak sinusoidal excitation from 5 to $2000 \mathrm{cps}$ (limited by $1 / 2^{\prime \prime} \mathrm{D}$. A.). Time duration was five minutes for each axis. The maximum vibration response in the sensitive axis (i.e., perpendicular to diaphragm) was recorded.

3. The unit was given an acceleration test of $100 \mathrm{~g}^{\prime} \mathrm{s}$ along each of its three mutually perpendicular axes. The maximum acceleration response which occurred in the sensitive axis of the transducer was recorded. 


\section{DEVELOPMENT HISTORY}

Code No: DPr-5

Model No. 171835-0101
Mfgr: Consolidated Electrodynamics

P. $0 . \quad 30635$

\section{REMARKS:}

4. The unit was subjected to three shocks in each axis of $50 \mathrm{~g}$ 's half sine with a time duration of $11 \pm 1 \mathrm{~ms}$. The residual unbalance was recorded both before and after shock.

5. To measure the natural frequency of the unit, it was installed in a pressure shock tube and a step pressure function was applied to excite the natural frequency of the unit. The output of the unit was connected to an oscilloscope and the natural frequency as displayed on the scope was recorded.

6. Two units, S/N's 17660 and 17673 , were tested at ambient and liquid nitrogen ( $\mathrm{LN}_{2}$ ) temperatures. Combined linearity-hysteresis and zero shift were measured and recorded.

in all cases.

The results of these tests indicate that the transducers were within specification limits

$$
12505
$$

Residual Linearity and Vibration Error Acceleration Error Natural Frequency $\underline{\mathrm{S} / \mathrm{N}}$ Unbalance (mv) Hysteresis (\% FR)

$(\% \mathrm{FR} / \mathrm{g})$
(\% FR/g)

$$
0.020
$$

0.019

0.020

0.020

0.018

0.022

0.022

0.022
0.055

0.057

0.054

0.053

0.053

0.055

0.044

0.055 (cps)

10,000

9,700

10,100

10,200

10,000

10,500

9,790

10,300 $\pm 0.14$

Ambient Linearity

$\mathrm{S} / \mathrm{N}$

17660

17673 $\pm 0.187$

$\pm 0.135$

\section{6 \\ $\mathrm{LN}_{2}$ Linearity \& Hysteresis (\% FR)}
$\pm 0.37$
$\pm 0.15$
0.0147
0.005

Zero Shift

$\left(\% \mathrm{FR} /{ }^{\circ} \mathrm{F}\right)$ 


\section{PRESSURE TRANSDUCER}

Code No: _ DPr -6

Type: $\quad$ Strain Gage

Mfgr: Consolidated Electrodynamics

Range: $0-100$ PSID
Spec. Control Dwg. No.

Evaluation By:

Model No: 171835-0101

Sensing Element: Diaphragm

PERFORMANCE \& ENVIRONMENTAL SPECIFICATIONS

\begin{tabular}{|c|c|c|c|c|}
\hline Test & Condition & NERVA Requirements & Manufacturer's Specs & $\begin{array}{l}\text { Summary of } \\
\text { Test Results }\end{array}$ \\
\hline A & Pressure Overrange & $\begin{array}{l}3.5 \text { FR } 3 \mathrm{~min},<0.5 \% \\
\text { zero drift }\end{array}$ & $\begin{array}{l}1.5 \mathrm{FR}, 3 \mathrm{~min} .<1 \% \\
\text { zero drift }\end{array}$ & \\
\hline B & Compt. Temp Range & $140^{\circ}-535^{\circ} \mathrm{R}$ & $140^{\circ}-1110^{\circ} \mathrm{R}$ (operable) & \\
\hline $\mathrm{C}$ & Excitation & $5 \mathrm{~V}$ (nom) DC or AC rms & 5VDC or $\mathrm{AC}(\mathrm{rms})$ & \\
\hline D. & Sensitivity & $20 \mathrm{mv}$ (nom) & $20 \mathrm{mv}+30 \%-10 \% \mathrm{FR}$ & \\
\hline$E$ & Input Impedance & 330 ohms min. & 350 ohms $\pm 5 \%$ at $77^{\circ} \mathrm{F}$ & \\
\hline $\mathbf{F}$ & Output Impedance & 350 ohms $\pm 10 \%$ & $350 \mathrm{ohms} \pm 5 \%$ at $77^{\circ} \mathrm{F}$ & \\
\hline $\mathbf{G}$ & Response time & $5 \mathrm{msec}$ to $63 \%$ & info. later & \\
\hline $\mathrm{H}$ & Freq. Response & flat between $0-500 \mathrm{cps}$ & info. later & \\
\hline 1 & Resolution & $0.01 \% \mathrm{FR}$ & infinite & \\
\hline$J$ & Linearity combined & $< \pm 0.75 \%$ FR & $< \pm 0.50 \%$ FR & . \\
\hline $\mathrm{K}$ & Hysteresis effects & output & output & \\
\hline$L$ & Accuracy & info. later & info. later & \\
\hline$M$ & Acceleration Error & $<0.05 \% \mathrm{FR} / \mathrm{g}$ at $100 \mathrm{~g}$ & $<0.05 \% \mathrm{FR} / \mathrm{g}$ at $100 \mathrm{~g}$ & \\
\hline $\mathbf{N}$ & Vibration Error & $<0.03 \% \mathrm{FR} / \mathrm{g} 50 \mathrm{~g}$ & $<0.04 \%$ FR $/$ g 15 g peak & \\
\hline 0 & Shock & $1 \mathrm{msec}, 100 \mathrm{~g}$ & info. later & \\
\hline $\mathbf{P}$ & Noise Limit & $150 \mathrm{db}$ & info. later & \\
\hline Q & Neutron Flux & NA & & \\
\hline $\mathbf{R}$ & Gamma Flux & NA & & \\
\hline $\mathbf{S}$ & Dimensions & $0.75^{\prime \prime} \mathrm{OD} \times 3.9^{\prime \prime} \mathrm{Lg}$ & $0.75^{\prime \prime}$ OD $\times 3.9^{\prime \prime} \mathrm{Lg}$ & \\
\hline$T$ & Weight & info. later & 27 grams & \\
\hline U & Resonant Freq. & $>1000 \mathrm{cps}$ & $8000 \mathrm{cps}$ approximately & \\
\hline V & Insulation Res. & 100 megs at $45 \mathrm{VDC}$ & 500 megs at $45 \mathrm{VDC}$ & \\
\hline$W$ & Material & compatible with $\mathrm{LH}_{2}$ & 416 stainless steel & \\
\hline & & & & \\
\hline & & & & \\
\hline & & & & \\
\hline
\end{tabular}





\section{DEVELOPMENT HISTORY}

Code No: $\quad$ DPr-6

Model No. 171835-0101
Mfgr: Consolidated Electrodynamics

P. O. 30635

\section{REMARKS:}

In order to solve the mechanical mounting problems in final assembly, extreme emphasis was placed on physical size of these units.

A literature search for units specified by the manufacturers to satisfy the environmental conditions for NRX-A-1 has been made and the initial selection is based on these results.

Confirmation of the guarantees will be made in subsequent evaluation tests by WANL.

The actual models selected are similar in design principle in all instances to units previously tested.

The supplier reports that he has performed a submerged $\mathrm{LN}_{2}$ test on a standard unit temperature compensated only to $-65^{\circ} \mathrm{F}$. The performance meets with our specification requirements.

\section{$\underline{15}$ December 1963 - Vibration Test}

Several strain gage type pressure transducers of the types to be utilized in NRX-A-1 instrumentation have been vibrated to determine degree of vibration induced output and observe operation characteristics under conditions of vibration. This is a report of obtained test results.

\section{Test Equipment and Instrumentation}

An MB Model C10 Vibration Exciter was used as the vibration generator. This equipment, rated at $1200 \mathrm{lbs}$. force, is self-resonant at approximately $2.1 \mathrm{kcs}$. It is useable in the present application to about $2.0 \mathrm{kcs}$ although at this frequency operation is along the lower slope of the resonance curve.

Vibration level was sensed by an Endevco accelerometer and indicated by a Bruel and Kjaer VTVM. The accelerometer-voltmeter combination was calibrated by use of a standard accelerometer. The transducer excitation voltage was indicated by a Simpson Model 260 Multimeter. The oscilloscope was calibrated against its internal calibration voltage.

\section{Test Procedure}

The testing was generally in accordance with the following procedure.

A. The vibration frequency was set to $30 \mathrm{cps}$ and vibration level to $10 \mathrm{~g}$ 's $\mathrm{rms}$.

B. The frequency was slowly increased to $2000 \mathrm{cps}$. The vibration level was manually held to $10 \mathrm{~g}$ 's rms.

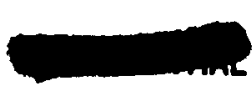




\section{DEVELOPMENT HISTORY}

Code No: $\quad$ DPr-6

Model No.

$171835-0101$
Mfgr:

P. 0. 30635

\section{REMARKS:}

C. The transducer and accelerometer outputs were observed on the dual beam oscilloscope and photographed.

D. The above steps were repeated with pressure applied to the transducer.

E. Transducer output waveforms were observed and recorded at the frequencies which resulted in the highest vibration induced output.

F. The transducer response to application and removal of pressure was observed and recorded at the frequency of highest vibration induced output.

The above procedures were employed for each of the three axes of the tested transducer.

\section{Summary of Results}

Vibration Induced ac Output: At the $10 \mathrm{~g}$ rms vibration level, the maximum observed vibration induced ac output was $0.08 \mathrm{mv}$ or $0.4 \%$ nominal FS.

Vibration Induced dc Output Shift: The maximum observed was $0.32 \mathrm{mv}$ or $1.6 \%$ nominal FS. This voltage also peaked at about $450 \mathrm{cps}$. at $450 \mathrm{cps}$.

Response to Pressure Variation: Response to $12.5 \%$ rated pressure variation was normal 


\section{PRESSURE TRANSDUCER}

Code No: DPr-7

Type: Variable Reluctance

Mfgr: Wiancko

Range: $0-50$ PSID
Planning Parts List No.

Evaluation By: WANL

Model No: P1464 (PX-105)

Sensing Element: Diaphragm

PERFORMANCE \& ENVIRONMENTAL SPECIFICATIONS

\begin{tabular}{|c|c|c|c|c|}
\hline Test & Condition & NERVA Requirements & Manufacturer's Specs & $\begin{array}{l}\text { Summary of } \\
\text { Test Results }\end{array}$ \\
\hline$A$ & Pressure Overrange & $1.5 \mathrm{FR}, 3 \mathrm{~min} .<0.5 \%$ & $\begin{array}{ll}\text { ero } & 535 \\
\text { rift }\end{array}$ & \\
\hline$B$ & Compt. Temp Range & $140^{\circ}-535^{\circ} \mathrm{R}$ & $140^{\circ} \mathrm{R}$ to $535^{\circ} \mathrm{R}$ & $140^{\circ} \mathrm{R}$ to $535^{\circ} \mathrm{R}$ \\
\hline C & Excitation & 5,10, or $20 \mathrm{VAC}, 3000$ & cps 200 volts, $3000 \mathrm{cps}$ & 20 volts, $3000 \mathrm{cp}$ \\
\hline D & Sensitivity & $0.1 \mathrm{~V} / \mathrm{V}$ for $\mathrm{FR}$ at $77^{\circ} \mathrm{F}$ & $0.08 \mathrm{~V} / \mathrm{V} \mathrm{FS}$ & $0.08 \mathrm{~V} / \mathrm{V} \mathrm{FS}$ \\
\hline $\mathbf{E}$ & Input Impedance & $<1000 \mathrm{ohms}$ & approx. 600 ohms & 625 ohms \\
\hline$F$ & Output Impedance & $<1000$ ohms at $77^{\circ} \mathrm{F}$ & approx. 120 & 120 ohms \\
\hline $\mathbf{G}$ & Response time & $10 \mathrm{msec}$ to $63 \%$ & $2 \mathrm{~ms}$ & $2 \mathrm{~ms}$ \\
\hline $\mathrm{H}$ & Freq. Response & $\begin{array}{l}\text { flat between } 0-500 \mathrm{cps} \\
\pm 3 \mathrm{db}\end{array}$ & approx. $5 \%$ at $500 \mathrm{cps}$ & $\begin{array}{l}\text { approx. 8\% at } \\
500 \text { cps }\end{array}$ \\
\hline 1 & Resolution & $<-.01 \% \mathrm{FR}$ & continuous & info. later \\
\hline $\mathrm{J}$ & Linearity Combined & $< \pm 0.75 \%$ of & $0.5 \%$ F.S. & $0.4 \%$ F.S. \\
\hline K & Hysteresis Effects & full range output & & \\
\hline$L$ & Accuracy & $6 \%$ & less $1 \%$ F.S. & $0.5 \%$ F.S. \\
\hline$M$ & Acceleration Error & $<0.05 \% \mathrm{FR} / \mathrm{g}$ at $100 \mathrm{~g}$ & 0.02 & $0.008 \%$ F.S. $/ \mathrm{g}$ \\
\hline $\mathbf{N}$ & Vibration Error & \multicolumn{2}{|c|}{$<0.02 \% \mathrm{FR} / \mathrm{g}$ at $25 \mathrm{~g}$ peaknegligible } & no change* \\
\hline 0 & Shock & $50 \mathrm{~g}, 11 \mathrm{msec}$ & no change at $50 \mathrm{~g}, 11 \mathrm{~ms}$ & no change* \\
\hline$P$ & Noise Limit & $150 \mathrm{db}$ & info. later & info. later \\
\hline$Q$ & Neutron Flux & NA & NA & NA \\
\hline$\underline{R}$ & Gamma Flux & NA & $\mathrm{NA}$ & NA \\
\hline $\mathbf{S}$ & Dimensions & $1.40^{\prime \prime}$ dia. $\times 2.8^{\prime \prime} \mathrm{lg}$. & $2.8^{\prime \prime} \mathrm{L} \times 1.4$ dia. & $2.8^{\prime \prime} \mathrm{L} \times 1.4 \mathrm{dia}$ \\
\hline$T$ & Weight & mfgr. to specify & $0.25 \mathrm{lb}$. & $5 \mathrm{oz}$ \\
\hline$U$ & Resonant Freq. & $>1000 \mathrm{cps}$ & $>1500 \mathrm{cps}$ & 1800 to $1900 \mathrm{cps}$ \\
\hline$V$ & Insulation Res. & $>100$ megohms at $50 \mathrm{VDC}$ & & 100 megohm $50 \mathrm{VI}$ \\
\hline$w$ & Material & & & \\
\hline & & & & \\
\hline & & & & \\
\hline & & & & \\
\hline
\end{tabular}





\section{DEVELOPMENT HISTORY}

Code No: DPr-7

Model No.

$\mathrm{P}-1464$ (PX-105)
Mfgr: Wiancko

P. O. 34727

\section{REMARKS:}

The ambient test results for Wiancko unit S/N 68787 (WANL No. WG-4) is tabulated on sheet 1 of DPr-7. This includes acceptance and qua lification test results.

The following tests were performed on two units which had passed acceptance test per WE 280 . All tests were performed at room temperature.

1.0 Vibration: The unit was mounted with the longitudinal axis of the tube parallel to the direction of vibration. (This is the most sensitive axis of the pickup.) The unit was vibrated as follows:

20 to $50 \mathrm{cps}$ at $0.25 \mathrm{in} . \mathrm{DA}(10 \mathrm{~g}$ at $30 \mathrm{cps})$

50 to $500 \mathrm{cps}$ at $\pm 20 \mathrm{~g}$

500 to $1000 \mathrm{cps}$ at $\pm 20 \mathrm{~g}$

1000 to 2000 cps at reduced "g" level. Record applied level.

Pickup output was monitored on the Moseley X-Y recorder during vibration. Change in output, with zero psid applied to the transducer, was to be less than $1 \%$ full scale output over the 20-500 cps range.

Output was recorded only, over the 500-2000 cps frequency range. This output record showed vibration sensitivity through the noted range and pinpointed the resonant frequency of the pickup.

2.0 Acceleration: The unit was mounted on a spin table which was rotated at a speed sufficient to produce a $25 \mathrm{~g}$ acceleration on the unit. The output of the pickup was monitored during acceleration, with 0 psid applied. Output due to acceleration sensitivity was to be less than $1.25 \%$ full scale $(0.05 \%$ F.S. /G). This test was repeated on each major axis. A performance test consisting of three pressure excursions was performed following the acceleration exposure.

3.0 Shock: The unit was subjected to two shocks on each of three mutually perpendicular axis. Shock applied was $50 \mathrm{~g}$ for a duration of 11 milliseconds. Before and after the shock exposure, a performance test consisting of three pressure excursions was performed.

4.0 Time Constant: Apply a 50 psid step to pickup with one foot 1/4" OD tube attached. Record electrical output change by photographing oscilloscope image. Time constant was to be less than 10 milliseconds.

5.0 Frequency Response: Apply a 50 psid step to pickup with no tubing attached. Record electrical output change as in 4.0 . 


\section{DEVELOPMENT HISTORY}

Code No:

Model No. P-1464 (PX-105)
Mfgr: Wiancko

P. 0.34727

\section{REMARKS:}

Test Summary

Performance Test

Vibration

Performance Test

Acceleration

Performance Test

Time Constant

Frequency Response

Performance Test

Shock Exposure

Performance Test
Passed

Passed

Passed

Passed

Passed

Passed

Recorded

Passed

Performed

Passed

\section{Discussion}

Performance tests which were performed consisted of three pressure excursions to determine linearity and hysteresis and to observe repeatibility, except that after acceleration only one excursior was performed. In all cases performance was within specification. The same carrier-demodulator system was used for all tests. Combined linearity and hysteresis figures and balance are tabulated for each unit.

\begin{tabular}{|c|c|c|c|c|}
\hline & Serial & WG-2 & Serial I & WG-4 \\
\hline & Lin. \& Hyst. & Balance & Lin. \& Hyst. & Balance \\
\hline $\begin{array}{l}\text { Pre-vibration } \\
\text { Post-vibration } \\
\text { Pre-vibration } \\
\text { Post-vibration } \\
\text { Pre-shock } \\
\text { Post-shock }\end{array}$ & $\begin{array}{l}+0.42 \% \text { F.S. } \\
+0.43 \% \text { F.S. } \\
+0.43 \% \text { F.S. } \\
+0.38 \% \text { F.S. } \\
+0.40 \% \text { F.S. } \\
+0.40 \% \text { F.S. }\end{array}$ & $\begin{array}{l}+0.68 \% \text { F.S. } \\
+1.8 \% \text { F.S. } \\
+1.8 \% \text { F.S. } \\
+1.8 \% \text { F.S. } \\
+1.5 \% \text { F.S. } \\
+1.8 \% \text { F.S. }\end{array}$ & $\begin{array}{l}+0.18 \% \text { F.S. } \\
+0.19 \% \text { F.S. } \\
+0.19 \% \text { F.S. } \\
+0.25 \% \text { F.S. } \\
+0.22 \% \text { F.S. } \\
+0.22 \% \text { F.S. }\end{array}$ & $\begin{array}{l}+1.2 \% \text { F.S. } \\
+1.12 \% \text { F.S. } \\
+1.1 \% \text { F.S. } \\
+1.1 \% \text { F.S. } \\
+1.0 \% \text { F.S. } \\
+0.7 \% \text { F.S. }\end{array}$ \\
\hline
\end{tabular}

Vibration was performed per enclosed procedure Section 1.0 , except that "g" level over 500-20 cps was maintained at the 20 " $g$ " level. Preliminary scans at lower " $g$ " levels determined that sensitivity was, in fact, lower at resonance than had been anticipated. Except for an output at resonance, no change in output due to vibration was discernible. The output at resonance (1800-1900 cps) was about $0.9 \%$ F.S. Specification of $1 \%$ F.S. maximum output over the $0-500$ cps range was me No specifications were effective over the 500-2000 cps range. The vibration tests show that the resonanct frequency of the pickups are about $1800-1900 \mathrm{cps}$. 


\section{DEVELOPMENT HISTORY}

Code No: DPr-7

Model No. P-1464 (PX-105)
Mfgr:

P. 0 .
Wiancko 34727

\section{REMARKS:}

The units were next exposed to a $25 \mathrm{~g}$ acceleration in each major axis per procedure Section 2.0. Maximum change in output $(0.008 \%$ F.S./g) was well below the $0.05 \%$ F.S. $/ g$ specification, and occurred with the acceleration along the longitudinal axis of the tube. Sensitivity in the other two axis of the unit was less than half of that along the tube.

Time constant and frequency response data were obtained as per procedure, Section 4.0 and 5.0. Figures 1 and 2 show response with the one foot of tubing attached to the pickups. Response time from full scale to $37 \%$ F.S. is on the order of 2 milliseconds.

Specification is less than 10 milliseconds. In addition to response of the $1 / 4$ inch tube-pickup system, the photos show the resonant ringing of the tube-armature at about 1800-2000 cps and the acoustical ringing of the $1 / 4$ inch $\times 12$ inch long tube at about $210 \mathrm{cps}$.

Frequency response, Figures 3 and 4, are presented for customer evaluation, per request. Observation of those photos clearly shows the lightly damped resonant ringing of the pickup sensing element at roughly $1000 \mathrm{cps}$. Assuming that this system approaches a damping of $h=0$, the response at $500 \mathrm{cps}$ would be flat within about $8 \%$.

\section{Conclusion}

The two units met and exceeded the specification. Performance was well above requirements in all phases except frequency response. In the latter area, since the pickup is undamped with a natural frequency around $1900 \mathrm{cps}$, frequency response is flat within about $8 \%$ over range specified. 


\section{PRESSURE TRANSDUCER}

Code No:

Type:

Mfgr:

Range:
DPr-8

LVDT

Consolidated Controls Corp.

$0-3$ psid
Spec. Control Dwg. No.

Evaluation By:

WANI

Model No: 413M21-3

Sensing Element: Diaphragm

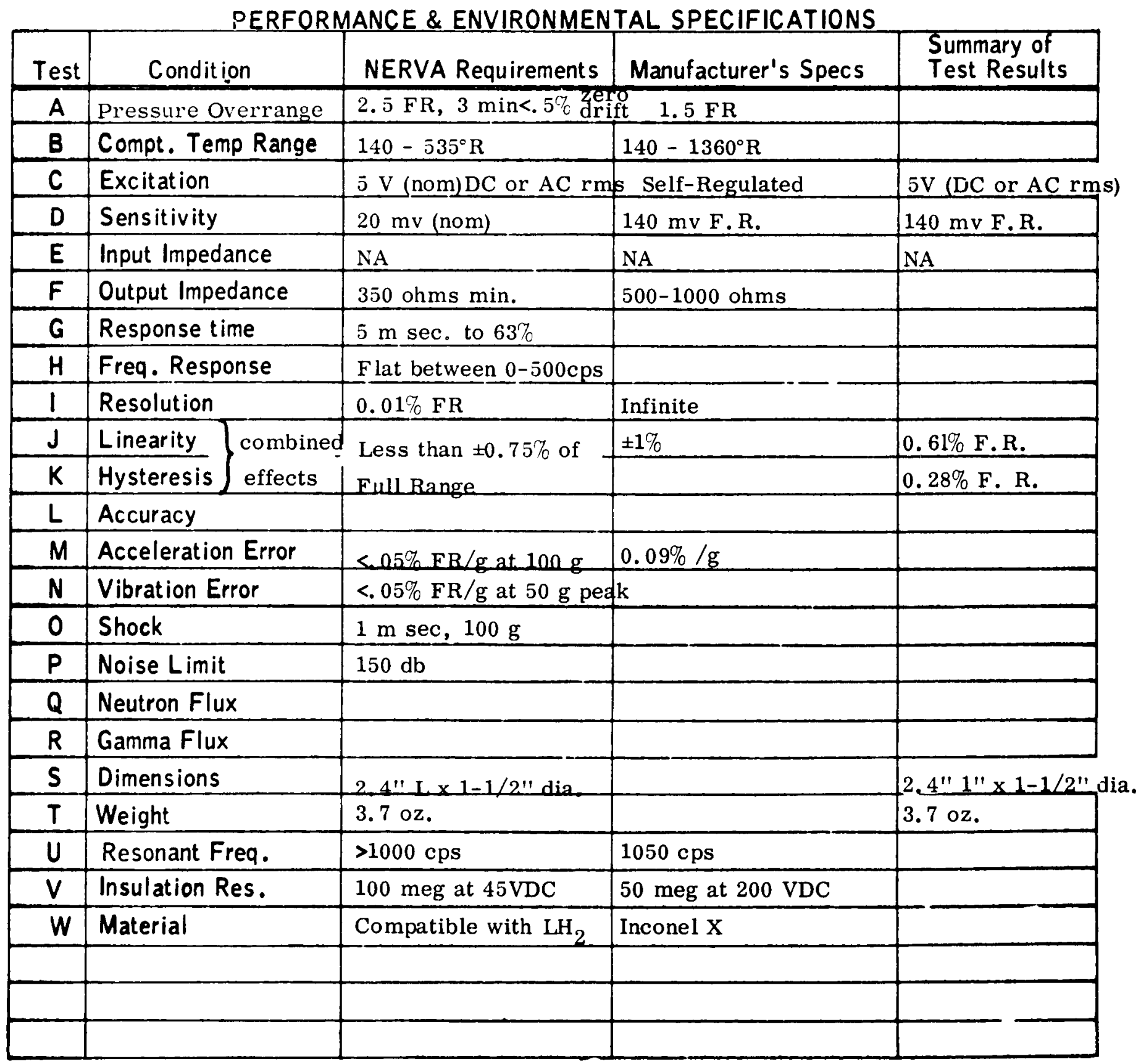


RADIATION TESTS

Code No. DPr-8

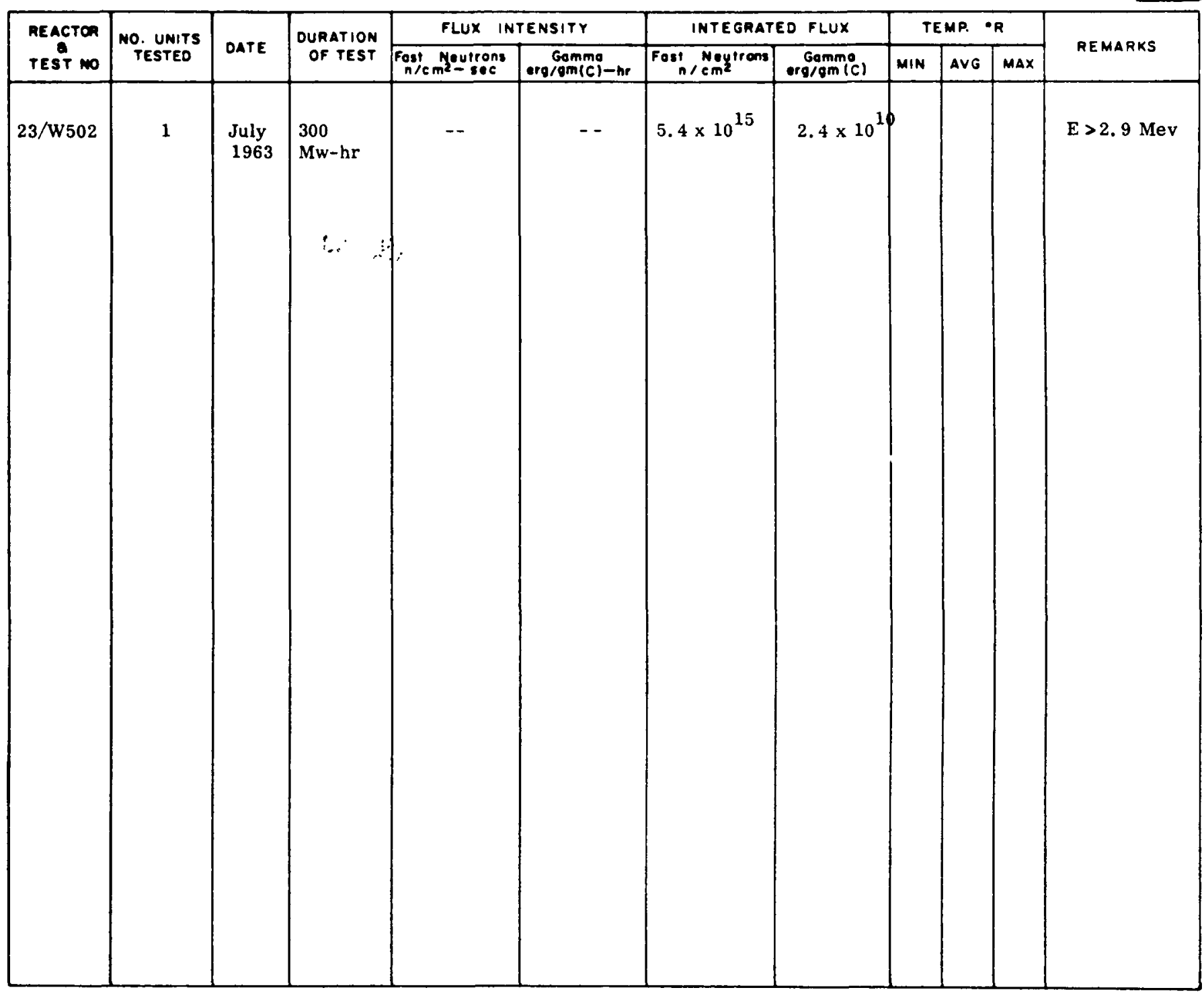




\section{DEVELOPMENT HISTORY}

\begin{tabular}{lll} 
Code No: $\frac{\text { DPr-8 }}{\text { Model No. }} 413 \mathrm{M} 21-3$ & Mfgr: $\frac{\text { Consolidated Controls Corp. }}{34459}$ \\
\hline
\end{tabular}

\section{REMARKS:}

\section{General}

1. The ambient data vs. the $\mathrm{LN}_{2}$ data indicates good performance as follows:

CCC No. 413M21-3

$0-3$ psid

Repeatability at ambient $0.35 \%$ F.R.

Zero shift from ambient to $\mathrm{LN}_{2}=4.6 \% \mathrm{~F}$. R.

Linearity $\left(\mathrm{LN}_{2}\right)-0.4 \%$

Hysteresis $\left(\mathrm{LN}_{2}\right)-2.0 \%$

Repeatability $\left(\mathrm{LN}_{2}\right)-1.5 \%$

Radiation Test No. 23/W502 Concluded July 1963

This test was performed in the Radiation Effects Testing System of the Nuclear Aerospace Research Facility of General Dynamics/Fort Worth.

The validity of the test data on some of the items that were in $\mathrm{LN}_{2}$ Dewars was affected by detonations that took place in and around the Dewars after a reactor shutdown at 1409 on May 14 (to repair a control-rod magnet). A preliminary report concerning the detonations is contained in Appendix B of Vol. I; GTR Test 4, FZK-170-1. Some units failed during or shortly after the detonations and, in these cases, failure can probably be attributed to the detonations. In other cases, however, the data indicate impaired operation or subsequent failure so that it is impossible to separate the effects of the detonations from the effects of the radiation. The problem is made more difficult by the wide variance in operating temperatures before and after the detonations. After the detonations, temperatures were restricted to a low of $-170^{\circ} \mathrm{F}$ (using gaseous nitrogen as coolant) in order to preclude the possibility of further detonations. While operating with gaseous nitrogen it was impossible to maintain constant temperatures in the Dewars.

A separate pneumatic system was used for each of the pressure transducers. Helium pressure, monitored with Heise gages, was applied in ten increments covering the transducer range, then was decreased in ten increments. At each point, increasing and decreasing, the transducer output was read on an NLS digital voltmeter and recorded.

Prior to submerging the transducer in liquid nitrogen, the lines were evacuated to 30 microns and purged with helium.

Excitation voltage was applied to the CCC unit $(28$ VDC) from a Hewlett-Packard 024-09232 power supply. 


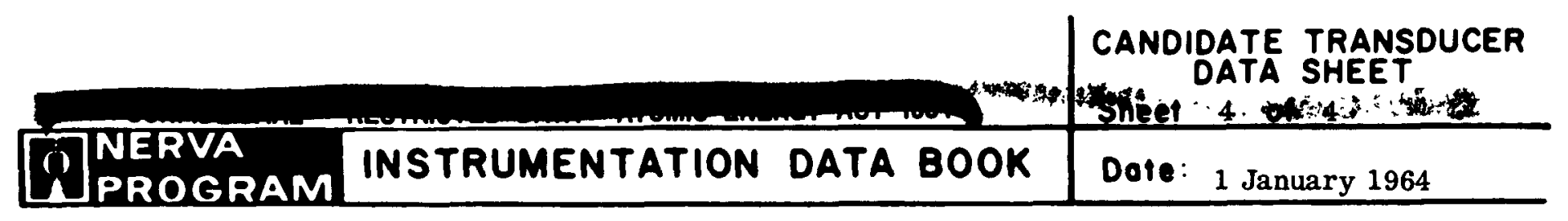

DEVELOPMENT HISTORY

\begin{tabular}{ll} 
Code No: $\frac{\text { DPr-8 }}{\text { Model No. }} \quad$ Mf13Mr: & Consolidated Controls Corp. \\
\hline
\end{tabular}

REMARKS:

The CCC pressure transducer showed a sudden decrease in output following the detonations. On the last day of the irradiation, the output indicated a leak, which is believed to have been in the pressure system. After the test, the transducer was pressurized to 3 psi and checked for leaks, but none were detected - either externally or through the diaphragm from the pressure port. The unit was then disassembled for inspection. All internal parts appeared normal except for the stainless-steel core, which showed signs of oxidation. This core is on the reference-pressure side, which was open to the atmosphere throughout the test. Postirradiation pin-to-pin resistance measurements indicated no significant change from the "as built" values.

It is not known to what extent the pressure transducer failures can be attributed to the detonations in the Dewar--either directly, or as a result of possible damage to pressure lines and signal leads when the Dewar was withdrawn from the irradiation cell for examination. Since the dewar was highly radioactive, special care could not be given to the handling of the lines and leads during movement of the system out of, and back into, the irradiation cell. Before the detonations occurred, the transducer was operative. After the detonations, the CCC transducer was operative.

This CCC transducer passed this combined effects test. 


\section{PRESSURE TRANSDUCER}

$\begin{array}{lll}\text { Code No: } \frac{\text { DPr-9 }}{\text { Variable Permeance }} & \text { Spec. Control Dwg. No. } \\
\text { Type: } & \text { Evaluation By: } & \text { WANL } \\
\text { Mfgr: } & \text { Physical Sciences } & \text { Model No: } \frac{\text { PT-1001 }}{\text { Range: }}\end{array} \quad$\begin{tabular}{l} 
Sensing Element Diaphragm \\
\hline
\end{tabular}

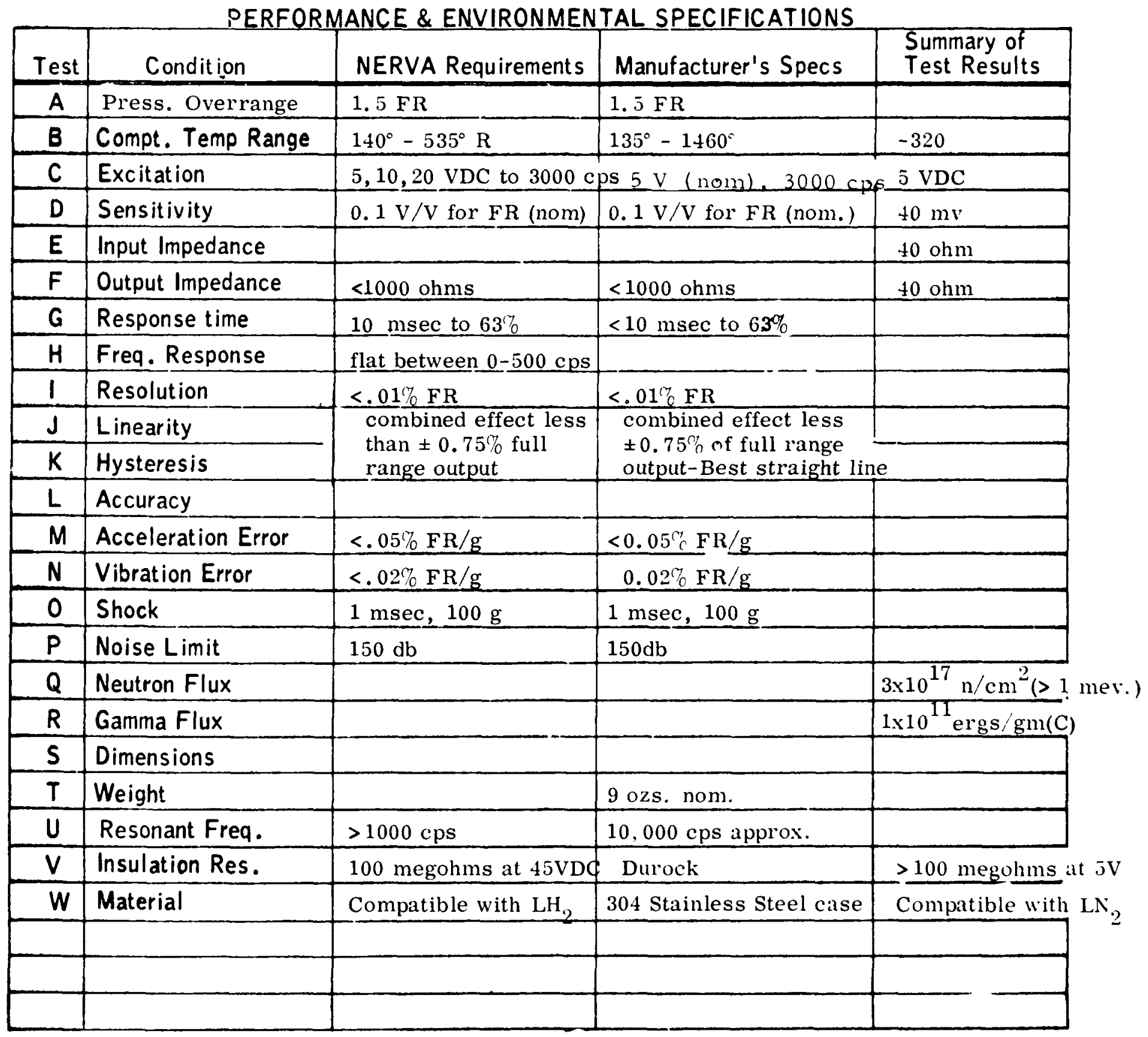





\section{DEVELOPMENT HISTORY}

$\begin{array}{ll}\text { Code No: } & \text { Dpr-9 } \\ \text { Model No. } & \text { PT-1001 }\end{array}$

$$
\text { Mfgr: }
$$

Physical Sciences

REMARKS:

\section{General:}

One unit was procured in August 1963. Laboratory cryogenic tests under vibration were performed in August. Combined effects tests, cryogenic, radiation and vibration were performed at GTR, Fort Worth in August 1963.

The test was performed with the Radiation Effects Testing System and the 3-Mw Ground Test Reactor (GTR). The irradiation period was $300 \mathrm{Mw}-\mathrm{hr}$. for all of the test items. In order to observe dose-rate effects, data were recorded at reactor power levels of $10 \mathrm{kw}, 100 \mathrm{kw}$, and $1 \mathrm{Mw}$ before reaching the 3-Mw power level.

All of the test items were submerged in liquid nitrogen ( $\left.\mathrm{LN}_{2}\right)$ during the test. A modified NASA-type $\mathrm{LN}_{2}$ Dewar was used at each of the three irradiation positions in the irradiation cell.

Before moving the items to the reactor area, all instrumentation was connected to the test specimens (using the same harnesses to be used in the irradiation test) and data were recorded in the laboratory with the specimens at ambient temperature and at the test temperatures.

The pressure transducers were pressure cycled while being vibrated. Helium pressure, monitored with Heise gages, was increased and decreased in increments of the transducer ranges. Before starting the pressure cycle, 600 psig was applied to both sides of the differential units. At each step in pressure the outputs from the transducers were read on an NLS digital voltmeter, and were recorded on the nagnetic tape system. Preirradiation data were recorded at vibration frequencies of 50, 450 and $1050 \mathrm{cps}$. During the irradiation, data were recorded at only one of these frequencies during each cycle. The vibration level was from $31 / 2 \mathrm{G}$ 's at $50 \mathrm{cps}$ to $1 \mathrm{G}$ at $1050 \mathrm{cps}$ for 100 hours.

Resistance measurements were made on the pressure transducer signal leads periodically during the test. Also, the $\mathrm{AC}$ and $\mathrm{DC}$ vibration-generator coil resistances were measured. The vibration-generators were energized throughout the test except while the resistance measurements were being made.

Sample test data for the pressure transducer is presented in Table 3.6 of GD/FW Preliminary Test Report GTR-7A. Pin-to-pin resistance measurements and transducer outputs (in millivolts) are included in the tables.

After the test specimens were returned to the IML and removed from the Dewar, calibration checks were made individually on the components.

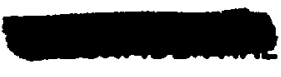




\section{DEVELOPMENT HISTORY}

Code No:

Dpr-9

Mfgr:

Physical Sciences

Model No. PT-1001

P. 0 .

REMARKS:

The pressure transducers were pressure cycled in the IML (at ambient temperature) in the same manner as during the irradiation. The data obtained for the three transducers compared favorably with preirradiation ambient data. A preliminary examination of the test data leads to the conclusion that none of the pressure transducers were affected by the radiation or the vibration.

$\underline{\text { Summary of Test Results: }}$

Preliminary Analysis of Data indicates unit performed satisfactorily in laboratory tests and at GTR. Variation in linearity and hysteresis could have been due to supporting electronics. 


\section{PRESSURE TRANSDUCER}

Code No:

DPr -10

Type:

Strain Gage

Mfgr:

Statham

Range:

$0-50$ PSID

Spec. Control Dwg. No.

$963 \mathrm{~B} 385 \mathrm{H} 03$

Evaluation By:

WANL

Model No:

PL $131 \mathrm{r}$

Sensing Element:

Diaphragm

\begin{tabular}{|c|c|c|c|c|}
\hline Test & Cond it ion & NERVA Requirements & Manufacturer's Specs & $\begin{array}{l}\text { Summary of } \\
\text { Test Results }\end{array}$ \\
\hline$A$ & Pressure Orerrange & $\begin{array}{l}2.5 \mathrm{FR}^{2} \mathrm{~m} \min . \\
\text { zero drift }\end{array}$ & $200^{\mathrm{C}_{0}} \mathrm{FR}$ & \\
\hline B & Compt. Temp Range & $140^{\circ}-535^{\circ} \mathrm{R}$ & $395^{\circ}-710^{\circ} \mathrm{R}$ & \\
\hline C & Excitation & $\overline{5 V}$ (nom) DC or AC rms & $5 \mathrm{VDC}$ or $\mathrm{AC} \mathrm{rms}$ & \\
\hline$D$ & Sensitivity & $20 \mathrm{mv}$ (nom) & $40 \mathrm{mv}$ approx. & \\
\hline$E$ & Input Impedance & 330 ohms min. & 300 ohms nom & \\
\hline$F$ & Output Impedance & 350 ohms $\pm 10_{c}^{r}$ & 300 ohms nom & \\
\hline $\mathbf{G}$ & Response time & $\bar{J} \mathrm{msec}$ to $63_{C}^{C}$ & & \\
\hline $\mathrm{H}$ & Freq. Response & flat between $0-500 \mathrm{cps}$ & & \\
\hline 1 & Resolution & $<0.01{ }_{C} \mathrm{FR}$ & infinitesimal & \\
\hline$J$ & Linearity & \multirow{2}{*}{$\begin{array}{l}\text { combined effects less } \\
\text { than } \pm 0.75 c \text { of full } \\
\text { range output }\end{array}$} & \multirow{2}{*}{$\begin{array}{l}\text { combined effects less } \\
\text { than } \pm 0.75 \% \text { of full } \\
\text { range output }\end{array}$} & \\
\hline K & Hysteresis & & & \\
\hline$L$ & Accuracy & & & \\
\hline$M$ & Acceleration Error & $<0.0 J^{C_{C}} \mathrm{FR} / \mathrm{g}$ at $100 \mathrm{~g}$ & $0.03 \% \mathrm{FR} / \mathrm{g}$ & \\
\hline$N$ & Vibration Error & $<0.03^{\circ}{ }_{c} \mathrm{FR} / \mathrm{g}$ at $50 \mathrm{~g}$ & $0.02 \% \mathrm{FR} / \mathrm{g}$ & \\
\hline 0 & Shock & $1 \mathrm{msec}, 100 \mathrm{~g}$ & & \\
\hline$P$ & Noise Limit & $150 \mathrm{db}$ & & \\
\hline$Q$ & Neutron Flux & $\mathrm{NA}$ & & \\
\hline $\mathbf{R}$ & Gamma Flux & NA & & \\
\hline$S$ & Dimensions & $0.75^{\prime \prime} \mathrm{OD} \times 3.9^{\prime \prime} \mathrm{lg}$ & $\left.0.612^{\prime \prime}\right) \mathrm{D} \times 2.7^{\prime \prime} \mathrm{lg}$ & \\
\hline$T$ & Weight & & $0.5 \mathrm{oz}$. approx. & \\
\hline U & Resonant Freq. & $>1000 \mathrm{cps}$ & $9000 \mathrm{cps}$ & \\
\hline$V$ & Insulation Res. & $100 \mathrm{megohms}$ at $45 \mathrm{VD}$ & & \\
\hline$W$ & Material & compatible with $\mathrm{LH}_{2}$ & & \\
\hline & & & & \\
\hline & & & & \\
\hline & & & & \\
\hline
\end{tabular}





\section{DEVELOPMENT HISTORY}

Code No:

DPr-10

Mfgr: Statham

Model No. PL $131 \mathrm{r}$

P. 0 . 30635

\section{REMARKS:}

In order to solve the mechanical mounting problems in final assembly, extreme emphasis was placed on physical size of these units.

A literature search for units specified by the manufacturers to satisfy the environmental conditions for NRX-A-1 has been made and the initial selection is based on these results.

Confirmation of the guarantees will be made in subsequent evaluation tests by WANL.

The actual models selected are similar in all instances to units previously tested.

\section{December 1963 - Vibration Test}

Several strain gage type pressure transducers of the types to be utilized in NRX-A-1 instrumentation have been vibrated to determine degree of vibration induced output and observe operation characteristics under conditions of vibration. This is a report of obtained test results.

Test Equipment and Instrumentation

An MB Model C10 Vibration Exciter was used as the vibration generator. This equipment, rated at $1200 \mathrm{lbs}$. force, is self-resonant at approximately $2.1 \mathrm{kcs}$. It is useable in the present application to about $2.0 \mathrm{kcs}$ although at this frequency operation is along the lower slope of the resonance curve.

Vibration level was sensed by an Endevco accelerometer and indicated by a Bruel and Kjaer VTVM. The accelerometer-voltmeter combination was calibrated by use of a standard accelerometer. The transducer excitation voltage was indicated by a Simpson Model 260 Multimeter. The oscilloscope was calibrated against its internal calibration voltage.

\section{Test $\underline{\text { Procedure }}$}

The testing was generally in accordance with the following procedure.

A. The vibration frequency was set to $30 \mathrm{cps}$ and vibration level to $10 \mathrm{~g}$ 's $\mathrm{rms}$.

B. The frequency was slowly increased to $2000 \mathrm{cps}$. The vibration level was manually held to $10 \mathrm{~g}$ 's rms.

C. The transducer and accelerometer outputs were observed on the dual beam oscilloscope and photographed. 


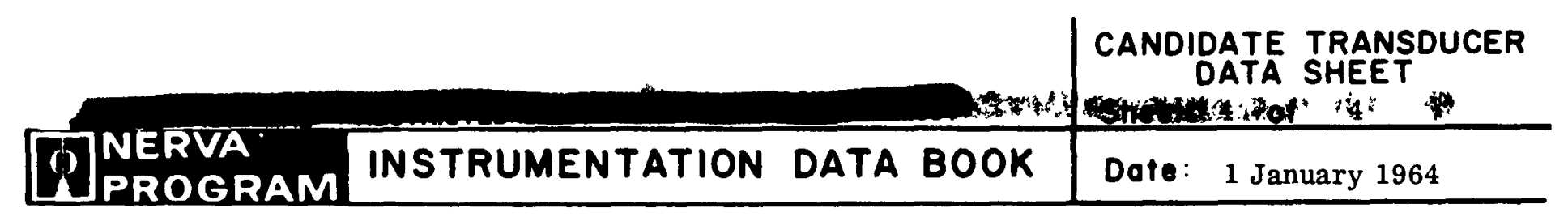

\section{DEVELOPMENT HISTORY}

Code No:

$\operatorname{DPr}-10$

Mfgr:

Statham

Model No.

PL $131 \mathrm{r}$

P. 0 .

30635

\section{REMARKS:}

D. The above steps were repeated with pressure applied to the transducer.

E. Transducer output waveforms were observed and recorded at the frequencies which resulted in the highest vibration induced output.

F. The transducer response to application and removal of pressure was observed and recorded at the frequency of highest vibration induced output.

The above procedures were employed for each of the three axes of the tested transducer.

Summary of Results

Vibration Induced ac Output: The maximum observed vibration induced ac output at the $10 \mathrm{~g}$ vibration level was about $0.5 \mathrm{mv}$ or $1.25 \%$ nominal.

Vibration Induced de Output Shift: No dc output shift was observed under conditions of vibration at the $10 \mathrm{~g} \mathrm{rms}$ level.

Response to Pressure Variation: Response to $25 \%$ rated pressure application was normal in all cases at the $10 \mathrm{~g}$ rms vibration level. 


\section{PRESSURE TRANSDUCER}

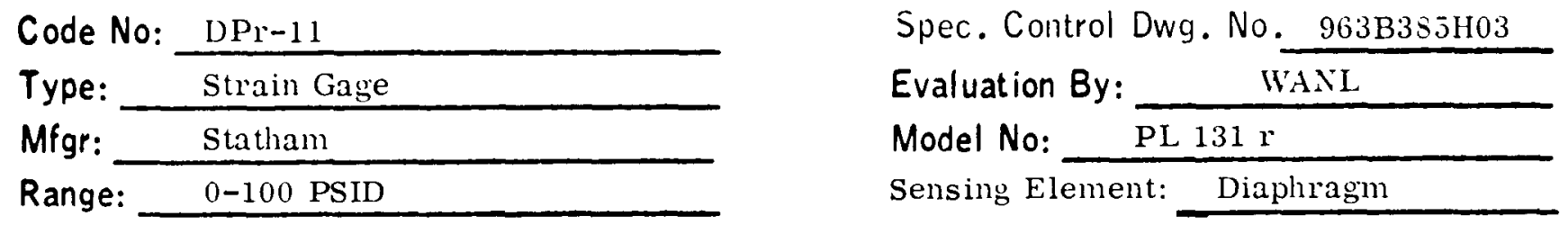

\section{PERFORMANCE \& ENVIRONMENTAL SPECIFICATIONS}

\begin{tabular}{|c|c|c|c|c|}
\hline Test & Condition & NERVA Requirements & Manufacturer's Specs & $\begin{array}{l}\text { Summary of } \\
\text { Test Results }\end{array}$ \\
\hline$A$ & Pressure Overrange & 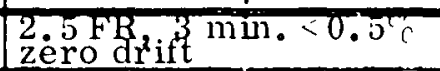 & $200^{c} \mathrm{FR}$ & \\
\hline$B$ & Compt. Temp Range & $140^{\circ}-535^{\circ} \mathrm{R}$ & $395^{\circ}-710^{\circ} \mathrm{R}$ & \\
\hline $\mathrm{C}$ & Excitation & $5 \mathrm{~V}$ (nom) DC or $\mathrm{AC} \mathrm{rms}$ & $5 \mathrm{VDC}$ or $\mathrm{AC}$ rms & \\
\hline$D$ & Sensitivity & $20 \mathrm{mv}$ (nom) & 40 mv approx. & \\
\hline$E$ & Input Impedance & 350 ohms min & 350 ohms nom. & \\
\hline$F$ & Output Impedance & 300 ohms $\pm 10_{0}^{c_{0}}$ & 350 ohms nom. & \\
\hline$G$ & Response time & $5 \mathrm{msec}$ to $63 \mathrm{c}$ & & \\
\hline $\mathrm{H}$ & Freq. Response & flat between $0-500 \mathrm{cps}$ & & \\
\hline 1 & Resolution & $0.01 \mathrm{FR}$ & infinitesimal & \\
\hline$J$ & Linearity & \multirow{2}{*}{$\begin{array}{l}\text { combined effect less } \\
\text { than } \pm 0.75 \text { c of full } \\
\text { range output }\end{array}$} & \multirow{2}{*}{\begin{tabular}{|l|} 
combined effect less \\
than $\pm 0.7 j \%$ of full \\
range output \\
\end{tabular}} & \\
\hline$K$ & Hysteresis & & & \\
\hline$L$ & Accuracy & & & \\
\hline$M$ & Acceleration Error & $<0.05 \% \mathrm{FR} / \mathrm{g}$ at $100 \mathrm{~g}$ & $0.01 \sim \mathrm{FR} / \mathrm{g}$ & \\
\hline$N$ & Vibration Error & $<0.03(\% \mathrm{FR} / \mathrm{g}$ at $50 \mathrm{~g}$ & $0.01 \% \mathrm{FR} / \mathrm{g}$ & \\
\hline 0 & Shock & $1 \mathrm{msec}, 100 \mathrm{~g}$ & & \\
\hline$P$ & Noise Limit & $150 \mathrm{db}$ & & \\
\hline$Q$ & Neutron Flux & $\mathrm{NA}$ & & \\
\hline$R$ & Gamma Flux & $\mathrm{NA}$ & & \\
\hline $\mathrm{s}$ & Dimensions & $0.75^{\prime \prime} \mathrm{OD} \times 3.9^{\prime \prime} \mathrm{lg}$ & $0.612 " \mathrm{OD} \times 2.7 " \mathrm{lg}$ & \\
\hline$T$ & Weight & & $0.5 \mathrm{oz}$. approx. & \\
\hline U & Resonant Freq. & $>1000 \mathrm{cps}$ & $11000 \mathrm{cps}$ & \\
\hline $\mathrm{v}$ & Insulation Res. & $100 \mathrm{megohm}$ at $45 \mathrm{VDC}$ & & \\
\hline$w$ & Material & Compatible with $\mathrm{LH}_{2}$ & & \\
\hline & & & & \\
\hline & & & & \\
\hline & & & & \\
\hline
\end{tabular}





\section{DEVELOPMENT HISTORY}

Code No: DPr -11

Model No. PL $131 \mathrm{r}$
Mfgr: Statham

P. 0 . 30635

\section{REMARKS:}

In order to solve the mechanical mounting problems in final assembly, extreme emphasis was placed on physical size of these units.

A literature search for units specified by the manufacturers to satisfy the environmental conditions for NRX-A-1 has been made and the initial selection is based on these results.

Confirmation of the guarantees will be made in subsequent evaluation tests by WANL.

The actual models selected are similar in all instances to units previously tested.

\section{December 1963 - Vibration Test}

Several strain gage type pressure transducers of the types to be utilized in NRX-A-1 instrumentation have been vibrated to determine degree of vibration induced output and observe operation characteristics under conditions of vibration. This is a report of obtained test results.

Test Requirement and Instrumentation

An MB Model C10 Vibration Exciter was used as the vibration generator. This equipment, rated at $1200 \mathrm{lbs}$. force, is self-resonant at approximately $2.1 \mathrm{kcs}$. It is useable in the present application to about $2.0 \mathrm{kcs}$ although at this frequency operation is along the lower slope of the resonance curve.

Vibration level was sensed by Endevco accelerometer and indicated by a Bruel and Kjaer VTVM. The accelerometer-voltmeter combination was calibrated by use of a standard accelerometer. The transducer excitation voltage was indicated by a Simpson Model 260 Multimeter. The oscilloscope was calibrated against its internal calibration voltage.

\section{Test Procedure}

The testing was generally in accordance with the following procedure.

A. The vibration frequency was set to $30 \mathrm{cps}$ and vibration level to $10 \mathrm{~g}^{\prime} \mathrm{s} \mathrm{rms}$.

B. The frequency was slowly increased to $2000 \mathrm{cps}$. The vibration level was manually held to $10 \mathrm{~g}$ 's rms.

C. The transducer and accelerometer outputs were observed on the dual beam oscilloscope and photographed.

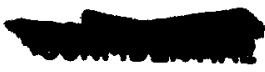




\section{DEVELOPMENT HISTORY}

Code No:

DPr-11

Model No.

PL $131 \mathrm{r}$
Mfgr:

P. 0 . Statham

\section{REMARKS:}

D. The above steps were repeated with pressure applied to the transducer.

E. Transducer output waveforms were observed and recorded at the frequencies which resulted in the highest vibration induced output.

F. The transducer response to application and removal of pressure was observed and recorded at the frequency of highest vibration induced output.

The above procedures were employed for each of the three axes of the tested transducer.

\section{Summary of Results}

Vibration Induced ac Output: The maximum observed was $0.26 \mathrm{mv}$ or $0.65 \%$ nominal FS.

Vibration Induced de Output Shift: No output de shift was observed when unit was vibrated at the $10 \mathrm{~g}$ rms level.

Response to Pressure Variation: Device response to $12.5 \%$ rated pressure was normal.

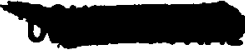




\section{THERMOCOUPLE}

Code No: $\mathrm{Tr}-1$

Type: Tungsten/Tungsten-26\% Rhenium

Mfgr: Aero Research

Range:
Spec. Control Dwg. No.

Evaluation By: WANL

Model No:

Application:

PERFORMANCE \& ENVIRONMENTAL SPECIFICATIONS

\begin{tabular}{|c|c|c|c|c|}
\hline Test & Condition & NERVA Requirements & Manufacturer's Specs. & $\begin{array}{l}\text { Summary of } \\
\text { Test Results }\end{array}$ \\
\hline$A$ & Proof Pressure & 650 psia & & \\
\hline$B$ & Sheath Material & & $\begin{array}{l}\mathrm{W}-26 \% \text { Re and } \\
304 \text { Stainless Steel }\end{array}$ & \\
\hline $\mathrm{C}$ & Accel. Error & & & \\
\hline D & Vibration Error & $10 \mathrm{~g}(20-2000 \mathrm{cps})$ & & \\
\hline$E$ & Shock & & & \\
\hline $\mathbf{F}$ & Noise Limit & & & \\
\hline $\bar{G}$ & Neutron Flux & $5.2 \times 10^{15} \mathrm{n} / \mathrm{cm}^{2}-\mathrm{sec}$ & & \\
\hline $\mathrm{H}$ & Gamma Flux & $2.3 \times 10^{12} \mathrm{ergs} / \mathrm{gm}(\mathrm{C})-\mathrm{hr}$ & & \\
\hline 1 & Sensitivity & & & \\
\hline $\mathrm{J}$ & Dimensions & & $0.060^{\prime \prime}$ to $0.070^{\prime \prime} \mathrm{OD}$ & \\
\hline$K$ & Weight & & & \\
\hline$L$ & Insulation Res. & & & \\
\hline$M$ & Material & & $\mathrm{ThO}_{2}$ and $\mathrm{MgO}$ & $\mathrm{ThO}_{2}$ not \\
\hline $\mathrm{N}$ & Wire Size & & & satisfactory \\
\hline & & & & \\
\hline & & & & \\
\hline & & & & \\
\hline & & & & \\
\hline & & & & \\
\hline & & & & \\
\hline & & & & \\
\hline & & & & \\
\hline & & & & \\
\hline & & & & \\
\hline & & & & \\
\hline & & & & \\
\hline
\end{tabular}





\begin{tabular}{l|l|l}
\hline C) & \multicolumn{2}{|c|}{ DATA SHEET } \\
PROG & Sheet 3 of 5 \\
\hline
\end{tabular}

\section{DEVELOPMENT HISTORY}

\begin{tabular}{ll} 
Code No: $\quad$ Tr-1 & Mfgr: \\
Model No. & P. 0. \\
\hline
\end{tabular}

\section{REMARKS:}

The basis for the use of $\mathrm{W} / \mathrm{W}-26 \mathrm{Re}$ thermocouples for high temperature measurements dates back to studies made by Haase and Schneider ${ }^{1}$ in Germany (1956), by Sims ${ }^{2}$ et al (1958), Davies $^{3}$ in England (1958), and Lachman ${ }^{4}$ (1957).

From these studies on various refractory metals, it appeared that the combination of tungsten vs. rhenium was attractive from the standpoint of reproducibility of EMF, thermal stability (i.e. the ability to repeat after thermal cycling), and ability to withstand high temperatures (high melting points).

Considerable development work was then carried out by F. W. Kuether and J. C. Lachman $5,6,7$ which resulted in a commercially available thermocouple of tungsten vs. tungsten $-26 \%$ rhenium. The wires for such thermocouples are supplied to a calibration curve claimed to hold within $\pm 1 \%$.

Thermocouples of tungsten and rhenium are the only commercially a vailable, reasonably well established sensors suitable, for high temperature measurements in KIWI and NERVA, other than the thermal capsules used for post-mortem indications.

One drawback to this type of thermocouple is the room temperature brittleness of the tungsten leg, after heating beyond the recrystallization temperature. (Various estimates give this a $1500^{\circ} \mathrm{F}$. to $2000^{\circ} \mathrm{F}$.) Efforts have been made to overcome this problem by adding rhenium to the tungsten leg, resulting in a $\mathrm{W}-5 \mathrm{Re} / \mathrm{W}-26 \mathrm{Re}$ thermocouple. This alloy retains room temperature ductility after being heated to $3100^{\circ} \mathrm{F}$., but suffers severe embrittlement after being heated to $4000^{\circ} \mathrm{F}$. In addition, the $\mathrm{EMF}$ vs. temperature curve flattens out in the range of $4000^{\circ} \mathrm{F}$. and above, the most important area of measurement. For these reasons, W/W-26\%Re has been specified for NRX tests.

\section{USE IN KIWI}

This type of thermocouple has been used for the high temperature measurements on all KIWI hot tests except the first one, and has in general performed satisfactorily, although in one test a large number of unexplained failures occurred.

The major problem to date in its use is that the molybdenum sheath used will fail at $4000^{\circ} \mathrm{F}$ (the eutectic point with carbon).

In KIWI B-1B, 13 thermocouples showed evidence of melting of the sheath, when temperatures made an excursion beyond programmed values.

In subsequent laboratory tests at LASL, of 6 molybdenum sheathed couples, all failed at $4000^{\circ} \mathrm{F}$. except one which failed at $3300^{\circ} \mathrm{F}$. 


\section{DEVELOPMENT HISTORY}

Code No: $\mathrm{Tr}-1$

Mfgr: Aero Research

Model No.

P. 0 .

\section{REMARKS:}

Four $\mathrm{W}-25 \mathrm{Re}$ sheathed couples with $\mathrm{ThO}_{2}$ insulation all failed between $4440^{\circ} \mathrm{F}$ and $4600^{\circ} \mathrm{F}$, and of two $\mathrm{W}-25 \mathrm{Re}$ sheathed couples with $\mathrm{BeO}$ insulation, one failed at $3500^{\circ} \mathrm{F}$ and one failed at $3900^{\circ} \mathrm{F}$.

Further investigation is being made at LASL. Investigation of alternate sheath materials will begin at WANL in June, 1963.

It should be noted that the failure of the sheath at the eutectic joint involves only a certain percentage of the high-temperature thermocouples (those used in the highest temperature regions).

Testing will begin at WANL in June 1963 to establish lifetimes of these thermocouples at elevated temperatures.

\section{REFERENCES}

1. G. Haase and G. Schneider, X. Physics 144, 256 (1956).

2. C. T. Sims, G. B. Gaines, and R. I. Daffee, Rev Sci Inst, Vol. 30, No. 2, Feb. 1959.

3. D. A. Davies, "Two Thermocouples Suitable for Measurement of Temperatures up to $2000^{\circ} \mathrm{C}$," J Sci Inst, Vol. 37, Jan. 1960.

4. J. Lachman, "Calibration of Rhenium Molybdenum and Rhenium-Tungsten Thermocouples to $3200^{\circ}$ F," G. E. Aircraft Nuclear Propulsion Department, Rept. No. DC 57-8-150 (Aug. 21, 1958) Unclassified.

5. John C. Lachman and F. W. Kuether, "Stability of Rhenium/Tungsten "Thermocouples in Hydrogen Atmospheres," ISA Journal, Vol. 7, No. 3, March 1960.

6. F. W. Kuether and John C. Lachman, "How Reliable Are the Two New High Temperature Thermocouples in Vacuum?," ISA Journal, Vol. 7, No. 4, April 1960.

7. J. C. Lachman, "New Developments in Tungsten/Tungsten-Rhenium Thermocouples," Fall Instrument-Automation Conference and Exhibit, Los Angeles, Calif., Sept. 11-15, 1961 .

8. W. C. Kuhlman, "Research and Evaluation of Materials for Thermocouple Application Suitable for Temperature Measurements Up to $4500^{\circ} \mathrm{F}$ on the Surface of Glide Re-Entry Vehicles," Technical Documentary Report No. ASD-TDR-63-233, May 1963. 


\section{DEVELOPMENT HISTORY}

Code No: $\operatorname{Tr}-1$

Model No.

Mfgr: Aero Research

P. 0 .

\section{REMARKS:}

9. A. R. Driesner, et al, "High Temperature Thermocouples in the Rover Program," LASL Report N-3-1051.

\section{$\underline{30}$ September $\underline{1963}$}

$\mathrm{ThO}_{2}$ was found to be a poor insulator at the temperature this thermocouple was to be used. Therefore, testing has been discontinued on this type. Thermocouples containing BeO (See $\mathrm{Tr}-4)$ shall be used for future high temperature work. 
it: "x:

THIS PAGE INTENTIONALLY LEFT BLANK 


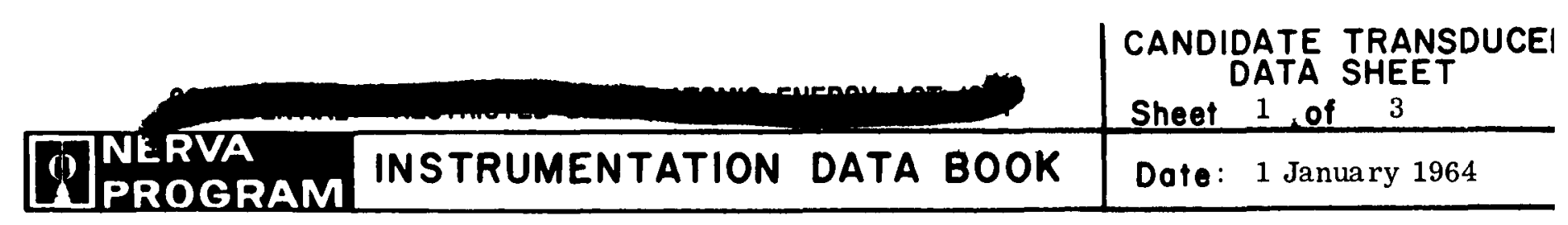

\section{THERMOCOUPLE}

$\begin{array}{ll}\text { Code No: } \frac{\mathrm{Tr}-2}{\text { Copper-Constantan }} & \begin{array}{l}\text { Spec. Control Dwg. No. } \\ \text { Type: }\end{array} \quad \begin{array}{l}\text { Evaluation By: } \\ \text { Mfgr: }\end{array} \quad \begin{array}{l}\text { Model No: } \\ \text { Range: }\end{array} \quad \text { Application: }\end{array}$

\begin{tabular}{|c|c|c|c|c|}
\hline Test & Condition & NERVA Requirements & Manufacturer's Specs. & $\begin{array}{l}\text { Summary of } \\
\text { Test Results }\end{array}$ \\
\hline$A$ & Proof Pressure & 0 to $650 \mathrm{psia}$ & & \\
\hline B & Sheath Material & & 304 Stainless Steel & \\
\hline$C$ & Accel. Error & & & \\
\hline D & Vibration Error & $10 \mathrm{~g}(20-2000 \mathrm{cps})$ & & \\
\hline$E$ & Shock & & & \\
\hline$F$ & Noise Limit & & & \\
\hline $\mathbf{G}$ & Neutron Flux & $5.2 \times 10^{15} \mathrm{n} / \mathrm{cm}^{2}-\mathrm{sec}$ & & \\
\hline $\mathrm{H}$ & Gamma Flux & $2.3 \times 10^{12} \mathrm{ergs} / \mathrm{gm}(\mathrm{C})$ & $\mathrm{hr}$ & \\
\hline 1 & Sensitivity & & & \\
\hline $\mathrm{J}$ & Dimensions & & $0.035^{\prime \prime}$ to $0.060^{\prime \prime} \mathrm{OD}$. & \\
\hline $\mathbf{K}$ & Weight & & & \\
\hline$L$ & Insulation Res. & & $>500 \mathrm{megohms}$ & \\
\hline$M$ & Material & & & \\
\hline$N$ & Wire Size & 2 & 2 & \\
\hline & & & & \\
\hline & & & & \\
\hline & & & & \\
\hline & & & & \\
\hline & & & & \\
\hline & & & & \\
\hline & & & & \\
\hline & & & & \\
\hline & & & & \\
\hline & & & & \\
\hline & & & & \\
\hline & & & & \\
\hline
\end{tabular}




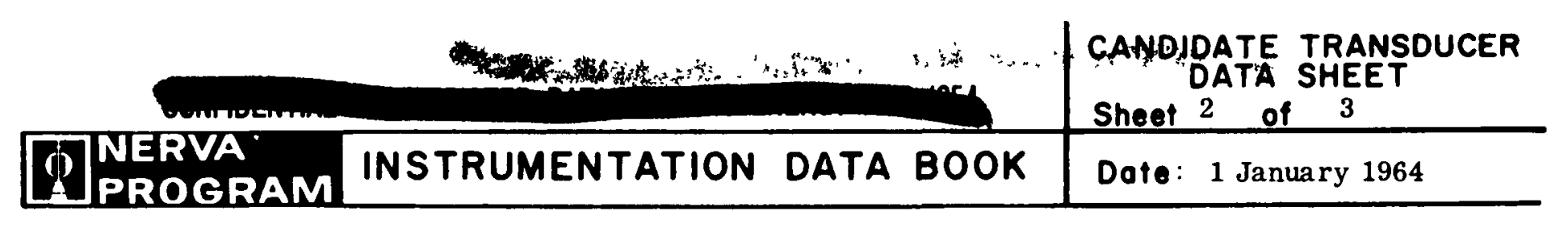

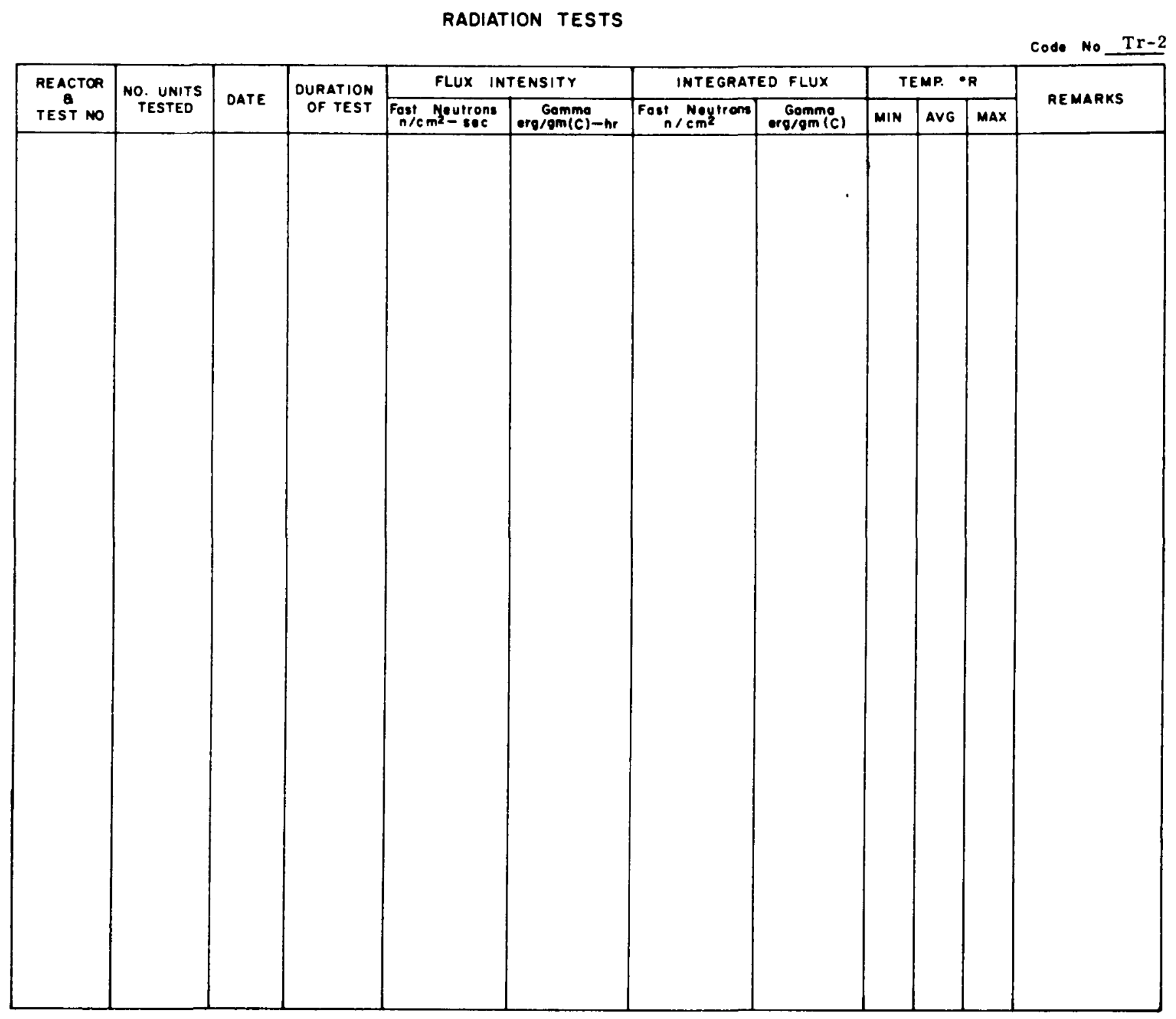




\section{DEVELOPMENT HISTORY}

Code No: $\quad \mathrm{Tr}-2$

Mfgr: Aero-Research

Model No.

P. 0 .

REMARKS:

\section{Copper-Constantan}

A recent unpublished transducer survey by Battelle Memorial Institute summarizes most of the irradiation studies of thermocouples to date. As a general conclusion it is stated that changes of $1 \%$ to $2 \%$ in measured temperature may occur as a result of irradiation.

One study at Oak Ridge showed changes of $\pm 1^{\circ} \mathrm{C}$ at liquid nitrogen temperature for copperconstantan thermocouples irradiated to $5 \times 10^{16} \mathrm{nvt}$.

$\underline{30}$ September 1963

This thermocouple has been superseded by Code Nos. $\operatorname{Tr}-13$ and $\operatorname{Tr}-14$. No further evaluation testing will be conducted on this thermocouple. 


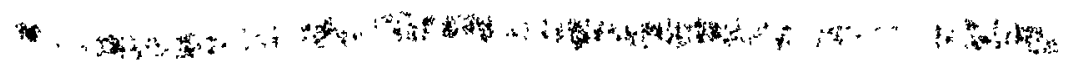

THIS PAGE INTENTIONALLY LEFT BLANK 


\section{THERMOCOUPLE}

Code No: $\quad$ Tr-3

Type:

Mfgr:

Tungsten/Tungsten-26\% Rhenium

Range:
Spec. Control Dwg. No.

Evaluation By: WANL

Model No:

Application:

PERFORMANCE \& ENVIRONMENTAL SPECIFICATIONS

\begin{tabular}{|c|c|c|c|c|}
\hline Test & Condition & NERVA Requirements & Manufacturer's Specs. & $\begin{array}{l}\text { Summary of } \\
\text { Test Results }\end{array}$ \\
\hline$A$ & Proof Pressure & $0-650$ psia & & \\
\hline$B$ & Sheath Material & & $\begin{array}{l}\text { Rhenium and } 304 \\
\text { Stainless Steel }\end{array}$ & \\
\hline C & Accel. Error & & & \\
\hline D & Vibration Error & & & \\
\hline$E$ & Shock & & & \\
\hline$F$ & Noise Limit & & & \\
\hline $\bar{G}$ & Neutron Flux & $5.2 \times 10^{15} \mathrm{n} / \mathrm{cm}^{2}-\mathrm{sec}$ & & \\
\hline $\mathrm{H}$ & Gamma Flux & $2.3 \times 10^{12} \mathrm{ergs} / \mathrm{gm}(\mathrm{C})$ & -hr & \\
\hline 1 & Sensitivity & & & \\
\hline$J$ & Dimensions & & $0.070^{\prime \prime} \mathrm{OD}$ & \\
\hline K & Weight & & & \\
\hline $\mathbf{L}$ & Insulation Res. & & & \\
\hline$M$ & Material & & $\mathrm{ThO}_{2}$ and $\mathrm{MgO}$ & $\mathrm{ThO}_{2}$ not \\
\hline $\mathrm{N}$ & Wire Size & & & satisfactory \\
\hline & & & & \\
\hline & & & & \\
\hline & & & & \\
\hline & & & & \\
\hline & & & & \\
\hline & & & & \\
\hline & & & & \\
\hline & & & & \\
\hline & & & & \\
\hline & & & & \\
\hline & & . & & \\
\hline
\end{tabular}




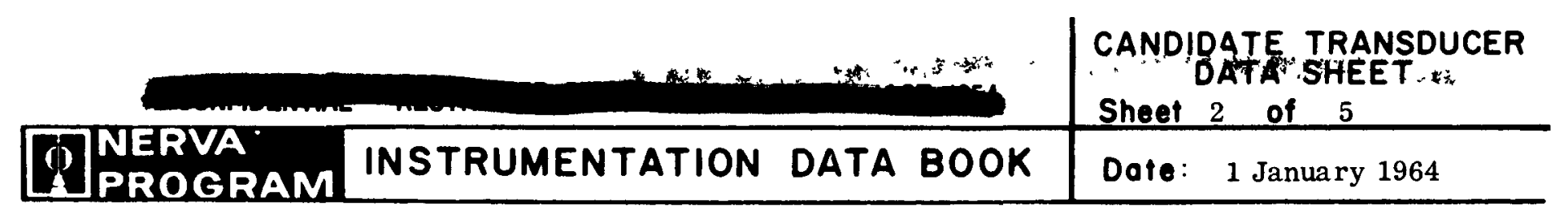

RADIATION TESTS

Code No $\mathrm{Tr}-3$

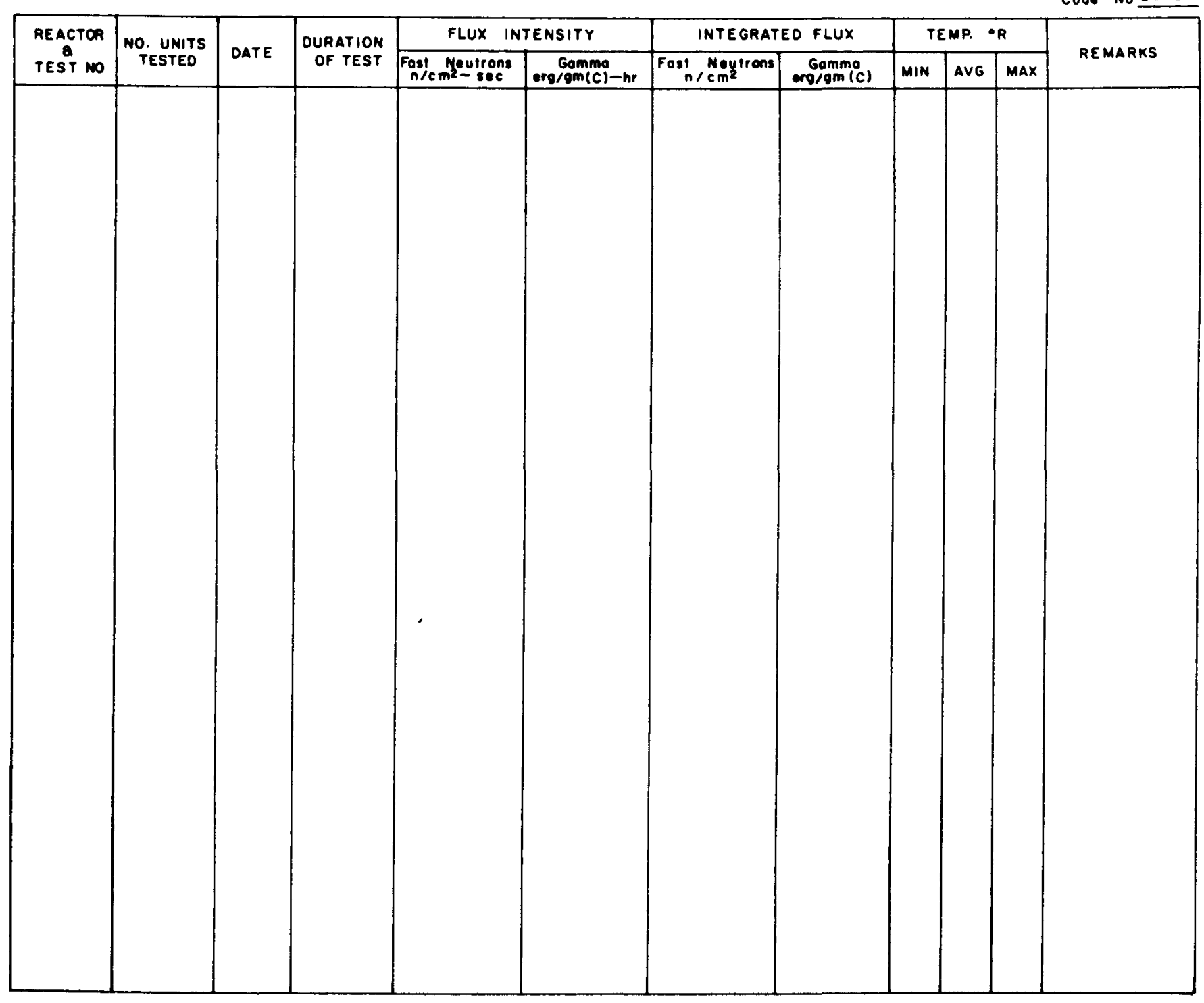




\section{DEVELOPMENT HISTORY}

Code No: $\operatorname{Tr}-3$

Mfgr:

Model No.

P. 0 .

\section{REMARKS:}

The basis for the use of $\mathrm{W} / \mathrm{W}-26 \mathrm{Re}$ thermocouples for high temperature measurements dates back to studies made by Haase and Schneider ${ }^{1}$ in Germany (1956), by Sims $^{2}$ et al (1958), Davies $^{3}$ in England (1958), and Lachman ${ }^{4}$ (1957).

From these studies on various refractory metals, it appea red that the combination of tungsten vs. rhenium was attractive from the standpoint of reproducibility of EMF, thermal stability (i.e. the ability to repeat after thermal cycling), and ability to withstand high temperatures (high melting points).

Considerable development work was then carried out by F. W. Kuether and J. C. Lachman $5,6,7$ which resulted in a commercially available thermocouple of tungsten vs. tungsten $-26 \%$ rhenium. The wires for such thermocouples are supplied to a calibration curve claimed to hold within $\pm 1 \%$.

Thermocouples of tungsten and rhenium are the only commercially available, reasonably well established sensors suitable, for high temperature measurements in KIWI and NERVA, other than the thermal capsules used for post-mortem indications.

One drawback to this type of thermocouple is the room temperature brittleness of the tungsten leg, after heating beyond the recrystallization temperature. (Various estimates give this a $1500^{\circ} \mathrm{F}$ to $2000^{\circ} \mathrm{F}$.) Efforts have been made to overcome this problem by adding rhenium to the tungsten leg, resulting in a $\mathrm{W}-5 \mathrm{Re} / \mathrm{W}-26 \mathrm{Re}$ thermocouple. This alloy retains room temperature ductility after being heated to $3100^{\circ} \mathrm{F}$, but suffers severe embrittlement aft er being heated to $4000^{\circ} \mathrm{F}$. In addition, the EMF vs. temperature curve flattens out in the range of $4000^{\circ} \mathrm{F}$ and above, the most important area of measurement. For these reasons, W/W-26\%Re has been specified for NRX tests.

\section{USE IN KIWI}

This type of thermocouple has been used for the high temperature measurements on all KIWI hot tests except the first one, and has in general performed satisfactorily, although in one test a large number of unexplained failures occurred.

The major problem to date in its use is that the molybdenum sheath used will fail at $4000^{\circ} \mathrm{F}$ (the eutectic point with carbon).

In KIWI B-1B, 13 thermocouples showed evidence of melting of the sheath, when temperatures made an excursion beyond programmed values.

In subsequent laboratory tests at LASL, of 6 molybdenum sheathed couples, all failed at $4000^{\circ} \mathrm{F}$ except one which failed at $3300^{\circ} \mathrm{F}$. 


\begin{tabular}{|l|l|l}
\hline NERVA & $\begin{array}{l}\text { CANDIDATE TRANSDUCER } \\
\text { PROGRAM INSTRUMENTATION DATA BOOK }\end{array}$ & Date: 1 January 1964 \\
\hline
\end{tabular}

\section{DEVELOPMENT HISTORY}

Code No:

$-\underline{T r}-3$

Mfgr:

Model No.

P. 0 .

\section{REMARKS:}

Four W-25Re sheathed couples with $\mathrm{ThO}_{2}$ insulation all failed between $4440^{\circ} \mathrm{F}$ and $4600^{\circ} \mathrm{F}$, and of two $\mathrm{W}-25 \mathrm{Re}$ sheathed couples with $\mathrm{BeO}$ insulation, one failed at $3500^{\circ} \mathrm{F}$ and one failed at $3900^{\circ} \mathrm{F}$.

Further investigation is being made at LASL. Investigation of alternate sheath materials will begin at WANL in June, 1963.

It should be noted that the failure of the sheath at the eutectic joint involves only a certain percentage of the high-temperature thermocouples (those used in the highest temperature regions).

Testing will begin at WANL in June 1963 to establish lifetimes of these thermocouples at elevated temperatures.

\section{REFERENCES}

1. G. Haase and G. Schneider, X. Physics 144, 256 (1956).

2. C. T. Sims, G. B. Gaines, and R. I. Daffee, Rev Sci Inst, Vol. 30, No. 2, Feb. 1959.

3. D. A. Davies, "Two Thermocouples Suitable for Measurement of Temperatures up to $2000^{\circ} \mathrm{C}$, " J Sci Inst, Vol. 37, Jan. 1960.

4. J. Lachman, "Calibration of Rhenium Molybdenum and Rhenium-Tungsten Thermocouples to $3200^{\circ} \mathrm{F}, "$ G. E. Aircraft Nuclear Propulsion Department, Rept No. DC 57-8-150 (Aug 21, 1957) Unclassified.

5. John C. Lachman and F. W. Kuether, "Stability of Rhenium/Tungsten Thermocouples in Hydrogen Atmospheres," ISA Journal, Vol. 7, No. 3, March 1960.

6. F. W. Kuether and John C. Lachman, "How Reliable Are the Two New High Temperature Thermocouples in Vacuum?, "ISA Journal, Vol. 7, No. 4, April 1960.

7. J. C. Lachman, "New Developments in Tungsten/Tungsten-Rhenium Thermocouples, " Fall Instrument-Automation Conference and Exhibit, Los Angeles, Calif. Sep. 11-15, 1961.

8. W. C. Kuhlman, "Research and Evaluation of Materials for Thermocouple Application Suitable for Temperature Measurements Up to $4500^{\circ} \mathrm{F}$ on the Surface of Glide Re-Entry Vehicles," Technical Documentary Report No. ASD-TDR-63-233, May 1963.

9. A. R. Driesner et al, "High Temperature Thermocouples in the Rover Program," LASL Report N-3-1051. 


\begin{tabular}{|l|l|l|}
\hline RERVA: & \multicolumn{2}{|c}{$\begin{array}{c}\text { CANDIDATE TRANSDUCER } \\
\text { DATA SHEET } \\
\text { SROGRAM }\end{array}$} \\
Sheet 5 of 5
\end{tabular}

\section{DEVELOPMENT HISTORY}

Code No: $\mathrm{Tr}-3$

Model No.

Mfgr:

P. 0 .

REMARKS:

\section{$\underline{30} \underline{\text { September }} 1963$}

$\mathrm{ThO}_{2}$ was found to be a poor insulator at the temperature this thermocouple was to be used. Therefore, testing has been discontinued on this type. Thermocouples containing BeO (See $\operatorname{Tr}-4)$ shall be used for future high temperature work. 
4 "

\section{THIS PAGE INTENTIONALLY LEFT BLANK}




\section{THERMOCOUPLE}

Code No: $\mathrm{Tr}-4$

Type: Tungsten/Tungsten-26 $6^{\circ}$ Rhenium

Mfgr: Aero Research

Range:
Spec. Control Dwg. No.

Evaluation By: WANL

Model No:

Application:

\section{PERFORMANCE \& ENVIRONMENTAL SPECIFICATIONS}

\begin{tabular}{|c|c|c|c|c|}
\hline Test & Condition & NERVA Requirements & Manufacturer's Specs. & $\begin{array}{l}\text { Summary of } \\
\text { Test Results }\end{array}$ \\
\hline$A$ & Proof Pressure & 0 to 650 psia & & $>1000$ psia \\
\hline$B$ & Sheath Material & & $\begin{array}{l}\text { Molybdenum and } 304 \\
\text { Stainless Steel }\end{array}$ & \\
\hline $\mathrm{C}$ & Accel. Error & & & see vibration \\
\hline$D$ & Vibration Error & $10 \mathrm{~g}(20-2000 \mathrm{cps})$ & & $\begin{array}{l}<10 \mu \mathrm{v} \text { at } 10 \mathrm{~g} \text { is } \\
30-2000 \mathrm{cps}\end{array}$ \\
\hline$E$ & Shock & & & \\
\hline $\mathbf{F}$ & Noise Limit & & & \\
\hline $\mathbf{G}$ & Neutron Flux & $5.2 \times 10^{15} \mathrm{n} / \mathrm{cm}^{2}-\mathrm{sec}$ & & \\
\hline $\mathrm{H}$ & Gamma Flux & $2.3 \times 10^{12} \mathrm{ergs} / \mathrm{gm}(\mathrm{C})$ & & \\
\hline 1 & Sensitivity & & & $8.7 \mu \mathrm{v} /{ }^{\circ} \mathrm{F}$ at 4000 \\
\hline $\mathrm{J}$ & Dimensions & & $0.035 "$ to $0.060 "$ OD & $0.035^{\prime \prime}$ to $0.060^{\prime \prime}$ \\
\hline $\mathrm{K}$ & Weight & & & \\
\hline$L$ & Insulation Res. & & $>500$ megohms & $>500 \mathrm{megohms}$ \\
\hline M & Material & & $\mathrm{BeO}$ & \\
\hline$N$ & Wire Size & & & \\
\hline & & & & \\
\hline & & & & \\
\hline & & & & \\
\hline & & & & \\
\hline & & & & \\
\hline & & & & \\
\hline & & & & \\
\hline & & & & \\
\hline & & & & \\
\hline & & & & \\
\hline & & & & \\
\hline
\end{tabular}





\begin{tabular}{|c|c|c|}
\hline 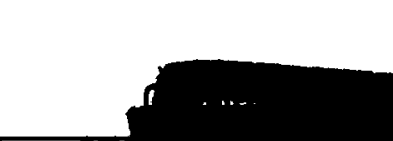 & & $\begin{array}{l}\text { CANDIDATE TRANSDUCER } \\
\text { DATA SHEET } \\
\text { Sheet } 3 \text { of } 5 \\
\end{array}$ \\
\hline $\begin{array}{l}\text { WERVA } \\
\text { PROGRAM }\end{array}$ & INSTRUMENTATION DATA BOOK & Dote: 1 January 1964 \\
\hline
\end{tabular}

\section{DEVELOPMENT HISTORY}

Code No: $\operatorname{Tr}-4$

Mfgr: Aero Research

Model No.

P. 0 .

\section{REMARKS:}

The basis for the use of $\mathrm{W} / \mathrm{W}-26 \mathrm{Re}$ thermocouples for high temperature measurements dates back to studies made by Haase and Schneider ${ }^{1}$ in Germany (1956), by Sims ${ }^{2}$ et al (1958), Davies $^{3}$ in England (1958), and Lachman ${ }^{4}$ (1957).

From these studies on various refractory metals, it appeared that the combination of tungsten vs. rhenium was attractive from the standpoint of reproducibility of EMF, thermal stability (i.e. the ability to repeat after thermal cycling), and ability to withstand high temperatures (high melting points).

Considerable development work was then carried out by F. W. Kuether and J. C. Lachman $5,6,7$ which resulted in a commercially available thermocouple of tungsten vs. tungsten-26\% rhenium. The wires for such thermocouples are supplied to a calibration curve claimed to hold within $\pm 1 \%$.

Thermocouples of tungsten and rhenium are the only commercially available, reasonably well established sensors suitable, for high temperature measurements in KIWI and NERVA, other than the thermal capsules used for post-mortem indications.

One drawback to this type of thermocouple is the room temperature brittleness of the tungsten leg, after heating beyond the recrystallization temperature. (Various estimates give this as $1500^{\circ} \mathrm{F}$ to $2000^{\circ} \mathrm{F}$.) Efforts have been made to overcome this problem by adding rhenium to the tungsten leg, resulting in a $\mathrm{W}-5 \mathrm{Re} / \mathrm{W}-26 \mathrm{Re}$ thermocouple. This alloy retains room temperature ductility after being heated to $3100^{\circ} \mathrm{F}$, but suffers severe embrittlement after being heated to $4000^{\circ} \mathrm{F}$. In addition, the EMF vs. temperature curve flattens out in the range of $4000^{\circ} \mathrm{F}$ and above, the most important area of measurement. For these reasons, W/W-26\%Re has been specified for NRX tests.

\section{USE IN KIWI}

This type of thermocouple has been used for the high temperature measurements on all KIWI hot tests except the first one, and has in general performed satisfactorily, although in one test a large number of unexplained failures occurred.

The major problem to date in its use is that the molybdenum sheath used will fail at $4000^{\circ} \mathrm{F}$ (the eutectic point with carbon).

In KIWI B-1B, 13 thermocouples showed evidence of melting of the sheath, when temperatures made an excursion beyond programmed values.

In subsequent laboratory tests at LASL, of 6 molybdenum sheathed couples, all failed at $4000^{\circ} \mathrm{F}$ except one which failed at $3300^{\circ} \mathrm{F}$.

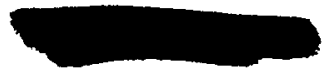




\section{DEVELOPMENT HISTORY}

Code No: $\operatorname{Tr}-4$

Model No.
Mfgr: Aero Research

P. 0 .

\section{REMARKS:}

Four W-25Re sheathed couples with $\mathrm{ThO}_{2}$ insulation all failed between $4440^{\circ} \mathrm{F}$ and $4600^{\circ} \mathrm{F}$, and of two $\mathrm{W}-25 \mathrm{Re}$ sheathed couples with $\mathrm{BeO}$ insulation, one failed at $3500^{\circ} \mathrm{F}$ and one failed at $3900^{\circ} \mathrm{F}$.

Further investigation is being made at LASL. Investigation of alternate sheath materials will begin at WANL in June, 1963.

It should be noted that the failure of the sheath at the eutectic joint involves only a certain percentage of the high-temperature thermocouples (those used in the highest temperature regions).

Testing will begin at WANL in June 1963 to establish lifetimes of these thermocouples at elevated temperatures.

\section{REFERENCES}

1. G. Haase and G. Schneider, X. Physics 144, 256 (1956).

2. C. T. Sims, G. B. Gaines, and R. I. Daffee, Rev Sci Inst, Vol. 30, No. 2, Feb. 1959.

3. D. A. Davies, "Two Thermocouples Suitable for Measurement of Temperatures up to $2000^{\circ} \mathrm{C}$, " J Sci Inst, Vol. 37, January 1960.

4. J. Lachman, "Calibration of Rhenium Molybdenum and Rhenium-Tungsten Thermocouples to $3200^{\circ}$ F," G. E. Aircraft Nuclear Propulsion Department, Rept No. DC 57-8-150 (Aug. 21, 1957) Unclassified.

5. John C. Lachman and F. W. Kuether, "Stability of Rhenium/Tungsten Thermocouples in Hydrogen Atmospheres," ISA Journal, Vol. 7, No. 3, March 1960.

6. F. W. Kuether and John C. Lachman, "How Reliable Are the Two New High Temperature Thermocouples in Vacuum?," ISA Journal, Vol. 7, No. 4, April 1960.

7. J. C. Lachman, "New Developments in Tungsten/Tungsten-Rhenium Thermocouples, " Fall Instrument-Automation Conference and Exhibit, Los Angeles, California, September 11-15, 1961.

8. W. C. Kuhlman, "Research and Evaluation of Materials for Thermocouple Application Suitable for Temperature Measurements Up to $4500^{\circ} \mathrm{F}$ on the Surface of Glide Re-Entry Vehicles, "Technical Documentary Report No. ASD-TDR-63-233, May 1963.

9. A. R. Driesner et al, "High Temperature Thermocouples in the Rover Program, " LASL Report N-3-1051. 


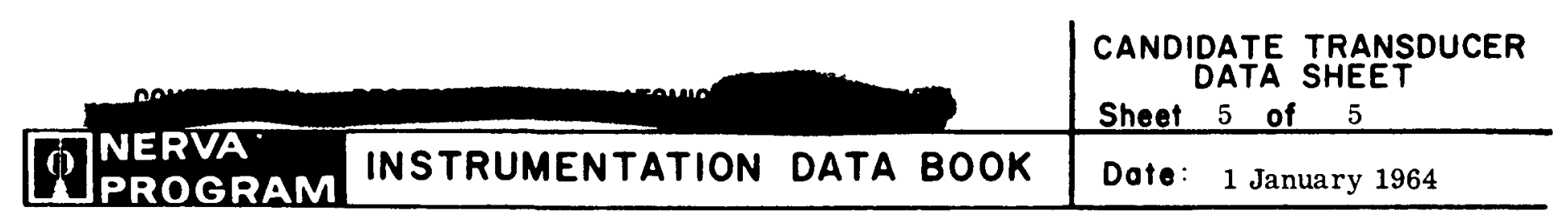

\section{DEVELOPMENT HISTORY}

Code No: $\operatorname{Tr}-4$

Model No.

REMARKS:
Mfgr: Aero Research

P. 0 .

High temperature tests have been conducted at WANL on $17 \mathrm{~W} / \mathrm{W}-26 \%$ Re thermocouples, this Code No. Results of those tests are tabulated below.

\begin{tabular}{|c|c|c|c|c|c|c|}
\hline \multirow[b]{2}{*}{$\begin{array}{l}\text { Test } \\
\text { Date }\end{array}$} & \multirow[b]{2}{*}{$\begin{array}{l}\mathrm{T} / \mathrm{C} \\
\text { No. }\end{array}$} & \multirow[b]{2}{*}{$\begin{array}{l}\text { Time }(\mathrm{min}) \\
>3000^{\circ} \mathrm{F}\end{array}$} & \multirow[b]{2}{*}{$\begin{array}{c}\text { Time }(\mathrm{min}) \\
>3500^{\circ} \mathrm{F}\end{array}$} & \multicolumn{2}{|c|}{ Time to Show Degradation } & \multirow[b]{2}{*}{$\begin{array}{c}\text { Failure } \\
\text { Temp. }\left({ }^{\circ} \mathrm{F}\right)\end{array}$} \\
\hline & & & & $\begin{array}{c}\text { Minutes } \\
\text { from } 3000^{\circ} \mathrm{F}\end{array}$ & $\begin{array}{c}\text { Minutes } \\
\text { from } 3500^{\circ} \mathrm{F}\end{array}$ & \\
\hline $6 / 10 / 63$ & 4 & 18 & 8 & 20 & 2 & 3983 \\
\hline $6 / 11 / 63$ & 2 & 43 & 13 & 19 & 2 & 3922 \\
\hline $6 / 11 / 63$ & 8 & 38 & 10 & 13 & 8 & 3776 \\
\hline $6 / 12 / 63$ & 7 & 42 & 29 & 22 & 9 & 4028 \\
\hline $6 / 12 / 63$ & 9 & 42 & 29 & 22 & 9 & 4028 \\
\hline $6 / 12 / 63$ & 1 & 38 & 21 & 11 & Before $3500^{\circ} \mathrm{F}$ & 4181 \\
\hline $6 / 12 / 63$ & 3 & 38 & 21 & 11 & Before $3500^{\circ} \mathrm{F}$ & 4181 \\
\hline $6 / 12 / 63$ & 5 & .38 & 21 & 11 & Before $3500^{\circ} \mathrm{F}$ & 4181 \\
\hline $6 / 12 / 63$ & 14 & 38 & 22 & 16 & Before $3500^{\circ} \mathrm{F}$ & 4181 \\
\hline $6 / 12 / 63$ & 15 & 38 & 22 & 16 & Before $3500^{\circ} \mathrm{F}$ & 4181 \\
\hline $6 / 12 / 63$ & 20 & 38 & 22 & 19 & Before $3500^{\circ} \mathrm{F}$ & 4181 \\
\hline $6 / 13 / 63$ & 6 & 41 & 37 & $\dagger^{*}$ & $\dagger^{*}$ & 3884 \\
\hline $6 / 13 / 63$ & 13 & 41 & 37 & $35 *$ & $35 *$ & 3884 \\
\hline $6 / 13 / 63$ & 17 & 32 & 26 & 23 & 17 & 3740 \\
\hline $6 / 13 / 63$ & 19 & 41 & 35 & $23^{*}$ & $21 \dagger \dagger$ & 3884 \\
\hline $6 / 14 / 63$ & 11 & 25 & 14 & $\dagger$ & $\dagger$ & $* *$ \\
\hline $6 / 14 / 63$ & 22 & 25 & 14 & $\dagger$ & $\dagger$ & ** \\
\hline
\end{tabular}

$\uparrow$ No degradation

* Sheath not in direct contact with graphite

** No failure

$\dagger \dagger$ Cracked sheath

Before $3500^{\circ} \mathrm{F}$

Before $3500^{\circ} \mathrm{F}$

Before $3500^{\circ} \mathrm{F}$

Before $3500^{\circ} \mathrm{F}$

Before $3500^{\circ} \mathrm{F}$

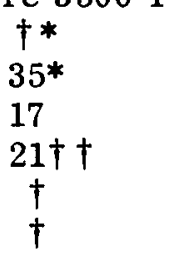

3983

3922

3776

4181

4181

4181

4181

4181

3884

3884

3740

** 


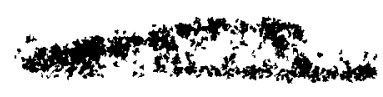

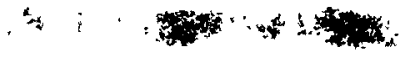

THIS PAGE INTENTIONALLY LEFT BLANK 


\section{THERMOCOUPLE}

Code No: $\quad$ Tr-.j

Type:

Chromel-P-Alumel

Mfgr: Aero Research

Range:
Spec. Control Dwg. No.

Evaluation By: WANL

Model No:

Application:

PERFORMANCE \& ENVIRONMENTAL SPECIFICATIONS

\begin{tabular}{|c|l|l|l|l|}
\hline Test & \multicolumn{1}{|c|}{ Condition } & NERVA Requirements & Manufacturer's Specs. & $\begin{array}{c}\text { Summary of } \\
\text { Test Results }\end{array}$ \\
\hline A & Proof Pressure & 0 to 650 psia & & \\
\hline B & Sheath Material & & 304 Stainless Steel & \\
\hline C & Accel. Error & & & \\
\hline D & Vibration Error & $10 \mathrm{~g}(20-2000 \mathrm{cps})$ & & \\
\hline E & Shock & & & \\
\hline F & Noise Limit & & & \\
\hline G & Neutron Flux & $5.2 \times 10^{15} \mathrm{n} / \mathrm{cm}^{2}-\mathrm{sec}$. & & \\
\hline H & Gamma Flux & $2.3 \times 10^{12} \mathrm{ergs} / \mathrm{gm}(\mathrm{C})$-pr & \\
\hline I & Sensitivity & & & \\
\hline J & Dimensions & & $0.035^{\prime \prime}$ to $0.060^{\prime \prime}$ oD & \\
\hline K & Weight & & & \\
\hline L & Insulation Res. & & & \\
\hline M & Material & & & \\
\hline N & Wire Size & & & \\
\hline & & & & \\
\hline & & & & \\
\hline & & & & \\
\hline & & & & \\
\hline & & & & \\
\hline & & & & \\
\hline & & & & \\
\hline & & & & \\
\hline & & & & \\
\hline & & & & \\
\hline
\end{tabular}





\section{DEVELOPMENT HISTORY}

Code No: $\operatorname{Tr}-\overline{5}$

Model No.

REMARKS:
Mfgr: Aero Research

P. 0 .

\section{Chromel-Alumel}

A recent unpublished transducer survey by Battelle Memorial Institute summarizes most of the irradiation studies of thermocouples to date. As a general conclusion, it is stated that, at most, changes of $1{ }_{c}$ to $2{ }^{\circ}$ in measured temperature may occur as a result of irradiation. Various tests referred to in this survey showed little or no permanent change in chromel-alumel calibration due to irradiation.

\section{September 1963}

This thermocouple has been superseded by Code Nos. $\operatorname{Tr}-11$ and $\operatorname{Tr}-12$. No further evaluation testing will be conducted on this thermocouple. 


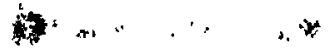
th

THIS PAGE INTENTIONALLY LEFT BLANK 


\section{THERMOCOUPLE}

Code No: $\operatorname{Tr}-6$

Type: Copper/Constantan - Shielded Junction

Mfgr: Aero Research

Range: $40^{\circ}$ to $1160^{\circ} \mathrm{R}$
Spec. Control Dwg. No. 94.5C $+19 H 01$

Evaluation By: WANL

Model No: $T-5+18$ Non-nuclear Lse Only

Application: Measure Seal Leakage

PERFORMANCE \& ENVIRONMENTAL SPECIFICATIONS

\begin{tabular}{|c|c|c|c|c|}
\hline Test & Condition & NERVA Requirements & Manufacturer's Specs. & $\begin{array}{l}\text { Summary of } \\
\text { Test Results }\end{array}$ \\
\hline$A$ & Proof Pressure & $600 \mathrm{psig}$ & $2000 \mathrm{psig}$ & $>1000$ psig \\
\hline B & Sheath Material & thermal compatible & 347 Stainless Steel & suitable \\
\hline $\mathrm{C}$ & Accel. Error & info. later & info. later & sec vibration \\
\hline$D$ & Vibration Error & $0-300 \mathrm{cps}, 10 \mathrm{~g}$ & $0-300 \mathrm{cps}, 10 \mathrm{~g}$ & $\begin{array}{l}<10 \mu \mathrm{v} \text { at } 10 \mathrm{~g} \\
30-2000 \mathrm{cps}\end{array}$ \\
\hline$E$ & Shock & info. later & info. later & $>10 \mathrm{~g}$ \\
\hline$F$ & Noise Limit & $\mathrm{NA}$ & not a vailable & $\mathrm{NA}$ \\
\hline G & Neutron Flux & $\mathrm{NA}$ & $\mathrm{NA}$ & $\mathrm{NA}$ \\
\hline $\mathrm{H}$ & Gamma Flux & $\mathrm{NA}$ & $\mathrm{NA}$ & NA \\
\hline 1 & Sensitivity & $\begin{array}{l}0.010 \mathrm{mv} /{ }^{\circ} \mathrm{R} \text { to } \\
0.035 \mathrm{mv} /{ }^{\circ} \mathrm{R}\end{array}$ & $\begin{array}{l}0.010 \mathrm{mv} /{ }^{\circ} \mathrm{R} \text { to } \\
0.035 \mathrm{mv} /{ }^{\circ} \mathrm{R}\end{array}$ & $\begin{array}{l}0.010 \mathrm{mv} /{ }^{\circ} \mathrm{R} \text { to } \\
0.035 \mathrm{mv} /{ }^{\circ} \mathrm{B}\end{array}$ \\
\hline J & Dimensions & OD $0.045^{\prime \prime}$ & sheath oD $0.045^{\prime \prime}$ & $0.045^{\prime \prime O D}$ \\
\hline $\mathrm{K}$ & Weight & info. later & info. later & \\
\hline$L$ & Insulation Res. & 100 Megs at $50 \mathrm{~V}$ & 500 Megs at $500 \mathrm{VDC}$ & $\begin{array}{l}<500 \mathrm{Megs} \text { at } \\
500 \mathrm{VpC}\end{array}$ \\
\hline$M$ & Material Insulation & thermal compatible & $\begin{array}{l}\text { EPY - 400 epoxy } \\
\text { sealant }\end{array}$ & $\begin{array}{l}\text { sultable to } \\
\text { LHe temp. }\end{array}$ \\
\hline$N$ & Wire Size & $0.006^{\prime \prime}$ & $0.006^{\prime \prime}$ & \\
\hline $\mathrm{O}$ & Junction Type & half sheath $(\mathrm{C} / \mathrm{C})$ & half sheath $(\mathrm{C} / \mathrm{C})$ & half sheath $(\mathrm{C} / \mathrm{C}$ \\
\hline $\mathrm{P}$ & Accuracy & $\pm 2^{\circ} \mathrm{R}$ or $\pm 2 \%$ & $\pm 2^{\circ} \mathrm{R}$ or $\pm 2 \%$ & $\pm 2^{\circ} \mathrm{R}$ or $\pm 2 \%$ \\
\hline & & & & \\
\hline & & & & \\
\hline & & & & \\
\hline & & & & \\
\hline & & & & \\
\hline & & & & \\
\hline & & & & \\
\hline & & & & \\
\hline & & & & \\
\hline
\end{tabular}





\section{DEVELOPMENT HISTORY}

Code No: $\quad \mathrm{Tr}-6$

Model No. T-5 -18
Mfgr: Aero Research

P. 0.30504

REMARKS:

This thermocouple is to be used in a non-nuclear environment since the effects of nuclear radiation on the EPY-400 epoxy moisture sealant have not been determined.

A discussion of copper/constantan thermocouples in cryogenic and nuclear environments is included in the general evaluation history.

Thermocouples with MgO insulation and EPY-400 sealant have been tested by WANL for the diffusion of high pressure gas through the porous MgO insulation. When 1000 psi helium was applied to one end and a helium leak detector was attached to the other end, the time required for $10^{-7}$ standard $c c$ of helium per second to appear at the output was $91 \pm$ 10 seconds.

The EPY-400 moisture sealant has been tested by WANL for cryogenic effects and chemical reaction with hydrogen. The EPY-400 has been tested in liquid helium with no evidence of physical deterioration when examined by a microscope. The EPY-400 has also been exposed to 450 psi hydrogen for 2 hours at room temperature with no evidence of chemical attack or physical deterioration.

Sheathed conductors with MgO insulation and EPY- 400 sealant have been tested by WANL for the effects of moisture absorption by the MgO on the insulation resistance. After being submersed in water for 100 continuous hours, the insulation resistance was greater than 1000 megohms.

\section{November $\underline{1963}$}

The following test data has been summarized from the Acceptance, Qualification, and Calibration tests conducted by manufacturer. Thirty (30) units have been tested S/N AR-2584 through 2613,

Insulation Resistance - $>100$ megohms at 500VDC on all units, no loss of insulation when belt abraded with 150 grit paper.

$\underline{\mathrm{X}-\text { Ray }} \underline{\text { Analysis }}$ -

Metallurgical Test -
$\mathrm{S} / \mathrm{N} \mathrm{AR-2612} \mathrm{was} \mathrm{rejected} \mathrm{due} \mathrm{to} \mathrm{incomplete} \mathrm{fusion} \mathrm{of} \mathrm{one}$ wire at junction.

Samples were taken from all units and mounted for examination under $100 \mathrm{x} / 200 \mathrm{x} / 400 \mathrm{x}$ microscopic examination, no evidence of cracks, porosity, or harmful inclusions were noted. In the etched condition, nothing was found to indicate grain boundary attack due to carbide precipitation.

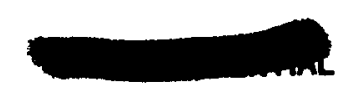




\section{DEVELOPMENT HISTORY}

Code No: $\quad$ Tr-6

Model No. T-5418

REMARKS:

Continuity Tests -

The following data includes manufacturers data and test data by WANL at assembly of NRX-A1. Only those thermocouples installed in NRX-A1 are included.

\begin{tabular}{|c|c|c|c|c|}
\hline Symbol & $\underline{S} / \mathrm{N}$ & Location & $\begin{array}{l}\text { Mfgrs. } \\
\text { Value }\end{array}$ & $\begin{array}{l}\text { Assembly } \\
\text { Value }\end{array}$ \\
\hline & 2586 & Inner Refl. & 150.80 & 150.72 \\
\hline$T-481$ & 2585 & Inner Refl. & 144.70 & 144.26 \\
\hline
\end{tabular}

Leak Rate -

1000 psi Helium was applied to junction end of the thermocouple and the gas leakage through the insulation was measured by a calibrated detector.

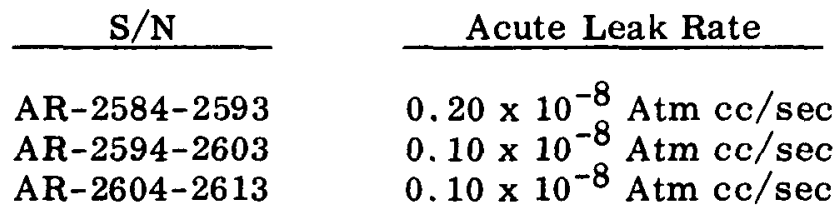

Calibration Data - The output EMF was determined for each thermocouple at four (4) temperature points. Only those installed in the NRX-A1 reactor are included in this tabulation.

\begin{tabular}{|c|c|c|c|c|c|c|c|c|c|}
\hline \multirow[b]{2}{*}{ Symbol } & \multirow[b]{2}{*}{$\mathrm{S} / \mathrm{N}$} & \multicolumn{2}{|c|}{1} & \multicolumn{2}{|c|}{2} & \multicolumn{2}{|c|}{3} & \multicolumn{2}{|c|}{4} \\
\hline & & Temp ${ }^{\circ} \mathbf{R}$ & EMFmv & Temp ${ }^{\circ} \mathbf{R}$ & EMFmv & Temp ${ }^{\circ} \mathrm{R}$ & EMFmv & Temp ${ }^{\circ} \mathbf{R}$ & EMFmv \\
\hline$T-4$ & 2586 & 492 & -0.0005 & 349.6 & -2.736 & 139.8 & -5.473 & 7.9 & -5.954 \\
\hline & 2585 & 492 & -0.0007 & 349.6 & -2.736 & 139.8 & -5.472 & 7.9 & -5.951 \\
\hline
\end{tabular}

Mfgr: Aero Research

P. 0. 30504 


\section{THERMOCOUPLE}

Code No: $\quad \mathrm{Tr}-7$

Type: Copper/Constantan-exposed junction

Mfgr: Aero Rescarch

Range: $40^{\circ}$ to $1160^{\circ} \mathrm{R}$
Spec. Control Dwg. No. 945C420H01

Evaluation By: WANL

Model No: Non-nuclear use only T-5411.

Application: Gas temp.

\begin{tabular}{|c|c|c|c|c|}
\hline \multicolumn{4}{|c|}{ PERFORMANCE \& ENVIRONMENTAL SPECIFICATIONS } & \multirow{2}{*}{$\begin{array}{l}\text { Summary of } \\
\text { Test Results }\end{array}$} \\
\hline Test & Condition & NERVA Requirements & Manufacturer's Specs. & \\
\hline A & Proof Pressure & 600 psig & $2000 \mathrm{psig}$ & $>1000 \mathrm{psig}$ \\
\hline B & Sheath Material & thermal compatible & 347 Stainless Steel & suitable \\
\hline C & Accel. Error & info. later & info. later & See Vibration \\
\hline D & Vibration Error & $0-300 \mathrm{cps}, 10 \mathrm{~g}$ & $0-300 \mathrm{cps}, 10 \mathrm{~g}$ & $\begin{array}{l}<10 \mu \mathrm{v} \text { at } 10 \mathrm{~g} \\
30-2000 \mathrm{cps}\end{array}$ \\
\hline$E$ & Shock & info. later & info, later & $>10 \mathrm{~g}$ \\
\hline $\mathbf{F}$ & Noise Limit & $\mathrm{NA}$ & not available & NA \\
\hline G & Neutron Flux & $\mathrm{NA}$ & NA & $\mathrm{NA}$ \\
\hline$H$ & Gamma Flux & NA & NA & NA \\
\hline 1 & Sensitivity & $\begin{array}{l}0.010 \mathrm{mv} /{ }^{\circ} \mathrm{R} \text { to } \\
0.035 \mathrm{mv} /{ }^{\circ} \mathrm{R}\end{array}$ & $\begin{array}{l}0.010 \mathrm{mv} / \% \mathrm{R} \text { to } \\
0.035 \mathrm{mv} / \% \mathrm{R}\end{array}$ & $\begin{array}{l}0.010 \mathrm{mv} /{ }^{\circ} \mathrm{R} \text { to } \\
0.035 \mathrm{mv} /{ }^{\circ} \mathrm{R}\end{array}$ \\
\hline $\mathrm{J}$ & Dimensions & OD $0.062^{\prime \prime}$ & $0.062 \mathrm{OD}$ & $0.062^{\prime \prime}$ OD \\
\hline$K$ & Weight & info. later & info. later & \\
\hline L & Insulation Res. & 100 Megs at $50 \mathrm{~V}$ & 500 Megs at $500 \mathrm{VDC}$ & $\begin{array}{l}3500 \mathrm{Megs} \text { at } \\
500 \mathrm{VDC}\end{array}$ \\
\hline$M$ & Material & thermal compatible & MgO - EPY-400 epoxy & MgO- EPY $-400 \mathrm{e}$ \\
\hline $\mathrm{N}$ & Wire Size & $0.011^{\prime \prime}$ & $0.011^{\prime \prime}$ & \\
\hline $\mathrm{O}$ & Junction Type & exposed $(\mathrm{C} / \mathrm{C})$ & exposed $(\mathrm{C} / \mathrm{C})$ & exposed $(\mathrm{C} / \mathrm{C})$ \\
\hline$\underline{p}$ & Accuracy & $\pm 2^{\circ} \mathrm{R}$ or $\pm 2 \%$ & $\pm 2^{\circ} \mathrm{R}$ or $\pm 2 \%$ & $\pm 2^{\circ} \mathrm{R}$ or $\pm 2 \%$ \\
\hline & & & & \\
\hline & & & & \\
\hline & & & & \\
\hline & & & & \\
\hline & & & & \\
\hline & & & & \\
\hline & & & & \\
\hline & & & & \\
\hline & & & & \\
\hline & & & & \\
\hline
\end{tabular}





\begin{tabular}{|l|l|l}
\hline MERVA & \multicolumn{2}{|c}{$\begin{array}{c}\text { CANDIDATE TRANSDUCER } \\
\text { DATA SHET }\end{array}$} \\
\hline PROGRAM & INSTRUMENTATION DATA BOOK & Date: 1 January 1964 \\
\hline
\end{tabular}

\section{DEVELOPMENT HISTORY}

Code No: $\quad \operatorname{Tr}-7$

Model No. T-5411

Mfgr: Aero Research

P. 0.30504

\section{REMARKS:}

This thermocouple is to be used in a non-nuclear environment since the effects of nuclear radiation on the EPY-400 epoxy moisture sealant have not been determined.

A discussion of copper/constantan thermocouples in cryogenic and nuclear environments is included in the general evaluation history.

Thermocouples with MgO insulation and EPY-400 sealant have been tested by WANL for diffusion of high pressure gas through the porous $\mathrm{MgO}$ insulation. When 1000 psi helium was applied to one end and a helium leak detector attached to the other end, the time required for $10^{-7}$ standard cc of helium per second to appear at the output was $91 \pm 10$ seconds.

The EPY-400 sealant has been tested by WANL for cryogenic effects and chemical reaction with hydrogen. The EPY -400 has been tested in liquid helium with no evidence of physical deterioration when examined under a microscope. The EPY -400 has also been exposed to 450 psi hydrogen for 2 hours at room temperature with no evidence of chemical attack or physical deterioration.

Sheathed conductors with MgO insulation and EPY -400 sealant have been tested by WANL for the effects of moisture absorption by the MgO on the insulation resistance. After being submersed in water for 100 continuous hours, the insulation resistance was greater than $1000 \mathrm{megohms}$.

Tests have been performed by WANL to determine the effects of hydrodynamic forces on the mechanical integrity of the exposed function. Small weights were suspended from thermocouple wire and the wire deflection observed through a microscope. Results show the required force to deflect the thermocouple wire is from 50 to 250 times the expected hydrodynamic force from the fluid flow.

Time constant tests have been run by WANL to determine the effect of the high thermal conductivity of the $\mathrm{MgO}$ insulation. Results show that thermocouples with the high thermal conductivity insulation have faster time response, $27 \mathrm{~ms}$, than thermocouples which have electrical insulation material with lower thermal conductivities.

\section{$\underline{15} \underline{\text { November }} \underline{1963}$}

The following test data has been summerized from the Acceptance, Qualification, and Calibration tests conducted by manufacturer. 105 units have been tested, S/N AR-2478 through 2583.

Insulation Resistance - $\quad>100$ megohms at 500VDC on all units no loss of insulation when abraded with 150 grit paper.

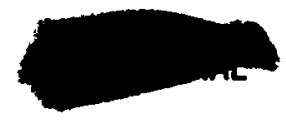




\section{DEVELOPMENT HISTORY}

Code No: $\mathrm{Tr}-7$

Model No. T-5411

\section{REMARKS:}

Mfgr: Aero Research

P. 0.30504
$\underline{X-R a y}$ Analysis -

Continuity Tests -

\section{Metallurgical Tests -}

\begin{tabular}{ccc} 
Symbol & & S/N \\
\cline { 1 - 1 } $\mathrm{T}-451$ & & 2547 \\
$\mathrm{~T}-455$ & & 2540 \\
$\mathrm{~T}-302$ & & 2493 \\
$\mathrm{~T}-311$ & & 248 \\
$\mathrm{~T}-724$ & & 2492 \\
$\mathrm{~T}-728$ & & 2516 \\
$\mathrm{~T}-345$ & & 2486 \\
$\mathrm{~T}-511$ & & 248 \\
$\mathrm{~T}-730$ & & 248 \\
$\mathrm{~T}-720$ & & 2487
\end{tabular}

No rejects reported.

Samples were taken from all units and mounted for examination under $100 \mathrm{x} / 200 \mathrm{x} / 400 \mathrm{x}$ microscopic examination, no evidence of cracks, porosity, or harmful inclusions were noted. In the etched condition, no evidence was found of grain boundary attack due to precipitated carbides.

The following data includes manufacturers data and test data by WANL at assembly of NRX-A1. Only a sampling of those thermocouples installed in NRX-A 1 are included.

\section{Leak Rate -}

\begin{tabular}{|c|c|c|}
\hline Location & $\begin{array}{l}\text { Mfgrs. } \\
\text { Value }\end{array}$ & $\begin{array}{c}\text { Assembly } \\
\text { Value }\end{array}$ \\
\hline Inner Refl. & 88.09 & 88.01 \\
\hline Inner Refl. & 93.10 & 93.04 \\
\hline Outer Refl. & 85.45 & 85.20 \\
\hline Outer Refl. & 96.10 & 96.05 \\
\hline Supp. Plate & 90.74 & 90.73 \\
\hline Supp. Plate & 92.96 & 92.87 \\
\hline Shield & 96.10 & 96.05 \\
\hline Shield & 90.59 & 90.63 \\
\hline Sector 5 & 90.60 & 90.43 \\
\hline Sector 1 & 95.81 & 91.73 \\
\hline
\end{tabular}

1000 psi Helium was applied to junction end of the thermocouple and the gas leakage through the insulation was measured by a calibrated detector.

\begin{tabular}{c}
$\mathrm{S} / \mathrm{N}$ \\
\hline AR-2478-2487 \\
AR-2488-2497 \\
AR-2498-2507 \\
AR-2508-2517 \\
AR-2518-2527 \\
AR-2528-2537 \\
AR-2538-2547 \\
AR-2548-2557 \\
AR-2558-2567 \\
AR-2568-2583
\end{tabular}

Acute Leak Rate

$0.204 \times 10^{-8} \mathrm{Atm} \mathrm{cc} / \mathrm{sec}$
$0.255 \times 10^{-8} \mathrm{Atm} \mathrm{cc} / \mathrm{sec}$
$0.306 \times 10^{-8} \mathrm{Atm} \mathrm{cc} / \mathrm{sec}$
$0.255 \times 10^{-8} \mathrm{Atm} \mathrm{cc} / \mathrm{sec}$
$0.051 \times 10^{-8} \mathrm{Atm} \mathrm{cc} / \mathrm{sec}$
$0.204 \times 10^{-8} \mathrm{Atm} \mathrm{cc} / \mathrm{sec}$
$0.255 \times 10^{-8} \mathrm{Atm} \mathrm{cc} / \mathrm{sec}$
$0.153 \times 10^{-8} \mathrm{Atm} \mathrm{cc} / \mathrm{sec}$
$0.102 \times 10^{-8} \mathrm{Atm} \mathrm{cc} / \mathrm{sec}$
$0.204 \times 10^{-8} \mathrm{Atm} \mathrm{cc} / \mathrm{sec}$




\title{
DEVELOPMENT HISTORY
}

Code No: $\quad \operatorname{Tr}-7$

Model No. T-5411

Mfgr: Aero Research

P. 0.30504

\section{REMARKS:}

\author{
Calibration Data -
}

The output EMF was determined for each thermocouple at four (4) temperature points. Only a sampling of those installed in the NRX-A1 reactor are included in this tabulation.

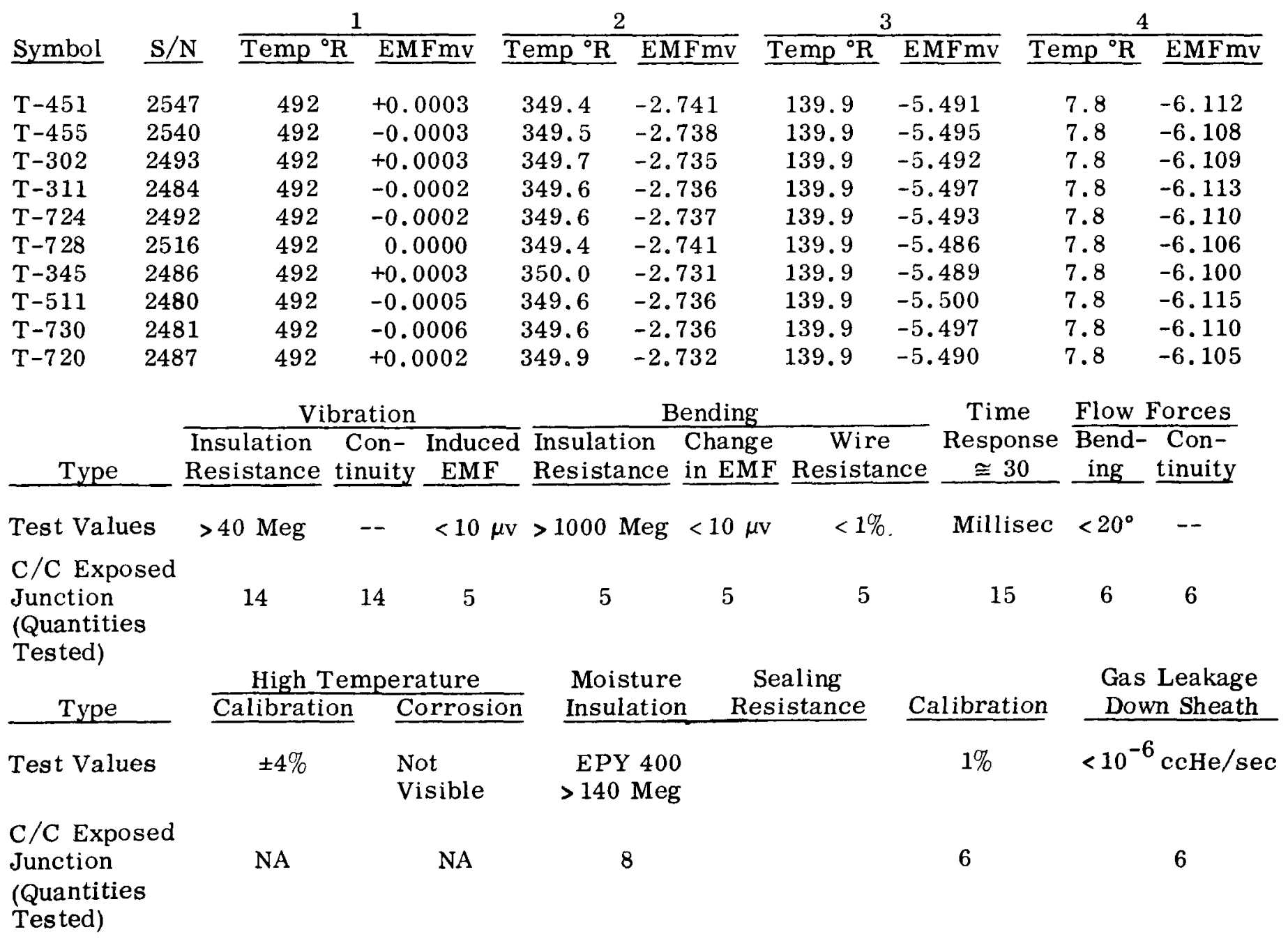


THIS PAGE INTENTIONALLY LEFT BLANK 


\section{THERMOCOUPLE}

Code No: $\quad \operatorname{Tr}-8$

Type:

Mfgr:

Range:
Chromel-P/Alumel

Aero Research

$40^{\circ}$ to $2660^{\circ} \mathrm{R}$
Spec. Control Dwg. No. 945C421H01

Evaluation By: WANU

Model No: $\quad$ T-5412 Non-nuclear use only

Application: Gas temp.

PERFORMANCE \& ENVIRONMENTAL SPECIFICATIONS

\begin{tabular}{|c|c|c|c|c|}
\hline Test & Condition & NERVA Requirements & Manufacturer's Specs. & $\begin{array}{l}\text { Summary of } \\
\text { Test Results }\end{array}$ \\
\hline$A$ & Proof Pressure & $600 \mathrm{psig}$ & $2000 \mathrm{psig}$ & $>1000$ psig \\
\hline$B$ & Sheath Material & thermal compatible & 347 stainless steel & suitable \\
\hline$C$ & Accel. Error & info. later & info. later & see vibration \\
\hline$D$ & Vibration Error & $0-300 \mathrm{cps}, 10 \mathrm{~g}$ & $0-300 \mathrm{cps}, 10 \mathrm{~g}$ & $\begin{array}{l}<10 \mu \mathrm{v} \text { at } 10 \mathrm{~g} \\
30-2000 \mathrm{cps}\end{array}$ \\
\hline$E$ & Shock & info. later & info. later & $>10 \mathrm{~g}$ \\
\hline $\mathbf{F}$ & Noise Limit & NA & not a vailable & $\mathrm{NA}$ \\
\hline $\mathbf{G}$ & Neutron Flux & $\mathrm{NA}$ & NA & NA \\
\hline$H$ & Gamma Flux & $\mathrm{NA}$ & $\mathrm{NA}$ & NA \\
\hline 1 & Sensitivity & $0.025 \mathrm{mv} /{ }^{\circ} \mathrm{R}$ & $0.025 \mathrm{mv} /{ }^{\circ} \mathrm{R}$ & $\begin{array}{l}0.023 \mathrm{mv} /{ }^{\circ} \mathrm{R} \mathrm{at} \\
500^{\circ} \mathrm{F}\end{array}$ \\
\hline $\mathrm{J}$ & Dimensions & OD $0.045^{\prime \prime}$ & sheath OD $0.045^{\prime \prime}$ & $0.045^{\prime \prime} \mathrm{OD}$ \\
\hline $\mathrm{K}$ & Weight & info. later & info. later & \\
\hline$L$ & Insulation Res. & $100 \mathrm{Megs}$ at $50 \mathrm{~V}$ & 500 Megs at $500 \mathrm{VDC}$ & $\begin{array}{l}3500 \text { Megs at } \\
500 \mathrm{VDC}\end{array}$ \\
\hline$M$ & Material Insulation & thermal compatible & 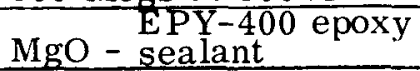 & $\begin{array}{l}\text { Suitable to } \\
\text { LHe temp. }\end{array}$ \\
\hline$N$ & Wire Size & $0.006^{\prime \prime}$ & $0.006^{\prime \prime}$ & \\
\hline $\mathrm{O}$ & Junction Type & $\operatorname{exposed}(C / A)$ & exposed $(C / A)$ & exposed (C/A) \\
\hline$P$ & Accuracy & $\begin{array}{l} \pm 2^{\circ} \mathrm{F} 460-1000^{\circ} \mathrm{R} \\
0.375 \% 1000-2660^{\circ} \mathrm{R}\end{array}$ & $\begin{array}{l} \pm 2^{\circ} \mathrm{F} 460-1000^{\circ} \mathrm{R} \\
0.375^{\circ} 01000-2660^{\circ} \mathrm{R}\end{array}$ & $\pm 7 \%$ \\
\hline Q & Application & Gas temp. & & \\
\hline & & & & \\
\hline & & & & \\
\hline & & & & \\
\hline & & & & \\
\hline & & & & \\
\hline & & & & \\
\hline & & & & \\
\hline & & & & \\
\hline
\end{tabular}





\section{DEVELOPMENT HISTORY}

Code No: $\quad$ Tr-8

Model No. T-5412 Non-nuclear use only
Mfgr: Aero Research

P. $0 . \quad 30504$

\section{REMARKS:}

This thermocouple is to be used in a non-nuclear environment since the effects of nuclear radiation on the EPY-400 epoxy moisture sealant have not been determined.

A discussion of chromel-P/alumel thermocouples in cryogenic and nuclear environments is included in the general evaluation history.

Thermocouples with MgO insulation and EPY-400 sealant have been tested by WANL for the diffusion of high pressure gas through the porous MgO insulation. When 1000 psi helium was applied to one end and a helium leak detector was attached to the other end, the time required for $10^{-7}$ standard cc of helium per second to appear at the output was $91 \pm 10$ seconds.

The EPY-400 moisture sealant has been tested by WANL for cryogenic effects and chemical reaction with hydrogen. The EPY -400 has been tested in liquid helium with no evidence of physical deterioration when examined by a microscope. The EPY-400 has also been exposed to 450 psi hydrogen for 2 hours at room temperature with no evidence of chemical attack or physical deterioration.

Sheathed conductors with MgO insulation and EPY-400 sealant have been tested by WANL for the effects of moisture absorption by the $\mathrm{MgO}$ on the insulation resistance. After being submersed in water for 100 continuous hours, the insulation resistance was greater than 1000 megohms.

Tests have been performed by WANL to determine the effects of hydrodynamic forces on the mechanical integrity of the exposed junction. Small weights were suspended from the thermocouple wire and the wire deflection observed through a microscope. Results show the required force to deflect the thermocouple wire is from 50 to 250 times the expected hydrodynamic from the fluid flow.

Time constant tests have been run by WANL to determine the effect of the high thermal conductivity of the MgO insulation. Results show that thermocouples with the high thermal conductivity insulation have faster time response, $27 \mathrm{~ms}$, than thermocouples which have electrical insulating material with lower thermal conductivities.

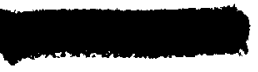




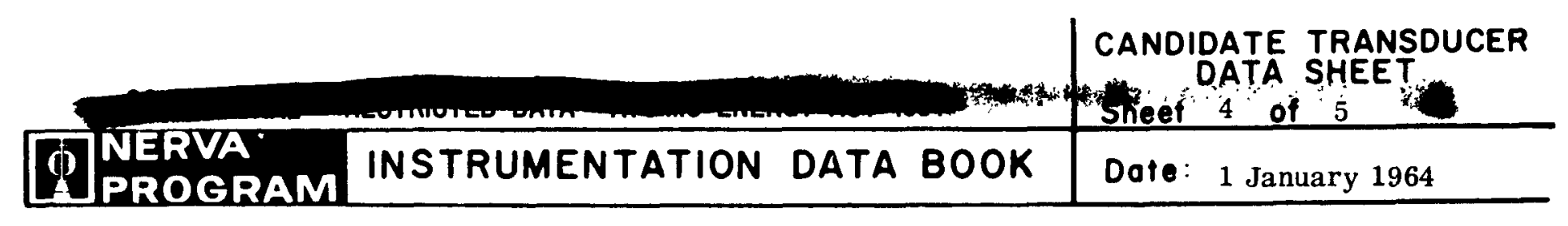

\section{DEVELOPMENT HISTORY}

Code No: $\operatorname{Tr}-8$

Model No. T-5412

Mfgr: Aero Research

P. 0. 30504

REMARKS:

15 November 1963

The following test data has been summarized from the acceptance, qualification, and calibration tests conducted by manufacturers. Fourteen (14) units have been tested S/N AR-2447 through 2460 .

Insulation Resistance - $>100$ megohms at $500 \mathrm{VDC}$ on all units. No loss of insulation when belt abraded with 150 grit paper. Weld rod Used was class $5 \mathrm{~A}$ of MIL-R-5031A.

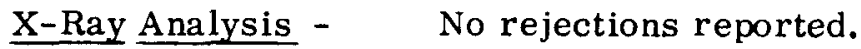

Continuity Tests - The following data includes manufacturers data and test data by WANL at assembly of NRX-A1. Only those thermocouples installed in NRX-A1 are included.

\begin{tabular}{|c|c|c|c|c|}
\hline Symbol & $\underline{S / N}$ & Location & $\begin{array}{c}\text { Mfgrs. } \\
\text { Value } \\
\end{array}$ & $\begin{array}{c}\text { Assembly } \\
\text { Value }\end{array}$ \\
\hline$T-732$ & 2453 & Cluster 1E5 & 302.00 & 296.97 \\
\hline $\mathrm{T}-733$ & 2451 & Cluster 2A1 & 302.10 & 296.50 \\
\hline $\mathrm{T}-734$ & 2457 & Cluster $3 \mathrm{~A} 1$ & 300.80 & 294.40 \\
\hline$T-735$ & 2459 & Cluster 3E 5 & 303.00 & 298.35 \\
\hline $\mathrm{T}-736$ & 2452 & Cluster $3 \mathrm{H} 7$ & 301.40 & 297.75 \\
\hline $\mathrm{T}-737$ & 2460 & Cluster $4 \mathrm{~A} 1$ & 301.60 & 297.01 \\
\hline $\mathrm{T}-738$ & 2455 & Cluster $5 \mathrm{G} 1$ & 305.00 & 298.18 \\
\hline $\mathrm{T}-739$ & 2454 & Cluster 5E 5 & 302.20 & 297.36 \\
\hline$T-740$ & 2449 & Cluster $5 \mathrm{H} 7$ & 301.40 & 298.23 \\
\hline $\mathrm{T}-741$ & 2456 & Cluster $6 \mathrm{~A} 1$ & 302.70 & 297.45 \\
\hline $\mathrm{T}-742$ & 2458 & Cluster 6E 5 & 301.10 & 296.63 \\
\hline$T-743$ & 2450 & Cluster $1 \mathrm{H} 5$ & 301.00 & 297.07 \\
\hline
\end{tabular}

$\underline{\text { Leak Rate - }}$

1000 psi Helium was applied to junction end of the thermocouple and the gas leakage through the insulation was measured by a calibrated detector.

$\frac{\mathrm{S} / \mathrm{N}}{\text { AR-2447-2460 }} \quad \frac{\text { Acute Leak Rate }}{0.20 \times 10^{-8} \mathrm{~atm} \mathrm{cc} / \mathrm{sec}}$

Calibration Data - The output EMF was determined for each thermocouple at four (4) temperature points. Only those installed in the NRX-A1 reactor are included in this tabulation.

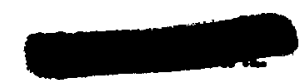




\section{DEVELOPMENT HISTORY}

Code No:

$\operatorname{Tr}-8$

Model No.

$\mathrm{T}-5412$
Mfgr:

P. 0 . Aero Research

\section{REMARKS:}

\begin{tabular}{|c|c|c|c|c|c|c|c|c|c|}
\hline \multirow[b]{2}{*}{ Symbol } & \multirow[b]{2}{*}{$\mathrm{S} / \mathrm{N}$} & \multicolumn{2}{|c|}{1} & \multicolumn{2}{|c|}{2} & \multicolumn{2}{|c|}{3} & \multicolumn{2}{|c|}{4} \\
\hline & & Temp ${ }^{\circ} \mathrm{R}$ & EMFmv & Temp ${ }^{\circ} \mathrm{R}$ & EMFmv & Temp ${ }^{\circ} \mathrm{R}$ & EMFmv & Temp ${ }^{\circ} \mathrm{R}$ & EMFmv \\
\hline $\mathrm{T}-732$ & 2453 & 1099.3 & 13.766 & 492 & +0.0004 & 347.0 & -2.890 & 320.1 & -5.852 \\
\hline $\mathrm{T}-733$ & 2451 & 1099.3 & 13.766 & 492 & -0.0004 & 345.9 & -2.902 & 320.1 & -5.859 \\
\hline $\mathrm{T}-734$ & 2457 & 1099.2 & 13.763 & 492 & -0.0002 & 347.0 & -2.890 & 320.1 & -5.852 \\
\hline $\mathrm{T}-735$ & 2459 & 1099.7 & 13.773 & 492 & +0.0010 & 345.5 & -2.909 & 320.1 & -5.885 \\
\hline $\mathrm{T}-736$ & 2452 & 1099.4 & 13.768 & 492 & +0.0007 & 346.6 & -2.894 & 320.1 & -5.849 \\
\hline $\mathrm{T}-737$ & 2460 & 1099.6 & 13.772 & 492 & +0.0006 & 347.0 & -2.890 & 320.1 & -5.850 \\
\hline $\mathrm{T}-738$ & 2455 & 1099.4 & 13.767 & 492 & -0.0001 & 346.7 & -2.893 & 320.1 & -5.855 \\
\hline $\mathrm{T}-739$ & 2454 & 1099.1 & 13.761 & 492 & -0.0004 & 347.0 & -2.890 & 320.1 & -5.852 \\
\hline $\mathrm{T}-740$ & 2449 & 1099.3 & 13.765 & 492 & -0.0003 & 345.6 & -2.908 & 320.1 & -5.884 \\
\hline $\mathrm{T}-741$ & 2456 & 1099.5 & 13.770 & 492 & +0.0003 & 346.6 & -2.894 & 320.1 & -5.849 \\
\hline $\mathrm{T}-742$ & 2458 & 1099.3 & 13.766 & 492 & +0.0002 & 345.7 & -2.906 & 320.1 & -5.886 \\
\hline $\mathrm{T}-743$ & 2450 & 1099.3 & 13.766 & 492 & -0.0005 & 346.4 & -2.896 & 320.1 & -5.854 \\
\hline
\end{tabular}

Vibration

Bending

Time Flow Forces Insulation Con- Induced Insulation Change Wire Response Bend- ConResistance tinuity EMF Resistance in EMF Resistance

$\approx 30$ ing tinuity

Test Values $>40 \mathrm{Meg}$ $--<10 \mu \mathrm{V}$

$>1000 \mathrm{Meg}<10 \mu \mathrm{v}$ $<1 \%$ Millisec. $<20^{\circ}--$

C/A Exposed Junction (Quantities Tested)

Type
Test Values
C/A Exposed
Junction

High Temperature Calibration Corrosion $\pm 4 \%$ Not
Visible NA NA Tested)

\section{Moisture Sealing} Insulation Resistance

EPY 400 $>140 \mathrm{Meg}$
5

Cal $1 \%$ Gas Leakage Down Sheath $<10^{-6} \mathrm{ccHe} / \mathrm{sec}$

\footnotetext{
*Covered by testing on $\mathrm{C} / \mathrm{C}$ thermocouples.
} 


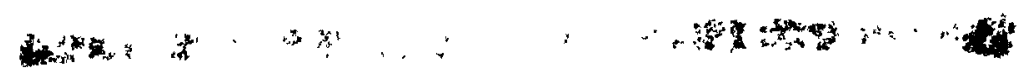

THIS PAGE INTENTIONALLY LEFT BLANK 


\section{THERMOCOUPLE}

Code No:

Type: Copper/Constantan - Staked Junction

Mfgr: Aero Research

Range: $40^{\circ}$ to $1160^{\circ} \mathrm{R}$

Spec. Control Dwg. No. 945C422H01

Evaluation By: WANL

Model No: T-5413 Non-nuclear use only

Application: Material temp.

\section{PERFORMANCE \& ENVIRONMENTAL SPECIFICATIONS}

\begin{tabular}{|c|c|c|c|c|}
\hline Test & Condition & NERVA Requirements & Manufacturer's Specs. & $\begin{array}{l}\text { Summary of } \\
\text { Test Results }\end{array}$ \\
\hline$A$ & Proof Pressure & 600 psig & 2000 psig & $>1000 \mathrm{psig}$ \\
\hline $\mathrm{B}$ & Sheath Material & thermal compatible & 347 stainless steel & suitable \\
\hline $\mathrm{C}$ & Accel. Error & info. later & info. later & see vibration \\
\hline D & Vibration Error & $0-300 \mathrm{cps}, 10 \mathrm{~g}$ & $0-300 \mathrm{cps}, 10 \mathrm{~g}$ & $\begin{array}{l}<10 \mu \mathrm{v} \text { at } 10 \mathrm{~g} \text {, } \\
30-2000 \mathrm{cps}\end{array}$ \\
\hline$E$ & Shock & info. later & info. later & $>10 \mathrm{~g}$ \\
\hline$F$ & Noise Limit & $\mathrm{NA}$ & not available & NA \\
\hline G & Neutron Flux & NA & NA & NA \\
\hline $\mathrm{H}$ & Gamma Flux & NA & $\mathrm{NA}$ & \\
\hline 1 & Sensitivity & $\begin{array}{l}0.010 \mathrm{mv} /{ }^{\circ} \mathrm{R} \\
0.035 \mathrm{mv} /{ }^{\circ} \mathrm{R}\end{array}$ & $\begin{array}{l}0.010 \mathrm{mv} /{ }^{\circ} \mathrm{R} \\
0.035 \mathrm{mv} /{ }^{\circ} \mathrm{R}\end{array}$ & $\begin{array}{l}0.010 \mathrm{mv} / /{ }^{\circ} \mathrm{R} \\
0.035 \mathrm{mv} /{ }^{\circ} \mathrm{R}\end{array}$ \\
\hline $\mathrm{J}$ & Dimensions & OD $0.045^{\prime \prime}$ & sheath OD $0.045^{\prime \prime}$ & $0.045^{\prime \prime O D}$ \\
\hline K & Weight & info. later & info. later & \\
\hline$L$ & Insulation Res. & 100 Megs at $50 \mathrm{~V}$ & 500 Megs at 500VDC & $\begin{array}{l}>500 \text { Megs at } \\
500 \mathrm{VpC}\end{array}$ \\
\hline$M$ & Material Insulation & thermal compatible & $\begin{array}{l}\text { Mgo, fiberglass, } \\
\text { EPY }-400 \text { epoxy }\end{array}$ & $\begin{array}{l}\text { suitable to } \\
\text { LHe temp. }\end{array}$ \\
\hline$N$ & Wire Size & $0.006^{\prime \prime}$ & $0.006^{\prime \prime}$ & \\
\hline 으 & Junction Type & staking $(\mathrm{C} / \mathrm{C})$ & staking $(\mathrm{C} / \mathrm{C})$ & staking $(C / C)$ \\
\hline$\underline{P}$ & Accuracy & $\pm 2^{\circ} \mathrm{R}$ or $\pm 2 \%$ & $\pm 2^{\circ} \mathrm{R}$ or $\pm 2 \%$ & $\pm 2^{\circ} \mathrm{R}$ or $\pm 2 \%$ \\
\hline & & & & \\
\hline & & & & \\
\hline & & & & \\
\hline & & & & \\
\hline & & & & \\
\hline & & & & \\
\hline & & & & \\
\hline & & & & \\
\hline & & & & \\
\hline
\end{tabular}




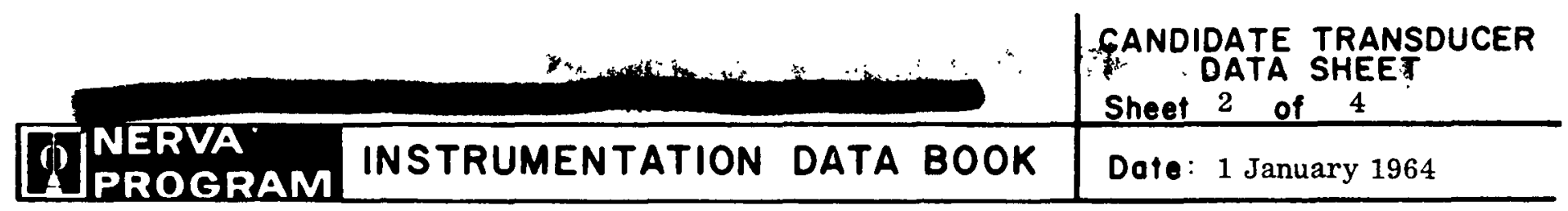

RADIATION TESTS

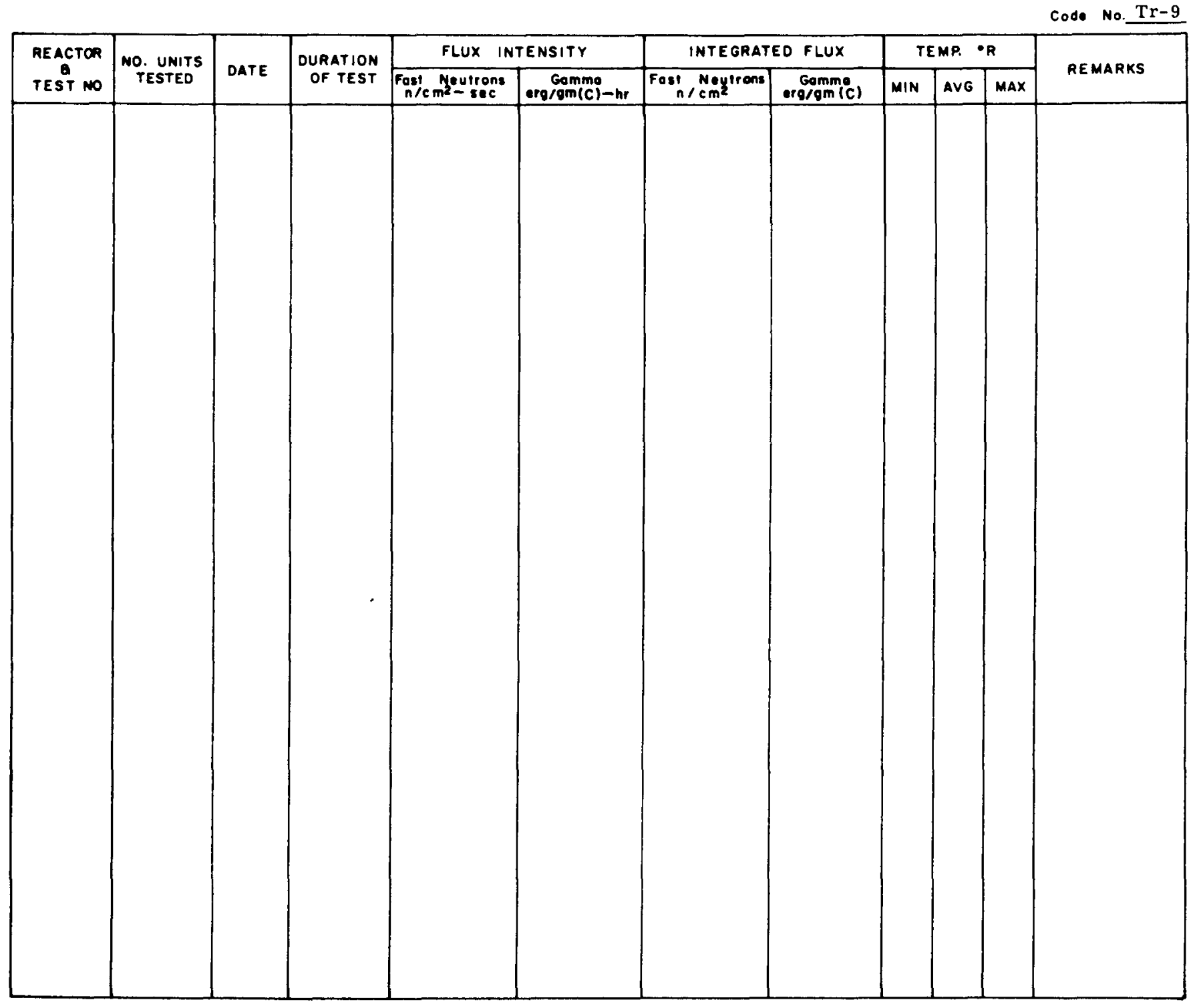




\section{DEVELOPMENT HISTORY}

Code No: $\frac{\text { Tr-9 }}{\text { Model No. T-5413 for Non-nuclear Use Only }}$

\section{REMARKS:}

This thermocouple is to be used in a non-nuclear environment since the effects of nuclear radiation on the EPY-400 epoxy moisture sealant have not been determined.

A discussion of copper/constantan thermocouples in cryogenic and nuclear environments is included in the general evaluation history.

Thermocouples with MgO insulation and EPY-400 sealant have been tested by WANL for the diffusion of high pressure gas through the porous $\mathrm{MgO}$ insulation. When 1000 psi helium was applied to one end and a helium leak detector was attached to the other end, the time required for $10^{-7}$ standard cc of helium per second to appear at the output was $91 \pm 10$ seconds.

The EPY-400 moisture sealant has been tested by WANL for cryogenic effects and chemical reaction with hydrogen. The EPY- 400 has been tested in liquid helium with no evidence of physical deterioration when examined by a microscope. The EPY-400 has also been exposed to $450 \mathrm{psi}$ hydrogen for 2 hours at room temperature with no evidence of chemical attack or physical deterioration.

Sheathed conductors with MgO insulation and E PY -400 sealant have been tested by WANL for the effects of moisture absorption by the MgO on the insulation resistance. After being submersed in water for 100 continuous hours, the insulation resistance was greater than 1000 megohms.

\section{$\underline{15}$ November 1963}

The following test data has been summarized from the Acceptance, Qualification, and Calibration tests conducted by manufacturer. Five (5) units have been tested S/N AR-2619 through 2623.

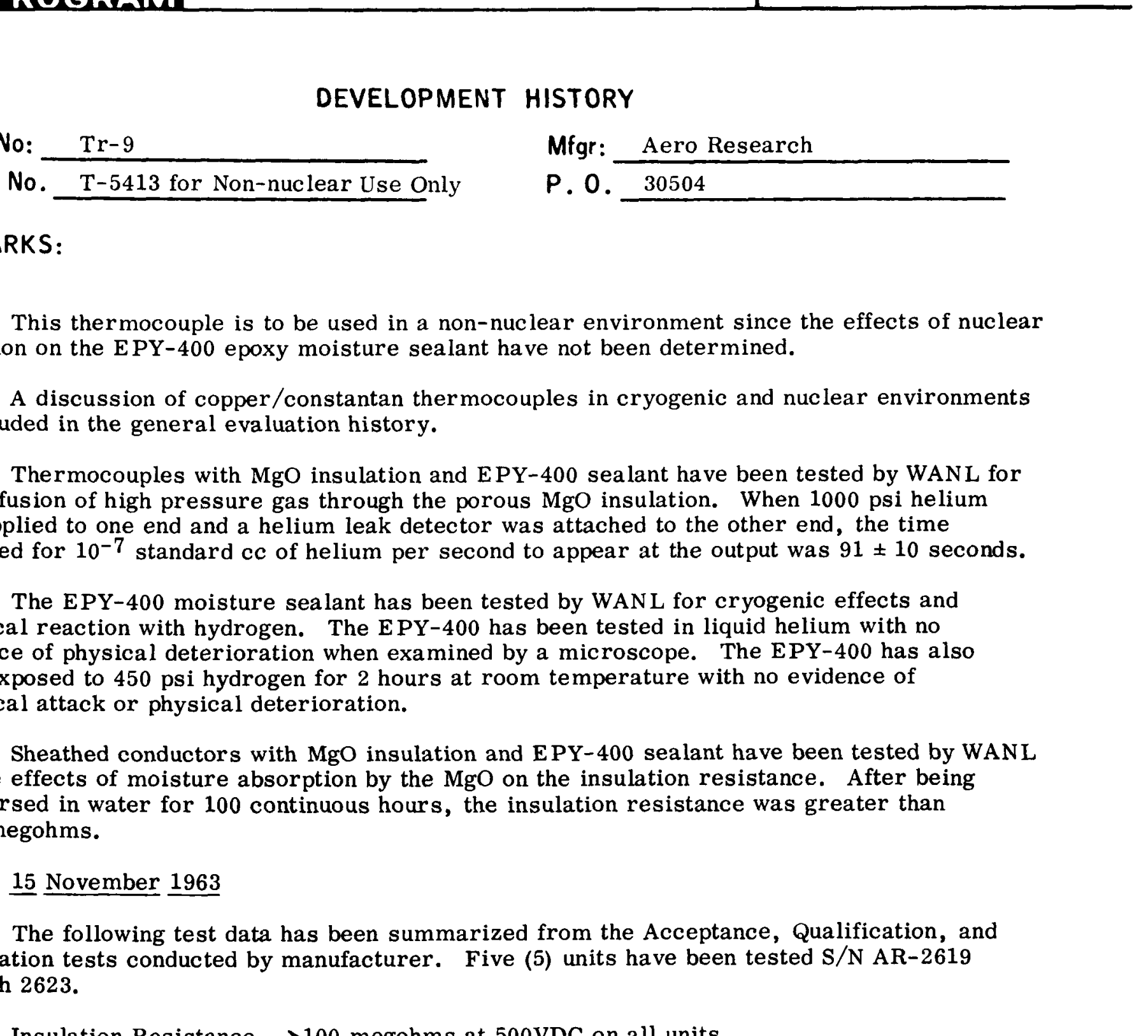

Insulation Resistance - $>100$ megohms at 500VDC on all units. No loss of insulation when belt abraded with 150 grit paper.

$\underline{\mathrm{X}-\mathrm{R} a y} \underline{\text { Analysis }}$ - $\quad \mathrm{X}$-rays were taken at $0^{\circ}$ and $90^{\circ}$ views at the junction pad no rejections are reported. 


\section{DEVELOPMENT HISTORY}

Code No: $\operatorname{Tr}-9$

Mfgr: Aero Research

Model No. T-5413 for Non-nuclear Use Only

P. 0. 30504

\section{REMARKS:}

Metallurgical Test -

Samples were taken from all units and mounted for examination. Under $100 \mathrm{X} / 200 \mathrm{X} / 400 \mathrm{X}$ microscopic examination, no evidence of cracks, porosity, or harmful inclusions were noted. In the etched condition, nothing was found to indicate grain boundary attack due to carbide precipitation.

Continuity Tests -

Leak Rate -

Calibration Data -

1

\begin{tabular}{|c|c|c|c|c|c|c|c|c|}
\hline \multirow[b]{2}{*}{$\mathrm{S} / \mathrm{N}$} & \multicolumn{2}{|c|}{1} & \multicolumn{2}{|c|}{2} & \multicolumn{2}{|c|}{3} & \multicolumn{2}{|l|}{4} \\
\hline & Temp & EMFmV & Temp $\mathrm{R}$ & EMFmv & Temp ${ }^{\circ} \mathrm{R}$ & EMFmv & Temp $p^{\circ}$ & EMF mv \\
\hline 2619 & 492 & -0.0001 & 350.5 & -2.722 & 139.9 & -5.441 & 7.9 & -5.933 \\
\hline 2620 & 492 & -0.0004 & 350.0 & -2.730 & 139.9 & -5.443 & 7.9 & -5.977 \\
\hline 2621 & 492 & -0.0003 & 349.6 & -2.736 & 139.9 & -5.479 & 7.9 & -5.978 \\
\hline 2622 & 492 & -0.0003 & 349.5 & -2.738 & 139.9 & -5.479 & 7.9 & -5.971 \\
\hline 2623 & 492 & -0.0007 & 350.1 & -2.728 & 139.9 & -5.466 & 7.8 & -5.960 \\
\hline
\end{tabular}

\begin{tabular}{|c|c|c|c|c|c|c|c|c|}
\hline \multirow[b]{2}{*}{$\mathrm{S} / \mathrm{N}$} & \multicolumn{2}{|c|}{1} & \multicolumn{2}{|c|}{2} & \multicolumn{2}{|c|}{3} & \multicolumn{2}{|l|}{4} \\
\hline & Temp & EMFmV & Temp $\mathrm{R}$ & EMFmv & Temp ${ }^{\circ} \mathrm{R}$ & EMFmv & Temp $p^{\circ}$ & EMF mv \\
\hline 2619 & 492 & -0.0001 & 350.5 & -2.722 & 139.9 & -5.441 & 7.9 & -5.933 \\
\hline 2620 & 492 & -0.0004 & 350.0 & -2.730 & 139.9 & -5.443 & 7.9 & -5.977 \\
\hline 2621 & 492 & -0.0003 & 349.6 & -2.736 & 139.9 & -5.479 & 7.9 & -5.978 \\
\hline 2622 & 492 & -0.0003 & 349.5 & -2.738 & 139.9 & -5.479 & 7.9 & -5.971 \\
\hline 2623 & 492 & -0.0007 & 350.1 & -2.728 & 139.9 & -5.466 & 7.8 & -5.960 \\
\hline
\end{tabular}

Mfgrs.

S/N Value

$2619 \quad 144.2$

$2620 \quad 150.9$

$2621 \quad 140.5$

$2622 \quad 139.4$

$2623 \quad 151.2$

1000 psi Helium was applied to junction end of the thermocouple and the gas leakage through the insulation was measured by a calibrated detector.

$\frac{\mathrm{S} / \mathrm{N}}{\mathrm{AR}-2619-2623} \quad \frac{\text { Acute Leak Rate }}{0.102 \times 10^{-8} \mathrm{Atm} \mathrm{cc} / \mathrm{sec}}$

No He was detected at the open end of each unit when 1000 psi was applied at the junction end for two minutes.

The output EMF was determined for each thermocouple at four (4) temperature points. 
Sheet 1 of 4

\section{THERMOCOUPLE}

Code No: $\operatorname{Tr}-10$

Type: Copper/Constantan-Surface Temp.

Mfgr: Aero Research

Range: $40^{\circ}$ to $1160^{\circ} \mathrm{R}$
Spec. Control Dwg. No. 945C423H01

Evaluation By: WANL

Model No: Non-nuclear Use Only T-5414.

Application: Skin Temp.

PERFORMANCE \& ENVIRONMENTAL SPECIFICATIONS

\begin{tabular}{|c|c|c|c|c|}
\hline Test & Condition & NERVA Requirements & Manufacturer's Specs. & $\begin{array}{l}\text { Summary of } \\
\text { Test Results }\end{array}$ \\
\hline$A$ & Proof Pressure & $600 \mathrm{psig}$ & 2000 psig & $>1000$ psig \\
\hline B & Sheath Material & thermal compatible & 347 Stainless Steel & suitable \\
\hline $\mathrm{C}$ & Accel. Error & info. later & info. later & \\
\hline D & Vibration Error & $0-300 \mathrm{cps}, 10 \mathrm{~g}$ & $0-300 \mathrm{cps}, 10 \mathrm{~g}$ & \\
\hline$E$ & Shock & info. later & info. later & \\
\hline$F$ & Noise Limit & NA & not available & NA \\
\hline $\mathbf{G}$ & Neutron Flux & $\mathrm{NA}$ & $\mathrm{NA}$ & NA \\
\hline $\mathrm{H}$ & Gamma Flux & NA & NA & NA \\
\hline 1 & Sensitivity & $\begin{array}{l}0.010 \mathrm{mv} /{ }^{\circ} \mathrm{R} \text { to } \\
0.035 \mathrm{mv} /{ }^{\circ} \mathrm{R}\end{array}$ & $\begin{array}{l}0.010 \mathrm{mv} /{ }^{\circ} \mathrm{R} \text { to } \\
0.035 \mathrm{mv} /{ }^{\circ} \mathrm{R}\end{array}$ & $\begin{array}{l}0.010 \mathrm{mv} /{ }^{\circ} \mathrm{R} \text { to } \\
0.035 \mathrm{mv} / 0^{\circ} \mathrm{R}\end{array}$ \\
\hline $\mathrm{J}$ & Dimensions & OD $0.045^{\prime \prime}$ & sheath OD $0.045^{\prime \prime}$ & $0.045^{\prime \prime} \mathrm{OD}$ \\
\hline$K$ & Weight & info. later & info. later & \\
\hline$L$ & Insulation Res. & 100 Megs at $50 \mathrm{~V}$ & 500 Megs at 500VDC & $\begin{array}{l}3500 \mathrm{Meg} \text { at } \\
500 \mathrm{VDC}\end{array}$ \\
\hline$M$ & Material Insulation & thermal compatible & MgO, fiberglass, epoxy & $\begin{array}{l}00 \text { suitable to } \\
\text { LHe temp. }\end{array}$ \\
\hline$N$ & Wire Size & $0.006^{\prime \prime}$ & $0.006^{\prime \prime}$ & \\
\hline $\mathrm{O}$ & Junction Type & skin type (C/C) & skin type $(\mathrm{C} / \mathrm{C})$ & skin type $(C / C)$ \\
\hline $\mathrm{P}$ & Accuracy & $\pm 2^{\circ} \mathrm{R}$ or $\pm 2 \%$ & $\pm 2^{\circ} \mathrm{R}$ or $\pm 2 \%$ & $\pm 2^{\circ} \mathrm{R}$ or $\pm 2 \%$ \\
\hline & & & & \\
\hline & & & & \\
\hline & & & & \\
\hline & & & & \\
\hline & & & & \\
\hline & & & & \\
\hline & & & & \\
\hline & & & & \\
\hline & & & & \\
\hline
\end{tabular}





\begin{tabular}{|l|l|l}
\hline TINERVA & $\begin{array}{l}\text { CANDIDATE TRANSDUCER } \\
\text { DATA SHEET } \\
\text { PROGRAM INSTRUMENTATION DATA BOOK }\end{array}$ & Dote: 1 January 1964 \\
\hline
\end{tabular}

\section{DEVELOPMENT HISTORY}

Code No: $\quad$ Tr-10

Model No. T-5414 Non-nuclear Use Only

Mfgr: Aero Research

P. $0 . \quad 30504$

\section{REMARKS:}

This thermocouple is to be used in a non-nuclear environment since the effects of nuclear radiation on the EPY-400 epoxy moisture sealant have not been determined.

A discussion of copper/constantan thermocouples in cryogenic and nuclear environments is included in the general evaluation history.

Thermocouples with MgO insulation and EPY-400 sealant have been tested by WANL for the diffusion of high pressure gas through the porous MgO insulation. When 1000 psi helium was applied to one end and a helium leak detector was attached to the other end, the time required for $10^{-7}$ standard cc of helium per second to appear at the output was $91 \pm 10$ seconds.

The EPY -400 moisture sealant has been tested by WANL for cryogenic effects and chemical reaction with hydrogen. The EPY- 400 has been tested in liquid helium with no evidence of physical deterioration when examined by a microscope. The EPY- 400 has also been exposed to 450 psi hydrogen for 2 hours at room temperature with no evidence of chemical attack or physical deterioration.

Sheathed conductors with MgO insulation and EPY- 400 sealant have been tested by WANL for the effects of moisture absorption by the MgO on the insulation resistance. After being submersed in water for continuous hours, the insulation resistance was greater than 1000 megohms.

$\underline{15}$ November 1963

The following test data has been summarized from the Acceptance, Qualification, and Calibration tests conducted by manufacturers. Six (6) units have been tested, S/N AR-2625 through 2628, $2630,2631$.

Insulation Resistance $->100$ megohms at $500 \mathrm{VDC}$ on all units no loss of insulation when belt abraded with 150 grit paper.

X-Ray Analysis - $\quad X$-rays were taken at $0^{\circ}$ and $90^{\circ}$ views at the measuring junction, no rejects reported.

Metallurgical Test - Samples were taken from all units and mounted for examination. Under $100 \mathrm{x} / 200 \mathrm{x} / 400 \mathrm{x}$ microscopic examination, no evidence of cracks, porosity, or harmful inclusions were noted. In the etched condition, nothing was found to indicate grain boundary attack due to carbide precipitation.

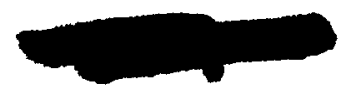




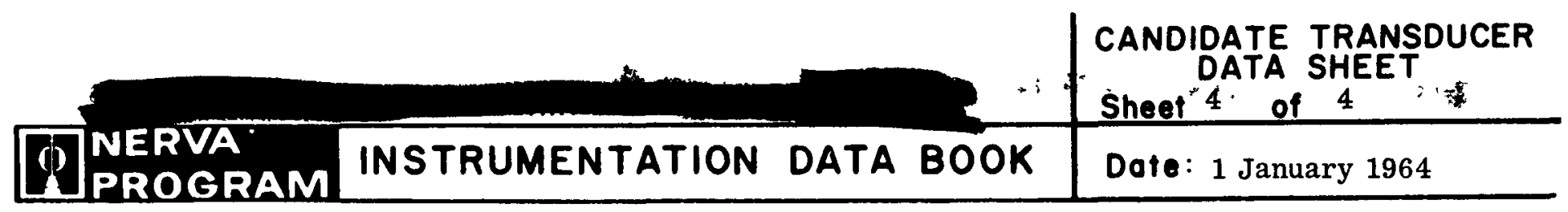

\section{DEVELOPMENT HISTORY}

Code No: $\operatorname{Tr}-10$

Model No. T-5414 Non-nuclear Use Only
Mfgr: Aero Research

P. O. 30504

\section{REMARKS:}

Continuity Tests -

$\begin{array}{lll}\text { S/N } & & \begin{array}{c}\text { Mfgrs. } \\ \text { Value }\end{array} \\ 2625 & & 146.7 \\ 2626 & & 147.5 \\ 2627 & & 133.0 \\ 2628 & & 148.2 \\ 2630 & & 147.5 \\ 2631 & & 145.3\end{array}$

Leak Rate -

1000 psi Helium was applied to junction end of the thermocouple and the gas leakage through the insulation was measured by a calibrated detector.

\begin{tabular}{|c|c|}
\hline $\mathrm{S} / \mathrm{N}$ & Acute Leak Rate \\
\hline 2625 & $0.05 \times 10^{-8} \mathrm{Atm} \mathrm{cc} / \mathrm{sec}$ \\
\hline 2626 & $0.05 \times 10^{-8} \mathrm{Atm} \mathrm{cc} / \mathrm{sec}$ \\
\hline 2627 & $0.05 \times 10^{-8} \mathrm{Atm} \mathrm{cc} / \mathrm{sec}$ \\
\hline 2628 & $0.05 \times 10^{-8} \mathrm{Atm} \mathrm{cc} / \mathrm{sec}$ \\
\hline 2630 & $0.05 \times 10^{-8} \mathrm{Atm} \mathrm{cc} / \mathrm{sec}$ \\
\hline 2631 & $0.05 \times 10^{-8} \mathrm{Atm} \mathrm{cc} / \mathrm{sec}$ \\
\hline
\end{tabular}

Calibration Data -

\begin{tabular}{lccc} 
& \multicolumn{2}{c}{1} \\
$\mathrm{~S} / \mathrm{N}$ & & Temp ${ }^{\circ} \mathrm{R}$ & EMFmv \\
2625 & 492 & -0.0001 \\
2626 & 492 & -0.0003 \\
2627 & 492 & -0.0004 \\
2628 & 492 & +0.0007 \\
2630 & 492 & -0.0006 \\
2631 & 492 & +0.0003
\end{tabular}

The output EMF was determined for each thermocouple at four (4) temperature points.

\begin{tabular}{|c|c|}
\hline \\
\hline Temp ${ }^{\circ} \mathrm{F}$ & EMFmv \\
\hline 349.5 & -2.738 \\
\hline 349.5 & -2.738 \\
\hline 350 & -2.730 \\
\hline 350 & -2.730 \\
\hline 350 & -2.729 \\
\hline 350 & -2.730 \\
\hline
\end{tabular}

\begin{tabular}{cc}
\multicolumn{2}{c}{3} \\
\hline Temp ${ }^{\circ} \mathrm{R}$ & EMFmv \\
139.8 & -5.483 \\
139.8 & -5.481 \\
139.8 & -5.470 \\
139.8 & -5.475 \\
139.8 & -5.471 \\
139.8 & -5.462
\end{tabular}

\begin{tabular}{cc}
\multicolumn{2}{c}{4} \\
\hline Temp ${ }^{\circ} \mathrm{R}$ & EMFmv \\
$\mathbf{7 . 9}$ & -5.975 \\
7.9 & -5.974 \\
7.9 & -5.960 \\
7.9 & -5.975 \\
7.9 & -5.969 \\
7.9 & -5.958
\end{tabular}




\section{THERMOCOUPLE}

Code No: $\quad \operatorname{Tr}-11$

Type: Chromel-P/Alumel - Gnd. Junction

Mfgr: Aero Research

Range: $40^{\circ}$ to $2660^{\circ} \mathrm{R}$

Spec. Control Dwg. No. 963B361H01

Evaluation By:

WANL

Model No: For nuclear use T-11-260AK8F

Application: Material temp.

\section{PERFORMANCE \& ENVIRONMENTAL SPECIFICATIONS}

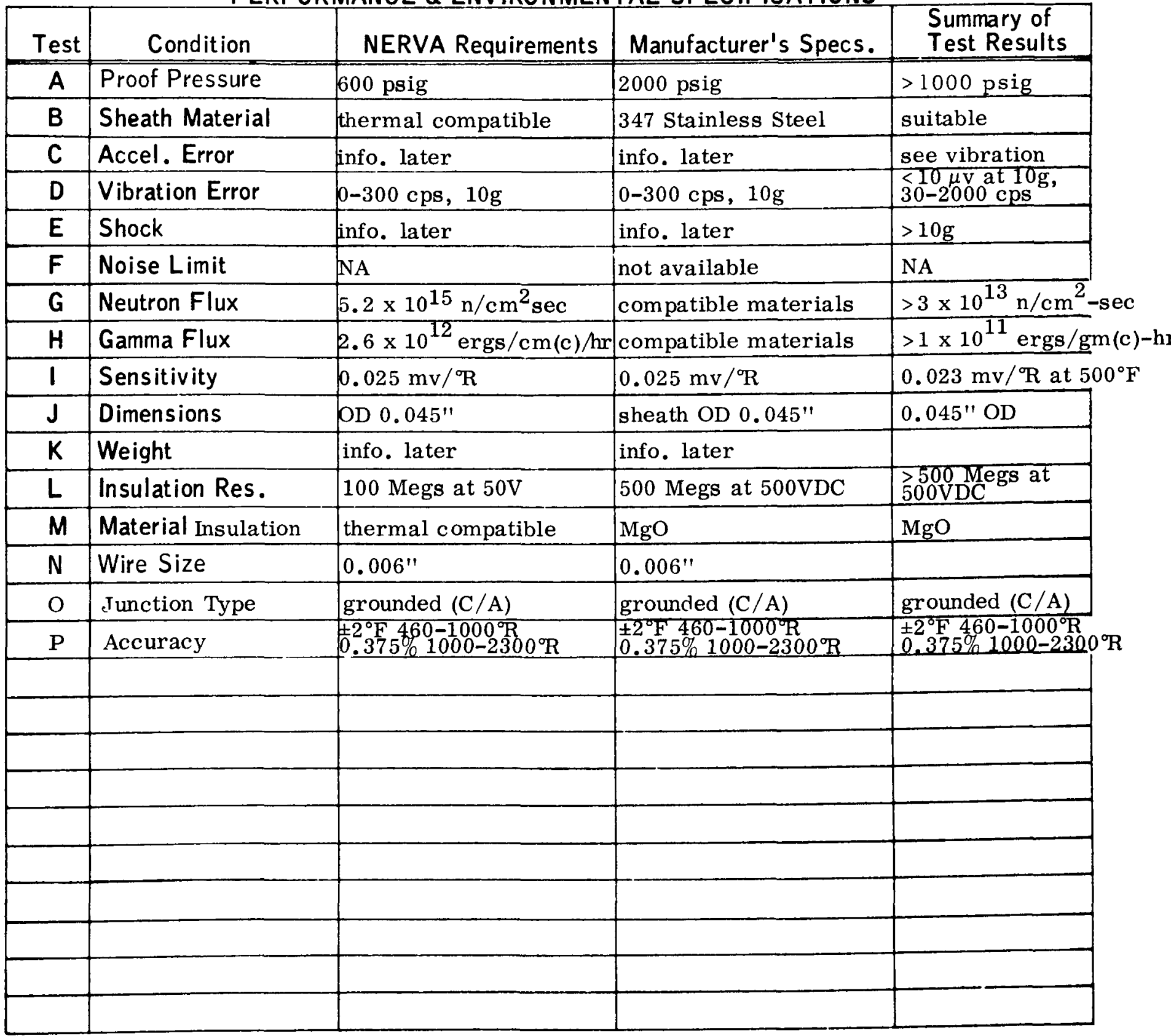




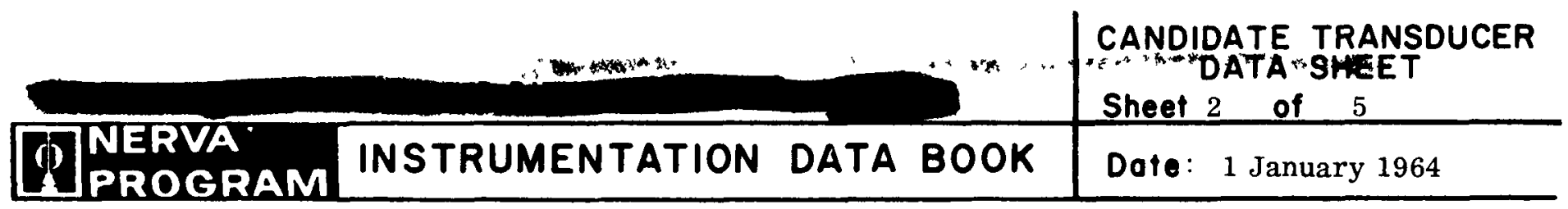

RADIATION TESTS

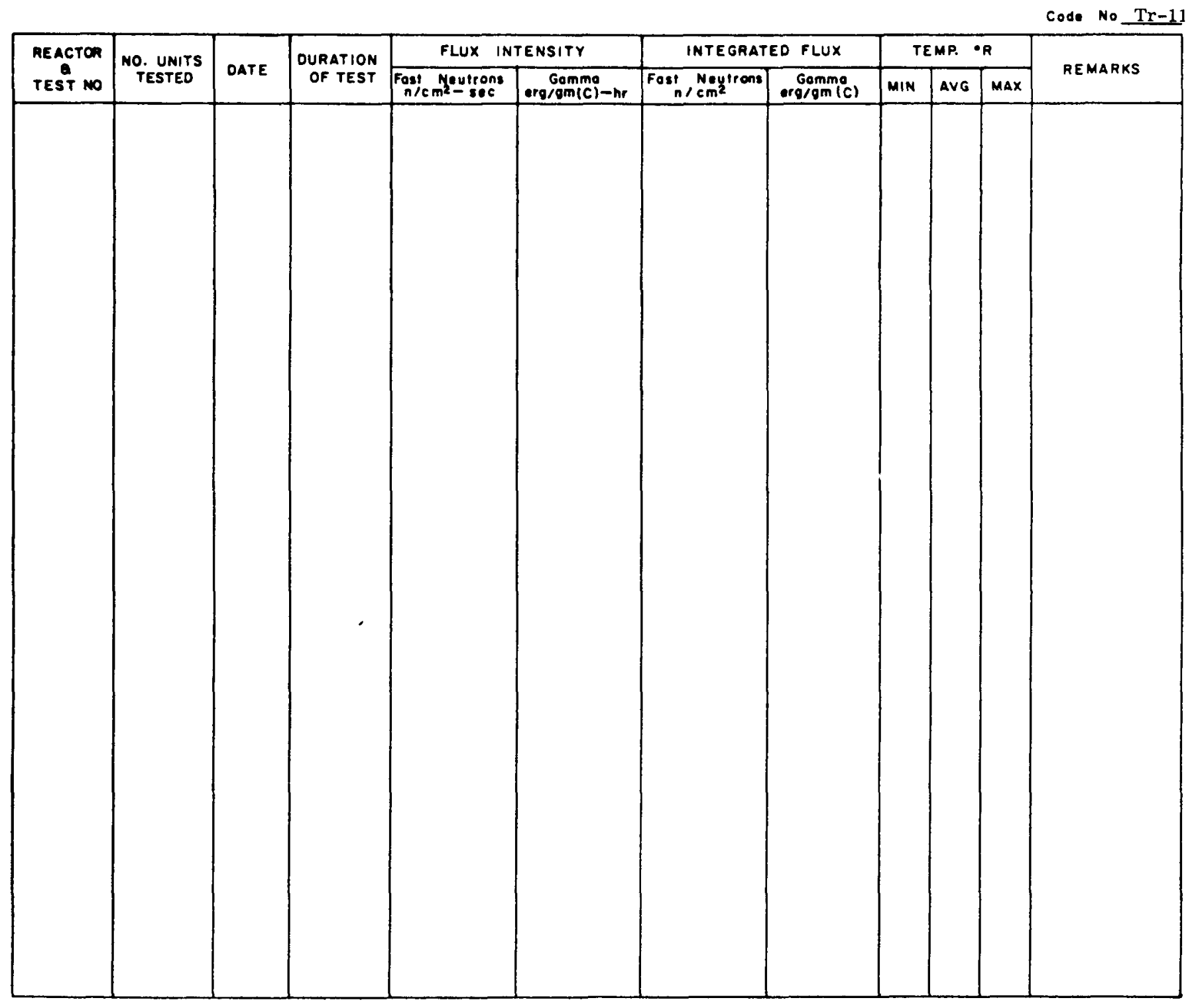




\section{DEVELOPMENT HISTORY}

Code No:

$\operatorname{Tr}-11$

Mfgr: Aero Research

Model No. T-11-260AK8F

P. 0 .

30504

\section{REMARKS:}

Evaluation history of chromel-P/alumel thermocouples which are fully sheathed, grounded junction and have sheathed leads with MgO insulation is given in the general evaluation history.

\section{$\underline{15}$ November 1963}

The following test data has been summarized from the Acceptance, Qualification, and Calibration tests conducted by manufacturer. Twenty-nine (29) units have been tested S/N AR-2373 through 2401 .

Insulation Resistance $->100$ megohms at 500VDC on all units. No loss of insulation when belt abraded with 150 grit paper. Weld rod used was class 5A of MIL-R-5031A.

$\underline{X-R a y ~ A n a l y s i s ~-~} \quad X$-rays were taken at $0^{\circ}$ and $90^{\circ}$ views taken at the measuring junction. No rejects reported.

Continuity Tests - The following data includes manufacturers data and test data by WANL at assembly of NRX-A1. Only those thermocouples installed in NRX-A1 are included.

\begin{tabular}{|c|c|c|c|c|}
\hline Symbol & $\underline{\mathrm{S} / \mathrm{N}}$ & Location & $\begin{array}{l}\text { Mfgrs. } \\
\text { Value } \\
\end{array}$ & $\begin{array}{c}\text { Assembly } \\
\text { Values } \\
\end{array}$ \\
\hline $\mathrm{T}-674$ & 2382 & Filler Strip Sect. 4 & 282.60 & 278.96 \\
\hline $\mathrm{T}-675$ & 2381 & Filler Str ip Sect. 4 & 309.90 & 305.13 \\
\hline $\mathrm{T}-676$ & 2384 & Filler Strip Sect. 6 & 281.60 & 278.07 \\
\hline $\mathrm{T}-677$ & 2389 & Filler Strip Sect. 6 & 311.80 & 302.66 \\
\hline $\mathrm{T}-707$ & 2390 & Cluster $1 \mathrm{~A} 1$ & 306.30 & 305.30 \\
\hline $\mathrm{T}-708$ & 2386 & Cluster $1 \mathrm{~A} 1$ & 292.20 & 288.48 \\
\hline $\mathrm{T}-709$ & 2388 & Cluster $4 \mathrm{~N} 1$ & 300.80 & 293.19 \\
\hline $\mathrm{T}-710$ & 2395 & Cluster 3J9 & 308.90 & 300.23 \\
\hline $\mathrm{T}-711$ & 2387 & Cluster $5 \mathrm{~J} 9$ & 307.20 & 299.89 \\
\hline $\mathrm{T}-712$ & 2400 & Cluster $5 E 4$ & 296.91 & 291.46 \\
\hline $\mathrm{T}-713$ & 2399 & Cluster $3 \mathrm{~J} 9$ & 282.10 & 274.75 \\
\hline $\mathrm{T}-714$ & 2396 & Cluster 3J9 & 303.00 & 298.91 \\
\hline $\mathrm{T}-715$ & 2383 & Cluster 3J9 & 302.90 & 298.50 \\
\hline $\mathrm{T}-716$ & 2394 & Cluster $6 \mathrm{~J} 9$ & 303.90 & 298.84 \\
\hline $\mathrm{T}-717$ & 2392 & Cluster 2J9 & 392.70 & 385.94 \\
\hline $\mathrm{T}-718$ & 2397 & Cluster $4 \mathrm{~J} 5$ & 301.70 & 297.59 \\
\hline
\end{tabular}




\section{DEVELOPMENT HISTORY}

Code No:

$\mathrm{Tr}-11$

Mode! No.

T-11-260AK8F
Mfgr: Aero Research

P. 0 . 30504

\section{REMARKS:}

Leak Rate -

Calibration Data -

Symbol

$\mathrm{T}-674$

$\mathrm{T}-675$

$\mathrm{T}-676$

$\mathrm{T}-677$

T-707

$\mathrm{T}-708$

$\mathrm{T}-709$

$\mathrm{T}-710$

$\mathrm{T}-711$

$\mathrm{T}-712$

$\mathrm{T}-713$

$\mathrm{T}-714$

$\mathrm{T}-715$

$\mathrm{T}-716$

$\mathrm{T}-717$

$\mathrm{T}-718$
1

$\frac{1}{\text { Temp EMF }}$

$\underline{\mathrm{S} / \mathrm{N}}$

$\begin{array}{lll}2382 & 1714.7 & 28.263\end{array}$

$\begin{array}{lll}2381 & 1714.8 & 28.265\end{array}$

$\begin{array}{lll}2384 & 1714.7 & 28.283\end{array}$

$\begin{array}{lll}2389 & 1714.6 & 28.281\end{array}$

$2390 \quad 1714.6 \quad 28.261$

$2386 \quad 1714.0 \quad 28.249$

$\begin{array}{lll}2388 & 1714.4 & 28.257\end{array}$

$\begin{array}{lll}2395 & 1714.8 & 28.266\end{array}$

$\begin{array}{lll}2387 & 1714.1 & 28.251\end{array}$

$\begin{array}{lll}2400 & 1714.2 & 28.254\end{array}$

$\begin{array}{lll}2399 & 1715.0 & 28.270\end{array}$

$\begin{array}{lll}2396 & 1714.9 & 28.267\end{array}$

$\begin{array}{lll}2383 & 1714.7 & 28.242\end{array}$

$\begin{array}{lll}2394 & 1714.1 & 28.251\end{array}$

$\begin{array}{lll}2392 & 1714.7 & 28.264\end{array}$

$2397 \quad 1714.7$

1000 psi Helium was applied to junction end of the thermocouple and the gas leakage through the insulation was measured by a calibrated detector.

$\mathrm{S} / \mathrm{N}$

AR-2373-2401
Acute Leak Rate

$0.188 \times 10^{-8} \mathrm{Atm} \mathrm{cc} / \mathrm{sec}$

The output EMF was determined for each thermocouple at five (5) temperature points. Only those installed in the NRX-A1 reactor are included in this tabulation.

\begin{tabular}{|c|c|c|c|}
\hline \multicolumn{2}{|c|}{2} & \multicolumn{2}{|r|}{3} \\
\hline $\begin{array}{c}\text { Temp } \\
{ }^{\circ} \mathrm{R}\end{array}$ & $\begin{array}{c}\mathrm{EMF} \\
\mathrm{mv}\end{array}$ & $\begin{array}{c}\text { Temp } \\
{ }^{\circ} \\
\end{array}$ & $\begin{array}{c}\mathrm{EMF} \\
\mathrm{mv}\end{array}$ \\
\hline 1098.8 & 13.755 & 492.0 & -0.0003 \\
\hline 1099.3 & 13.765 & 492.0 & -0.0003 \\
\hline 1099.7 & 13.773 & 492.0 & +0.0006 \\
\hline 1099.9 & 13.778 & 492.1 & +0.0012 \\
\hline 1099.1 & 13.761 & 492.0 & +0.0001 \\
\hline 1099.6 & 13.771 & 492.0 & +0.0005 \\
\hline 1098.8 & 13.756 & 492.0 & -0.0007 \\
\hline 1099.2 & 13.763 & 492.1 & +0.0010 \\
\hline 1099.3 & 13.766 & 492.0 & +0.0002 \\
\hline 1099.0 & 13.760 & 492.0 & +0.0009 \\
\hline 99.0 & 13.759 & 492.0 & +0.0002 \\
\hline 1099.2 & 13.763 & 492.0 & +0.0006 \\
\hline 1099.4 & 13.747 & 492.0 & +0.0002 \\
\hline 1099.1 & 13.761 & 492.0 & -0.0003 \\
\hline 1098.8 & 13.756 & 492.0 & +0.0004 \\
\hline 099.3 & 13.765 & 492.0 & -0.0002 \\
\hline
\end{tabular}

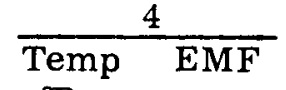

${ }^{\mathrm{O}} \mathrm{mv}$

$346.8-2.892$

$346.6-2.894$

$346.7-2.893$

$345.7-2.905$

$346.2-2.898$

$346.1 \quad-2.899$

$345.5 \quad-2.909$

$346.2-2.898$

$347.0-2.890$

$345.7-2.906$

$346.8-2.892$

$345.6-2.908$

$345.5-2.909$

$345.8-2.903$

$346.6-2.894$

$345.8-2.904$

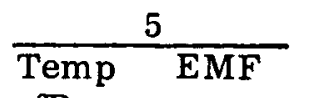

${ }^{\circ} \mathrm{mv}$

$-320.2-5.865$

$-320.2-5.856$

$-320.2-5.855$

$\begin{array}{lll}-320.2 & -5.885\end{array}$

$-320.2-5.863$

$\begin{array}{lll}-320.2 & -5.882\end{array}$

$\begin{array}{lll}-320.2 & -5.889\end{array}$

$\begin{array}{lll}-320.2 & -5.859\end{array}$

$-320.2 \quad-5.852$

$\begin{array}{lll}-320.2 & -5.889\end{array}$

$\begin{array}{lll}-320.0 & -5.853\end{array}$

$\begin{array}{ll}-320.2 & -5.893\end{array}$

$-320.2-5.890$

$\begin{array}{lll}-320.2 & -5.887\end{array}$

$-320.2-5.865$

$\begin{array}{ll}-320.2 & -5.887\end{array}$ 


\section{DEVELOPMENT HISTORY}

Code No: $\operatorname{Tr}-11$

Mfgr: Aero Research

Model No. T-11-260AK8F

P. 0 .

30504

REMARKS:

\begin{tabular}{|c|c|c|c|c|c|c|c|c|c|}
\hline \multirow[b]{2}{*}{ Type } & \multicolumn{3}{|c|}{ Vibration } & \multicolumn{3}{|c|}{ Bending } & \multirow{2}{*}{$\begin{array}{c}\text { Time } \\
\text { Response } \\
\cong 30 \\
\end{array}$} & \multicolumn{2}{|c|}{ Flow Forces } \\
\hline & $\begin{array}{l}\text { Insulation } \\
\text { Resistance } \\
\end{array}$ & $\begin{array}{l}\text { Con- } \\
\text { tinuity }\end{array}$ & $\begin{array}{c}\text { Induced } \\
\text { EMF } \\
\end{array}$ & $\begin{array}{l}\text { Insulation } \\
\text { Resistance } \\
\end{array}$ & $\begin{array}{l}\text { Change } \\
\text { in EMF } \\
\end{array}$ & $\begin{array}{c}\text { Wire } \\
\text { Resistance } \\
\end{array}$ & & $\begin{array}{l}\text { Bend- } \\
\text { ing } \\
\end{array}$ & $\begin{array}{l}\text { Con- } \\
\text { tinuity }\end{array}$ \\
\hline Test Values & $>40 \mathrm{Meg}$ & -- & $<10 \mu \mathrm{v}$ & $>1000 \mathrm{Meg}$ & $<10 \mu v$ & $<1 \%$ & Millisec & $<20^{\circ}$ & - \\
\hline $\begin{array}{l}\text { C/A Grnd. } \\
\text { Junction } \\
\text { (Quantities } \\
\text { Tested) }\end{array}$ & * & * & * & 5 & 5 & 5 & NA & NA & NA \\
\hline
\end{tabular}

\begin{tabular}{|c|c|c|c|c|c|c|c|c|}
\hline \multirow[b]{3}{*}{ Type } & \multirow{2}{*}{\multicolumn{2}{|c|}{ High Temperature }} & \multirow{3}{*}{$\begin{array}{l}\text { Moisture } \\
\text { Insulation }\end{array}$} & \multirow{3}{*}{$\begin{array}{c}\text { Sealing } \\
\text { Resistance }\end{array}$} & \multicolumn{3}{|c|}{ Reactor Testing } & \multirow{3}{*}{$\begin{array}{l}\text { Gas Leakage } \\
\text { Down Sheath }\end{array}$} \\
\hline & & & & & Aeroseal & Insulation & & \\
\hline & alibration & Corrosion & & & Sealant & Resistance & Calibration & \\
\hline $\begin{array}{l}\text { Test } \\
\text { Values }\end{array}$ & $\pm 4 \%$ & $\begin{array}{l}\text { Not } \\
\text { Visible }\end{array}$ & $\begin{array}{l}\text { EPY } 400 \\
>140 \mathrm{Meg}\end{array}$ & $\begin{array}{c}\text { Aeroseal } \\
>34 \mathrm{Meg}\end{array}$ & $>10 \mathrm{Meg}$ & $>10 \mathrm{Meg}$ & $1 \%$ & $<10^{-6} \mathrm{cc} \mathrm{He} / \mathrm{sec}$ \\
\hline $\begin{array}{l}\text { C/A Grnd. } \\
\text { Junction } \\
\text { (Quantities } \\
\text { Tested) }\end{array}$ & NA & NA & NA & NA & NA & 32 & 32 & NA \\
\hline
\end{tabular}


and

\section{THIS PAGE INTENTIONALLY LEFT BLANK}




\section{THERMOCOUPLE}

Code No: $\operatorname{Tr}-12$

Type: Chromel-P/Alumel Gnd. Junction

Mfgr: Aero Research

Range: $\pm 0^{\circ}$ to $2660^{\circ} \mathrm{R}$
Spec. Control Dwg. No. 963B362H01

Evaluation By: WANL

Model No: For Nuclear use T-11-260BK8F

Application: Material temp.

PERFORMANCE \& ENVIRONMENTAL SPECIFICATIONS

\begin{tabular}{|c|c|c|c|c|}
\hline Test & Condition & NERVA Requirements & Manufacturer's Specs. & $\begin{array}{l}\text { Summary of } \\
\text { Test Results }\end{array}$ \\
\hline$A$ & Proof Pressure & $600 \mathrm{psig}$ & 2000 psig & $>1000$ psig \\
\hline B & Sheath Material & thermal compatible & 347 Stainless Steel & suitable \\
\hline C & Accel. Error & info. later & info. later & see vibration \\
\hline D & Vibration Error & $0-300 \mathrm{cps}, 10 \mathrm{~g}$ & $0-300 \mathrm{cps}, 10 \mathrm{~g}$ & $\begin{array}{l}>10 \mu \mathrm{v} \text { at } 10 \mathrm{~g} \\
30-2000 \mathrm{cps}\end{array}$ \\
\hline$E$ & Shock & info. later & info. later & $>10 \mathrm{~g}$ \\
\hline $\mathbf{F}$ & Noise Limit & NA & not available & NA \\
\hline G & Neutron Flux & $5.2 \times 10^{15} \mathrm{n} / \mathrm{cm}^{2}-\mathrm{sec}$ & compatible material & $>3 \times 10^{13} \mathrm{n} / \mathrm{cm}^{2}-\mathrm{sec}$ \\
\hline $\mathrm{H}$ & Gamma Flux & \multicolumn{2}{|c|}{$2.6 \times 10^{12} \mathrm{ergs} / \mathrm{gm}(\mathrm{c}) / \mathrm{hr}$ compatible material } & $>1 \times 10^{11} \mathrm{erge} / \mathrm{gm}(\mathrm{c})-\mathrm{hr}$ \\
\hline 1 & Sensitivity & $0.025 \mathrm{mv} /{ }^{\circ} \mathrm{R}$ & $0.025 \mathrm{mv} /{ }^{\circ} \mathrm{R}$ & $0.023 \mathrm{mb} /{ }^{\circ} \mathrm{R}$ at $500^{\circ} \mathrm{F}$ \\
\hline $\mathrm{J}$ & Dimensions & OD $0.062^{\prime \prime}$ & sheath OD $0.062^{\prime \prime}$ & $0.062 " \mathrm{OD}$ \\
\hline$K$ & Weight & info. later & info. later & \\
\hline$L$ & Insulation Res. & 100 Megs at $50 \mathrm{~V}$ & 500 Megs at $500 \mathrm{VDC}$ & $>500$ Megs at $500 \mathrm{VDC}$ \\
\hline$M$ & Material Insulation & thermal compatible & $\mathrm{MgO}$ & $\mathrm{MgO}$ \\
\hline $\mathbf{N}$ & Wire Size & $0.011^{\prime \prime}$ & $0.011^{\prime \prime}$ & \\
\hline $\mathrm{O}$ & Junction Type & \multicolumn{3}{|c|}{ sheathed grounded (C/A) sheathed grounded (C/A) sheathed gnd. (C/A) } \\
\hline $\mathbf{P}$ & Accuracy & $\begin{array}{l} \pm 2^{\circ} \mathrm{F} 460-1000^{\circ} \mathrm{R} \\
0.375 \% 1000-2300^{\circ} \mathrm{R}\end{array}$ & $\begin{array}{l} \pm 2^{\circ} \mathrm{F} 460-1000^{\circ}{ }^{\circ} \mathrm{R} \\
0.375 \% 1000-2300^{\circ} \mathrm{R}\end{array}$ & $\begin{array}{l} \pm 2^{\circ} \mathrm{F} 460-1000^{\circ} \mathrm{R} \\
0.375 \% 1000-2300^{\circ} \mathrm{R}\end{array}$ \\
\hline $\mathbf{Q}$ & Application & Material temp. & $\mathrm{NA}$ & \\
\hline & & & & \\
\hline & & & & \\
\hline & & & & \\
\hline & & & & \\
\hline & & & & \\
\hline & & & & \\
\hline & & & & \\
\hline & & & & \\
\hline
\end{tabular}





\section{DEVELOPMENT HISTORY}

Code No: $\mathrm{Tr}-12$

Mfgr: Aero Research

Model No. T-11-260BK8 F

P. 0. 30504

\section{REMARKS:}

Evaluation history of chromel-P/alumel thermocouples which are fully sheathed, grounded junction and have sheathed leads with $\mathrm{MgO}$ insulation is given in the general evaluation history.

15 November 1963

The following test data has been summarized from the acceptance, qualification, and calibration tests conducted by manufacturer. Seventy-one (71) units have been tested $\mathrm{S} / \mathrm{N}$ AR-2024 thru 2026, AR-2028, AR-2030 thru 2082, AR-2084 thru 2098.

Insulation Resistance - $>100$ megohms at $500 \mathrm{VDC}$ on all units. No loss of insulation when belt abraded with 150 grit paper.

X-Ray Analysis - $\quad \mathrm{X}$-rays were made at $0^{\circ}$ and $90^{\circ}$ views of measuring junction. No rejects are reported.

Metallurgical Tests - Samples were taken of all units and mounted for examination. Under $100 \mathrm{X} / 200 \mathrm{X} / 400 \mathrm{X}$ microscopic examination, no evidence of cracks, porosity, or harmful inclusions were noted. In the etched condition, nothing was found to indicate grain boundary attack due to carbide precipitation.

Continuity Tests - The following data includes manufacturers data and test data by WANL at assembly of NRX-A1. Only those thermocouples installed in NRX-A 1 a re included.

\begin{tabular}{|c|c|c|c|c|}
\hline Symbol & $\mathrm{S} / \mathrm{N}$ & Location & $\begin{array}{c}\text { Mfgrs. } \\
\text { Value }\end{array}$ & $\begin{array}{c}\text { Assembly } \\
\text { Value }\end{array}$ \\
\hline $\mathrm{T}-401$ & 2051 & Inner Reflector & 117.00 & 116.59 \\
\hline $\mathrm{T}-402$ & 2035 & Inner Reflector & 113.60 & 113.18 \\
\hline$T-403$ & 2053 & Inner Reflector & 115.60 & 115.00 \\
\hline$T-404$ & 2085 & Inner Reflector & 112.40 & 111.82 \\
\hline$T-405$ & 2036 & Inner Reflector & 113.70 & 113.13 \\
\hline $\mathrm{T}-406$ & 2084 & Inner Reflector & 112.80 & 112.22 \\
\hline $\mathrm{T}-407$ & 2034 & Inner Reflector & 113.80 & 113.53 \\
\hline$T-408$ & 2052 & Inner Reflector & 115.20 & 114.79 \\
\hline $\mathrm{T}-314$ & 2030 & Shim Rod & 116.90 & 111.34 \\
\hline $\mathrm{T}-315$ & 2047 & Shim Rod & 113.70 & 113.16 \\
\hline $\mathrm{T}-316$ & 2046 & Shim Rod & 113.80 & 113.10 \\
\hline$T-318$ & 2049 & Shim Rod & 112.60 & 111.74 \\
\hline $\mathrm{T}-\mathbf{3 1 9}$ & 2050 & Shim Rod & 110.90 & 110.35 \\
\hline
\end{tabular}




\section{DEVELOPMENT HISTORY}

Code No: $\operatorname{Tr}-12$

Model No. T-11-260BK8F

\section{REMARKS:}

Mfgr: Aero Research

P. 0. 30504

\begin{tabular}{|c|c|c|c|c|}
\hline Symbol & $\underline{\mathrm{S} / \mathrm{N}}$ & Location & $\begin{array}{l}\text { Mfgrs. } \\
\text { Value } \\
\end{array}$ & $\begin{array}{c}\text { Assembly } \\
\text { Value }\end{array}$ \\
\hline $\mathrm{T}-320$ & 2044 & Shim Rod & 112.40 & 111.36 \\
\hline $\mathrm{T}-325$ & 2045 & Shim Rod & 113.80 & 113.42 \\
\hline $\mathrm{T}-326$ & 2041 & Shim Rod & 114.00 & 113.90 \\
\hline$T-328$ & 2042 & Shim Rod & 114.90 & 114.41 \\
\hline $\mathrm{T}-329$ & 2048 & Shim Rod & 112.90 & 112.24 \\
\hline
\end{tabular}

Leak Rate -

1000 psi Helium was applied to junction end of the thermocouple and the gas leakage through the insulation was measured by a calibrated detector.

$\mathrm{S} / \mathrm{N}$

AR-2024-2026

AR-2028

AR-2030-2035

AR-2036-2047

AR-2048-2059

AR-2060-2071

AR-2072-2082

AR-2084-2098
Acute Leak Rate

$0.104 \times 10^{-8} \mathrm{~atm} \mathrm{cc} / \mathrm{sec}$

$0.104 \times 10^{-8} \mathrm{~atm} \mathrm{cc} / \mathrm{sec}$

$0.153 \times 10^{-8} \mathrm{~atm} \mathrm{cc} / \mathrm{sec}$

$0.104 \times 10^{-8} \mathrm{~atm} \mathrm{cc} / \mathrm{sec}$

$0.104 \times 10^{-8} \mathrm{~atm} \mathrm{cc} / \mathrm{sec}$

$0.153 \times 10^{-8} \mathrm{~atm} \mathrm{cc} / \mathrm{sec}$

Calibration Data -

The output EMF was determined for each the rmocouple at four (4) temperature points. Only those installed in the NRX-A1 reactor are included in this tabulation.

\begin{tabular}{|c|c|c|c|c|c|c|c|c|c|}
\hline \multirow[b]{2}{*}{ Symbol } & \multirow[b]{2}{*}{$\underline{S} / \mathbf{N}$} & \multicolumn{2}{|c|}{1} & \multicolumn{2}{|c|}{2} & \multicolumn{2}{|c|}{3} & \multicolumn{2}{|c|}{4} \\
\hline & & Temp ${ }^{\circ} \mathbf{R}$ & EMFmv & Temp ${ }^{\circ} \mathrm{R}$ & EM Fmv & Temp ${ }^{\circ} \mathbf{R}$ & EMFmv & Temp ${ }^{\circ} R$ & EMFmv \\
\hline$T-401$ & 2051 & 1600.8 & 27.936 & 1100.2 & 13.786 & 346.1 & -2.899 & 139.7 & -5.888 \\
\hline & 2035 & 1601.4 & 27.951 & 1100.0 & 13.780 & 346.5 & -2.895 & 139.7 & -5.879 \\
\hline$T-403$ & 2053 & 1601.1 & 27.944 & 1100.5 & 13.795 & 346.5 & -2.895 & 139.7 & -5.885 \\
\hline$T-404$ & 2085 & 1601.1 & 27.943 & 1100.1 & 13.784 & 346.5 & -2.895 & 139.7 & -5.885 \\
\hline$T-405$ & 2036 & 1601.2 & 27.946 & 1100.1 & 13.784 & 346.6 & -2.894 & 139.7 & -5.878 \\
\hline$T-406$ & 2084 & 1601.4 & 27.951 & 1100.2 & 13.787 & 346.5 & -2.895 & 139.7 & -5.886 \\
\hline$T-407$ & 2034 & 1601.1 & 27.942 & 1100.0 & 13.781 & 346.6 & -2.894 & 139.7 & -5.880 \\
\hline$T-408$ & 2052 & 1600.8 & 27.936 & 1100.4 & 13.793 & 346.5 & -2.895 & 139.7 & -5.884 \\
\hline $\mathrm{T}-314$ & 2030 & 1600.7 & 27.933 & 1099.6 & 13.771 & 346.9 & -2.891 & 139.7 & -5.879 \\
\hline$T-315$ & 2047 & 1600.9 & 27.937 & 1100.1 & 13.782 & 346.2 & -2.898 & 139.7 & -5.883 \\
\hline$T-316$ & 2046 & 1601.4 & 27.953 & 1100.2 & 13.785 & 346.2 & -2.899 & 139.7 & -5.882 \\
\hline
\end{tabular}




\section{DEVELOPMENT HISTORY}

Code No: $\operatorname{Tr}-12$

Model No. T-11-260BK8F

\section{REMARKS:}

Mfgr:

P. 0 . Aero Research 30504
Symbol

$\underline{\mathrm{S} / \mathrm{N}} \frac{1}{\text { Temp }^{\circ} \mathrm{R}} \underline{\mathrm{EMFmv}}$ $\frac{2}{\text { Temp }{ }^{\top} \text { EMFmv }}$ $\frac{3}{\text { Temp }{ }^{\circ} \mathrm{R}}$ EMFmv $\frac{4}{\underline{\text { Temp }}{ }^{\circ} \mathrm{R} \text { EMFmv }}$

$\mathrm{T}-318 \quad 2049$

$\mathrm{T}-319 \quad 2050$

$\mathrm{T}-320 \quad 2044$

$\mathrm{T}-325 \quad 2045$

$\mathrm{T}-326 \quad 2041$

$\mathrm{T}-328 \quad 2042$

T-329 2048

$\begin{array}{ll}1100.2 & 13.787 \\ 1100.3 & 13.790 \\ 1099.9 & 13.777 \\ 1100.2 & 13.786 \\ 1100.1 & 13.783 \\ 1100.0 & 13.780 \\ 1100.3 & 13.788\end{array}$

346.5
346.6
346.6
346.1
346.7
346.8
346.6

$-2.895$

$-2.894$

$-2.894$

$-2.899$

$-2.893$

$-2.892$
$-2.894$

$$
\begin{array}{ll}
139.7 & -5.885 \\
139.7 & -5.884 \\
139.7 & -5.885 \\
139.7 & -5.882 \\
139.7 & -5.881 \\
139.7 & -5.882 \\
139.7 & -5.884
\end{array}
$$
$\frac{\text { Vibration }}{\text { Insulation Induced }} \frac{\text { Bending }}{\text { Insulation Change Wire }}$ Time $\begin{gathered}\text { Flow Forces } \\ \text { Rend- Con- }\end{gathered}$

Type Resistance Continuity EMF Resistance in EMF Resistance $\cong 30 \quad$ ing tinuity

Values

C/A Grnd. Junction

(Quantities

Tested)

Reactor Testing

High Temperature Moisture Sealing Aeroseal Insulation Gas Leakage Type Calibration Corrosion Insulation Resistance Sealant Resistance Calibration Down Sheath

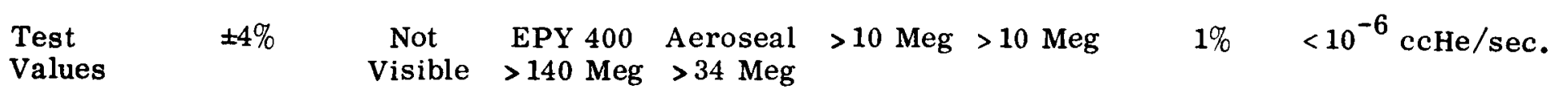

C/A Grnd. Junction (Quantities NA NA NA NA NA 32 32 NA Tested)

\footnotetext{
*Covered by testing on $\mathrm{C} / \mathrm{C}$ thermocouples.
} 


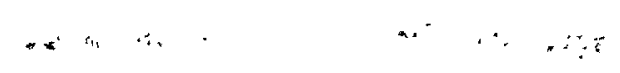

THIS PAGE INTENTIONALLY LEFT BLANK 


\section{THERMOCOUPLE}

Code No: $\operatorname{Tr}-13$

Type: Copper/Constantan-Gnd, Junction

Mfgr: Aero Research

Range: $40^{\circ}$ to $1500^{\circ} \mathrm{R}$
Spec. Control Dwg. No. 963B363H01

Evaluation By: WANL

Model No: For Nuclear Use - T-11-240BT8F

Application: Material Temp.

PERFORMANCE \& ENVIRONMENTAL SPECIFICATIONS

\begin{tabular}{|c|c|c|c|c|}
\hline Test & Condition & NERVA Requirements & Manufacturer's Specs. & $\begin{array}{l}\text { Summary of } \\
\text { Test Results }\end{array}$ \\
\hline$A$ & Proof Pressure & 600 psig & 2000 psig & $>1000$ psig \\
\hline $\mathrm{B}$ & Sheath Material & thermal compatible & 347 Stainless Steel & suitable \\
\hline $\mathrm{C}$ & Accel. Error & info. later & info. later & see vibration \\
\hline D & Vibration Error & $0-300 \mathrm{cps}, 10 \mathrm{~g}$ & $0-300 \mathrm{cps}, 10 \mathrm{~g}$ & $\begin{array}{l}<10 \mu \mathrm{v} \text { at } 10 \mathrm{~g} \\
30-2000 \mathrm{cps}\end{array}$ \\
\hline$E$ & Shock & info. later & info. later & $>10 \mathrm{~g}$ \\
\hline $\mathbf{F}$ & Noise Limit & $\mathrm{NA}$ & not a vailable & $\mathrm{NA}$ \\
\hline $\mathbf{G}$ & Neutron Flux & $5.2 \times 10^{15} \mathrm{n} / \mathrm{cm}^{2}-\mathrm{sec}$ & compatible material & $>3 \times 10^{13} \mathrm{n} / \mathrm{m}^{2}-\mathrm{s}$ \\
\hline $\mathrm{H}$ & Gamma Flux & $2.6 \times 10^{12} \mathrm{ergs} / \mathrm{gm}(\mathrm{c}) / \mathrm{hr}$ & compatible material & $>1 \times 10^{\prime \prime} \mathrm{ergs} / \mathrm{gm}$ \\
\hline 1 & Sensitivity & $\begin{array}{l}0.010 \mathrm{mv} / / \circ \mathrm{R} \text { to } \\
0.035 \mathrm{mv} /{ }^{\circ} \mathrm{R}\end{array}$ & $\begin{array}{l}0.010 \mathrm{mv} /{ }^{\circ} \mathrm{R} \\
0.035 \mathrm{mv} /{ }^{\circ} \mathrm{R}\end{array}$ & {$\left[\begin{array}{l}0.010 \mathrm{mv} /{ }^{\circ} \mathrm{R} \text { to } \\
0.35 \mathrm{mv} /{ }^{\circ} \mathrm{R}\end{array}\right.$} \\
\hline$J$ & Dimensions & OD $0.062^{\prime \prime}$ & sheath OD $0.062 "$ & $0.062 " \mathrm{OD}$ \\
\hline$K$ & Weight & info. later & info, later & \\
\hline$L$ & Insulation Res. & 100 Megs at $50 \mathrm{~V}$ & 500 Megs at $500 \mathrm{VDC}$ & $\begin{array}{l}3500 \text { Megs at } \\
500 \mathrm{VDC}\end{array}$ \\
\hline M & Material Insulation & thermal compatible & $\mathrm{MgO}$ & \\
\hline $\mathrm{N}$ & Wire Size & $0.011^{\prime \prime}$ & $0.011^{\prime \prime}$ & \\
\hline $\mathrm{O}$ & Junction Type & sheathed grounded $(C / C)$ & sheathed grounded $(C / C)$ & sheathed, gnd (c) \\
\hline $\mathbf{p}$ & Accuracy & $\pm 2 \%$ or $+2^{\circ} \mathrm{R}$ & $\pm 2 \%$ or $\pm 2^{\circ} \mathrm{R}$ & $\pm 2 \%$ or $\pm 2^{\circ} \mathrm{R}$ \\
\hline Q & Application & Material Temp. & NA & \\
\hline & & & & \\
\hline & & & & \\
\hline & & & & \\
\hline & & & & \\
\hline & & & & \\
\hline & & & & \\
\hline & & & & \\
\hline & & & & \\
\hline
\end{tabular}




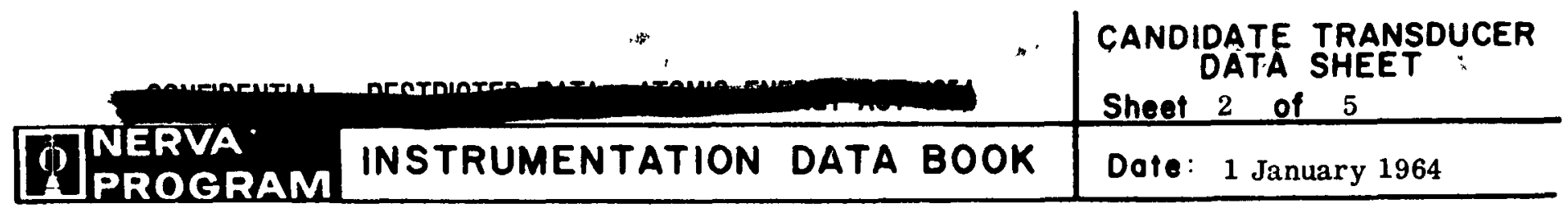

RADIATION TESTS

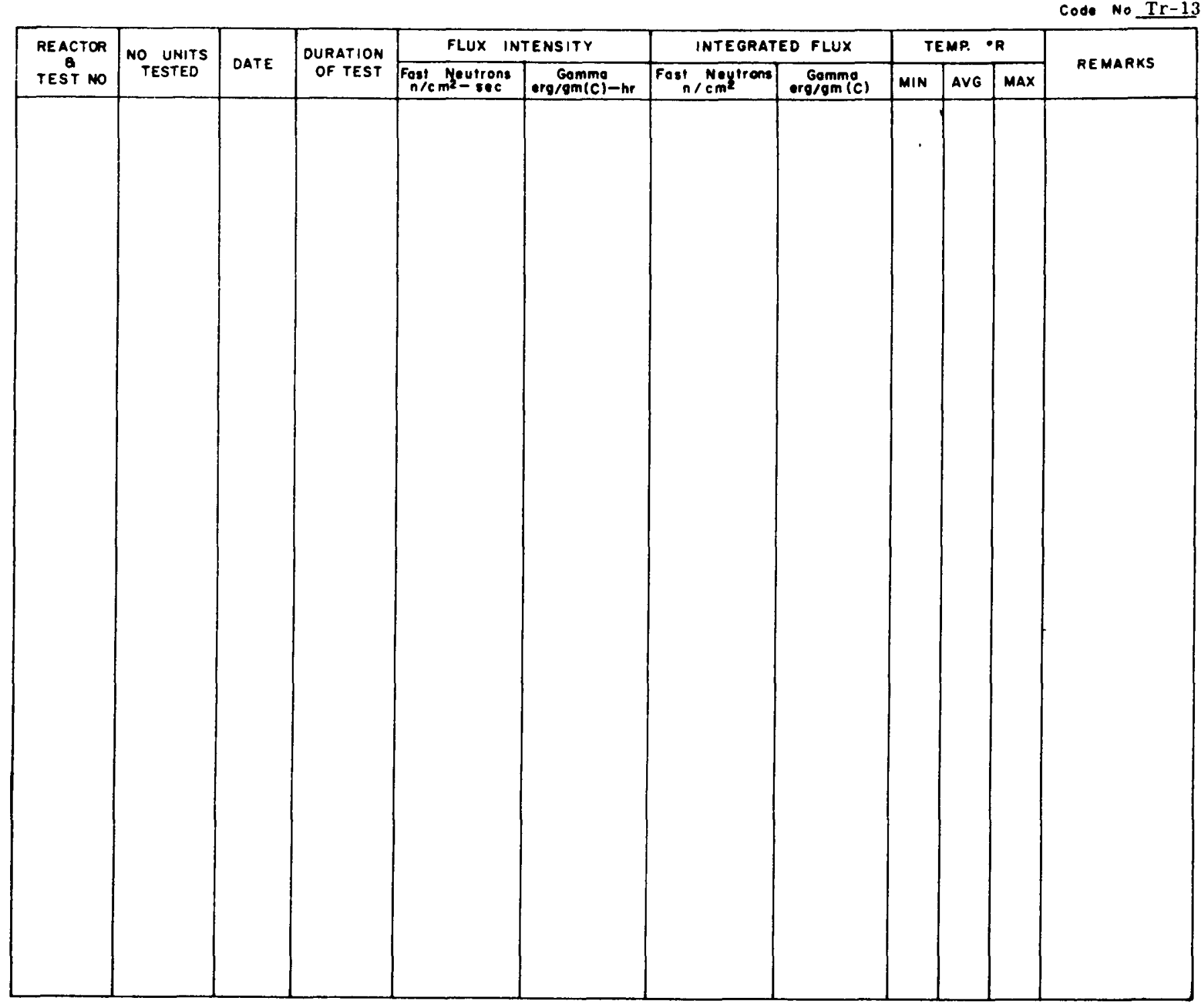




\section{DEVELOPMENT HISTORY}

Code No: $\quad \mathrm{Tr}-13$

Model No. T-11-240BT8F
Mfgr: Aero Research

P. 0. 30504

\section{REMARKS:}

Evaluation history of copper/constantan thermocouples which are fully sheathed, grounded junction and have sheathed leads with $\mathrm{MgO}$ insulation is given in the general evaluation history.

$\underline{15} \underline{\text { November }} \underline{1963}$

The following test data has been summarized from the Acceptance, Qualification and Calibration tests conducted by manufacturer. Eighty-nine (89) units have been tested S/N AR-2103 through 2128,2130 through 2171,2173 through 2182,2184 through 2194 .

Insulation Resistance - $>100$ megohm at 500VDC on all units no loss of insulation when belt abraded with 100 grit paper.

$\underline{X-R a y}$ Analysis - $\quad X$-rays were made at $0^{\circ}$ and $90^{\circ}$ views at measuring junction - no rejects reported.

Metallurgical Tests - Samples were taken from all units and mounted for examination under $100 \mathrm{x} / 200 \mathrm{x} / 400 \mathrm{x}$ microscopic examination, no evidence of cracks, porosity, or harmful inclusion were noted. In the etched condition, nothing was found to indicate grain boundary attack due to carbide precipitation.

Continuity Tests - The following data includes manufacturers data and test data by WANL at assembly of NRX-A1. Only those thermocouples installed in NRXA1 are included.

$\begin{array}{ccc}\text { Symbol } & & \text { S/N } \\ \mathrm{T}-701 & & 2106 \\ \mathrm{~T}-702 & & 2192 \\ \mathrm{~T}-703 & 2194 \\ \mathrm{~T}-704 & 2104 \\ \mathrm{~T}-339 & 2107 \\ \mathrm{~T}-340 & 2112 \\ \mathrm{~T}-341 & 2140 \\ \mathrm{~T}-342 & & 2111 \\ \mathrm{~T}-417 & 2109 \\ \mathrm{~T}-418 & 2136 \\ \mathrm{~T}-438 & & 2105\end{array}$

\begin{tabular}{l}
\multicolumn{1}{c}{ Location } \\
\hline O.R. Sector 3 \\
O.R. Sector 3 \\
O.R. Sector 3 \\
O.R. Sector 3 \\
O.R. Sector 7 \\
O.R. Sector 12 \\
Cont. Drum \\
Cont. Drum
\end{tabular}

Al. Barrel

Al. Barrel

Ring Ass'y Support

\begin{tabular}{ccc}
$\begin{array}{c}\text { Mfgrs. } \\
\text { Value }\end{array}$ & & $\begin{array}{c}\text { Assembly } \\
\text { Value }\end{array}$ \\
\cline { 1 - 1 } 61.62 & & 60.96 \\
71.71 & & 71.23 \\
58.90 & & 58.93 \\
61.39 & & 60.00 \\
61.69 & & 61.59 \\
59.47 & & 59.36 \\
73.80 & & 73.74 \\
60.92 & & 60.59 \\
60.73 & & 60.76 \\
55.57 & & 55.94 \\
72.48 & & 72.03
\end{tabular}

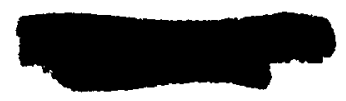


Code No: $\operatorname{Tr}-13$

Model No. T-11-240BT8F

\section{REMARKS:}

Leak Rate -

1000 psia Helium was applied to junction end of thermocouple and the gas leakage through the insulation was measured by a calibrated detector.

$\underline{\mathrm{S} / \mathrm{N}}$

AR-2103-2194

Mfgr:

Aero Research

P. 0. 30504

Calibration Data -

\section{DEVELOPMENT HISTORY}

\section{Dote:}

\begin{tabular}{|c|c|c|c|c|c|c|c|c|c|}
\hline & & & $\mathrm{S} / \mathrm{N}$ & & Acute & eak Rate & & & \\
\hline & & & AR-2103-2 & & $.188 \times 10^{0}$ & $\mathrm{~atm} \mathrm{cc} / \mathrm{s}$ & & & \\
\hline & alibra & on Data - & $\begin{array}{l}\text { The c } \\
\text { temp } \\
\text { are in }\end{array}$ & $\begin{array}{l}\text { atput EMF } \\
\text { rature poi } \\
\text { cluded in }\end{array}$ & $\begin{array}{l}\text { s. Only t } \\
\text { is tabulati }\end{array}$ & $\begin{array}{l}\text { ose instal } \\
\text { n. }\end{array}$ & $\mathrm{d}$ in the $\mathrm{N}$ & -A1 rea & $\begin{array}{l}\text { (4) } \\
\text { or }\end{array}$ \\
\hline & & & & & & & & 4 & \\
\hline Symbol & $\underline{\mathrm{S} / \mathrm{N}}$ & Temp ${ }^{\circ} \mathbf{R}$ & EMFmv & Temp ${ }^{\circ} R$ & EMFmv & Temp ${ }^{\circ} R$ & EMFmv & Temp ${ }^{\circ} \mathrm{R}$ & EMFmv \\
\hline$T-701$ & 2106 & 492.0 & +0.0001 & & -2.720 & 139.7 & -5.439 & 7.9 & -5.868 \\
\hline $\mathrm{T}-702$ & 2196 & 492.0 & +0.0007 & 350.5 & -2.722 & & -5.4 & & -5.897 \\
\hline T-703 & 2194 & 492.0 & -0.0004 & 350.1 & -2.728 & $\begin{array}{l}139.7 \\
139.7\end{array}$ & -5.487 & 7.9 & -6.095 \\
\hline$T-704$ & 2104 & 492.0 & +0.0003 & 350.7 & -2.718 & $\begin{array}{l}139.7 \\
139.7\end{array}$ & -5.435 & 7.9 & -5.867 \\
\hline T-339 & 2107 & 492.0 & +0.0010 & 350.3 & -2.715 & $\begin{array}{l}139.7 \\
139.7\end{array}$ & -5.436 & 7. & -5.913 \\
\hline$T-340$ & 2112 & 492.0 & -0.0004 & 351.2 & -2.710 & 139.7 & -5.433 & 7. & -5.867 \\
\hline $\mathrm{T}-341$ & 2140 & 492.0 & +0.0004 & 350.2 & -2.727 & 139.7 & -5.469 & 7.9 & -6.057 \\
\hline $\mathrm{T}-342$ & 2111 & 492.0 & -0.0002 & 351.1 & -2.712 & $\begin{array}{l}139.7 \\
139.7\end{array}$ & -5.437 & 7. & -5.870 \\
\hline$T-417$ & 2109 & 492.0 & +0.00 & 350.7 & -2.718 & 139.7 & -5.433 & 7. & -5.863 \\
\hline $\mathrm{T}-418$ & 2136 & 492.0 & -0.0006 & 350.8 & -2.716 & & -5.434 & & -5.882 \\
\hline $\mathrm{T}-438$ & 2105 & 492.0 & +0.0004 & 350.9 & -2.715 & 139.7 & -5.433 & 7.9 & -5.865 \\
\hline
\end{tabular}




\begin{tabular}{|l|l|l}
\hline TERVA & $\begin{array}{l}\text { CANDIDATE TRANSDUCER } \\
\text { DATA SHEET } \\
\text { Sheet } 5 \text { of 5 }\end{array}$ \\
\hline PROGRAM INSTRUMENTATION DATA BOOK & Dote: \\
\hline
\end{tabular}

\section{DEVELOPMENT HISTORY}

Code No: $\quad \operatorname{Tr}-13$

Model No. T-11-240BT8F

Mfgr: Aero Research

P. 0. 30504

REMARKS:

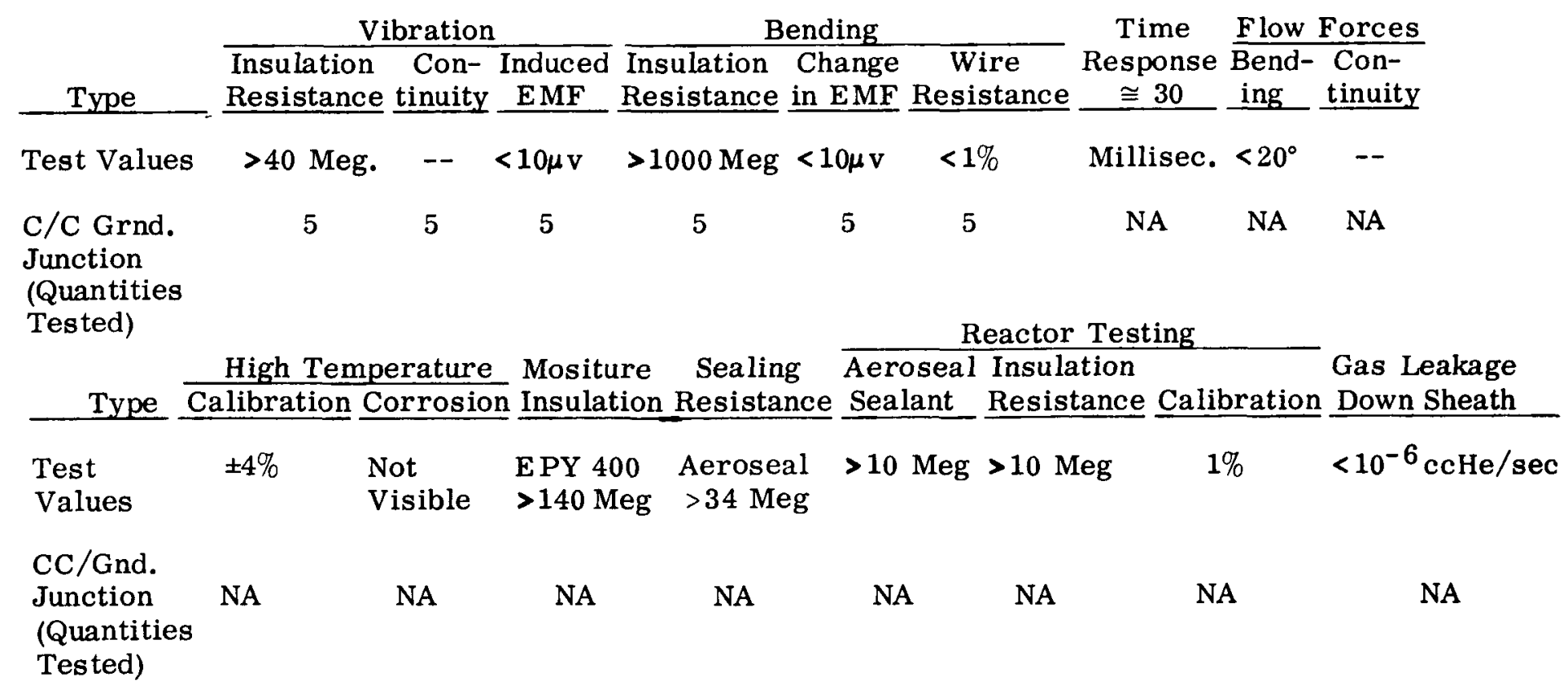




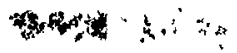

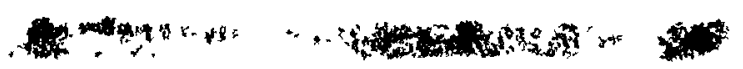

THIS PAGE INTENTIONALLY LEFT BLANK 
Sheet 1 of 4

Dote: 1 January 1964

\section{THERMOCOUPLE}

Code No:

$\operatorname{Tr}-14$

Type: Copper Constantan - Gnd, Junction

Mfgr: Aero Research

Range: $40^{\circ}$ to $1160^{\circ} \mathrm{R}$
Spec. Control Dwg. No, 964B039H02

Evaluation By: WANL

Model No: T-11-260AT8F, T-11-284AT 8F

Application: Material temp.

PERFORMANCE \& ENVIRONMENTAL SPECIFICATIONS

\begin{tabular}{|c|c|c|c|c|}
\hline Test & Condition & NERVA Requirements & Manufacturer's Specs. & $\begin{array}{l}\text { Summary of } \\
\text { Test Results } \\
\end{array}$ \\
\hline A & Proof Pressure & 600 psig & $2000 \mathrm{psig}$ & $>1000$ psig \\
\hline B & Sheath Material & thermal compatible & 347 Stainless steel & suitable \\
\hline $\mathbf{C}$ & Accel. Error & info. later & info. later & see vibration \\
\hline $\bar{D}$ & Vibration Error & $0-300 \mathrm{cps}, 10 \mathrm{~g}$ & $0-300 \mathrm{cps}, 10 \mathrm{~g}$ & $\begin{array}{l}<10 \mu \mathrm{at} 10 \mathrm{~g} \\
30-2000 \mathrm{cps}\end{array}$ \\
\hline $\mathbf{E}$ & Shock & info. later & info. later & $>10 \mathrm{~g}$ \\
\hline $\mathbf{F}$ & Noise Limit & $\mathrm{Na}$ & not available & NA \\
\hline $\mathbf{G}$ & Neutron Flux & $5.2 \times 10^{15} \mathrm{n} / \mathrm{cm}^{2}-\mathrm{sec}$ & compatible material & $>3 \times 10^{13} \mathrm{n} / \mathrm{cm}^{2}-\mathrm{sec}$ \\
\hline $\mathrm{H}$ & Gamma Flux & \multicolumn{2}{|c|}{$2.6 \times 10^{12} \mathrm{ergs} / \mathrm{gm}(\mathrm{c}) / \mathrm{hr}$ compatible material } & $>1 \times 10^{11} \mathrm{ergs} / \mathrm{gm}(\mathrm{c}) \mathrm{hr}$ \\
\hline 1 & Sensitivity & $\begin{array}{ll}0.010 \mathrm{mv} /{ }^{\circ} \mathrm{R} \text { to } \\
0.035 \mathrm{mb} /{ }^{\circ} \mathrm{R}\end{array}$ & $\begin{array}{l}0.010 \mathrm{mv} / \circ \mathrm{R} \text { to } \\
0.035 \mathrm{mv} / \mathrm{R}^{\circ}\end{array}$ & $\begin{array}{l}0.010 \mathrm{mv} /: \% \text { to } \\
0.035 \mathrm{mb} / \circ \mathrm{R}\end{array}$ \\
\hline $\mathrm{J}$ & Dimensions & OD $0.045^{\prime \prime}$ & sheath oD $0,045^{\prime \prime}$ & $1.045 " \mathrm{OD}$ \\
\hline K & Weight & info. later & info. later & \\
\hline$L$ & Insulation Res. & 100 Megs at $50 \mathrm{~V}$ & $500 \mathrm{Megs}$ at $500 \mathrm{VDC}$ & $\begin{array}{l}3500 \mathrm{Megs} \text { at } \\
500 \mathrm{VDC}\end{array}$ \\
\hline$M$ & Material Insulation & thermal compatible & $\mathrm{MgO}$ & $\mathrm{MgO}$ \\
\hline$\underline{N}$ & Wire Size & $0.006^{\prime \prime}$ & $0.006^{\prime \prime}$ & \\
\hline o & Junction Type & \multicolumn{3}{|c|}{ sheathed grounded $(C / C)$ sheathed grounded $(C / C)$ sheathed gnd. $(C / C)$} \\
\hline $\mathrm{P}$ & Accuracy & $\pm 2 \%$ or $\pm 2^{\circ} \mathrm{R}$ & $\pm 2 \%$ or $\pm 2^{\circ} \mathrm{R}$ & $\pm 2 \%$ or $\pm 2^{\circ} \mathrm{R}$ \\
\hline & & & & \\
\hline & & & & \\
\hline & & & & \\
\hline & & & & \\
\hline & & & & \\
\hline & & & & \\
\hline & & & & \\
\hline & & & & \\
\hline & & & & \\
\hline
\end{tabular}




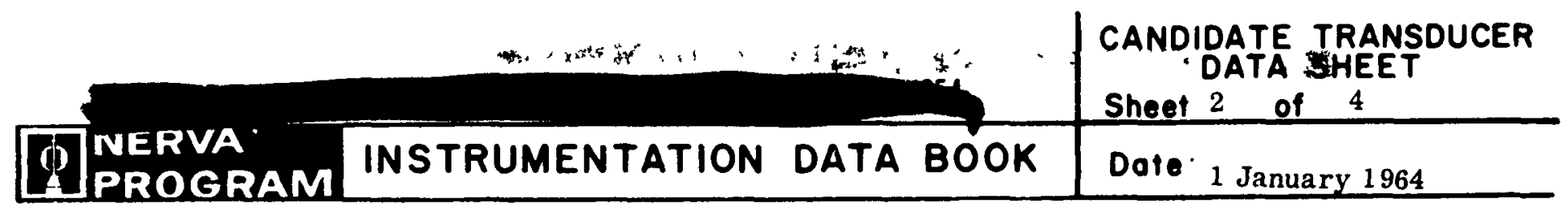

RADIATION TESTS

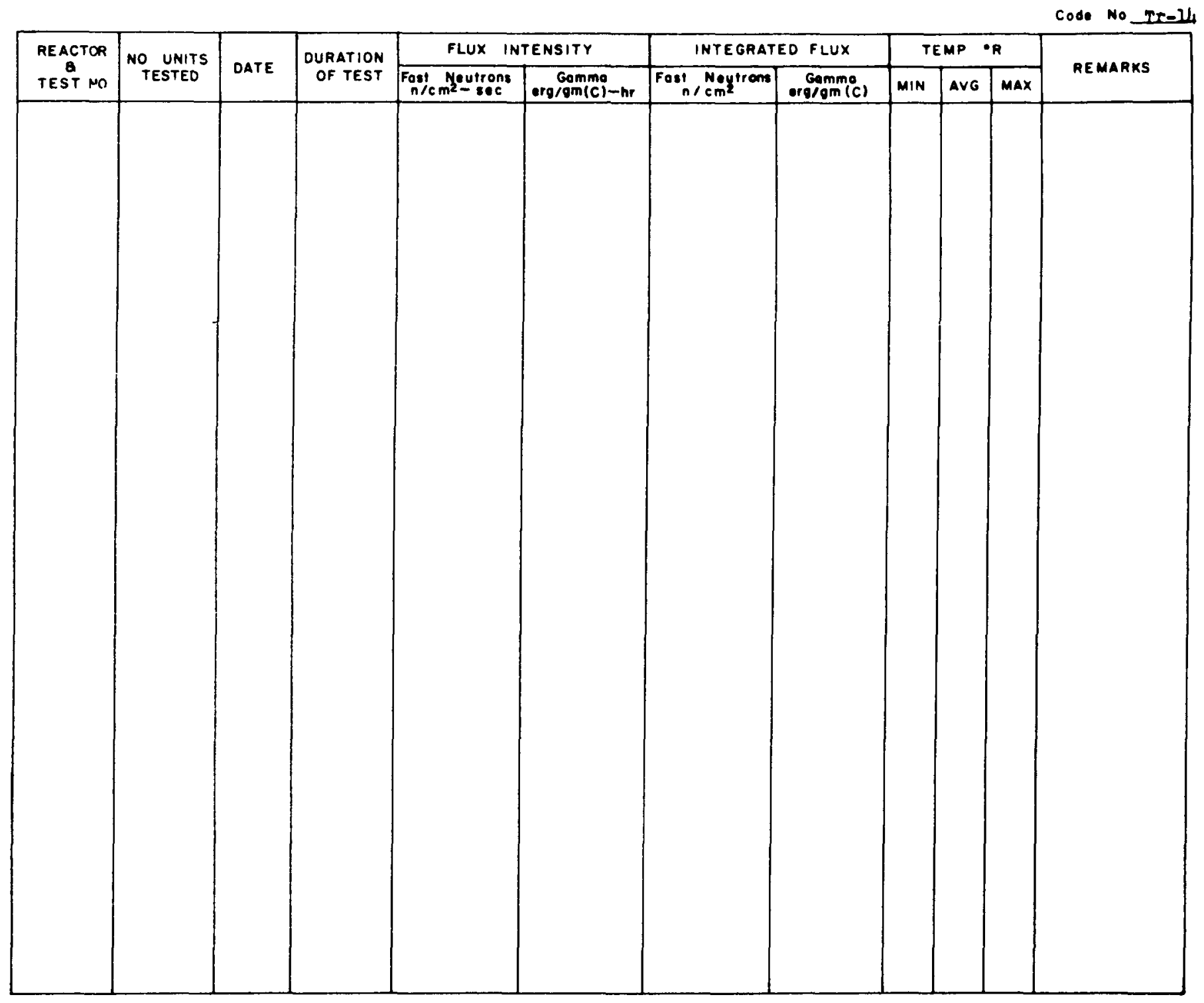

(․) Astionuclear 


\section{DEVELOPMENT HISTORY}

Code No:

Model No.

$\operatorname{Tr}-14$

T-11-260AT 8F, T-11-284AT $8 \mathrm{~F}$
Mfgr: Aero Research

P. 0. 30504

\section{REMARKS:}

Evaluation history of copper/constantan thermocouples which are fully sheathed, grounded junction and have sheathed leads with MgO insulation is given in the general evaluation history.

\section{November 1963}

The following test data has been summarized from the acceptance, qualification and calibration tests conducted by manufacturer. Nine (9) units have been tested, S/N AR-1805 through 1813.

Insulation Resistance - $>100$ megohms at $500 \mathrm{VDC}$ on all units no loss of insulation when belt abraded with 150 grit paper.

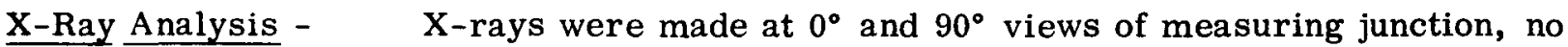
rejects were reported.

Metallurgical Tests - Samples were taken from all units and mounted for examination under $100 \mathrm{x} / 200 \mathrm{x} / 400 \mathrm{x}$ microscopic examination, no evidence of cracks, porosity, or harmful inclusions were noted. In the etched condition, nothing was found to indicate grain boundary attack due to carbide precipitation.

Continuity Tests -

$\begin{array}{lll}\text { Symbol } & & \text { S/N } \\ \mathrm{T}-331 & & 1808 \\ \mathrm{~T}-332 & & 1807 \\ \mathrm{~T}-333 & & 1809 \\ \mathrm{~T}-334 & 1810 \\ \mathrm{~T}-335 & & 1811 \\ \mathrm{~T}-336 & & 1813\end{array}$

Leak Rate -
The following data includes manufacturer's data and test data by WANL at assembly of NRX-A1. Only those thermocouples installed in NRX-A 1 are included.

\begin{tabular}{|c|c|c|}
\hline Location & $\begin{array}{l}\text { Mfgrs. } \\
\text { Value } \\
\end{array}$ & $\begin{array}{l}\text { Assembly } \\
\text { Value }\end{array}$ \\
\hline Outer.Refl. Cont. Drum & 219.30 & 224.54 \\
\hline Outer Refl. Cont. Drum & 208.10 & 219.12 \\
\hline Outer Refl. Cont. Drum & 205.60 & 207.43 \\
\hline Outer Refl. Cont. Drum & 225.70 & 205.57 \\
\hline Outer Refl. Cont. Drum & 222.30 & 223.75 \\
\hline Outer Refl. Cont. Drum & 225.10 & 218.74 \\
\hline
\end{tabular}

1000 psi Helium was applied to junction end of the thermocouple and the gas leakage through the insulation was measured by a calibrated detector.
$\frac{\mathrm{S} / \mathrm{N}}{\mathrm{AR}-1805-1806}$
Acute Leak Rate
$0.208 \times 10^{-8} \mathrm{Atm} \mathrm{cc} / \mathrm{sec}$
$0.052 \times 10^{-8} \mathrm{Atm} \mathrm{cc} / \mathrm{sec}$




\section{DEVELOPMENT HISTORY}

\begin{tabular}{|c|c|}
\hline Code No: $\quad \operatorname{Tr}-14$ & Aero Research \\
\hline Model No. T-11-260AT 8F, T-11-284AT 8F & P. 0. 30504 \\
\hline
\end{tabular}

\section{REMARKS:}

Calibration Data - The output EMF was determined for each thermocouple at four (4) temperature points. Only those installed in the NRX-A1 reactor are included in this tabulation.

\begin{tabular}{|c|c|c|c|c|c|c|c|c|c|}
\hline \multirow[b]{2}{*}{ Symbol } & \multirow[b]{2}{*}{$\mathrm{S} / \mathrm{N}$} & \multicolumn{2}{|c|}{1} & \multicolumn{2}{|c|}{2} & \multicolumn{2}{|r|}{3} & \multicolumn{2}{|c|}{4} \\
\hline & & $\operatorname{Temp}^{\circ} \mathrm{R}$ & EMFmv & Temp ${ }^{\circ} \mathrm{R}$ & EMFmv & Temp ${ }^{\circ} \mathrm{R}$ & EMFMv & Temp ${ }^{\circ} \mathbf{R}$ & EMFmv \\
\hline & & & -0 . & & -2 & & -5.4 & 7.9 & -6.0 \\
\hline & $180^{\prime}$ & 91.9 & -0.0 & & -2 . & & & & -6 . \\
\hline $\mathrm{T}-333$ & 1809 & 491.9 & -0.0032 & 350.3 & -2.7253 & 139.6 & -5.4 & 7.9 & -6.0121 \\
\hline $\mathrm{T}-334$ & 1810 & 491.9 & -0.0024 & 350.3 & -2.7251 & 139.6 & -5.4 & 7.9 & -6.0114 \\
\hline $\mathrm{T}-335$ & 1811 & 492.0 & -0.0004 & 350.8 & -2.7170 & 139.6 & -5.4544 & 7.9 & -6.0483 \\
\hline$T-336$ & 1813 & 491.9 & -0.0019 & 350.0 & -2.7292 & 139.6 & -5.4821 & 7.9 & -6.0515 \\
\hline
\end{tabular}

\begin{tabular}{|c|c|c|c|c|c|c|c|c|c|}
\hline \multirow[b]{2}{*}{ Type } & \multicolumn{3}{|c|}{$\begin{array}{l}\text { Vibration } \\
\end{array}$} & \multicolumn{3}{|c|}{ Bending } & \multirow{2}{*}{$\begin{array}{c}\text { Time } \\
\text { Response } \\
\mathrm{e} \quad \cong 30 \\
\end{array}$} & \multicolumn{2}{|c|}{ Flow Forces } \\
\hline & $\begin{array}{l}\text { Insulation } \\
\text { Resistance }\end{array}$ & Continuity & $\begin{array}{l}\text { Induced } \\
\text { EMF }\end{array}$ & $\begin{array}{l}\text { Insulation } \\
\text { Resistance }\end{array}$ & $\begin{array}{l}\text { Change } \\
\text { in EMF }\end{array}$ & $\begin{array}{c}\text { Wire } \\
\text { Resistance }\end{array}$ & & $\begin{array}{l}\text { Bend- } \\
\text { ing }\end{array}$ & $\begin{array}{l}\text { Con- } \\
\text { tinuity }\end{array}$ \\
\hline $\begin{array}{l}\text { Test } \\
\text { Values }\end{array}$ & $>40$ Meg. & - & $<10 \mu \mathrm{v}$ & $>1000 \mathrm{Meg}$. & $\cdot<10_{\mu \mathrm{v}}$ & $<1 \%$ & Millisec. & $<20^{\circ}$ & -- \\
\hline $\begin{array}{l}\text { C/A Grnd. } \\
\text { Junction } \\
\text { (Quantities } \\
\text { Tested) }\end{array}$ & • & 5 & 5 & 5 & 5 & 5 & NA & NA & NA \\
\hline
\end{tabular}

Reactor Testing

High Temperature Moisture Sealing - Aeroseal Insulation $\quad$ Gas Leakage Type Calibration Corrosion Insulation Resistance Sealant Resistance Calibration Down Sheath Test $\quad \pm \%$ Not EPY 400 Aeroseal $>10 \mathrm{Meg}>10 \mathrm{Meg} 1 \% \quad<10^{-6} \mathrm{ccHe} / \mathrm{sec}$. Values Visible $>140 \mathrm{Meg}>34 \mathrm{Meg}$

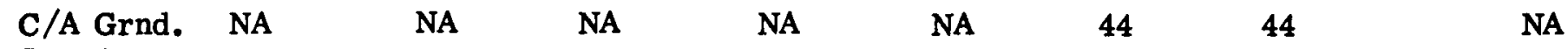
Junction (Quantities Tested) 
Code No: $\quad \mathrm{Tr}-15$

Type: Copper/Constantan-Gnd. Junction Mfgr: Various

Range: $40^{\circ}$ to $1160^{\circ} \mathrm{R}$
WANL Dwg. No.

Spec. Control Dwg. No. 799C539

Evaluation By: WANL

Model No: For Nuclear Use

Application: Material Temperature

PERFORMANCE \& ENVIRONMENTAL SPECIFICATIONS

\begin{tabular}{|c|c|c|c|c|}
\hline Test & Condition & NERVA Requirements & Manufacturer's Specs. & $\begin{array}{l}\text { Summary of } \\
\text { Test Results }\end{array}$ \\
\hline$A$ & Proof Pressure & $600 \mathrm{psig}$ & 2000 psig & $>1000$ psig \\
\hline$B$ & Sheath Material & $\begin{array}{l}\text { radiation and thermal } \\
\text { cumpatible }\end{array}$ & 347 Stainless Steel & suitable \\
\hline C & Accel. Error & info. later & info. later & see vibration \\
\hline$D$ & Vibration Error & $0-300 \mathrm{cps} ; 10 \mathrm{~g}$ 's & $0.300 \mathrm{cps} ; 10 \mathrm{~g}$ 's & $\begin{array}{l}<10 \mu \mathrm{v} \text { at } 10 \mathrm{~g} \\
30-2000 \mathrm{cps}\end{array}$ \\
\hline$E$ & Shock & info. later & info. later & $>10 \mathrm{~g}$ \\
\hline $\mathbf{F}$ & Noise Limit & $\mathrm{NA}$ & not available & NA \\
\hline $\mathbf{G}$ & Neutron Flux & $5.2 \times 10^{15} \mathrm{n} / \mathrm{cm}^{2}-\mathrm{sec}$ & compatible materials & $>3 \times 10^{13} \mathrm{n} / \mathrm{cm}^{2}$ \\
\hline $\mathrm{H}$ & Gamma Flux & $2.6 \times 10^{12} \mathrm{erg} / \mathrm{gm}(\mathrm{c}) / \mathrm{hr}$ & compatible materials & $>1 \times 10^{11} \mathrm{ergs} / \mathrm{g}$ \\
\hline 1 & Sensitivity & 0.010 to $0.035 \mathrm{mv} /{ }^{\circ} \mathrm{R}$ & 0.010 to $0.035 \mathrm{mv} /{ }^{\circ} \mathrm{R}$ & $\begin{array}{l}0.010 \text { to } \\
0.035 \mathrm{mv} /{ }^{\circ} \mathrm{R}\end{array}$ \\
\hline $\mathrm{J}$ & Dimensions & OD $0.062^{\prime \prime}$ & $\begin{array}{l}\text { sheath OD } 0.062^{\prime \prime} \text { to } \\
0.090^{\prime \prime}\end{array}$ & $\begin{array}{l}\mathrm{OD} 0.062^{\prime \prime} \text { to } \\
0.090^{\prime \prime}\end{array}$ \\
\hline$K$ & Weight & info. later & info. later & info. later \\
\hline$L$ & Insulation Res. & $100 \mathrm{Meg}$ 's at $50 \mathrm{~V}$ & 500 Meg's at 500VDC & $\begin{array}{l}>500 \mathrm{Meg}^{\prime} \mathrm{s} \text { at } \\
500 \mathrm{VDC}\end{array}$ \\
\hline$M$ & Material Insulation & $\begin{array}{l}\text { radiation and thermal } \\
\text { compatible }\end{array}$ & $\mathrm{MgO}$, fiberglass & suitable \\
\hline$N$ & Wire Size & $0.011^{\prime \prime}$ & $0.011^{\prime \prime}$ & \\
\hline $\mathrm{O}$ & Junction Type & sheathed $(\mathrm{C} / \mathrm{C})$ & sheathed $(\mathrm{C} / \mathrm{C})$ & sheathed $(\mathrm{C} / \mathrm{C})$ \\
\hline$P$ & Accuracy & $\pm 2^{\circ} \mathrm{R}$ or $\pm 2 \%$ & $\pm 2^{\circ} \mathrm{R}$ or $\pm 2 \%$ & $\pm 2^{\circ} \mathrm{R}$ or $\pm 2 \%$ \\
\hline & & & & \\
\hline & & & & \\
\hline & & & & \\
\hline & & & & \\
\hline & & & & \\
\hline & & & & \\
\hline & & & & \\
\hline & & & & \\
\hline & & & & \\
\hline & & & & \\
\hline
\end{tabular}





\section{DEVELOPMENT HISTORY}

Code No:

$\operatorname{Tr}-15$

Mfgr:

Various

Model No.

P. 0 .

\section{REMARKS:}

This thermocouple was purchased for evaluation testing in conjunction with instrumentation stalk connectors. The transition from sheathed $\mathrm{MgO}$ insulation to fiberglass insulation will allow for easier and more reliable assembly of the connect or than an all sheathed thermocouple.

A discussion of copper/constantan thermocouples in nuclear and cryogenic environments is included in the general evaluation history.

These thermocouples will be radiation tested at GTR in July 1963 under reactor test number 23/W302. The serial no. of the thermocouples to be tested are G63T-1, G63T-2, G63T-3, G63T-4, G63T-5, G63T-33, G63T-34, G63T-35, G63T-36, and G63T-37. 
a

THIS PAGE INTENTIONALLY LEFT BLANK 
Code No: $\operatorname{Tr}-16$

Type: Chromel-P/Alumel-Gnd. Junction

Mfgr: Various

Range: $40^{\circ}$ to $2660^{\circ} \mathrm{R}$

\section{THERMOCOUPLE}

WANL Dwg. No.

Spec. Control Dwg. No. 799C538

Evaluation By: WANL

Model No: For Nuclear Use

Application: Material Temperature

PERFORMANCE \& ENVIRONMENTAL SPECIFICATIONS

\begin{tabular}{|c|c|c|c|c|}
\hline Test & Condition & & Manufacturer's Specs. & $\begin{array}{l}\text { Summary of } \\
\text { Test Results }\end{array}$ \\
\hline$A$ & Proof Pressure & 600 psig & 2000 psig & info. later \\
\hline$B$ & Sheath Material & $\begin{array}{l}\text { radiation and thermal } \\
\text { compatible }\end{array}$ & 347 Stainless Steel & suitable \\
\hline $\mathrm{C}$ & Accel. Error & info. later & info. later & info. later \\
\hline D & Vibration Error & $0-300 \mathrm{cps} ; 10 \mathrm{~g}$ 's & $0-300 \mathrm{cps} ; 10 \mathrm{~g}$ 's & info. later \\
\hline$E$ & Shock & info. later & info. later & info. later \\
\hline $\mathbf{F}$ & Noise Limit & $0.001 \mathrm{mv}$ & not available & $<0.001 \mathrm{mv}$ \\
\hline $\mathbf{G}$ & Neutron Flux & $5.2 \times 10^{15} \mathrm{n} / \mathrm{cm}^{2}-\mathrm{sec}$ & compatible materials & $>3 \times 10^{13} \mathrm{n} / \mathrm{cm}^{2}-\mathrm{sec}$ \\
\hline $\mathrm{H}$ & Gamma Flux & $2.6 \times 10^{12} \mathrm{ergs} / \mathrm{gm}(\mathrm{c}) / \mathrm{l}$ & r compatible materials & $>1 \times 10^{11} \mathrm{ergs} / \mathrm{gm}(\mathrm{c}) \mathrm{hr}$ \\
\hline 1 & Sensitivity & $0.025 \mathrm{mv} /{ }^{\circ} \mathrm{R}$ & $0.025 \mathrm{mv} /{ }^{\circ} \mathrm{R}$ & $0.025 \mathrm{mv} /{ }^{\circ} \mathrm{R}$ \\
\hline $\mathrm{J}$ & Dimensions & OD $0.045^{\prime \prime}$ & $\begin{array}{l}\text { sheath. OD } 0.062 " \text { to } \\
0.090 \% \text {. }\end{array}$ & $\begin{array}{l}\text { OD } 0.062^{\prime \prime} \text { to } \\
0.090^{\circ}\end{array}$ \\
\hline$K$ & Weight & info. later & info. later & info. later \\
\hline$L$ & Insulation Res. & $100 \mathrm{Meg}$ 's at $50 \mathrm{~V}$ & $500 \mathrm{Meg}$ 's at 500VDC & $\begin{array}{l}300 \mathrm{Meg} \text { 's at } \\
500 \mathrm{VDC}\end{array}$ \\
\hline$M$ & Material Insulation & $\begin{array}{l}\text { radiation and thermal } \\
\text { compatible }\end{array}$ & MgO, fiberglass< & suitable \\
\hline $\mathrm{N}$ & Wire Size & $0.011^{\prime \prime}$ & $0.011^{\prime \prime}$ & \\
\hline $\mathrm{O}$ & Junction Type & sheathed (C/A) & sheathed $(\mathrm{C} / \mathrm{A})$ & sheathed $(\mathrm{C} / \mathrm{A})$ \\
\hline $\mathrm{P}$ & Accuracy & $\begin{array}{l}E^{\circ} \mathrm{R} 460^{\circ}-1000^{\circ} \mathrm{R} \\
\pm 0.375 \% 1000-2660^{\circ} \mathrm{R}\end{array}$ & $\begin{array}{l} \pm 2^{\circ} \mathrm{R} 460-100^{\circ} \mathrm{R} \\
\pm 0.375 \% 1000-2660^{\circ} \mathrm{R}\end{array}$ & $\begin{array}{l} \pm 2^{\circ} \mathrm{R} 460-1000^{\circ} \mathrm{R} \\
\pm 0.375 \% 1000-2660^{\circ} \mathrm{R}\end{array}$ \\
\hline & & & & \\
\hline & & & & \\
\hline & & & & \\
\hline & & & & \\
\hline & & & & \\
\hline & & & & \\
\hline & & & & \\
\hline & & & & \\
\hline & & & & \\
\hline
\end{tabular}




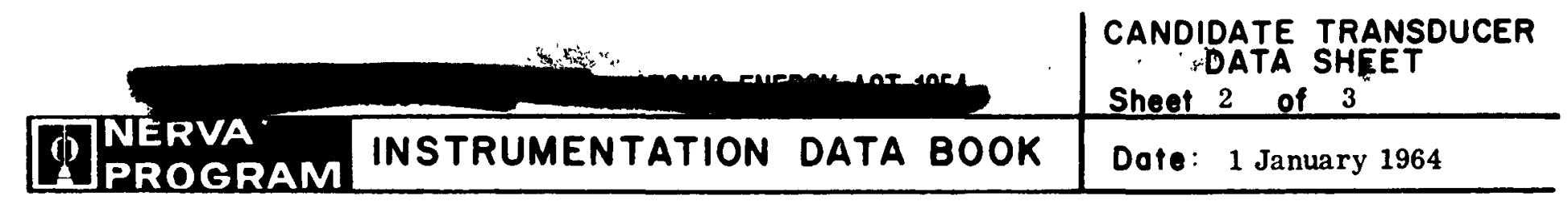

RADIATION TESTS

Code No. $\mathrm{Tr}-16$

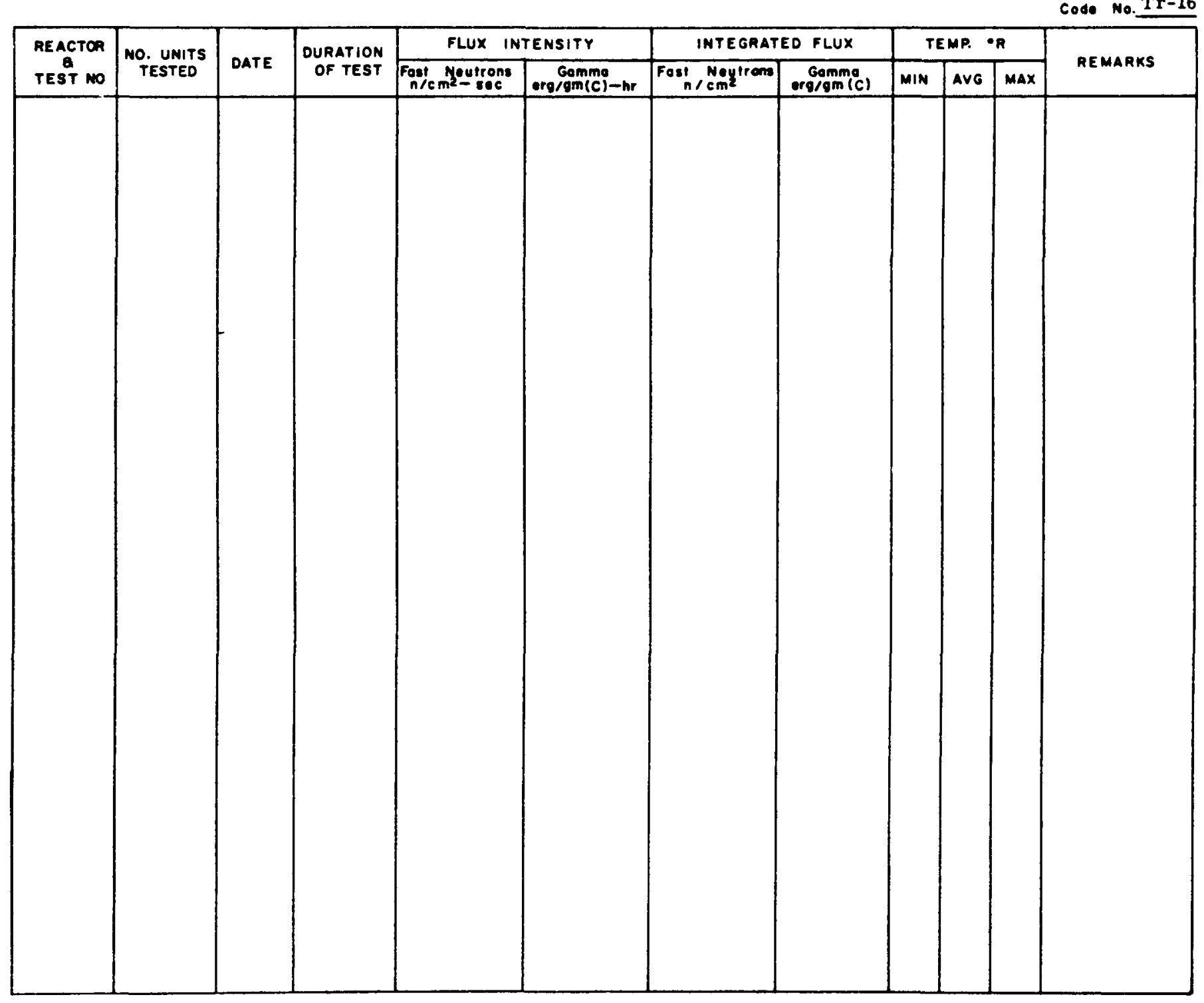

(w) 


\section{DEVELOPMENT HISTORY}

Code No:

$\operatorname{Tr}-16$

Model No.

REMARKS:

Mfgr: Various

P. 0 .

This thermocouple was purchased for evaluation testing in conjunction with instrumentation stalk connectors. The transition from sheathed $\mathrm{MgO}$ insulation to fiberglass insulation will allow for easier and more reliable assembly of the connector than an all sheathed thermocouple.

A discussion of chromel-P/alumel thermocouples in nuclear and cryogenic environments is included in the general evaluation history.

These thermocouples will be radiated at GTR in July 1963 under reactor test number 23/W302. The serial numbers of the thermocouples to be tested are G63T-9, G63T-10, G63T-11, G63T-12, G63T-13, G63T-41, G63T-42, G63T-43, G63T-44, and G63T-45. 
THIS PAGE INTENTIONALLY LEFT BLANK 


\section{THERMOCOUPLE}

Code No:

Type: High Temp. W/W26/ Re

Mfgr: Tuttle \& Kift

Range: 2,500 to $5,000^{\circ} \mathrm{R}$
Spec. Control Dwg. No.386D666H02

Evaluation By: WANL

Model No: Experimental

Application:

PERFORMANCE \& ENVIRONMENTAL SPECIFICATIONS

\begin{tabular}{|c|c|c|c|c|}
\hline Test & Condition & NERVA Requirements & Manufacturer's Specs. & $\begin{array}{l}\text { Summary of } \\
\text { Test Results }\end{array}$ \\
\hline A & Proof Pressure & $800 \mathrm{psi}$ & & $>1000 \mathrm{psi}$ \\
\hline B & Sheath Material & & \multicolumn{2}{|c|}{$\begin{array}{l}\text { Molybdenum covered with vapor- } \\
\text { deposited tungsten } S, S \text {, tubing } \\
\end{array}$} \\
\hline $\mathbf{C}$ & Accel. Error & & & see vibration \\
\hline D & Vibration Error & & & $\begin{array}{l}<10 \mu \mathrm{v} \text { at } 10 \mathrm{~g} \\
30 \text { to } 2000 \text { cycles }\end{array}$ \\
\hline $\mathbf{E}$ & Shock & & & $>10 \mathrm{~g}$ \\
\hline $\mathbf{F}$ & Noise Limit & & & \\
\hline $\mathbf{G}$ & Neutron Flux & & & \\
\hline $\mathrm{H}$ & Gamma Flux & & & \\
\hline 1 & Sensitivity & & $8.7 \mu \mathrm{v} /{ }^{\circ} \mathrm{F}$ at $4000^{\circ} \mathrm{F}$ & $8.7 \mu \mathrm{v} /{ }^{\circ} \mathrm{F}$ at 4000 \\
\hline $\mathrm{J}$ & Dimensions & & $\begin{array}{l}0.090 \text { dia } \times 24 " 1 \text { mo } \\
0.062 \text { dia } \times 122^{\prime \prime}\end{array}$ & \\
\hline K & Weight & & & \\
\hline$L$ & Insulation Res. & & $>500 \mathrm{meg}$ & $>500 \mathrm{meg}$ \\
\hline$M$ & Material & & $\mathrm{BeO}$ & \\
\hline $\mathrm{N}$ & Wire Size & \multicolumn{3}{|c|}{$\mathrm{T} / \mathrm{C}$ wire $0.010^{\prime \prime} \pm 0.001 " \mathrm{~T} / \mathrm{C}$ wire $0.010^{\prime \prime} \pm 0.001 "$} \\
\hline & & & & \\
\hline & & & & \\
\hline & & & & \\
\hline & & & & \\
\hline & & & & \\
\hline & & & & \\
\hline & & & & \\
\hline & & & & \\
\hline & & & & \\
\hline & & & & \\
\hline & & & & \\
\hline
\end{tabular}




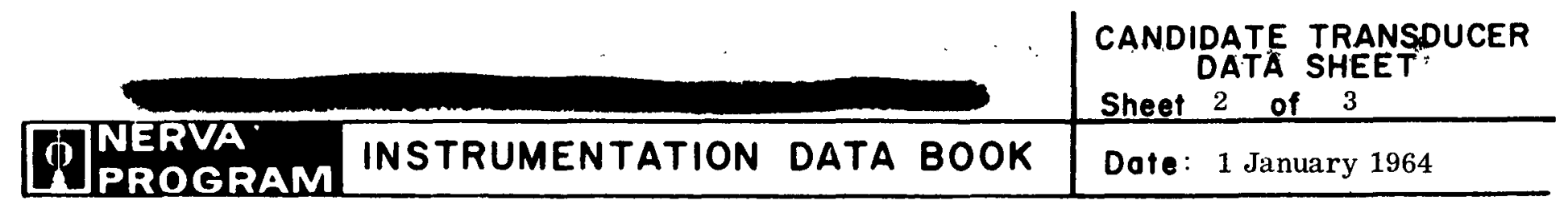

RADIATION TESTS

Code No.Tr-25

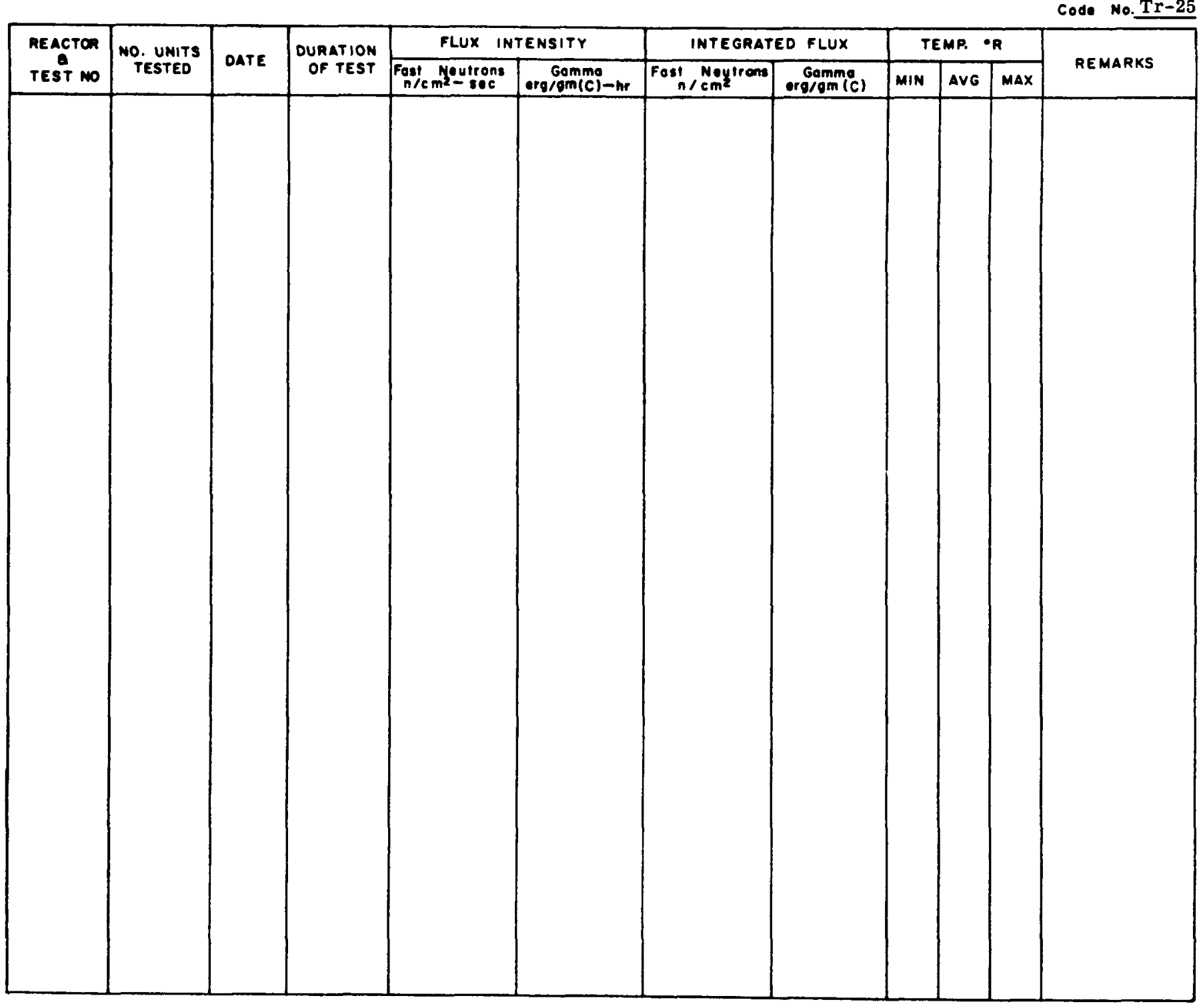

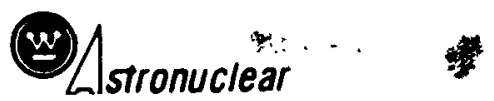




\begin{tabular}{|l|l|l}
\hline NERVA & $\begin{array}{l}\text { CANDIDATE TRANSDUCER } \\
\text { DATA SHEET } \\
\text { Sheet } 3 \text { of } 3\end{array}$ \\
\hline PROGRAM INSTRUMENTATION DATA BOOK & Dote: 1 January 1964 \\
\hline
\end{tabular}

\section{DEVELOPMENT HISTORY}

Code No: $\quad \operatorname{Tr}-25$

Mfgr: Tuttle \& Kift

Model No. Experimental

P. 0 .

39268

\section{REMARKS:}

No testing has been done on this thermocouple to date. Units have been ordered and are planned for laboratory tests at WANL during October, 1963.

The data listed in the Summary of Test Results column of sheet 1 of 2 is based on tests conducted on physically similar thermocouples at WANL. Confirmation of this data will be established upon receipt of this unit at WANL. 
$\therefore 4$

THIS PAGE INTENTIONALLY LEFT BLANK 
Sheet 1 of 3

Date: 1 January 1964

\section{THERMOCOUPLE}

Code No: $\operatorname{Tr}-26$

Type: High Temp. W vs. W-26\% Re

Mfgr: Tuttle \& Kift

Range:

2,500 to $5,000^{\circ} R$
Spec. Control Dwg. No. 386D666H05

Evaluation By: WANL

Model No: Experimental

Application:

PERFORMANCE \& ENVIRONMENTAL SPECIFICATIONS

\begin{tabular}{|c|c|c|c|c|}
\hline Test & Condition & NERVA Requirements & Manufacturer's Specs. & $\begin{array}{l}\text { Summary of } \\
\text { Test Results }\end{array}$ \\
\hline A & Proof Pressure & & & $>1000 \mathrm{psi}$ \\
\hline B & Sheath Material & & Tantalum $\mathrm{s} / \mathrm{s}$ tubing & \\
\hline C & Accel. Error & & & see vibration \\
\hline D & Vibration Error & & & $\begin{array}{l}\langle 10 \mu \mathrm{v} \text { at } 10 \mathrm{~g} \\
30 \text { to } 2000 \mathrm{cps}\end{array}$ \\
\hline $\mathbf{E}$ & Shock & & & $>10 \mathrm{~g}$ \\
\hline$F$ & Noise Limit & & & \\
\hline G & Neutron Flux & & & \\
\hline $\mathrm{H}$ & Gamma Flux & & & \\
\hline 1 & Sensitivity & & $8.7 \mu \mathrm{v} /{ }^{\circ} \mathrm{F}$ at $4000^{\circ} \mathrm{F}$ & $\begin{array}{l}8.7 \mu \mathrm{V} /{ }^{\circ} \mathrm{F} \text { at } \\
4000^{\circ} \mathrm{F}\end{array}$ \\
\hline$J$ & Dimensions & & $\begin{array}{l}0.090 \pm 0.001 \text { dia } \times 24 \\
0.062 \pm 0.003-0.000 \mathrm{dia}\end{array}$ & $12 " \mathrm{~s} / \mathrm{s}$ \\
\hline$K$ & Weight & & & \\
\hline$L$ & Insulation Res. & & $>500 \mathrm{Meg}$ & $>500 \mathrm{Meg}$ \\
\hline$M$ & Material & & $\mathrm{BeO}$ & \\
\hline$N$ & Wire Size & $0.010^{\prime \prime} \pm 0.001 "$ & $0.010^{\prime \prime} \pm 0.001 "$ & \\
\hline & & & & \\
\hline & & & & \\
\hline & & & & \\
\hline & & & & \\
\hline & & & & \\
\hline & & & & \\
\hline & & & & \\
\hline & & & & \\
\hline & & & & \\
\hline & & & & \\
\hline & & & & \\
\hline & & & & \\
\hline
\end{tabular}




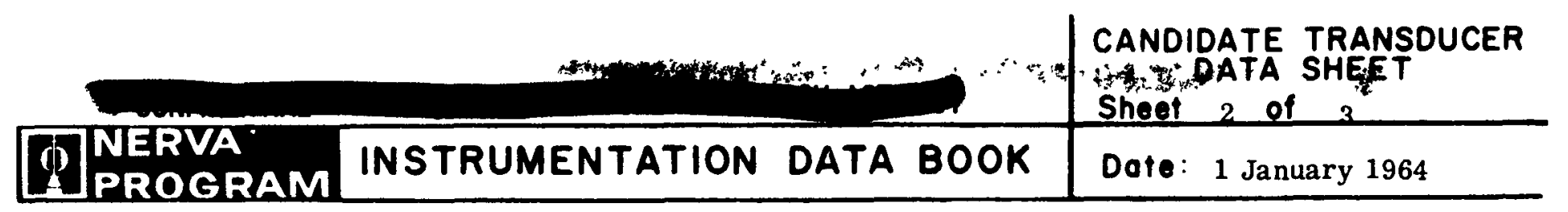

RADIATION TESTS

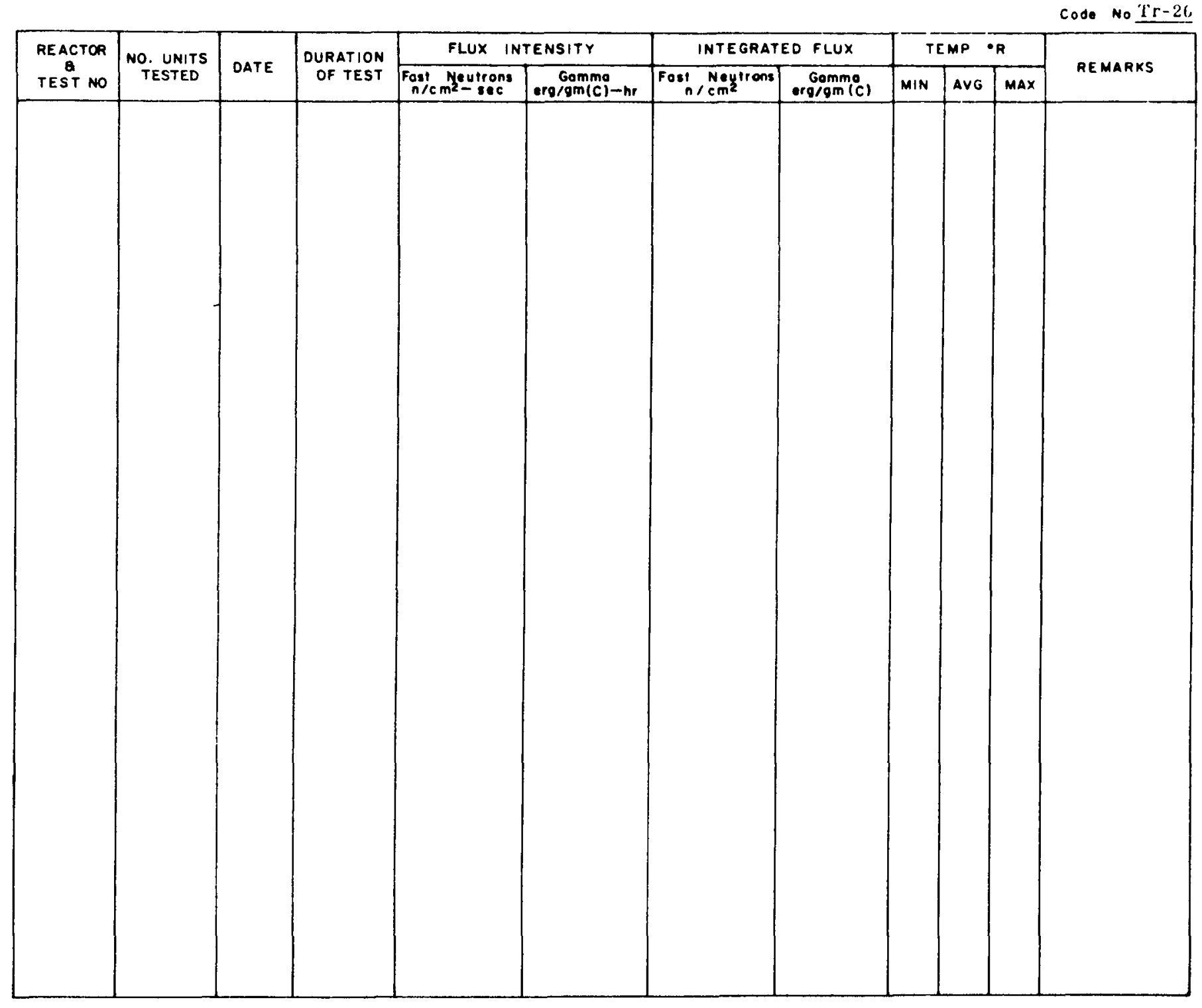




\begin{tabular}{|l|l|l}
\hline MERVA & \multicolumn{2}{|c}{$\begin{array}{l}\text { CANDIDATE TRANSDUCER } \\
\text { DATA SHEET } \\
\text { SROGRAM INSTRUMENTATION DATA BOOK }\end{array}$} \\
Sheef 3 of 3
\end{tabular}

\section{DEVELOPMENT HISTORY}

Code No: $\operatorname{Tr}-26$

Mfgr: Tuttle \& Kift

Model No. Experimental

P. 0 .

39268

\section{REMARKS:}

No testing has been done on this thermocouple to date. Units have been ordered and are planned for laboratory tests at WANL during October, 1963.

The data listed in the Summary of Test Results column of sheet 1 or 2 is based on tests conducted on physically similar thermocouples at WANL. Confirmation of this data will be established upon receipt of this unit at WANL. 


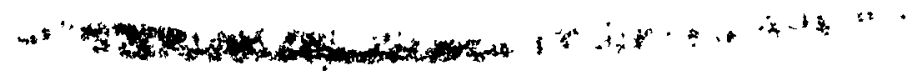

THIS PAGE INTENTIONALLY LEFT BLANK 


\section{THERMOCOUPLE}

Code No: $\quad \operatorname{Tr}-27$

Type: High Temp W vs. W-26\% Re

Mfgr: Tuttle \& Kift

Range: 2,500 to $5000^{\circ} \mathrm{R}$
Spec. Control Dwg. No. 386D666H04

Evaluation By: WANL

Model No: Experimental

Application:

PERFORMANCE \& ENVIRONMENTAL SPECIFICATIONS

\begin{tabular}{|c|c|c|c|c|}
\hline Test & Condition & NERVA Requirements & Manufacturer's Specs. & $\begin{array}{l}\text { Summary of } \\
\text { Test Results }\end{array}$ \\
\hline$A$ & Proof Pressure & & & $>1000 \mathrm{psi}$ \\
\hline B & Sheath Material & & $\begin{array}{l}\text { tantalum covered with } \\
\text { vapor deposited tungsten }\end{array}$ & $s / s$ \\
\hline C & Accel. Error & & & see vibration \\
\hline$D$ & Vibration Error & & & $\begin{array}{l}<10 \mu \mathrm{v} \text { at } 10 \mathrm{~g} \\
30-2000 \mathrm{cos}\end{array}$ \\
\hline $\mathbf{E}$ & Shock & & & $>10 \mathrm{~g}$ \\
\hline $\mathbf{F}$ & Noise Limit & & & \\
\hline $\mathbf{G}$ & Neutron Flux & & & \\
\hline $\mathrm{H}$ & Gamma Flux & & & \\
\hline I & Sensitivity & & $8.7 \mu \mathrm{v} /{ }^{\circ} \mathrm{F}$ at $4000^{\circ} \mathrm{F}$ & $8.7 \mu \mathrm{v} /{ }^{\circ} \mathrm{F}$ at 400 \\
\hline $\mathrm{J}$ & Dimensions & & $\begin{array}{l}0.090^{\prime \prime} \pm 0.001 \mathrm{dia} \times 24^{\prime \prime} \\
0.062^{\prime \prime}+0.003-0.000^{\prime \prime}\end{array}$ & Ta $\times 12 " \mathrm{~s} / \mathrm{s}$ \\
\hline $\mathrm{K}$ & Weight & & & \\
\hline$L$ & Insulation Res. & & $>500 \mathrm{Meg}$ & $>500 \mathrm{Meg}$ \\
\hline$M$ & Material & & $\mathrm{BeO}$ & \\
\hline $\mathrm{N}$ & Wire Size & $0.010^{\prime \prime} \pm 0.001 "$ & $0.010^{\prime \prime} \pm 0.001 "$ & \\
\hline & & & & \\
\hline & & & & \\
\hline & & & & \\
\hline & & & & \\
\hline & & & & \\
\hline & & & & \\
\hline & & & & \\
\hline & & & & \\
\hline & & & & \\
\hline & & & & \\
\hline & & & & \\
\hline
\end{tabular}





\begin{tabular}{|l|l|l}
\hline Q & $\begin{array}{l}\text { CANDIDATE TRANSDUCER } \\
\text { DATA SHEET }\end{array}$ \\
PROGRAM INSTRUMENTATION DATA BOOK & Dofe: 1 January 1964 \\
\hline
\end{tabular}

\section{DEVELOPMENT HISTORY}

Code No:

$\operatorname{Tr}-27$

Model No.

Experimental
Mfgr: Tuttle \& Kift

P. 0.

\section{REMARKS:}

No testing has been done on this thermocouple to date. Units have been ordered and are planned for laboratory tests at WANL during October, 1963.

The data listed in the Summary of Test Results column of sheet 1 of 2 is based on tests conducted on physically similar thermocouples at WANL. Confirmation of this data will be established upon receipt of this unit at WANL. 
2 and

THIS PAGE INTENTIONALLY LEFT BLANK 
Sheet 1 of 3

\section{THERMOCOUPLE}

Code No:

$\mathrm{Tr}-28$

Type: High Temp. W-5\% Re/W-26\% Re

Mfgr: Tuttle \& Kift

Range: 2,500 to $5,000^{\circ} \mathrm{R}$
Spec. Control Dwg. No. 386D666H03

Evaluation By: WANL

Model No: Experimental

Application:

PERFORMANCE \& ENVIRONMENTAL SPECIFICATIONS

\begin{tabular}{|c|c|c|c|c|}
\hline Test & Condition & NERVA Requirements & Manufacturer's Specs. & $\begin{array}{l}\text { Summary of } \\
\text { Test Results }\end{array}$ \\
\hline$A$ & Proof Pressure & & & $>1000 \mathrm{psi}$ \\
\hline$B$ & Sheath Material & & $\begin{array}{l}\text { tantalum covered with } \\
\text { yapor deposited tungsten }\end{array}$ & $\mathrm{s} / \mathrm{s}$ \\
\hline C & Accel. Error & & & see vibration \\
\hline$D$ & Vibration Error & & & $\begin{array}{l}<10 \mu \mathrm{v} \text { at } 10 \mathrm{~g} \\
30-2000 \mathrm{cns}\end{array}$ \\
\hline$E$ & Shock & & & $>10 \mathrm{~g}$ \\
\hline$F$ & Noise Limit & & & \\
\hline G & Neutron Flux & & & \\
\hline $\mathrm{H}$ & Gamma Flux & & & \\
\hline 1 & Sensitivity & & $5.6 \mu \mathrm{v} /{ }^{\circ} \mathrm{F}$ at $4000^{\circ} \mathrm{F}$ & $5.6 \mu \mathrm{v} /{ }^{\circ} \mathrm{F}$ at 400 \\
\hline$J$ & Dimensions & & $\begin{array}{l}8.092^{\prime \prime} \pm 0.081 " \text { dia } \times 24 \\
0.062 " \\
\end{array}$ & dia $\mathrm{Mo} 12^{\prime \prime} \mathrm{s} / \mathrm{s}$ \\
\hline$K$ & Weight & & & \\
\hline$L$ & Insulation Res. & & $>500 \mathrm{Meg}$ & $>500 \mathrm{Meg}$ \\
\hline M & Material & & $\mathrm{BeO}$ & \\
\hline $\mathrm{N}$ & Wire Size & $0.010 " \pm 0.001 "$ & $0.010 " \pm 0.001 "$ & \\
\hline & & & & \\
\hline & & & & \\
\hline & & & & \\
\hline & & & & \\
\hline & & & & \\
\hline & & & & \\
\hline & & & & \\
\hline & & & & \\
\hline & & & & \\
\hline & & & & \\
\hline 1 & 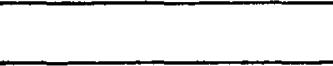 & & & \\
\hline
\end{tabular}





\section{DEVELOPMENT HISTORY}

Code No: $\operatorname{Tr}-28$

Mfgr: Tuttle \& Kift

Model No. Experimental

P. 0.39268

\section{REMARKS:}

No testing has been done on this thermocouple to date. Units have been ordered and are planned for laboratory tests at WANL during October, 1963.

The data listed in the Summary of Test Results column of sheet 1 of 2 is based on tests conducted on physically similar thermocouples at WANL. Confirmation of this data will be established upon receipt of this unit at WANL. 


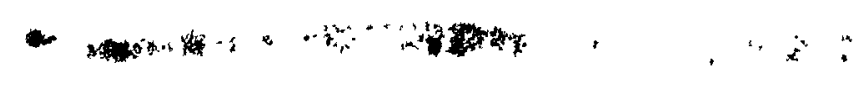

THIS PAGE INTENTIONALLY LEFT BLANK 


\section{THERMOCOUPLE}

Code No: $\quad \operatorname{Tr}-30$

Type: High Temp. W/W-26\% Re

Mfgr: Tuttle \& Kift

Range: $2500-5000^{\circ} \mathrm{R}$
Spec. Control Dwg. No. 386D666H01

Evaluation By: WANL

Model No: Experimental

Application:

PERFORMANCE \& ENVIRONMENTAL SPECIFICATIONS

\begin{tabular}{|c|c|c|c|c|}
\hline Test & Condition & NERVA Requirements & Manufacturer's Specs. & $\begin{array}{l}\text { Summary of } \\
\text { Test Results }\end{array}$ \\
\hline A & Proof Pressure & & & $>1000 \mathrm{psi}$ \\
\hline$B$ & Sheath Material & & molybdenum, $\mathrm{S} / \mathrm{s}$ & \\
\hline C & Accel. Error & & & see vibration \\
\hline$D$ & Vibration Error & & & $\begin{array}{l}1 \text { t pvat } 10 \mathrm{~g} \\
30 \text { to } 2000 \mathrm{cps}\end{array}$ \\
\hline E & Shock & & & $>10 \mathrm{~g}$ \\
\hline $\mathbf{F}$ & Noise Limit & & & \\
\hline G & Neutron Flux & & & \\
\hline $\mathrm{H}$ & Gamma Flux & & & \\
\hline$I$ & Sensitivity & & $8.7 \mu \mathrm{V} /{ }^{\circ} \mathrm{F}$ at $4000^{\circ} \mathrm{F}$ & $\begin{array}{l}8.7{ }_{4}^{\mu \mathrm{V}} /{ }^{\circ} \mathrm{F} \text { at } \\
4000^{\circ} \mathrm{F}\end{array}$ \\
\hline $\mathrm{J}$ & Dimensions & & $\begin{array}{l}0.090 " \pm 0.001 " \text { dia } \times 2 \\
0.062 " \pm 0.003^{\prime \prime}-0.000\end{array}$ & dia $\times 12 " \mathrm{~s} / \mathrm{s}$ \\
\hline $\mathrm{K}$ & Weight & & & \\
\hline$L$ & Insulation Res. & & $>500 \mathrm{Meg}$ & $>500 \mathrm{Meg}$ \\
\hline M & Material & & $\mathrm{BeO}$ & \\
\hline$N$ & Wire Size & $0.010^{\prime \prime} \pm 0.001 "$ & $0.010^{\prime \prime} \pm 0.001 "$ & \\
\hline & & & & \\
\hline & & & & \\
\hline & & & & \\
\hline & & & & \\
\hline & & & & \\
\hline & & & & \\
\hline & & & & \\
\hline & & & & \\
\hline & & & & \\
\hline & & & & \\
\hline & & & & \\
\hline & & & & \\
\hline
\end{tabular}





\section{DEVELOPMENT HISTORY}

Code No: $\quad \operatorname{Tr}-30$

Mfgr:

Tuttle \& Kift

Model No. Experimental

P. 0 .

39268

\section{REMARKS:}

No testing has been done on this thermocouple to date. Units have been ordered and are planned for laboratory tests at WANL during October, 1963.

The data listed in the Summary of Test Results column of sheet 1 of 2 is based on tests conducted on physically similar thermocouples at WANL. Confirmation of this data will be established upon receipt of this unit at WANL. 


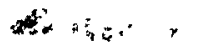

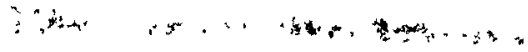

THIS PAGE INTENTIONALLY LEFT BLANK 


\section{RESISTANCE THERMOMETER}

Code No:

$\mathrm{R} \operatorname{Tr}-1$

Type :

Mfgr:

Range:

Probe

Englehard

$30^{\circ} \mathrm{R}$ to $1482^{\circ} \mathrm{R}$
Planning Parts List No.

Evaluation By:

WANL

Model No: $30707-5 \mathrm{~A}$

Element Material:

Platinum

PERFORMANCE \& ENVIRONMENTAL SPECIFICATIONS

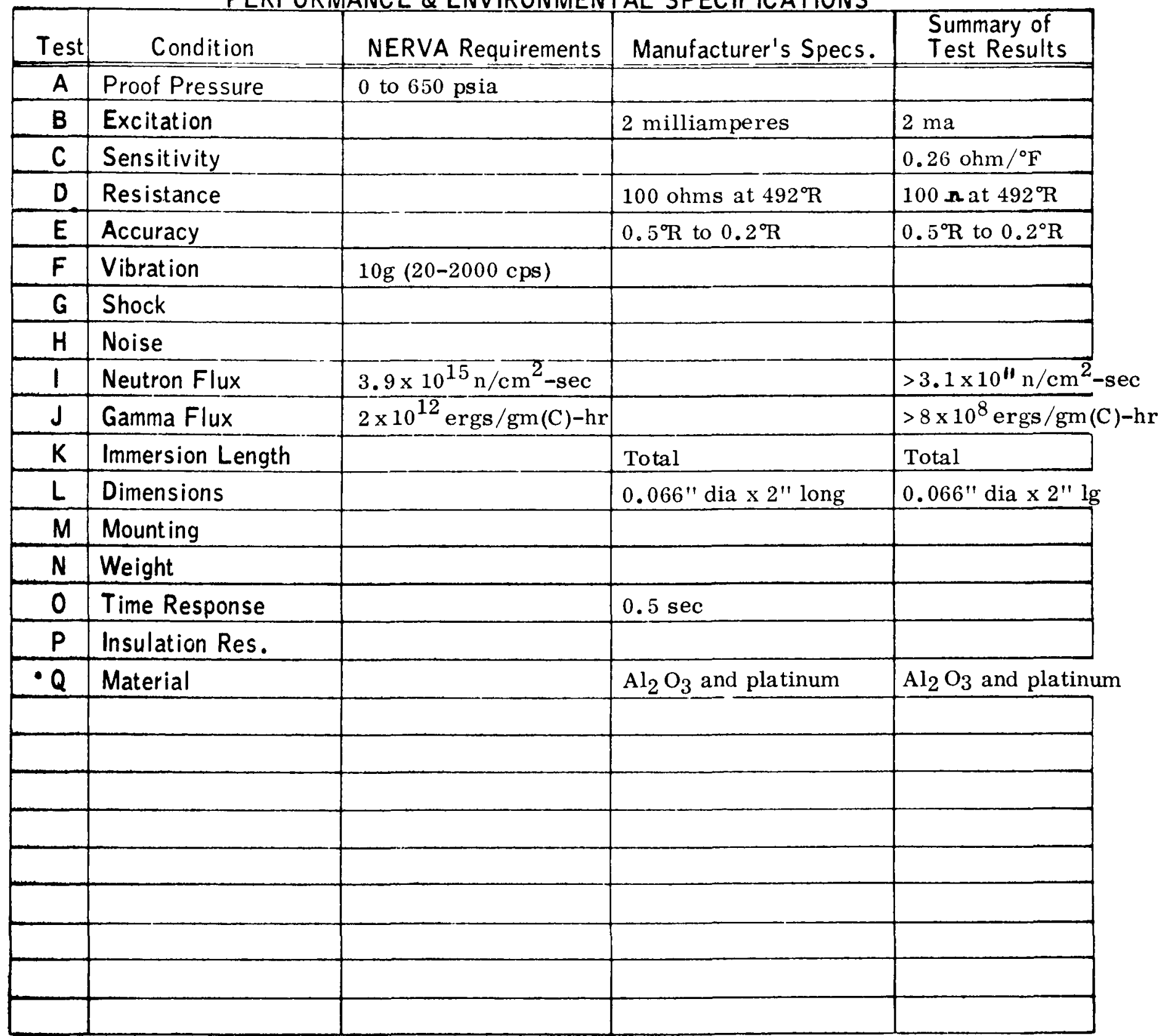




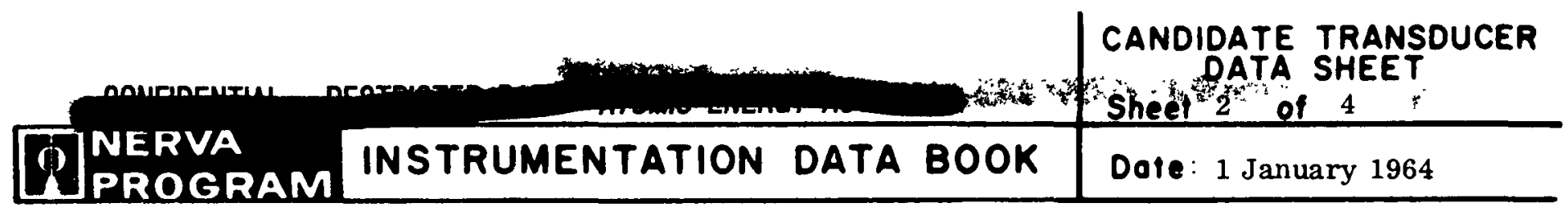

RADIATION TESTS

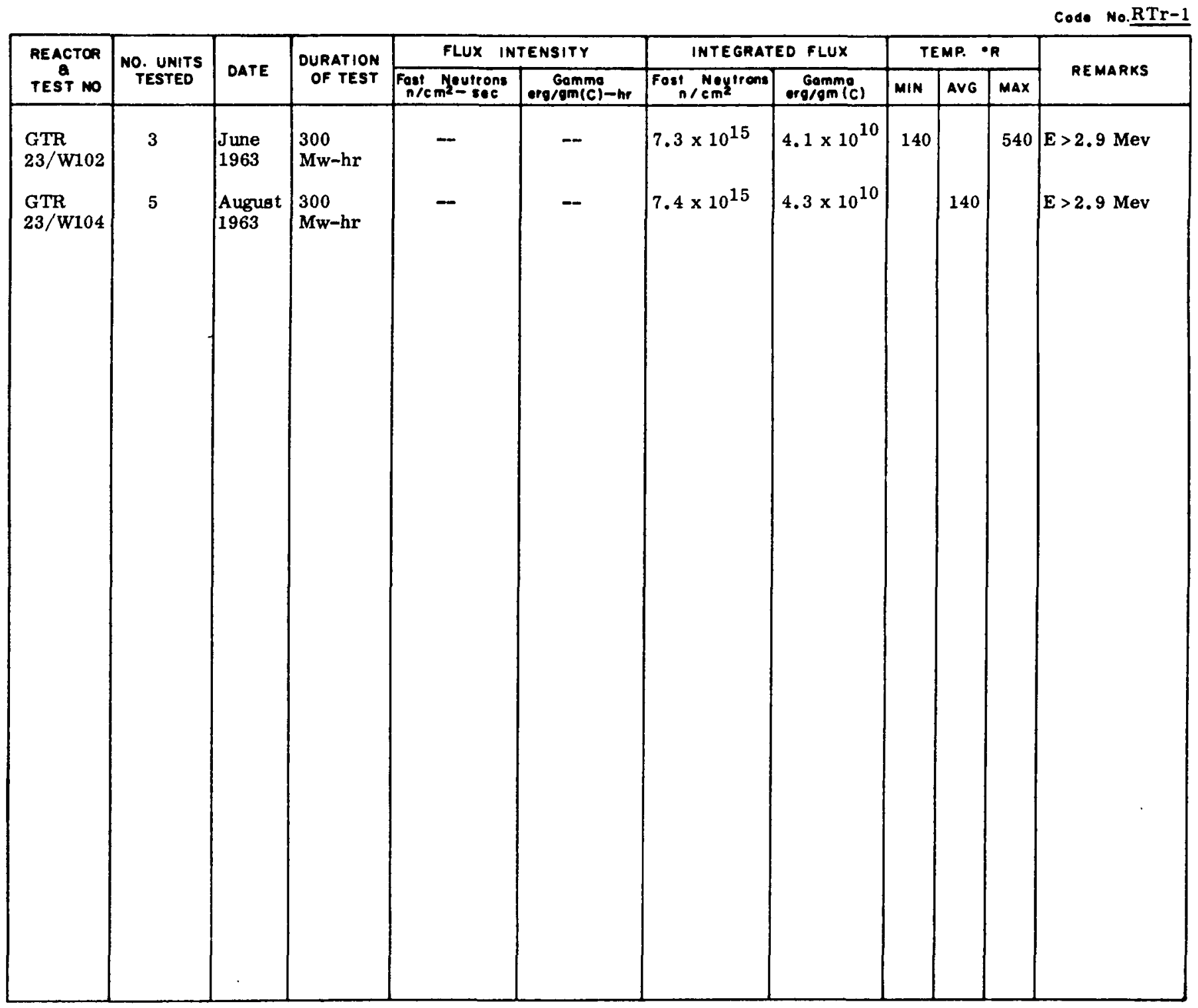




\section{DEVELOPMENT HISTORY}

Code No:

$\mathrm{RTr}-1$

Model No. 30707-5A

Mfgr: Engelhard

P. 0 .

\section{REMARKS:}

$\underline{15}$ December 1963 GTR Test No. 23/W102, June, 1963

\section{Test Plan}

Three Engelhard No. 30707-5A (platinum) resistance thermometers (RTD) were mounted on a test fixture and irradiated in the east $\mathrm{LN}_{2}$ Dewar. The RTD's were installed near the bottom of a tube projecting downward from the top part of the fixture. Two $\mathrm{C} / \mathrm{C}$ thermocouples were attached (with fiber glass tape) to the tube in which the RTD's were installed.

Voltages were measured with an NLS digital voltmeter and the resistance of each RTD was calculated from the following relation:

$$
R_{R T D}=\frac{E_{j 2}}{E_{j 1}} R_{j 1} ; \text { where } j=1,2,3,4,5
$$

Leakage resistances to the test fixture were measured with a Tera ohmmeter.

\section{Test Results}

Plots of the resistance of each of the RTD's as a function of dose were obtained. Environmental temperatures recorded during the test are also ahown on the plots. Leakage resistances vs dose were also obtained.

The resistance of each of the RTD's, as measured from the connections in the terminal box during postirradiation examinations, was $109 \mathrm{ohms.} \mathrm{Apparently,} \mathrm{the} \mathrm{RTD's} \mathrm{were} \mathrm{not}$ affected by the test.

The detonations in the Dewar made it impossible to compare the performance of two types of resistance thermometers. The positions in which the Winsco units $(\mathrm{RTr}-2)$ were mounted made them more susceptible to physical damage than these units.

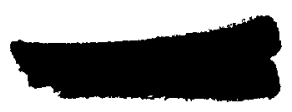




\title{
DEVELOPMENT HISTORY
}

Code No: $\frac{\mathrm{RTr}-1}{30707-5 \mathrm{~A}}$

\author{
Mfgr: \\ Engelhard
}

\section{REMARKS:}

GTR Test No. 23/W104

\section{Test Plan}

Five Engelhard 30707-5A resistance thermometers (RTD's) were mounted in a cylindrical tube and irradiated in the east $\mathrm{LN}_{2}$ Dewar.

The temperatures inside the tube were monitored by means of three copper-constantan thermocouples. Voltages were measured with an NLS digital voltmeter and the resistance of each RTD was calculated from the following relation:

$$
R_{R T D}=\frac{E_{x}}{E_{1}} \times 100
$$

The leakage resistance between the sensing resistance wire and its protective sheath on the test fixture was measured with a Tera ohmmeter for each of the RTD's.

\section{Test Results}

Samples of RTD test data are presented in Table 4.1 of GD/FW test report \#GTR 7-A. It can be seen from the calculated resistances in the table that the performance of the RTD's was very good. All of the postirradiation resistances were within $1 \%$ of preirradiation values. The decrease in insulation resistance during the irradiation was probably due to ionization in the test leads. Slightly over an hour after the reactor was shut down, the insulation resistance for the five RTD's ranged from 390 to 480 megohms. 


\section{RESISTANCE THERMOMETER}

Code No: RTr-2

Type: $\quad$ Surface Temp.

Mfgr: Winsco Instruments and Controls

Range:

$25^{\circ} \mathrm{R}$ to $740^{\circ} \mathrm{R}$
Planning Parts List No:

Evaluation By: WANL

Model No: 2534 (2518 modified)

Element Material: Platinum

\begin{tabular}{|c|c|c|c|c|}
\hline Test & Condition & NERVA Requirements & Manufacturer's Specs. & $\begin{array}{l}\text { Summary of } \\
\text { Test Results }\end{array}$ \\
\hline A & Proof Pressure & 0 to $650 \mathrm{psia}$ & & \\
\hline $\mathrm{B}$ & Excitation & $5 \mathrm{ma}$ & $5 \mathrm{ma}$ & \\
\hline $\mathrm{C}$ & Sensitivity & $1.3 \mathrm{ohm} /{ }^{\circ} \mathrm{R}$ & $1.3 \mathrm{ohm} /{ }^{\circ} \mathrm{R}$ & \\
\hline D. & Resistance & 600 ohms at $740^{\circ} \mathrm{R}$ & 600 ohms $\left(740^{\circ} \mathrm{R}\right)$ & \\
\hline$E$ & Accuracy & & & \\
\hline $\mathbf{F}$ & Vibration & $10 \mathrm{~g}(20-2000 \mathrm{cps})$ & & \\
\hline G & Shock & $50 \mathrm{~g}, 11 \mathrm{msec}$ & $100 \mathrm{~g}(100-700 \mathrm{cps})$ & \\
\hline$H$ & Noise & $150 \mathrm{db}$ & & \\
\hline 1 & Neutron Flux & $3.9 \times 10^{15} \mathrm{n} / \mathrm{cm}^{2}-\mathrm{sec}$ & & \\
\hline $\mathrm{J}$ & Gamma Flux & \multicolumn{2}{|l|}{$2 \times 10^{12} \mathrm{ergs} / \mathrm{gm}(\mathrm{C})-\mathrm{hr}$} & \\
\hline $\mathrm{K}$ & Immersion Length & Total & & \\
\hline$L$ & Dimensions & $3 / 4^{\prime \prime} \times 3 / 4^{\prime \prime} \times 1 / 16^{\prime \prime}$ & $3 / 4^{\prime \prime} \times 3 / 4^{\prime \prime} \times 1 / 16^{\prime \prime}$ & \\
\hline M & Mounting & Bolt on & Bolt on & \\
\hline $\mathrm{N}$ & Weight & Mfgr. to specify & & \\
\hline 0 & Time Response & & 0.7 second & \\
\hline$P$ & Insulation Res. & \multicolumn{2}{|c|}{$>10$ megohms at $50 \mathrm{VDC} 20$ megohms at $50 \mathrm{VDC}$} & \\
\hline Q & Material & Platinum & Platinum & \\
\hline & & & & \\
\hline & & & & \\
\hline & & & & \\
\hline & & & & \\
\hline & & & & \\
\hline & & & & \\
\hline & & & & \\
\hline & & & & \\
\hline
\end{tabular}





\section{DEVELOPMENT HISTORY}

Code No: $\mathrm{RTr}-2$

Model No. 2534 (Modified 2518)
Mfgr: Winsco 32301

\section{REMARKS:}

15 December 1963 GTR Test No. 23/W402, June, 1963

\section{Test Plan}

Two Winsco No. 2534 (platinum) resistance thermometers (RTD) were mounted on a test fixture and irradiated in the east $\mathrm{LN}_{2}$ Dewar. The Winsco RTD's were attached to the outside of the cylindrical pan at the bottom of the fixture $180^{\circ}$ apart. A copper-constantan thermocouple was attached (with fiber glass tape) at the sensing element of each of the Winsco RTD's.

Voltages were measured with an NLS digital voltmeter and the resistance of each RTD was calculated from the following relation:

$$
R_{R T D}=\frac{E_{j 2}}{E_{j 1}} \quad R_{j 1} ; \text { where } j=1,2,3,4,5
$$

Leakage resistances to the test fixture were measured with a Tera ohmmeter.

\section{Test Results}

Plots of the resistance of each of the RTD's as a function of dose were obtained. Environmental temperatures recorded during the test are also shown on the plots. Leakage resistances vs dose were obtained also.

The RTD's failed during the test. Failure of Winsco 1 is attributed to an open circuit that developed immediately after the detonations. Winsco 2 began to show extremely high resistance readings at an integrated flux of $4.0 \times 10^{13} \mathrm{n} / \mathrm{cm}^{2}$. Postirradiation investigation showed that Winsco 1 was broken at the point where it was mounted to the test fixture. The resistance of Winsco 2 measured at the terminal box on the test fixture was 560 ohms; however, very slight pressure at the point where the RTD was attached to the mount produced an intermittent open. Winsco 2 could have been damaged during the detonations. Both of the thermocouples that had been attached to the Winsco RTD's were loose and dangling when the Dewar was opened. 


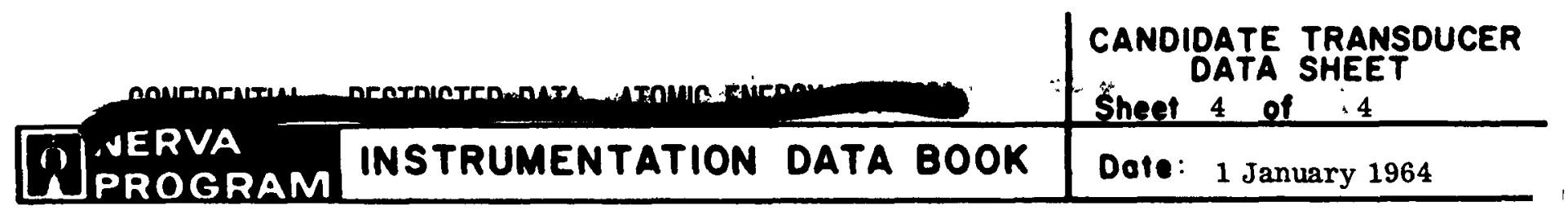

\section{DEVELOPMENT HISTORY}

Code No:

RTr-2

Mfgr:

Winsco

Model No. 2534 (Modified 2518)

P. 0 .

32301

\section{REMARKS:}

The detonations in the Dewar made it impossible to compare the performance of two types of resistance thermometers. The positions in which the Winsco units were mounted made them more susceptible to physical damage than the Engelhard units $(\mathrm{RTr}-1)$. It is not known whether the Winsco units would have performed satisfactorily had there been no detonations in the Dewar.

No further tests will be conducted on this unit because of its poor time response, and gamma heating effects.

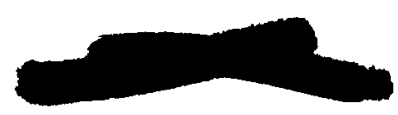




\section{STRAIN GAGE TRANSDUCER}

Code No:

Type:

Mfgr:

Range:
Sr-3

Weldable

Microdot, Inc.

$\pm 6000 \mu$ in. /in.
Spec. Control Dwg. No.

Evaluation by: WANL

Model No:

$A L-E-6 A$

Application:

PERFORMANCE \& ENVIRONMENTAL SPECIFICATIONS

\begin{tabular}{|c|c|c|c|c|}
\hline Test & Condition & NERVA Requirements & Manufacturer's Specs & $\begin{array}{l}\text { Summary of } \\
\text { Test Results }\end{array}$ \\
\hline$A$ & Thermocouple & $\mathrm{NA}$ & $\mathrm{NA}$ & \\
\hline B & Comp. Temp. Range & $140^{\circ}-535^{\circ} \mathrm{R}$ & $140^{\circ}-1110^{\circ} \mathrm{R}$ (operable) & \\
\hline C & Resistance & 120 ohm nom. & $120 \mathrm{ohm} \pm 3 \mathrm{ohm}$ & \\
\hline D & Mounting & weldable & weldable & \\
\hline$E$ & Excitation & 10 VDC nominal & $6 \mathrm{~V}$ up to $50 \mathrm{ma}$. & \\
\hline$F$ & Sensitivity & 2.0 gage factor nom. & $1.75 \pm 5.09$ gage factor & \\
\hline$G$ & Transverse Sens. & Nill & Negligible & \\
\hline $\mathrm{H}$ & Parent Material & aluminum & aluminum & \\
\hline 1 & Gage Materiat & Inorganic, Boron free & Even Ohm & \\
\hline J & Max. Power & 0.25 watt & 0.3 watt & \\
\hline$k$ & Cycle Life & $1 \times 10^{6}$ cycles & $>10^{6}$ cycles at $\pm 1000 \mathrm{~min}$ & in. \\
\hline$L$ & Insulation Res. & \multicolumn{2}{|c|}{$>50$ megohms at $50 \mathrm{VDC} 500$ megohms at $50 \mathrm{VDC}$} & \\
\hline M & Dimensions & \multicolumn{3}{|c|}{$3 / 16^{\prime \prime} \mathrm{W} \times 15 / 32^{\prime \prime} \mathrm{L}$ nom. $3 / 16^{\prime \prime} \mathrm{W} \times 15 / 32^{\prime \prime} \mathrm{L}$ nom. } \\
\hline$N$ & Neutron Flux & $7.9 \times 10^{14} \mathrm{n} / \mathrm{cm}^{2}-\mathrm{sec}$. & & \\
\hline 0 & Gamma Flux & $6 \times 10^{11} \mathrm{ergs} / \mathrm{gm}(\mathrm{c})-\mathrm{hr}$ & & \\
\hline & & & & \\
\hline & & & & \\
\hline & & & & \\
\hline & & & & \\
\hline & & & & \\
\hline & & & & \\
\hline & & & & \\
\hline & & & & \\
\hline & & & & \\
\hline & & & & \\
\hline
\end{tabular}




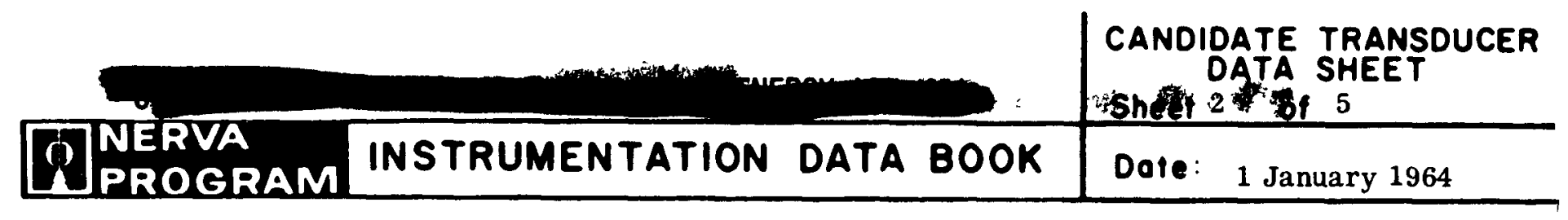

RADIATION TESTS

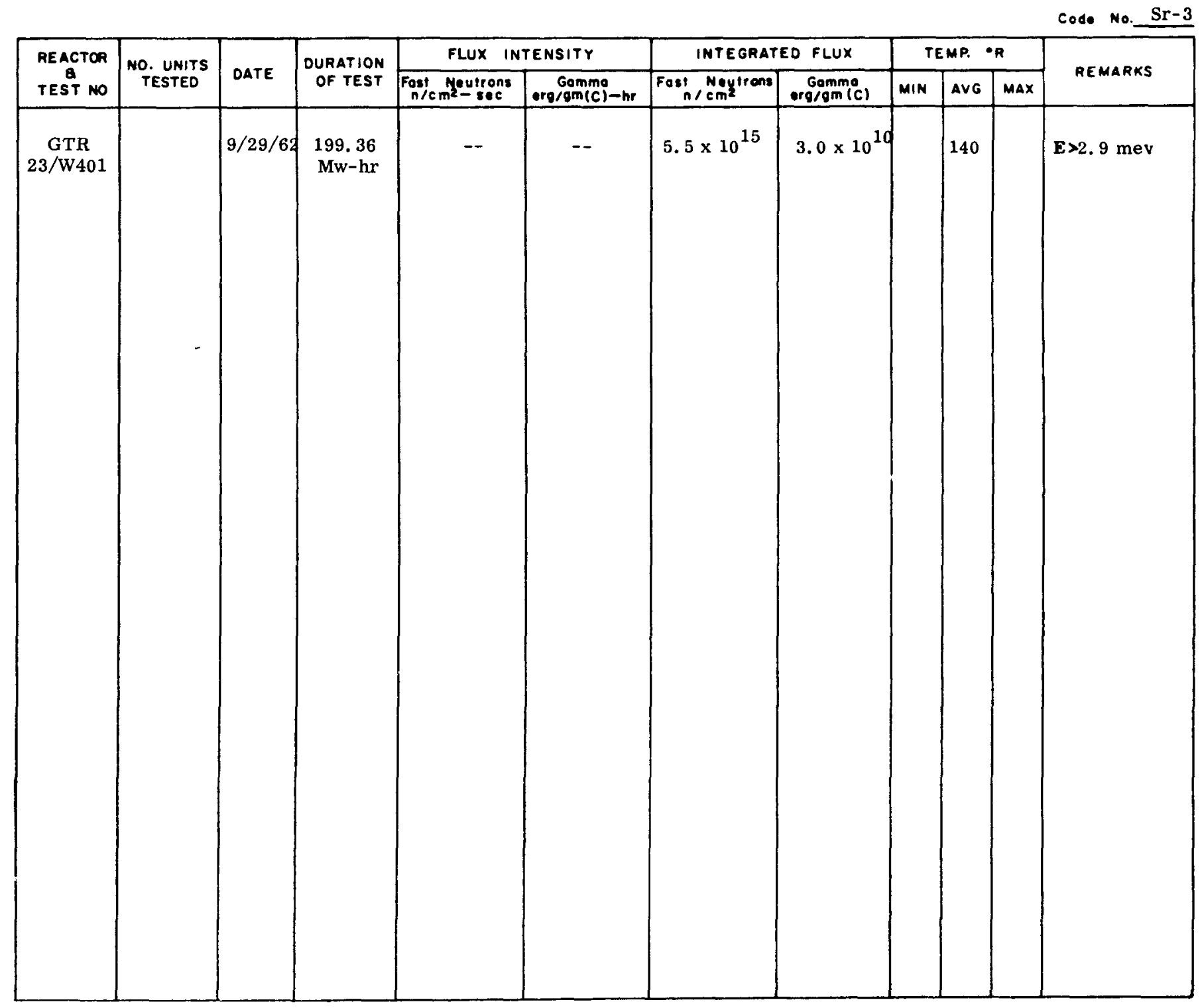




\section{DEVELOPMENT HISTORY}

Code No:

$\mathrm{Sr}-3$

Model No. A1-E-6A
Mfgr: Microdot

\section{REMARKS:}

\section{Radiation Test No. 23/W401}

Three Microdot strain-gage circuits were subjected to a combined radiation and cryogenic environment test. The gages and fixture were supplied by Westinghouse; the data-acquisition system was furnished by GD/FW. The remperature of the test specimens was that of liquid nitrogen boiling at atmospheric pressure $\left(-320.4^{\circ} \mathrm{F}\right)$. The strain-gage circuits are listed in Table 3.1.

Table 3.1

\section{Strain Gage Circuits}

\begin{tabular}{cc} 
Circuit No. & Description \\
\hline 1 & Aluminum 1 \\
2 & Aluminum 3 \\
3 & Aluminum 2
\end{tabular}

\section{Type}

$A L-E-6 A$

A L-E-6A

A L-E-6A
No. of

Gages

2

2

2

The strain gages were attached to $1 / 8$-in. tapered test beams mounted in a fixture which, by means of a helium-pressurized bellows arrangement, allowed each beam to be deflected against a stop. The strain gages were actuated automatically every two hours.

The excitation voltage (5.00 VDC) was supplied by an 8-channel, Type R Offner Recorder. The output of each strain-gage circuit was amplified at a fixed gain and recorded by the Offner Recorder. The gages on each test beam were connected into a bridge circuit to cancel the effects of temperature and radiation heating.

The fixture, with strain gages installed, and the data acquisition system were set up in the IML for an operational check at ambient temperature. Several data cycles were taken there to check the entire system and acquaint the test personnel with the operational test procedure. The system was then moved to the reactor area and the strain gages immersed in $\mathrm{LN}_{2}$. Several preirradiation data cycles were taken and recorded at this temperature. After the irradiation, one data cycle was taken at $\mathrm{LN}_{2}$ temperature and one at ambient temperature $\left(+50^{\circ} \mathrm{F}\right) /$ These data cycles were measured and recorded.

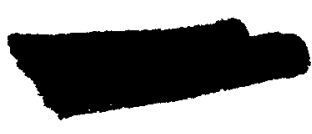




\section{DEVELOPMENT HISTORY}

Code No:

$\mathrm{Sr}-3$

Model No.

A1-E-6A
Mfgr:

Microdot

P. 0.

REMARKS:

\section{Summary:}

The strain gages were exposed to an integrated neutron flux of $5.5 \times 10^{15} \mathrm{n} / \mathrm{cm}^{2}$ (E>2.9 Mev) and a gamma dose of $3.0 \times 10^{10} \mathrm{ergs} / \mathrm{gm}(\mathrm{c})$. The resistance of each strain gage before and after the irradiation is listed in Table 4.1.

Table 4.1

Gage Resistance

\begin{tabular}{|c|c|c|c|c|}
\hline \multirow[b]{2}{*}{$\begin{array}{c}\text { Circuit } \\
\text { No. }\end{array}$} & \multicolumn{2}{|c|}{ Preirradiation } & \multicolumn{2}{|c|}{ Postirradiation } \\
\hline & $\begin{array}{l}\text { Gage 1 } \\
\text { (ohms) }\end{array}$ & $\begin{array}{l}\text { Gage 2 } \\
\text { (ohms) }\end{array}$ & $\begin{array}{l}\text { Gage 1 } \\
\text { (ohms) }\end{array}$ & $\begin{array}{l}\text { Gage 2 } \\
\text { (ohms) }\end{array}$ \\
\hline 1 & 121.0 & 121.7 & 124.1 & 131.1 \\
\hline 2 & 120.7 & 121.3 & 123.5 & 124.0 \\
\hline 3 & 122.2 & & 125.4 & \\
\hline
\end{tabular}

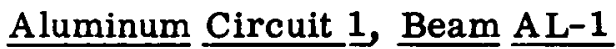

The welded bond between the aluminum gages and the tapered test beam broke prior to the irradiation; therefore, the pressure-versus-output curves were not plotted. During the test the resistance of Gage 1 increased from $121 \mathrm{ohms}$ to $124.1 \mathrm{ohms}$ and Gage 2 from $121.7 \mathrm{ohms}$ to 131. $1 \mathrm{ohms}$, with the insulation resistance decreasing from more than 10 megohms to $5 \mathrm{megohms.}$

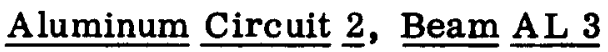

This curcuit consisted of two gages - one in compression and one in tension - on a movable aluminum beam. The output of this circuit varied between 0.6 millivolt and 0.0 millivolt. This varying output was caused by a broken weld between the gages and the beams and by malfunctions of the strain-gage actuator. The resistance of Gage 1 measured $120.7 \mathrm{ohms}$ before the irradiation and $123.5 \mathrm{ohms}$ after the irradiation. The resistance of Gage 2 measured 121. $3 \mathrm{ohms}$ before and $124.0 \mathrm{ohms}$ after the irradiation. The insulation resistance of this circuit measured more than 10 megohms before the irradiation and $7 \mathrm{kohms}$ after the irradiation. The results of this test are therefore inconclusive. 


\begin{tabular}{|c|c|c|}
\hline 4 & 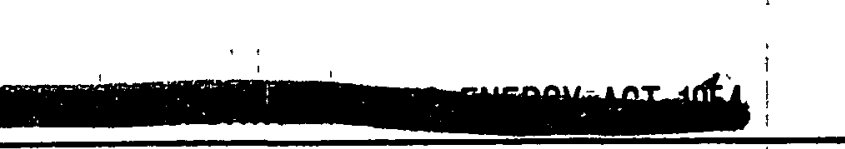 & $\begin{array}{l}\text { CANDIDATE TRANSDUCER } \\
\text { DATA SHEET } \\
\text { Sheet } 5 \text { of } 5\end{array}$ \\
\hline $\begin{array}{l}\text { DERVA } \\
\text { PROGRAM }\end{array}$ & INSTRUMENTATION DATA BOOK & 1 January 1964 \\
\hline
\end{tabular}

\section{DEVELOPMENT HISTORY}

Code No:

$\mathrm{Sr}-3$

Mfgr:

Microdot

Model No.

A1-E-6A

P. 0 .

\section{REMARKS:}

\section{Aluminum Circuit $3_{2}$ Beam $\underline{\mathrm{AL}-2}$}

This circuit was composed of one strain gage on an actuated beam. The gage shorted to the aluminum beam immediately after being immersed in $\mathrm{LN}_{2}$. Therefore, output-versus-strain curve was not plotted. The resistance of this gage increased from $122.2 \mathrm{ohms}$ to $125.4 \mathrm{ohms}$ during the test. The insulation resistance decreased from approximately 10 megohms to $2.5 \mathrm{ohms}$ after immersion in $\mathrm{LN}_{2}$. The resistance decrease on this strain gage was caused by a breakdown in insulation between the beam and the gage.

No dynamic results were obtained due to failure of the welds holding the gages to the beams. This problem is not associated with radiation effects, but indicates the need for a satisfactory technique for welding aluminum.

The lack of zero shift during the reactor tests tends to indicate that good temperature and radiation effects compensation can be obtained by the dummy gage technique.

Reference "Radiation Effects Investigation of Selected Transducers and Materials for NERVA Program" FZK-159-2. 


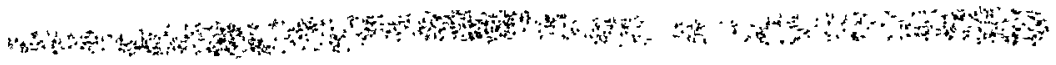

THIS PAGE INTENTIONALLY LEFT BLANK 


\section{STRAIN GAGE TRANSDUCER}

$\begin{array}{lll}\text { Code No: } \frac{\text { Sr-4 }}{\text { Weldable }} & \text { Spec. Control Dwg. No. } \\ \text { Type: } & \text { Evaluation by: } & \text { WANL } \\ \text { Mfgr: } & \text { Model No: } & \text { SS-E-6A } \\ \text { Range: } & \text { Application: }\end{array}$

PERFORMANCE \& ENVIRONMENTAL SPECIFICATIONS

\begin{tabular}{|c|c|c|c|c|}
\hline Test & Condition & NERVA Requirements & Manufacturer's Specs & $\begin{array}{l}\text { Summary of } \\
\text { Test Results }\end{array}$ \\
\hline $\mathrm{A}$ & Thermocouple & $\mathrm{NA}$ & $\mathrm{NA}$ & \\
\hline$B$ & Comp. Temp. Range & $140^{\circ}-535^{\circ} \mathrm{R}$ & $140^{\circ}-1110^{c} \mathrm{R}$ (operable) & \\
\hline C & Resistance & $120 \mathrm{ohm}$ nom. & $120 \mathrm{ohm} \pm 3 \mathrm{ohm}$ & \\
\hline$D$ & Mounting & weldable & weld or $\mathrm{Al}_{2} \mathrm{O}_{3}$ & \\
\hline$E$ & Excitation & 10 VDC nominal & $6 \mathrm{~V}$ up to $50 \mathrm{ma}$ & \\
\hline$F$ & Sensitivity & 20 gage factor nom & $1.80 \pm 5 \%$ gage factor & \\
\hline$G$ & Transverse Sens. & nill & neglıgible & \\
\hline$H$ & Parent Material & staunless steel & stainless steel & \\
\hline 1 & Gage Materiat & norganic, Boron free & Evenohm & \\
\hline $\mathrm{J}$ & Max. Power & 0.25 watt & 0.3 watt & \\
\hline$K$ & Cycle Life & $1 \times 10^{6}$ cycles & $210^{6}$ cycles & \\
\hline$L$ & Insulation Res. & $>50$ megohm at $50 \mathrm{VDC}$ & 500 megohm at $50 \mathrm{VDC}$ & \\
\hline$M$ & Dimensions & $1 / 8^{\prime \prime W} \times 15 / 32^{\prime \prime} \mathrm{L}$ & $1 / 8^{\prime \prime} \times 1 / 16^{\prime \prime} \times 15 / 32 "$ & \\
\hline $\mathrm{N}$ & Neutron Flux & $7.9 \times 10^{14} \mathrm{n} / \mathrm{cm}^{2}-\mathrm{sec}$ & & \\
\hline 0 & Gamma Flux & \multicolumn{2}{|l|}{$6 \times 10^{11} \mathrm{ergs} / \mathrm{gm} /(\mathrm{C})-\mathrm{hr}$} & \\
\hline & & & & \\
\hline & & & & \\
\hline & & & & \\
\hline & & & & \\
\hline & & & & \\
\hline & & & & \\
\hline & & & & \\
\hline & & & & \\
\hline & & & & \\
\hline & & & & \\
\hline
\end{tabular}


RADIATION TESTS

Code No Sr-4

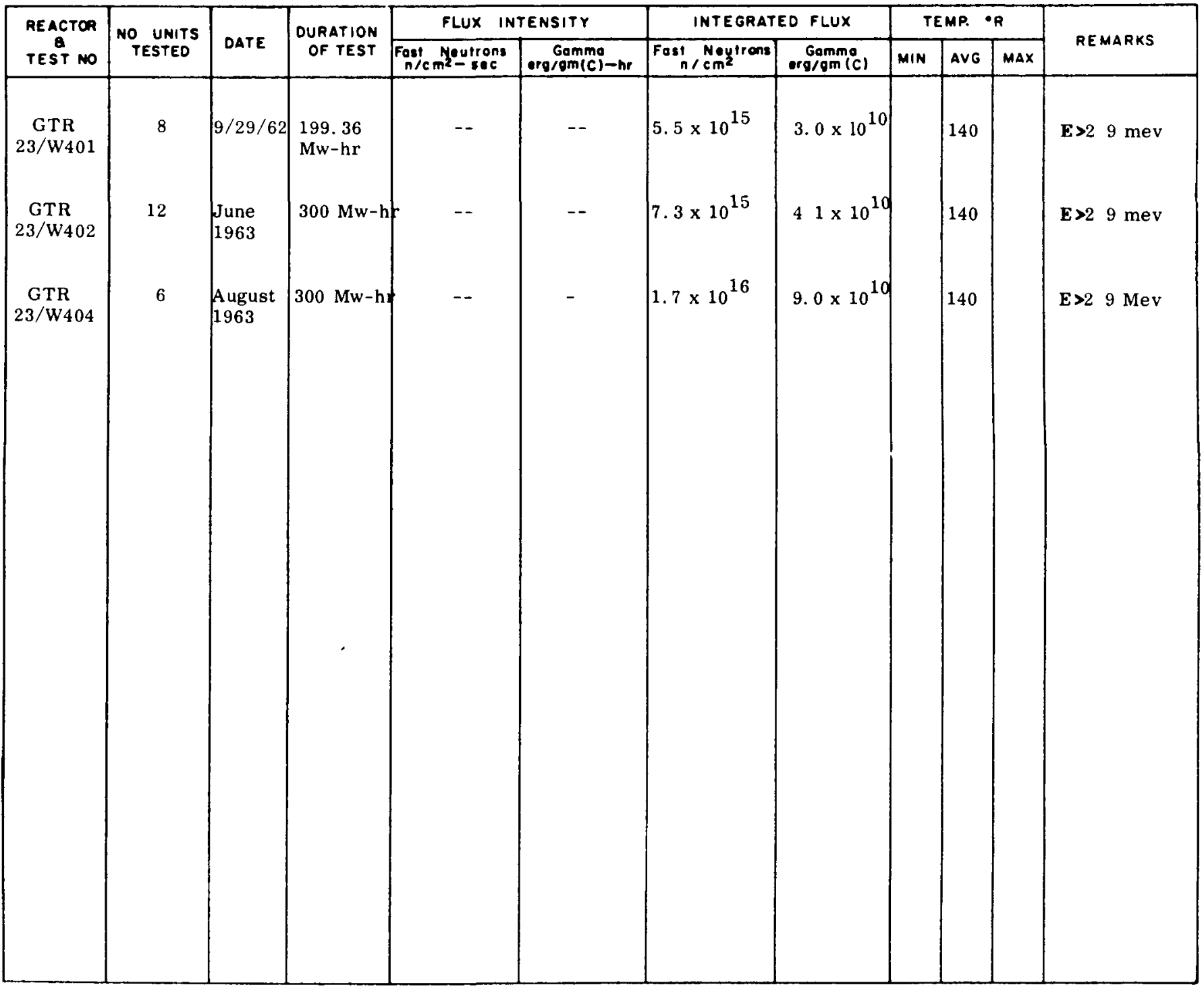




\section{DEVELOPMENT HISTORY}

\begin{tabular}{ll} 
Code No: $\frac{\text { Sr-4 }}{\text { Model No. }}$ SS-E-6A & Mfgr: \\
\hline
\end{tabular}

\section{REMARKS:}

\section{December 1963}

Radiation Test No. 23/W401

Four Microdot strain-gage circuits were subjected to a combined radiation and cryogenic environment test. The gages and fixture were supplied by Westinghouse, the data-acquisition system was furnished by GD/FW. The temperature of the test specimens was that of liquid nitrogen boiling at atmospheric pressure $\left(-320.4^{\circ} \mathrm{F}\right)$. The strain-gage circuits are listed in Table 3.1.

Table 3.1

\section{Strain Gage Circuits}

Circuit No.
1
2
3
4

\begin{tabular}{l} 
Description \\
\hline Stainless Steel 1 \\
Stainless Steel 2 \& Dummy \\
Stainless Steel 3 \\
Stainless Steel Dummy
\end{tabular}

The strain gages were attached to $1 / 8$-in. tapered test beams mounted in a fixture which, by means of a helium-pressurized bellows arrangement, allowed each beam to be deflected against a stop. The strain gages were actuated automatically every two hours.

The excitation voltage (5.00 vdc) was supplied by an 8-channel, Type $R$ Offner Recorder. The output of each straingage circuit was amplified at a fixed gain and recorded by the Offner Recorder. The gages on each test beam were connected into a bridge circuit to cancel the effects of temperature and radiation heating.

The fixture, with strain gages installed, and the data acquisition system were set up in the IML for an operational check at ambient temperature. Several data cycles were taken there to check the entire system and acquaint the test personnel with the operational test procedure. The system was then moved to the reactor area and the strain gages immersed in $\mathrm{LN}_{2}$. Several preirradiation data cycles were taken at this temperature. After the irradiation, one data cycle was taken at $\mathrm{LN}_{2}$ temperature and one at ambient temperature $\left(+50^{\circ} \mathrm{F}\right)$. These data cycles were measured recorded.

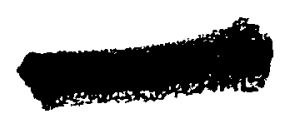




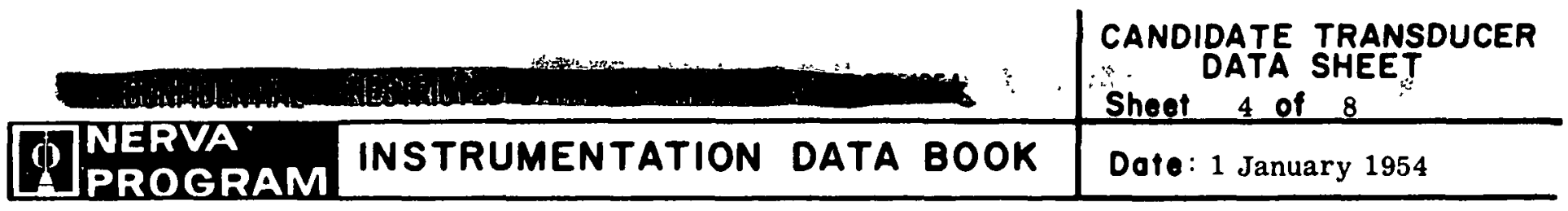

\section{DEVELOPMENT HISTORY}

Code No:

SR-4

Model No.

SS-E-6A

Mfgr:

Microdot

P. 0 .

\section{REMARKS:}

\section{Summary:}

The strain gages were exposed to in integrated neutron flux of $5.5 \times 10^{15} \mathrm{n} / \mathrm{cm}^{2}$ (E >2.9 Mex) and a gamma dose of $3.0 \times 10$ ergs/gm(c). The resistance of each strain gage before and after the irradiation is listed in Table 4.1.

Table 4.1

Gage Resistance

\begin{tabular}{c}
$\begin{array}{c}\text { Circuit } \\
\text { No. }\end{array}$ \\
\hline 1 \\
2 \\
3 \\
4
\end{tabular}

\begin{tabular}{r} 
Pre \\
\hline $\begin{array}{r}\text { Gage 1 } \\
\text { (ohms) }\end{array}$ \\
119.3 \\
118.9 \\
119.9 \\
121.3
\end{tabular}

\section{Preirradiation}

Gage 2

(ohms)

118.0

118.7

120.7
Post irradiation

\begin{tabular}{ccc}
$\begin{array}{c}\text { Gage 1 } \\
\text { (ohms) }\end{array}$ & $\begin{array}{r}\text { Gage 2 } \\
\text { (ohms) }\end{array}$ \\
\hline 121.4 & & 120.5 \\
121.4 & & 120.7 \\
122.3 & 122.9 \\
123.9 & \\
\hline
\end{tabular}

\section{Stainless-Steel Circuit 1, Beam SST 1}

This strain-gage circuit had a minimum output of 1.03 millivolts and a maximum of 1.15 millivolts during the irradiation. The strain was the same for each data measurement. All strain gage outputs were near zero on Run 18. The output of this strain gage circuit varied a maximum of $11 \%$ during the test. The preirradiation insulation resistance of this circuit was greater than 10 megohms. The postirradiation insulation resistance at ambient temperature was $140 \mathrm{kohms}$. This high resistance probably resulted from the moisture due to the melting of frost on the wiring.

\section{Stainless-Steel Circuit 2 , Beam SST 2 , Dummy}

This circuit consisted of one gage mounted on a fixed or non-moving beam and one gage mounted on a movable beam. The bellows or strain-gage actuating mechanism malfunctioned on data runs $5,16,18,21$, and 22 , with the output being low. These low data points were not used in calculating the drift. The output of this strain-gage circuit varied $29 \%$ from the average during the test. The preirradiation insulation resistance of this circuit was greater than 10 megohms, and the postirradiation insulation resistance at ambient temperature was $120 \mathrm{kokms}$. 


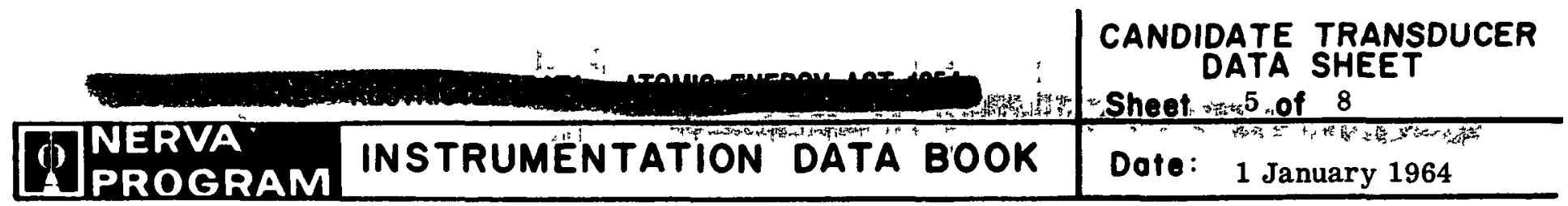

\section{DEVELOPMENT HISTORY}

Code No: $\frac{\text { Sr-4 }}{\text { Model No. }}$

Mfgr:

REMARKS:

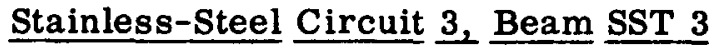

Strain-gage circuit 3 consisted of two gages on a tapered movable beam; one gage in compression and the other in tension. This strain-gage circuit operated satisfactorily during the preirradiation testing, but its output decreased to zero after two hours of irradiation. The zero output was caused by a mechanical malfunction of the bellows in the strain actuating mechanism. The insulation resistance of this strain gage decreased from 10 megohms to $78 \mathrm{kohms}$ at the end of the test. The results are therefore inconclusive on this gage due to mechanical problems. However, the gage resistances changed less than $1 \%$ during the test - an indication that damage to the gages was negligible.

\section{Stainless-Steel Circuit 4 , Beam SS, Dummy}

Circuit 4 consisted of a single gage on a fixed beam. This beam was not moved and, consequently, there was a zero output from the gage: The purpose of this test was to determine the magnitude and direction of any change in the zero output. The zero output seemed erratic in that it took no definite direction. The maximum output was 0.74 millivolt, the minimum -0.54 millivolt. A visual inspection of the gage after the test revealed no damage. The insulation resistance measured more than 10 megohms at the beginning of the test and 14 kohms at the end of the test.

The test indicated that:

1. Good temperature and radiation effects compensation can be obtained by the dummy gage technique.

2. One circuit showed variations of $11 \%$ in measured strain, and another variations of 29\% during the test. Difficulties were encountered due to malfunctioning of the bellows system applying strain, so that the results of this first test are preliminary only.

Reference: "Radiation Effects Investigation of Selected Transducers and Materials for Nerva Program" FZK-159-2.

Radiation Test No. 23/W402; GTR; June, 1963

Test $\underline{\text { Plan }}$

Twelve Microdot SS-E-6A strain gages were mounted in pairs on six tapered beams in a test fixture. Pressurized helium applied to six bellows in the fixture deflected the beams against fixed stops.

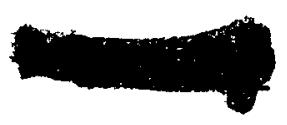




\section{DEVELOPMENT HISTORY}

Code No: $\frac{\mathrm{Sr}-4}{\mathrm{SS}-\mathrm{E}-6 \mathrm{~A}}$

$$
\text { Mfgr: }
$$

Microdot

REMARKS:

Strain data were recorded manually from a Baldwin-Lima-Hamilton strain indicator and on a Sanborn oscillograph recorder. The resistance of each gage was measured with an NLS digital ohmmeter. The insulation resistance (between the gage and the beam) of each gage pair was measured with a Tera ohmeter.

There were no thermocouples on the beams. After the detonations in the Dewar, temperatures for the strain gages were recorded from thermocouples attached to the resistance thermometers mounted on the same test fixture.

\section{Test Results}

The WANL strain gages were exposed to an integrated neutron flux of $7.3 \times 10^{15} \mathrm{n} / \mathrm{cm}^{2}$ and a gamma dose of $4.1 \times 10^{10} \mathrm{ergs} / \mathrm{gm}(\mathrm{c})$. Strain outputs for the six pairs of strain gages were presented. Zero shifts, in $\mu$ in. /in., are listed across the bottom of the strain-output plots. Wide variations in temperature are indicative of the fact that it was not possible to maintain stable operating temperatures with gaseous nitrogen.

Just prior to the detonations, strain readings were within $4 \%$ of preirradiation values. After the detonations, there was no strain output from Beam 3. Resistance checks showed that the top gage was open and the bottom gage had a resistance of only $5 \mathrm{ohms}$. Postirradiation examination revealed that both strain gages were broken.

Strain readings for the gages on Beam 1 were fairly uniform throughout the test; there was little zero shift for this beam. Postirradiation gage resistances were within $0.3 \mathrm{ohm}$ of the preirradiation values for both gages.

Strain readings for Beam 2 were slightly less uniform than for Beam 1 and the zero shift was a little greater. The erratic strain reading near the end of the test is accompanied by a zero shift of approximately $-1250 \mu \mathrm{in}$. /in. from the adjacent points. Gage resistances at the end of the test were within $0.5 \mathrm{ohm}$ of the preirradiation values for both gages.

At an integrated neutron flux of approximately $3.5 \times 10^{15} \mathrm{n} / \mathrm{cm}^{2}$, there was a large decrease in the strain output from the gages on Beam 4 which was not accompanied by any significant zero shift. Nor was there any appreciable change in the resistance of the gages or the insulation resistance at this point. It is assumed that ice had formed to prevent full deflection of this beam, causing the low output readings. This assumption is supported by the fact that when the Dewar was warmed up at the end of the test the strain reading returned to a value almost identical to the preirradiation value. Postirradiation resistances were within $0.2 \mathrm{ohm}$ of preirradiation values for both gages. 


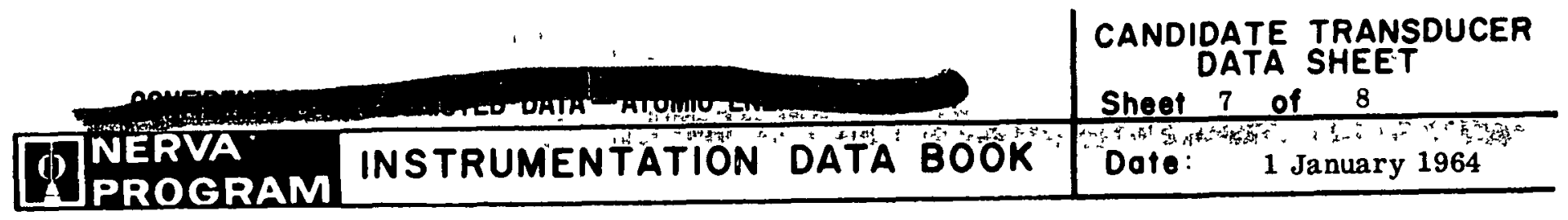

\section{DEVELOPMENT HISTORY}

$\begin{array}{ll}\text { Code No: } \frac{\mathrm{Sr}-4}{\mathrm{SS}-\mathrm{E}-6 \mathrm{~A}} & \text { Mfgr: } \\ \text { Model No. } & \text { P. } 0 .\end{array}$

Microdot

REMARKS:

A permanent zero shift greater than $-8000 \mu$ in. /in. occurred in the readings for Beam 5 following the detonations. The large shift was probably due to an unexplained increase of 1.6 ohms in the resistance of the bottom gage at an integrated neutron flux of $9.5 \times 10^{13} \mathrm{n} / \mathrm{cm}^{2}$. Strain outputs during operation with gageous nitrogen fluctuated with changed in zero shift, but returned to a postir radiation ambient reading that was almost identical to the preirradiation ambient reading that was almost identical to the preirradiation ambient value. At the end of the test, the resistance of the top gage had increased $0.2 \mathrm{ohm}$; the resistance of the bottom gage had increased 2.5 ohms.

There was a large zero shift for Beam 6 following the detonations and the strain output from the gages decreased. Postirradiation ambient strain output and zero shift were very near preirradiation values. Resistances of both gages at the end of the test were within $0.3 \mathrm{ohm}$ of preirradiation resistances.

When the Dewar was opened after the test, an accumulation of water and foreign matter was found in the pan at the bottom of the test fixture.

The bellows were operationally checked in the Irradiated Materials Laboratory and were found to be operating satisfactorily. There was no visible damage inside the terminal box at the top of the test fixture or to any of the strain gages except those on Beam 3.

In summary, one pair of strain gages was broken by the detonations. Operation with gaseous nitrogen as coolant presented some problems. When the Dewar was warmed up for examination after the detonations, moisture may have collected inside so that during subsequent operation at low temperatures ice formed on the bellows and the beams and caused erroneous strain readings. When the Dewar was warmed up for the post-irradiation data cycle at ambient temperature, all strain measurements except those from the broken gages were within $4 \%$ of those recorded in the preirradiation ambient data cycles.

Reference: "Radiation Effects Investigation of Selected Transducers and Materials for NERVA Program" FZK-170-1.

Radiation Test No. 23/W404, GTR August, 1963.

Test Plan

Six Microdot (weldable) strain gages were tested. The gages were mounted in pairs on three tapered beams in a test fixture.

fixed stops.

Pressurized helium applied to six bellows in the test fixture deflected the beams against

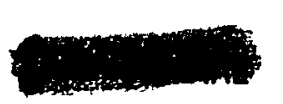




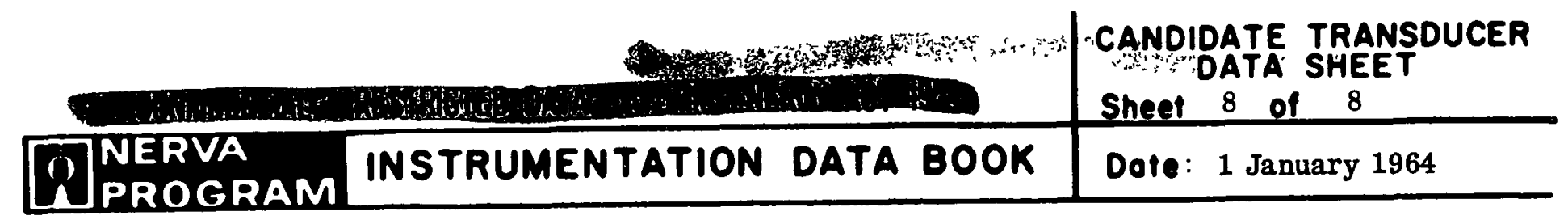

\section{DEVELOPMENT HISTORY}

Code No: $\mathrm{Sr}-4$

Model No. SS-E-6A

Mfgr: Microdot

P. 0.

\section{REMARKS:}

Strain data and zero shift were recorded manually from a Baldwin-Lima-Hamilton strain indicator and on a Sanborn oscillograph recorder. The resistance of each gage was measured with a NLS digital ohmeter. Insulation resistance between each pair of gages and the beam on which they were mounted was measured with a Tera ohmeter.

In order to prevent the formation of ice in the pressure lines and bellows, the pressure system was evacuated to 30 microns and the system was purged with helium before the Dewar was filled with $\mathrm{LN}_{2}$. Slight helium pressure (5psig) was then maintained on the system throughout the test.

\section{Test Results}

Table 7.2 of GD/FW GTR test 7-A report contains four cycles of test data. Gage resistances at the end of the test were within one ohm of preirradiation values for all gages. At $\mathrm{LN}_{2}$ temperature, large values of zero shift for the gages on beam 5 were observed throughout the test. However, the strain readings for the gages on this beam compare favorably with the strain readings for beams 1 and 3 except for the erratic postirradiation reading. The postirradiation strain output readings for the Microdot gages on beams 1 and 3 were within 1.3\% of preirradiation values. 


\section{STRAIN GAGE TRANSDUCER}

\begin{tabular}{|c|c|c|c|}
\hline Code No & $\mathrm{Sr}-5$ & \multicolumn{2}{|c|}{ Spec. Control Dwg. No. 964B036H01 } \\
\hline Type: & Metal film & \multicolumn{2}{|c|}{ Evaluation by: $\quad$ WANL } \\
\hline Mfgr: & Budd Company & Model No: & $\mathrm{C} 6-634$ \\
\hline Range: & $0-10,000 \mu$ in. $/$ in. & Application: & \\
\hline
\end{tabular}

\begin{tabular}{|c|c|c|c|c|}
\hline Test & Condition & NERVA Requirements & Manufacturer's Specs & $\begin{array}{l}\text { Summary of } \\
\text { Test Results }\end{array}$ \\
\hline A & Thermocouple & $\mathrm{Na}$ & None & \\
\hline$B$ & Comp. Temp. Range & $140-535^{\circ} \mathrm{R}$ & $140-535^{\circ} \mathrm{R}$ & \\
\hline $\mathrm{C}$ & Resistance & $260 \pm 0.5 \mathrm{ohms}$ & $260 \pm 0.5 \mathrm{ohms}$ & \\
\hline$D$ & Mounting & Eastman 910 adhesive & adhesive & \\
\hline$E$ & Excitation & $10 \mathrm{VDC}$ & $10 \mathrm{VDC}$ & \\
\hline$F$ & Sensitivity & $2.20 \pm 0.5 \%$ gage facto & $2.20 \pm 0.5 \%$ gage fact & \\
\hline$G$ & Transverse Sens. & Nill & Nill & \\
\hline $\mathrm{H}$ & Parent Material & Graphite & Graphite & \\
\hline 1 & Gage Materiat & coef. of exp. $=6 \mathrm{PPM} /{ }^{\circ} \mathrm{H}$ & Budd Karma Alloy & \\
\hline $\mathrm{J}$ & Max. Power & $1 / 4$ watt & $1 / 4$ watt & \\
\hline $\mathrm{K}$ & Cycle Life & $1 \times 10^{6}$ cycles & $1 \times 10^{6}$ cycles & \\
\hline$L$ & Insulation Res. & $>50$ megohms & $>50$ megohms & \\
\hline$M$ & Dimensions & $5 / 16^{\prime \prime} \times 1 / 2^{\prime \prime}$ & $5 / 16^{\prime \prime} \times 1 / 2^{\prime \prime}$ & \\
\hline$N$ & Neutron Flux & $\mathrm{NA}$ & & \\
\hline 0 & Gamma Flux & $\mathrm{NA}$ & & \\
\hline & & & & \\
\hline & & & & \\
\hline & & & & \\
\hline & & & & \\
\hline & & & & \\
\hline & & & & \\
\hline & & & & \\
\hline & & & & \\
\hline & & & & \\
\hline & & & & \\
\hline
\end{tabular}




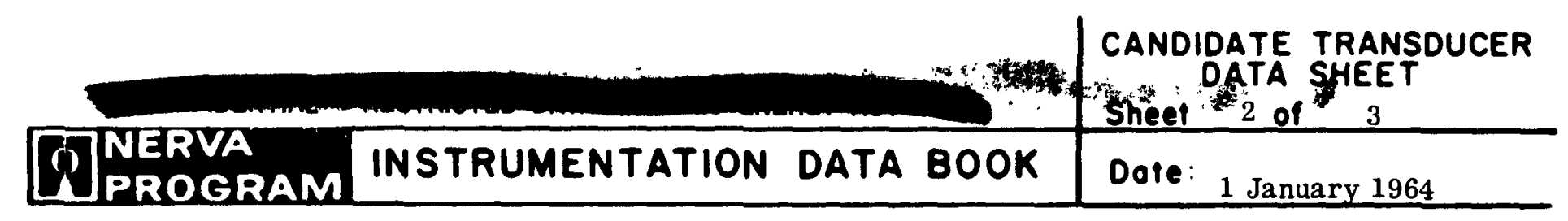

RADIATION TESTS

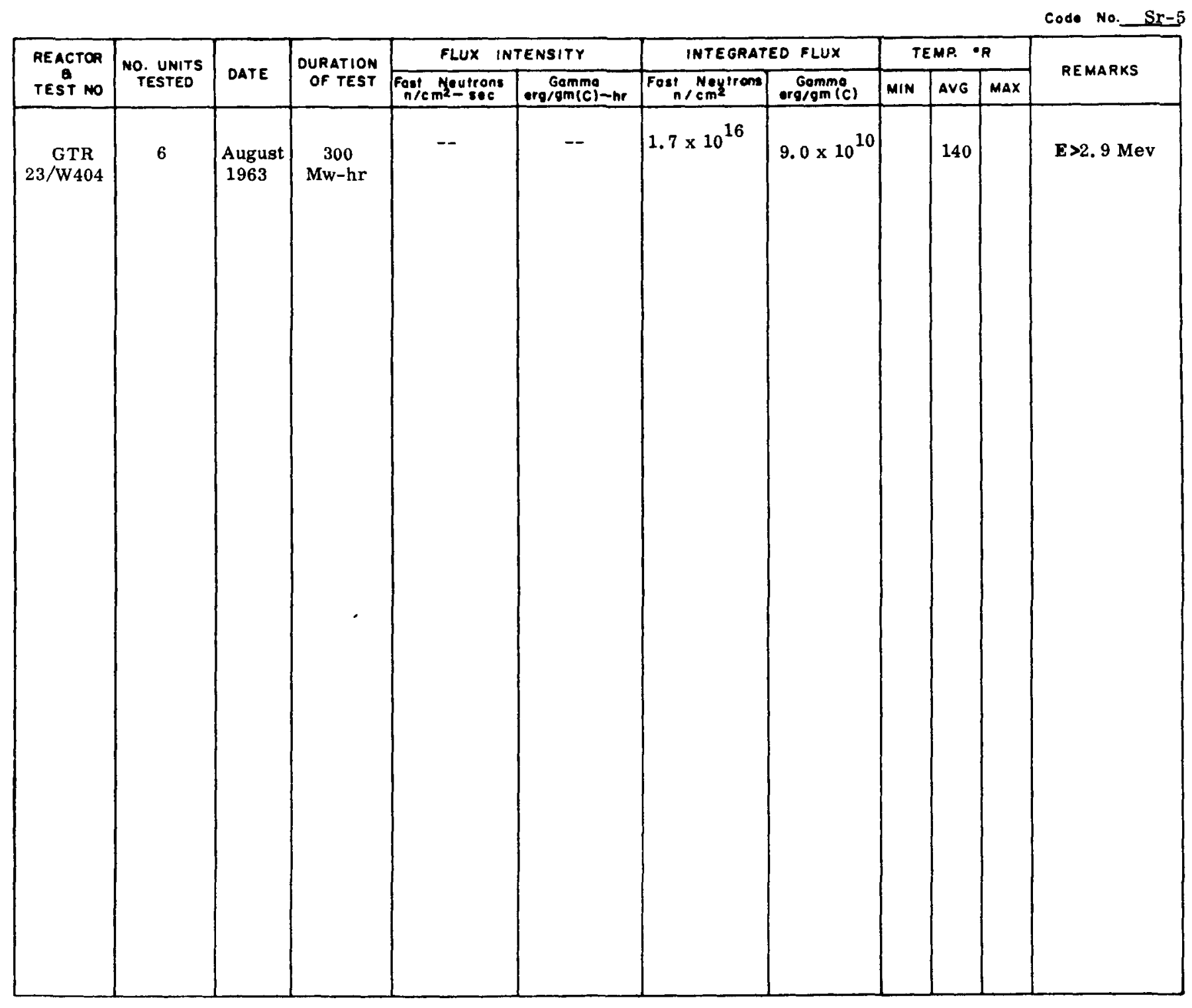




\section{DEVELOPMENT HISTORY}

Code No:

$\mathrm{Sr}-5$

Model No. C6-634
Mfgr:

P. 0 .
Budd Company

\section{REMARKS:}

The selection of this strain gage is based on the test results outlined in detail under Code No. Sr-8. Although no actual tests have been conducted using this type, the same results would be obtained since the only difference between the two units is physical gage size.

\section{$\underline{15} \underline{\text { December }} \underline{1963}$}

Radiation test No. 23/W404, GTR, August, 1963

Test Plan

Six Budd (bondable) strain gages were tested. The gages were mounted in pairs on three tapered beams in a test fixture. Pressurized helium applied to six bellows in the test fixture deflected the beams against fixed stops. Strain data and zero shift were recorded manually from a Baldwin-Lima-Hamilton strain indicator and on a Sanborn oscillograph recorder. The resistance of each gage was measured with an NLS digital ohmeter. Insulation resistance between each pair of gages and the beam on which they were mounted was measured with a Tera ohmeter.

In order to prevent the formation of ice in the pressure lines and bellows, the pressure system was evacuated to 30 microns and the system was purged with helium before the Dewar was filled with $\mathrm{LN}_{2}$. Slight helium pressure (5 psig) was then maintained on the system throughout the test.

\section{Test Results}

Table 7.2 of GD/FW GTR-7A test report contains four cycles of test data. Gage resistances at the end of the test were within one ohm of preirradiation values for all gages.

The strain gages showed a zero shift of $-236 \mathrm{M}$-in. /in., accompanied by a reduction in strain output of $212 \mathrm{M}$-in. /in., during the fifth data cycle (recorded at 0543 , Aug. 22). The strain output was low for the remainder of the test and the postirradiation reading was approximately $24 \%$ below the preirradiation value.

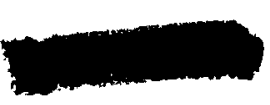




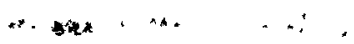

THIS PAGE INTENTIONALLY LEFT BLANK 


\section{VIBRATION TRANSDUCER}

Code No: Gr-1

Type: Piezoelectric

Mfgr: Endevco Corp.

Range: (Dynamic) $500 \mathrm{~g}$ Sinusoidal
Spec. Control Dwg. No.

Evaluation by: WANL

Model No: $2242 \mathrm{M} 5 \mathrm{C}$

Application:

\section{PERFORMANCE \& ENVIRONMENTAL SPECIFICATIONS}

\begin{tabular}{|c|c|c|c|c|}
\hline Test & Condition & NERVA Requirements & Manufacturer's Specs & $\begin{array}{l}\text { Summary of } \\
\text { Test Results }\end{array}$ \\
\hline$A$ & $\begin{array}{l}\text { Overload (Vibration } \\
\text { Shock) }\end{array}$ & $100 \mathrm{~g}$ & $\begin{array}{l}\text { to } 500 \mathrm{~g} \text { sinusoidal to } 10,0 \bar{c} \\
150 \mathrm{~m}-\mathrm{sec} \text {. half sine wave }\end{array}$ & $\begin{array}{l}\text { pul'se } \\
\text { pugh }\end{array}$ \\
\hline $\mathrm{B}$ & Comp. Temp. Range & $140^{\circ} \mathrm{R}$ to $800^{\circ} \mathrm{R}$ & $140^{\circ} \mathrm{R}$ to $810^{\circ} \mathrm{R}$ & \\
\hline C & Input Impedance & $\mathrm{NA}$ & 500 megohms $\mathrm{min}$. at 964 & \\
\hline $\mathrm{D}$ & Output Impedance & NA & & \\
\hline$E$ & Excitation & $\mathrm{NA}$ & & \\
\hline $\mathrm{F}$ & Sensitivity & $10 \mathrm{pk}-\mathrm{mv} / \mathrm{pk}-\mathrm{g}$ & $5 \%$ max., any axis & \\
\hline G & Transverse Accel & $5 \% \max$. & & \\
\hline $\mathrm{H}$ & Linearity & $\pm 2 \% 0-50 \mathrm{~g}$ & $\pm 1 \%$ & \\
\hline 1 & Hysteresis & NA & & \\
\hline$J$ & Resolution & NA & & \\
\hline$K$ & Accuracy & $5 \%$ & & \\
\hline$L$ & Freq. Response & $0-1 \mathrm{KC}$ flat $\pm 3 \mathrm{db}$ & $5-20 \mathrm{cps}$ to $4 \mathrm{KC}$ & \\
\hline$M$ & Noise Limit & MIL-S-446A & $\begin{array}{l}\text { response to acoustic noisc } \\
\text { of } 100 \mathrm{db} 4 ; 0.01 \mathrm{mv}\end{array}$ & \\
\hline$N$ & Neutron Flux & $4.5 \times 10^{14} \mathrm{n} / \mathrm{cm}^{2}-\mathrm{sec}$ & & \\
\hline 0 & Gamma Flux & \multicolumn{2}{|c|}{$1.9 \times 10^{11} \mathrm{ergs} / \mathrm{gm}(\mathrm{C})-\mathrm{hr}$} & \\
\hline $\mathbf{P}$ & Dimensions & \multicolumn{3}{|c|}{$11 / 16^{\prime \prime}$ hex, x $0.88^{\prime \prime}$ high $11 / 16^{\prime \prime}$ hex, x $0.88^{\prime \prime}$ high } \\
\hline$Q$ & Weight & $2 \mathrm{oz}$ & $1.4 \mathrm{oz}$ & \\
\hline $\mathrm{R}$ & Resonant Freq. & $>7 \mathrm{KC}$ & $25 \mathrm{KC} \min$. & \\
\hline $\mathrm{S}$ & Insulation Res. & \multicolumn{2}{|l|}{$>1000$ megohm at 50VDC } & \\
\hline $\mathrm{T}$ & Material & stainless steel & stainless steel & \\
\hline & \multicolumn{2}{|c|}{ Sensitivity-Voltage (With $100 \mathrm{pf}$ ext.) } & $12 \pm 2 \mathrm{pk}-\mathrm{mv} / \mathrm{pk}-\mathrm{g}$ & \\
\hline & Sensitivity-Charge & & 2.5 peak-pcmb/pk-g & \\
\hline & \multicolumn{2}{|c|}{ Capacitance (With 100 pf ext.) } & $200 \mathrm{pf}$ & \\
\hline & & & & \\
\hline & & & & \\
\hline
\end{tabular}


CANDIDATE TRANSDUCER

DATA SHEET

NERVA

INSTRUMENTATION DATA BOOK

Dote: 1 January 1964

RADIATION TESTS

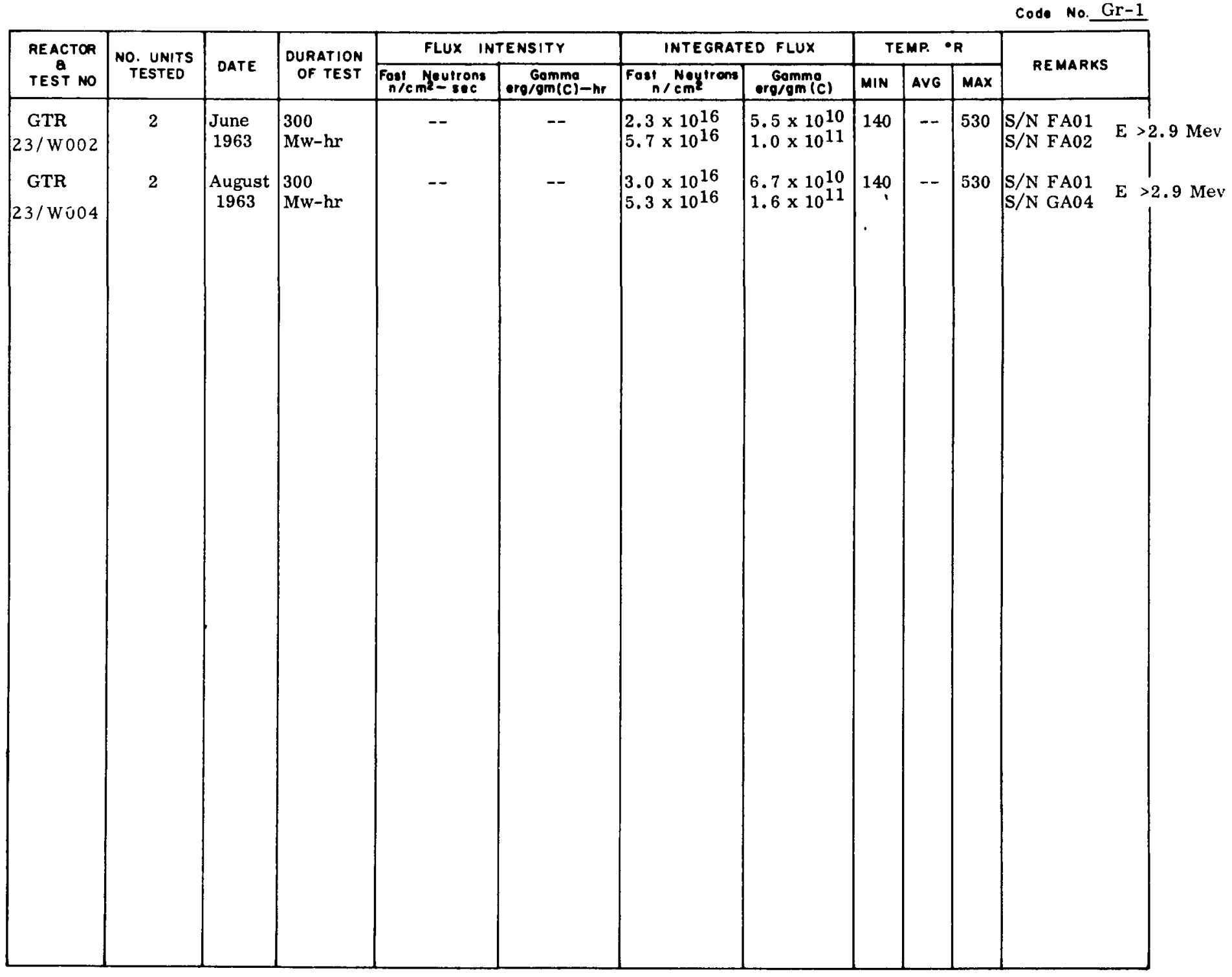




\section{DEVELOPMENT HISTORY}

Code No: $\mathrm{Gr}-1$

Model No. 2242M5C

REMARKS:
Mfgr:

Endevco

P. $0 . \quad 27089$

Serial Number FA02 and FA03 -

Summary Test Results:

Tested at WANL on 12/31/62 submerged in liquid nitrogen in a dewar mounted on an MB vibration table at $20 \mathrm{~g}$ for $50 \mathrm{cps}, 100 \mathrm{cps}$ and $200 \mathrm{cps}$, and at $20 \mathrm{cps}$ at $10 \mathrm{~g}$. Room temperature test results compared favorably with $\mathrm{LN}_{2}$ test results.

This unit will be combined effects tested in the second GTR test in April 1963.

\section{General:}

Endevco selection based on reports of tests conducted by C. E. Hanford, Combustion Engineering, Chance Vought and LASL. Some details available.

\section{December 1963 - GTR Test No. $4 \quad 23 /$ W 002}

Two units were placed in the combined environment of $\mathrm{LN}_{2}$ and Radiation at GTR during June, 1963 (S/N FA01, FA02).

Each accelerometer was mounted on the spring-like, spider-web-type platform of a vibration table consisting of an electromagnet and a voice coil. By varying the frequency of the input signal to the voice coil, each accelerometer was vibrated at several different frequencies during each data cycle. The signal frequency was supplied by a Hewlett-Packard 650-A test oscillator, the frequency of which was monitored by an EPUT meter. The voice coils were driven by a McIntosh 200-watt power amplifier.

After the current to the electromagnetic $\left(I_{D C}\right)$ and the current to the voice coil $\left(I_{A C}\right)$ were adjusted to provide the desired displacement at each frequency, the values were recorded. The accelerometer output was read from a Ballentine Peak-to-peak voltmeter, and recorded. Oscilloscope photographs were made of the voice-coil input, and the accelerometer output traces displayed simultaneously on a Tektronix 545 oscilloscope.

After the irradiation, the accelerometers were removed from the test fixture and tested on a standard shaker table in the Irradiated Materials Laboratory.

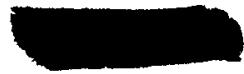




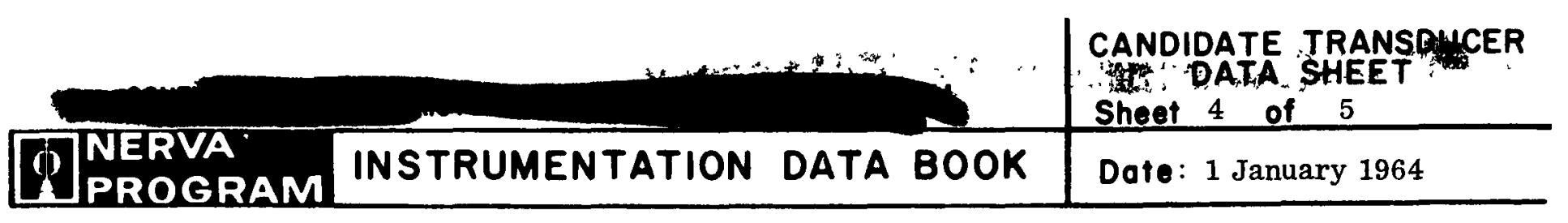

\section{DEVELOPMENT HISTORY}

Code No: $\frac{\mathrm{Gr}-1}{\text { Model No. } 2242 \mathrm{M} 5 \mathrm{C}}$

MFgr: $\frac{\text { Endevco }}{27089}$

\section{REMARKS:}

\section{$\underline{\text { Test }} \underline{\text { Results }}$} sheet 2.

The accelerometers were exposed to the integrated neutron fluxes and gamma doses given on

The accelerometer outputs vs radiation exposure are shown in Figures 4.11 and 4.12 of GD/FW report FZK-170-1 for two vibration frequencies (operating temperatures are also shown for each accelerometer). Although some of the accelerometers were vibrated at as many as 17 frequencies, the accelerometer output at two of these frequencies is sufficient to demonstrate the problems encountered after the detonations. The point at which the detonations occurred is indicated in each of the figures.

The validity of some of the data for test items in the dewars was questionable because of the detonations. This becomes evident after a study of the data in Figures 4.11 and 4.12 .

After the irradiation both of the accelerometers were tested on a standard shaker table with the following results:

Both units were operative and showed very little change in sensi-

tivity; results were very close to factory calibration information.

The detonations in the $\mathrm{LN}_{2}$ dewar affected the output of all of the accelerometers. Both of these units continued to operate, but with noisy output and/or reduced sensitivity. Some of the problems were caused by damage (resulting from the detonations and the effects of radiation) to the signal leads and to the vibration table leads. The unimpaired operation in postirradiation testing with the standard shaker table makes it possible to separate the effects of the detonations from the effects of radiation.

\section{December 1963 - GTR Test No.7A 23/W004}

In August, 1963 one (1) unit from the June, 1963 test (S/N FA01) and one (1) additional unit (S/N GA04) were placed in the combined environment of $\mathrm{LN}_{2}$ and irradiation while being vibrated continuously. The purpose of this test was to determine the effects of nuclear radiation on selected components proposed for application in the NERVA engine.

Vibration generators were used to vibrate the components. Each generator consisted of two tandem-mounted electro-magnets and two mechanically connected voice coils. The voice coils for the four vibration generators were connected in series and were driven simultaneously with a 


\begin{tabular}{|l|l|l|l|}
\hline Q NERVA & $\begin{array}{l}\text { CANDIDATE TRANSDUCER } \\
\text { DATA SHEET } \\
\text { Sheet 5 of } 5\end{array}$ \\
\hline PROGRAM INSTRUMENTATION DATA BOOK & Dote: 1 January 1964 \\
\hline
\end{tabular}

\section{DEVELOPMENT HISTORY}

Code No:

$\mathrm{Gr}-1$

Mfgr: Endevco

Model No.

$2242 \mathrm{M} 5 \mathrm{C}$

P. 0. 27089

\section{REMARKS:}

McIntosh 200-watt power amplifier. The signal frequency to the voice coils was supplied by a Hewlett-Packard $200 \mathrm{CD}$ signal generator, the frequency being monitored by an EPUT meter. The outputs were read from an Endevco Dyna-Monitor and were recorded with an analog magnetic-tape system. The units were vibrated at the following frequencies (cps) during the test: $50,75,100$, $125,150,300,450,600,750,900$, and 1050 .

Resistance and/or capacitance measurements were made on the signal leads periodically during the test. Also the AC and DC vibration-generator coil resistances were measured.

\section{Test Results}

Output data during four data cycles (pre- and post-irradiation and the first and last $3 \mathrm{Mw}$ cycles) were read from the Dyna-Monitor and are recorded in GD/FW report GTR-7A. These values probably show a relative indication of the performance of the units; however, to establish the validity of the data, it is necessary to refer to the magnetic tape to ascertain the waveshape of the output signal and the amount of noise present.

After the test specimens were returned to IML and removed from the Dewar, calibration checks were made individually on a standard vibration table with the following results:

Both units performed satisfactorily. Deviations from the factory calibration data were within $3.7 \%$ for $\mathrm{S} / \mathrm{N} \mathrm{GAO} 4$ and within $4.8 \%$ for S/N FA01. 


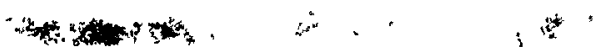

THIS PAGE INTENTIIONALLY LEFT BLANK 


\section{VIBRATION TRANSDUCER}

Code No: Gr-2

Type: (Piezite Crystal) Piezoelectric

Mfgr: Endevco Corp.

Range: (Dynamic) 500g Sinusoidal
Spec. Control Dwg. No.

Evaluation by: WANL

Model No: 2245

Application:

PERFORMANCE \& ENVIRONMENTAL SPECIFICATIONS

\begin{tabular}{|c|c|c|c|c|}
\hline Test & Condition & NERVA Requirements & Manufacturer's Specs & $\begin{array}{l}\text { Summary of } \\
\text { Test Results }\end{array}$ \\
\hline A & Overload & $100 \mathrm{~g}$ & & \\
\hline$B$ & Comp. Temp. Range & $140^{\circ} \mathrm{R}$ to $800^{\circ} \mathrm{R}$ & $140^{\circ} \mathrm{R}$ to $810^{\circ} \mathrm{R}$ & \\
\hline $\mathrm{C}$ & Input Impedance & NA & \multicolumn{2}{|l|}{500 megohms min. at $960^{\circ} \mathrm{R}$} \\
\hline D & Output Impedance & $\mathrm{NA}$ & & \\
\hline$E$ & Excitation & $\mathrm{NA}$ & & \\
\hline $\mathrm{F}$ & Sensitivity & $10 \mathrm{pk}-\mathrm{mv} / \mathrm{pk}-\mathrm{g}$ & $5 \%$ max., any axis & \\
\hline G & Transverse Accel & $5 \%$ max. & & \\
\hline $\mathrm{H}$ & Linearity & $\pm 2 \% 0-50 \mathrm{~g}$ & $\pm 1 \%$ & \\
\hline 1 & Hysteresis & $\mathrm{NA}$ & & \\
\hline $\mathrm{J}$ & Resolution & $\mathrm{NA}$ & & \\
\hline$k$ & Accuracy & $5 \%$ & & \\
\hline$L$ & Freq. Response & $0-1$ KC flat $\pm 3 \mathrm{db}$ & $5-20 \mathrm{cps}$ to $4 \mathrm{KC}$ & \\
\hline$M$ & Noise Limit & MIL-S-446A & $\begin{array}{l}\text { response to acoustic nois } \\
\text { of } 100 \mathrm{db}^{4} \approx 0.01 \mathrm{mV} \\
\approx 0.0 .\end{array}$ & \\
\hline$N$ & Neutron Flux & $4.5 \times 10^{14} \mathrm{n} / \mathrm{cm}^{2}$-sec. & & \\
\hline 0 & Gamma Flux & \multicolumn{2}{|l|}{$1.9 \times 10^{11} \mathrm{ergs} / \mathrm{gm}(\mathrm{C})-\mathrm{hr}$} & \\
\hline$P$ & Dimersions & \multicolumn{3}{|c|}{$11 / 16^{\prime \prime}$ hex, x $0.88^{\prime \prime}$ high $11 / 16^{\prime \prime}$ hex, x $0.88^{\prime \prime}$ high } \\
\hline$Q$ & Weight & $2 \mathrm{oz}$. & \begin{tabular}{|l|l}
$1.4 \mathrm{oz}$. \\
\end{tabular} & \\
\hline$R$ & Resonant Freq. & $>7 \mathrm{KC}$ & $25 \mathrm{KC}$ min. & \\
\hline$S$ & Insulation Res. & \multicolumn{2}{|c|}{$>1000$ megohm at $50 \mathrm{VDC}$} & \\
\hline $\mathrm{T}$ & Material & stainless steel & stainless steel & \\
\hline & \multicolumn{2}{|c|}{ Sensitivity-Voltage (With 100 pf ext.) } & $12 \pm 2 \mathrm{pk}-\mathrm{mv} / \mathrm{pk}-\mathrm{g}$ & \\
\hline & Sensitivity-Charge & & 2.5 peak-pcmb/pk-g & \\
\hline & \multicolumn{2}{|c|}{ Capacitance (With 100 pf ext.) } & $200 \mathrm{pf}$ & \\
\hline & & & & \\
\hline & & & & \\
\hline & & & & \\
\hline
\end{tabular}





\section{DEVELOPMENT HISTORY}

Code No: $\mathrm{Gr}-2$

Model No. 2245

\section{REMARKS:}

Serial Number EA11 -

Summary Test Results:

Tested at WANL on 12/31/62 submerged in liquid nitrogen in a Dewar mounted on an MB vibration table at $20 \mathrm{~g}$ for $50 \mathrm{cps}, 100 \mathrm{cps}$, and $200 \mathrm{cps}$, and at $20 \mathrm{cps}$ at $10 \mathrm{~g}$. Room temperature test results compared favorably with $\mathrm{LN}_{2}$ test results.

This unit will be combined effects tested in the second GTR test in April 1963.

\section{General:}

Endevco selection based on reports of tests conducted by G. E. Hanford, Combustion Engineering, Chance Vought and LASL. Some details available.

\section{September 1963}

Additional tests on this unit are not planned at this time. It has been supplanted by the Endevco 2242 series (refer to Code No. Gr-1).
Mfgr: Endevco
P. 0 . 23780 
THIS PAGE INTENTIONALLY LEFT BLANK 


\section{VIBRATION TRANSDUCER}

Code No:

Type: Piezoelectric (Natural Quartz Crystal)

Mfgr: Kistler

Range: $0-10,000 \mathrm{~g}$
Spec. Control Dwg. No.

Evaluation by: WANL

Model No: $818 \mathrm{~S}$

Application:

PERFORMANCE \& ENVIRONMENTAL SPECIFICATIONS

\begin{tabular}{|c|c|c|c|c|}
\hline Test & Condition & NERVA Requirements & Manufacturer's Specs & $\begin{array}{l}\text { Summary of } \\
\text { Test Results }\end{array}$ \\
\hline$A$ & Overload & $100 \mathrm{~g}$ & $>10,000 \mathrm{~g}$ & \\
\hline $\mathrm{B}$ & Comp. Temp. Range & $140^{\circ} \mathrm{R}$ to $800^{\circ} \mathrm{R}$ & & \\
\hline C & Input Impedance & NA & & \\
\hline D & Output Impedance & $\mathrm{NA}$ & & \\
\hline$E$ & Excitation & $\mathrm{NA}$ & & \\
\hline$F$ & Sensitivity & & $5 \%$ & \\
\hline G & Transverse Accel & $5 \% \max$. & & \\
\hline $\mathrm{H}$ & Linearity & $\pm 2 \% 0-50 \mathrm{~g}$ & $1 \%$ & \\
\hline 1 & Hysteresis & NA & & \\
\hline $\mathrm{J}$ & Resolution & $\mathrm{NA}$ & $0.01 \mathrm{~g}$ & \\
\hline $\mathrm{K}$ & Accuracy & $5 \%$ & & \\
\hline$L$ & Freq. Response & $0-1 \mathrm{KC}$ flat $\pm 3 \mathrm{db}$ & $0.01 \mathrm{cps}$ to $5000 \mathrm{cps}$ & \\
\hline$M$ & Noise Limit & MIL-S-446A & & \\
\hline$N$ & Neutron Flux & $4.5 \times 10^{14} \mathrm{n} / \mathrm{cm}^{2}-\mathrm{sec}$ & & \\
\hline 0 & Gamma Flux & \multicolumn{2}{|l|}{$1.9 \times 10^{11} \mathrm{ergs} / \mathrm{gm}(\mathrm{C})-\mathrm{hr}$} & \\
\hline$\underline{P}$ & Dimensions & $0.63^{\prime \prime}$ hex, x $1.5^{\prime \prime}$ & $0.63^{\prime \prime}$ hex, x $1.5^{\prime \prime}$ & \\
\hline$Q$ & Weight & $2 \mathrm{oz}$ & $2 \mathrm{oz}$ & \\
\hline$R$ & Resonant Freq. & $>7000 \mathrm{cps}$ & $50,000 \mathrm{cps}$ & \\
\hline$S$ & Insulation Res. & \multicolumn{2}{|c|}{$>1000 \mathrm{megohm}$ at $50 \mathrm{VDC}$} & \\
\hline \multirow[t]{5}{*}{$T$} & Material & stainless steel & 303 Stainless Steel & \\
\hline & Sensitivity-Charge & & $2.5 \mathrm{pcb} / \mathrm{g}$ & \\
\hline & \multicolumn{2}{|c|}{ Sensitivity-Voltage $(1 \mathrm{ft})}$. & $50 \mathrm{mv} / \mathrm{g}$ & \\
\hline & Capacitance & & $40 \mu \mu \mathrm{Fd}$ & \\
\hline & Freq. Range & & $0-25,000 \mathrm{cps}(5 \%)$ & \\
\hline & & & & \\
\hline & & & & \\
\hline
\end{tabular}




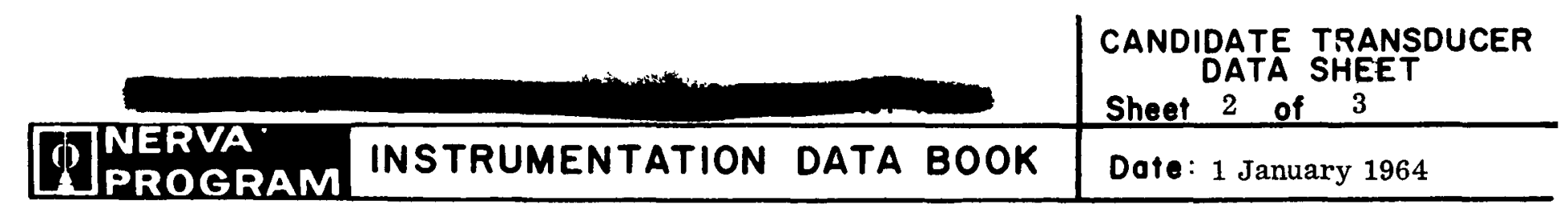

RADIATION TESTS

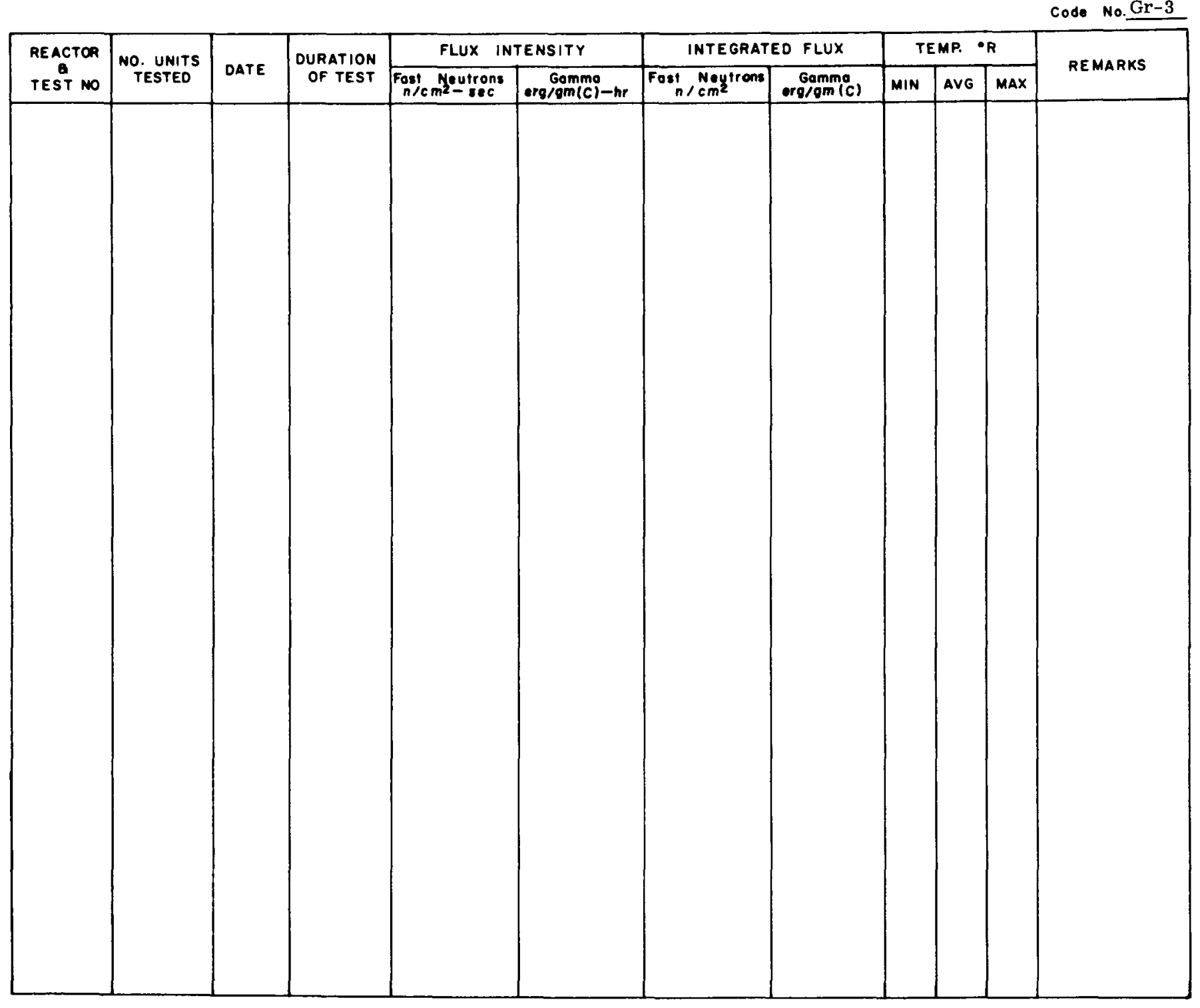




\begin{tabular}{|l|l|l}
\hline WERVA & $\begin{array}{l}\text { CANDIDATE TRANSDUCER } \\
\text { DATA SHEET } \\
\text { Sheet } 3 \text { of } 3\end{array}$ \\
\hline PROGRAM INSTRUMENTATION DATA BOOK & Dote: 1 January 1964 \\
\hline
\end{tabular}

\section{DEVELOPMENT HISTORY}

Code No: $\mathrm{Gr}-3$

Mfgr: Kistler

Model No. $818 \mathrm{~S}$

P. 0.16883

\section{REMARKS:}

Serial Number 12 and $16-$

\section{Summary Test Results:}

Test at WANL on 12/31/62 submerged in liquid nitrogen in a Dewar mounted on an MB vibration table at $20 \mathrm{~g}$ for $50 \mathrm{cps}, 100 \mathrm{cps}$, and $200 \mathrm{cps}$, and at $20 \mathrm{cps}$ at $10 \mathrm{~g}$. Room temperature test results compared favorably with $\mathrm{LN}_{2}$ test results.

This unit will be combined effects tested in the second GTR test in April 1963.

General:

Kistler selection based on reports of tests conducted by Atomics International and Oregon Laboratories. Results unknown.

\section{$\underline{30}$ September 1963}

There have been no further tests conducted on this model. Testing has been directed at units known to be radiation resistant. The $818 \mathrm{~S}$ is to be replaced by the Kistler model 808 , Code No. Gr-4. 
THIS PAGE INTENTIONALLY LEFT BLANK 


\section{VIBRATION TRANSDUCER}

Code No: $\mathrm{Gr}-4$

Type: (Natural Quartz Crystal) Piezoelectric

Mfgr: Kistler

Range: $\underline{0-10,000 \mathrm{~g}}$
Spec. Control Dwg. No.

Evaluation by: WANL

Model No: 808

Application:

PERFORMANCE \& ENVIRONMENTAL SPECIFICATIONS

\begin{tabular}{|c|c|c|c|c|}
\hline Test & Condition & NERVA Requirements & Manufacturer's Specs & $\begin{array}{l}\text { Summary of } \\
\text { Test Results }\end{array}$ \\
\hline A & Overload & $100 \mathrm{~g}$ & $\rightarrow 10,000 \mathrm{~g}$ & \\
\hline B & Comp. Temp. Range & $140^{\circ} \mathrm{R}$ to $800^{\circ} \mathrm{R}$ & $60^{\circ} \mathrm{R}$ to $960^{\circ} \mathrm{R}$ & \\
\hline C & Input Impedance & $\mathrm{NA}$ & & \\
\hline D & Output Impedance & $\mathrm{NA}$ & & \\
\hline$E$ & Excitation & $\mathrm{NA}$ & & \\
\hline$F$ & Sensitivity & & $1 \%$ & \\
\hline G & Transverse Accel & $5 \% \max$. & & \\
\hline $\mathrm{H}$ & Linearity & $\pm 2 \% 0-50 \mathrm{~g}$ & $1 \%$ & \\
\hline 1 & Hysteresis & NA & & \\
\hline $\mathrm{J}$ & Resolution & $\mathrm{NA}$ & $0.01 \mathrm{~g}$ & \\
\hline K & Accuracy & $5 \%$ & & \\
\hline$L$ & Freq. Response & $0-1 \mathrm{KC}$ flat $\pm 3 \mathrm{db}$ & $5 \%>0.01$ to $10,000 \mathrm{cps}$ & \\
\hline$M$ & Noise Limit & MIL-S-446A & & \\
\hline $\mathrm{N}$ & Neutron Flux & $4.5 \times 10^{14} \mathrm{n} / \mathrm{cm}^{2}-\mathrm{sec}$. & & \\
\hline 0 & Gamma Flux & \multicolumn{2}{|c|}{$1.9 \times 10^{11} \mathrm{ergs} / \mathrm{gm}(\mathrm{C})-\mathrm{hr}$} & \\
\hline P & Dimensions & $5 / 8^{\prime \prime} \times 1^{\prime \prime}$ & $5 / 8 " \times 1 "$ & \\
\hline Q & Weight & $7 \mathrm{oz}$ & $7 \mathrm{oz}$ & \\
\hline$R$ & Resonant Freq. & $\geqslant 7000 \mathrm{cps}$ & $50,000 \mathrm{cps}$ & \\
\hline$S$ & Insulation Res. & \multicolumn{2}{|c|}{$\geqslant 1000$ megohm at $50 \mathrm{VDC}$} & \\
\hline \multirow[t]{5}{*}{$T$} & Material & Stainless Steel & & \\
\hline & Sensitivity-Charge & & $1 \mathrm{pcb} / \mathrm{g}$ & \\
\hline & Sensitivity-Voltage & (1 ft.) & & \\
\hline & Capacitance & & $40 \mu \mu \mathrm{Fd}$ & \\
\hline & Freq. Range & & $0-25,000$ cps. $(5 \%)$ & \\
\hline & & & & \\
\hline & & & & \\
\hline
\end{tabular}





\begin{tabular}{|l|l|l}
\hline M.RVA & $\begin{array}{l}\text { CANDIDATE TRANSDUCER } \\
\text { DATA SHEET } \\
\text { Sheet } 3 \text { of } 3\end{array}$ \\
\hline
\end{tabular}

\section{DEVELOPMENT HISTORY}

Code No: $\quad$ Gr-4

Model No. 808
Mfgr: Kistler

P. 0 .

REMARKS:

Serial Number 113 -

Summary Test Results:

Tested at WANL on 12/31/62 submerged in liquid nitrogen in a dewar mounted on an MB vibration table at $20 \mathrm{~g}$ for $50 \mathrm{cps}, 100 \mathrm{cps}$, and $200 \mathrm{cps}$, and at $20 \mathrm{cps}$ at $10 \mathrm{~g}$. $\mathrm{LN}_{2}$ test results did not compare favorably with ambient test results. This unit will not be tested further.

\section{General:}

Kistler selection based on reports of tests conducted by Atomics International and Oregon Laboratories. Results unknown.

30 September 1963

Further tests have not been conducted on this model. Tests have been directed at other types that are more radiation resistant. New units delivered to WANL are to be tested at both ambient and cryogenic temperatures. If the results are favorable more tests will be designated. 
THIS PAGE INTENTIONALLY LEFT BLANK 


\section{VIBRATION TRANSDUCER}

Code No: Gr-5

Type: Strain Gage-Gas Damped

Mfgr: Statham

Range: $\pm 25 \mathrm{~g}$
Spec. Control Dwg. No.

Evaluation by: WANL

Model No: A515 TC-25-350

Application:

\section{PERFORMANCE \& ENVIRONMENTAL SPECIFICATIONS}

\begin{tabular}{|c|c|c|c|c|}
\hline Test & Condition & NERVA Requirements & Manufacturer's Specs & $\begin{array}{l}\text { Summary of } \\
\text { Test Results }\end{array}$ \\
\hline $\bar{A}$ & Overload & $100 \mathrm{~g}=$ & $\pm 200 \mathrm{~g}$ & \\
\hline B & Comp. Temp. Range & $140^{\circ} \mathrm{R}$ to $800^{\circ} \mathrm{R}$ & $140^{\circ} \mathrm{R}$ to $735^{\circ} \mathrm{R}$ & \\
\hline $\mathrm{C}$ & Input Impedance & 350 ohms (nom.) & $350 \mathrm{ohms} \pm 10 \%$ & \\
\hline D & Output Impedance & $<1000$ ohms (nom.) & 350 ohms $\pm 10 \%$ & \\
\hline$E$ & Excitation & $5 \mathrm{VDC}$ or $\mathrm{AC} \mathrm{rms}$ & \multicolumn{2}{|c|}{ 5VDC or AC (rms) through carrier freq. } \\
\hline$F$ & Sensitivity & $5 \mathrm{mv} / \mathrm{v}$ approx. & $4 \mathrm{mv} / \mathrm{v}$ & \\
\hline G & Transverse Accel & $5 \% \max$. & \multicolumn{2}{|c|}{$<0.01 \mathrm{~g} / \mathrm{g}$ up to $3 \mathrm{x}$ rated $\mathrm{g}$ or $\pm 150 \mathrm{~g}$} \\
\hline $\mathrm{H}$ & Linearity & $\pm 2 \% 0-50 \mathrm{~g}$ & $\pm 0.75 \% \mathrm{FR}$ & \\
\hline 1 & Hysteresis & NA & $\pm 0.75 \% \mathrm{FR}$ & \\
\hline $\mathrm{J}$ & Resolution & $\mathrm{NA}$ & & \\
\hline$K$ & Accuracy & $5 \%$ & & \\
\hline$L$ & Freq. Response & 0 - 1 KC flat $\pm 3 \mathrm{db}$ & $\pm 5 \%$ & \\
\hline$M$ & Noise Limit & MIL-S-446A & & \\
\hline $\mathrm{N}$ & Neutron Flux & $4.5 \times 10^{14} \mathrm{n} / \mathrm{cm}^{2}-\mathrm{sec}$. & & \\
\hline 0 & Gamma Flux & \multicolumn{2}{|c|}{$1.9 \times 10^{11} \mathrm{ergs} / \mathrm{gm}(\mathrm{C})-\mathrm{hr}$} & \\
\hline$P$ & Dimensions & $1 " \times 1 " \times 1.5 "$ high & $1 " \times 1 " \times 1.52 "$ high & \\
\hline$Q$ & Weight & $4 \mathrm{oz}$ & $4 \mathrm{oz}$ & \\
\hline$R$ & Resonant Freq. & $>1000 \mathrm{cps}$ & $1000 \mathrm{cps}$ & \\
\hline$S$ & Insulation Res. & \multicolumn{2}{|c|}{$>1000$ megohms at $50 \mathrm{VDC}$} & \\
\hline $\bar{T}$ & Material & stainless steel & & \\
\hline & & & & \\
\hline & & & & \\
\hline & & & & \\
\hline & & & & \\
\hline & & & & \\
\hline
\end{tabular}


CANDIDATE TRANSDUCER

DATA SHEET

Sheet 2 of 4

Dote: 1 January 1964

\section{RADIATION TESTS}

Code No. Gr-5

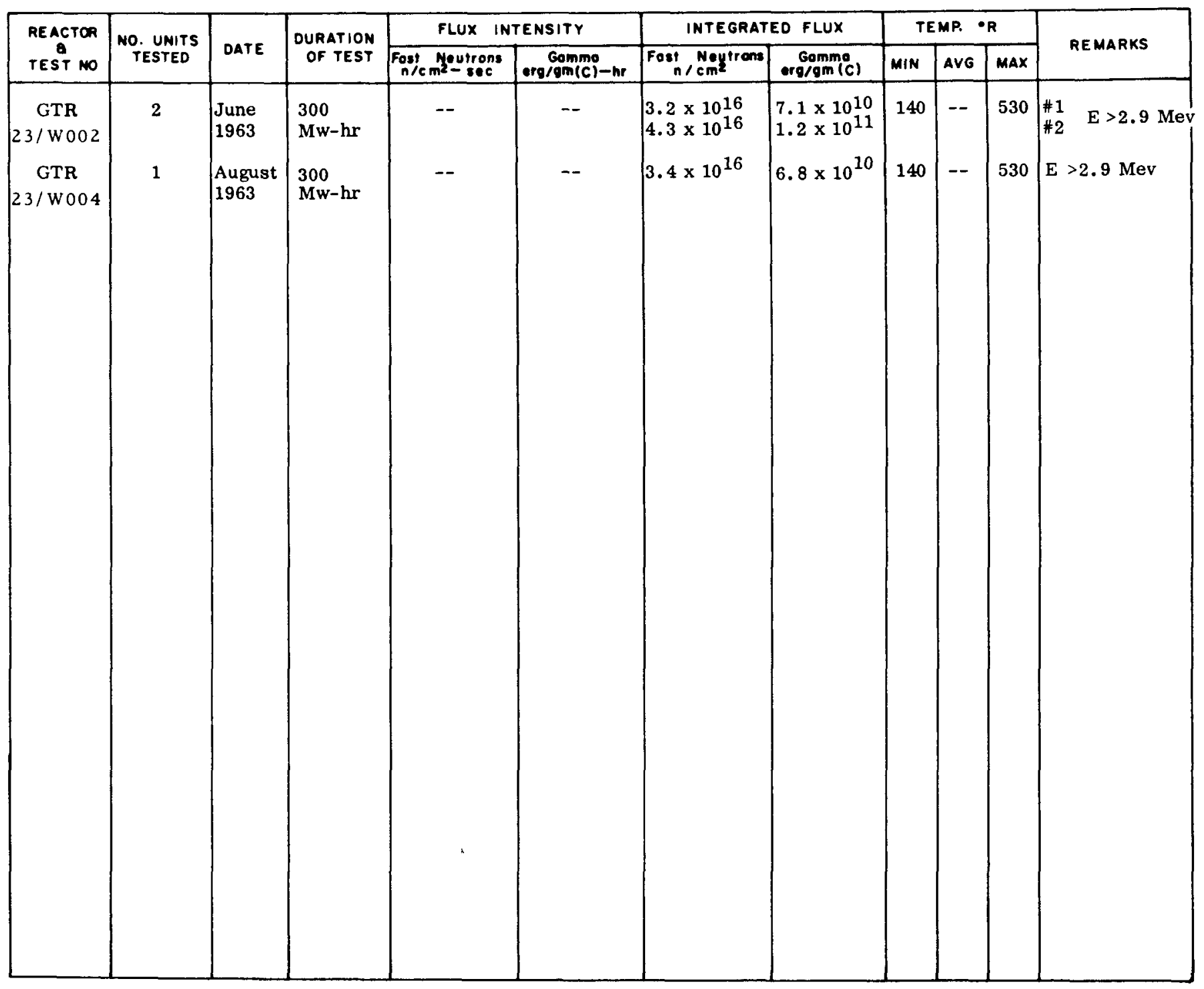




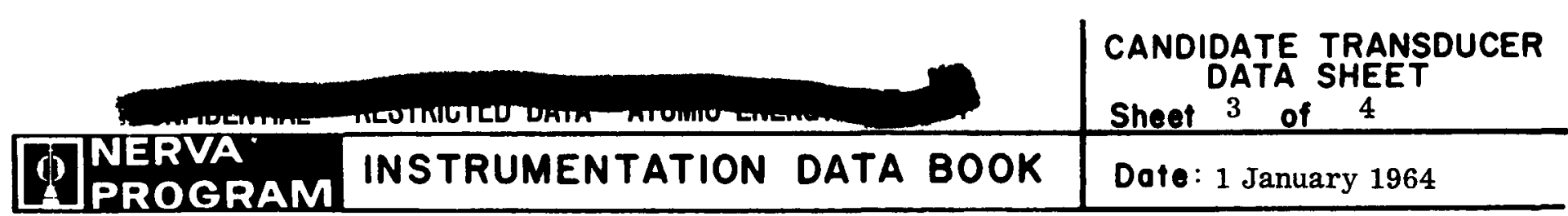

\section{DEVELOPMENT HISTORY}

Code No:

Model No. A515
Mfgr: Statham

P. 0. 32406

\section{REMARKS:}

Two units are on order for the middle of February delivery. These units will be combined effects tested in the second GTR test in April 1963.

The experience gained by testing a Statham pressure transducer on the first GTR combined effects test (and the post-irradiation examination) indicates a reliable type strain gage operation. Statham will use a mixture of helium and neon for gas damping.

\section{December 1963 - GTR Test No. 4 23/W002}

Two units were tested in combined environments at GTR in June, 1963. They became inoperative after a detonation in the cryostat during the test. (Ref. GD/FW report FZK-170-1).

Each accelerometer was mounted on the spring-like, spider-web-type platform of a vibration table consisting of an electromagnet and a voice coil. By varying the frequency of the input signal to the voice coil, each accelerometer was vibrated at several different frequencies during each data cycle. The signal frequency was supplied by a Hewlett-Packard 650-A test oscillator, the frequency of which was monitored by an EPUT meter. The voice coils were driven by a McIntosh 200-watt power amplifier.

After the current to the electromagnetic $\left(\mathrm{I}_{\mathrm{DC}}\right)$ and the current to the voice coil $\left(\mathrm{I}_{\mathrm{AC}}\right)$ were adjusted to provide the desired displacement at each frequency, the values were recorded. The accelerometer output was read from a Ballentine peak-to-peak voltmeter, and recorded. Oscilloscope photographs were made of the voice-coil input, and the accelerometer output traces displayed simultaneously on a Tektronix 545 oscilloscope.

After the irradiation, the accelerometers were removed from the test fixture and tested on a standard shaker table in the Irradiated Materials Laboratory. Some of the units were then disassembled for examination of the internal components.

\section{$\underline{\text { Test }} \underline{\text { Results }}$}

The accelerometers were exposed to the integrated neutron fluxes and gamma doses given on sheet 2 .

The accelerometer outputs vs radiation exposure are shown in Figures 4.5 and 4.6 of GD/FW report FZK-170-1 for two vibration frequencies (operating temperatures are also shown for each accelerometer). Although some of the accelerometers were vibrated at as many as 17 frequencies, the accelerometer output at two of these frequencies is sufficient to demonstrate the problems encountered after the detonations. The point at which the detonations occurred is indicat ed in each of the figures. 


\begin{tabular}{|l|l|l|l|l|}
\hline TERVA & $\begin{array}{l}\text { CANDIDATE TRANSDUCER } \\
\text { DATA SHEET }\end{array}$ \\
\hline PROGRAM INSTRUMENTATION DATA BOOK & Dote: 1 January 1964 \\
\hline
\end{tabular}

\section{DEVELOPMENT HISTORY}

Code No: Gr-5

Model No. A515
Mfgr: Statham

P. 0.32406

\section{REMARKS:}

In Section I, it was pointed out that the validity of some of the data for test items in the Dewars was questionable because of the detonations. This becomes evident after a study of the data in Figures 4.5 and 4.6.

After the irradiation both of the accelerometers were tested on a standard shaker table with the results that neither unit was operative.

The accelerometers were disassembled after being tested on the shaker table. In one of the units the strain wires in all four legs were broken; in the other, the strain wires in two of the four legs were broken.

The detonations in the $\mathrm{LN}_{2}$ Dewar affected the output of all of the accelerometers, these units failed completely. Some of the problems were caused by damage (resulting from the detonations and the effects of radiation) to the signal leads and to the vibration table leads. The complete failure during the detonations makes it possible to separate the effects of the detonations from the effects of radiation.

\section{December 1963 - GTR Test No. 7A 23/W004}

One additional unit was satisfactorily tested in WANL laboratory through several cycles of ambient and cryogenic conditions. It was installed in a Dewar for the August, 1963 GTR test but failed before irradiation. Therefore, no data is available. A post-irradiation examination determined that one leg of the unbonded strain gage bridge was open.

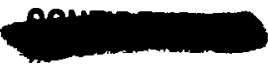




\section{VIBRATION TRANSDUCER}

Code No: $\mathrm{Gr}-6$

Type: Variable Reluctance

Mfgr: Wiancko

Range: $\pm 25 \mathrm{~g}(0-125 \mathrm{cps})$
Spec. Control Dwg. No.

Evaluation by: WANL

Model No: AX40

Application:

PERFORMANCE \& ENVIRONMENTAL SPECIFICATIONS

\begin{tabular}{|c|c|c|c|c|}
\hline Test & Condition & NERVA Requirements & Manufacturer's Specs & $\begin{array}{l}\text { Summary of } \\
\text { Test Results }\end{array}$ \\
\hline $\mathbf{A}$ & Overload & $100 \mathrm{~g}$ & 5 times rated range & \\
\hline B & Comp. Temp. Range & $140^{\circ} \mathrm{R}$ to $800^{\circ} \mathrm{R}$ & $140^{\circ} \mathrm{R}$ to $560^{\circ} \mathrm{R}$ & \\
\hline $\mathrm{C}$ & Input Impedance & $<1000$ ohms (nom.) & 28VDC, $18 \mathrm{ma}$ (Carrier) & \\
\hline D & Output Impedance & $<1000$ ohms (nom.) & less 500 ohms (Carrier) & \\
\hline$E$ & Excitation & $35 \mathrm{VAC}$ rms & \multicolumn{2}{|c|}{ 28VDC (reg.) $18 \mathrm{ma}$ (Carrier) } \\
\hline$F$ & Sensitivity & $100 \mathrm{mv} / \mathrm{v}$ & \multicolumn{2}{|c|}{ $\pm 21 / 2 \mathrm{v}$ from bias pt. $+21 / 2 \mathrm{v}$} \\
\hline G & Transverse Accel & $<0.02 \mathrm{~g} / \mathrm{g}$ & $<0.01 \mathrm{~g} / \mathrm{g}$ & \\
\hline $\mathrm{H}$ & Linearity & combined effects less & $1 \%$ & \\
\hline 1 & Hysteresis & $\int$ than $\pm 0.5 \% \mathrm{FR}$ & $0.1 \%$ & \\
\hline $\mathrm{J}$ & Resolution & $<0.1 \% \mathrm{FR}$ & Continuous & \\
\hline$K$ & Accuracy & $\pm 3.5 \%$ & & \\
\hline$L$ & Freq. Response & $0-80 \mathrm{cps}$ flat $\pm 3 \mathrm{db}$ & flat within $5 \%$ to $80 \mathrm{cps}$ & \\
\hline$M$ & Noise Limit & MIL-S-446A & output ripple $<0.3 \% \mathrm{rms}$ & \\
\hline$N$ & Neutron Flux & $4.5 \times 10^{14} \mathrm{n} / \mathrm{cm}^{2}-\mathrm{sec}$ & & \\
\hline 0 & Gamma Flux & \multicolumn{2}{|l|}{$1.9 \times 10^{11} \mathrm{ergs} / \mathrm{cm}(\mathrm{C})-\mathrm{hr}$} & \\
\hline $\mathbf{P}$ & Dimensions & \multicolumn{2}{|c|}{$11 / 16^{\prime \prime}$ hex, x $0.88^{\prime \prime}$ high $1^{\prime \prime} \times 11 / 2^{\prime \prime} \times 3 / 4^{\prime \prime}$ high } & \\
\hline$Q$ & Weight & $3 \mathrm{oz}$. & $3 \mathrm{oz}$ & \\
\hline $\mathrm{R}$ & Resonant Freq. & $>500 \mathrm{cps}$ & $500 \mathrm{cps}$ & \\
\hline $\mathrm{S}$ & Insulation Res. & $>100$ megohm at $50 \mathrm{VDC}$ & 100 megohms at 50VDC & \\
\hline$T$ & Material & stainless steel & stainless steel case & \\
\hline & & & & \\
\hline & & & & \\
\hline & & & & \\
\hline & & & & \\
\hline & & & & \\
\hline
\end{tabular}




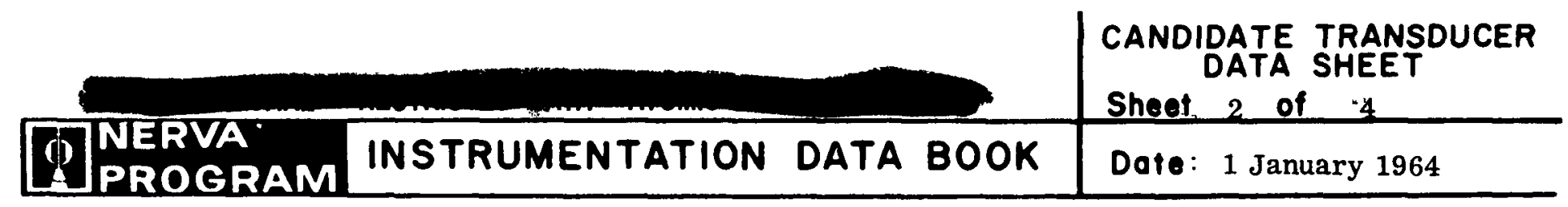

RADIATION TESTS

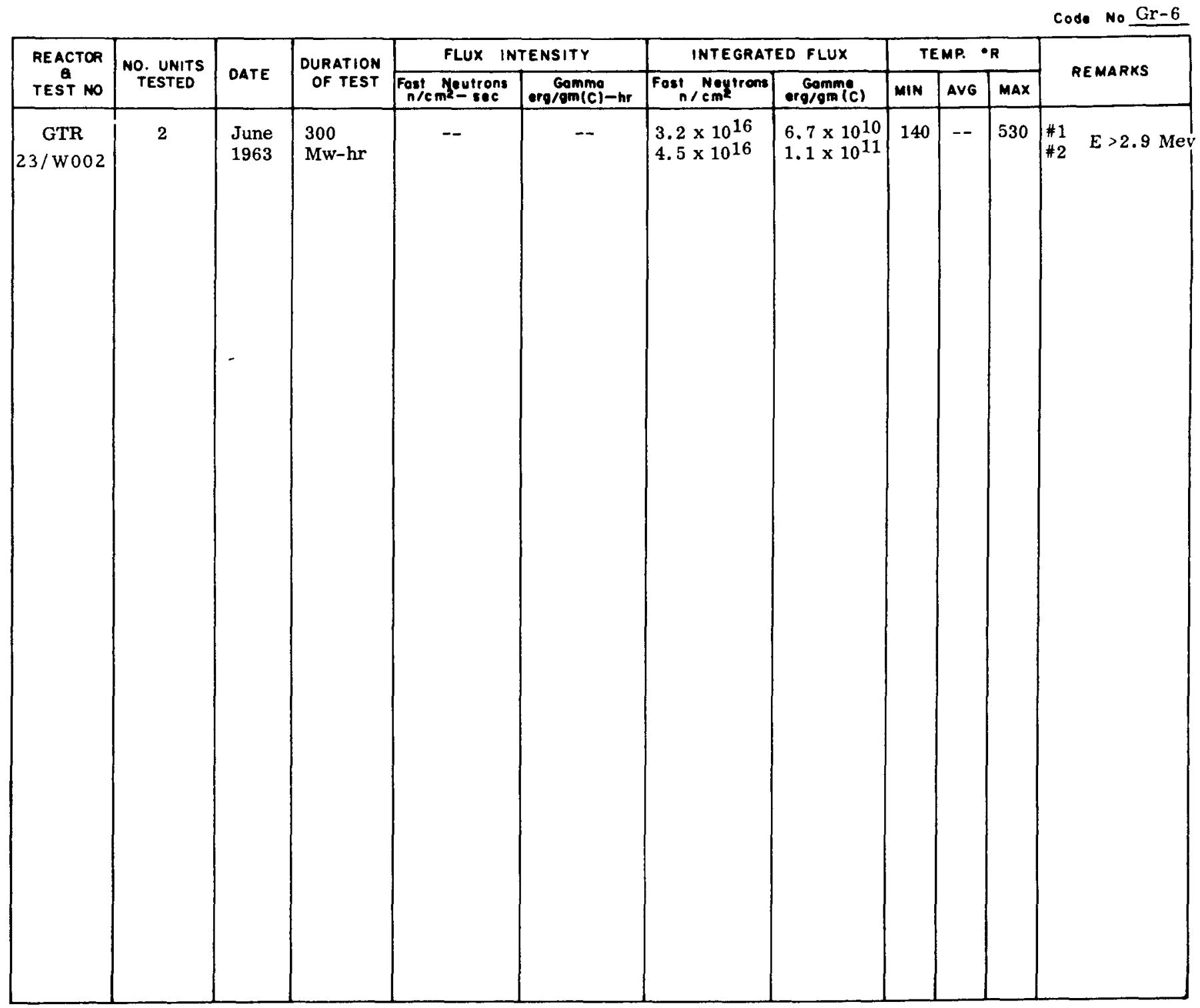

(w) Lstronuclear * 


\begin{tabular}{|l|l|l}
\hline QNERVA & \multicolumn{2}{c}{$\begin{array}{l}\text { CANDIDATE TRANSDUCER } \\
\text { DATA SHEET } \\
\text { Sheet } 3 \text { of } 4\end{array}$} \\
\hline PROGRAM INSTRUMENTATION DATA BOOK & Dote: 1 January 1964 \\
\hline
\end{tabular}

\section{DEVELOPMENT HISTORY}

Code No: $\frac{\mathrm{Gr}-6}{\mathrm{~A}-6}$

Mfgr: Wiancko

P. 0.32377

\section{REMARKS:}

Two units are on order for the middle of February delivery. These units will be combined effects tested in the second GTR test in April.

From the success of the Wiancko variable reluctance type pressure transducer on the first GTR combined effects test, indication is that a variable reluctance accelerometer for low temperature operation may be developed.

\section{December 1963 - GTR Test No. $4 \quad 23 /$ W 002}

Two units built by Wiancko per WANL specifications were placed in the combined environment of $\mathrm{LN}_{2}$ and irradiation at GTR in June, 1963 and dynamically tested. One became inoperative after a detonation occuring in the Dewar. The second unit operated throughout the 100 hour test (Ref. GD/FW report FZK-170-1).

Each accelerometer was mounted on the spring-like, spider-web-type platform of a vibration table consisting of an electromagnet and a voice coil. By varying the frequency of the input signal to the voice coil, each accelerometer was vibrated at several different frequencies during each data cycle. The signal frequency was supplied by a Hewlett-Packard 650-A test oscillator, the frequency of which was monitored by an EPUT meter. The voice coils were driven by a McIntosh 200-watt power amplifier.

After the current to the electromagnetic $\left(\mathrm{I}_{\mathrm{DC}}\right)$ and the current to the voice coil $\left(\mathrm{I}_{\mathrm{AC}}\right)$ were adjusted to provide the desired displacement at each frequency, the values were recorded. The accelerometer output was read from a Ballentine peak-to-peak voltmeter, and recorded. Oscilloscope photographs were made of the voice-coil input, and the accelerometer output traces displayed simultaneously on a Tektronix 545 oscilloscope.

After the irradiation, the accelerometers were removed from the test fixture and tested on a standard shaker table in the Irradiated Materials Laboratory. Some of the units were then disassembled for examination of the internal components.

\section{$\underline{\text { Test }} \underline{\text { Results }}$} sheet 2.

The accelerometers were exposed to the integrated neutron fluxes and gamma doses given on

The accelerometer outputs vs radiation exposure are shown in Figures 4.9 and 4.10 for two vibration frequencies (operating temperatures are also shown for each accelerometer). Although some of the accelerometers were vibrated at as many as 17 frequencies, the accelerometer output at two of these frequencies is sufficient to demonstrate the problems encountered after the detonations. The point at which the detonations occurred is indicated in each of the figures.

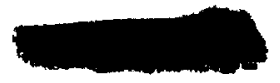




\section{DEVELOPMENT HISTORY}

Code No: $\mathrm{Gr}-6$

Model No. $\mathrm{AX} 40$
Mfgr: Wiancko

P. 0.32377

\section{REMARKS:}

The validity of some of the data for test items in the Dewars was questionable because of the detonations. This becomes evident after a study of the data in Figures 4.9 and 4.10.

Unit No. 1 became noisy during the data cycle at the 1-Mw power level. After the detonations, a resistance check indicated that this unit had developed an open circuit in one of the coils. After the test, the cover was removed for inspection. It was determined that the open circuit was in the lower coil since the lead wires was very brittle and had flaked off in several places.

Coil resistances of unit No. 2 compare very favorably with factory values. Testing of this unit on a shaker table has been delayed pending receipt of the necessary carrier amplifier.

The detonations in the $\mathrm{LN}_{2}$ Dewar affected the output of both accelerometers but they continued to operate but with noisy output and/or reduced sensitivity. Some of the problems were caused by damage (resulting from the detonations and the effects of radiation) to the signal leads and to the vibration table leads. Except in the case of complete failure during the detonations (unit No. 1), it is not possible to separate the effects of the detonations from the effects of radiation. 


\section{VIBRATION TRANSDUCER}

Code No: $\quad \mathrm{Gr}-7$

Type: LVDT-Vibrometer

Mfgr: Physical Sciences

Range: \pm 0.025 to \pm 0.05 inches Displacement
Spec. Control Dwg. No.

Evaluation by: WANL

Model No: XT1-A

Application:

\section{PERFORMANCE \& ENVIRONMENTAL SPECIFICATIONS}

\begin{tabular}{|c|c|c|c|c|}
\hline Test & Condition & NERVA Requirements & Manufacturer's Specs & $\begin{array}{l}\text { Summary of } \\
\text { Test Results }\end{array}$ \\
\hline $\bar{A}$ & Overload & $100 \mathrm{~g}$ & \pm 0.05 inches & \\
\hline$B$ & Comp. Temp. Range & $140^{\circ} \mathrm{R}$ to $800^{\circ} \mathrm{R}$ & $140^{\circ} \mathrm{R}$ to $1260^{\circ} \mathrm{R}$ & \\
\hline $\mathrm{C}$ & Input Impedance & $<100 \mathrm{ohm}$ & $40 \mathrm{ohms}$ & \\
\hline D & Output Impedance & $<100 \mathrm{ohm}$ & $40 \mathrm{ohms}$ & \\
\hline$E$ & Excitation & 5,10, or $20 \mathrm{VDC}$ or $\mathrm{AC}$ & $5 \mathrm{VAC}(4000 \mathrm{cps})$ & \\
\hline $\mathrm{F}$ & Sensitivity & $40 \mathrm{mv}$ FR (nom.) & $30 \mathrm{mv} / 0.005$ inches & \\
\hline G & Transverse Accel & $<0.02 \mathrm{~g} / \mathrm{g}$ & $2 \%$ for $50 \mathrm{~g}$ & \\
\hline $\mathrm{H}$ & Linearity & & 50 to $500 \mathrm{cps} \pm 5 \%$ & \\
\hline 1 & Hysteresis & & & \\
\hline $\mathrm{J}$ & Resolution & $<0.1 \% \mathrm{FR}$ & Infinite & \\
\hline$K$ & Accuracy & $\pm 3.5 \%$ & Up to $500 \mathrm{cps} 5 \%$ & \\
\hline$L$ & Freq. Response & $50-500 \mathrm{cps}$ flat $\pm 3 \mathrm{db}$ & 50 to $500 \mathrm{cps}$ & \\
\hline$M$ & Noise Limit & MIL-S-446A & & \\
\hline$N$ & Neutron Flux & $4.5 \times 10^{14} \mathrm{n} / \mathrm{cm}^{2}$-sec. & $1 \times 10^{21} \mathrm{nvt}$ & \\
\hline 0 & Gamma Flux & $1.9 \times 10^{11} \mathrm{ergs} / \mathrm{gm}(\mathrm{C})-$ & hr $8.8 \times 10^{16} \mathrm{ergs} / \mathrm{gm}$ & $\mathrm{hr}$ \\
\hline $\mathbf{P}$ & Dimensions & $3 / 4^{\prime \prime}$ dia. $\times 1-3 / 4^{\prime \prime} \lg$. & $3 / 4 "$ dia. $\times 1-3 / 4 "$ lg. & \\
\hline$Q$ & Weight & $2 \mathrm{oz}$. & $5-1 / 2$ oz. & \\
\hline$R$ & Resonant Freq. & $>500 \mathrm{cps}$ & & \\
\hline$S$ & Insulation Res. & $50 \mathrm{M}$ ohms to $250 \mathrm{VDC}$ & $50 \mathrm{M}$ ohms & \\
\hline$T$ & Material & stainless steel & stainless steel & \\
\hline $\mathrm{U}$ & Full Scale Sensitivity & & $0.10 \mathrm{v} / \mathrm{v}$ to $0.30 \mathrm{v} / \mathrm{v}$ & \\
\hline & & & & \\
\hline & & & & \\
\hline & & & & \\
\hline & & & & \\
\hline
\end{tabular}


RADIATION TESTS

Code No. Gr-7

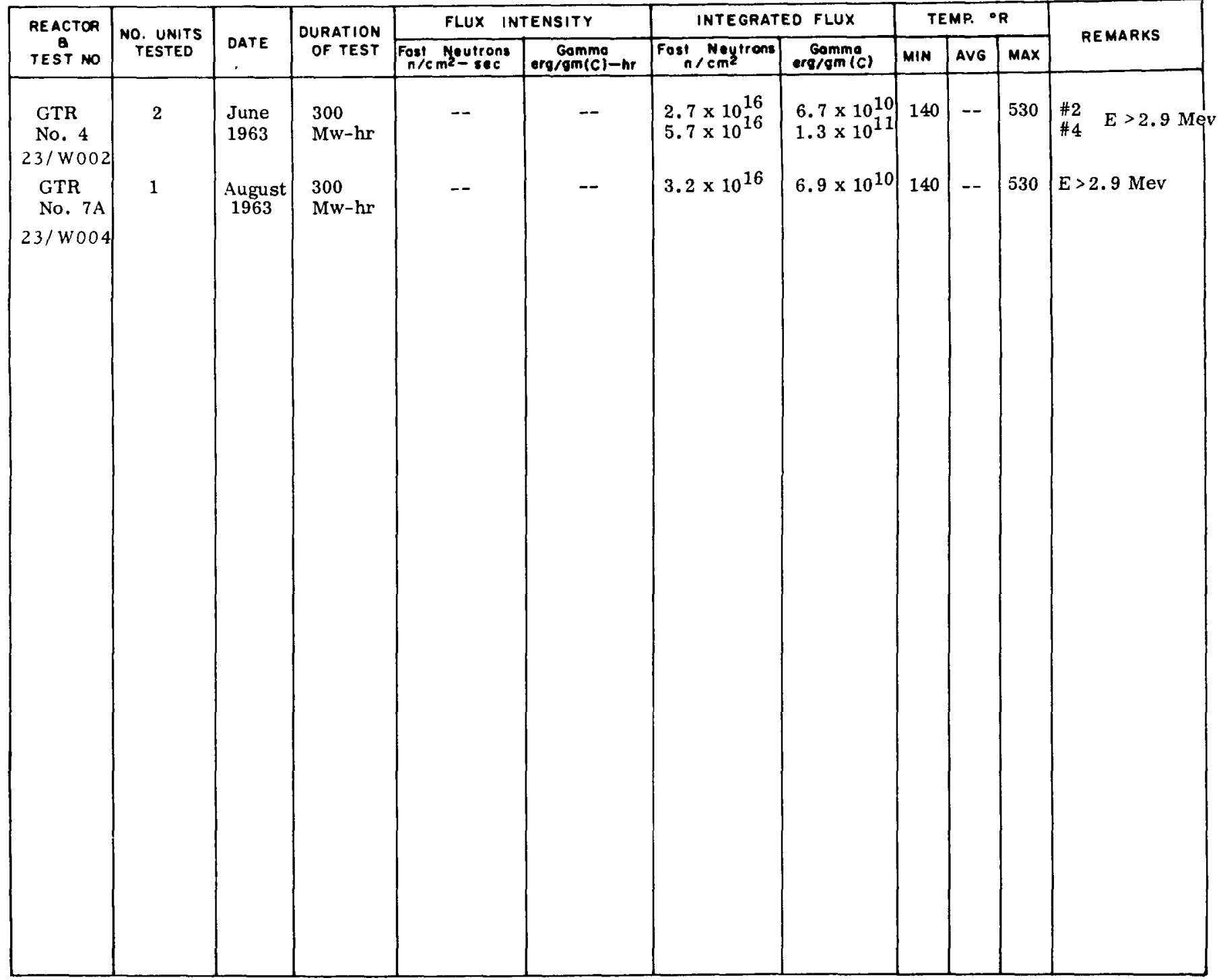




\begin{tabular}{|l|l|l}
\hline NERVA & $\begin{array}{l}\text { CANDIDATE TRANSDUCER } \\
\text { DATA SHEET }\end{array}$ \\
PROGRAM & INSTRUMENTATION DATA BOOK & Dafe: 1 January 1964 \\
\hline
\end{tabular}

\section{DEVELOPMENT HISTORY}

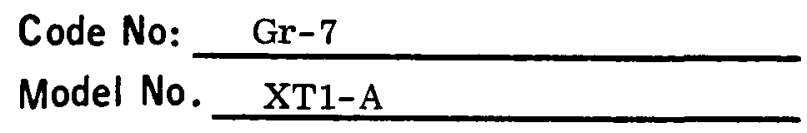

Mfgr: Physical Sciences

P. 0 . 32380

\section{REMARKS:}

Ambient and $\mathrm{LN}_{2}$ tests at WANL compare favorably.

Two units on order now will be used in the combined effects test No. 2 at GTR in April. Reports indicate that units have been exposed to greater than $10^{20}$ nvt at G. E. Hanford. 15 December 1963 - GTR Test No. 4 23/W002 100 hours.

Two units were placed in $\mathrm{LN}_{2}$ at GTR in June, 1963 and vibrated at variable frequencies for

Each accelerometer was mounted on the spring-like, spider-web-type platform of a vibration table consisting of an electromagnet and a voice coil. By varying the frequency of the input signal to the voice coil, each accelerometer was vibrated at several different frequencies during each data cycle. The signal frequency was supplied by a Hewlett-Packard 650-A test oscillator, the frequency of which was monitored by an EPUT meter. The voice coils were driven by a McIntosh 200-watt power amplifier.

After the current to the electromagnetic $\left(I_{D C}\right)$ and the current to the voice coil ( $\left.I_{A C}\right)$ were adjusted to provide the desired displacement at each frequency, the values were recorded. The accelerometer output was read from a Ballentine peak-to-peak voltmeter, and recorded. Oscilloscope photographs were made of the voice-coil input, and the accelerometer output traces displayed simultaneously on a Tektronix 545 oscilloscope.

After the irradiation, the accelerometers were removed from the test fixture and tested on a standard shaker table in the Irradiated Materials Laboratory. The units were then disassembled for examination of the internal components.

Test Results

The accelerometers were exposed to the integrated neutron fluxes and gamma doses given on sheet 2.

The accelerometer outputs vs radiation exposure are shown in Figures 4.7 and 4.8 of GD/FW report FZK-170-1 for two vibration frequencies (operating temperatures are also shown for each accelerometer). Although some of the accelerometers were vibrated at as many as 17 frequencies, the accelerometer output at two of these frequencies is sufficient to demonstrate the problems encountered after the detonations. The point at which the detonations occurred is indicated in each of the figures. 


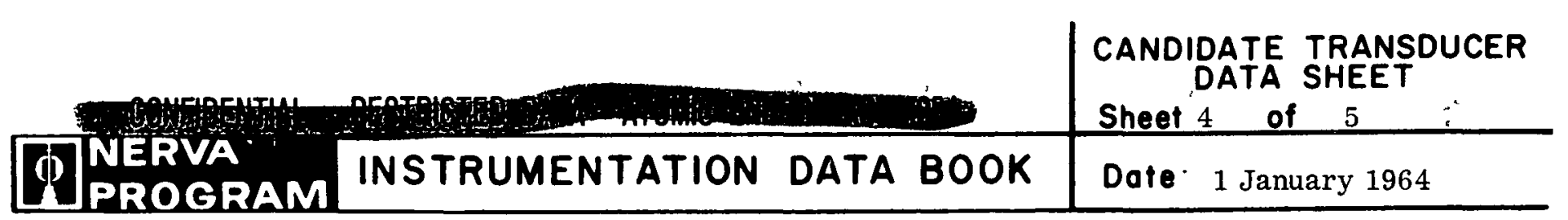

\section{DEVELOPMENT HISTORY}

Code No: $\mathrm{Gr}-7$

Model No. XT1-A
Mfgr: Physical Sciences

P. 0.32380

\section{REMARKS:}

The validity of some of the data for test items in the Dewars was questionable because of the detonations. This becomes evident after a study of the data in Figures 4.7 and 4.8.

After the irradiation both units were tested on a standard shaker table. This test indicated that one unit was inoperable and the sensitivity of the other was considerably reduced.

The accelerometers were disassembled after being tested on the shaker table.

The units showed no change in the leakage resistance or in the resistance of the coils. It was found that the inoperative unit had some foreign material in the dynamic-mass area. This caused the unit to "hang up." After being cleaned, the unit was found to be operative. The other unit, which had a decreased output, contained a smaller amount of the foreign matter. Cleaning this unit improved its operation.

The detonations in the $\mathrm{LN}_{2}$ Dewar affected the output of both accelerometers. Some of the problems were caused by damage (resulting from the detonations and the effects of radiation) to the signal leads and to the vibration table leads. It is not possible to separate the effects of the detonations from the effects of radiation.

\section{December 1963 - GTR Test No. 7A 23/W004}

One (1) unit was tested at GTR in August, 1963 under the same conditions as the June, 1963 test.

Vibration generators were used to vibrate the components. Each generator consisted of two tandem-mounted electromagnets and two mechanically-connected voice coils. The voice coils for the vibration generators were connected in series and were driven simultaneously with a McIntosh 200-watt power amplifier. The signal frequency to the voice coils was supplied by a Hewlett-Packard $200 \mathrm{CD}$ signal generator, the frequency of which was monitored by an EPUT meter. Output from the vibrometer was read from a Hewlett-Packard $400 \mathrm{H}$ rms voltmeter. A dual-beam oscilloscope (Tektronix model 535 with 53/54 C preamplifier) was used to selectively monitor the accelerometer outputs and the audio oscillator frequency.

The accelerometers were vibrated at the following frequencies (cps) during the test: 50,75 , $100,125,150,300,450,600,750,900$, and 1050 .

Resistance and/or capacitance measurements (as applicable) were made on the accelerometer signal leads periodically during the test. Also, the AC and DC vibration-generator coil resistances were measured. The vibration-generators were energized throughout the test except while the resistance and capacitance measurements were being made. 


\section{DEVELOPMENT HISTORY}

Code No: $\mathrm{Gr}-7$

Model No. XT1-A
Mfgr: Physical Sciences

P. 0.32380

\section{REMARKS:}

\section{$\underline{\text { Test }} \underline{\text { Results }}$}

Output data was recorded for the accelerometers during four data cycles (pre- and postirradiation and the first and last 3-Mw cycles). It should be noted that the outputs obtained were read from the HP $400 \mathrm{H}$ voltmeter for the Physical Science unit. The values probably show a relative indication of the performance of the units; however, to establish the validity of the data, it would be necessary to refer to magnetic tape to ascertain the waveshape of the output signal and the amount of noise present. Resistance and capacitance measurements were made on the accelerometer leads during the four data cycles.

After the test specimens were returned to the IML and removed from the Dewar, calibration checks were made individually on the components. The accelerometers were tested on a standard vibration table with the following results that this unit operated at vibration frequencies up to $300 \mathrm{cps}$. No output at $300 \mathrm{cps}$ and above. No factory calibraton data available for comparison. (The output of this vibrometer became erratic in the last data cycle during the irradiation.) 
THIS PAGE INTENTIONALLY LEFT BLANK 


\section{VIBRATION TRANSDUCER}

Code No: $\mathrm{Gr}-8$

Type: Piezoelectric

Mfgr: Gulton

Range: $0-600 \mathrm{~g}$
Spec. Control Dwg. No.

Evaluation by: WANL

Model No: A-315T

Application:

PERFORMANCE \& ENVIRONMENTAL SPECIFICATIONS

\begin{tabular}{|c|c|c|c|c|}
\hline Test & Condition & NERVA Requirements & Manufacturer's Specs & $\begin{array}{l}\text { Summary of } \\
\text { Test Results }\end{array}$ \\
\hline A & Overload & $100 \mathrm{~g}$ & $600 \mathrm{~g}$ peak & \\
\hline$B$ & Comp. Temp. Range & $140^{\circ} \mathrm{R}$ to $800^{\circ} \mathrm{R}$ & $140^{\circ} \mathrm{R}$ to $710^{\circ} \mathrm{R}$ & \\
\hline $\mathrm{C}$ & Input Impedance & NA & & \\
\hline D & Output Impedance & $\mathrm{NA}$ & $1000 \mathrm{pf}$ & \\
\hline$E$ & Excitation & $\mathrm{NA}$ & & \\
\hline$F$ & Sensitivity & $1.5 \mathrm{mv} / \mathrm{g} \mathrm{min}$. & $1.5 \mathrm{mv} / \mathrm{g} \mathrm{min.}$ & \\
\hline $\mathbf{G}$ & Transverse Accel & $5 \% \max$ & $3 \%$ & \\
\hline $\mathrm{H}$ & Linearity & $\pm 2 \% 0-50 \mathrm{~g}$ & $1 \%$ & \\
\hline 1 & Hysteresis & NA & & \\
\hline $\mathrm{J}$ & Resolution & NA & & \\
\hline $\mathrm{K}$ & Accuracy & $5 \%$ & & \\
\hline$L$ & Freq. Response & 0 - 1 KC flat $\pm 3 \mathrm{db}$ & 3 to $7.5 \mathrm{KC}$ & \\
\hline$M$ & Noise Limit & MIL-S-446A & & \\
\hline $\mathrm{N}$ & Neutron Flux & $4.5 \times 10^{14} \mathrm{n} / \mathrm{cm}^{2}-\mathrm{sec}$ & & \\
\hline 0 & Gamma Flux & \multicolumn{2}{|l|}{$1.9 \times 10^{11} \mathrm{ergs} / \mathrm{gm}(\mathrm{C})-\mathrm{hr}$} & \\
\hline$P$ & Dimensions & $0.67 " \mathrm{~N} 0.45 " \mathrm{dia}$ & $0.67 " \times 0.45^{\prime \prime}$ dia. & \\
\hline$Q$ & Weight & & 5 grams & \\
\hline$R$ & Resonant Freq. & $>7000 \mathrm{cps}$ & $30 \mathrm{KC}$ min. & \\
\hline 5 & Insulation Res. & \multicolumn{2}{|c|}{$>1000$ megohm at 50VDC $1000 \mathrm{M}$ ohms 50VDC } & \\
\hline$T$ & Material & & Titanium Case & \\
\hline $\mathrm{U}$ & Sensitivity-Charge & & 1.5 p.c./g min. & \\
\hline $\mathrm{V}$ & Capacitance & & $1000 \mathrm{pf}$ & \\
\hline & & & & \\
\hline & & & & \\
\hline & & & & \\
\hline & & & & \\
\hline
\end{tabular}


RADIATION TESTS

Code No. Gr-8

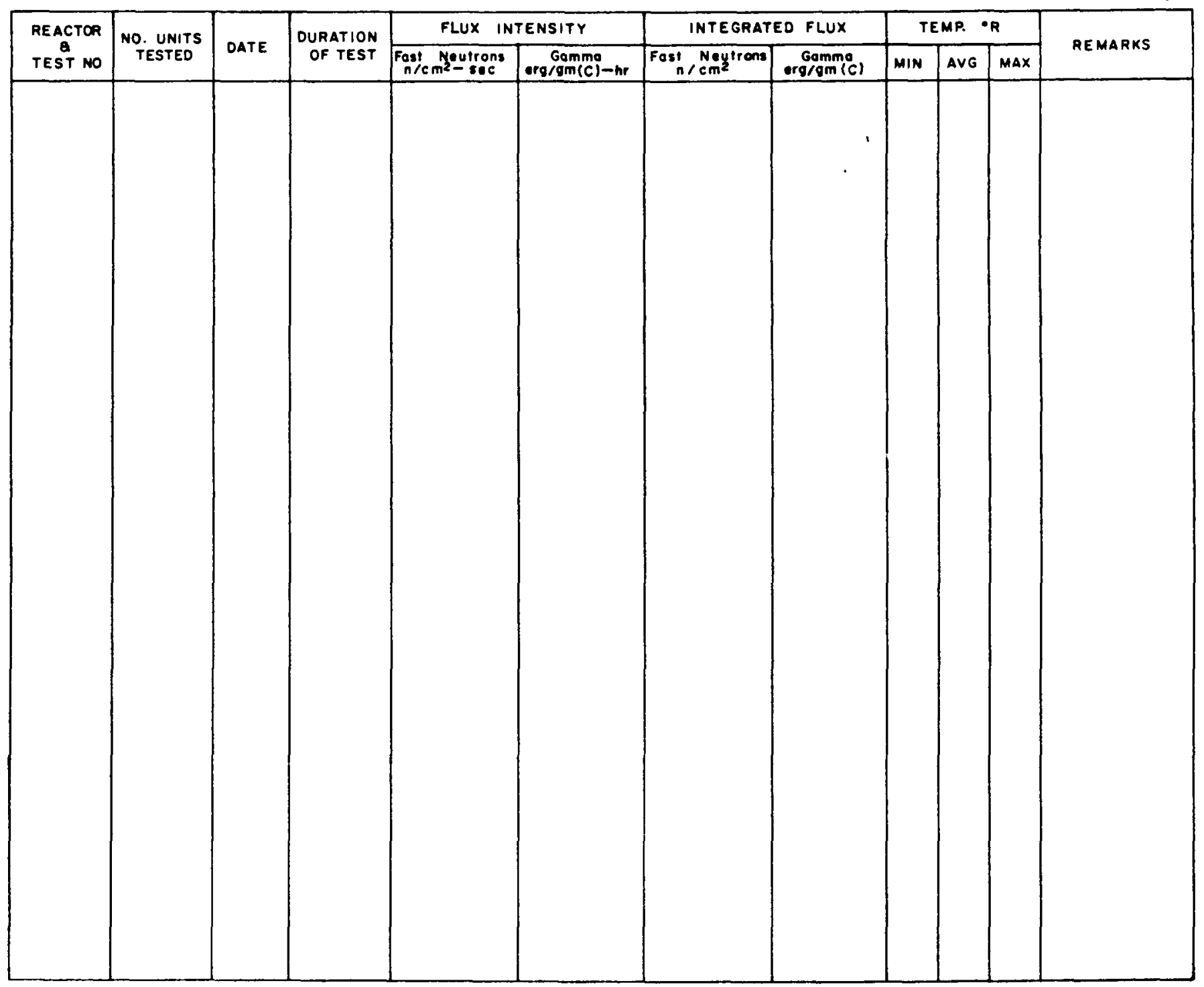


Dote: 1 January 1964

\section{DEVELOPMENT HISTORY}

Code No: $\mathrm{Gr}-8$

Model No. A-315T

REMARKS:
Mfgr:

P. 0. Donated

\section{Summary Test Results:}

Tested at WANL on $1 / 21 / 63$ submerged in $\mathrm{LN}_{2}$ in a Dewar mounted on a $\mathrm{MB}$ vibration table at $20 \mathrm{~g}$ for $50 \mathrm{cps}, 100 \mathrm{cps}$ and $200 \mathrm{cps}$. Room temperature test results compared favorably with $\mathrm{LN}_{2}$ test results.

This unit will be combined effects tested in the second GTR test in April 1963.

\section{General:}

Gulton selection based on small size. Irradiation testing work has been done, but specific details are not known at this time.

\section{$\underline{30}$ September 1963}

No further development testing will be conducted on this unit. All further testing will be conducted on models of Code No. Gr-21 which supercedes this unit. 
THIS PAGE INTENTIONALLY LEFT BLANK 
Sheet 1 of 3

\section{VIBRATION TRANSDUCER}

Code No: Gr-9

Type: Piezoelectric

Mfgr: Gulton

Range: $\quad 0-1500 \mathrm{~g}$
Spec. Control Dwg. No.

Evaluation by: WANL

Model No:

$\mathrm{A}-321 \mathrm{~T}$

Application:

PERFORMANCE \& ENVIRONMENTAL SPECIFICATIONS

\begin{tabular}{|c|l|l|l|l|}
\hline Test & \multicolumn{1}{|c|}{ Condition } & NERVA Requirements & Manufacturer's Specs & $\begin{array}{l}\text { Summary of } \\
\text { Test Results }\end{array}$ \\
\hline \hline A & Overload & $100 \mathrm{~g}$ & $1500 \mathrm{~g}$ & \\
\hline B & Comp. Temp. Range & $140^{\circ}-560^{\circ} \mathrm{R}$ & $140^{\circ} \mathrm{R}$ to $710^{\circ} \mathrm{R}$ & \\
\hline C & Input Impedance & NA & & \\
\hline D & Output Impedance & NA & 1250 pf with $4^{\prime}$ cable & \\
\hline E & Excitation & NA & & \\
\hline F & Sensitivity & $10 \mathrm{mv} / \mathrm{g}$ (nom) & $8.5 \mathrm{mv} / \mathrm{g}$ min. & \\
\hline G & Transverse Accel & $5 \% \mathrm{max}$ & $3 \%$ & \\
\hline H & Linearity & $\pm 2 \% 0-50 \mathrm{~g}$ & $1 \%$ & \\
\hline I & Hysteresis & NA & & \\
\hline J & Resolution & NA & & \\
\hline K & Accuracy & $5 \%$ & & \\
\hline L & Freq. Response & $0-1 \mathrm{KC}$ flat $\pm 3 \mathrm{db}$ & $3-3000 \mathrm{cps}$ & \\
\hline M & Noise Limit & MIL-S-446A & & \\
\hline N & Neutron Flux & NA & & \\
\hline O & Gamma Flux & NA & & \\
\hline P & Dimensions & & $0.69^{\prime \prime} \mathrm{x} \mathrm{0.5"} \mathrm{dia.}$ & \\
\hline Q & Weight & & $7 \mathrm{grams}$ & \\
\hline R & Resonant Freq. & $>7 \mathrm{KC}$ & $10 \mathrm{KC}$ & \\
\hline S & Insulation Res. & $>1000 \mathrm{megohm} 50 \mathrm{VDC} 1000 \mathrm{M}$ ohms at 50VDC & \\
\hline T & Material & & Titanium Case & \\
\hline U & Sensitivity-Charge & & $10 \mathrm{pc} / \mathrm{g}$ & \\
\hline V & Capacitance & & $1250 \mathrm{pf}$ with 4' cable & \\
\hline & & & & \\
\hline & & & & \\
\hline & & & & \\
\hline & & & & \\
\hline
\end{tabular}




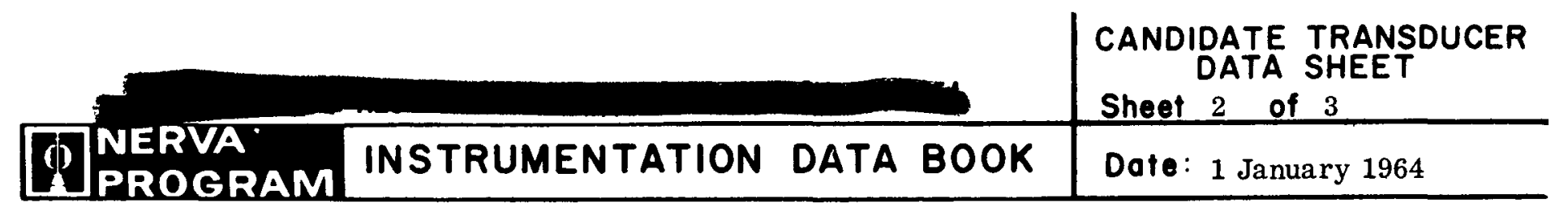

RADIATION TESTS

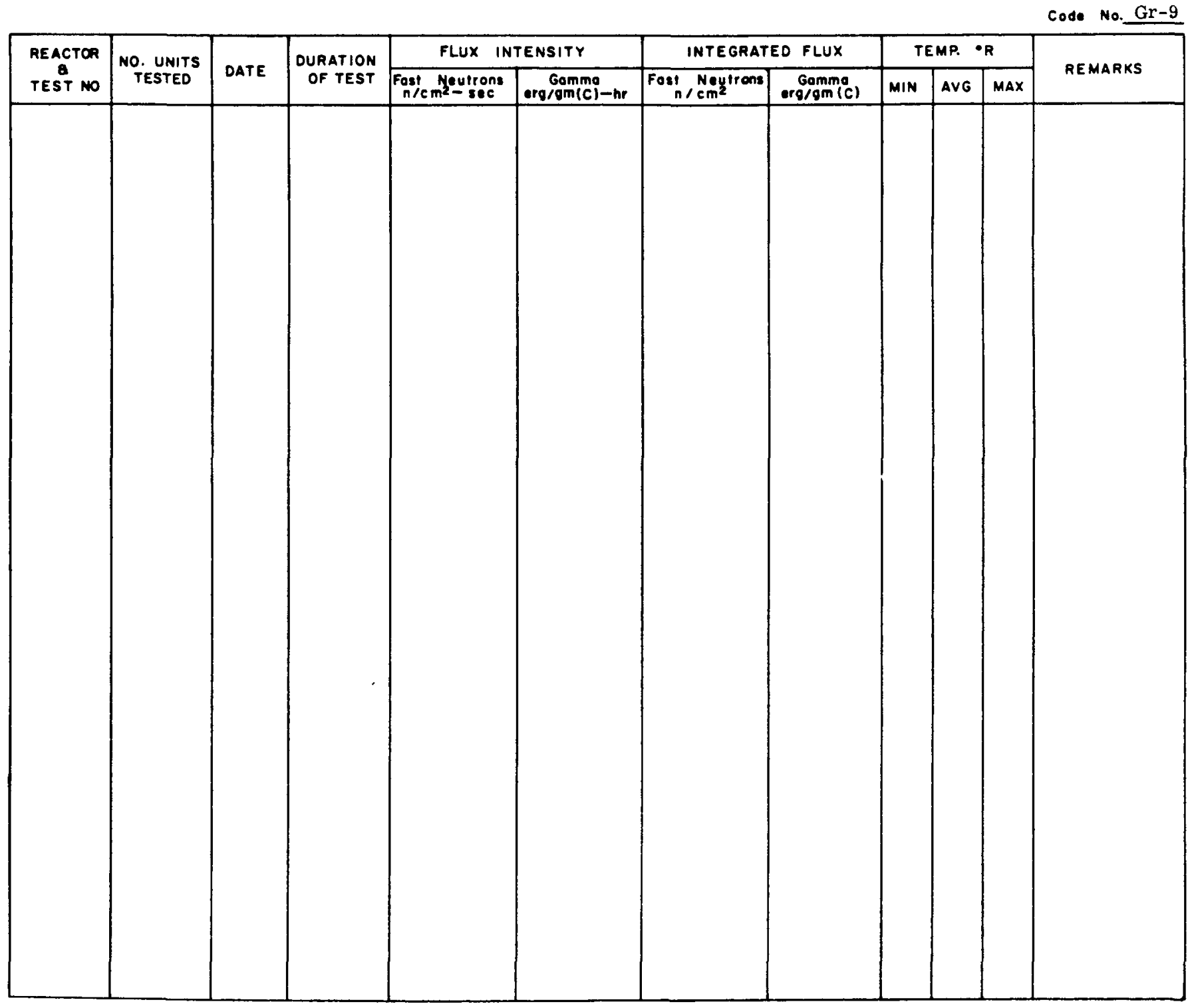

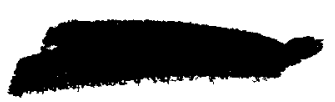

(w) 


\section{DEVELOPMENT HISTORY}

Code No: Gr-9

Model No. A-321T

\section{REMARKS:}

\section{Summary Test Results:}

Tested at WANL on $1 / 21 / 63$ submerged in $\mathrm{LN}_{2}$ in a Dewar mounted on a MB vibration table at $20 \mathrm{~g}$ for $50 \mathrm{cps}, 100 \mathrm{cps}$ and $200 \mathrm{cps}$. Room temperature test results compared favorably with $\mathrm{LN}_{2}$ test results.

This unit will be combined effects tested in the second GTR test in April 1963.

\section{General:}

Gulton selection based on small size. Irradiation testing work has been done, but specific details are not known at this time.

\section{$\underline{30}$ September 1963}

No further development testing will be conducted on this unit. All further testing will be conducted on models of Code No. Gr-21 which supercedes this unit. 
THIS PAGE INTENTIONALLY LEFT BLANK 


\section{VIBRATION TRANSDUCER}

Code No: Gr-10

Type: Piezoelectric

Mfgr: Gulton Industries, Inc.

Range: $0-10 \mathrm{~g}$
Spec. Control Dwg. No. 964B017H01

Evaluation by: WANL

Model No: AA220108

PERFORMANCE \& ENVIRONMENTAL SPECIFICATIONS

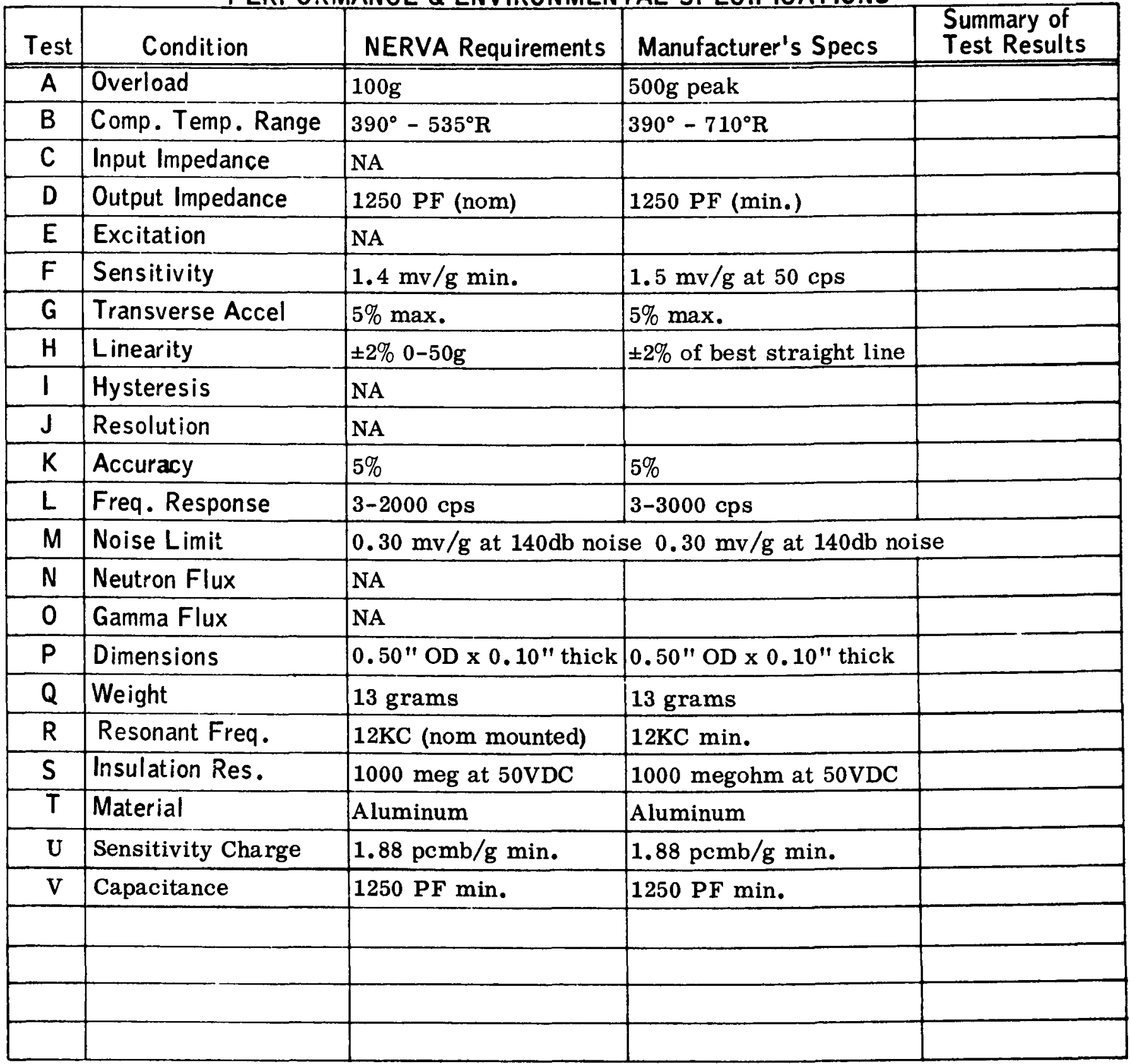





\section{DEVELOPMENT HISTORY}

Code No: Gr-10

Model No. AA220108

\section{REMARKS:}

In order to solve the mechanical mounting problems in final assembly, extreme emphasis was placed on physical size of these units.

A literature search for units specified by the manufacturers to satisfy the environmental conditions for NRX-A1 has been made and the initial selection is based on these results.

Confirmation of the guarantees will be made in subsequent evaluation tests by WANL.

Tests were conducted on one (1) of these units by the manufacturer. Frequency response at ambient and in $\mathrm{LN}_{2}$ were conducted with good results. Test data and unit shipped to date to WANL for further evaluation.

\section{$\underline{30} \underline{\text { September }} \underline{1963}$}

Tests conducted at WANL were made to determine the output of the accelerometer due to a thermal shock of ambient to $-320^{\circ} \mathrm{F}$. The unit was placed between two graphite blocks after being potted in EPY-150 to simulate actual test conditions. Using an amplifier with a low frequency cutoff of $1 \mathrm{cps}$, the output of the accelerometer due to thermal shock for the first 23 seconds was $2 \mathrm{~g}$ 's. Using an amplifier with a low frequency cut-off of $10 \mathrm{cps}$, the output for the first 23 seconds was $0.5 \mathrm{~g}$.

More tests are to be conducted to determine the change of output of the accelerometer due to thermal shock while being vibrated.

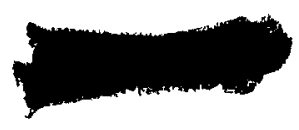


THIS PAGE INTENTIONALLY LEFT BLANK 


\section{VIBRATION TRANSDUCER}

Code No: $\mathrm{Gr}-11$

Type: Pieozelectric

Mfgr: Gulton Industries, Inc.

Range: $0-10 \mathrm{~g}$
Spec. Control Dwg. No. 964B0108H01

Evaluation by: WANL

Model No: AA310504

Application:

PERFORMANCE \& ENVIRONMENTAL SPECIFICATIONS

\begin{tabular}{|c|c|c|c|c|}
\hline Test & Condition & NERVA Requirements & Manufacturer's Specs & $\begin{array}{l}\text { Summary of } \\
\text { Test Results }\end{array}$ \\
\hline A & Overload (Vibr.) & $25 \mathrm{~g}$ & $300 \mathrm{~g}$ peak & $>25 \mathrm{~g}(\mathrm{rms})$ \\
\hline$B$ & Comp. Temp. Range & $390^{\circ}-535^{\circ} \mathrm{R}$ & $390^{\circ}-710^{\circ} R$ & $140^{\circ}$ and $540^{\circ} \mathrm{R}$ \\
\hline C & Input Impedance & $\mathrm{NA}$ & & $\mathrm{NA}$ \\
\hline $\mathrm{D}$ & Output Impedance & $900 \mathrm{PF}$ min. & $900 \mathrm{PF}$ min. & \\
\hline$E$ & Excitation & $\mathrm{NA}$ & & $\mathrm{NA}$ \\
\hline$F$ & Sensitivity & $7.5 \mathrm{mv} / \mathrm{g}$ & $7.5 \mathrm{mv} / \mathrm{g}$ (w/6' cable) & $12.5 \mathrm{mv} / \mathrm{g}$ \\
\hline $\mathbf{G}$ & Transverse Response & $5 \% \max$. & $5 \% \max$. & $1.0 \%$ of $\mathrm{F}$ \\
\hline $\mathrm{H}$ & Linearity & $\pm 2 \% 0-25 \mathrm{~g}$ & $\pm 2 \%$ of best straight line & $0.7 \%$ of $\mathrm{BSL}$ \\
\hline 1 & Hysteresis & NA & & $\mathrm{NA}$ \\
\hline $\mathrm{J}$ & Resolution & $\mathrm{NA}$ & & $\overline{\mathrm{NA}}$ \\
\hline$K$ & Accuracy & $5 \%$ & $5 \%$ & $0.7 \%$ of $\mathrm{BSL}$ \\
\hline$L$ & Freq. Response & $3-2000 \mathrm{cps}$ & $2-7000 \mathrm{cps}$ & $1.7 \%$ of $\mathrm{F}$ \\
\hline$M$ & Noise Limit & \multicolumn{3}{|c|}{$1.5 \mathrm{mv} / \mathrm{g}$ at $140 \mathrm{db}$ noise $1.5 \mathrm{mv} / \mathrm{g}$ at $140 \mathrm{db}$ noise } \\
\hline $\mathrm{N}$ & Neutron Flux & NA & & $\mathrm{NA}$ \\
\hline 0 & Gamma Flux & $\mathrm{NA}$ & & $\mathrm{NA}$ \\
\hline$P$ & Dimensions & \multicolumn{3}{|c|}{$0.66^{\prime \prime}$ OD $\times 0.135^{\prime \prime}$ thick $0.66^{\prime \prime}$ OD $\times 0.135^{\prime \prime}$ thick Same } \\
\hline Q & Weight & 3.2 grams & \begin{tabular}{l|l}
3.2 grams \\
\end{tabular} & Same \\
\hline$R$ & Resonant Freq. & 9KC (nom mounted) & $9 \mathrm{KC}$ min. & $21000 \mathrm{cps}$ \\
\hline$S$ & Insulation Res. & $1000 \mathrm{meg}$ at $50 \mathrm{VDC}$ & 1000 megohm at $50 \mathrm{VDC}$ & \\
\hline$T$ & Material & $303 \mathrm{~S} / \mathrm{s}$ & $303 \mathrm{~S} / \mathrm{s}$ & $303 \mathrm{~s} / \mathrm{s}$ \\
\hline $\mathrm{U}$ & Sensitivity Charge & $6.75 \mathrm{pcmb} / \mathrm{g}$ & $6.75 \mathrm{pcmb} / \mathrm{g}$ & $17.0 \mathrm{pcb} / \mathrm{g}$ \\
\hline & & & & \\
\hline & & & & \\
\hline & & & & \\
\hline & & & & \\
\hline
\end{tabular}




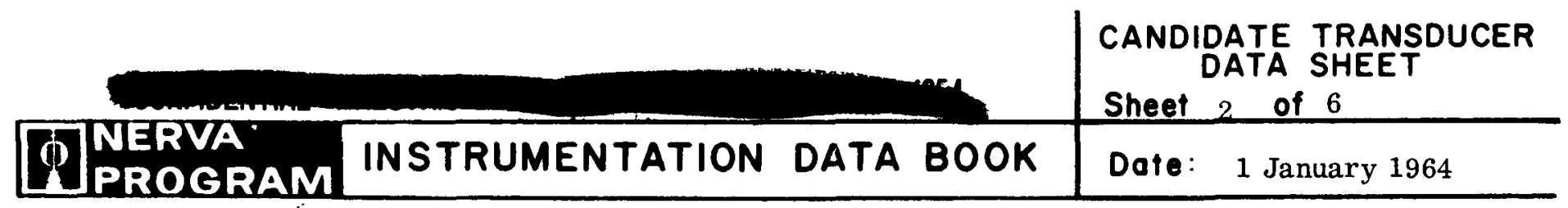

RADIATION TESTS

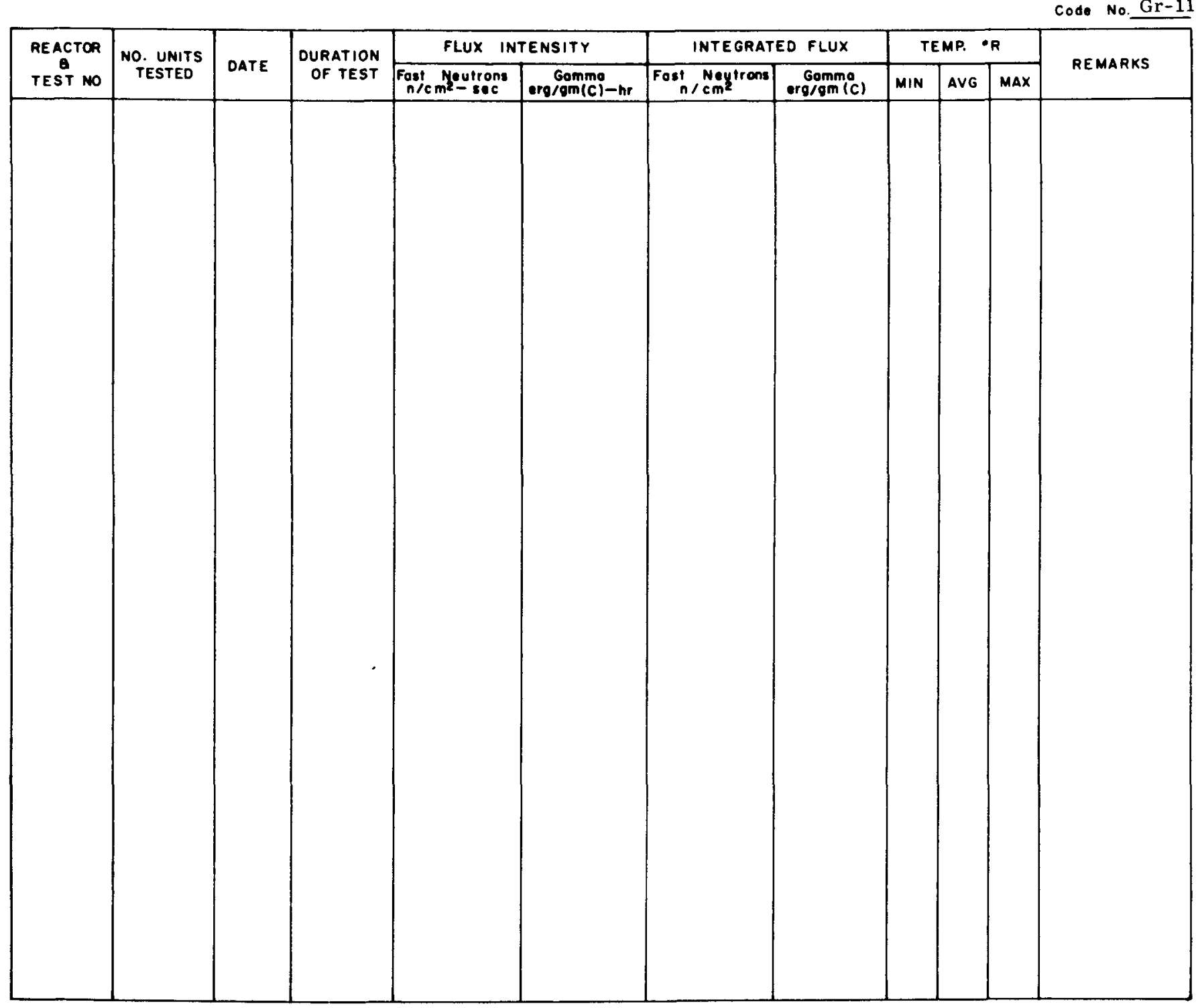

w 


\section{DEVELOPMENT HISTORY}

Code No: Gr-11

Model No. AA310504
Mfgr: Gulton Industries, Inc.

P. 0. 30495

\section{REMARKS:}

In order to solve the mechanical mounting problems in final assembly, extreme emphasis was placed on physical size of these units.

A literature search for units specified by the manufacturers to satisfy the environmental conditions for NRX-A1 has been made and the initial selection is based on these results.

Confirmation of the guarantees will be made in subsequent evaluation tests by WANL.

Tests were conducted on one (1) of these units by the manufacturer. Frequency response at ambient and in $\mathrm{LN}_{2}$ were conducted with good results. Test data and unit shipped to date to WANL for further evaluation.

\section{$\underline{30}$ September 1963}

Tests were conducted to determine the effects of a thermal shock from ambient to $-320^{\circ} \mathrm{F}$ on the accelerometer. The unit was mounted between two graphite blocks to simulate actual test conditions. The sensitivity of the unit was $16 \mathrm{mv}(\mathrm{rms}) / \mathrm{g}$.

Using an amplifier with low frequency cut-off of $10 \mathrm{cps}$, the accelerometer output due to thermal shock was $1.8 \mathrm{~g}$ 's. Using an amplifier with a low frequency cut-off of $1 \mathrm{cps}$, the output due to thermal shock was $1.5 \mathrm{~g}$ 's.

More tests are being conducted to determine the effects of thermal shock while the accelerometer is being vibrated.

\section{$15 \underline{\text { November }} 1963$}

The tests indicated by the following tables and notes were conducted. The listed results are with respect to Gulton Industries standard accelerometer model DA 321501 serial No. 101. 


\section{DEVELOPMENT HISTORY}

Code No: Gr-11

Mfgr: Gulton Industries, Inc.

Model No. AA310504

P. $0 . \underline{30495}$

\section{REMARKS:}

The following tests were conducted at WANL during the week of October 12, 1963 to October 19, 1963. Two units, which constituted a sample of those available from Gulton Industries, were tested. They were S/N G1-5 and G1-11.

The vibration level and frequency was limited by the equipment available in the laboratory. Maximum $g$ level attainable was slightly greater than $25 \mathrm{~g}$ 's. Also, the vibration equipment was self resonating at about $2.1 \mathrm{kcs}$. Therefore, the given data is considered valid within the above restrictions imposed by the equipment limitations. The sensitivity measurements were made at a $1 \mathrm{~g}$ input at $50 \mathrm{cps}$. The linearity was calculated as a per cent deviation from the straight line average of three successive runs from 0 to $25 \mathrm{~g}$ 's at $50 \mathrm{cps}$. The accuracy reading was taken from the linearity reading. The charge sensitivity was calculated from $Q=E\left(C_{p}+C_{t}\right)$ where, $Q=$ charge sensitivity, $E=$ voltage sensitivity, $C_{p}$ capacitance of the accelerometer and $C_{t}=$ total external capacitance. The results of these tests are summarized in the following tabulation:

\begin{tabular}{|c|c|c|c|c|c|c|c|c|c|}
\hline & $\begin{array}{l}\text { Overload } \\
\text { (g's peak) }\end{array}$ & $\begin{array}{c}\text { Comp. } \\
\text { Temp. } \\
\text { Range } \\
\left({ }^{\circ} \mathrm{R}\right) \\
\end{array}$ & $\begin{array}{l}\text { Sensi- } \\
\text { tivity } \\
\mathrm{mv} / \mathrm{g} \\
\end{array}$ & $\begin{array}{c}\text { Transverse } \\
\text { Accel. } \\
\% \text { of Sens. }\end{array}$ & $\begin{array}{l}\text { Linearity } \\
\% \text { of BSL }\end{array}$ & $\begin{array}{l}\text { Accuracy } \\
\% \text { of BSL }\end{array}$ & $\begin{array}{l}\text { Freq. of Resp. } \\
\% \text { of Sens. }\end{array}$ & $\begin{array}{l}\text { Resonant } \\
\text { Freq. } \\
\text { (kcs) }\end{array}$ & $\begin{array}{c}\text { Sensitivity } \\
\text { Charge } \\
\text { (PCB/g) }\end{array}$ \\
\hline $\begin{array}{l}\text { G1-5 } \\
540^{\circ} \mathrm{R}\end{array}$ & $\Rightarrow 25$ & 540 & 12.5 & 1.0 & 0.7 & 0.7 & 1.7 & $>1.0$ & 17 \\
\hline $\begin{array}{l}\mathrm{G} 1-5 \\
140^{\circ} \mathrm{R}\end{array}$ & $>25$ & 140 & 10.7 & 1.02 & 0.6 & 0.6 & $9.2^{*}$ & $>1.0$ & 15.2 \\
\hline
\end{tabular}

*At $1.0 \mathrm{kcs}$ only. Maximum deviation at any other measurement frequency was $3.7 \%$.

\begin{tabular}{|c|c|c|c|c|c|c|c|c|c|}
\hline $\begin{array}{l}\mathrm{G} 1-11 \\
540^{\circ} \mathrm{R}\end{array}$ & $>25$ & 540 & 13.2 & 1.2 & 0.5 & 0.5 & 3.8 & $>5$ & 16.1 \\
\hline $\begin{array}{l}\mathrm{G} 1-11 \\
140^{\circ} \mathrm{R}\end{array}$ & $>25$ & 140 & 12.7 & 2.4 & 1.9 & 1.9 & $10.6^{* *}$ & $>1.0$ & 15.5 \\
\hline
\end{tabular}

**At $1 \mathrm{kcs}$ only. Maximum deviation at any other measurement frequency was $2.7 \%$. 


\section{DEVELOPMENT HISTORY}

Code No: $\mathrm{Gr}-11$

Model No. AA310504

Mfgr: Gulton Industries

P. 0. $\mathbf{3 0 4 9 5}$

\section{REMARKS:}

In order to ascertain that the accelerometers received from the vendor were qualified and would still meet the NERVA requirements, WANL certified calibration data was required with each transducer. These tests and results are summarized here.

A. The capacitance of the accelerometer was measured at $1000 \mathrm{cps}$ ( 1 volt, rms) using a General Radio Bridge, Model 716 C.

B. Resonant Frequency - With the accelerometer being vibrated at a constant 2 volt output, the frequency was increased until the output indicated a resonance, (i.e., first inflection greater than $2 \mathrm{db}$ ). This frequency was measured and recorded.

C. Sensitivity, Frequency Response - While the accelerometer was vibrated at a constant $1 \mathrm{~g}(\mathrm{rms})$, the frequency was varied over the frequency range $(1 \mathrm{cps}$ to $2.7 \mathrm{kc})$. The percent output deviation from the value at $50 \mathrm{cps}$ was calculated and recorded.

D. Amplitude Linearity - The accelerometer was vibrated at a constant frequency of $500 \mathrm{cps}$ while the $\mathrm{g}$ level was varied over the accelerometers maximum range. The percent deviation, from the best straight line through this design range, was calculated and recorded.

E. Transverse Response - The accelerometer was vibrated in an axis perpendicular to its sensitive axis at $10 \mathrm{~g}$ ( $\mathrm{rms}$ ) and $100 \mathrm{cps}$. The transducer was turned slowly while being vibrated. The output was monitored for the maximum transverse response. This maximum transverse response was calculated and recorded as a percentage of the sensitive axis sensitivity at $10 \mathrm{~g}(\mathrm{rms})$.

F. Temperature and Pressure Response - The accelerometer was vibrated in a cryostat at $2 \mathrm{~g}$ (rms), $100 \mathrm{cps}$ and ambient (room) conditions. While monitoring the output, the pressure was increased to $200 \mathrm{psig}$. Any output change was recorded in $\mathrm{mv} / \mathrm{g} / \mathrm{psi}$. This test was then repeated at $-320^{\circ} \mathrm{F}$.

G. Pressure Pulse Response - The transducer was vibrated at $2 \mathrm{~g}(\mathrm{rms}), 100 \mathrm{cps}$ and ambient (room) conditions. The maximum response of the transducer to a uniformly increasing pressure pulse, 0 to $200 \mathrm{psig}$ in 20 seconds, was measured and recorded. This test was then repeated at $-320^{\circ} \mathrm{F}$.

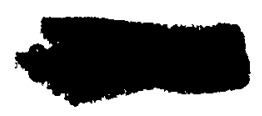




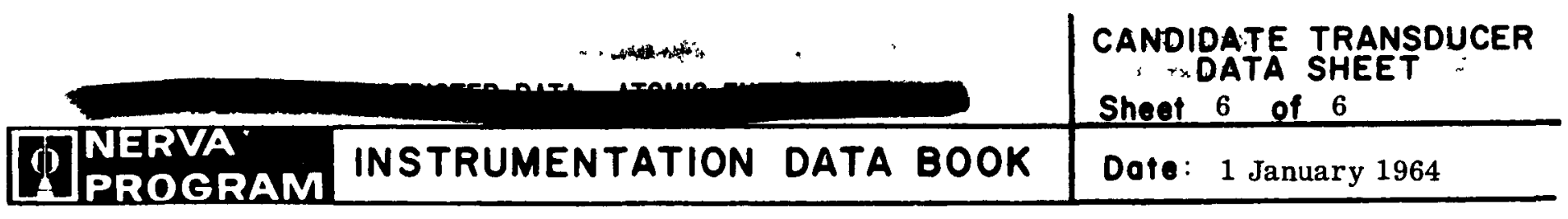

\section{DEVELOPMENT HISTORY}

Code No: Gr-11

Model No. AA310504

\section{REMARKS:}

15 November 1963
Mfgr: Gulton Industries

P. 0.30495

\section{Capacitance $\quad 20-3000 \mathrm{cps}$}

Symbol $\underline{\mathrm{S} / \mathrm{N}} \underline{\frac{\mu \mu \mathrm{f}}{\text { Total }} \text { Cable }}$ Freq. KC Variation $\%$

$\begin{array}{ccccccc}\text { G-710 } & \text { GI-1 } & 1270 & - & 13.8 & 2.2 \% & <1 \% \\ \text { G-708 } & \text { GI-2 } & 1390 & - & 14.3 & 3.2 \% & <1 \% \\ \text { G-712 } & \text { GI-3 } & 1260 & - & 14.9 & 2.2 \% & <1 \% \\ \text { G-711 } & \text { GI-4 } & 1320 & - & 14.7 & 2.1 \% & <1 \% \\ - & \text { GI-5 } & 1425 & - & 13.7 & 3.1 \% & <1 \% \\ \text { G-713 } & \text { GI-6 } & 1292 & - & 13.8 & 4.2 \% & <1 \% \\ - & \text { GI-7 } & 1360 & - & 13.4 & 9.1 \% & <1 \% \\ \text { G-607 } & \text { GI-8 } & 1320 & - & 14.2 & 7.1 \% & <1 \% \\ - & \text { GI-9 } & 1225 & - & 9.0 & 5.7 \% & <1 \% \\ \text { G-608 } & \text { GI-10 } & 1370 & - & 13.4 & 6.4 \% & <1 \% \\ - & \text { GI-11 } & 1220 & - & 14.1 & 9.0 \% & <1 \% \\ \text { G-609 } & \text { GI-12 } & 1410 & - & 13.7 & 9.5 \% & <1 \%\end{array}$

Ampl. Linearity Transverse Temp. Press. Variation \% Response\% Variation Variation

$3.8 \% \quad 1.52 \mu \mathrm{v} /{ }^{\circ} \mathrm{F} \quad 3.0 \mu \mathrm{v} / \mathrm{psi}$

$1.7 \% \quad 1.27 \mu \mathrm{v} /{ }^{\circ} \mathrm{F} \quad 2.5 \mu \mathrm{v} / \mathrm{psi}$

$2.0 \% \quad 9.65 \mu \mathrm{v} /{ }^{\circ} \mathrm{F} \quad 2.0 \mu \mathrm{v} / \mathrm{psi}$

$1.8 \%$

2. $3 \%$

$2.0 \%$

$1.0 \%$

$1.0 \%$

$4.5 \%$

$1.5 \%$

$2.7 \%$

$2.2 \%$
$1.78 \mu \mathrm{v} /{ }^{\circ} \mathrm{F} \quad 1.27 \mu \mathrm{v} / \mathrm{psi}$

$3.56 \mu \mathrm{v} /{ }^{\circ} \mathrm{F} \quad 2.0 \mu \mathrm{v} / \mathrm{psi}$

$5.83 \mu \mathrm{v} /{ }^{\circ} \mathrm{F}$

$2.03 \mu \mathrm{v} /{ }^{\circ} \mathrm{F} \quad 2.0 \mu \mathrm{v} / \mathrm{psi}$

$5.57 \mu \mathrm{v} /{ }^{\circ} \mathrm{F}$

$\begin{array}{ll}5.57 \mu \mathrm{v} /{ }^{\circ} \mathrm{F} & 0 \\ 6.10 \mu \mathrm{v} /{ }^{\circ} \mathrm{F} & 2.5 \mathrm{v} / \mathrm{psi}\end{array}$

$7.61 \mu \mathrm{v} /{ }^{\circ} \mathrm{F}$

$8.63 \mu \mathrm{v} /{ }^{\circ} \mathrm{F}$

$2.79 \mu \mathrm{v} /{ }^{\circ} \mathrm{F}$

0 


\section{VIBRATION TRANSDUCER}

Code No: $\mathrm{Gr}-12$

Type: Piezoelectric

Mfgr: Endevco Corp.

Range: $\quad 0-10 \mathrm{~g}$
Spec. Control Dwg. No. 964B019H01

Evaluation by: WANL

Model No: $2242 \mathrm{C}$

Application:

PERFORMANCE \& ENVIRONMENTAL SPECIFICATIONS

\begin{tabular}{|c|c|c|c|c|}
\hline Test & Condition & NERVA Requirements & Manufacturer's Specs & $\begin{array}{l}\text { Summary of } \\
\text { Test Results }\end{array}$ \\
\hline$A$ & Overload & $100 \mathrm{~g}$ & $1000 \mathrm{~g}$ & \\
\hline$B$ & Comp. Temp. Range & $40^{\circ}-535^{\circ} \mathrm{R}$ & $140^{\circ}-960^{\circ} \mathbf{R}$ & \\
\hline $\mathrm{C}$ & Input Impedance & $\mathrm{NA}$ & & \\
\hline $\mathrm{D}$ & Output Impedance & $200 \mathrm{PF}$ min & $200 \mathrm{PF}$ min & \\
\hline$E$ & Excitation & $\mathrm{NA}$ & & \\
\hline $\mathrm{F}$ & Sensitivity & $10 \mathrm{pk}-\mathrm{mv} / \mathrm{pk}-\mathrm{g}$ & $10 \mathrm{pk}-\mathrm{mv} / \mathrm{pk}-\mathrm{g}$ & \\
\hline G & Transverse Accel & $5 \% \max$. & $5 \% \max$. & \\
\hline $\mathrm{H}$ & Linearity & $\pm 2 \% 0-50 \mathrm{~g}$ & $\pm 2 \% 0-500 \mathrm{~g}$ & \\
\hline 1 & Hysteresis & NA & & \\
\hline $\mathrm{J}$ & Resolution & $\mathrm{NA}$ & & \\
\hline$K$ & Accuracy & $5 \%$ & $5 \%$ & \\
\hline$L$ & Freq. Response & $5-2000 \mathrm{cps}$ & $5-6000 \mathrm{cps}$ & \\
\hline$M$ & Noise Limit & \multicolumn{3}{|c|}{$1.4 \mathrm{mv} / \mathrm{g}$ at $135 \mathrm{db}$ noise $1.4 \mathrm{mv} / \mathrm{g}$ at $135 \mathrm{db}$ noise } \\
\hline $\mathbf{N}$ & Neutron Flux & NA & & \\
\hline 0 & Gamma Flux & $\mathrm{NA}$ & & \\
\hline$P$ & Dimensions & $0.97 " \mathrm{OD} \times 1.12$ " LG & $5 / 8 "$ Hex x $0.80 \mathrm{~h}$ & \\
\hline$Q$ & Weight & $1 \mathrm{oz}$ & $1 \mathrm{oz} .(28 \mathrm{grams})$ & \\
\hline$R$ & Resonant Freq. & $20 \mathrm{KC}$ (nom mounted) & $33 \mathrm{KC}$ (nom) & \\
\hline$S$ & Insulation Res. & $1000 \mathrm{Meg}$ at $50 \mathrm{VDC}$ & \multicolumn{2}{|c|}{$20,000 \mathrm{meg}$ at room temp. } \\
\hline $\mathrm{T}$ & Material & $303 \mathrm{~s} / \mathrm{s}$ & $303 \mathrm{~S} / \mathrm{s}$ & \\
\hline $\mathrm{U}$ & Sensitivity Charge & $2.0 \mathrm{pk}-\mathrm{pcmb} / \mathrm{pk}-\mathrm{g}$ & $2.0 \mathrm{pk}-\mathrm{pcmb} / \mathrm{pk}-\mathrm{g}$ & \\
\hline $\mathrm{V}$ & Capacitance & $200 \mathrm{PF}$ min. & $200 \mathrm{PF}$ min. & \\
\hline & & & & \\
\hline & & & & \\
\hline & & & & \\
\hline
\end{tabular}


RADIATION TESTS

Code No $\mathrm{Gr}-12$

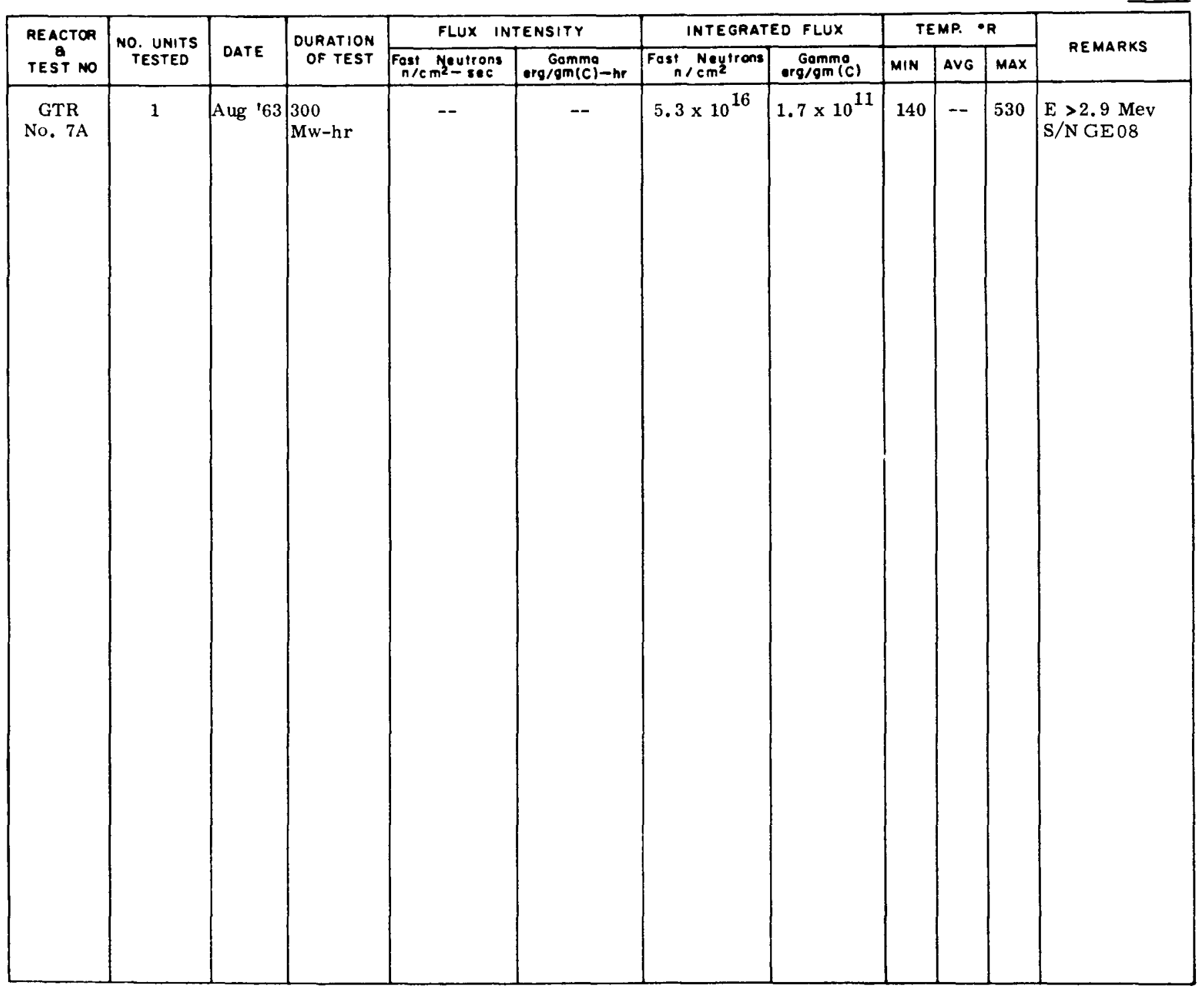




\section{DEVELOPMENT HISTORY}

Code No: $\frac{\mathrm{Gr}-12}{\text { Model No. } 2242 \mathrm{C}}$

Mfgr: Endevco Corp.

P. 0.37581

\section{REMARKS:}

In order to solve the mechanical mounting problems in final assembly, extreme emphasis was placed on physical size of these units.

A literature search for units specified by the manufacturers to satisfy the environmental conditions for NRX-A1 has been made and the initial selection is based on these results.

Confirmation of the guarantees will be made in subsequent evaluation tests by WANL.

The actual models selected are similar in design principle in all instances to units previously tested. Refer to $\mathrm{Gr}-1$ in which a $2242 \mathrm{M} 5$ was tested at WANL.

Irradiation tests are being conducted on two (2) of these units; serial numbers GEO6 and GEO8; at Ground Test Reactor during August, 1963 under Test Plan Reference No. 23/W004.

Ambient, $\mathrm{LN}_{2}$ and Vibration Tests have been conducted at the WANL Laboratories on the above two (2) units. Performance indicated satisfactory operation although complere data is inconclusive at this time.

\section{$\underline{15} \underline{\text { December }} \underline{1963}$}

One unit (S/N GEO8) GTR Test No. 7A was tested in combined environment of $\mathrm{LN}_{2}$ and radiation at GTR in August, 1963. It was continuously vibrated during the test and operated satisfactorily throughout.

Vibration generators were used to vibrate the components. Each generator consisted of two tandem-mounted electromagnets and two mechanically-connected voice coils. The voice coils for the vibration generators were connected in series and were driven simultaneously with a McIntosh 200-watt power amplifier. The signal frequency to the voice coils was supplied by a HewlettPackard $200 \mathrm{CD}$ signal generator, the frequency of which was monitored by an EPUT meter. The outputs from the piezoelectric accelerometers were read from an Endevco Dyna-Monitor and were recorded with an analog magnetic-tape system. A dual-beam oscilloscope (Tektronix model 535 with 53/54 C preamplifier) was used to selectively monitor the accelerometer outputs and the audio oscillator frequency.

The accelerometers were vibrated at the following frequencies (cps) during the test: 50,75 , $100,125,150,300,450,600,750,900$, and 1050 .

Resistance and/or capacitance measurements (as applicable) were made on the accelerometer and pressure transducer signal leads periodically during the test. Also, the AC and DC vibrationgenerator coil resistances were measured. The vibration-generators were energized throughout the test except while the resistance and capacitance measurements were being made.

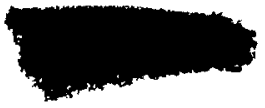




\section{DEVELOPMENT HISTORY}

Code No: $\quad \mathrm{Gr}-12$

Model No. $2242 \mathrm{C}$

\section{REMARKS:}

\section{Test Results}

Output data was recorded for the accelerometers during four data cycles (pre- and postirradiation and the first and last 3-Mw cycles). It should be noted that the outputs were read from the Dyna-Monitor for the piezoelectric accelerometers. The values probably show a relative indication of the performance of the units; however, to establish the validity of the data, it would be necessary to refer to the magnetic tape to ascertain the waveshape of the output signal and the amount of noise present. Resistance and capacitance measurements made on the accelerometer leads during the four data cycles were obtained.

After the test specimens were returned to the IML and removed from the Dewar, calibration checks were made individually on the components. The accelerometers were tested on a standard vibration table with the results that the unit operated satisfactorily. Evaluation on the standard shaker table indicated deviation from factory calibration data was within $4.7 \%$. 


\section{VIBRATION TRANSDUCER}

Code No:

Type: Piezoelectric

Mfgr: Endevco Corp.

Range: $0-10 \mathrm{~g}$

Spec. Control Dwg. No. 964B020H01

Evaluation by: WANL

Model No: 2217

Application:

PERFORMANCE \& ENVIRONMENTAL SPECIFICATIONS

\begin{tabular}{|c|c|c|c|c|}
\hline Test & Condition & NERVA Requirements & Manufacturer's Specs & $\begin{array}{l}\text { Summary of } \\
\text { Test Results }\end{array}$ \\
\hline A & Overload (Vibr.) & $100 \mathrm{~g}$ & $500 \mathrm{~g}$ & \\
\hline$B$ & Comp. Temp. Range & $140^{\circ}-535^{\circ} \mathrm{R}$ & $395^{\circ}-645^{\circ} \mathrm{R}$ & $140^{\circ}-535^{\circ} \mathrm{R}$ \\
\hline $\mathrm{C}$ & Input Impedance & $\mathrm{NA}$ & & \\
\hline$D$ & Output Impedance & 500 PF min. & 500 PF min. & \\
\hline$E$ & Excitation & NA & & \\
\hline$F$ & Sensitivity & $70 \mathrm{pk}-\mathrm{ms} / \mathrm{pk}-\mathrm{g}$ & $70 \mathrm{pk}-\mathrm{mv} / \mathrm{pk}-\mathrm{g}$ & \\
\hline$G$ & Transverse Accel & $5 \% \max$. & $5 \%$ & \\
\hline $\mathrm{H}$ & Linearity & $\pm 2 \% 0-50 \mathrm{~g}$ & $\pm 2 \% 0-300 \mathrm{~g}$ & \\
\hline 1 & Hysteresis & NA & & \\
\hline$J$ & Resolution & $\mathrm{NA}$ & & for preliminary \\
\hline$K$ & Accuracy & $5 \%$ & $5 \%$ & see evaluation \\
\hline$L$ & Freq. Response & $2-2000 \mathrm{cps}$ & $2-6000 \mathrm{cps}$ & $200-500 \mathrm{cps}$ \\
\hline M & Noise Limit & $9.8 \mathrm{mv} / \mathrm{g}$ at $135 \mathrm{db}$ nois & $9.8 \mathrm{mv} / \mathrm{g}$ at $135 \mathrm{db} \mathrm{no}$ & \\
\hline $\mathbf{N}$ & Neutron Flux & $\mathrm{NA}$ & & \\
\hline 0 & Gamma Flux & NA & & \\
\hline$P$ & Dimensions & $0.97^{\prime \prime} \mathrm{OD} \times 1.04 " \mathrm{LG}$ & $5 / 8 "$ Hex $\times 0.70^{\prime \prime} \mathrm{h}$ & \\
\hline$Q$ & Weight & $1.1 \mathrm{oz}$ & $1.1 \mathrm{oz}$. (31 grams) & \\
\hline$R$ & Resonant Freq. & $20 \mathrm{KC}$ (nom mounted) & $30 \mathrm{KC}$ (nom) & \\
\hline$S$ & Insulation Res. & $1000 \mathrm{meg}$ at $50 \mathrm{VDC}$ & \multicolumn{2}{|c|}{50,000 meg at room temp. } \\
\hline$T$ & Material & $303 \mathrm{~S} / \mathrm{s}$ & $303 \mathrm{~S} / \mathrm{s}$ & \\
\hline $\mathrm{U}$ & Sensitivity Charge & 35 pk-pcmb/pk-g & 35 pk-pcmb/pk-g & \\
\hline $\mathrm{V}$ & Capacitance & 500 PF min. & 500 PF min. & \\
\hline & & & & \\
\hline & & & & \\
\hline & & & & \\
\hline
\end{tabular}





\section{DEVELOPMENT HISTORY}

Code No:

$\mathrm{Gr}-13$

Mfgr: Endevco Corp.

Model No. 2217

P. 0.

\section{REMARKS:}

This specific model was mounted on a special WANL designed voice coil shaker and vibrated at ambient and then submerged in $\mathrm{LN}_{2}$ on $6 / 6 / 63$. While a complete test evaluation was not done, the preliminary data is as follows:

G LEVEL

\begin{tabular}{|c|c|c|c|c|c|c|c|}
\hline \multirow[b]{2}{*}{ Freq. cps } & \multicolumn{4}{|c|}{$\mathbf{L N}_{2}-\mathrm{Runs}$} & \multicolumn{3}{|c|}{ Ambient - Runs } \\
\hline & 1 & 2 & 3 & 4 & 1 & 2 & 3 \\
\hline $\begin{array}{l}200 \\
300 \\
400 \\
500\end{array}$ & $\begin{array}{l}7.6 \\
7.8 \\
7.6 \\
7.2\end{array}$ & $\begin{array}{l}7.6 \\
7.6 \\
7.75 \\
7.4\end{array}$ & $\begin{array}{l}7.6 \\
7.6 \\
7.8 \\
7.5\end{array}$ & $\begin{array}{l}7.8 \\
7.6 \\
7.7 \\
7.45\end{array}$ & $\begin{array}{l}7.6 \\
7.35 \\
6.8 \\
7.0\end{array}$ & $\begin{array}{l}7.3 \\
7.0 \\
6.6 \\
6.95\end{array}$ & $\begin{array}{l}7.4 \\
7.1 \\
6.6 \\
7.0\end{array}$ \\
\hline
\end{tabular}

The deviation between ambient and $\mathrm{LN}_{2}$ ranges from 6.4 to $15.2 \%$. Repeatability at a given frequency for four runs is $2.5 \%$ to $4 \%$.

\section{September 1963}

A number of tests have been conducted using this model at both ambient and cryogenic temperatures. The results were very favorable. Many tests have been conducted on one particular unit and is still operating satisfactorily. However, this is not a radiation resistant unit. Therefore, testing has been directed at the Endevco Model 2242C, Code No. Gr-12.

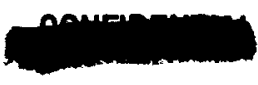


THIS PAGE INTENTIONALLY LEFT BLANK 


\section{VIBRATION TRANSDUCER}

Code No: $\quad$ Gr-14

Type: Piezoelectric - Self Calibrating

Mfgr: Gulton Industries, Inc.

Range: $0-10 \mathrm{~g}$
Spec. Control Dwg. No.964B021H01

Evaluation by: WANL

Model No:

SA324401

Application:

PERFORMANCE \& ENVIRONMENTAL SPECIFICATIONS

\begin{tabular}{|c|c|c|c|c|}
\hline Test & Condition & NERVA Requirements & Manufacturer's Specs & $\begin{array}{l}\text { Summary of } \\
\text { Test Results }\end{array}$ \\
\hline$A$ & Overload (Vibr.) & $100 \mathrm{~g}$ & $600 \mathrm{~g}$ peak & \\
\hline$B$ & Comp. Temp. Range & $140^{\circ}-535^{\circ} \mathrm{R}$ & $390^{\circ}-710^{\circ} \mathrm{B}$ & $140^{\circ}=535^{\circ} \mathrm{R}$ \\
\hline $\mathrm{C}$ & Input Impedance & & & \\
\hline$D$ & Output Impedance $\left(E_{\left(E_{0}\right)}\right)$ & $900 \mathrm{PF}$ min. & $\begin{array}{l}500 \text { PF min. } \\
900 \text { PF min. }\end{array}$ & \\
\hline$E$ & Excitation (for self- & $1 \mathrm{~V}$ rms approx. & $1 \mathrm{~V} \mathrm{rms}$ input $-0.5 \mathrm{~g}$ out & out \\
\hline$F$ & Sensitivity ( $\left(\mathrm{E}_{1}\right)$ & \multicolumn{3}{|c|}{$\begin{array}{l}7.5 \mathrm{mv} / \mathrm{g} \text { output element } 7.5 \mathrm{mx} / \mathrm{g} \text { output element } \\
4.5 \mathrm{mv} / \mathrm{g} \text { input element } 4.5 \mathrm{mv} / \mathrm{g} \text { input element }\end{array}$} \\
\hline $\mathrm{G}$ & Transverse Accel & $3 \% \max$ & $3 \%$ max. & \\
\hline $\mathrm{H}$ & Linearity & $\pm 2 \% \quad 0-50 \mathrm{~g}$ & $\pm 2 \%$ of best straight line & For preliminary \\
\hline 1 & Hysteresis & $\mathrm{NA}$ & & data see evalu- \\
\hline $\mathrm{J}$ & Resolution & $\mathrm{NA}$ & & ation history \\
\hline $\mathrm{K}$ & Accuracy & $5 \%$ & $5 \%$ & \\
\hline $\mathrm{L}$ & Freq. Response & $3-2000 \mathrm{cps}$ & $3-4000 \mathrm{cps}$ & $30-3000 \mathrm{cps}$ \\
\hline$M$ & Noise Limit & \multicolumn{3}{|c|}{$1.5 \mathrm{mv} / \mathrm{g}$ at $140 \mathrm{db}$ noise $1 / 5 \mathrm{mv} / \mathrm{g}$ at $140 \mathrm{db}$ noise } \\
\hline $\mathrm{N}$ & Neutron Flux & $\mathrm{NA}$ & & \\
\hline 0 & Gamma Flux & NA & & \\
\hline$P$ & Dimersions & $1.065^{\prime \prime} \mathrm{OD} \times 1.22^{\prime \prime} \mathrm{LG}$ & $1.065^{\prime \prime} \mathrm{OD} \times 1.22^{\prime \prime} \mathrm{LG}$ & \\
\hline Q & Weight & 16 grams & 16 grams & \\
\hline$R$ & Resonant Freq. & $20 \mathrm{KC}$ (nom mounted) & $15 \mathrm{KC}$ min. & \\
\hline $\mathrm{S}$ & Insulation Res. & 1000 meg. at 50 VDC & $1000 \mathrm{meg}$. at $50 \mathrm{~V}$ & \\
\hline T & Material & Titanium & Titanium & \\
\hline $\mathrm{u}$ & \multicolumn{4}{|c|}{ 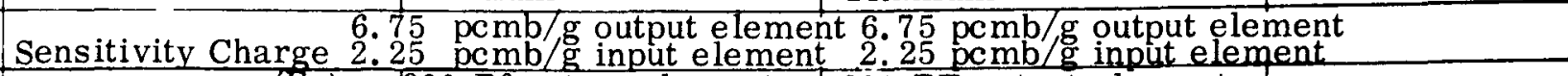 } \\
\hline $\mathrm{v}$ & Capacitance (E) & $500 \mathrm{Pf}$ output element & $\begin{array}{l}900 \mathrm{PF} \text { output element } \\
500 \mathrm{PF} \text { input element }\end{array}$ & \\
\hline & & & & \\
\hline & & & & \\
\hline & & & & \\
\hline & & & & \\
\hline
\end{tabular}




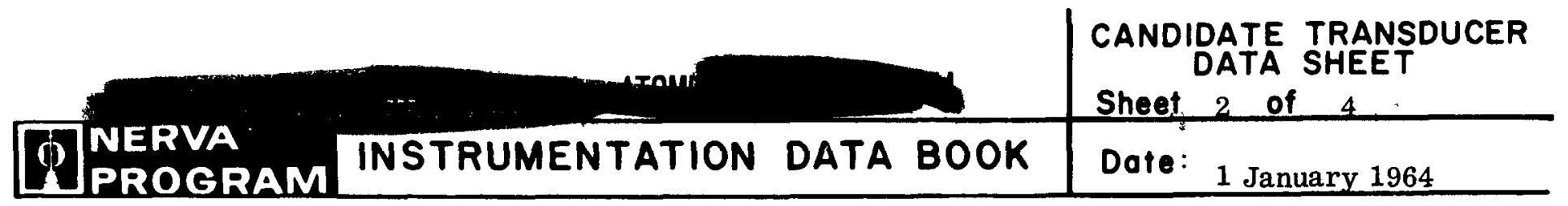

RADIATION TESTS

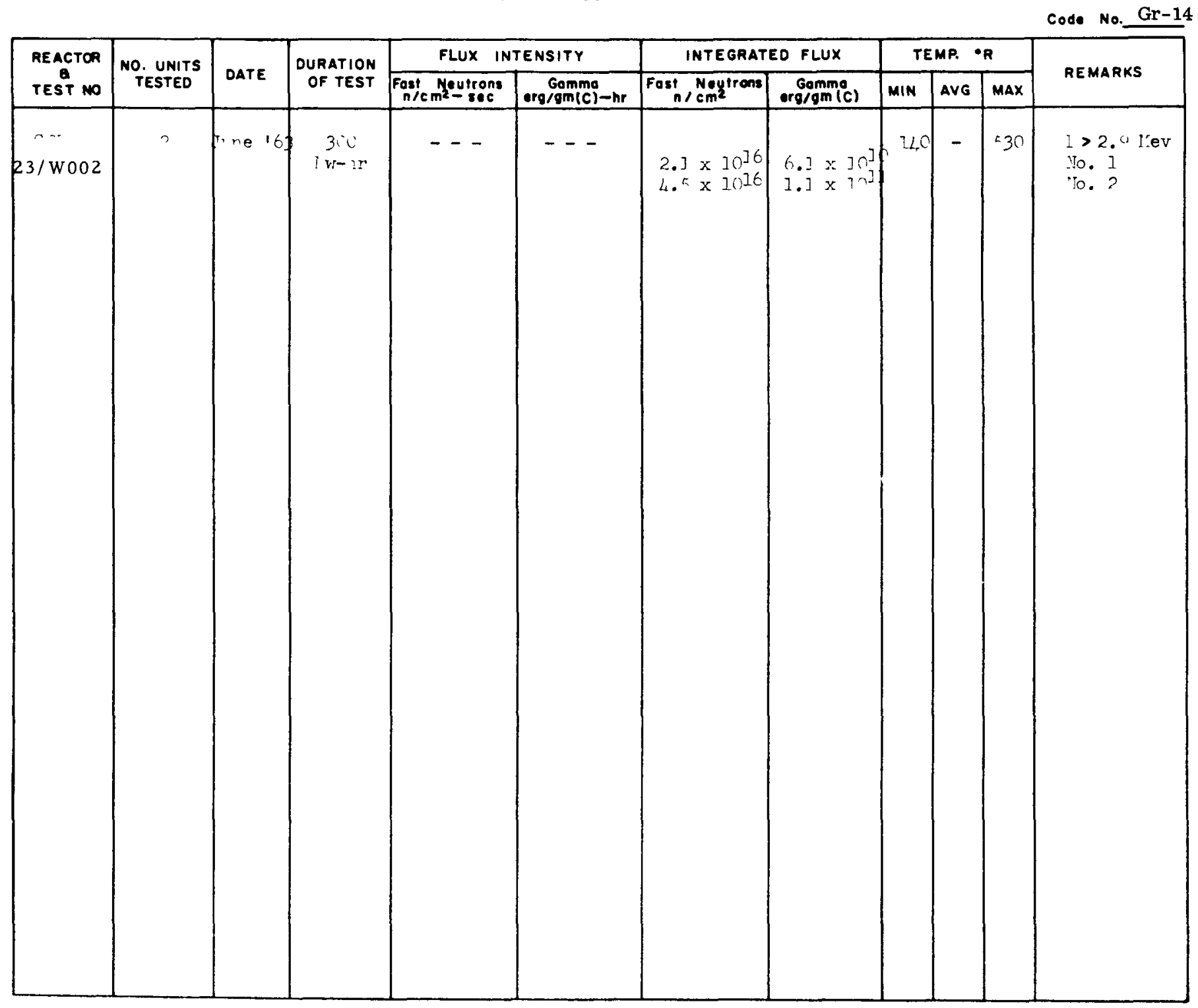

w 


\section{DEVELOPMENT HISTORY}

Code No:

Gr-14

Model No.

SA324401
Mfgr:

P. 0 . 34732

REMARKS:

Two of these units have been tested at GTR in June, 1963 in a combined cryogenic vibration and radiation environment. (140 Temp., from 5 to $9 \mathrm{~g}$ and $30-3000 \mathrm{cps}$ vibration.)

Pre-irradiation data consisted of mounting this specific model on a special WANL designed voice coil shaker and running frequency response for repeatable data. The ambient and submerged $\mathrm{LN}_{2}$ runs show repeatability as follows:

\begin{tabular}{|c|c|c|c|c|c|c|c|c|c|c|}
\hline 2 & & & $\mathrm{Ambi}$ & $t$ & & & & & & \\
\hline$f$ & & ${ }_{1} \mathrm{Ru}$ & & & $2_{2}^{R u}$ & & & & & \\
\hline & 1 & 2 & 3 & 1 & 2 & 3 & 1 & 2 & 1 & 2 \\
\hline 30 & 25 & 28 & 29 & 49 & 50 & 59 & 10.5 & 15 & 23.5 & 32 \\
\hline 50 & 71 & 71 & 71 & 136 & 135 & 134 & 11.5 & 13 & 24 & 27 \\
\hline 100 & 64 & 63 & 64 & 120 & 120 & 121 & 44 & 45 & 87 & 90 \\
\hline 200 & 56 & 55 & 52 & 102 & 101 & 96 & 52 & 60 & 105 & 110 \\
\hline 500 & 54 & 54 & 54 & 101 & 100 & 101 & 50 & 51 & 100 & 100 \\
\hline 750 & 48 & 48 & 47 & 88 & 88 & 89 & 46 & 46 & 93 & 92 \\
\hline 1000 & 54 & 49 & 54 & 101 & 95 & 101 & 38 & 37 & 74 & 73 \\
\hline 1500 & 49 & 48 & 49 & 88 & 90 & 92 & 41 & 43 & 83 & 82 \\
\hline 2000 & 49 & 49 & 49 & 88 & 89 & 91 & 32 & 34 & 64 & 66 \\
\hline 2500 & 47 & 48 & 47 & 82 & 84 & 86 & 34 & 34 & 66 & 64 \\
\hline 3000 & 46 & 46 & 45 & 78 & 78 & 79 & 32 & 33 & 61 & 61 \\
\hline
\end{tabular}

\section{September $1963 \quad 23 / \mathrm{W} 002$}

After detonation during irradiation, one accelerometer became inoperative while the other continued to respond at a reduced output. Post-irradiation examination showed that the crystal to metal bond had deteriorated (Ref. WANL-TME-491).

Capacitance readings for Gulton 1 were approximately the same as the preirradiation values. When disassembled, fracture of the conductor insulation and deterioration of the bond between the element and its armature were indicated. During the test, this accelerometer had operated satisfactorily until the detonations occurred, after which it became noisy and erratic.

Capacitance measurements on Gulton 2 showed a $20 \%$ reduction from its original values. The ceramic material used in this unit was of a different type than that used in Gulton 1. The insulation of the conductor in this unit appeared to have been affected. After the detonations occurred, this accelerometer operated with reduced sensitivity to the end of the test.

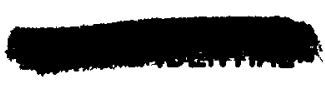




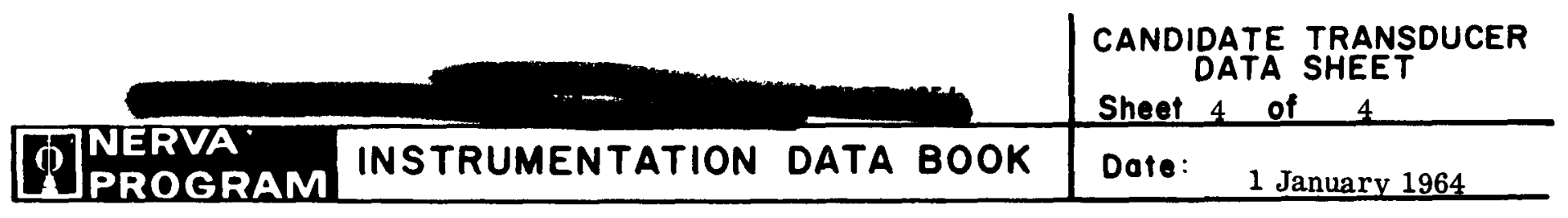

\section{DEVELOPMENT HISTORY}

Code No:

Model No. Gr-14

SA324401
Mfgr: Gulton Industries, Inc. 34732

\section{REMARKS:}

Utilization of this information and that from prior WANL laboratory tests has resulted in the development of a new type unit (Refer Code No. Gr-21) by Gulton which is expected to be more resistant to radiation effects. 


\section{VIBRATION TRANSDUCER}

Code No: $\mathrm{Gr}-15$

Type: Piezoelectric - Triaxial

Mfgr: Gulton Industries, Inc.

Range:
Spec. Control Dwg. No.964B033H01

Evaluation by: WANL

Model No: TA320214

Application:

PERFORMANCE \& ENVIRONMENTAL SPECIFICATIONS

\begin{tabular}{|c|c|c|c|c|}
\hline Test & Condition & NERVA Requirements & Manufacturer's Specs & $\begin{array}{l}\text { Summary of } \\
\text { Test Results }\end{array}$ \\
\hline A & Overload (Vibr.) & $25 \mathrm{~g}$ & $1200 \mathrm{~g}$ peak & $>25 \mathrm{~g}$ \\
\hline$B$ & Comp. Temp. Range & $40^{\circ}-535^{\circ} \mathrm{R}$ & $390^{\circ}-710^{\circ} \mathrm{R}$ & $140^{\circ}-540^{\circ} \mathrm{R}$ \\
\hline $\mathrm{C}$ & Input Impedance & NA & & $\mathrm{NA}$ \\
\hline D & Output Impedance & 900 PF (each element) & $900 \mathrm{PF}$ (each element) & \\
\hline$E$ & Excitation & $\mathrm{NA}$ & & NA \\
\hline $\mathrm{F}$ & Sensitivity & $\begin{array}{l}8.5 \mathrm{mv} / \mathrm{g} \text { (each } \\
\text { element) }\end{array}$ & $\begin{array}{l}8,5 \text { mv/g (each } \\
\text { element) }\end{array}$ & $\mathrm{x}=11.9, \mathrm{y}=10.5$ \\
\hline G & Transverse Accel & $5 \%$ max. (each element) & $5 \%$ max. (each element) & $\begin{array}{l}x=4.05 \%, \quad y=4.7 \\
z=1 ; 25 \%\end{array}$ \\
\hline $\mathrm{H}$ & Linearity & $\pm 2 \% 0-25 \mathrm{~g}$ & $\pm 2 \%$ of best straight line & 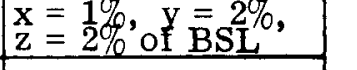 \\
\hline 1 & Hysteresis & $\mathrm{NA}$ & & NA \\
\hline$J$ & Resolution & $\mathrm{NA}$ & & $\mathrm{NA}$ \\
\hline$K$ & Accuracy & $5 \%$ & $5 \%$ & \\
\hline$L$ & Freq. Response & $3-2000 \mathrm{cps}$ & $3-4000 \mathrm{cps}$ & $\mathrm{x}=1.7 \% \mathrm{y}=1.0$ \\
\hline$M$ & Noise Limit & \multicolumn{3}{|c|}{$1.7 \mathrm{mv} / \mathrm{g}$ at $140 \mathrm{db}$ noise $1.7 \mathrm{mv} / \mathrm{g}$ at $140 \mathrm{db}$ noise } \\
\hline $\mathrm{N}$ & Neutron Flux & NA & & NA \\
\hline 0 & Gamma Flux & NA & & NA \\
\hline$\underline{P}$ & Dimensions & $1.20 " \times 1.20^{\prime \prime} \times 0.83^{\prime \prime}$ & $1.20 " \mathrm{~N} 1.20^{\prime \prime} \mathrm{x} 0.83^{\prime \prime}$ & $1.20^{\prime \prime} \times 1.20^{\prime \prime} \times 0$ \\
\hline Q & Weight & $1.5 \mathrm{oz}$. & $1.5 \mathrm{oz}$. & $1.5 \mathrm{oz}$. \\
\hline$R$ & Resonant Freq. & $20 \mathrm{KC}$ (nom mounted) & $20 \mathrm{KC}$ min. & $>1000 \mathrm{cps}$ \\
\hline $\mathrm{S}$ & Insulation Res. & $1000 \mathrm{meg}$ at $50 \mathrm{~V}$ & $1000 \mathrm{meg}$ at $50 \mathrm{~V}$ & \\
\hline $\mathrm{T}$ & Material & Aluminum & Aluminum & Aluminum \\
\hline $\mathrm{U}$ & Sensitivity Charge & $10 \mathrm{pcmb} / \mathrm{g}$ & $10 \mathrm{pcmb} / \mathrm{g}$ & $\begin{array}{l}x=13: 3, y=11.7 \\
z=\end{array}$ \\
\hline $\mathrm{V}$ & Capacitance & 900 PF min. & $900 \mathrm{PF}$ min. & \\
\hline & & & & \\
\hline & & & & \\
\hline & & & & \\
\hline
\end{tabular}





\section{DEVELOPMENT HISTORY}

Code No: Gr-15

Model No. TA320214

\section{REMARKS:}

In order to solve the mechanical mounting problems in final assembly, extreme emphasis was placed on physical size of these units.

A literature search for units specified by the manufacturers to satisfy the environmental conditions for NRX-A1 has been made and the initial selection is based on these results.

Confirmation of the guarantees will be made in subsequent evaluation tests by WANL. tested.

The actual models selected are similar in design principle in all instances to units previously

\section{$\underline{30} \underline{\text { September }} \underline{1963}$}

Preliminary tests show the accelerometer to be satisfactory on all three axes at both ambient and $\mathrm{LN}_{2}$. Tests are being conducted to determine the effects of thermal shock and the effects of numerous temperature cycles.

\section{$\underline{15} \underline{\text { November }} \underline{1963}$}

The tests indicated by the following tables and notes were conducted. The tabulated results are with respect to Gulton Industries Standard accelerometer model DA321501 serial no. 101.

The following tests were conducted at WANL during the week of October 12, 1963 to October 19, 1963. One tri-axial unit, which constituted a sample of those available from Gulton Industries, was tested. It was S/N G1-2.

The vibration level and frequency was limited by the equipment available in the laboratory. Maximum g level attainable was slightly greater than $25 \mathrm{~g}$ 's. Also, the vibration equipment was self resonating at about $2.1 \mathrm{kcs}$. Therefore the given data is considered valid within the above restrictions imposed by the equipment limitations. The sensitivity measurements were made at a $1 \mathrm{~g}$ input at $50 \mathrm{cps}$. The linearity was calculated as a per cent deviation from the straight line average of three successive runs from 0 to $25 \mathrm{~g}$ 's at $50 \mathrm{cps}$. The accuracy reading was taken from the linearity reading. The charge sensitivity was calculated from $Q=E\left(C_{p}+C_{t}\right)$ where, $Q=$ charge sensitivity, $E=$ voltage sensitivity, $C_{p}=$ capacitance of the accelerometer and $C_{t}=$ total external capacitance. The results of these tests are summarized in the following tabulation:

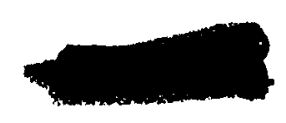




\section{DEVELOPMENT HISTORY}

Code No: Gr-15

Model No. TA320214

\section{REMARKS:}

Mfgr: Gulton Industries, Inc.

P. $0 . \quad 30495$

\begin{tabular}{|c|c|c|c|c|c|c|c|c|c|c|}
\hline $\mathrm{S} / \mathrm{N}$ & Axis & $\begin{array}{c}\text { Over- } \\
\text { load } \\
\text { (g's } \\
\text { rms) } \\
\end{array}$ & $\begin{array}{c}\text { Comp. } \\
\text { Temp. } \\
\text { Range } \\
\left({ }^{\circ} \mathrm{R}\right)\end{array}$ & $\begin{array}{c}\text { Sensitivity } \\
\mathrm{mv} / \mathrm{g}\end{array}$ & $\begin{array}{c}\text { Trans- } \\
\text { verse } \\
\text { Accel. } \\
\% \text { of } \\
\text { Sens. } \\
\end{array}$ & $\begin{array}{l}\text { Linearity } \\
\% \text { of BSL }\end{array}$ & $\begin{array}{l}\text { Accuracy } \\
\% \text { of BSL }\end{array}$ & $\begin{array}{l}\text { Treq. } \\
\text { Resp. } \\
\% \text { of } \\
\text { Siens. }\end{array}$ & $\begin{array}{c}\text { Resonant } \\
\text { Freq. } \\
\text { (kcs) }\end{array}$ & $\begin{array}{c}\text { Sensitivity } \\
\text { Charge } \\
\text { (PCB/g) }\end{array}$ \\
\hline \multirow[t]{3}{*}{ G1-5 } & $X$ & $\begin{array}{l}25 \\
25\end{array}$ & $\begin{array}{l}140 \\
540\end{array}$ & $\begin{array}{l}10.4 \\
11.9\end{array}$ & $\begin{array}{l}5 \\
4.05\end{array}$ & $\begin{array}{l} \pm 2 \\
\pm 1\end{array}$ & $\begin{array}{l} \pm 2 \\
\pm 1\end{array}$ & $\begin{array}{l} \pm 6.7 \\
\pm 1.7\end{array}$ & $\begin{array}{l}1 \\
1\end{array}$ & $\begin{array}{l}11.5 \\
13.3\end{array}$ \\
\hline & $\mathrm{Y}$ & $\begin{array}{l}25 \\
25\end{array}$ & $\begin{array}{l}140 \\
540\end{array}$ & $\begin{array}{c}9.26 \\
10.5\end{array}$ & $\begin{array}{l}2.03 \\
4.75\end{array}$ & $\begin{array}{l} \pm 1 \\
\pm 2\end{array}$ & $\begin{array}{l} \pm 1 \\
\pm\end{array}$ & $\begin{array}{l} \pm 5 \\
\pm 1\end{array}$ & $\begin{array}{l}1 \\
1\end{array}$ & $\begin{array}{l}9.26 \\
11.7\end{array}$ \\
\hline & $\mathrm{Z}$ & $\begin{array}{l}25 \\
25\end{array}$ & $\begin{array}{l}140 \\
540\end{array}$ & $\begin{array}{l}10.6 \\
11.8\end{array}$ & $\begin{array}{l}1.75 \\
1.25\end{array}$ & $\begin{array}{l} \pm 4.3 \\
\pm 2\end{array}$ & $\begin{array}{l} \pm 4.3 \\
\pm 2\end{array}$ & $\begin{array}{l} \pm 3 \\
1.7\end{array}$ & $\begin{array}{l}1 \\
1\end{array}$ & $\begin{array}{l}11.4 \\
12.7\end{array}$ \\
\hline
\end{tabular}

In order to ascertain that the accelerometers received from the vendor were qualified and would still meet the NERVA requirements, WANL certified calibration data was required with each transducer. These tests and results are summarized here.

A. The capacitance of the accelerometer was measured at $1000 \mathrm{cps}$ (1 volt, rms) using a General Radio Bridge, Model $716 \mathrm{C}$.

B. Resonant Frequency - With the accelerometer being vibrated at a constant 2 volt output, the frequency was increased until the output indicated a resonance, (i.e., first inflection greater than $2 \mathrm{db}$ ). This frequency was measured and recorded.

C. Sensitivity, Frequency Response - While the accelerometer was vibrated at a constant $1 \mathrm{~g}(\mathrm{rms})$, the frequency was varied over the frequency range $(1 \mathrm{cps}$ to $2.7 \mathrm{kc})$. The percent output deviation from the value at $50 \mathrm{cps}$ was calculated and recorded.

D. Amplitude Linearity - The accelerometer was vibrated at a constant frequency of $500 \mathrm{cps}$ while the $\mathrm{g}$ level was varied over the accelerometers maximum range. The percent deviation, from the best straight line through this design range, was calculated and recorded.

E. Transverse Response - The accelerometer was vibrated in its $x$-axis at $10 \mathrm{~g}$ ( $\mathrm{rms}$ ) and $100 \mathrm{cps}$. The output in the $\mathrm{Y}$ and $\mathrm{Z}$ axis was monitored for maximum transverse response. This maximum transverse in the $\mathrm{Y}-\mathrm{Z}$ axis was calculated and recorded as a percentage of the response in the $\mathrm{x}$-axis.

The above procedure was repeated for the $\mathrm{Y}$ and $\mathrm{Z}$ axes. 


\section{DEVELOPMENT HISTORY}

Code No: Gr-15

Mfgr: Gulton Industries, Inc.

Model No. TA320214

P. $0 . \quad 30495$

\section{REMARKS:}

F. Temperature and Pressure Response - The accelerometer was vibrated in a cryostat at $2 \mathrm{~g}$ (rms), $100 \mathrm{cps}$ and ambient (room) conditions. While monitoring the output, the pressure was increased to 200 psig. Any output change was recorded in $\mathrm{mv} / \mathrm{g} / \mathrm{psi}$. This test was then repeated at $-320^{\circ} \mathrm{F}$.

G. Pressure Pulse Response - The transducer was vibrated at $2 \mathrm{~g}$ (rms), $100 \mathrm{cps}$ and ambient (room) conditions. The maximum response of the transducer to a uniformly increasing pressure pulse, 0 to $200 \mathrm{psig}$ in 20 seconds, was measured and recorded. This test was then reprater it $-320^{\circ} \mathrm{F}$.

$15 \underline{\text { Not mhrr } 1963}$

\begin{tabular}{|c|c|c|c|c|c|c|c|c|c|}
\hline Symbol & $\mathrm{S} N$ & $\begin{array}{l}\text { Capac- } \\
\text { itance } \\
\text { Total } \\
\end{array}$ & $\begin{array}{c}\mu \mu \mathrm{f} \\
\text { Cable } \\
\end{array}$ & $\begin{array}{c}\text { Reso- } \\
\text { nant } \\
\text { Freq. } \\
\text { KC } \\
\end{array}$ & $\begin{array}{c}20-3000 \mathrm{cps} \\
\text { Sensitivity } \\
\text { Variation } \\
\% \\
\end{array}$ & $\begin{array}{c}\text { Ampl. } \\
\text { Linearity } \\
\text { Variation } \\
\% \\
\end{array}$ & $\begin{array}{c}\text { Trans- } \\
\text { verse } \\
\text { Response } \\
72 \\
\end{array}$ & 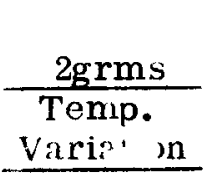 & $\begin{array}{l}\text { 2grms } \\
\text { Press. } \\
\text { Vartation }\end{array}$ \\
\hline & GI- $1 x$ & 1216 & 228 & 23.5 & $5.1 \%$ & $<1 \%$ & $4.5 \%$ & $2.79 \mu \mathrm{v} /{ }^{\circ} \mathrm{F}$ & 0 \\
\hline & GI-1y & 1210 & 228 & 21.6 & $5.2 \%$ & $<1 \%$ & ¿. $4^{4}$ & $56 \mu \mathrm{r} /{ }^{\circ} \mathrm{F}$ & 0 \\
\hline & GI- $1 z$ & 1296 & 228 & 22.5 & $6.3 \%$ & $<7.7 \%$ & $4.3 \%$ & $1 . j 2 \mu \mathrm{v} /{ }^{\circ} \mathrm{F}$ & 0 \\
\hline
\end{tabular}




$$
\text { in }
$$

THIS PAGE INTENTIONALLY LEFT BLANK 


\section{VIBRATION TRANSDUCER}

Code No:

$\mathrm{Gr}-16$

Type:

Mifgr:

Piezoelectric

Range:

Gulton Industries

$0-10 \mathrm{~g}$
Spec. Control Dwg. No.964B040H01

Evaluation by: WANL

Model No: $\quad$ AC316403

Application:

PERFORMANCE \& ENVIRONMENTAL SPECIFICATIONS

\begin{tabular}{|c|c|c|c|c|}
\hline Test & Condition & NERVA Requirements & Manufacturer's Specs & $\begin{array}{l}\text { Summary of } \\
\text { Test Results }\end{array}$ \\
\hline $\mathrm{A}$ & Overload & $100 \mathrm{~g}$ & $500 \mathrm{~g}$ peak & \\
\hline$B$ & Comp. Temp. Range & $390^{\circ}-535^{\circ} R$ & $360^{\circ}-960^{\circ} R$ & \\
\hline $\mathrm{C}$ & Input Impedance & $\mathrm{NA}$ & & \\
\hline$D$ & Output Impedance & 500 PF min. & $500 \mathrm{PF}$ min. & \\
\hline$E$ & Excitation & NA & & \\
\hline$F$ & Sensitivity & $5 \mathrm{mv} / \mathrm{g}$ & $5 \mathrm{mv} / \mathrm{g}$ & \\
\hline G & Transverse Accel & $3 \%$ max. & $3 \% \max$. & \\
\hline $\mathrm{H}$ & Linearity & $\pm 2 \% 0-50 \mathrm{~g}$ & $\pm 2 \%$ of best straight line & \\
\hline 1 & Hysteresis & $\mathrm{NA}$ & & \\
\hline$J$ & Resolution & NA & & \\
\hline$k$ & Accuracy & $5 \%$ & $5 \%$ & \\
\hline$L$ & Freq. Response & $3-2000 \mathrm{cps}$ & $3-3000 \mathrm{cps}$ & \\
\hline$M$ & Noise Limit & $1.0 \mathrm{mv} / \mathrm{g}$ at $140 \mathrm{db}$ noise & $1.0 \mathrm{mv} / \mathrm{g}$ at $140 \mathrm{db}$ noise & \\
\hline $\mathrm{N}$ & Neutron Flux & $\mathrm{NA}$ & & \\
\hline 0 & Gamma Flux & NA & & \\
\hline$P$ & Dimensions & $0.50^{\prime \prime} \mathrm{OD} \times 1.07^{\prime \prime} \mathrm{LG}$ & $0.50 "$ OD $\times 1.07 "$ LG & \\
\hline$Q$ & Weight & 7.5 grams & 7.5 grams & \\
\hline$R$ & Resonant Freq. & $10 \mathrm{KC}$ (nom. mounted) & $10 \mathrm{KC} \min$. & \\
\hline $\mathrm{s}$ & Insulation Res. & $1000 \mathrm{meg}$ at $50 \mathrm{~V}$ & $1000 \mathrm{meg}$ at $50 \mathrm{~V}$ & \\
\hline$T$ & Material & Titanium & Titanium & \\
\hline $\mathrm{u}$ & Sensitivity Charge & $2.5 \mathrm{pcmb} / \mathrm{g}$ & $2.5 \mathrm{pcmb} / \mathrm{g}$ & \\
\hline $\mathrm{V}$ & Capacitance & $500 \mathrm{PF}$ min & $500 \mathrm{PF}$ min & \\
\hline & & & & \\
\hline & & & & \\
\hline & & & & \\
\hline & & & & \\
\hline
\end{tabular}





\section{DEVELOPMENT HISTORY}

Code No: $\frac{\text { Gr-16 }}{\text { Model No. }}$

Mfgr: Gulton Industries, Inc.

REMARKS:

In order to solve the mechanical mounting problems in final assembly, extreme emphasis was placed on physical size of these units.

A literature search for units specified by the manufacturers to satisfy the environmental conditions for NRX-A1 has been made and the initial selection is based on these results.

Confirmation of the guarantees will be made in subsequent evaluation tests by WANL. tested.

The actual models selected are similar in design principle in all instances to units previously

\section{$\underline{30} \underline{\text { September }} \underline{1963}$}

Tests have been conducted to determine the effects on accelerometer output due to a thermal shock of ambient to $-320^{\circ} \mathrm{F}$. The accelerometer was subjected to thermal shock with and without heat sinks.

With no heat sink and using an amplifier with low-frequency cutoff at $1 \mathrm{cps}$, the output of the unit was equivalent to $10 \mathrm{~g}$ 's. With a heat sink, the output reduced to $6 \mathrm{~g}^{\prime} \mathrm{s}$.

With no heat sink and low frequency cutoff at $10 \mathrm{cps}$, the output decreased to $2 \mathrm{~g}$ 's. With a heat sink the output was near $2 \mathrm{~g}$ 's. vibrated.

Tests are to be conducted with the thermal shock occuring while the accelerometer is being

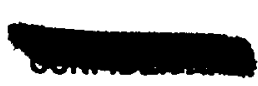


THIS PAGE INTENTIONALLY LEFT BLANK 


\section{VIBRATION TRANSDUCER}

Code No: Gr-17

Type:

Mfgr:

Vibrometer

Range:
Physical Sciences

\section{PERFORMANCE \& ENVIRONMENTAL SPECIFICATIONS}

\begin{tabular}{|c|c|c|c|c|}
\hline Test & Condition & NERVA Requirements & Manufacturer's Specs & $\begin{array}{l}\text { Summary of } \\
\text { Test Results }\end{array}$ \\
\hline$A$ & Overload & $100 \%$ & $100 \%$ & \\
\hline$B$ & Comp. Temp. Range & $390-535^{\circ} \mathrm{R}$ & $135-960^{\circ} \mathrm{R}$ & \\
\hline $\mathrm{C}$ & Input Impedance & 40 ohms (nom.) & $40 \mathrm{ohms}$ at $6600 \mathrm{cps}$ & \\
\hline$D$ & Output Impedance & 400 ohms (nom.) & $400 \mathrm{ohms}$ at $6600 \mathrm{cps}$ & \\
\hline$E$ & Excitation & $5 \mathrm{~V}$ (nom.) AC rms & $6000-6600 \mathrm{cps} / 5$ volts & \\
\hline $\mathrm{F}$ & Sensitivity & $0.1 \mathrm{~V} / \mathrm{V}$ & $0.1 \mathrm{~V} / \mathrm{V}$ for 0.1 inch displ & \\
\hline $\mathbf{G}$ & Transverse Accel & $5 \% \max$. & $25 \mathrm{~g}$ 's for $1 \%$ interaction & \\
\hline $\mathrm{H}$ & Linearity & $\pm 5 \% 0-50 \mathrm{~g}$ & $\pm 5 \%$ & \\
\hline 1 & Hysteresis & $\pm 2 \%$ & $\pm 2 \%$ & \\
\hline $\mathrm{J}$ & Resolution & Infinite & Infinite & \\
\hline $\mathrm{K}$ & Accuracy & $\pm 8 \%$ & $\pm 8 \%$ & \\
\hline$L$ & Freq. Response & $55 \mathrm{cps}-500 \mathrm{cps} \pm 5 \%$ & $55 \mathrm{cps}-500 \mathrm{cps} \pm 5 \%$ & \\
\hline M & Noise Limit & $135 \mathrm{db}$ & $135 \mathrm{db}$ white noise & \\
\hline $\mathrm{N}$ & Neutron Flux & & $1 \times 10^{20}$ NVT Mixed Flux & \\
\hline 0 & Gamma Flux & & $1 \times 10^{14}$ RADS & \\
\hline$P$ & Dimensions & 2" dia, $\times 3 " 1 \mathrm{~g}$. max. & 2.75" dia. 2.6" $1 \mathrm{~g}$. & \\
\hline$Q$ & Weight & $10 \mathrm{oz} \cdot \max$. & $9 \mathrm{oz}$. & \\
\hline$R$ & Resonant Freq. & & $40 \mathrm{cps}$. & \\
\hline $\mathrm{S}$ & Insulation Res. & $100 \mathrm{meg}$. at $45 \mathrm{VDC}$ & Durock D-133 & \\
\hline$T$ & Material & Compatible with $\mathrm{LH}_{2}$ & \multicolumn{2}{|c|}{304 Stainless Steel, Inconel X } \\
\hline & & & & \\
\hline & & & & \\
\hline & & & & \\
\hline & & & & \\
\hline & & & & \\
\hline
\end{tabular}

Spec. Control Dwg. No.

Evaluation by: WANL

Model No: $\quad$ VT100

Application: 


\section{RADIATION TESTS}

Cade No $\mathrm{Gr}-17$

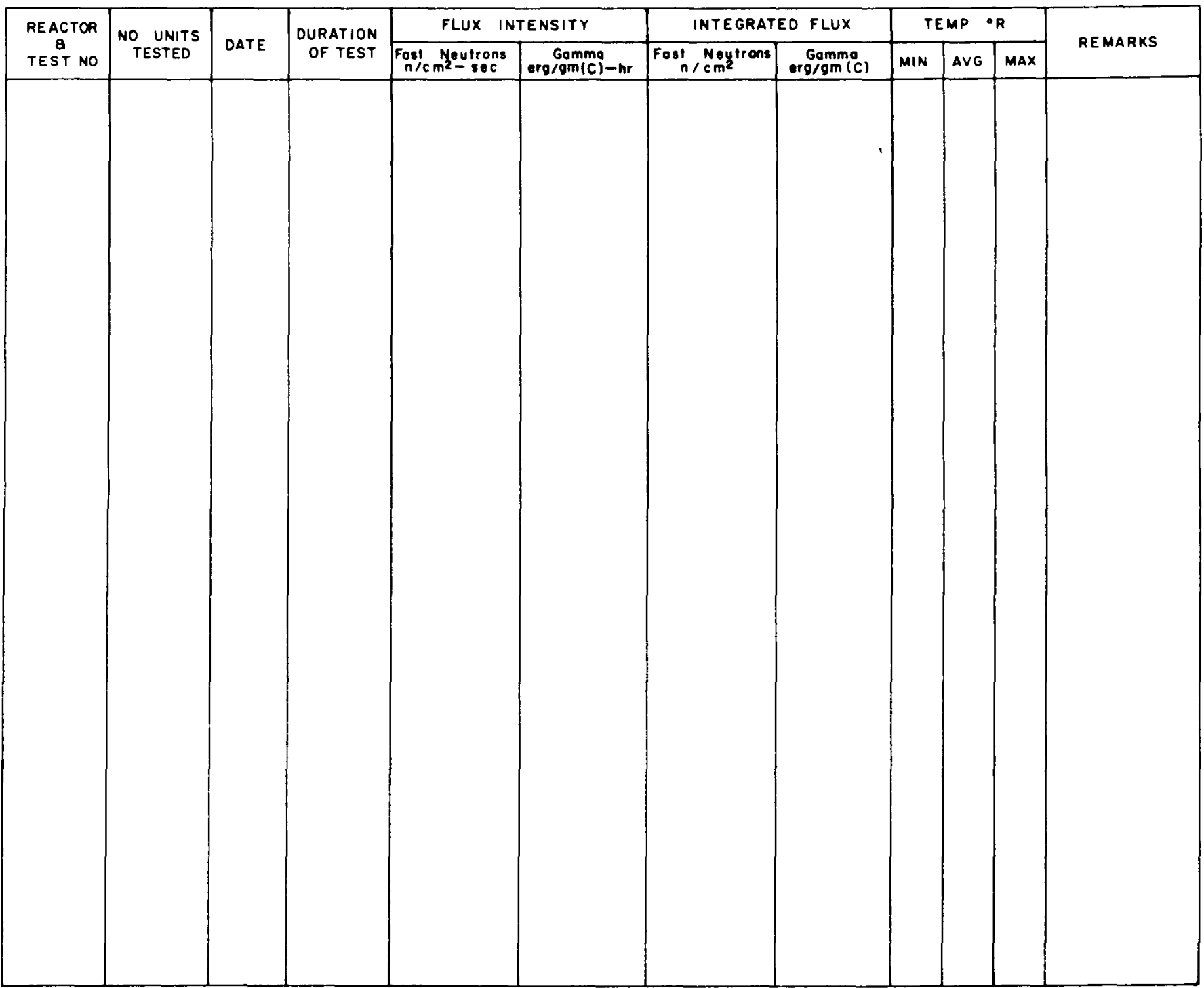




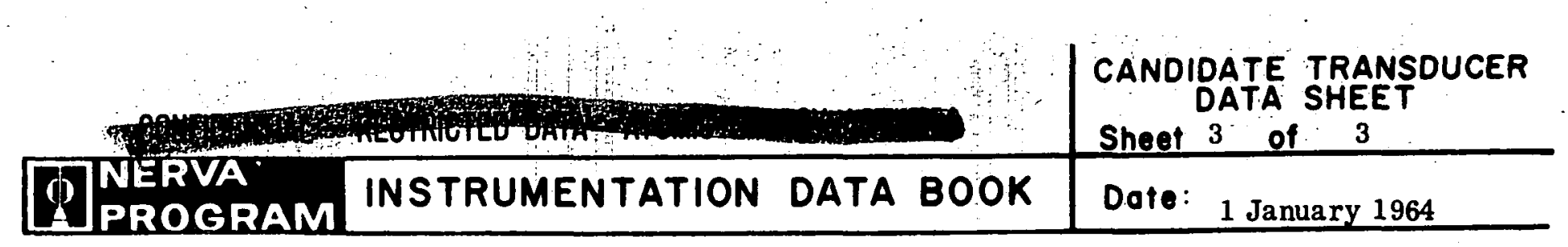

\section{DEVELOPMENT HISTORY}

Code No: $\frac{\text { Gr-17 }}{\text { VT100 }} \quad$ Mfgr: $\frac{\text { Physical Science }}{34731,65043}$
Model No. $\quad$ P. $0 . \frac{343}{}$

\section{REMARKS:}

Radiation testing is planned for this unit at Ground Test Reactor during September, 1963. 
THIS PAGE INTENTIONALLY LEFT BLANK 


\section{VIBRATION TRANSDUCER}

Code No: $\mathrm{Gr}-18$

Type: Piezoelectric

Mfgr: Gulton

Range: $\underline{0-10 \mathrm{~g}}$
Spec. Control Dwg. No. 964B019H01

Evaluation by: WANL

Model No: AA314405

Application:

PERFORMANCE \& ENVIRONMENTAL SPECIFICATIONS

\begin{tabular}{|c|c|c|c|c|}
\hline Test & Condition & NERVA Requirements & Manufacturer's Specs & $\begin{array}{l}\text { Summary of } \\
\text { Test Results }\end{array}$ \\
\hline $\mathrm{A}$ & Overload & $100 \mathrm{~g}$ & $500 \mathrm{~g}$ peak & \\
\hline$B$ & Comp. Temp. Range & $390-535^{\circ} \mathrm{R}$ & $360-960^{\circ} \mathrm{R}$ & \\
\hline $\mathrm{C}$ & Input Impedance & $\mathrm{NA}$ & & \\
\hline $\mathrm{D}$ & Output Impedance & 500 PF min. & $500 \mathrm{PF}$ min. & \\
\hline$E$ & Excitation & $\mathrm{NA}$ & & \\
\hline $\mathrm{F}$ & Sensitivity & $5 \mathrm{mv} / \mathrm{g}$ & $5 \mathrm{mv} / \mathrm{g}$ & \\
\hline G & Transverse Accel & $3 \% \max$. & $3 \% \max$. & \\
\hline $\mathrm{H}$ & Linearity & $\pm 2 \% 0-50 \mathrm{~g}$ & $\pm 2 \%$ of best straight line & \\
\hline 1 & Hysteres is & $\mathrm{NA}$ & & \\
\hline $\mathrm{J}$ & Resolution & $\mathrm{NA}$ & & \\
\hline$K$ & Accuracy & $5 \%$ & $5 \%$ & \\
\hline$L$ & Freq. Response & $3-2000 \mathrm{cps}$ & 3-3000 cps & \\
\hline$M$ & Noise Limit & $1.0 \mathrm{mv} / \mathrm{g}$ at $140 \mathrm{db}$ nois & $1.0 \mathrm{mv} / \mathrm{g}$ at $140 \mathrm{db}$ noise & \\
\hline$N$ & Neutron Flux & $\mathrm{NA}$ & & \\
\hline 0 & Gamma Flux & $\mathrm{NA}$ & & \\
\hline$P$ & Dimensions & $0.97 "$ OD x $1.12 " \mathrm{lg}$. & $0.50 "$ OD x $1.07 " \mathrm{lg}$. & \\
\hline$Q$ & Weight & $7.5 \mathrm{gms}$ & $7.5 \mathrm{gms}$ & \\
\hline$R$ & Resonant Freq. & $10 \mathrm{KC}$ (nom. mounted) & $10 \mathrm{KC}$ min. & \\
\hline$S$ & Insulation Res. & $1000 \mathrm{meg}$ at $50 \mathrm{VDC}$ & $1000 \mathrm{meg}$ at $50 \mathrm{VDC}$ & \\
\hline$T$ & Material & Titanium & Titanium & \\
\hline $\mathrm{U}$ & Sensitivity Charge & $2.0 \mathrm{pk} \mathrm{pcmb} / \mathrm{pk}-\mathrm{g}$ & $2.0 \mathrm{pk} \mathrm{pcmb} / \mathrm{pk}-\mathrm{g}$ & \\
\hline $\mathrm{V}$ & Capacitance & 500 PF min. & $500 \mathrm{PF}$ min. & \\
\hline & & & & \\
\hline - & & & & \\
\hline & & & & \\
\hline & & & & \\
\hline
\end{tabular}





\section{DEVELOPMENT HISTORY}

Code No:

Model No. AA314405
Mfgr:

P. 0 .

\section{REMARKS:}

In order to solve the mechanical mounting problems in final assembly, extreme emphasis was placed on physical size of these units.

A literature search for units specified by the manufacturers to satisfy the environmental conditions for NRX-A-1 has been made and the initial selection is based on these results.

Confirmation of the guarantees will be made in subsequent evaluation tests by WANL.

Tests were conducted on one (1) of these units by the manufacturer. Frequency response at ambient and in $\mathrm{LN}_{2}$ were conducted with good results. Test data and unit shipped to date to WANL for further evaluation. 
THIS PAGE INTENTIONALLY LEFT BLANK 


\section{VIBRATION TRANSDUCER}

$\begin{array}{lll}\text { Code No: } \frac{\text { Gr-19 }}{\text { Servo Accelerometer }} & \text { Spec. Control Dwg. No. } 945 \mathrm{C} 945 \mathrm{H} 02 \\ \text { Type: } \frac{\text { Evaluation by: }}{\text { Gulton }} & \text { Model No: } \\ \text { Mfgr: } \frac{\text { WANL }}{\text { LA640203 }} \\ \text { Range: }\end{array}$

PERFORMANCE \& ENVIRONMENTAL SPECIFICATIONS

\begin{tabular}{|c|c|c|c|c|}
\hline Test & Condition & NERVA Requirements & Manufacturer's Specs & $\begin{array}{l}\text { Summary of } \\
\text { Test Results }\end{array}$ \\
\hline A & Overload & $20 \mathrm{~g}$ (static) & $100 \mathrm{~g}$ (static) & \\
\hline B & Comp. Temp. Range & $420-672^{\circ} \mathrm{R}$ & $420-672^{\circ} \mathrm{R}$ & \\
\hline $\mathrm{C}$ & Input Impedance & $1.4 \mathrm{~K}$ ohms approx. & $2 \mathrm{~K}$ ohms nom. & \\
\hline D & Output Impedance & $<500$ ohms & info. later & \\
\hline$E$ & Excitation & $28 \mathrm{VDC}$ (nom) & $28 \mathrm{VDC}$ & \\
\hline$F$ & Sensitivity & $\begin{array}{l}7 . \overline{5 V \text { and/or } 1.5 \mathrm{ma}} \\
\pm 2 \% \mathrm{FR}\end{array}$ & $\pm 7.5 \mathrm{~V}$ FR (5K int. res.) & \\
\hline$G$ & Transverse Accel & $<0.5 \%$ FR (static) & $0.2 \%$ FR (static load) & \\
\hline $\mathrm{H}$ & Linearity & $\begin{array}{l}\text { combined effects less } \\
\text { than } 0.2 \% \text { FR at } 70^{\circ} \pm 5^{\circ} \mathrm{F}\end{array}$ & $\pm 0.05 \%$ FR (static load) & \\
\hline 1 & Hysteresis & ambient temperature & $\pm 0.05 \%$ FR (static load) & \\
\hline $\mathrm{J}$ & Resolution & $0.05 \% \mathrm{FR}$ & $0.05 \% \mathrm{FR}$ & \\
\hline$K$ & Accuracy & $5 \%$ & info. later & \\
\hline L & Freq. Response & $0-85 \mathrm{cps}$ & $0-85 \mathrm{cps}$ & \\
\hline$M$ & Noise Limit & $\mathrm{NA}$ & & \\
\hline$N$ & Neutron Flux & NA & & \\
\hline 0 & Gamma Flux & $\mathrm{NA}$ & & \\
\hline$P$ & Dimensions & $1.21 " \times 1.21 " \times 3.39 "$ & $1.21 " \times 1.21 " \times 3.39 "$ & \\
\hline$Q$ & Weight & mfgr. to specify & 3 ozs. & \\
\hline $\mathrm{R}$ & Resonant Freq. & $85 \mathrm{cps}$ & $85 \mathrm{cps}$ & \\
\hline$S$ & Insulation Res. & $>50$ megohms at $50 \mathrm{VDq}$ & & \\
\hline$T$ & Material & & & \\
\hline & & & & \\
\hline & & & & \\
\hline & & & & \\
\hline & & & & \\
\hline & & & & \\
\hline
\end{tabular}




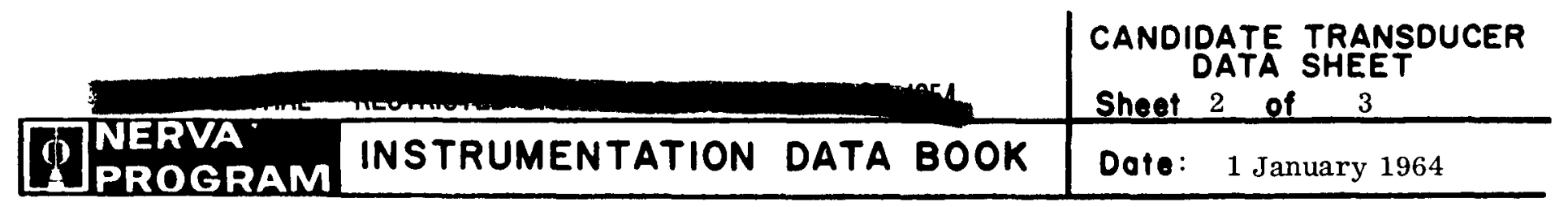

RADIATION TESTS

Code No. $\mathrm{Gr}-19$

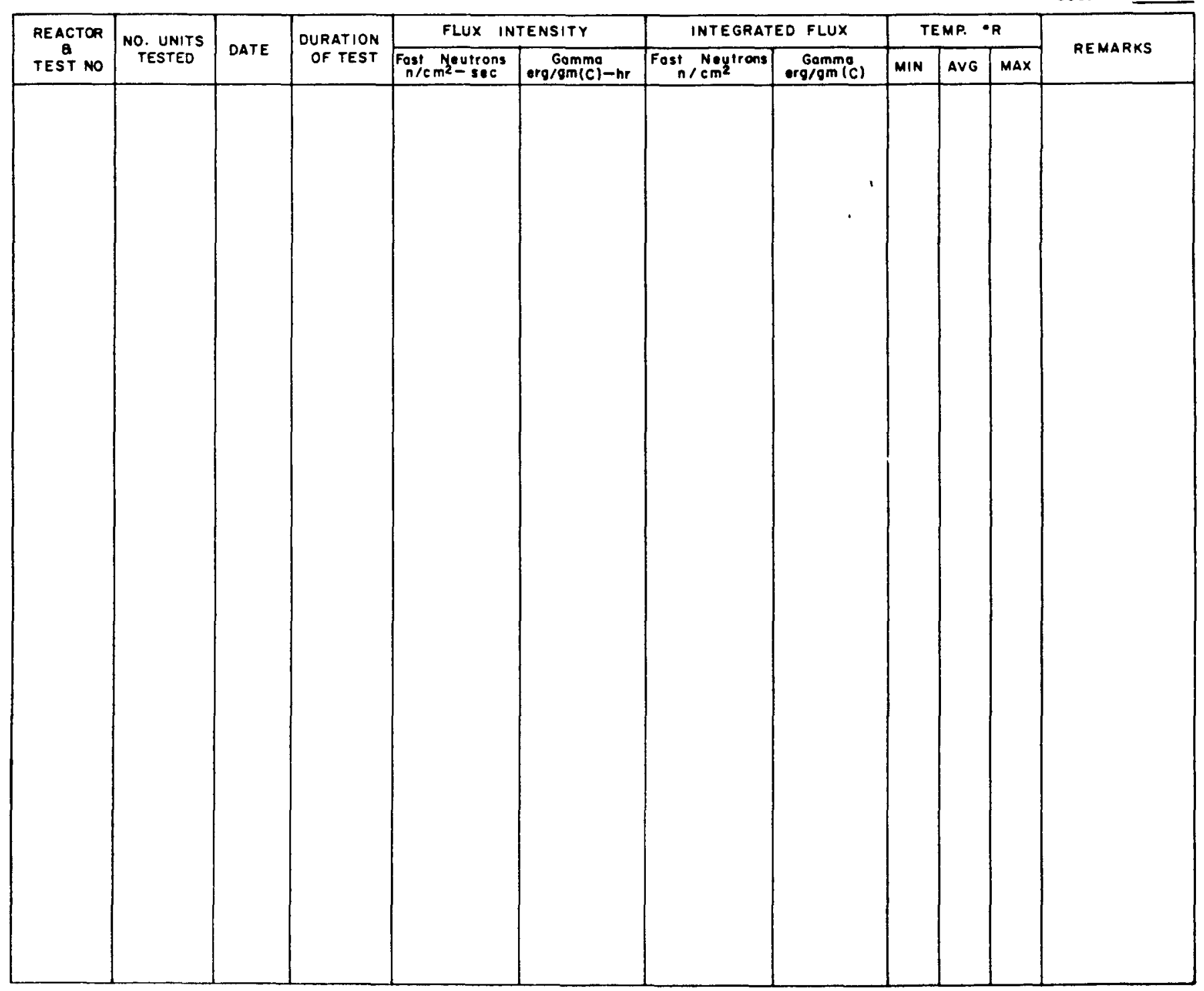




\section{DEVELOPMENT HISTORY}

Code No:

Gr-19

Model No.

LA640203

Mfgr: Gulton

P. 0 .

\section{REMARKS:}

This unit has been selected for use on the test car privy roof for the NRX-A1 Test. Consequently, it is not subject to extreme environmental conditions.

Tests are planned at WANL during September, 1963 to verify the manufacturer's specifications. 
THIS PAGE INTENTIONALLY LEFT BLANK 


\section{VIBRATION TRANSDUCER}

Code No: $\quad$ Gr-20

Type: Variable Reluctance

Mfgr: Wiancko

Range: $\quad 0-10 \mathrm{~g}$
Spec. Control Dug. No. 945C927H01

Evaluation by: WANL

Model No: $\mathrm{AX}-40$

Application:

\section{PERFORMANCE \& ENVIRONMENTAL SPECIFICATIONS}

\begin{tabular}{|c|c|c|c|c|}
\hline Test & Condition & NERVA Requirements & Manufacturer's Specs & $\begin{array}{l}\text { Summary of } \\
\text { Test Results }\end{array}$ \\
\hline $\bar{A}$ & Overload & info. later & $5.0 \mathrm{FR}$ & \\
\hline $\mathrm{B}$ & Comp. Temp. Range & $140^{\circ}-6600 R$ & $140^{\circ}-560^{\circ} \mathrm{R}$ & \\
\hline C & Input Impedance & info. later & $28 \mathrm{VDC}, 18 \mathrm{ma}$ (carrier) & \\
\hline$D$ & Output Impedance & info. later & $<500$ ohms (carrier) & \\
\hline$E$ & Excitation & $35 \mathrm{VAC} \mathrm{rms}$ & \multicolumn{2}{|c|}{ 28VDC (reg) $18 \mathrm{ma}$ (carrier) } \\
\hline$F$ & Sensitivity & $100 \mathrm{mv} / \mathrm{V}$ & \pm 2.5 volts from bias pt. & \\
\hline G & Transverse Accel & $<0.02 \mathrm{~g} / \mathrm{g}$ & $<0.01 \mathrm{~g} / \mathrm{g}$ & \\
\hline $\mathrm{H}$ & Linearity & \multirow{2}{*}{$\begin{array}{l}\text { combined effects less } \\
\text { than } \pm 0.5 \% \text { full range } \\
\text { output }\end{array}$} & $1 \%$ & \\
\hline 1 & Hysteresis & & $0.1 \%$ & \\
\hline$J$ & Resolution & $<0.1 \% \mathrm{FR}$ & Continuous & \\
\hline$K$ & Accuracy & $\pm 3.5 \%$ & & \\
\hline$L$ & Freq. Response & flat between $0-80 \mathrm{cps}$ & flat within $5 \%$ to $80 \mathrm{cps}$ & \\
\hline$M$ & Noise Limit & $150 \mathrm{db}$ & output ripple $<0.3 \% \mathrm{rms}$ & \\
\hline $\mathrm{N}$ & Neutron Flux & $2.4 \times 10^{14} \mathrm{n} / \mathrm{cm}^{2}-\mathrm{sec}$. & & \\
\hline 0 & Gamma Flux & \multicolumn{2}{|l|}{$3.3 \times 10^{11} \mathrm{ergs} / \mathrm{gm}(\mathrm{c})-\mathrm{hr}$} & \\
\hline$P$ & Dimensions & & & \\
\hline$Q$ & Weight & mfgr. to specify & 3 ozs. & \\
\hline$R$ & Resonant Freq. & $>500 \mathrm{cps}$ & $500 \mathrm{cps}$ & \\
\hline $\mathrm{S}$ & Insulation Res. & $>100$ megohms at $50 \mathrm{VDC}$ & 100 megohms at $50 \mathrm{VDC}$ & \\
\hline$T$ & Material & & stainless steel case & \\
\hline & & & & \\
\hline & & & & \\
\hline & & & & \\
\hline & & & & \\
\hline & & & & \\
\hline
\end{tabular}




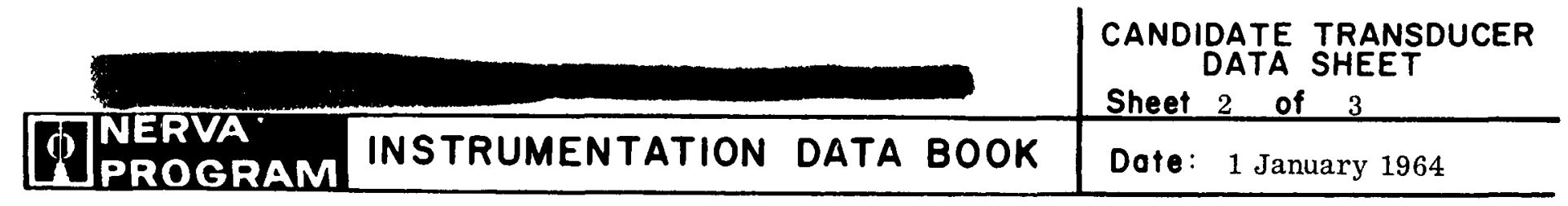

RADIATION TESTS

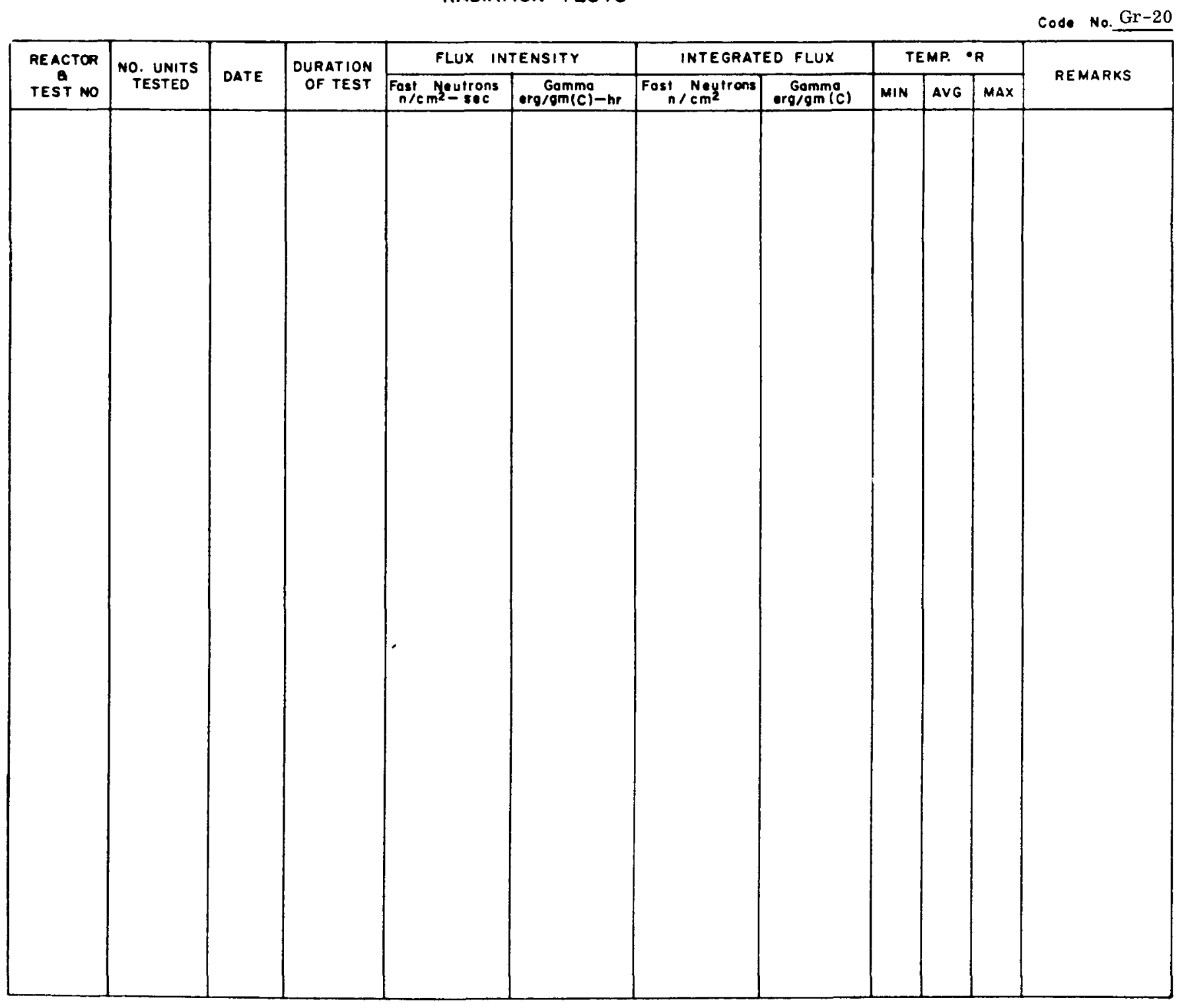

(w) Stronuclear 


\begin{tabular}{|c|c|c|c|}
\hline & & & $\begin{array}{l}\text { CANDIDATE TRANSDUCER } \\
\text { DATA SHEET } \\
\text { Sheet } 3 \text { of } 3 \\
\end{array}$ \\
\hline Q NERVA. & INSTRUMENTATION & DATA BOOK & 1 January 1964 \\
\hline
\end{tabular}

\section{DEVELOPMENT HISTORY}

Code No: $\mathrm{Gr}-20$

Mfgr: Wiancko

Model No. AX-40

P. 0.32377

\section{REMARKS:}

\section{General}

1. Two units tested on WANL shakers submerged in $\mathrm{LN}_{2}$ at Fort Worth in May, 1963, Test No. 23/W002. After an explosion in the cryostat one unit remained operable. A laboratory calibration will be performed on this unit in September, 1963.

$\underline{\text { Summary Test Results }}$

1. Refer to WANL-TME-466, July 31, 1963 - Figure V-15. 
THIS PAGE INTENTIONALLY LEFT BLANK 


\section{VIBRATION TRANSDUCER}

Code No: Gr-21

Type: Piezoelectric-Self Calibrating

Mfgr: Gulton Industries

Range: $\quad 0-600 \mathrm{~g}$
Spec. Control Dwg. No.

Evaluation by: WANL

Model No: SD434601

Application:

PERFORMANCE \& ENVIRONMENTAL SPECIFICATIONS

\begin{tabular}{|c|c|c|c|c|}
\hline Test & Condition & NERVA Requirements & Manufacturer's Specs & $\begin{array}{l}\text { Summary of } \\
\text { Test Results }\end{array}$ \\
\hline$A$ & Overload & $100 \mathrm{~g}$ & $600 \mathrm{~g}$ peak & \\
\hline$B$ & Comp. Temp. Range & $140^{\circ}-535^{\circ} \mathrm{R}$ & $140^{\circ}-710^{\circ} \mathrm{R}$ & \\
\hline $\mathrm{C}$ & Input Impedance & 500 pf min. & $1610 \mathrm{pf}$ & \\
\hline$D$ & Output Impedance & $900 \mathrm{pf} \min$. & $1180 \mathrm{pf}$ & \\
\hline$E$ & Excitation $\begin{array}{l}\text { for self- } \\
\text { calibr. onl }\end{array}$ & 1 v rms approx. & $1 \mathrm{v} \mathrm{rms}$ input $-0.5 \mathrm{~g}$ output & \\
\hline$F$ & Sensitivity & $\begin{array}{l}E_{\mathrm{j}}=7.5 \mathrm{mv} / \mathrm{g} \min . \\
=4.5 \mathrm{mv} / \mathrm{gin}\end{array}$ & $E_{\mathrm{i}}=16 \mathrm{mv} / \mathrm{g}$ & \\
\hline$G$ & Transverse Accel & $3 \% \max$ & & \\
\hline $\mathrm{H}$ & Linearity & $\pm 2 \% 0-50 \mathrm{~g}$ & $\pm 2 \%$ of best st. line & \\
\hline 1 & Hysteresis & $\mathrm{NA}$ & & \\
\hline $\mathrm{J}$ & Resolution & NA & & \\
\hline$K$ & Accuracy & $5 \%$ & & \\
\hline$L$ & Freq. Response & $3-2000 \mathrm{cps}$ & $4-7500 \mathrm{cps}$ & \\
\hline$M$ & Noise Limit & $1.5 \mathrm{mv} / \mathrm{g}$ at $140 \mathrm{db}$ & $1.5 \mathrm{mv}$ at $140 \mathrm{db}$ & \\
\hline$N$ & Neutron Flux & $2.4 \times 10^{14} \mathrm{n} / \mathrm{cm}^{2}-\mathrm{sec}$ & & \\
\hline 0 & Gamma Flux & $3.3 \times 10^{11} \mathrm{ergs} / \mathrm{gm}(\mathrm{C})-\mathrm{h}$ & $\mathrm{hr}$ & \\
\hline$P$ & Dimensions & 1.1" OD x $1.25^{\prime \prime}$ lg. max & & \\
\hline$Q$ & Weight & mfgr. to specify & & \\
\hline$R$ & Resonant Freq. & $20 \mathrm{KC}$ (nom. mounted) & $32,000 \mathrm{cps}$ & \\
\hline $\mathrm{S}$ & Insulation Res. & $1000 \mathrm{megohm}$ at 50VDC & 1000 megohm at 50VDC & \\
\hline$T$ & Material & Titanium & Titanium & \\
\hline & & & & \\
\hline & & & & \\
\hline & & & & \\
\hline & & & & \\
\hline & & & & \\
\hline & & & & \\
\hline
\end{tabular}




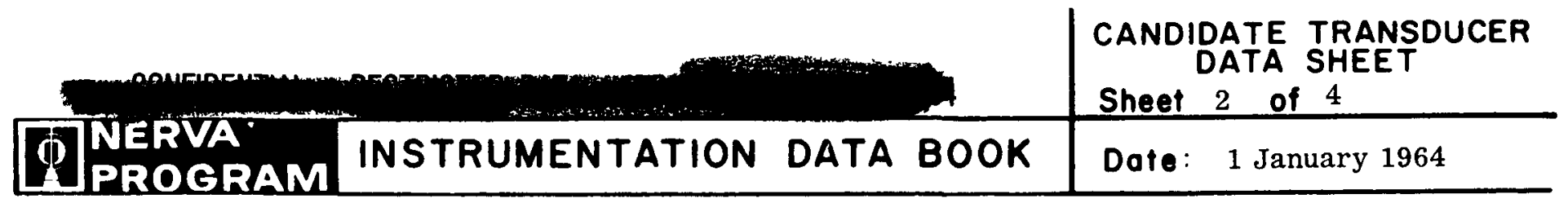

RADIATION TESTS

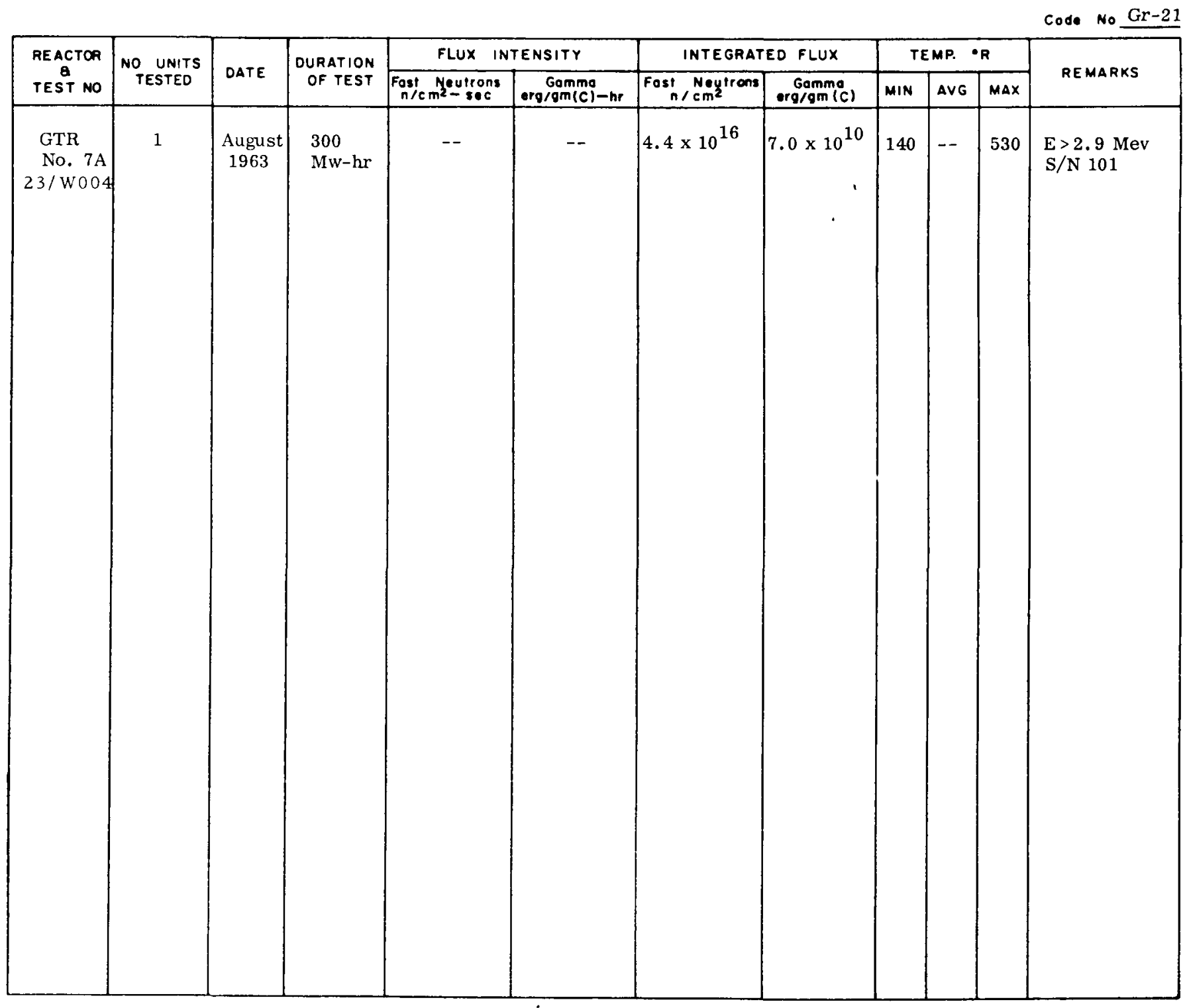




\section{DEVELOPMENT HISTORY}

Code No: $\mathrm{Gr}-21$

Model No. SD434601

REMARKS:

15 December 1963

Description - $\quad$ The unit utilizes a piezoelectric crystal sensing element. The crystal is mounted in a Titanium case, cylindrical in shape and provided with an insulated stud for mouting of unit. The insulated stud provides for ungrounded operation. A self-calibrating feature is provided by a connection for an electrical input signal from which the output calibration can be determined while unit is installed. This unit is a special type being developed for WANL.

Intended Use - The present use is primarily an experimental unit to be tested and analyzed under cryogenic, vibration and radiation environments. The tests are to be conducted at GTR and Plumbrook test reactors. The results of these tests will determine the feasibility of this type for use in the NRX test series for diagnostic purposes.

Basis of Selection - The development of this unit is based on the results of laboratory tests at WANL and radiation tests at GTR in June, 1963 conducted on a standard Gulton unit, Code No. Gr-14.

Problem Areas - From the tests conducted on Gr-14, it was found that a severe effect on sensitivity is caused due to radiation. To overcome this problem, the use of a different crystal was considered. Presently nine different manmade ceramic crystals are under study.

Tests Conducted - GTR Test No. 7A 23/W004

One (1) unit (S/N 101) was tested in a combined environment of $\mathrm{LN}_{2}$ and radiation under dynamic conditions. Satisfactory operation of both crystals throughout $100 \mathrm{hrs}$ of irradiation.

Vibration generators were used to vibrate the components. Each generator consisted of two tandem-mounted electro-magnets and two mechanically-connected voice coils. The voice coils for the vibration generators were connected in series and were driven simultaneously with a McIntosh 200-watt power amplifier. The signal frequency to the voice coils was supplied by a Hewlett-Packard $200 \mathrm{CD}$ signal generator, the frequency of which was monitored by an EPUT meter. The outputs from the peizoelectric accelerometers were read from an Endevco Dyna-Monitor and were recorded with an analog magnetic-tape system. A dual-beam oscilloscope (Tektronix model 535 with $53 / 54 \mathrm{C}$ preamplifier) was used to selectively monitor the accelerometer outputs and the audio oscillator frequency.

The accelerometers were vibrated at the following frequencies (cps) during the test: $50,75,100$, $125,150,300,450,600,750,900$, and 1050 .

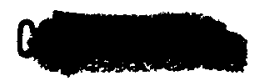




\section{DEVELOPMENT HISTORY}

Code No: Gr-21

Model No. SD434601
Mfgr: Gulton Industries

P. $0.34732,65037$

\section{REMARKS:}

Resistance and/or capacitance measurements (as applicable) were made on the accelerometer signal leads periodically during the test. Also, the AC and DC vibration-generator coil resistances were measured. The vibration-generators were energized throughout the test except while the resistance and capacitance measurements were being made.

\section{Test Results}

Output data was recorded for the accelerometers during four data cycles (pre- and postirradiation and the first and last 3-Mw cycles). It should be noted that the outputs shown in the table were read from the Dyna-Monitor. The values probably show a relative indication of the performance of the units; however, to establish the validity of the data, it would be necessary to refer to the magnetic tape to ascertain the waveshape of the output signal and the amount of noise present.

Resistance and capacitance measurements were made on the accelerometer leads during the four data cycles.

After the test specimens were returned to the IML and removed from the Dewar, calibration checks were made individually on the components. The accelerometers were tested on a standard vibration table with the results that this unit operated satisfactorily; however, insufficient factory calibration data available to determine deviation.

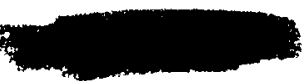




\section{POSITION TRANSDUCER}

Code No: Lr-1

Type: LVDT

Mfgr:

Physical Science Corp.

Range:

0 to $0.500 \pm 0.010$ inches
Spec. Control Dwg. No.

Evaluation By: WANL

Model No:

TI-A Series

PERFORMANCE \& ENVIRONMENTAL SPECIFICATIONS

\begin{tabular}{|c|c|c|c|c|}
\hline Test & Condition & NERVA Requirements & Manufacturer's Specs. & $\begin{array}{l}\text { Summary of } \\
\text { Test Results }\end{array}$ \\
\hline A & Comp. Temp Range & $90^{\circ} \mathrm{R}$ to $1000^{\circ} \mathrm{R}$ & \multicolumn{2}{|c|}{$135^{\circ} \mathrm{R}$ to $1460^{\circ} \mathrm{R} \quad 0.008 \% / \mathrm{RS} . /{ }^{\circ} \mathrm{R}$} \\
\hline$B$ & Excitation & & 6 to $12 \mathrm{vdc}$ & \\
\hline $\mathrm{C}$ & Sensitivity & & & \\
\hline$D$ & Input Impedance & & 22 to $120 \mathrm{ohms}$ & \\
\hline$E$ & Output Impedance & & & \\
\hline $\mathrm{F}$ & Response Time & & & \\
\hline$G$ & Resolution & & & \\
\hline $\mathrm{H}$ & Linearity & & & \\
\hline 1 & Hysteresis & & & \\
\hline J & Accuracy & & & \\
\hline $\mathrm{K}$ & Acceleration Error & & & \\
\hline$L$ & Vibration Error & & & \\
\hline $\bar{M}$ & Shock & & & \\
\hline $\mathrm{N}$ & Noise Limit & & & \\
\hline 0 & Neutron Flux & $1.5 \times 10^{14} \mathrm{n} / \mathrm{cm}^{2}-\mathrm{sec}$ & & \\
\hline$P$ & Gamma Flux & \multicolumn{2}{|l|}{$7.5 \times 10^{10} \mathrm{ergs} / \mathrm{gm}(\mathrm{C})-\mathrm{hr}$} & \\
\hline$Q$ & Resonant Freq. & & & \\
\hline $\mathrm{R}$ & Freq. Respons. & & & \\
\hline $\mathrm{S}$ & Dimensions & $1 / 2 "$ dia $\times 2 " 1 g$ & $1 / 2 "$ dia $\times 2 " \lg$ & \\
\hline$T$ & Weight & $2 \mathrm{oz}$. & $2 \mathrm{oz}$ & \\
\hline$U$ & Insulation Res. & 50 megohms $250 \mathrm{vdc}$ & & \\
\hline \multirow[t]{5}{*}{$\mathrm{V}$} & Material & & & \\
\hline & Zero Shift & & $<0.003 \% / \mathrm{F} . \mathrm{S} . /{ }^{\circ} \mathrm{R}$ & \\
\hline & Full Scale Sensitivit & (at Rec. Carrier Volt) 0 & $.10 \mathrm{v} / \mathrm{v}$ to $0.30 \mathrm{v} / \mathrm{v}$ & \\
\hline & & & & \\
\hline & & & & \\
\hline
\end{tabular}





\section{DEVELOPMENT HISTORY}

Code No:

Lr-1

Model No.

TI-A

Mfgr:

Physical Science

P. 0 . 26905

\section{REMARKS:}

\section{General:}

Ambient and $\mathrm{LN}_{2}$ tests at WANL compare favorably. This unit will be in the combined effects test \#2 at GTR in April.

Reports indicate that units have been exposed to greater than $10^{20}$ nvt at G. E. Hanford.

\section{December 1963}

Two LVDT's were mounted on a spring-like, spider-web-type platform of a vibration table consisting of an electromagnet and a voice coil. One of these was mounted on the same vibration table as the Endevco $1(\mathrm{Gr}-1)$ accelerometer; the other was mounted on the same vibration table as the Gulton 2 accelerometer (Gr-14). By varying the frequency of the input signal to the voice coil, the unit was vibrated at several different frequencies during each data cycle. The signal frequency was supplied by a Hewlett-Packard 650-A test oscillator, the frequency of which was monitored by an EPUT meter. The voice coils were driven by a McIntosh 200-watt power amplifier.

After the current to the electromagnetic ( $\mathrm{IDC}_{\mathrm{DC}}$ ) and the current to the voice coil $\left(\mathrm{I}_{\mathrm{AC}}\right)$ were adjusted to provide the desired displacement at each frequency, the values were recorded. The LVDT output was read from a Ballentine peak-to-peak voltmeter, and recorded. Oscilloscope photographs were made of the voice-coil input, and the accelerometer output traces displayed simultaneously on a Tektronix 545 oscilloscope.

\section{Test Results}

The LVDT's were exposed to the integrated neutron fluxes and gamma doses given on sheet 2 .

The LVDT outputs vs radiation exposure are shown in Figures 4.13 and 4.14 of GD/FW report No. FZK-170-1 for two vibration frequencies (operating temperatures are also shown for each LVDT). Although some of the accelerometers were vibrated at as many as 17 frequencies, the LVDT output at two of these frequencies is sufficient to demonstrate the problems encountered after the detonations. The point at which the detonations occurred is indicated in each of the figures. 


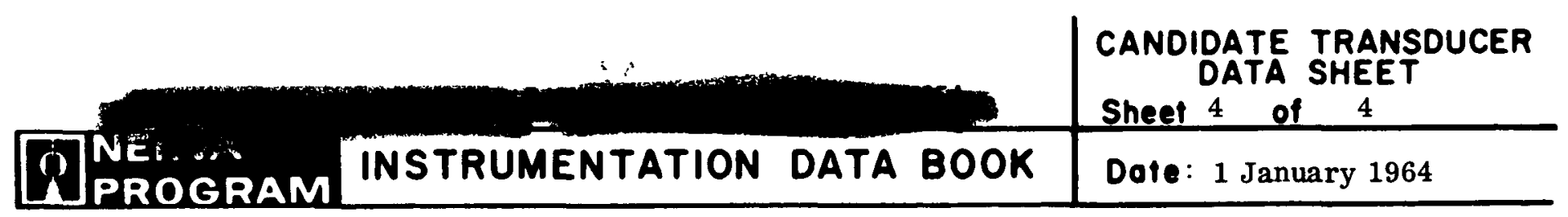

\section{DEVELOPMENT HISTORY}

Code No:

Lr-1

Model No.

TI-A

Mfgr:

Physical Science

P. 0 .

26905

\section{REMARKS:}

The validity of some of the data for test items in the Dewars was questionable because of the detonations. This becomes evident after a study of the data in Figures 4.13 and 4.14.

The detonations in the $\mathrm{LN}_{2}$ Dewar affected the output of the LVDT's; they continued to operate, but with noisy output and/or reduced sensitivity. Some of the problems were caused by damage (resulting from the detonations and the effects of radiation) to the signal leads and to the vibration table leads. Except in the cases of complete failure during the detonations (LVDT 1), it is not possible to separate the effects of the detonations from the effects of radiation. This unit has been superceded by Code No.'s $\mathrm{Lr}-10$ and $\mathrm{Lr}-11$. No further evaluation testing will be conducted on this unit. 


\section{POSITION TRANSDUCER}

Code No: Lr-2

Type:

Mfgr:

Range:

LVDT

Crescent

\pm 0.15 inches
Spec. Control Dwg. No.

Evaluation By:

WANL

Model No: 100237

Application:

PERFORMANCE \& ENVIRONMENTAL SPECIFICATIONS

\begin{tabular}{|c|c|c|c|c|}
\hline Test & Condition & NERVA Requirements & Manufacturer's Specs. & $\begin{array}{l}\text { Summary of } \\
\text { Test Results }\end{array}$ \\
\hline A & Comp. Temp Range & $90^{\circ} \mathrm{R}$ to $1000^{\circ} \mathrm{R}$ & $300^{\circ} \mathrm{R}$ to $1460^{\circ} \mathrm{R}$ & \\
\hline$B$ & Excitation & $5 \mathrm{~V} \mathrm{rms} 3 \mathrm{KC}$ & $3 \mathrm{~V} \mathrm{rms}$ at $5 \mathrm{KC}$ & \\
\hline $\mathrm{C}$ & Sensitivity & $1 \mathrm{mv} / \mathrm{v} / \mathrm{mil} \mathrm{min}$ & $0.79 \mathrm{mv} / \mathrm{v} / \mathrm{mil}$ & \\
\hline D & Input Impedance & 500 ohms max & 95 ohms & \\
\hline$E$ & Output Impedance & 750 ohms max & & \\
\hline$F$ & Response Time & $5 \mathrm{msec}$ & & \\
\hline G & Resolution & Infinite & Infinite & \\
\hline $\mathrm{H}$ & Linearity & $1 \%$ & $0.75 \%$ & \\
\hline 1 & Hysteresis & $0.1 \%$ & & \\
\hline$J$ & Accuracy & $1 \%$ & $1 \%$ & \\
\hline$K$ & Acceleration Error & Nill & & \\
\hline$L$ & Vibration Error & Nill & & \\
\hline$M$ & Shock & $50 \mathrm{~g}, 15 \mu \mathrm{sec}$ & & \\
\hline$N$ & Noise Limit & $150 \mathrm{db}$ & & \\
\hline 0 & Neutron Flux & $1.5 \times 10^{14} \mathrm{n} / \mathrm{cm}^{2}-\mathrm{sec}$ & & \\
\hline $\mathrm{P}$ & Gamma Flux & \multicolumn{2}{|c|}{$7.5 \times 10^{10} \mathrm{ergs} / \mathrm{gm}(\mathrm{C})-\mathrm{hr}$} & \\
\hline$Q$ & Resonant Freq. & NA & $\mathrm{NA}$ & \\
\hline$R$ & Freq. Respons. & $300 \mathrm{cps}$ & $300 \mathrm{cps}$ & \\
\hline$S$ & Dimensions & $5 / 8$ "dia $21 / 4 " \mathrm{lg}$ & $5 / 8$ "dia $21 / 4$ " lg body & \\
\hline$T$ & Weight & $20 \mathrm{gm}$ & $57 \mathrm{gm}$ & \\
\hline$U$ & Insulation Res. & 50 megohms & & \\
\hline $\mathrm{V}$ & Material & & & \\
\hline & & & & \\
\hline & & & & \\
\hline & & & & \\
\hline & & & & \\
\hline
\end{tabular}




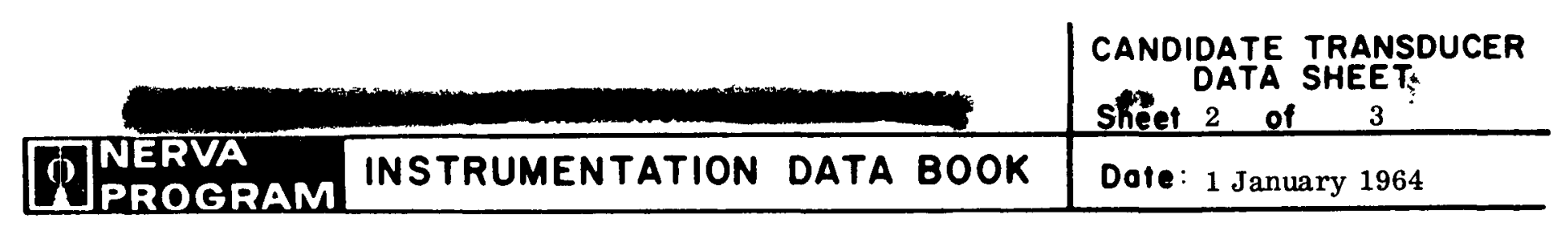

RADIATION TESTS

Code No. Lr-2

\begin{tabular}{|c|c|c|c|c|c|c|c|c|c|c|c|}
\hline \multirow{2}{*}{$\begin{array}{l}\text { REACTOR } \\
\text { Q } \\
\text { TEST NO }\end{array}$} & \multirow{2}{*}{$\begin{array}{l}\text { NO. UNITS } \\
\text { TESTEO }\end{array}$} & \multirow{2}{*}{ DATE } & \multirow{2}{*}{$\begin{array}{l}\text { OURATION } \\
\text { OF TEST }\end{array}$} & \multicolumn{2}{|c|}{ FLUX INTENSITY } & \multicolumn{2}{|c|}{ INTEGRATEO FLUX } & \multicolumn{3}{|c|}{ TEMP. •R } & \multirow{2}{*}{ REMARKS } \\
\hline & & & & $\begin{array}{l}\text { Fost Neufrons } \\
\mathrm{n}^{\prime} / \mathrm{m}^{2}-\mathrm{sec}\end{array}$ & $\begin{array}{l}\text { Gammo } \\
\text { erg/gm(c)-hr }\end{array}$ & Fost Neuirons] & $\begin{array}{r}\text { Gommo } \\
\operatorname{mog} / g m(C)\end{array}$ & MIN & AvG & $\max$ & \\
\hline & & & & & & & & & & & \\
\hline & & & & & & & & & & & \\
\hline & & & & & & & & & & & \\
\hline & & & & & & & & & & & \\
\hline & & & & & & & & & & & \\
\hline & & & & & & & & & & & \\
\hline & & & & & & & & & & & \\
\hline & & & & & & & & & & & \\
\hline & & & & & & & & & & & \\
\hline & & & & & & & & & & & \\
\hline & & & & & & & & & & & \\
\hline & & & & & & & & & & & \\
\hline & & & & & & & & & & & \\
\hline & & & & & & & & & & & \\
\hline & & & & & & & & & & & \\
\hline & & & & & & & & & & & \\
\hline
\end{tabular}




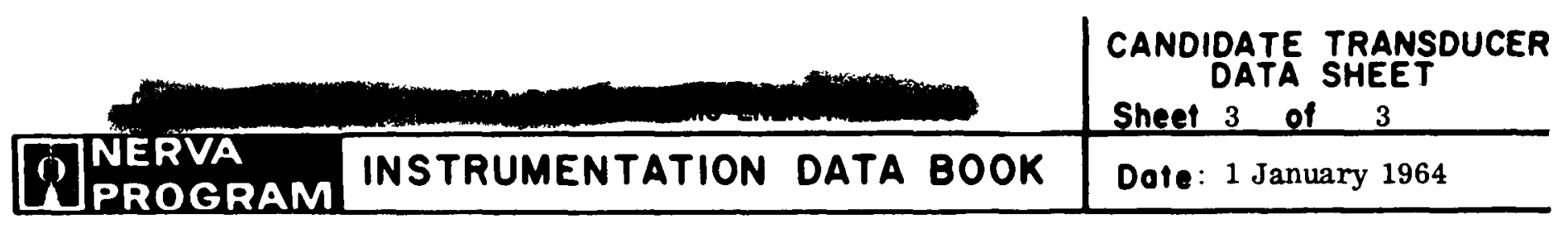

\section{DEVELOPMENT HISTORY}

Code No: $\frac{\text { Lr-2 }}{100237} \quad$ Mfgr:

Model No. $100237 \quad$ P. 0 .

\section{REMARKS:}

No tests have been performed on this unit by WANL. Reports indicate good results on KIWT tests. No specific details known.

\section{September 1963}

This unit was not tested at WANL because of its large size and weight. However, units with the same materials have been tested and are being considered for NRX applications. 
THIS PAGE INTENTIONALLY LEFT BLANK 


\section{POSITION TRANSDUCER}

$\begin{array}{lll}\text { Code No: } \frac{\text { Lr-5 }}{\text { LVDT }} & \text { Spec. Control Dwg. No. } \\ \text { Type: } & \text { Evaluation By: } \frac{\text { WANL }}{250-3 \mathrm{k}-5 / 51} \\ \text { Mfgr: } \frac{\text { Crescent }}{ \pm .250 \mathrm{in} .} & \text { Model No: } \\ \text { Range: } & \text { Application: }\end{array}$

\begin{tabular}{|c|c|c|c|c|}
\hline \multicolumn{5}{|c|}{ PERFORMANCE \& ENVIRONMENTAL SPECIFICATIONS } \\
\hline Test & Condition & NERVA Requirements & Manufacturer's Specs. & Test Results \\
\hline A & Comp. Temp Range & $200^{\circ} \mathrm{R}$ & $530^{\circ} \mathrm{R}$ & $140^{\circ} \mathrm{R}$ \\
\hline B & Excitation & 5 VRMS 3KC & 5 VRMS $3 \mathrm{KC}$ & 5 VRMS $3 \mathrm{KC}$ \\
\hline C & Sensitivity & $1 \mathrm{MV} / \mathrm{V} / \mathrm{mil}$. min. & $1.70 \mathrm{MV} / \mathrm{V} / \mathrm{mil}$ & $2.29 \mathrm{MV} / \mathrm{V} / \mathrm{mil}$ \\
\hline D & Input Impedance & 500 ohms max. & $130 \mathrm{ohms}$ & 110 ohms \\
\hline$E$ & Output Impedance & 750 ohms max. & 170 ohms & 140 ohms \\
\hline $\mathbf{F}$ & Response Time & 5 MS & $10 \%$ of $3 \mathrm{KC}$ & $10 \%$ of $3 \mathrm{KC}$ \\
\hline G & Resolution & Infinite & infinite & infinite \\
\hline $\mathrm{H}$ & Linearity & $1 \%$ & $1 \%$ & $0.1 \%$ \\
\hline 1 & Hysteresis & b. $1 \%$ & $0.1 \%$ & $0.1 \%$ \\
\hline $\mathrm{J}$ & Accuracy & $1 \%$ & $1 \%$ & $0.33 \%$ \\
\hline K & Acceleration Error & $\mathrm{NA}$ & NA & NA \\
\hline $\mathrm{L}$ & Vibration Error & NA & NA & Na \\
\hline$M$ & Shock & $50 \mathrm{~g}, 15 \mu \mathrm{sec}$. & $50 \mathrm{~g}, 15 \mu \mathrm{sec}$. & $50 \mathrm{~g}, 15$ \& sec. \\
\hline $\mathrm{N}$ & Noise Limit & $150 \mathrm{db}$ & $150 \mathrm{db}$ & $150 \mathrm{db}$ \\
\hline 0 & Neutron Flux & & & \\
\hline$P$ & Gamma Flux & & & \\
\hline Q & Resonant Freq. & $\mathrm{NA}$ & $\mathrm{NA}$ & $\mathrm{NA}$ \\
\hline $\mathbf{R}$ & Freq. Respons. & $300 \mathrm{cps}$ & $300 \mathrm{cps}$ & $300 \mathrm{cps}$ \\
\hline $\mathbf{s}$ & Dimensions & $1 / 2^{\prime \prime} \times 2 "$ max. & $1 / 2^{\prime \prime} \times 17 / 8^{\prime \prime}$ & $1 / 2 " \times 17 / 8$ \\
\hline$T$ & Weight & $30 \mathrm{gm} . \max$ & $21.0 \mathrm{gm}$. & $21.5 \mathrm{gm}$ \\
\hline U & Insulation Res. & over $50 \mathrm{M}$. & over $50 \mathrm{M}$. & Infinity \\
\hline $\mathrm{v}$ & Material & stainless steel & stainless steel & stainless steel \\
\hline & & & & \\
\hline & & & & \\
\hline & & & & \\
\hline & & & & \\
\hline
\end{tabular}





\section{DEVELOPMENT HISTORY}

Code No:

Lr-5

Model No. $250-3 \mathrm{~K}-5 / 51$
Mfgr: Crescent

REMARKS:

Several units of this model were tested at the WANL laboratories in ambient and cryogenic temperatures under shock and vibration. Results of these tests are tabulated under summary of test results sheet 1 of 2 .

Irradiation tests are being conducted on two (2) of these units; serial numbers $3142-3$ and 3142-4; at the Ground Test Reactor during August, 1963 under Test Plan Reference Number $23 /$ W203.

\section{$\underline{15} \underline{\text { December }} 1963$}

Radiation test No. 23/W203, GTR, August, 1963

TwoLVDT's (S/N 3142-3 \& 3142-4) were installed on a test fixture. The fixture was submerged in $\mathrm{LN}_{2}$ in the east Dewar during the test. The fixture contained a bellows-operated ratchet that rotated a shaft $15^{\circ}$ each time gaseous helium pressure was applied to the bellows. Cams on the ends of the shafts produced deflection of the LVDT cores. Total deflection on the fixture was \pm 0.250 in.

Excitation voltage $(5.0 \mathrm{~V} \mathrm{rms} \mathrm{at} 3.0 \mathrm{kc})$ to the LVDT's was supplied by a Hewlett-Packard oscillator and a Krohn-Hite ultra-low-distortion power amplifier. A T̂́ ektronix 545 oscilloscope (with a high-gain differential calibrated DC preamplifier) and a Berkeley Model 5510 universal counter were used to monitor the excitation voltage. Outputs were measured with a Hewlett-Packard $400 \mathrm{H}$ rms voltmeter. On these differential-transformer type LVDT's, winding-to-case insulation resistances and secondary-winding resistances were measured periodically with a Hewlett-Packard $410 B$ VTVM.

\section{$\underline{\text { Test }} \underline{\text { Results }}$}

Four cycles of test data are presented in Tables $5.2 \mathrm{E}$ and $5.2 \mathrm{~K}$ in GD/FW GTR-7A test report. Malfunctions in the stepping mechanisms (or binding of the cores) occurred early in the test. Therefore, the post irradiation output measurements are inconclusive.

The tabulation below indicates the values of secondary-coil resistance and insulation resistance of the units:

\begin{tabular}{|c|c|c|c|c|c|}
\hline Value & $\mathrm{S} / \mathrm{N}$ & $\begin{array}{c}\text { Pre- } \\
\text { Irradiation } \\
\end{array}$ & $\begin{array}{c}\text { Initial } \\
3 \mathrm{Mw} \\
\end{array}$ & $\begin{array}{l}\text { Final } \\
3 \mathrm{Mw} \\
\end{array}$ & $\begin{array}{c}\text { Post- } \\
\text { Irradiation }\end{array}$ \\
\hline Insulation & $3142-3$ & 500 & 30 & 23 & 400 \\
\hline $\begin{array}{l}\text { Resistance } \\
\text { (megohms) }\end{array}$ & $3142-4$ & $>500$ & 60 & 22 & 200 \\
\hline
\end{tabular}

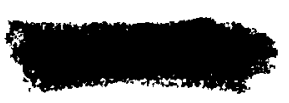




\section{DEVELOPMENT HISTORY}

Code No: Model No. Lr-5

\section{REMARKS:}

\begin{tabular}{|c|c|c|c|c|c|}
\hline Value & $\mathrm{S} / \mathrm{N}$ & $\begin{array}{c}\text { Pre- } \\
\text { Irradiation }\end{array}$ & $\begin{array}{l}\text { Initial } \\
3 \mathrm{Mw} \\
\end{array}$ & $\begin{array}{l}\text { Final } \\
3 \text { Mw } \\
\end{array}$ & $\begin{array}{c}\text { Post- } \\
\text { Irradiation }\end{array}$ \\
\hline $\begin{array}{l}\text { Secondary } \\
\text { Coil }\end{array}$ & $3142-3$ & 27 & 27 & 28 & 26 \\
\hline $\begin{array}{l}\text { Resistance } \\
\text { (ohms) }\end{array}$ & $3142-4$ & 27 & 27 & 26 & 26 \\
\hline
\end{tabular}

Mfgr: Crescent

P. 0 . (ohms)

$3142-4$ 


\section{POSITION TRANSDUCER}

\begin{tabular}{|c|c|c|c|}
\hline Code No & $\mathrm{Lr}-6$ & \multicolumn{2}{|c|}{ Spec. Control Dwg. No. } \\
\hline Type: & LVDT & Evaluation By: & WANL \\
\hline Mfgr: & Crescent & Model No: & $125-3 \mathrm{~K}-5 / 52$ \\
\hline Range: & $\pm 0.125 \mathrm{in}$. & Application: & \\
\hline
\end{tabular}

\begin{tabular}{|c|c|c|c|c|}
\hline Test & Condition & NERVA Requirements & Manufacturer's Specs. & $\begin{array}{l}\text { Summary of } \\
\text { Test Results }\end{array}$ \\
\hline $\mathrm{A}$ & Comp. Temp Range & $200^{\circ} \mathrm{R}$ & $530^{\circ} \mathrm{R}$ & $140^{\circ} \mathrm{R}$ \\
\hline$B$ & Excitation & $5 \mathrm{~V}$ RMS $3 \mathrm{KC}$ & $5 \mathrm{~V}$ RMS 3KC & $5 \mathrm{~V}$ RMS $3 \mathrm{KC}$ \\
\hline C & Sensitivity & $1 \mathrm{MV} / \mathrm{V} / \mathrm{mil} \mathrm{min}$. & $2 \mathrm{MV} / \mathrm{V} / \mathrm{mil}$ & $1.75 \mathrm{MV} / \mathrm{V} / \mathrm{mil}$ \\
\hline D & Input Impedance & 500 ohms max. & 120 ohms & 103 ohms \\
\hline$E$ & Output Impedance & 750 ohms max. & 170 ohms & $150 \mathrm{ohms}$ \\
\hline$F$ & Response Time & $5 \mathrm{msec}$ & $10 \%$ of $3 \mathrm{KC}$ & $10 \%$ of $3 \mathrm{KC}$ \\
\hline $\mathbf{G}$ & Resolution & Infinite & Infinite & Infinite \\
\hline H & Linearity & $1 \%$ & $1 \%$ & $0.2 \%$ \\
\hline 1 & Hysteresis & $0.1 \%$ & $0.1 \%$ & $0.2 \%$ \\
\hline $\mathrm{J}$ & Accuracy & $1 \%$ & $1 \%$ & $1.36 \%$ \\
\hline $\mathrm{K}$ & Acceleration Error & NA & $\mathrm{NA}$ & NA \\
\hline$L$ & Vibration Error & NA & $\mathrm{NA}$ & NA \\
\hline$M$ & Shock & $50 \mathrm{~g}, 15 \mu \mathrm{sec}$ & $50 \mathrm{~g}, 15 \mu \mathrm{sec}$ & $50 \mathrm{~g}, 15 \mu \mathrm{sec}$ \\
\hline$N$ & Noise Limit & $150 \mathrm{db}$ & $150 \mathrm{db}$ & $150 \mathrm{db}$ \\
\hline 0 & Neutron Flux & & & \\
\hline$P$ & Gamma Flux & & & \\
\hline$Q$ & Resonant Freq. & NA & NA & NA \\
\hline $\mathbf{R}$ & Freq. Respons. & $300 \mathrm{cps}$ & $300 \mathrm{cps}$ & $300 \mathrm{cps}$ \\
\hline $\mathbf{S}$ & Dimensions & $1 / 2^{\prime \prime} \times 13 / 4 " \max$ & $1 / 2 " \times 11 / 2 "$ & $1 / 2^{\prime \prime} \times 11 / 2^{\prime \prime}$ \\
\hline$T$ & Weight & $25 \mathrm{gm} \max$ & $16 \mathrm{gm}$ & $16 \mathrm{gm}$ \\
\hline $\mathrm{U}$ & Insulation Res. & over $50 \mathrm{M}$ & over $50 \mathrm{M}$ & Infinity \\
\hline V & Material & stainless steel & stainless steel & stainless steel \\
\hline & & & & \\
\hline & & & & \\
\hline & & & & \\
\hline
\end{tabular}




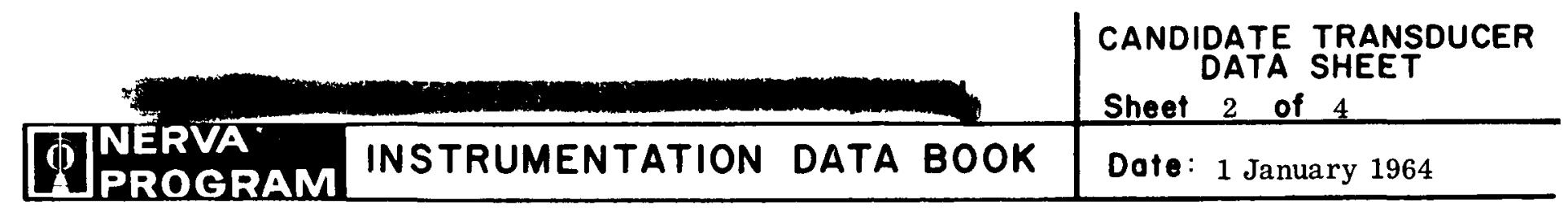

RADIATION TESTS

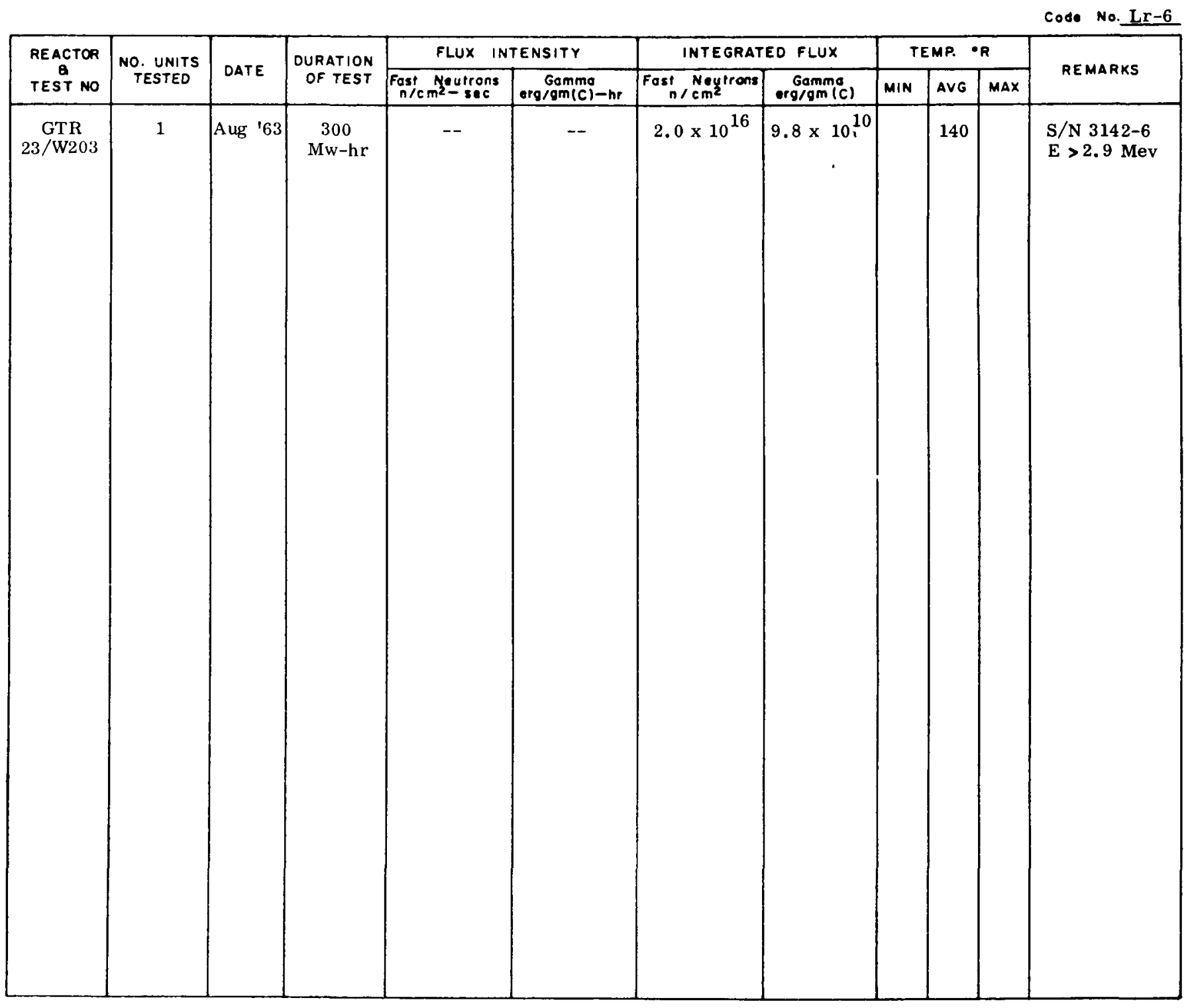

(6) /stronuclear 


\section{DEVELOPMENT HISTORY}

Code No: $\quad$ Lr-6

Model No. $125-3 \mathrm{~K}-5 / 52$

Mfgr: Crescent

P. 0 .

\section{REMARKS:}

Several units of this model were tested at the WANL laboratories in ambient and cryogenic temperatures under shock and vibration. Results of these tests are tabulated under summary of test results sheet 1 of 2 .

Irradiation tests are being conducted on one (1) of these units; serial number $3142-6$, at the Ground Test Reactor during August, 1963 under Test Plan Reference Number 23/W203.

$15 \underline{\text { December }} \underline{1963}$

Radiation test No. 23/W203, GTR, August, 1963

One LVDT was installed on a test fixture. The fixture was submerged in $\mathrm{LN}_{2}$ in the east Dewar during the test. The fixture contained a bellows-operated ratchet that rotated a shaft $15^{\circ}$ each time gaseous helium pressure was applied to the bellows. A cam on the end of the shaft produced deflection of the LVDT core. Total deflection of the fixture was \pm 0.125 in.

Excitation voltage $(5.0 \mathrm{~V} \mathrm{rms}$ at $3.0 \mathrm{kc})$ to the LVDT was supplied by a Hewlett-Packard oscillator and a Krohn-Hite ultra-low-distortion power amplifier. A Tektronix 545 oscilloscope (with a high-gain differential calibrated DC preamplifier) and a Berkeley Model 5510 universal counter were used to monitor the excitation voltage. Output was measured with a Hewlett-Packard $400 \mathrm{H} \mathrm{rms}$ voltmeter. On this differential-transformer type LVDT, winding-to-case insulation resistances and secondary-winding resistances were measured periodically with a Hewlett-Packard $410 \mathrm{~B}$ VTVM.

\section{$\underline{\text { Test }} \underline{\text { Results }}$}

Four cycles of test data are presented in Table 5.2L of GD/FW GTR-7A test report. Malfunctions in the stepping mechanisms (or binding of the cores) occurred early in the test. The malfunction was observed at the time listed in the table.

Therefore, the post irradiation output measurements a re inconclusive.

The tabulation below indicates the values of secondary-coil resistance and insulation resistance of the unit:

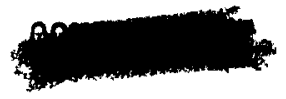




\section{DEVELOPMENT HISTORY}

Code No:

Model No.

Lr-6

$125-3 \mathrm{~K} 15 / 52$

\section{REMARKS:}

\begin{tabular}{l}
\multicolumn{1}{c}{ Value } \\
\hline $\begin{array}{l}\text { Insulation } \\
\text { Resistance } \\
\text { (megohms) }\end{array}$ \\
Secondary \\
Coil \\
Resistance \\
(ohms)
\end{tabular}

Resistance
Mfgr:

P. 0 .

Crescent

Pre-

Irradiation

500

Initial

Final

$3 \mathrm{Mw}$

Post-

$3 \mathrm{Mw}$

29

Irradiation

25

400

22

23

22

22

3142-6

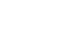

(23)




\section{POSITION TRANSDUCER}

Code No: $\quad$ Lr-7

Type:

LVDT

Mfgr:

Crescent

Range: \pm 0.100 in.
Spec. Control Dwg. No.

Evaluation By: WANL

Model No: $100-3 \mathrm{~K}-1 / 5$

Application:

\begin{tabular}{|c|c|c|c|c|}
\hline Test & Condition & $\begin{array}{l}\text { ANCE \& ENVIRONMEN } \\
\text { NERVA Requirements }\end{array}$ & $\begin{array}{l}\text { TAL SPECIFICATIONS } \\
\text { Manufacturer's Specs. }\end{array}$ & $\begin{array}{l}\text { Summary of } \\
\text { Test Results }\end{array}$ \\
\hline$A$ & Comp. Temp Range & $200^{\circ} \mathrm{R}$ & $530^{\circ} \mathrm{R}$ & $140^{\circ} \mathrm{R}$ \\
\hline B & Excitation & $5 \mathrm{~V}$ RMS & $5 \mathrm{~V}$ RMS $3 \mathrm{KC}$ & $5 \mathrm{~V}$ RMS $3 \mathrm{KC}$ \\
\hline $\mathrm{C}$ & Sensitivity & $1 \mathrm{MV} / \mathrm{V} / \mathrm{mil} \mathrm{min.}$ & $3 \mathrm{MV} / \mathrm{V} / \mathrm{mil}$ & $3.9 \mathrm{MV} / \mathrm{V} / \mathrm{mil}$ \\
\hline D & Input Impedance & 500 ohms max. & $240 \mathrm{ohms}$ & $220 \mathrm{ohms}$ \\
\hline$E$ & Output Impedance & 750 ohms max. & 280 ohms & $260 \mathrm{ohms}$ \\
\hline $\mathrm{F}$ & Response Time & $5 \mathrm{msec}$ & $10 \%$ of $3 \mathrm{KC}$ & $10 \%$ of $3 \mathrm{KC}$ \\
\hline G & Resolution & infinite & infinite & infinite \\
\hline $\mathrm{H}$ & Linearity & $1 \%$ & $1 \%$ & $0.8 \%$ \\
\hline I & Hysteresis & $0.1 \%$ & $0.1 \%$ & $0.2 \%$ \\
\hline $\mathrm{J}$ & Accuracy & $1 \%$ & $1 \%$ & $2.28 \%$ \\
\hline$K$ & Acceleration Error & $\mathrm{NA}$ & $\mathrm{NA}$ & NA \\
\hline$L$ & Vibration Error & $\mathrm{NA}$ & $\mathrm{NA}$ & $\mathrm{NA}$ \\
\hline$M$ & Shock & $50 \mathrm{~g}, 15 \mu \mathrm{sec}$ & $50 \mathrm{~g}, 15 \mu \mathrm{sec}$ & $50 \mathrm{~g}, 15 \mu \mathrm{sec}$ \\
\hline $\mathrm{N}$ & Noise Limit & $150 \mathrm{db}$ & $150 \mathrm{db}$ & $150 \mathrm{db}$ \\
\hline 0 & Neutron Flux & & & \\
\hline $\mathrm{P}$ & Gamma Flux & & & \\
\hline Q & Resonant Freq. & $\mathrm{NA}$ & $\mathrm{NA}$ & $\mathrm{NA}$ \\
\hline$R$ & Freq. Respons. & $300 \mathrm{cps}$ & $300 \mathrm{cps}$ & $300 \mathrm{cps}$ \\
\hline$S$ & Dimensions & $1 / 2 " \times 11 / 2 " \max$. & $1 / 2 " \times 11 / 4^{\prime \prime}$ & $1 / 2^{\prime \prime} \times 11 / 4^{\prime \prime}$ \\
\hline$T$ & Weight & $20 \mathrm{gm}$ & $15 \mathrm{gm}$ & $15 \mathrm{gm}$ \\
\hline U & Insulation Res. & over $50 \mathrm{M}$ & over $50 \mathrm{M}$ & infinity \\
\hline $\mathrm{V}$ & Material & stainless steel & stainless steel & stainless steel \\
\hline & & & & \\
\hline & & & & \\
\hline & & & & \\
\hline
\end{tabular}




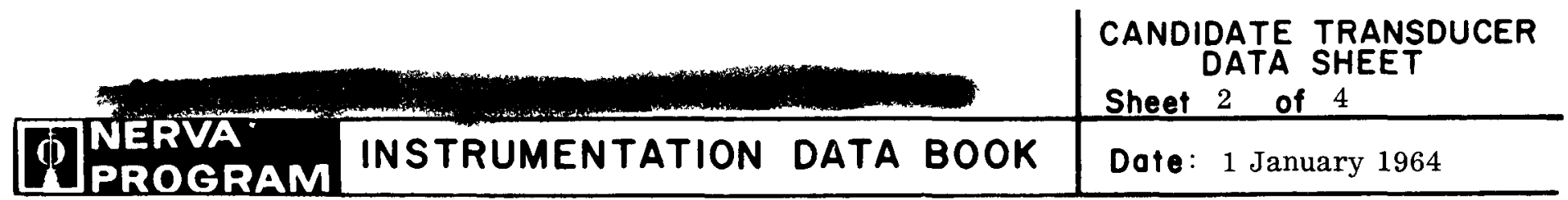

RADIATION TESTS

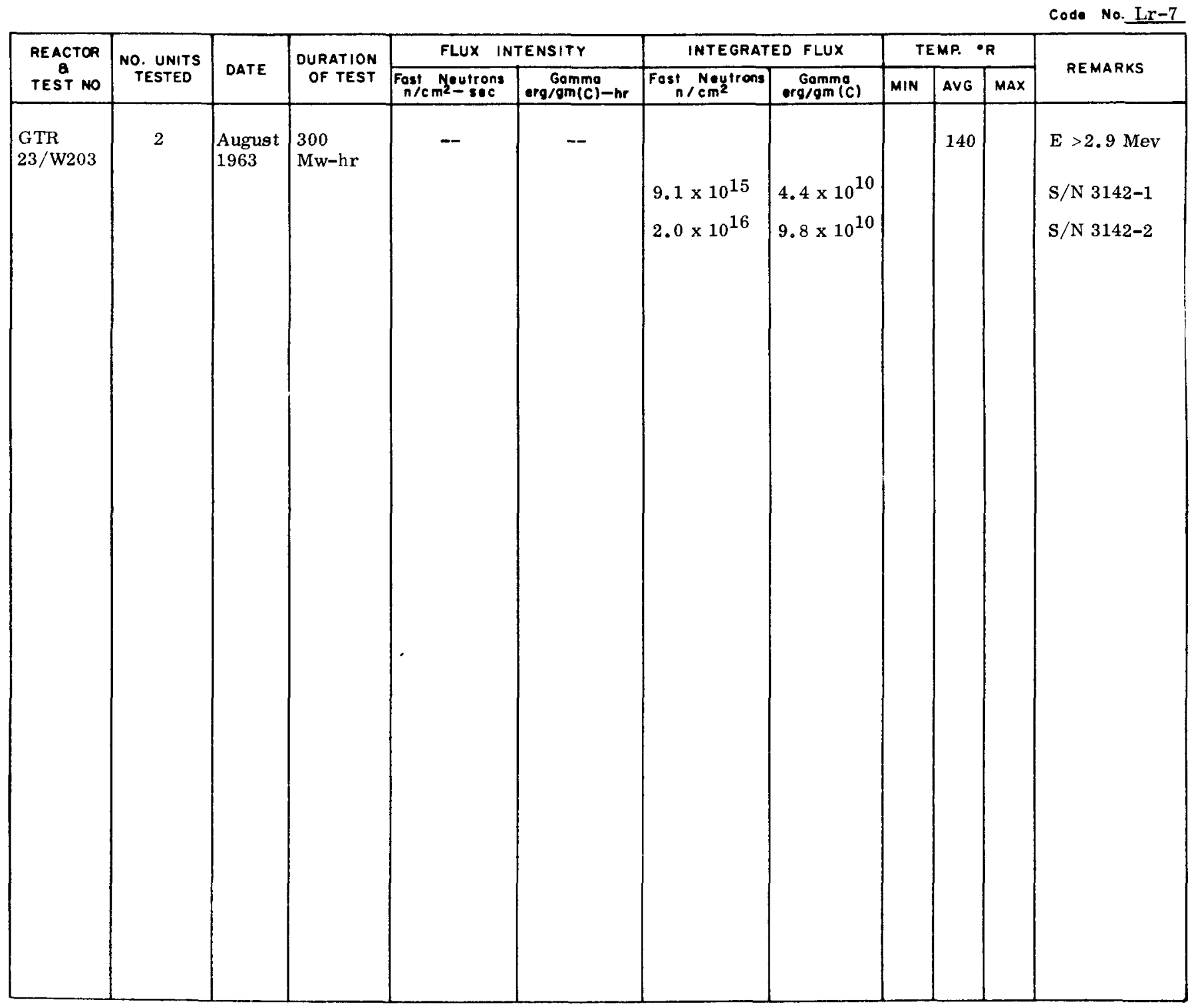

(9) Lstronuclear 


\begin{tabular}{|c|c|c|}
\hline . & & $\begin{array}{l}\text { DATA SHEET } \\
\text { Sheet } 3 \text { of } 4 \\
\end{array}$ \\
\hline W NEROAA & INSTRUMENTATION DATA BOOK & Dote: 1 January 1964 \\
\hline
\end{tabular}

\section{DEVELOPMENT HISTORY}

$\begin{array}{lll}\text { Code No: } \frac{\mathrm{Lr}-7}{100-3 \mathrm{~K}-1 / 5} & \text { Mfgr: } & \text { Crescent } \\ \text { Model No. } & \text { P. } 0 .\end{array}$

\section{REMARKS:}

Several units of this model were tested at the WANL laboratories in ambient and cryogenic temperatures under shock and vibration. Results of these tests are tabulated under summary of test results sheet 1 of 2 .

Irradiation tests are being conducted on two (2) of these units, serial numbers 3142-1 and 3142-2, at the Ground Test Reactor during August, 1963 under Test Plan Reference Number $23 / \mathrm{W} 203$.

\section{$\underline{15} \underline{\text { December }} \underline{1963}$}

Radiation Test No. 23/W203 GTR, August 1963

Two LVDT's were installed on a test fixture. The fixtures were submerged in $\mathrm{LN}_{2}$ in the east Dewar during the test. The fixture contained a bellows-operated ratchet that rotated a shaft $15^{\circ}$ each time gaseous helium pressure was applied to the bellows. Cams on the ends of the shafts produced deflection of the LVDT cores. Total deflection on the fixture was $\pm 0.125 \mathrm{in}$.

Excitation voltage $(5.0 \mathrm{~V} \mathrm{rms}$ at $3.0 \mathrm{kc}$ ) to the LVDT's was supplied by a Hewlett-Packard oscillator and a Krohn-Hite ultra-low-distortion power amplifier. A Tektronix 545 oscilloscope (with a high-gain differential calibrated DC preamplifier) and a Berkeley Model 5510 universal counter were used to monitor the excitation voltage. Outputs were measured with a HewlettPackard $400 \mathrm{H} \mathrm{rms}$ voltmeter. On these differential-transformer type LVDT's, winding-to-case insulation resistances and secondary-winding resistances were measured periodically with a Hewlett-Packard 410B VTVM.

\section{Test Results}

Four cycles of test data are presented in Tables 5.2D and 5.2J of GD/FW GTR-7A test report. The outputs in post-irradiation measurements ranged from approximately $4 \%$ to $9 \%$ below preirradiation values. 


\section{DEVELOPMENT HISTORY}

Code No:

Lr-7

Mfgr:

Crescent

Model No.

$100-3 \mathrm{~K}-1 / 5$

P. 0 .

\section{REMARKS:}

The tabulation below indicates the values of secondary-coil resistance and insulation resistance of the units:

\begin{tabular}{|c|c|c|c|c|c|}
\hline Value & $\mathrm{S} / \mathrm{N}$ & $\begin{array}{c}\text { Pre- } \\
\text { Irradiation }\end{array}$ & $\begin{array}{l}\text { Initial } \\
3 \mathrm{Mw} \\
\end{array}$ & $\begin{array}{l}\text { Final } \\
3 \mathrm{Mw} \\
\end{array}$ & $\begin{array}{c}\text { Post- } \\
\text { Irradiation }\end{array}$ \\
\hline Insulation & $3142-1$ & $>500$ & 100 & 32 & 300 \\
\hline $\begin{array}{l}\text { Resistance } \\
\text { (megohms) }\end{array}$ & $3142-2$ & 500 & 45 & 30 & 350 \\
\hline $\begin{array}{l}\text { Secondary } \\
\text { Coil }\end{array}$ & $3142-1$ & 40 & 40 & 39 & 40 \\
\hline $\begin{array}{l}\text { Resis tance } \\
\text { (ohms) }\end{array}$ & $3142-2$ & 40 & 40 & 45 & 48 \\
\hline
\end{tabular}




\section{POSITION TRANSDUCER}

Code No:

Type: LVDT

Mfgr:

Schaevitz

Range: \pm 0.250 in.
Spec. Control Dwg. No.

Evaluation By: WANL

Model No: $250 \mathrm{XS}-\mathrm{LT}$

Application:

PERFORMANCE \& ENVIRONMENTAL SPECIFICATIONS

\begin{tabular}{|c|c|c|c|c|}
\hline Test & Condition & NERVA Requirements & Manufacturer's Specs. & $\begin{array}{l}\text { Summary of } \\
\text { Test Results }\end{array}$ \\
\hline A & Comp. Temp Range & $200^{\circ} \mathrm{R}$ & $530^{\circ} \mathrm{R}$ & $140^{\circ} \mathrm{R}$ \\
\hline$B$ & Excitation & $5 \mathrm{~V} \mathrm{RMS} 3 \mathrm{KC}$ & $5 \mathrm{~V}$ RMS 3KC & $5 \mathrm{~V}$ RMS 3KC \\
\hline $\mathrm{C}$ & Sensitivity & $1 \mathrm{MV} / \mathrm{V} / \mathrm{mil} \mathrm{min}$ & $3.4 \mathrm{MV} / \mathrm{V} / \mathrm{mil}$ & $3.24 \mathrm{MV} / \mathrm{V} / \mathrm{mil}$ \\
\hline $\mathrm{D}$ & Input Impedance & 500 ohms $\max$. & 350 ohms & 325 ohms \\
\hline$E$ & Output Impedance & 750 ohms max. & 400 ohms & 375 ohms \\
\hline $\mathbf{F}$ & Response Time & $5 \mathrm{msec}$ & $10 \%$ of $3 \mathrm{KC}$ & $10 \%$ of $3 \mathrm{KC}$ \\
\hline $\mathbf{G}$ & Resolution & Infinite & Infinite & Infinite \\
\hline $\mathrm{H}$ & Linearity & $1 \%$ & $1 \%$ & $1 \%$ \\
\hline 1 & Hysteresis & $0.1 \%$ & $0.1 \%$ & $0.3 \%$ \\
\hline $\mathrm{J}$ & Accuracy & $1 \%$ & $1 \%$ & $10.5 \%$ \\
\hline $\mathrm{K}$ & Acceleration Error & $\overline{\mathrm{NA}}$ & $\overline{\mathrm{NA}}$ & $\mathrm{NA}$ \\
\hline$L$ & Vibration Error & $\mathrm{NA}$ & $\mathrm{NA}$ & $\mathrm{NA}$ \\
\hline$M$ & Shock & $50 \mathrm{~g}, 15 \mu \mathrm{sec}$. & $50 \mathrm{~g}, 15 \mu \mathrm{sec}$. & $50 \mathrm{~g}, 15 \mu$ sec. \\
\hline$N$ & Noise Limit & $150 \mathrm{db}$ & $150 \mathrm{db}$ & $150 \mathrm{db}$ \\
\hline 0 & Neutron Flux & & & \\
\hline$\underline{P}$ & Gamma Flux & & & \\
\hline$Q$ & Resonant Freq. & $\mathrm{NA}$ & NA & $\mathrm{NA}$ \\
\hline$R$ & Freq. Respons. & $300 \mathrm{cps}$ & $300 \mathrm{cps}$ & $300 \mathrm{cps}$ \\
\hline s & Dimensions & $1 / 2 " \times 2 " 1$ max. & $0.500^{\prime \prime} \times 1.8$ & $0.500^{\prime \prime} \times 1.800^{\prime \prime}$ \\
\hline$T$ & Weight & $30 \mathrm{gm} . \max$. & $22 \mathrm{gm}$. & $22 \mathrm{gm}$. \\
\hline$U$ & Insulation Res. & over $50 \mathrm{M}$ & over $50 \mathrm{M}$ & Infinity \\
\hline $\mathbf{V}$ & Material & stainless steel & stainless steel & stainless steel \\
\hline & & & & \\
\hline & & & & \\
\hline & & & & \\
\hline
\end{tabular}




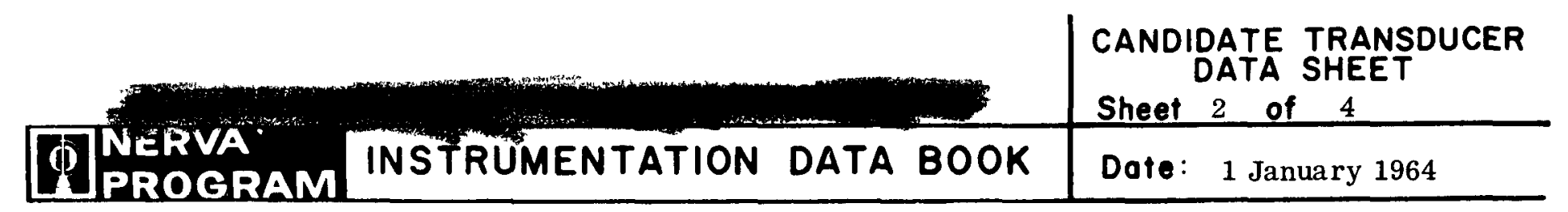

RADIATION TESTS

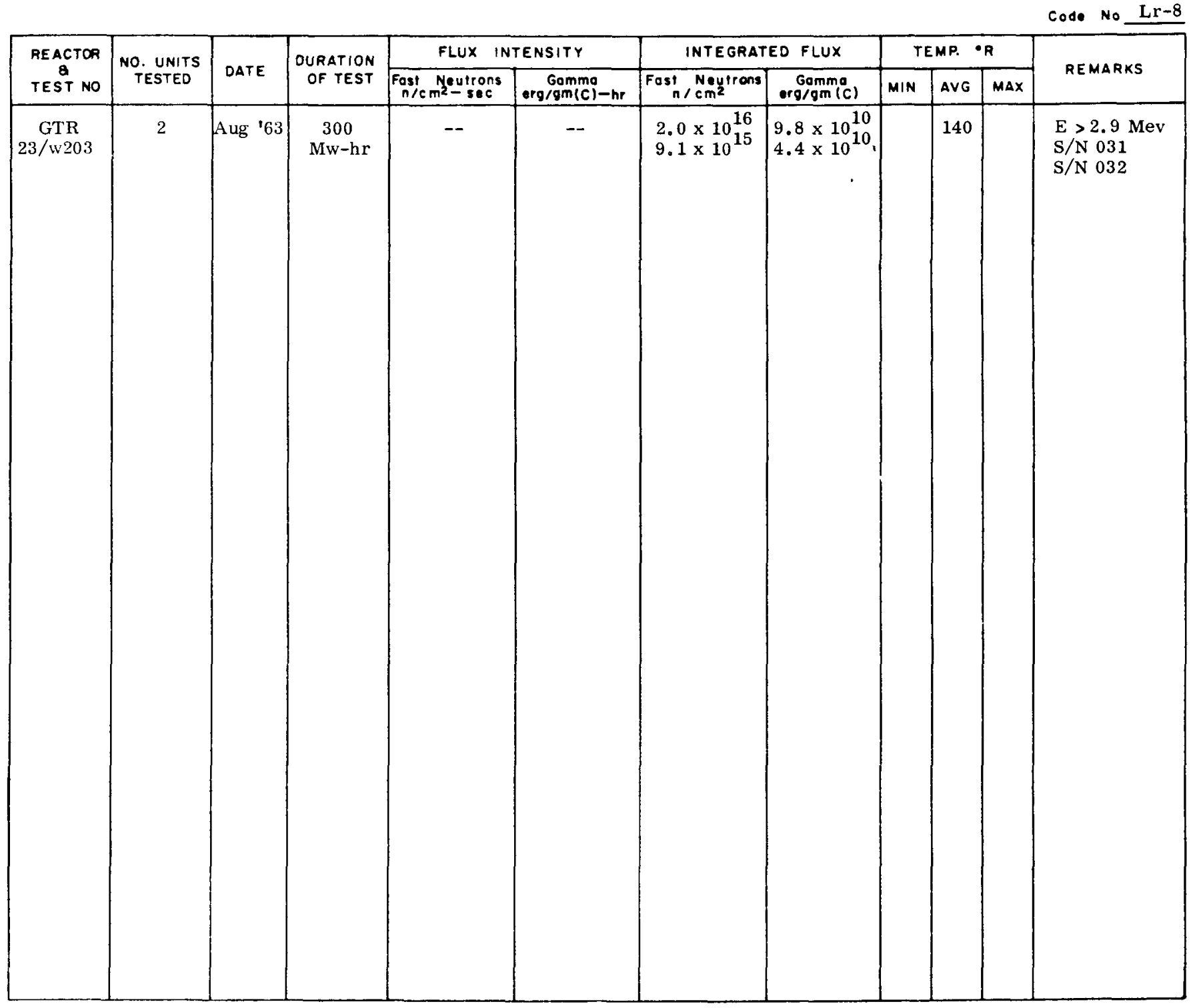

(w) 


\section{DEVELOPMENT HISTORY}

Code No: $\quad$ Lr-8

Model No. 250XS-LT

\section{REMARKS:}

Mfgr: Schaevitz P. 0 .

Several units of this model were tested at the WANL laboratories in ambient and cryogenic temperatures under shock and vibration. Results of these tests are tabulated under summary of test results sheet 1 of 2 .

Irradiation tests are being conducted on two (2) of these units, serial numbers 031 and 032 , at the Ground Test Reactor during August, 1963 under Test Plan Reference Number 23/W203.

\section{December 1963}

Radiation Test No. 23/W203 GTR, August, 1963

Two LVDT's (S/N 031 and 032) were installed on a test fixture. The fixture was submerged in $\mathrm{LN}_{2}$ in the east Dewar during the test. The fixture contained a bellows-operated ratchet that rotated a shaft $15^{\circ}$ each time gaseous helium pressure was applied to the bellows. Cams on the ends of the shafts produced deflection of the LVDT cores. Total deflection on the fixture was $\pm 0.250 \mathrm{in}$.

Excitation voltage $(5.0 \mathrm{~V} \mathrm{rms} \mathrm{at} 3.0 \mathrm{kc})$ to the LVDT's was supplied by a Hewlett-Packard oscillator and a Krohn-Hite ultra-low-distortion power amplifier. A Tektronix 545 oscilloscope (with a high-grain differential calibrated DC preamplifier) and a Berkeley Model 5510 universal counter were used to monitor the excitation voltage. Outputs were measured with a Hewlett-Packard $400 \mathrm{H} \mathrm{rms} \mathrm{voltmeter.} \mathrm{On} \mathrm{these} \mathrm{differential-transformer} \mathrm{type} \mathrm{LVDT's,} \mathrm{winding-to-case} \mathrm{insulation}$ resistances and secondary-winding resistances were measured periodically with a Hewlett-Packard $410 \mathrm{~B}$ VTVM.

\section{Test $\underline{\text { Results }}$}

Four cycles of test data are presented in Tables 5.20 through $5.2 \mathrm{M}$ of GD/FW GTR-7A test report. Malfunctions in the stepping mechanism (or binding of the core) occurred for LVDT S/N 031 early in the test. The malfunctions were observed at the times listed in the tables. For the remaining unit, the output in post-irradiation measurements ranged from approximately $4 \%$ to $9 \%$ below preirradiation values.

The tabulation below indicates the values of secondary-coil resistance and insulation resistance of the units:

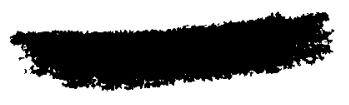




\section{DEVELOPMENT HISTORY}

Code No:

Model No. 250XS-LT

REMARKS:

\begin{tabular}{|c|c|c|c|c|c|}
\hline Value & $\mathrm{S} / \mathrm{N}$ & $\begin{array}{c}\text { Pre- } \\
\text { Irradiation } \\
\end{array}$ & $\begin{array}{l}\text { Initial } \\
3 \mathbf{M w} \\
\end{array}$ & $\begin{array}{l}\text { Final } \\
3 \mathrm{Mw} \\
\end{array}$ & $\begin{array}{c}\text { Post- } \\
\text { Irradiation }\end{array}$ \\
\hline Insulation & 031 & 500 & 30 & 16 & 250 \\
\hline $\begin{array}{l}\text { Resistance } \\
\text { (megohms) }\end{array}$ & 032 & 500 & 35 & 27 & 400 \\
\hline Secondary & 031 & 70 & 60 & 60 & 65 \\
\hline $\begin{array}{l}\text { Coil } \\
\text { Resistance } \\
\text { (ohms) }\end{array}$ & 032 & 70 & 60 & 60 & 65 \\
\hline
\end{tabular}

Mfgr: Schaevitz

P. 0 . 


\section{POSITION TRANSDUCER}

Code No:

Type:

LVDT

Mfgr:

Schaevitz

Range:

\pm 0.100 in.
Spec. Control Dwg. No.

Evaluation By: WANL

Model No: 100MS-LT

Application:

\begin{tabular}{|c|c|c|c|c|}
\hline Test & Condition & NERVA Requirements & Manufacturer's Specs. & $\begin{array}{l}\text { Summary of } \\
\text { Test Results }\end{array}$ \\
\hline$A$ & Comp. Temp Range & $200^{\circ} \mathrm{R}$ & $530^{\circ} \mathrm{R}$ & $140^{\circ} \mathrm{R}$ \\
\hline B & Excitation & $5 \mathrm{~V} \mathrm{rms} 3 \mathrm{KC}$ & $5 \mathrm{~V} \mathrm{rms} 3 \mathrm{KC}$ & $5 \mathrm{~V} \mathrm{rms} 3 \mathrm{KC}$ \\
\hline $\mathrm{C}$ & Sensitivity & $1 \mathrm{mv} / \mathrm{v} / \mathrm{mil} \mathrm{min}$. & $3 \mathrm{mv} / \mathrm{v} / \mathrm{mil}$ & $1.31 \mathrm{mv} / \mathrm{v} / \mathrm{mi}$ \\
\hline D & Input Impedance & 500 ohms max. & $260 \mathrm{ohms}$ & 235 ohms \\
\hline$E$ & Output Impedance & 750 ohms max & $310 \mathrm{ohms}$ & $290 \mathrm{ohms}$ \\
\hline$F$ & Response Time & $5 \mathrm{~m} \mathrm{sec}$. & $10 \%$ of $3 \mathrm{KC}$ & $10 \%$ of $3 \mathrm{KC}$ \\
\hline $\mathbf{G}$ & Resolution & Infinite & Infinite & Infinite \\
\hline $\mathrm{H}$ & Linearity & $1 \%$ & $1 \%$ & $0.5 \%$ \\
\hline 1 & Hysteresis & $0.1 \%$ & $0.1 \%$ & $0.4 \%$ \\
\hline $\mathrm{J}$ & Accuracy & $1 \%$ & $1 \%$ & $6.0 \%$ \\
\hline$K$ & Acceleration Error & NA & $\mathrm{NA}$ & $\mathrm{NA}$ \\
\hline$L$ & Vibration Error & $\mathrm{NA}$ & $\mathrm{NA}$ & $\mathrm{NA}$ \\
\hline$M$ & Shock & $50 \mathrm{~g} 15 \mu$ sec. & $50 \mathrm{~g} 15 \mu$ sec. & $50 \mathrm{~g} 15 \mu \mathrm{sec}$. \\
\hline$N$ & Noise Limit & $150 \mathrm{db}$ & $150 \mathrm{db}$ & $150 \mathrm{db}$ \\
\hline 0 & Neutron Flux & & & \\
\hline$P$ & Gamma Flux & & & \\
\hline$Q$ & Resonant Freq. & $\mathrm{NA}$ & $\mathrm{NA}$ & NA \\
\hline$R$ & Freq. Respons. & $300 \mathrm{cps}$ & $300 \mathrm{cps}$ & $300 \mathrm{cps}$ \\
\hline$S$ & Dimensions & $1 / 2^{\prime \prime} \times 1-1 / 2^{\prime \prime} \max$ & $.208^{\prime \prime} \times .585^{\prime \prime}$ & $.208^{\prime \prime} \times .585^{\prime \prime}$ \\
\hline$T$ & Weight & 20 gm. max. & $12 \mathrm{gm}$. & $12 \mathrm{gm}$. \\
\hline$U$ & Insulation Res. & over $50 \mathrm{M}$ & over $50 \mathrm{M}$ & Infinity \\
\hline$V$ & Material & & & \\
\hline & & & & \\
\hline & & & & \\
\hline & & & & \\
\hline & & & & \\
\hline
\end{tabular}




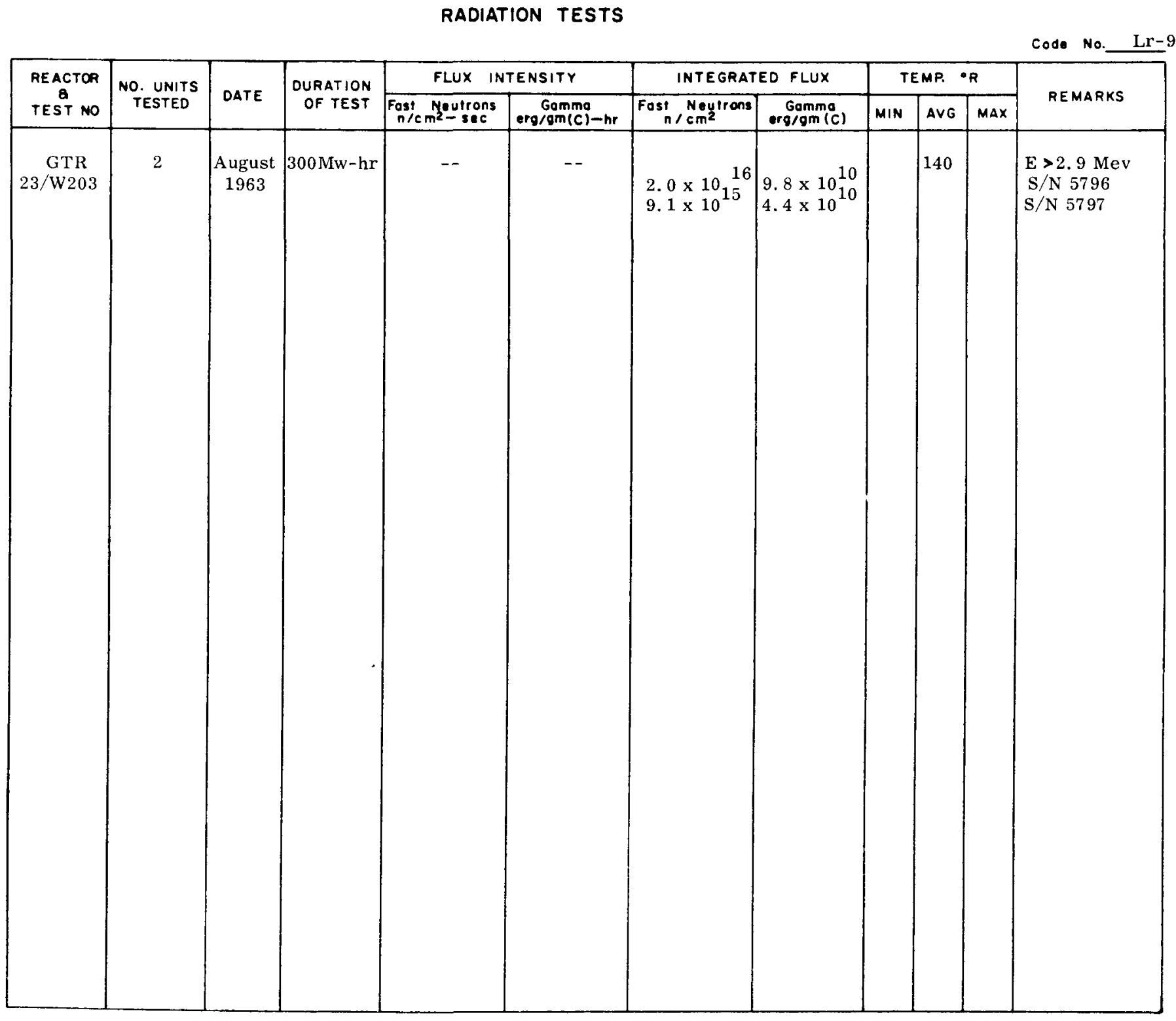




\section{DEVELOPMENT HISTORY}

Code No:

Lr-9

Model No. $100 \mathrm{MS}-\mathrm{LT}$
Mfgr:

Schaevitz

P. 0 .

\section{REMARKS:}

Several units of this model were tested at the WANL laboratories in ambient and cryogenic temperatures under shock and vibration. Results of these tests are tabulated under summary of test results sheet 1 of 2 .

Irradiation tests are being conducted on two (2) of these units, serial numbers 5796 and 5797, at the Ground Test Reactor during August, 1963 under Test Plan Reference number 23/W203.

\section{December 1963}

Radiation Test No. 23/W203, GTR, August, 1963.

Two LVDT's (S/N 5796 and 5797) were installed on a test fixture. The fixture was submerged in $\mathrm{LN}_{2}$ in the east dewar during the test. The fixture contained a bellows-operated ratchet that rotated a shaft $15^{\circ}$ each time gaseous helium pressure was applied to the bellows. Cams on the ends of the shafts produced deflection of the LVDT cores. Total deflection on the fixture was \pm 0.125 in.

Excitation voltage $(5.0 \mathrm{~V} \mathrm{rms}$ at $3.0 \mathrm{kc}$ ) to the LVDT's was supplied by a Hewlett-Packard oscillator and a Krohn-Hite ultra-low-distortion power amplifier. A Tektronix 545 oscilloscope (with a high-gain differential calibrated DC preamplifier) and a Berkeley Model 5510 universal counter were used to monitor the excitation voltage. Outputs were measured with a HewlettPackard $400 \mathrm{H}$ rms voltmeter. On these differential-transformer type LVDT's, winding-to-case insulation resistances and secondary-winding resistances were measured periodically with a Hewlett-Packard 410B VTVM.

\section{Test Results}

Four cycles of test data are presented in Tables $5.2 \mathrm{P}$ and $5.2 \mathrm{~N}$ of GD/FW GTR-7A test report. Malfunctions in the stepping mechanism (or binding of the core) occurred for LVDT S/N 5796 early in the test. The malfunctions were observed at the times listed in the tables. For the remaining unit, the output in post-irradiation measurements ranged from approximately $4 \%$ to $9 \%$ below preirradiation values.

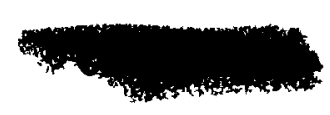




\section{DEVELOPMENT HISTORY}

Code No: $\quad$ Lr-9

Mfgr:

Schaevitz

Model No. 100MS-LT

P. 0 .

\section{REMARKS:}

The tabulation below indicates the values of secondary-coil resistance and insulation resistance of the units:

\begin{tabular}{|c|c|c|c|c|c|}
\hline Value & $\mathrm{S} / \mathrm{N}$ & $\begin{array}{c}\text { Pre- } \\
\text { Irradiation }\end{array}$ & $\begin{array}{l}\text { Initial } \\
3 \mathrm{Mw} \\
\end{array}$ & $\begin{array}{l}\text { Final } \\
3 \mathrm{Mw}\end{array}$ & $\begin{array}{c}\text { Post- } \\
\text { Irradiation }\end{array}$ \\
\hline Insulation & 5796 & 500 & 35 & 35 & 400 \\
\hline $\begin{array}{l}\text { Resistance } \\
\text { (megohms) }\end{array}$ & 5797 & 500 & 50 & 45 & 500 \\
\hline $\begin{array}{l}\text { Secondary } \\
\text { Coil } \\
\text { Resistance } \\
\text { (ohms) }\end{array}$ & 5796 & 40 & 30 & 34 & 33 \\
\hline
\end{tabular}


Sheet 1 of 3

Date: 1 January 1964

\section{POSITION TRANSDUCER}

Code No: $\quad$ Lr-10

Type: Variable Permeance

Mfgr: Physical Science

Range: \pm 0.200 in
Spec. Control Dwg. No.

Evaluation By:

WANL

Model No:

$\mathrm{T} 1-\mathrm{A}-20$

Application:

PERFORMANCE \& ENVIRONMENTAL SPECIFICATIONS

\begin{tabular}{|c|c|c|c|c|}
\hline Test & Condition & NERVA Requirements & Manufacturer's Specs. & $\begin{array}{l}\text { Summary of } \\
\text { Test Results }\end{array}$ \\
\hline$A$ & Comp. Temp Range & $200^{\circ} \mathrm{R}$ & $530^{\circ} \mathrm{R}$ & $140^{\circ} \mathrm{R}$ \\
\hline B & Excitation & $5 \mathrm{~V} \mathrm{rms} 3 \mathrm{KC}$ & $5 \mathrm{~V} \mathrm{rms} 3 \mathrm{KC}$ & $5 \mathrm{~V} \mathrm{rms} 3 \mathrm{KC}$ \\
\hline $\mathrm{C}$ & Sensitivity & $1 \mathrm{mv} / \mathrm{v} / \mathrm{mil} \mathrm{min}$. & $2.5 \mathrm{mv} / \mathrm{v} / \mathrm{mil}$ & $0.904 \mathrm{mv} / \mathrm{v} / \mathrm{mil}$ \\
\hline$D$ & Input Impedance & 500 ohms max. & 90 ohms & 80 ohms \\
\hline$E$ & Output Impedance & 750 ohms max. & $90 \mathrm{ohms}$ & $80 \mathrm{ohms}$ \\
\hline $\mathrm{F}$ & Response Time & $5 \mathrm{~m} \mathrm{sec}$. & $10 \%$ of $3 \mathrm{KC}$ & $10 \%$ of $3 \mathrm{KC}$ \\
\hline G & Resolution & Infinite & Infinite & Infinite \\
\hline $\mathrm{H}$ & Linearity & $1 \%$ & $1 \%$ & $0.2 \%$ \\
\hline 1 & Hysteresis & $0.1 \%$ & $0.1 \%$ & $0.2 \%$ \\
\hline$J$ & Accuracy & $1 \%$ & $1 \%$ & $2.5 \%$ \\
\hline $\mathrm{K}$ & Acceleration Error & $\mathrm{NA}$ & $\mathrm{NA}$ & $\mathrm{NA}$ \\
\hline$L$ & Vibration Error & $\mathrm{NA}$ & $\mathrm{NA}$ & $\mathrm{NA}$ \\
\hline$M$ & Shock & $50 \mathrm{~g} 15 \mu \mathrm{sec}$. & $50 \mathrm{~g} 15 \mu \mathrm{sec}$. & $50 \mathrm{~g} 15 \mu \mathrm{sec}$. \\
\hline $\mathrm{N}$ & Noise Limit & $150 \mathrm{db}$ & $150 \mathrm{db}$ & $150 \mathrm{db}$ \\
\hline 0 & Neutron Flux & & & \\
\hline$P$ & Gamma Flux & & & \\
\hline$Q$ & Resonant Freq. & NA & $\mathrm{NA}$ & $\mathrm{NA}$ \\
\hline $\mathrm{R}$ & Freq. Respons. & $300 \mathrm{cps}$ & $300 \mathrm{cps}$ & $300 \mathrm{cps}$ \\
\hline$S$ & Dimensions & $1 / 2^{\prime \prime} \times 1-3 / 4^{\prime \prime} \max$ & $1 / 2 " \times 2-3 / 4 "$ & $1 / 2^{\prime \prime} \times 2-3 / 4^{\prime \prime}$ \\
\hline$T$ & Weight & $30 \mathrm{gm} \max$ & $25 \mathrm{gm}$ & $25 \mathrm{gm}$ \\
\hline$U$ & Insulation Res. & over $50 \mathrm{M}$ & over $50 \mathrm{M}$ & Infinity \\
\hline$V$ & Material & stainless steel & stainless steel & stainless steel \\
\hline & & & & \\
\hline & & & & \\
\hline & & & & \\
\hline & & & & \\
\hline
\end{tabular}




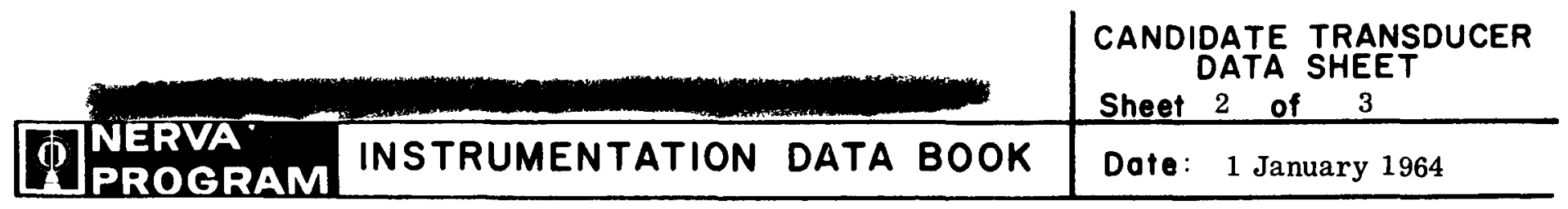

RADIATION TESTS

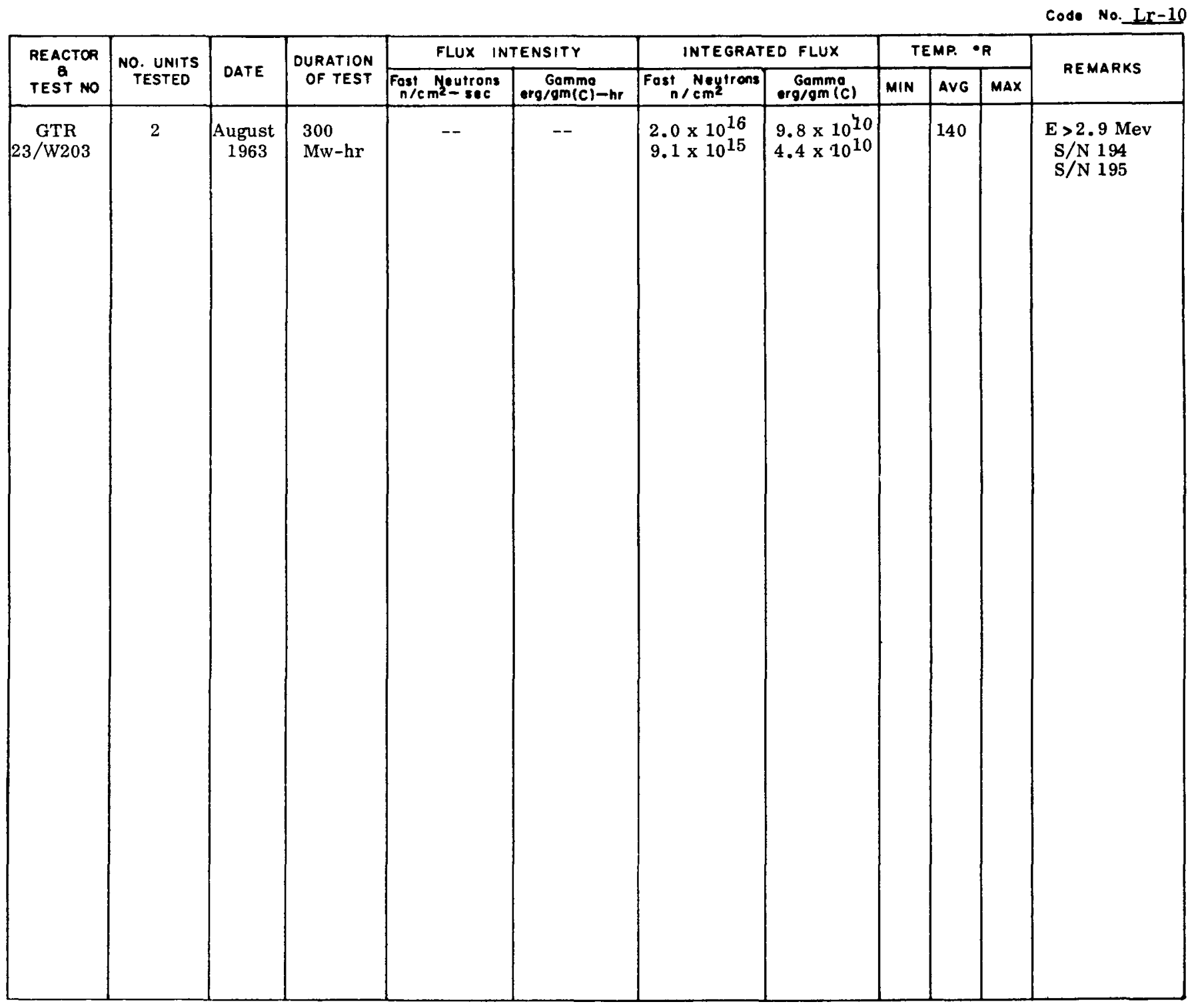




\section{DEVELOPMENT HISTORY}

Code No: Model No. Lr-10

$\mathrm{T} 1-\mathrm{A}-20$
Mfgr: Physical Science

REMARKS:

Code No. $\mathrm{Lr}-1$ is superseded by this unit, Lr-10, and Lr -11 .

Several units of this model were tested at the WANL laboratories in ambient and cryogenic temperatures under shock and vibration. Results of these tests are tabluated under summary of test results sheet 1 of 2 .

Irradiation tests are being conducted on two (2) of these units, serial numbers 194 and 195, at the Ground Test Reactor during August, 1963 under Test Plan Reference Number $23 / \mathrm{W} 203$.

Further irradiation tests are planned at Plum Brook during August, 1963 and GTR during September, 1963.

\section{$\underline{15}$ December 1963}

Radiation Test No. 23/W203, GTR, August, 1963

Two LVDT's (S/N 194 and 195) were installed on a test fixture. The fixture was submerged in $\mathrm{LN}_{2}$ in the east Dewar during the test. Each fixture contained a bellows-operated ratchet that rotated a shaft $15^{\circ}$ each time gaseous helium pressure was applied to the bellows. Cams on the ends of the shafts produced deflection of the LVDT cores. Total deflection on the fixture was \pm 0.250 in.

Excitation voltage $(5.0 \mathrm{rms}$ at $3.0 \mathrm{kc})$ to the LVDT's was supplied by a HewlettPackard oscillator and a Krohn-Hite ultra-low-distortion power amplifier. A Tektronix 545 oscilloscope (with a high-gain differential calibrated DC preamplifier) and a Berkeley Model 5510 universal counter were used to monitor the excitation voltage. Outputs were measured with a Hewlett-Packard $400 \mathrm{H}$ rms voltmeter.

\section{Test Results}

Four cycles of test data are presented in Tables $5.2 \mathrm{~A}$ and $5.2 \mathrm{G}$ of GD/FW GTR-7A test report. The outputs in post-irradiation measurements ranged from approximately $4 \%$ to $9 \%$ below preirradiation values.

The insulation resistances were measured at pre-irradiation only. The values recorded were:

S/N $194-300$ megohms

S/N 195 - 200 megohms

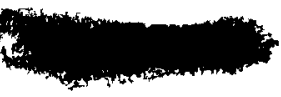


THIS PAGE INTENTIONALLY LEFT BLANK 


\section{POSITION TRANSDUCER}

Code No: $\quad$ Lr-11

Type: Variable Permeance

Mfgr: Physical Science

Range: $\pm 0.100 \mathrm{in}$.
Spec. Control Dwg. No.

Evaluation By: WANL

Model No: T1-A-10

Application:

\begin{tabular}{|c|c|c|c|c|}
\hline Test & Condition & NERVA Requirements & Manufacturer's Specs. & $\begin{array}{l}\text { Summary of } \\
\text { Test Results }\end{array}$ \\
\hline A & Comp. Temp Range & $200^{\circ} \mathrm{R}$ & $530^{\circ} \mathrm{R}$ & $140^{\circ} \mathrm{R}$ \\
\hline B & Excitation & $5 \mathrm{~V} \mathrm{rms} 3 \mathrm{KC}$ & $5 \mathrm{~V} \mathrm{rms} 3 \mathrm{KC}$ & $5 \mathrm{~V} \mathrm{rms} 3 \mathrm{KC}$ \\
\hline $\mathrm{C}$ & Sensitivity & $1 \mathrm{mv} / \mathrm{v} / \mathrm{mil} \mathrm{min}$. & $1 \mathrm{mv} / \mathrm{v} / \mathrm{mil}$ & $1 \mathrm{mv} / \mathrm{v} / \mathrm{mil}$ \\
\hline D & Input Impedance & 500 ohms max. & 90 ohms & $78 \mathrm{ohms}$ \\
\hline$E$ & Output Impedance & 750 ohms max. & 90 ohms & 79 ohms \\
\hline$F$ & Response Time & $5 \mathrm{~m} \mathrm{sec}$ & $10 \%$ of $3 \mathrm{KC}$ & $10 \%$ of $3 \mathrm{KC}$ \\
\hline G & Resolution & infinite & infinite & infinite \\
\hline $\mathrm{H}$ & Linearity & $1 \%$ & $1 \%$ & $0.1 \%$ \\
\hline 1 & Hysteresis & $0.1 \%$ & $0.1 \%$ & $0.1 \%$ \\
\hline $\mathrm{J}$ & Accuracy & $1 \%$ & $1 \%$ & $0.1 \%$ \\
\hline$K$ & Acceleration Error & $\mathrm{NA}$ & $\mathrm{NA}$ & $\mathrm{NA}$ \\
\hline$L$ & Vibration Error & $\mathrm{NA}$ & $\mathrm{NA}$ & NA \\
\hline$M$ & Shock & $50 \mathrm{~g} 15 \mu$ sec. & $50 \mathrm{~g} 15 \mu$ sec. & $50 \mathrm{~g} 15 \mu \mathrm{sec}$. \\
\hline$N$ & Noise Limit & $150 \mathrm{db}$ & $150 \mathrm{db}$ & $150 \mathrm{db}$ \\
\hline 0 & Neutron Flux & & & \\
\hline$P$ & Gamma Flux & & & \\
\hline Q & Resonant Freq. & $\mathrm{NA}$ & $\mathrm{NA}$ & NA \\
\hline$R$ & Freq. Respons. & $300 \mathrm{cps}$ & $300 \mathrm{cps}$ & $300 \mathrm{cps}$ \\
\hline 5 & Dimensions & $1 / 2 " \times 1-1 / 2^{\prime \prime} \max$ & $1 / 2^{\prime \prime} \times 1-1 / 2^{\prime \prime}$ & $1 / 2^{\prime \prime} \times 1-1 / 2^{\prime \prime}$ \\
\hline $\mathrm{T}$ & Weight & $20 \mathrm{gm} \max$. & $18 \mathrm{gr}$ & $18 \mathrm{gr}$ \\
\hline$u$ & Insulation Res. & over $50 \mathrm{~m}$ & over $50 \mathrm{~m}$ & infinity \\
\hline $\mathrm{V}$ & Material & & & \\
\hline & & & & \\
\hline & & & & \\
\hline & & & & \\
\hline
\end{tabular}




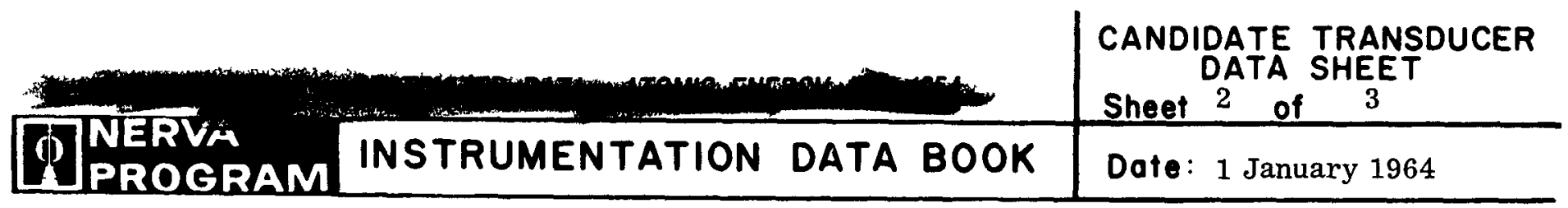

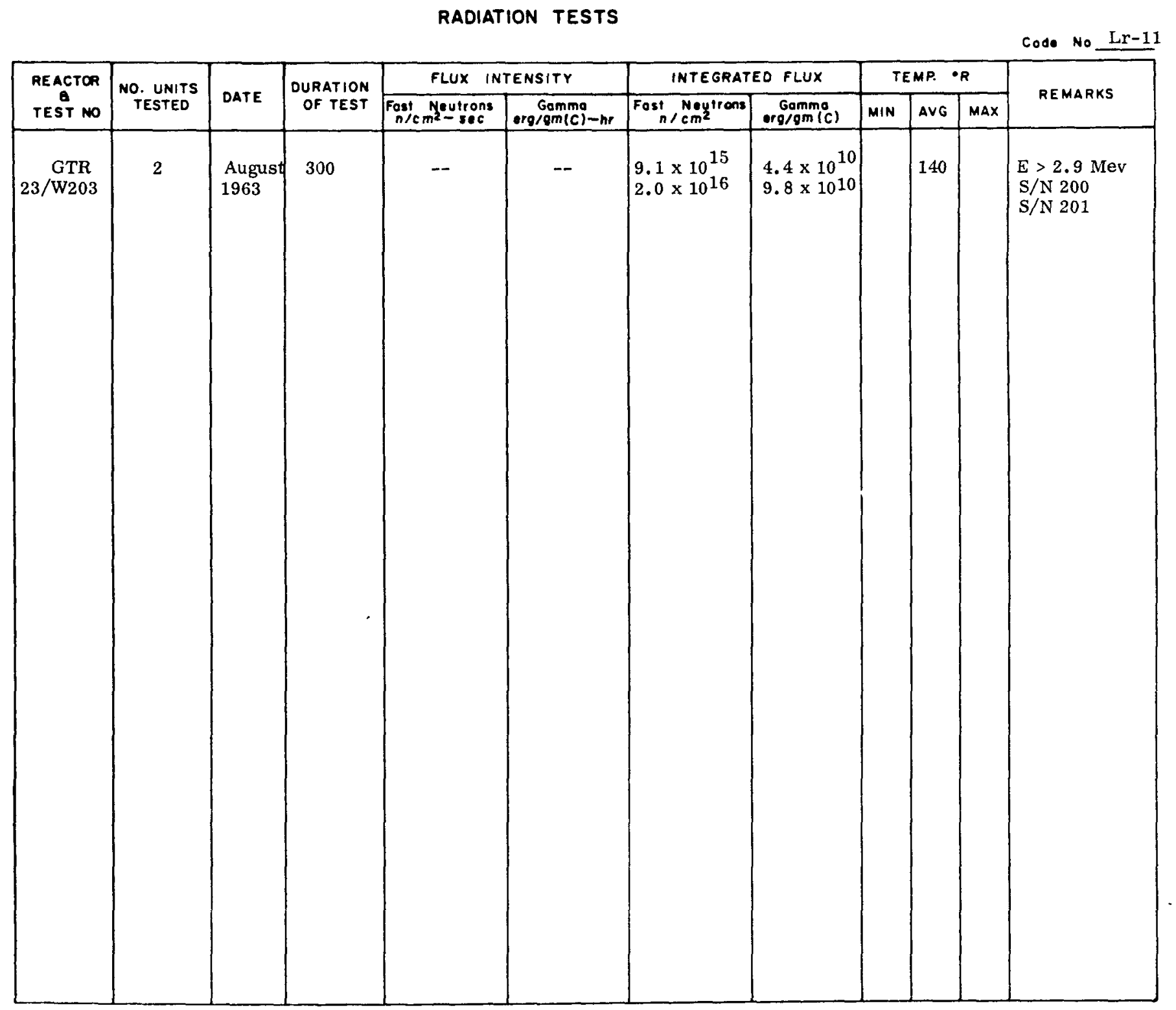

(4) Astronuclear 


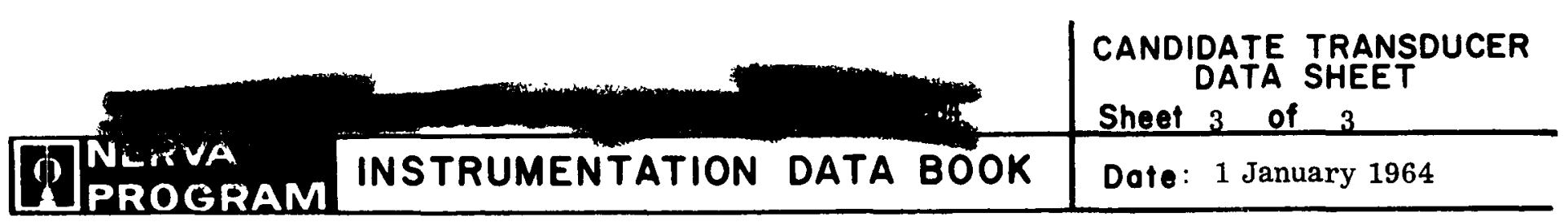

\section{DEVELOPMENT HISTORY}

Code No: $\quad$ Lr-11

Model No. T1-A-10
Mfgr: Physical Science

P. 0 .

\section{REMARKS:}

Code No. Lr-1 is superseded by this unit, Lr-11, and Lr-10.

Several units of this model were tested at the WANL latoratories in ambient and cryogenic temperatures under shock and vibration. Results of these tests are tabulated under summary of test results sheet 1 of 2 .

Irradiation tests are being conducted on two (2) of these units, serial numbers 200 and 201, at the Ground Test Reactor during August, 1963 under Test Plan Reference Number 23/W203.

Further irradiation tests are planned at Plumbrook, during August, 1963 and GTR during September, 1963.

\section{December 1963}

Radiation Test No. 23/W203, GTR, August, 1963

Two LVDT's (S/N 200 and 201) were installed on a test fixture. The fixture was submerged in $\mathrm{LN}_{2}$ in the east Dewar during the test. The fixture contained a bellows-operated ratchet that rotated a shaft $15^{\circ}$ each time gaseous helium pressure was applied to the bellows. Cams on the ends of the shafts produced deflection of the LVDT cores. Total deflection on the fixture was $\pm 0.125 \mathrm{in}$.

Excitation voltage $(5.0 \mathrm{~V} \mathrm{rms}$ at $3.0 \mathrm{kc})$ to the LVDT's was supplied by a Hewlett-Packard oscillator and a Krohn-Hite ultra-low-distortion power amplifier. A Tektronix 545 oscilloscope (with a high-gain differential calibrated DC preamplifier) and a Berkeley Model 5510 universal counter were used to monitor the excitation voltage. Outputs were measured with a Hewlett-Packard $400 \mathrm{H}$ rms voltmeter.

\section{Test Results}

Four cycles of test data are presented in Tables $5.2 \mathrm{~B}$ and $5.2 \mathrm{H}$ of GD/FW GTR-7A test report. The outputs in postirradiation measurements ranged from approximately $4 \%$ to $9 \%$ below preirradiation values.

The insulation values were measured at preirradiation only. The values recorded were:

$\mathrm{S} / \mathrm{N} 200-250$ megohms

$\mathrm{S} / \mathrm{N} 201$ - 300 megohms 
THIS PAGE INTENTIONALLY LEFT BLANK 


\section{POSITION TRANSDUCER}

Code No: Lr-12

Type:

LVDT

Mfgr:

Crescent

Range: $\pm 0.250 \mathrm{in}$.
Spec. Control Dwg. No.

Evaluation By: WANL

Model No: $250-3 \mathrm{~K}-5 / 57-9$

PERFORMANCE \& ENVIRONMENTAL SPECIFICATIONS

\begin{tabular}{|c|c|c|c|c|}
\hline Test & Condition & NERVA Requirements & Manufacturer's Specs. & $\begin{array}{l}\text { Summary of } \\
\text { Test Results } \\
\end{array}$ \\
\hline $\mathrm{A}$ & Comp. Temp Range & $200^{\circ} \mathrm{R}$ & $530^{\circ} \mathrm{R}$ & $140^{\circ} \mathrm{R}$ \\
\hline B & Excitation & $5 \mathrm{~V} \mathrm{rms} 3 \mathrm{KC}$ & $5 \mathrm{~V} \mathrm{rms} 3 \mathrm{KC}$ & $5 \mathrm{~V} \mathrm{rms} 3 \mathrm{KC}$ \\
\hline $\mathrm{C}$ & Sensitivity & $1 \mathrm{mv} / \mathrm{v} / \mathrm{mil} \mathrm{min}$ & $1.65 \mathrm{mv} / \mathrm{v} / \mathrm{mil}$ & $1.50 \mathrm{mv} / \mathrm{v} / \mathrm{mil}$ \\
\hline $\mathrm{D}$ & Input Impedance & 500 ohms max & $112 \mathrm{ohms}$ & $100 \mathrm{ohms}$ \\
\hline$E$ & Output Impedance & 750 ohms max & $138 \mathrm{ohms}$ & $120 \mathrm{ohms}$ \\
\hline $\mathrm{F}$ & Response Time & $5 \mathrm{msec}$ & $10 \%$ of $3 \mathrm{KC}$ & $10 \%$ of $3 \mathrm{KC}$ \\
\hline G & Resolution & Infinite & Infinite & Infinite \\
\hline H & Linearity & $1 \%$ & $1 \%$ & $0.4 \%$ \\
\hline$I$ & Hysteres is & $0.1 \%$ & $0.1 \%$ & $0.3 \%$ \\
\hline $\mathrm{J}$ & Accuracy & $1 \%$ & $1 \%$ & $3.0 \%$ \\
\hline$K$ & Acceleration Error & $\mathrm{NA}$ & NA & $\mathrm{NA}$ \\
\hline$L$ & Vibration Error & $\mathrm{NA}$ & NA & $\mathrm{NA}$ \\
\hline$M$ & Shock & $50 \mathrm{~g} 15 \mu \mathrm{sec}$ & $50 \mathrm{~g} 15 \mu \mathrm{sec}$ & $50 \mathrm{~g} 15 \mu \mathrm{sec}$ \\
\hline $\mathrm{N}$ & Noise Limit & $150 \mathrm{db}$ & $150 \mathrm{db}$ & $150 \mathrm{db}$ \\
\hline 0. & Neutron Flux & & & \\
\hline$P$ & Gamma Flux & & & \\
\hline Q & Resonant Freq. & NA & $\mathrm{NA}$ & $\mathrm{NA}$ \\
\hline R & Freq. Respons. & $300 \mathrm{cps}$ & $300 \mathrm{cps}$ & $300 \mathrm{cps}$ \\
\hline$S$ & Dimensions & $1 / 2^{\prime \prime} \times 2^{\prime \prime} \max$ & $1 / 2 " \times 1-7 / 8^{\prime \prime}$ & $1 / 2 " \times 1-7 / 8^{\prime \prime}$ \\
\hline$T$ & Weight & $30 \mathrm{gm} \max$ & $21.0 \mathrm{gm}$ & $21.5 \mathrm{gm}$ \\
\hline$U$ & Insulation Res. & over $50 \mathrm{~m}$ & over $50 \mathrm{~m}$ & Infinity \\
\hline V & Material & Stainless Steel & Stainless Steel & Stainless Steel \\
\hline & & & & \\
\hline & & & & \\
\hline & & & & \\
\hline
\end{tabular}




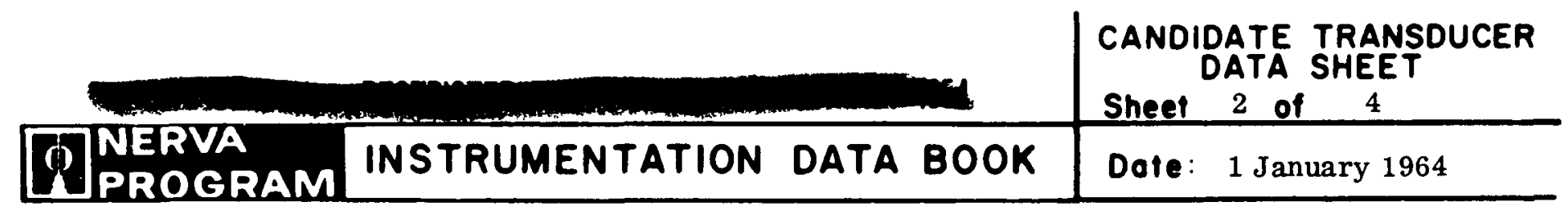

RADIATION TESTS

code No Lr -12

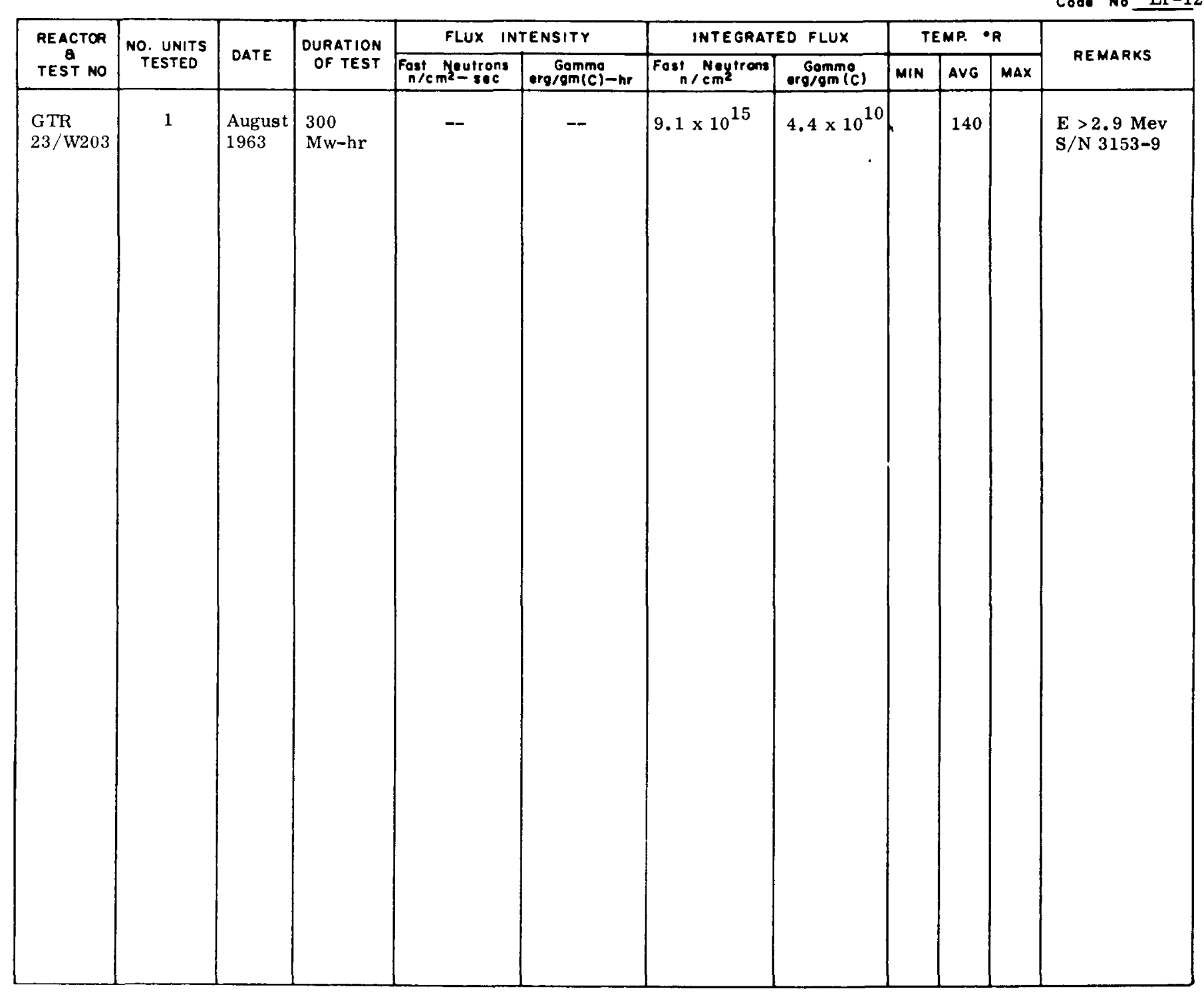

w 


\section{DEVELOPMENT HISTORY}

Code No:

$\mathrm{Lr}-12$

Model No.

250-3K-5/57-9
Mfgr: Crescent

\section{REMARKS:}

P. 0 .

Several units of this model were tested at the WANL laboratories in ambient and cryogenic temperatures under shock and vibration. Results of these tests are tabulated under summary of test results sheet 1 of 2 .

Irradiation tests are planned at Plum Brook during August, 1963 and Ground Test Reactor during Spetember, 1963.

\section{December 1963}

Radiation Test No. 23/W203, GTR, August, 1963

One LVDT (S/N 3153-9) was installed on a test fixture. The fixture was submerged in $\mathrm{LN}_{2}$ in the east Dewar during the test. The fixture contained a bellows-operated ratchet that rotated a shaft $15^{\circ}$ each time gaseous helium pressure was applied to the bellows. Cams on the end of the shaft produced deflection of the LVDT core. Total deflection on the fixture was \pm 0.250 in.

Excitation voltage $(5.0 \mathrm{~V} \mathrm{rms}$ at $3.0 \mathrm{kc})$ to the LVDT's was supplied by a HewlettPackard oscillator and a Krohn-Hite ultra-low-distortion power amplifier. A Tektronix 545 oscilloscope (with a high-gain differential calibrated DC preamplifier) and a Berkeley Model 5510 universal counter were used to monitor the excitation voltage. Output was measured with a Hewlett-Packard $400 \mathrm{H} \mathrm{rms}$ voltmeter. On this differential-transformer type LVDT, winding-to-case insulation resistances and secondary-winding resistances were measured periodically with a Hewlett-Packard 410B VTVM.

\section{Test Results}

Four cycles of test data are presented in Table 5.2C of GD/FW GTR-7A test report. The outputs in postirradiation measurements ranged from approximately $4 \%$ to $9 \%$ below preirradiation values.

The tabulation below indicate the values of secondary coil resistance and insulation resistance of the unit. 


\begin{tabular}{|l|l|l}
\hline NERVA & \multicolumn{2}{|c}{$\begin{array}{c}\text { CANDIDATE TRANSDUCER } \\
\text { DATA SHEET }\end{array}$} \\
SROGRAM INSTRUMENTATION DATA BOOK & Dote: 1 January 1964 \\
\hline
\end{tabular}

DEVELOPMENT HISTORY

Code No: $\mathrm{Lr}-12$

Mfgr: Crescent

Model No. $250-3 \mathrm{~K}-5 / 57-9$

P. 0 .

REMARKS:

\begin{tabular}{|c|c|c|c|c|c|}
\hline Value & $\mathbf{S} / \mathbf{N}$ & $\begin{array}{c}\text { Pre- } \\
\text { Irradiation }\end{array}$ & $\begin{array}{r}\text { Initial } \\
3 \mathrm{Mw} \\
\end{array}$ & $\begin{array}{l}\text { Final } \\
3 \mathrm{Mw} \\
\end{array}$ & $\begin{array}{c}\text { Post- } \\
\text { Irradiation }\end{array}$ \\
\hline $\begin{array}{l}\text { Insulation } \\
\text { Resistance } \\
\text { (megohms) }\end{array}$ & $3153-9$ & $>500$ & 100 & 39 & 400 \\
\hline $\begin{array}{l}\text { Secondary } \\
\text { Coil } \\
\text { Resistance } \\
\text { (ohms) }\end{array}$ & $3153-9$ & 15 & 15 & 15 & 15 \\
\hline
\end{tabular}




\section{POSITION TRANSDUCER}

Code No:

Type:

LVDT

Mfgr:

Crescent

Range: \pm 0.125 in.
Spec. Control Dwg. No.

Evaluation By:

WANL

Model No:

\begin{tabular}{|c|c|c|c|c|}
\hline Test & Condition & NERVA Requirements & Manufacturer's Specs. & $\begin{array}{l}\text { Summary of } \\
\text { Test Results }\end{array}$ \\
\hline$A$ & Comp. Temp Range & $200^{\circ} \mathrm{R}$ & $530^{\circ} \mathrm{R}$ & $140^{\circ} \mathrm{R}$ \\
\hline$B$ & Excitation & $5 \mathrm{~V} \mathrm{rms} 3 \mathrm{KC}$ & $5 \mathrm{~V} \mathrm{rms} 3 \mathrm{KC}$ & $5 \mathrm{~V} \mathrm{rms} 3 \mathrm{KC}$ \\
\hline C & Sensitivity & $1 \mathrm{mv} / \mathrm{v} / \mathrm{mil} \mathrm{min}$ & $2 \mathrm{mv} / \mathrm{v} / \mathrm{mil}$ & $1.85 \mathrm{mv} / \mathrm{v} / \mathrm{mil}$ \\
\hline D & Input Impedance & 500 ohms max & $112 \mathrm{ohms}$ & $103 \mathrm{ohms}$ \\
\hline$E$ & Output Impedance & 750 ohms max & $145 \mathrm{ohms}$ & 130 ohms \\
\hline $\mathrm{F}$ & Response Time & $5 \mathrm{msec}$ & $10 \%$ of $3 \mathrm{KC}$ & $10 \%$ of $3 \mathrm{KC}$ \\
\hline G & Resolution & Infinite & Infinite & Infinite \\
\hline $\mathrm{H}$ & Linearity & $1 \%$ & $1 \%$ & $0.3 \%$ \\
\hline 1 & Hysteresis & $0.1 \%$ & $0.1 \%$ & $0.2 \%$ \\
\hline 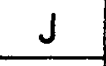 & Accuracy & $1 \%$ & $1 \%$ & $3.1 \%$ \\
\hline$K$ & Acceleration Error & NA & $\mathrm{NA}$ & $\mathrm{NA}$ \\
\hline$L$ & Vibration Error & $\mathrm{NA}$ & $\mathrm{NA}$ & $\mathrm{NA}$ \\
\hline M & Shock & $50 \mathrm{~g} 15 \mu \mathrm{sec}$ & $50 \mathrm{~g} 15 \mu \mathrm{sec}$ & $50 \mathrm{~g} 15 \mu \mathrm{sec}$ \\
\hline$N$ & Noise Limit & $150 \mathrm{db}$ & $150 \mathrm{db}$ & $150 \mathrm{db}$ \\
\hline 0 & Neutron Flux & & & \\
\hline$P$ & Gamma Flux & & & \\
\hline Q & Resonant Freq. & $\mathrm{NA}$ & $\mathrm{NA}$ & $\mathrm{NA}$ \\
\hline $\mathbf{R}$ & Freq. Respons. & $300 \mathrm{cps}$ & $300 \mathrm{cps}$ & $300 \mathrm{cps}$ \\
\hline$S$ & Dimensions & $1 / 2^{\prime \prime} \times 1-3 / 4^{\prime \prime} \max$ & $1 / 2 " \times 1-1 / 2^{\prime \prime}$ & $1 / 2 " \times 1-1 / 2 "$ \\
\hline $\mathrm{T}$ & Weight & $25 \mathrm{gm} \max$ & $16 \mathrm{gr}$ & $16 \mathrm{gr}$ \\
\hline$U$ & Insulation Res. & over $50 \mathrm{~m}$ & over $50 \mathrm{~m}$ & Infinity \\
\hline $\mathrm{V}$ & Material & Stainless Steel & Stainless Steel & Stainless Steel \\
\hline & & & & \\
\hline & & & & \\
\hline & & & & \\
\hline
\end{tabular}




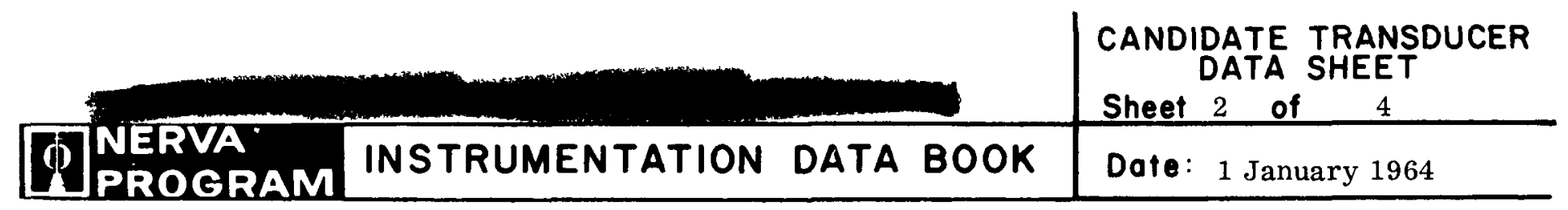

RADIATION TESTS

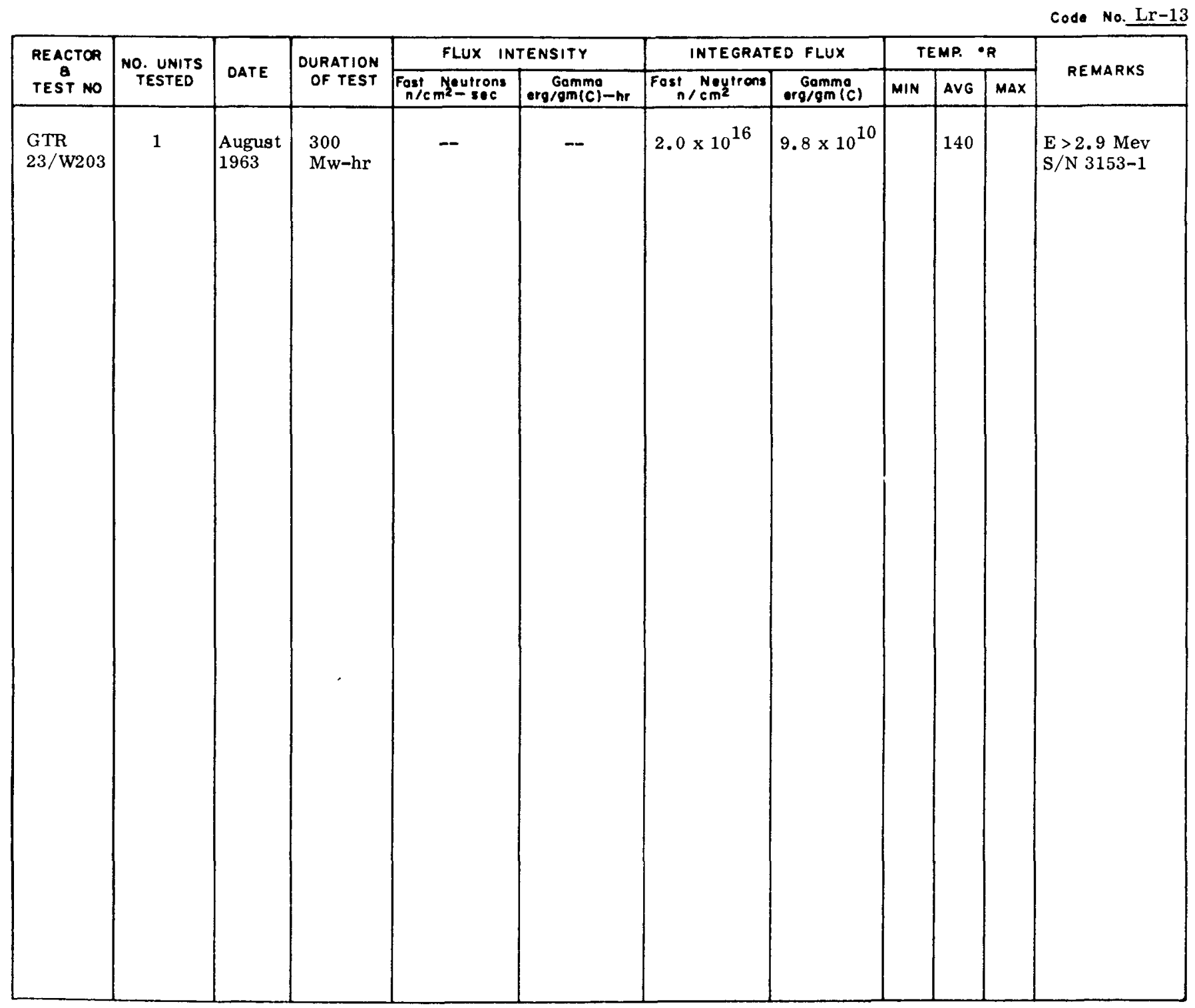




\section{DEVELOPMENT HISTORY}

Code No:

Lr-13

Model No.

$125-3 \mathrm{~K}-5 / 58-9$
Mfgr:

Crescent

\section{REMARKS:}

Several units of this model were tested at the WANL laboratories in ambient and cryogenic temperatures under shock and vibration. Results of these tests are tabulated under summary of test results sheet 1 of 2 .

Irradiation tests are planned at Plum Brook during August, 1963 and Ground Test Reactor during September, 1963.

\section{$\underline{15} \underline{\text { December }} \underline{1963}$}

Radiation Test No. 23/W203, GTR, August, 1963

One LVDT was installed on a test fixture. The fixture was submerged in $\mathrm{LN}_{2}$ in the east Dewar during the test. The fixture contained a bellows-operated ratchet that rotated a shaft $15^{\circ}$ each time gaseous helium pressure was applied to the bellows. Cams on the end of the shaft produced deflection of the LVDT core. Total deflection on the fixtures was \pm 0.125 in.

Excitation voltage $(5.0 \mathrm{~V} \mathrm{rms} \mathrm{at} 3.0 \mathrm{kc})$ to the LVDT was supplied by a Hewlett-Packard oscillator and a Krohn-Hite ultra-low-distortion power amplifier. A Tektronix 545 oscilloscope (with a high-gain differential calibrated DC preamplifier) and a Berkeley Model 5510 universal counter were used to monitor the excitation voltage. Output was measured with a HewlettPackard $400 \mathrm{H} \mathrm{rms} \mathrm{voltmeter.} \mathrm{On} \mathrm{this} \mathrm{differential-transformer} \mathrm{type} \mathrm{LVDT} \mathrm{winding-to-case}$ insulation resistances and secondary-winding resistances were measured periodically with a Hewlett-Packard 410B VTVM.

\section{Test Results}

Four cycles of test data are presented in Table 5.2I of GD/FW GTR-7A test report. The output in postirradiation measurements ranged from approximately $4 \%$ to $9 \%$ below preirradiation values.

The tabulation below indicates the values of secondary-coil resistance and insulation resistances of the unit.

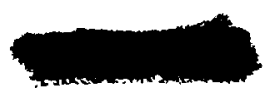




\section{DEVELOPMENT HISTORY}

Code No:

Model No.

$\mathrm{Lr}-13$

$125-3 \mathrm{~K}-5 / 58-9$

\section{REMARKS:}

\begin{tabular}{|c|c|c|c|c|}
\hline Value & $\mathrm{S} / \mathrm{N}$ & $\begin{array}{c}\text { Pre- } \\
\text { Irradiation }\end{array}$ & $\begin{array}{r}\text { Initial } \\
3 \mathrm{Mw} \\
\end{array}$ & $\begin{array}{l}\text { Final } \\
3 \mathrm{Mw} \\
\end{array}$ \\
\hline $\begin{array}{l}\text { Insulation } \\
\text { Resistance } \\
\text { (megohms) }\end{array}$ & $3153-1$ & 14 & 14 & 14 \\
\hline $\begin{array}{l}\text { Secondary } \\
\text { Coil } \\
\text { Resistance } \\
\text { (ohms) }\end{array}$ & $3153-1$ & 1.3 & 1.5 & 1.4 \\
\hline
\end{tabular}

It has been determined that low insulation and secondary-coil resistances for this LVDT were caused by a ground connection on one side of the transducer secondary. The values shown in the table for insulation resistance are actually secondary-coil resistance, and the values shown for secondary-coil resistance are actually the resistance of the lead wire.

P. 0 . Crescent 


\section{POSITION TRANSDUCER}

Code No: $\quad$ Lr-19

Type:

Mfgr:

Variable Permeance

Range:
Spec. Control Dwg. No.

Evaluation By:

WANL

Model No:

\begin{tabular}{|c|c|c|c|c|}
\hline Test & Condition & NERVA Requirements & Manufacturer's Specs. & $\begin{array}{l}\text { Summary of } \\
\text { Test Results }\end{array}$ \\
\hline A & Comp. Temp Range & $140^{\circ}-530^{\circ} \mathrm{R}$ & $300^{\circ}-910^{\circ} \mathrm{R}$ & $140^{\circ} \mathrm{R}$ \\
\hline B & Excitation & $5 \mathrm{~V} \mathrm{rms}, 3 \mathrm{KC}$ & $5 \mathrm{~V} \mathrm{rms}, 5 \mathrm{KC}$ carrier & $5 \mathrm{~V} \mathrm{rms}, 3 \mathrm{KC}$ \\
\hline $\mathrm{C}$ & Sensitivity & $1 \mathrm{mv} / \mathrm{v} / \mathrm{mil} \mathrm{min}$ & $1.42 \mathrm{v} / \mathrm{in} . / \mathrm{v}$ & $1.52 \mathrm{v} / \mathrm{in} . / \mathrm{v}$ \\
\hline D & Input Impedance & $500 \mathrm{ohms} \max$ & $300 \mathrm{ohms}$ nom. & \\
\hline$E$ & Output Impedance & 750 ohms $\max$ & 300 ohms nom. & \\
\hline $\mathrm{F}$ & Response Time & $5 \mathrm{msec}$ to $63 \%$ & & \\
\hline G & Resolution & Infinite & Infinite & \\
\hline $\mathrm{H}$ & Linearity & $1.0 \%$ & $1.0 \%$ max. (rated range) & \\
\hline 1 & Hysteresis & $0.1 \%$ & $0.01 \%$ or better & \\
\hline $\mathrm{J}$ & Accuracy & $1.0 \%$ & & \\
\hline$K$ & Acceleration Error & $\mathrm{NA}$ & $\mathrm{NA}$ & \\
\hline$L$ & Vibration Error & $\mathrm{NA}$ & $\mathrm{NA}$ & \\
\hline$M$ & Shock & $50 \mathrm{~g}, 15 \mu \mathrm{sec}$ & & \\
\hline $\mathrm{N}$ & Noise Limit & $150 \mathrm{db}$ & & \\
\hline 0 & Neutron Flux & & $\mathrm{NA}$ & \\
\hline$P$ & Gamma Flux & & $\mathrm{NA}$ & \\
\hline Q & Resonant Freq. & $\mathrm{NA}$ & $\mathrm{NA}$ & \\
\hline $\mathbf{R}$ & Freq. Respons. & $300 \mathrm{cps}$ & & \\
\hline$S$ & Dimensions & $3 / 4^{\prime \prime}$ dia $\times 2 "$ lg $\max$ & $5 / 8 "$ Hex $\times 2 " 1 g$ approx. & \\
\hline$T$ & Weight & Mfgr. to specify & 1.82 ozs. & \\
\hline$U$ & Insulation Res. & $>100$ megohm at $50 \mathrm{VDC}$ & & 300 megohm \\
\hline V & Material & & steel, nickel plated & \\
\hline & & & & \\
\hline & & & & \\
\hline & & & & \\
\hline
\end{tabular}




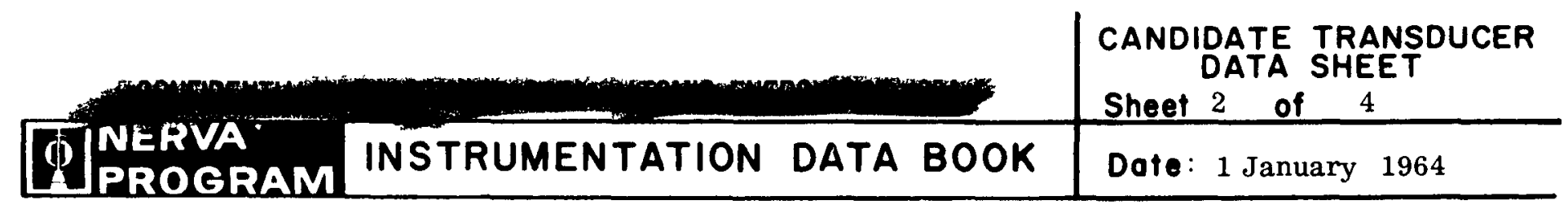

RADIATION TESTS

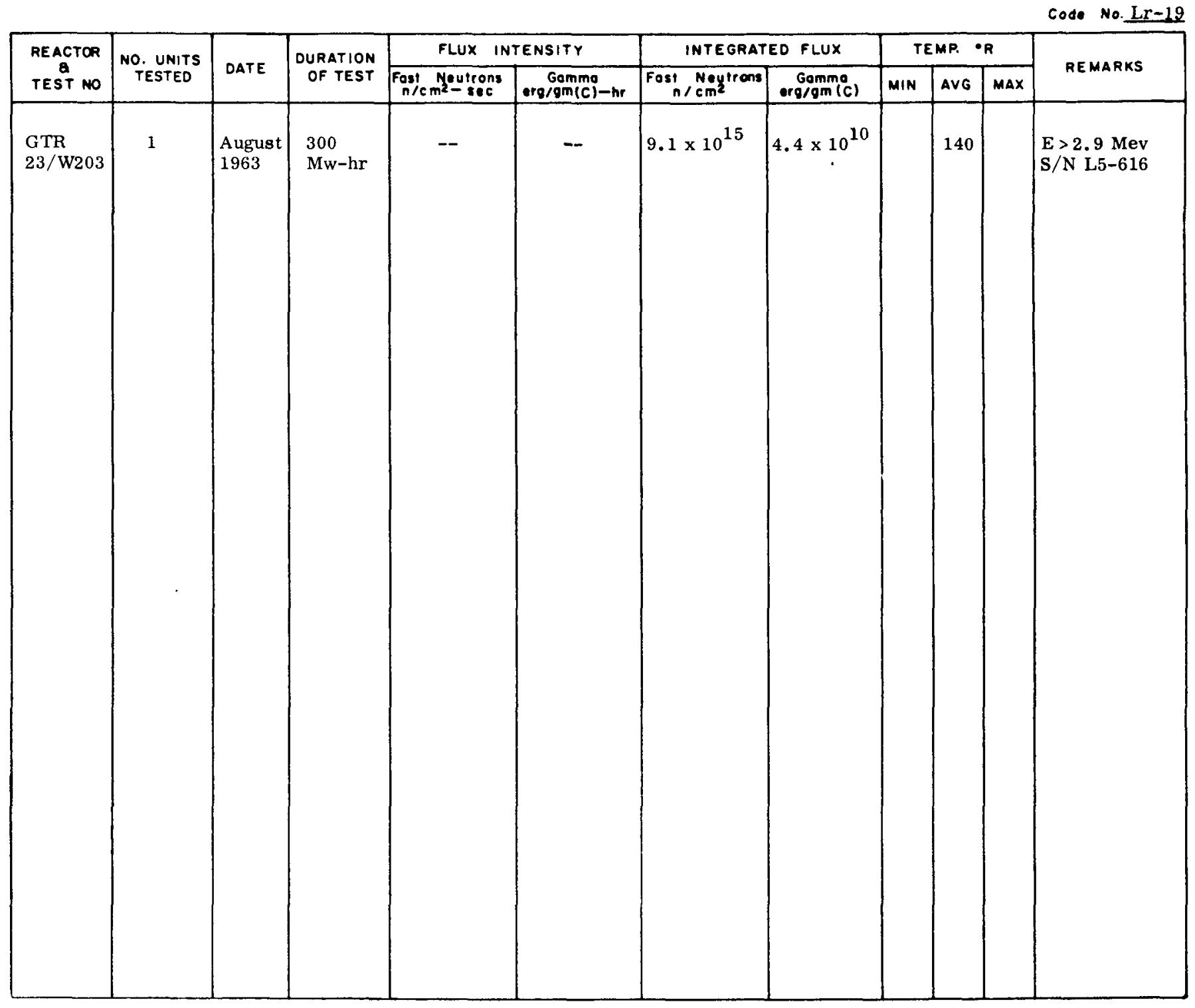

(w) Stronuclear 


\section{DEVELOPMENT HISTORY}

\begin{tabular}{ll} 
Code No: $\frac{\text { Lr-19 }}{\text { Model No. }}$ K025 & Mfgr: $\frac{\text { Crescent }}{34696}$ \\
\hline
\end{tabular}

\section{REMARKS:}

$\underline{15} \underline{\text { December }} \underline{1963}$

Description - This unit is an electromechanical, variable permeance type linear displacement transducer. It is designed for operation in an AC bridge circuit. A two-arm inductive or resistive divider is required as the reference half of the bridge. Movement of the probe to either side of null causes an AC output voltage across the bridge. This voltage is proportional to, and linear with, the probe displacement and reverses phase $180^{\circ}$ through null.

The unit is a standard stock item. A threaded housing and locknut provide secure and easy mounting. This mounting also facilitates adjustment of the null position. A spring loaded probe facilitates use where the probe cannot be physically connected to the moving member.

Intended Use - This unit was procured for evaluation under cryogenic and radiation conditions, specifically for the August GTR test. Eventual use would be for diagnostic purposes of the NRX-A test series.

Basis of Selection - The prime advantage of this unit is the spring loaded probe. This allows much more versatility of installation. The threaded body design also holds some promise to aid installation.

Problem Areas - Organic materials are present in this unit which poses problems in a radiation environment. However, a redesigned unit replacing this material can be accomplished rather easily if deemed worthwhile after analyzing test data on this stock unit.

Tests Conducted - Radiation Test No. 23/W203 GTR, August, 1963

Prior to GTR test, calibration tests were run at WANL in both ambient and $\mathrm{LN}_{2}$ environments.

One LVDT (S/N L5 -616) was installed on a test fixture. The fixture was submerged in $\mathrm{LN}_{2}$ in the east Dewar during the test. The fixture contained a bellows-operated ratchet that rotated a shaft $15^{\circ}$ each time gaseous helium pressure was applied to the bellows. Cams on the end of the shaft produced deflection of the LVDT core. Total deflection on the fixtures was $\pm 0.125 \mathrm{in}$. 


\section{DEVELOPMENT HISTORY}

Code No:

Lr-19

Model No. K025

Mfgr: Crescent

P. 0 . 34696

\section{REMARKS:}

Excitation voltage $(5.0 \mathrm{~V} \mathrm{rms}$ at $3.0 \mathrm{kc})$ to the LVDT's was supplied by a HewlettPackard oscillator and a Krohn-Hite ultra-low-distortion power amplifier. A Tektronix 545 oscilloscope (with a high-gain differential calibrated DC preamplifier) and a Berkeley Model 5510 universal counter were used to monitor the excitation voltage. Outputs were measured with a Hewlett-Packard $400 \mathrm{H}$ rms voltmeter.

\section{Test Results}

Four cycles of test data re presented in Table $5.2 \mathrm{~F}$ of GD/FW GTR-7A test report. The output in postirradiation measurements ranged from approximately $4 \%$ to $9 \%$ below preirradiation values.

The insulation value was measured at preirradiation only. The value recorded was 300 megohms.

It has been decided that due to the organic material present and the satisfactory performance of other units under the same environment, that further modifications of this unit would not be warranted. Therefore, no further testing will be done on this unit. 


\section{SOUND PRESSURE TRANSDUCER}

Code No: Ar-1

Type: High Intensity Microphone

Mfgr: Gulton Industries, Inc.

Range: $150-190 \mathrm{db}$
Spec. Control Dwg. No. 964B030H01

Evaluation By: WANL

Model No: MA299501 (Modified) P420M6

Application: Piezoelectric Crystal

PERFORMANCE \& ENVIRONMENTAL SPECIFICATIONS

\begin{tabular}{|c|c|c|c|c|}
\hline Test & Condition & NERVA Requirements & Manufacturer's Specs & $\begin{array}{l}\text { Summary of } \\
\text { Test Results }\end{array}$ \\
\hline$A$ & Overload & $150 \% \mathrm{FR}$ & $>200 \mathrm{db}$ & \\
\hline$B$ & Compt. Temp Range & $140^{\circ}-535^{\circ} \mathrm{R}$ & $395^{\circ}-710^{\circ} \mathrm{R}$ & $140->535^{\circ} \mathrm{R}$ \\
\hline C & Excitation & self-generating & self-generating & \\
\hline D & Sensitivity & $1.0 \mathrm{mv}$ at $120 \mathrm{db}$ SPL & $1.6 \mathrm{mv}$ at $120 \mathrm{db} \mathrm{SPL}$ & $1.2 \mathrm{mv}$ at $120 \mathrm{db}$ \\
\hline$E$ & Input Impedance & NA & $\mathrm{NA}$ & $\mathrm{NA}$ \\
\hline$F$ & Output Impedance & $2400 \mathrm{PF}$ (min open cet. $)$ & info. later & $>2700$ \\
\hline $\mathbf{G}$ & Response time & info. later NA & info. later & NA \\
\hline$H$ & Freq. Response & $< \pm 3 \mathrm{db} 10 \mathrm{cps}-10 \mathrm{KC}$ & $\begin{array}{l} \pm 2 \mathrm{db} \text { ref } 1 \mathrm{KC} \text { from } 2 \mathrm{cps} \\
\pm 3 \mathrm{db} \text { ref } 1 \mathrm{KC} \text { from } 6 \mathrm{KC} t\end{array}$ & $\begin{array}{l}\text { to } 6 \mathrm{KC}+3 \mathrm{db} \\
010 \mathrm{KC}-0.5 \mathrm{db} \\
\end{array}$ \\
\hline 1 & Resolution & $\mathrm{NA}$ & & NA \\
\hline$J$ & Linearity & $< \pm 0.5 \mathrm{db}$ of SPL FR & $< \pm 0.5 \mathrm{db}$ of SPL overrang & $e< \pm 0.1 \mathrm{db}-140 \mathrm{db}$ \\
\hline$K$ & Hysteresis & $< \pm 1 \mathrm{db}$ & & $< \pm 0.5 \mathrm{db}$ \\
\hline$L$ & Accuracy & $< \pm 3 \mathrm{db}$ & & $\leq \pm 3 \mathrm{db}$ \\
\hline$M$ & Acceleration Error & & & \\
\hline $\mathbf{N}$ & Vibration Error & $<100 \mathrm{db}$ SPL at $1 \mathrm{~g} \mathrm{rms}$ & $<90 \mathrm{db}$ SPL at $18 \mathrm{rms}$ & $\begin{array}{l}100 \text { db SPL at } \\
\text { Ig rms }\end{array}$ \\
\hline 0 & Shock & $100 \mathrm{~g}, 150 \mu \mathrm{sec}$. & $100 \mathrm{~g}, 10 \mathrm{~ms} 500 \mathrm{~g}, 1 \mathrm{~ms}$ & \\
\hline$P$ & Noise Limit & & & \\
\hline$Q$ & Neutron Flux & NA & & \\
\hline$R$ & Gamma Flux & $\mathrm{NA}$ & & \\
\hline 5 & Dimensions & $0.76^{\prime \prime} \mathrm{OD} \times 1.07 " \mathrm{LG}$ & $0.76 " \mathrm{OD} \times 1.07 " \mathrm{LG}$ & \\
\hline$T$ & Weight & $<1 \mathrm{oz}$. & $0.75 \mathrm{oz}$ & \\
\hline $\bar{U}$ & Resonant Freq. & $27 \mathrm{KC}$ min & $27 \mathrm{KC} \mathrm{min}$ & \\
\hline $\mathrm{V}$ & Insulation Res. & $\begin{array}{l}300 \text { megohms at } \\
50 \mathrm{VDC}\end{array}$ & info. later & $>10^{5}$ megohms \\
\hline$w$ & Material & compatible with $\mathrm{LH}_{2}$ & stainless steel & \\
\hline$x$ & Ambient Pressure & $500 \mathrm{psia}$ & info. later & \\
\hline & & & & \\
\hline & & & & \\
\hline
\end{tabular}




\section{RAOIATION TESTS}

Code No.Ar-1

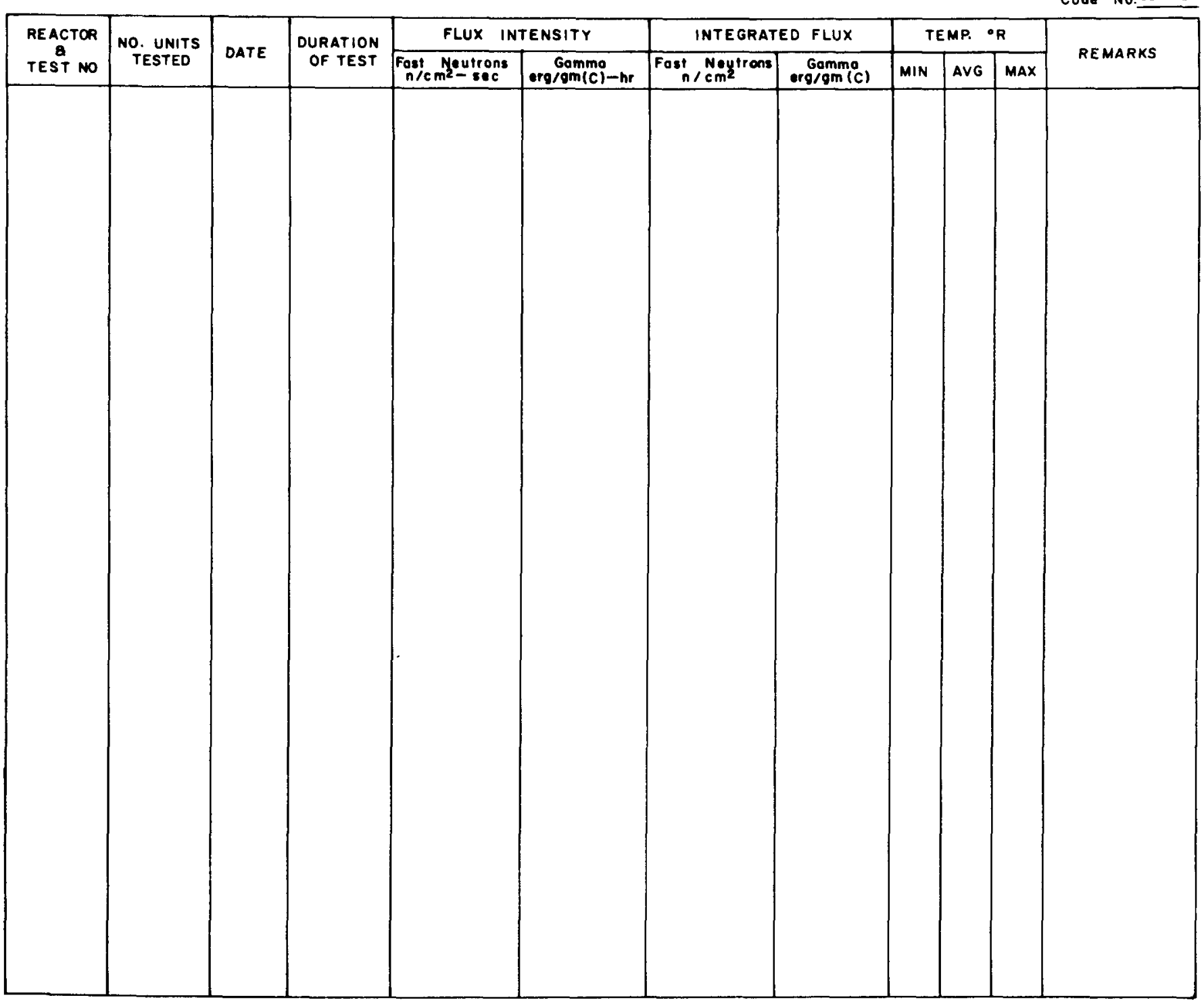




\begin{tabular}{|l|l|l}
\hline MERVA & \multicolumn{2}{|l}{$\begin{array}{l}\text { CANDIDATE TRANSDUCER } \\
\text { DATA SHEET }\end{array}$} \\
PROGRAM INSTRUMENTATION DATA BOOK & Date: 1 January 1964 \\
\hline
\end{tabular}

\section{DEVELOPMENT HISTORY}

Code No: Ar-1

Model No. MA299501 (Modified) P420M6
Mfgr: Gulton Industries, Inc.

P. 0. 30499

\section{REMARKS:}

In order to solve the mechanical mounting problems in final assembly, extreme emphasis was placed on physical size of this unit.

A literature search for units specified by the manufacturers to satisfy the environmental conditions for NRX-A 1 has been made and the initial selection is based on these results.

Confirmation of the guarantees will be made in subsequent evaluation tests by WANL.

This unit, using a piezoelectric crystal sensing element, is identical in design principle to accelerometers of the crystal type which have been previously tested by WANL. On the basis of these test results, performance of this unit is expected to be satisfactory under the environmental conditions of the NRX-A1 test.

15 November 1963

$\underline{\text { Intended Use }}$

Sound pressure level transducers are specified for use in the inlet and outlet plenums of the NRX-A1 Cold Flow reactor. The intent is to detect and measure sound pressure levels large enough to cause damage to the reactor, if such high intensity sound is present. In that case a frequency analysis of the recorded data will be made in an attempt to determine the probable sources of sound.

\section{Basis of Selection}

No standard microphone was found which met the NERVA requirements. At the request of WANL, Gulton Industries agreed to modify their model MA299501 (P-420-M6) in an attempt to meet these requirements. The modification involved venting the inside of the microphone case to atmosphere to meet the ambient pressure requirement. Tests were run on four (4) standard (unvented) unit to determine whether the units could be used down to $140^{\circ} \mathrm{R}$. Three (3) of these units showed shifts ranging from $-2 \mathrm{db}$ to $+0.6 \mathrm{db}$ and returned to their original sensitivities at ambient. The fourth unit showed $a+6 \mathrm{db}$ change but failed to return to its original sensitivity. Tests on vented units verified the above results.

\section{Tests Conducted}

Thermal shock tests conducted by measuring the microphone output as it was dropped into liquid nitrogen gave the following results:

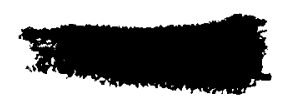




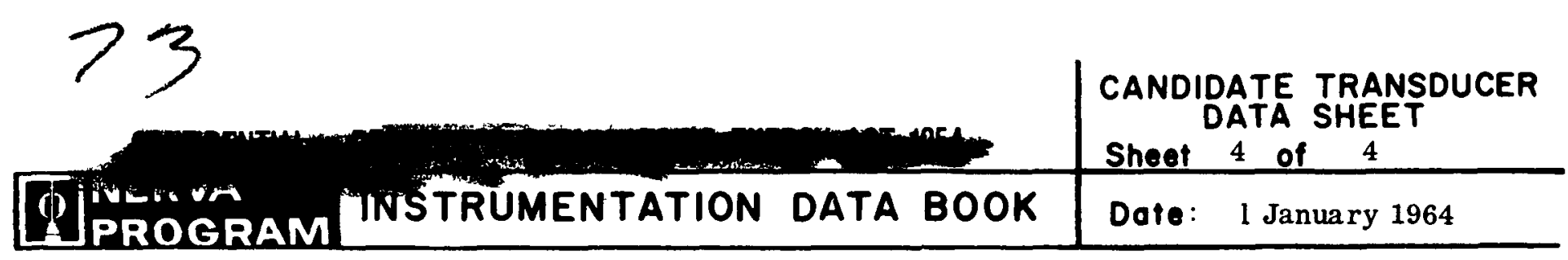

\section{DEVELOPMENT HISTORY}

Code No: $\quad$ Ar-1

Model No. MA299501 (Modified) P420M6
Mfgr: Gulton Industries, Inc.

P. 0. 30499

\section{REMARKS:}

$\begin{array}{rrrr}\begin{array}{c}\text { Low Frequency } \\ \text { Cut-Off }\end{array} & \begin{array}{c}\text { Noise for } \\ 1 \text { st 20 Sec. }\end{array} & \begin{array}{c}\text { Corresponding } \\ \text { SPL Level }\end{array} \\ 1 \mathrm{cps} & & 400 \mathrm{mv} & \\ 10 \mathrm{cps} & 60 \mathrm{mv} & & 169 \mathrm{db} \\ 100 \mathrm{cps} & 20 \mathrm{mv} & & 143 \mathrm{db}\end{array}$

These results indicate that for the SPL range specified (150-190db) a low frequency cut-off $10 \mathrm{cps}$ should be used. This will eliminate low frequency information which might result from thermal shock.

The following data has been summarized from the manufacturers calibration tests conducted for the units installed in the NRX-A1 reactor

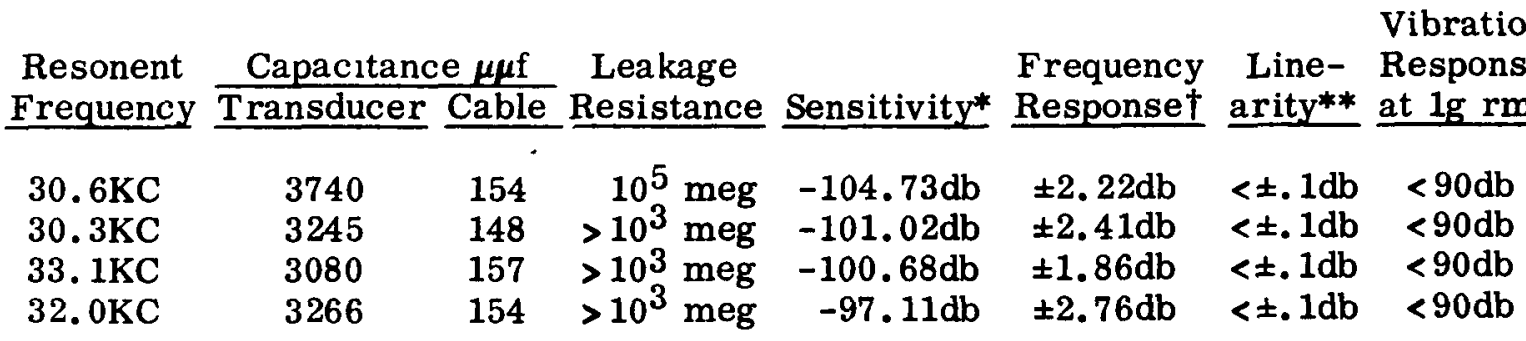

* re: $1 \mathrm{v} /$ dyne $/ \mathrm{cm}^{2}$ at $100 \mathrm{cps}$ w/cable

$\dagger$ Max. output deviation referenced to $1 \mathrm{KC}$

**From $110 \mathrm{db}$ to $140 \mathrm{db}$ input at $100 \mathrm{cps}$

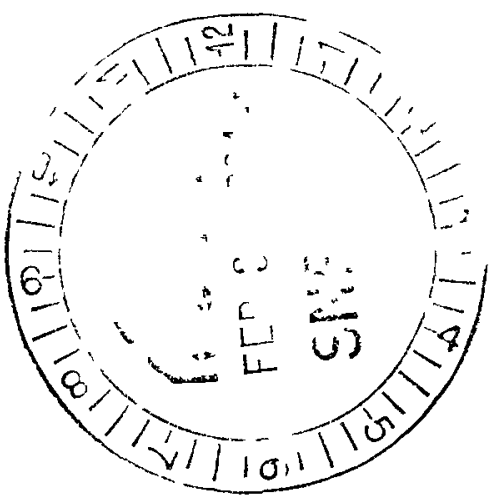

